KINDER- UND JUGENDKULTUR, -LITERATUR UND - MEDIEN THEORIE - GESCHICHTE - DIDAKTIK 100

\title{
Margarete Hopp
}

\section{Sterben, Tod und Trauer im Bilderbuch seit 1945}

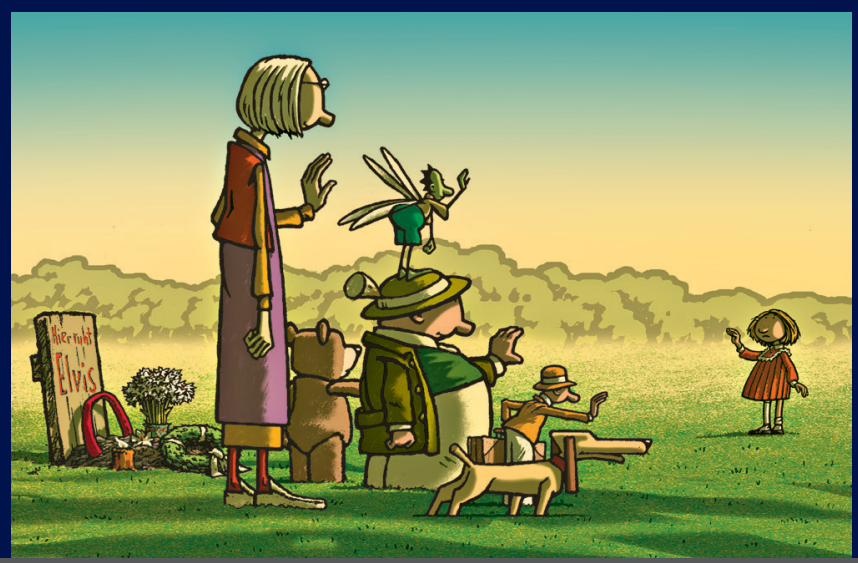


KINDER- UND JUGENDKULTUR, - LITERATUR UND - MEDIEN THEORIE - GESCHICHTE - DIDAKTIK 100

\section{Margarete Hopp}

\section{Sterben, Tod und Trauer im Bilderbuch seit 1945}

Die Studie befasst sich mit dem Erzählen vom Tod im Bilderbuch in historischer und gattungstheoretischer Perspektive und bildet anhand eines Textkorpus' von 287 deutschen bzw. ins Deutsche übersetzten Titeln die Entwicklung von 1945 bis 2011 ab. Entwickelt wird ein narratologisches Modell der Bilderbuchanalyse, das unter Berücksichtigung von Erfahrungswerten der Sterbeforschung in den Einzelanalysen zur Anwendung kommt. Die Untersuchung fächert ein breites Spektrum von Motiven, von realistischen und phantastischen, religiösen und philosophischen Darstellungskon- zepten auf. Eine besondere Rolle spielen Bilderbücher über das Sterben und den Tod von Kindern und die daran nachgewiesene Subgattung des psychologischen Bilderbuchs.

\section{Die Autorin}

Margarete Hopp studierte das Lehramt Primarstufe (Deutsch und kath. Theologie) an der Universität Duisburg-Essen. Sie arbeitet dort und an der Universität Bielefeld als Dozentin in der universitären Lehrerausbildung im Bereich Literaturwissenschaft und Literaturdidaktik. 
Sterben, Tod und Trauer im Bilderbuch seit 1945 
KINDER- UND JUGENDKULTUR, -LITERATUR UND - MEDIEN

\author{
THEORIE - GESCHICHTE - DIDAKTIK \\ Herausgegeben von Hans-Heino Ewers, \\ Ute Dettmar und Gabriele von Glasenapp
}

BAND 100

$\therefore \frac{\text { PETER LANG }}{\text { E D I TIO N }}$ 
Margarete Hopp

\section{Sterben, Tod und Trauer im Bilderbuch seit 1945}




\section{Bibliografische Information der Deutschen Nationalbibliothek}

Die Deutsche Nationalbibliothek verzeichnet diese Publikation in der Deutschen Nationalbibliografie; detaillierte bibliografische Daten sind im Internet über http://dnb.d-nb.de abrufbar.

Zugl.: Bielefeld, Univ., Diss., 2015

Die frei zugängliche digitale Publikation wurde ermöglicht mit Mitteln des BMBF-Projektes OGeSoMo der Universitätsbibliothek Duisburg-Essen. In diesem Projekt wird Open Access für geistesund sozialwissenschaftliche Monografien gefördert und untersucht. Informationen und Ergebnisse finden Sie unter www.uni-due.de/ogesomo.

Dieser Titel ist Teil des Projektes OGeSoMo und wird Open Access mit CC-BY-Lizenz publiziert.

Umschlagabbildung:

(c) Peter Schössow (Variation der Schlussszene seines Bilderbuchs "Gehört das so??!", Carl Hanser Verlag 2005)

D 361

ISSN 1435-4721

ISBN 978-3-631-66575-6 (Print)

E-ISBN 978-3-653-06019-5 (E-Book)

DOI 10.3726/978-3-653-06019-5

PETER LANG

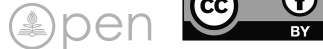

Open Access: Dieses Werk ist lizenziert unter einer Creative Commons Namensnennung 4.0 Internationalen Lizenz (CC-BY). Weitere Informationen: https:// creativecommons.org/licenses/by/4.0/

(C) Margarete Hopp, 2015

Peter Lang Edition ist ein Imprint der Peter Lang GmbH.

Peter Lang - Frankfurt am Main · Bern · Bruxelles ·

New York $\cdot$ Oxford $\cdot$ Warszawa $\cdot$ Wien

Diese Publikation wurde begutachtet. www.peterlang.com 
Sagt der Tod: „Du bist auf der Welt, um das Leben zu lieben.“ Aus: Wolf Erlbruch (2004): Die große Frage. Wuppertal: Peter Hammer Verlag 



\section{Abkürzungsverzeichnis}

Neben den gebräuchlichen, im Duden verzeichneten Abkürzungen:

Abk. i. O.

Abkürzung im Original

DJLP

Deutscher Jugendliteraturpreis

H. d. Verf.

Hervorhebung der Verfasserin

H. i. O.

Hervorhebung im Original

KJL

Kinder- und Jugendliteratur

M.H.

Initialen der Verfasserin

$\mathrm{OAN}$

Originalausgabe Norwegen (u. a. Länderkennzeichen)

TueB

1000 und ein Buch 



\section{Editorische Notiz}

In allen wörtlich übernommenen Texten, Textauszügen und Zitaten wurde die in den angegebenen Quellen vorgefundene originale Schreibweise beibehalten.

Wenn nicht anders eindeutig zuzuordnen, sind mit personenbezogenen Subjekten in der männlichen Form immer auch die weiblichen mit gemeint.

Zitierte Werk- bzw. Schriftentitel sind kursiv gesetzt.

Die ebenfalls kursiv gesetzten Textpassagen in den Auswertungskapiteln sind wörtliche Zitate des jeweils fokussierten Primärtextes und werden nicht mit einem Quellenkurztext versehen, wenn die Zuordnung eindeutig ist.

Wenn nicht anders angegeben, bezieht sich bei Primärtexten die Angabe des Erscheinungsjahres auf die deutsche Erstausgabe.

Die üblicherweise fehlende Paginierung der Primärtexte wurde nicht durch eigene Seitenzählungen ersetzt, sodass entsprechende Text- und Bildzitate über die bibliografischen Angaben hinaus i. d. R. nicht mit Seitenangaben versehen sind. 



\section{Danksagung}

Mein Dank gilt all den Menschen, die mich während des Promotionsprozesses in vielerlei Hinsicht unterstützt haben. Allen voran danke ich meiner Doktormutter, Prof. Dr. Petra Josting, die mir allzeit eine wertvolle Ratgeberin war. Ihre unermüdlichen Anstöße und motivierenden Rückmeldungen haben mich durch den mitunter auch zähen Schreibprozess getragen. Danke für das in mich gesetzte Vertrauen! PD Dr. Oliver Siebold danke ich sehr für sein Interesse an meiner Arbeit und die Bereitschaft, das Zweitgutachten zu verfassen. Prof. Dr. Walter Hussy bin ich sehr verbunden für seinen fachlichen Rat und den immer bestärkenden Zuspruch. Dr. Bettina Oeste hat mich von Beginn an mit ihren konstruktiven Reflexionen, ihrem kritischen (Korrektur-) Blick und ihrem Glauben an ein gutes Ende freundschaftlich begleitet. Frank Jarzina habe ich für seine Hilfe bei der Formatierung des Manuskripts zu danken. Für ihr immer geduldiges und unbeirrbares An-meiner-Seite-Sein bin ich meinen Freundinnen Barbara Klabuhn und Dr. med. Margret Pohl, meinen Brüdern Frank und Thomas auf der Lake und meiner Tante Susanna Alleker sehr dankbar. Herzlichen Dank schulde ich auch Dorothee Graf, Fachreferentin der Universitätsbibliothek Duisburg-Essen, für Rat und Tat. Ferner gab mir Carola Pohlmann von der Berliner Staatsbibliothek wertvolle Recherchehinweise, ebenso wie Werner Küffner von der Internationalen Jugendbuchbibliothek München. Prof. Dr. Ulrich Schmitz danke ich für sein positives Feedback zum theoretischen Teil meiner Arbeit. Mein Dank geht auch an den hospiz verlag Caro \& Die. oHG für das großzügige Überlassen der dort bis 2011 verlegten Bilderbücher. Und Peter Schössow danke ich herzlichst für die eigens gestaltete Umschlagabbildung, die eine Variation einer Szenerie aus seinem 2006 mit dem DJLP ausgezeichneten Bilderbuch Gehört das so??! (Hanser Verlag) zeigt.

Mein liebevoller Dank gebührt meinen Eltern und besonders meiner Mutter, die mir während des Studiums und der anschließenden Promotionsphase nach Kräften den Rücken frei hielt. Zu danken habe ich auch Christian Hopp, der mich in den vergangenen gemeinsamen Jahren immer ermuntert hat, meinen Weg zu gehen. Mein größter Dank gilt meinen mittlerweile erwachsenen Kindern Maximilian, Constantin und Melina. Ihnen ist diese Arbeit gewidmet. 



\section{Inhaltsverzeichnis}

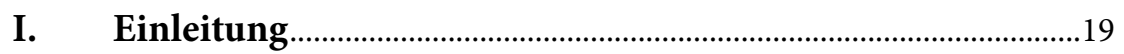

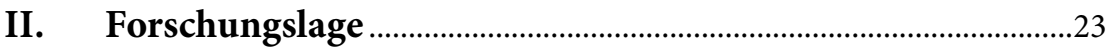

II.1 Das Bilderbuch im wissenschaftlichen Diskurs................................23

II.1.1 Die Anfänge einer Bilderbuch-Kritik................................... 24

II.1.2 Der bundesrepublikanische Diskurs ................................... 25

II.1.3 Die wichtigsten Bezugswissenschaften .............................. 29

II.1.3.1 Literaturwissenschaft und Literaturdidaktik .....30

II.1.3.2 Bildwissenschaft und Kunstwissenschaft......... 34

II.1.3.3 Bildungs- und Erziehungswissenschaften ........ 37

II.1.4 Exkurs: Das Bilderbuch in der DDR .................................... 39

II.2 Sterben und Tod in der Kinder- und Jugendliteratur ......................41

II.2.1 Forschungslage zur Kinder- und Jugendliteratur ............... 41

II.2.2 Historischer Rückblick ......................................................... 45

II.2.3 Die Enttabuisierung des Bilderbuchs und das kindliche Ich ........................................................................ 57

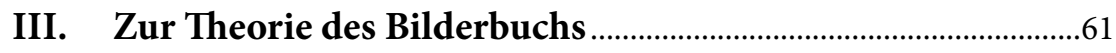

III.1 Das Verhältnis von Sprach- und Bildebene - der Ikonotext..........61

III.2 Das narratologische Modell der Bilderbuchanalyse.........................66

III.3 Die Trias des narratologischen Modells

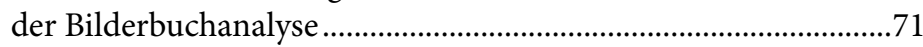

III.3.1 Die erzählerische Vermittlung.............................................. 71

III.3.2 Der Erzähldiskurs - Das WIE des Erzählens ....................... 78

III.3.2.1 Layout............................................................... 78

III.3.2.2 Die Erzählperspektive ....................................... 79

III.3.2.3 Das WIE des Erzählens auf der

Ebene des Verbaltextes......................................... 82 
III.3.2.4 Das WIE des Erzählens auf der Ebene des Bildtextes............................................................ 82

III.3.2.5 Inszenierungen von Sprache und Bild und ihre Interdependenzen........................ 85

III.3.3 Die Geschichte - Das WAS des Erzählens ............................ 85

III.3.4 Rezeptions- und wirkungsästhetische Anfragen an den Ikonotext 88

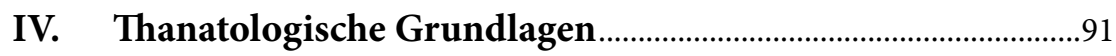

IV.1 Thanatologie und Thanatopsychologie ............................................91

IV.1.1 Das Kind in der Thanatopsychologie ................................... 95

IV.1.1.1 Todeskonzepte des gesunden Kindes................ 96

IV.1.1.2 Das sterbenskranke Kind und sein Todeskonzept ............................................... 105

IV.1.2 Die Sterbephasen nach E. Kübler-Ross ............................... 107

IV.1.3 Angst vor Tod und Sterben.................................................. 111

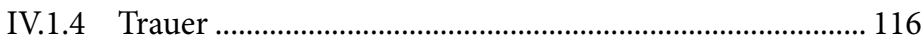

IV.1.4.1 Die erwachsene Trauer....................................... 116

IV.1.4.2 Die Trauer von Kindern..................................... 123

IV.1.4.2.1 Elternverlust .................................. 127

IV.1.4.2.2 Geschwisterverlust ..................... 129

IV.1.4.2.3 Verlust eines Freundes ............... 131

IV.1.4.2.4 Verlust eines Tieres...................... 132

IV.1.5 Zusammenfassung ............................................................. 133

IV.2 Religiöse Perspektiven auf den Tod................................................ 134

IV.2.1 Vorstellungen nachtodlicher Existenz............................... 137

IV.2.2 Das Memento-mori-Motiv und der Totentanz................. 139

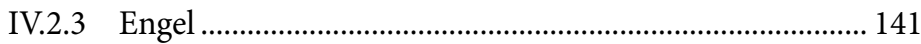

IV.2.4 Christliche Ritual- und Begräbniskultur ............................ 142

IV.2.5 Religionspädagogische Aspekte ......................................... 145

IV.2.6 Zusammenfassung ................................................................. 147 
V.1 Das Textkorpus ............................................................................. 149

V.2 Forschungsansatz und methodische Entscheidungen ................. 150

V.2.1 Forschungshypothesen...................................................... 150

V.2.2 Methodisches Konzept...................................................... 152

V.2.3 Der thanatologisch-diskursanalytische Ansatz................. 154

VI. Auswertungen ………………………………………………………... 159

VI.1 Gattungsspezifische Differenzierungen ......................................... 162

VI.1.1 Das anthropomorph-realistische Bilderbuch.................... 164

VI.1.2 Das anthropomorph-phantastische Bilderbuch ............... 168

VI.1.3 Das Tierbilderbuch ............................................................ 172

VI.1.4 Das Sachbilderbuch ............................................................ 179

VI.1.5 Das märchenhafte Bilderbuch.............................................. 182

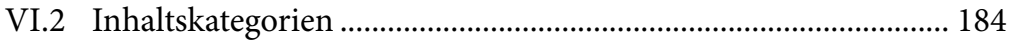

VI.2.1 Die ersten Bearbeitungen des Themas im Bilderbuch zwischen 1945 und 1981.................................. 185

VI.2.2 Das religiöse Bilderbuch ....................................................... 189

VI.2.3 Das philosophische Bilderbuch........................................... 197

VI.2.4 Todesfälle und ihre Ursachen............................................... 200

VI.2.4.1 Großeltern ........................................................... 202

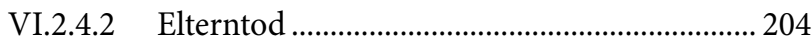

VI.2.4.3 Andere Todesfälle .............................................. 206

VI.2.4.4 Der Tod im Kindesalter ..................................... 207

VI.2.4.5 Tiere.................................................................... 207

VI.2.5 Sterben und Trauern............................................................. 209

VI.2.5.1 Sterbeprozesse _................................................ 211

VI.2.5.2 Trauerprozesse ................................................ 216

VI.2.5.3 Begegnungen mit dem
personifizierten Tod

VI.2.5.4 Gewalt, Krieg und Drogentod.......................... 238

VI.3 Zusammenfassung der Ergebnisse ................................................ 240 
VII.1 Ergebnisse der Inhaltsanalysen ........................................................ 244

VII.1.1 Subgattungen ........................................................................ 244

VII.1.2 Die Anfänge des Erzählens vom

Kindersterben bis 1985 ........................................................ 246

VII.1.3 Die Spezifik der erzählerischen Vermittlung..................... 247

VII.1.4 Das Spektrum der Inhaltsmotive im Teilkorpus

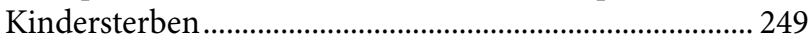

VII.1.5 Todeskonzepte, Religiosität und Jenseitsvorstellungen ......252

VII.2 Das psychologische Bilderbuch zum Sterben im Kindesalter ........257

VII.2.1 Sterbende Kinder ................................................................ 258

VII.2.1.1 Überblick …………………………………........ 258

VII.2.1.2 Die Königin und ich

(Udo Weigelt, Cornelia Haas 2011) ................. 259

VII.2.2 Trauernde Kinder................................................................... 273

VII.2.2.1 Überblick .......................................................... 273

VII.2.2.2 Trauer um einen Spielgefährten:

Ich und $d u$, du und ich

(Angelika Kaufmann 2004) .............................. 275

VII.2.2.3 Geschwistertrauer:

Die Blumen der Engel (Jutta Treiber,

Maria Blazejovsky 2001)................................... 282

VII.2.3 Trauernde Eltern ................................................................. 293

VII.3 Der gewaltsame Kindertod................................................................ 296

VII.3.1 Mord: Kevin Kanin oder Als es dunkel wurde am

Lohewald (Dagmar Krol, Pieter Kunstreich 2005)........... 297

VII.3.1.1 Erzählerische Vermittlung und Diskurs ........ 298

VII.3.1.2 Die Ebene der Geschichte................................ 299

VII.3.2 Krieg und Holocaust als Ursache für Kindersterben ....... 306

VII.3.2.1 Figuren und Geschehen..................................... 306

VII.3.2.2 Sprach- und Bildebene und ihre Ikonotexte ................................................. 313

VII.3.2.2.1 Sprachebene ................................. 313 
VII.3.2.2.2 Erzählperspektive und Komplexität des Erzählens ........ 313

VII.3.2.2.3 Bildstile und -konzepte.............. 314

VII.3.2.2.4 Die Ästhetik des Sterbens und der Trauer Todeskonzepte und Nachtodtheorien.......................... 318

VII.3.2.2.5 Symbolsprache, Traditionen und Rituale

VII.3.3 Kurzfassung der Ergebnisse zum gewaltsamen Kindertod 324

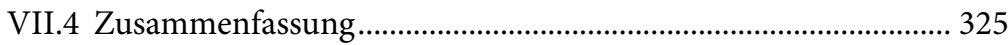

VIII. Abschließendes Resümee und Ausblick.

IX. Literaturverzeichnis 335

IX.1 Primärliteratur - Gesamtkorpus der untersuchten Titel............. 335

IX.2 Weitere erwähnte Primärliteratur.................................................. 351

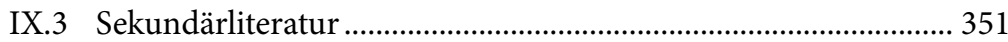

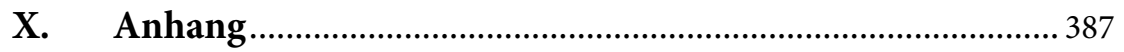





\section{Einleitung}

MORS CERTA, HORA INCERTA. Der Tod ist gewiss, nicht aber die Stunde - nichts ist sicherer als dies. Die Auseinandersetzung mit der Endlichkeit des Lebens und seinen Ungewissheiten bleibt aber in einer Gesellschaft, in der Jugendlichkeit und Vitalität die maßgeblichen Indikatoren für Lebensqualität sind, oft aus. Noch bis ins 20. Jahrhundert hatten Sterbeprozesse, Todesfälle und Trauerrituale in der abendländischen Gesellschaft ihren selbstverständlichen Platz im Leben, heute aber ist das natürliche Sterben längst kein kollektives Erlebnis mehr (vgl. Mischke 1996, 40ff.). Es findet zumeist in Krankenhäusern, Altenheimen und Hospizen statt, in jedem Fall aber möglichst fern vom kindlichen Erfahrungsradius. So verschwinden Menschen recht schnell und vor allem aus dem Blickfeld von Kindern, denen oftmals weder Krankenhausbesuche noch ein Abschied vom Sterbenden oder die Teilnahme am Begräbnis gestattet werden. Die erwachsene Abwehr und Sprachlosigkeit dem Tod gegenüber spiegeln sich darin ebenso wie das Bestreben, Kinder zu schonen.

Der Tod ist das Faszinosum, und er ist das Tremendum. Der Gedanke an ihn bringt uns in existenziellen Schrecken und zwingt uns zu existenzieller Neugier. Ihn anzuschauen, ihn zu fliehen, sind zwei Grundimpulse. (Schmidt-Henkel 1990, 209; H. i. O.)

Aber Kinder haben Fragen zum Tod, das ,ist heute in der psychologischen Literatur sehr gut belegt" (Dinges 1990, 3), doch sie erhalten nicht immer ehrliche Antworten darauf. Beschönigungen und Heimlichkeiten aus einer um Schonung bemühten Haltung heraus können jedoch bei Kindern phantasiegeprägte Ängste und Unsicherheiten hervorrufen, die nachhaltige Folgen für einen späteren Umgang mit Verlusterfahrungen haben können (vgl. Furman 1977, 161f.). Alle klinischen und empirischen Beobachtungen zeigen, dass in nahezu allen Lebensbereichen die Verdrängung nicht heilt, sondern pathologische Effekte eher noch befördert, und für die Verarbeitung eines Beziehungsverlusts wahrheitsgemäße Information und emotionale Unterstützung im Kindesalter grundsätzlich die wichtigsten Determinanten sind (vgl. ebd.). Bilderbücher können dazu einen Beitrag leisten, denn Kinder erwerben ihr Weltwissen nicht nur über soziale und kommunikative Interaktionen in und mit ihrem direkten Lebensumfeld, sondern auch in der Beschäftigung mit Literatur. Dass Bilderbücher im allgemeinen wie im literarischen Sozialisationsprozess bedeutsame Funktionen erfüllen, ist common sense, auch oder gerade im Zeitalter der Medienschwemme, wobei neben den pädagogischen und kognitiven Effekten der Unterhaltungswert ebenso 
wie die Befriedigung von elementaren Bedürfnissen nach Nähe, Geborgenheit und Orientierung nicht zu unterschätzende Größen darstellen.

Bilderbücher gelten als das für Kinder „adäquateste Informations- und Unterhaltungsmedium“ (Thiele 2003a, 11) und können als Mittler zwischen fragenden Kindern und sprachlosen Erwachsenen wirksam sein. Dazu bedarf es eines Angebots, das sich nicht auf die Darstellung einer stereotyp fröhlich-heilen Welt beschränkt, sondern Kinder ernst nimmt, Kindererleben authentisch aufgreift und breite literarästhetische Erfahrungen ermöglicht. Da sich auch der Bilderbuchsektor wie insgesamt die Kinder- und Jugendliteratur (KJL) in vielfältiger Weise den ehemals mit Tabu belegten Themen Sterben und Tod geöffnet hat, was schon allein die Nominierungs- und Preisträgerlisten des Deutschen Jugendliteraturpreises (DJLP) der letzten Jahre belegen, ist von Interesse, auf welche Weise und in welchem Umfang das Bilderbuch des 20. und 21. Jahrhunderts diesem Anspruch gerecht wurde bzw. wird.

Die vorliegende Studie geht dieser Frage mit einer umfassenden und systematischen, literaturwissenschaftlich begründeten Erfassung und Erschließung der thematisch einschlägigen deutschsprachigen Bilderbücher aus den Jahren 1945 bis 2011 nach. Zentrale Forschungsfragen sind u. a., welche motivischen Schwerpunkte und Entwicklungslinien nachweisbar sind, wie nah kindliche Protagonisten an die Geschehnisse und Rituale im Zusammenhang mit Sterbeprozessen und Trauerbewältigung herangelassen werden, welche Rolle Religiosität spielt, wie mit Kinderfragen und dem Bedürfnis nach Erklärungs- und Trostbildern umgegangen wird und letztlich auch, inwieweit Bilderbücher einen Beitrag zur Ausbildung eines altersgerechten bzw. reifen Todeskonzepts, d. h. eines Verständnisses vom Tod und seiner Determinanten leisten können. Diesen Fragestellungen ist die Forderung nach der Authentizität von Erzählkonzepten inhärent, die sich auf entwicklungspsychologische Erkenntnisse und Grundlagen der Thanatologie beruft.

Die Thanatologie ist ein interdisziplinäres Forschungsfeld, das mit dem Begriff Sterbeforschung nur unzureichend umrissen ist, denn es subsumiert kulturwissenschaftliche, psychologische, soziologische und theologische Perspektiven auf den Tod, stellt Fragen zum gesellschaftlichen Umgang damit, nach verschiedenen Todesvorstellungen und Bewältigungsstrategien u. a. m. (vgl. Wittkowski 1990, 6ff.). Insbesondere die Erkenntnisse aus dem Bereich der Thanatopsychologie, einer Subdisziplin dieses Feldes, deren „Interesse [...] dem Erleben und Verhalten gegenüber Sterben und Tod“ (ebd., 8) gilt, sind für die Erschließung und die Bewertung der Erzählkonzepte in den themenbezogenen Bilderbüchern, die nicht nur kindlichen Adressaten Identifikationsangebote machen, von Bedeutung. Ein Überblick über die wichtigsten Aspekte der Thanatopsychologie 
(Kap. IV.1) und religiöse Perspektiven auf den Tod (IV.2) bilden die Grundlage für die themen- und motivbezogene Kategorisierung und Aufbereitung des recherchierten Textmaterials, das eines diskursiven, an thanatologischen und erzähltheoretischen Gesichtspunkten orientierten Forschungskonzepts bedarf.

Das Forschungsinteresse ist verbunden mit dem Ziel, eine theoriegeleitete, an einschlägigen wissenschaftlichen Erkenntnissen orientierte Konzeption zur Beurteilung der literarästhetischen Qualität von Bilderbüchern zur Trias Sterben, Tod und Trauer im Speziellen und ihre Übertragbarkeit auf Bilderbücher im Allgemeinen zu generieren, wohl wissend, dass es keine universale Gebrauchsanweisung für das Erschließen aller Tiefenstrukturen des Erzählens im Bilderbuch geben kann. Vor dem Hintergrund des Methodenpluralismus der literatur- und kulturwissenschaftlichen Textanalyse ${ }^{1}$ und angesichts der noch unbefriedigenden Forschungslage zur Theorie des Bilderbuchs wird hier ein analytischer $\mathrm{Zu}$ gang zum Gegenstand entwickelt, der auf die Kategorien strukturalistischer und narratologischer Textanalyse ${ }^{2}$ rekurriert und diese um die Bildanalyse ergänzt. Dafür wurden narratologische Grundprinzipien in ein dreidimensionales narratologisches Modell der Bilderbuchanalyse (Kap. III) überführt, das die Mehrfachcodierung des Erzählens in Wort und Bild und ihre Synergieeffekte abbildet.

Zunächst zeigt ein Überblick über die vom Interesse am Bilderbuch sich von den Anfängen der KJL-Forschung bis heute stetig ausgestaltende Forschungslandschaft, dass das Bilderbuch gegenwärtig wie kaum eine andere Gattung im Fokus steht (Kap. II). Die Ansätze mehrerer Bezugswissenschaften, deren wichtigste die Literaturwissenschaft und Literaturdidaktik, die Kunst- und Bildwissenschaften und die Bildungs- und Erziehungswissenschaften sind, belegen und begründen in diesem Zusammenhang die Notwendigkeit einer interdisziplinär anzugehenden Erforschung des Bilderbuchs und seiner Theorie. Da die Ära der getrennten literarischen Entwicklungen im geteilten Deutschland in den Untersuchungszeitraum der vorliegenden Studie fällt, stellte sich zudem die Frage nach der DDR-Bilderbuchkultur und dem dortigen Forschungsdiskurs, dessen Umfang und Ergiebigkeit aber lediglich einen kurzen Exkurs zum Abschluss des Kapitels zur Forschungslage rechtfertigen.

Im Anschluss an die Vorstellung des narratologischen Modells der Bilderbuchanalyse (Kap. III) wird in Anlehnung an die bereits erwähnten thanatologischen Grundlagen (Kap. IV) die Forschungskonzeption (Kap. V) erläutert, die zwei Abschnitte umfasst. Datenerhebung und Analyse bedienen sich der Methoden

1 S. dazu: Nünning/ Nünning 2010a, 2010b.

2 S. dazu: Sommer 2010, $91 \mathrm{ff}$. 
der quantitativ-qualitativen Inhaltsanalyse, die sich hier als an das narratologische Modell der Bilderbuchanalyse angelehnte, narratologische Diskursanalyse darstellt und die oben beschriebenen, thematisch bedingten Anfragen an das Textkorpus impliziert. Die Aufteilung wird von dem Anliegen bestimmt, das Spektrum der Darstellungsvarianten des recherchierten Korpusmaterials von 287 Bilderbüchern sowohl gattungstheoretisch (Kap. VI.1) als auch hinsichtlich einzelner motivischer Entwicklungslinien (Kap. VI.2) zu differenzieren und zu kategorisieren und diesen zunächst weiten Blick in einem zweiten Schritt auf die Darstellungen der konkreten Problematik des Sterbens im Kindesalter (Kap. VII) zu fokussieren. Dieser Untersuchungsschwerpunkt gründet auf der Annahme, dass das Erzählen vom Kindertod sowohl für die Autoren und Illustratoren als auch für die Rezipienten eine besondere Herausforderung darstellt und im Bilderbuch erst eine Erscheinung jüngeren Datums ist, was zu belegen sein wird. Neben dem Auffächern der gattungs- und inhaltsspezifischen Erzähldimensionen wird der Bogen zu rezeptionsästhetischen Überlegungen gespannt. Im Zentrum steht dabei das psychologische Bilderbuch, dessen Darstellungsformen - in Anlehnung an die des modernen, psychologischen Kinderromans - in der Psychologisierung und Subjektivierung des Erzählens liegen und dieses mit besonderer Emotionalität belegte Textkorpus auszeichnen.

Schließlich wird mit der Dissertation auch die Frage nach der Ausgestaltung von Kindgemäßheit auf der thematischen und gestalterisch-formalen Ebene im Bilderbuch aufgeworfen. Eine verbindliche Antwort kann die Verfasserin jedoch nur schuldig bleiben, denn das dem Kind Gemäße ist nur am jeweils einzelnen Gegenstand und dem mit ihm interagierenden Kind festzumachen. Grundsätzlich gilt deshalb, dass bei der Auswahl von Bilderbüchern nicht erwachsene Perspektiven das Maß aller Dinge sein sollten, sondern mehr und vor allem die kindlichen Erfahrungen, Interessen und Fragen und das damit verbundene Bedürfnis nach Erklärungen. Dafür bietet der Bilderbuchmarkt mittlerweile eine inhaltliche und ästhetische Vielfalt, die es wahrzunehmen gilt, um den kindlichen Blick nicht vorzeitig zu verengen und auf tradierte, mehr der Bewahrhaltung verpflichtete und von Erwachsenen bevorzugte Seh- und Erzählmuster festzulegen. Die pädagogische und die didaktische Praxis bezeugen eine grundsätzliche Offenheit von Kindern für alles Neue. Es ist deshalb wichtig, weitere Kontraste zu setzen zu den niedlichen und bunten Heile-Welt-Darstellungen, die sicher ebenso ihre Berechtigung haben wie alles, was Kindergedanken- und -erlebniswelten anregt, entlastet und erweitert. Dass das Bilderbuch zum Thema Tod ein breites Spektrum gestalterischer Facetten aufweist, die das Kind im Blick haben und mehr oder weniger deutlich auch eine Mehrfachadressierung implizieren, wird im Folgenden gezeigt. 


\section{Forschungslage}

\section{II.1 Das Bilderbuch im wissenschaftlichen Diskurs}

Die allgemeine Literaturwissenschaft, die schon die Kinder- und Jugendliteratur insgesamt „nur zögerlich“ und quasi als „Sonderfall“ aufgenommen hat (Thiele 2007b, 13f.), tut sich nach wie vor schwer, dem Bilderbuch einen festen Platz in der Forschungskultur des Fachs einzuräumen. Die Erarbeitung einer grundlegenden Bilderbuchtheorie fehlt bis heute. Forschungsdesiderate und Neue Impulse der Bilderbuchforschung (Thiele 2007a) bündelte z. B. die wissenschaftliche Tagung der Forschungsstelle Kinder- und Jugendliteratur der Carl von Ossietzky Universität Oldenburg (Olfoki) 2006 unter der Leitung von Jens Thiele, der resümierte, es existierten mehr „Mutmaßungen“ als gesicherte Erkenntnisse zur "Erscheinungsform, Funktion, Rezeption und Wirkung des Bilderbuchs" (Thiele 2007b, 7f.). In jüngster Vergangenheit zeigen nun zunehmend mehr universitäre Einrichtungen mit einer beträchtlichen Anzahl an Tagungen und einschlägigen Publikationen ein deutliches Interesse am literarisch-ästhetischen Potenzial des Bilderbuchs, dem als ernst zu nehmendem Gegenstand einer an Bild und Text orientierten Lehr-Lern-Kultur wichtige Funktionen für literarisches und „kulturelles Lernen im Dialog“ (Hurrelmann 2010, 7) bescheinigt werden. Obwohl der Schwerpunkt der fachlichen Auseinandersetzung eindeutig im Bereich der didaktischen und pädagogischen Disziplinen ${ }^{3}$ liegt, zeigt sich die Forschungslandschaft mittlerweile vielgestaltig. Es ist evident, dass das Bilderbuch literatur-, bildungs-, kunst- und kulturwissenschaftliche Aspekte in sich vereint, weshalb mit den weiter unten aufgeführten Bezugswissenschaften lediglich die verschiedenen perspektivischen Schwerpunkte herausgestellt werden, keinesfalls aber eine Abgrenzung intendiert ist. Dafür sprechen ebenso die Publikationen der

3 Die bisher einzige fest installierte Einrichtung ist das Bremer Institut für Bilderbuchund Erzählforschung an der Universität Bremen (BIBF; seit 2005 im Fachbereich Erziehungs- und Bildungswissenschaften der Universität Bremen, Arbeitsbereich Deutschdidaktik), das sich „dem forschenden Lernen im Studium der Grundschulund der Frühpädagogik rund um das Bilderbuch verschrieben“ hat und „kleinere Forschungsvorhaben zur Bedeutung des Bilderbuchs und des Erzählens in Kindheit und literarischer Sozialisation" durchführt und begleitet, wobei der Fokus auf der Sprach- und Leseförderung liegt. (http://www.fb12.uni-bremen.de/de/literacy/ bremer-institut-fuer-bilderbuchforschung-bibf.html; 05.10.2013). 
Tagungsinhalte und -ergebnisse mehrerer interdisziplinär ausgerichteter Tagungen, die verschiedene wissenschaftliche Zugangswege zum Bilderbuch aufzeigen.

Im Folgenden wird der Prozess der sich langsam entwickelnden wissenschaftlichen Auseinandersetzung mit dem Bilderbuch historisch und im Kontext seiner Bezugswissenschaften aufgefächert.

\section{II.1.1 Die Anfänge einer Bilderbuch-Kritik}

Die lange zurückhaltende Bereitschaft zur wissenschaftlichen Auseinandersetzung mit dem Bilderbuch dürfte einerseits von der Schwierigkeit bestimmt sein, literatur-, kunst- und bildwissenschaftliche Ansätze zusammenzubringen, andererseits auch vom Duktus der Kindgemäßheit, mit dem vielfach noch immer die Vorstellung von notwendiger, bewahrpädagogischen Ansprüchen geschuldeter Simplizität im Bilderbuch einhergeht.

Eine der ältesten Stellungnahmen zu Gestaltungskriterien von Bilderbüchern (S. S. 1890) $)^{4}$ findet sich in der Zeitschrift Der Kunstwart. Aus psychologischpädagogischer Perspektive sollte das Bilderbuch "einfach und verständlich“ und zudem „dem Betrachter ein ständiger Begleiter sein und nicht bereits nach einmaligem Durchsehen den erzieherischen Wert für das Kind verloren haben" (ebd., 81f.). Umfangreichere Bilderbuch-Besprechungen erschienen kurz darauf von Konrad Lange (1893) und Heinrich Wolgast $(1892,1894)$. Wolgasts viel diskutierte Schriften Bilderbuch und Illustration (1894) und Das Elend unserer Jugendliteratur (1896) markieren die Anfänge einer Kinderliteraturkritik, die noch bis weit ins 20. Jahrhundert hinein zunächst Sache der Pädagogen blieb. Wolgast, Lehrer und Mitbegründer des Jungendschriftenausschusses, beschäftigte sich als Erster auf einem theoretischen Niveau mit den literarischen und künstlerischen Dimensionen der Bildkultur im Kinder- bzw. Jugendbuch und war damit der Impulsgeber für eine neue wissenschaftliche wie auch öffentliche Wahrnehmung der KJL. Die Ambivalenz seines streitbaren und zugleich widersprüchlichen Plädoyers für eine künstlerische Qualität im Kinderbuch ${ }^{5}$, mit dem er einerseits dem Kind die Fähigkeit zum Kunstgenuss absprach, gleichzeitig aber anmahnte, dass „schon das erste Bilderbuch des zweijährigen Kindes den Anforderungen des gebildeten Geschmacks genügen muß" (Wolgast 1894, 8), bestimmt bis in

4 Der Artikel ist lediglich mit den Initialen S. S. versehen, die nicht identifiziert werden konnten.

5 „Nicht nur das Bilderbuch als Ganzes, sondern jedes Bild einer Jugendschrift muß geeignet sein, die ästhetische Bildung der Jugend zu fördern.“ (Wolgast 1894, 8). 
die Gegenwart den allgemeinen Diskurs zur Angemessenheit literarischer Gestaltungskonzepte für Kinder.

\section{II.1.2 Der bundesrepublikanische Diskurs}

Die folgende Zusammenstellung führt zunächst die umfassendsten Aufarbeitungen der Geschichte des Bilderbuchs auf und im Anschluss daran die wichtigsten einschlägigen, teilweise nicht streng wissenschaftlichen Schriften in der weitgehend chronologischen Abfolge ihres Erscheinungszeitpunktes. Dabei tritt als Schwerpunkt der wissenschaftlichen Auseinandersetzung die illustrationsgeschichtliche Forschung hervor, die das Bilderbuch auf fachhistorischem Gebiet bereits relativ weit erschlossen hat.

Die erste bedeutende und umfassende Chronik der "Geschichte und Entwicklung des Bilderbuchs in Deutschland von den Anfängen bis zur Gegenwart“ veröffentlichten Klaus Doderer und Helmut Müller 1973 mit dem Sammelband Das Bilderbuch. Darin geht es um das „Kinderbilderbuch“, „die Gruppe von reich illustrierten Büchern, die speziell für Kinder gemacht oder aber in Kinderstuben benutzt worden ist“ (ebd., V). Trotz der von Doderer eingeräumten „Lücken“, die diese Schau auf ein Textkorpus von „ca. 1600 Bänden“ vom Mittelalter bis in die Gegenwart aufweist (ebd., VI) ${ }^{6}$, liegt damit eine umfassende Dokumentation einzelner Entwicklungslinien des Bilderbuches vor, darunter die für das 19. Jahrhundert postulierte Unterscheidung zwischen poetischem und bürgerlichem Bilderbuch. Deren Entwicklungen verliefen zeitlich etwa parallel und sind noch heute nachzuspüren. Neben dem realistischen "Genre-Bilderbuch" der „Selbstbestätigung des bürgerlichen Lebensideals“ als die „klar dominierende Richtung“ (Doderer 1973a, 101) konzentrierte sich das „poetische Bilderbuch spätromantischer Intention“ vor allem auf drei Themenbereiche: die ,illustrierte Darstellung des lyrischen Potentials an Volksliedern, Kinderreimen und erzählenden Gedichten“, die „Wiedergabe der Märchen“ und die „Darstellung von großen alten epischen Stoffen [...] und Fabeln" (ebd.). Im Lexikon der Kinder- und Jugendliteratur (Doderer 1975) wurden kurz darauf die Ausführungen

6 S. Beiträge in Doderer/Müller (1973) von: Helmut Müller (von den Vorläufern des Bilderbuchs, den Bilderbibeln, Bilderfibeln, Fabel- und Sachbüchern), Alfred Clemens Baumgärtner (Bilderbogen des späten Mittelalters), Klaus Doderer (über das „Poetische Bilderbuch“ und das „,bürgerliche Bilderbuch im 19. Jahrhundert“), Hans Adolf Halbey (das Bilderbuch im Jugendstil), Valentin Merkelbach (die 1920er-Jahre), Peter Aley (das Bilderbuch im Dritten Reich) Arianna Giachi (Bilderbuch nach 1945), Horst Künnemann („Gegenwartssituation der 1970er-Jahre“). 
zum Bilderbuch um z. T. ausführliche Artikel über Bilderbuchautoren und -illustratoren und wichtige Werke ergänzt.

Mit dem Handbuch zur Kinder- und Jugendliteratur (begr. v. Theodor Brüggemann 1982, 1987, 1991, 1998, 2006, 2008; weitere Bände in Planung) liegen in mittlerweile sechs Bänden ${ }^{7}$ „mehr als vier Jahrhunderte der Entwicklung der KJL im deutschsprachigen Raum“ als „historisch-bibliographische[s] Grundlagenwerk" (Hurrelmann 2008, 3) vor, und damit die bisher neuesten Erkenntnisse zur Bilderbuchillustrationsgeschichte bis zum Ende des 19. Jahrhunderts, darunter die Studien von Ulrich Kreidt (2008) zu Bildern in der Kinder- und Jugendliteratur des 19. Jahrhunderts, die Untersuchung der Bilderbücher und Bildergeschichten von 1850-1900 von Bettina Hurrelmann (2008) sowie der Beitrag von Hans Ries (1992) über Illustration und Illustratoren des Kinder- und Jugendbuchs im deutschsprachigen Raum 1871-1914. Weitere verschiedene Einzelprojekte zu wichtigen Bilderbuchillustratoren bzw. -autoren trugen zur Aufarbeitung der stilgeschichtlichen Entwicklungen bei (u. a.: Hoffmann/ Thiele 1986; Tabbert 1987; Guratzsch/ Neyer 2002; Abmeier 2008; Ausstellungskataloge des Bilderbuchmuseums Burg Wissem in Troisdorf 1986ff.).

Eine der ersten Schriften zur Definition und Typologisierung des modernen Bilderbuchs als Teil vom "Jugendschrifttum“ des 20. Jahrhunderts wurde 1964 von Karl Ernst Maier publiziert und bis zur 10. Auflage (1993; ab 1980 unter dem Titel Jugendliteratur) regelmäßig erweitert. Unterschieden werden darin zunächst Elementarbilderbuch, Szenenbilderbuch, Märchenbilderbuch und wirklichkeitsnahe Bildergeschichte (ebd., 5), wobei die Uneinheitlichkeit der herangezogenen Kriterien - adressatenbezogene, formale und inhaltliche kaum eine eindeutige Bestimmung zulassen. Später wurden die Formen und Themenkreise weiter ausdifferenziert und um die Bilderbuchgeschichte - mit den drei Untergruppen Märchenbilderbuch, wirklichkeitsnahe Bilderbuchgeschichte, phantastische Bilderbuchgeschichte -, das Sachbilderbuch sowie das Foto-Bilderbuch erweitert (Maier 1993). Einen weiteren Versuch zur „Typologie des zeitgenössischen Bilderbuchs“ stellt der "differentialdiagnostisch“ ausgerichtete Handbuchbeitrag von Horst Künnemann $(1974,108 f$.) dar, der vier Analysebereiche auflistet: Funktion, Technik, Stil und Thema. Doch auch dieser Ansatz scheint nicht geeignet, verbindliche Typologisierungen vorzunehmen, da formalästhetische und inhaltliche Kriterien mit funktionalen Zuordnungen vermischt und lediglich an Werken einzelner „Bilderbuchgraphiker“ (ebd., 109) der SBZ/DDR; Bd. 6, von 1900-1950, ist in Vorbereitung. 
nachgewiesen werden. Schon 1968 hatte Alfred Clemens Baumgärtner in der ersten, ausschließlich auf das Bilderbuch gerichteten Monographie Aspekte der gemalten Welt. 12 Kapitel über das Bilderbuch von heute auf die Notwendigkeit einer interdisziplinären Sicht auf das Bilderbuch hingewiesen.

Ulrich Hanns (1977) Erarbeitung der Entwicklungsgeschichte des deutschsprachigen Bilderbuches im 20. Jahrhundert verbindet kunst- und sozialgeschichtliche Ansätze zur „Untersuchung der Konstitution der Welt“ im Bilderbuch, dargelegt am Untersuchungsmaterial von 958 Primärtexten (1900 bis 1975). Hervorzuheben ist dort die Erschließung der thematischen und ästhetischen Zäsur in der Phase der nationalsozialistischen Einflüsse. Ines Brandt (1994) erforschte Die Entwicklung der Schwedischen Bilderbuchkunst zwischen 1880 und 1945 und legte dabei den Schwerpunkt auf die Biographien und Werke einzelner Bilderbuchkünstler. Mit dem Titel Zur bild- und sprachästhetischen Darstellung des Eigenen und Fremden im deutschsprachigen Bilderbuch ist die Disseration von Claudia Blei (1998) eine der wenigen zum Bilderbuch, eine weitere verzeichnet die Deutsche Nationalbibliothek von Franziska Hirlinger-Fuchs (1999: Normen, Werte und Rollenbilder in deutschsprachigen Bilderbüchern von 1844-1966), die einen thematischen Wandel im Bilderbuch an Einzelanalysen festmacht.

Ausdrücklich forderte Hans Adolf Halbey (1997) mit Bilderbuch: Literatur. Neun Kapitel über eine unterschätzte Literaturgattung eine wissenschaftliche und interdisziplinäre Auseinandersetzung mit dem Bilderbuch, wie sie auch die nur vereinzelt vorliegenden Tagungsbände und Sammelwerke zum Bilderbuch spiegeln (Paetzold/ Erler 1990; Raecke/ Baumann 1995; Thiele 1999, 2007a; Franz/ Lange 2005). Den Stilwandel im deutschen Bilderbuch 1950-2000 beschreibt Andreas Bode (2004, 2005), und Elisabeth Hohmeister $(1999,46)$ bescheinigt den Künstlern der 1990er-Jahre „[n]eue bildnerische Formen [und] eigenständige Konzepte, die Spiegel einer individuellen Gesellschaft und eigener künstlerischer Entwicklungsprozesse sind“. Das Bilderbuch, dessen Erzählpotenzial, wie insgesamt die Kinder- und Jugendliteratur, durch seinen „expliziten oder impliziten Adressatenbezug definiert“ (Kümmerling-Meibauer 2001, 1586) ist, zeigt sich seit den 1990er-Jahren zunehmend als Teil der sogenannten All-ageLiteratur, wie die Darstellungsformate der postmodernen Bilderbücher mit ihren „Entgrenzungen“ (Thiele 2002, 203) deutlich machen.

Dass die Bilderbuchästhetik der letzten Dekade des 20. und am Anfang des 21. Jahrhunderts geprägt ist von „Kontinuität und Diskontinuität“, ist das Ergebnis der umfassenden Forschungsarbeit von Mareile Oetken (2008).

Prozesse der Entgrenzung und Vernetzung des Bilderbuchs mit immer weiteren Medien setzen dann Ende der 1980er Jahre ein (Müller/Steiner 1989: Aufstand der Tiere oder 
Die neuen Stadtmusikanten). [...] Mit der großen Akzeptanz medialer Bildsprachen, crossmedialen Vermarktungsstrategien, dem Einzug der Postmoderne mit non-linearen Erzählstrukturen und dem Spiel mit Zeichen und Zeichenverschiebung in die Bilderbuchillustration, sind zentrale Stichworte der Innovationen umrissen. (Ebd., 82; H. i. O.)

Oetken $(2008,316)$ konstatiert, „keine andere Epoche der Bilderbuchliteraturgeschichte" habe eine solche ästhetische Vielfalt aufzuweisen, denn „tradierte Kontinuität" stehe neben medialen und innovativen Darstellungsformaten einer immer komplexer werdenden Bild- und Textsprache. Einen weiteren wichtigen Beitrag zur Bilderbuchforschung leistete Marlene Zöhrer (2010) mit ihrer Dissertation Weltliteratur im Bilderbuch. Aus ihrer Untersuchung der mittlerweile zahlreich vorliegenden „Transformationen“ (ebd.) weltliterarischer Texte ins Bilderbuch sind wertvolle Erkenntnisse über die Funktionalität verschiedener Formen der Text-Bild-Korrelationen im Kontext von Intertextualität, Intermedialität und Narratologie hervorgegangen. Farriba Schulz (2013) richtet in ihrer Dissertation „Spieglein, Spieglein an der Wand... “ den Blick auf die „Kindheit in nominierten Bilderbüchern des Deutschen Jugendliteraturpreises von 1956 bis $2009^{\prime \prime}$.

Die Studien zeigen insgesamt, dass von etwa der Mitte des 20. Jahrhunderts bis heute die Parallelität verschiedener Themen, Formen und Stile und vor allem unterschiedlicher Qualitätsmaßstäbe den Bilderbuchmarkt bestimmt. Neben dem hochwertigen Angebot bildet die Massenware trivialer und konservativ stereotyper Bilderbücher ein eigenes Textkorpus, das jedoch, obwohl die Absatzzahlen allein schon dazu Anlass gäben, bisher keine wissenschaftliche Beachtung fand (vgl. Berger 1986, 25f.) $)^{8}$. Auch Ingeborg Ramseger $(1979,165)$ moniert dieses Desiderat, lässt aber selbst in ihrem Überblick über die Bilderbuchproduktion einzelner Verlage und Autoren von der Nachkriegszeit bis zum Ende der 1970er-Jahre die sogenannten Kaufhausbilderbücher ${ }^{9}$ unbesprochen. Dagegen wagt Horst Künnemann (1994) ein positives, wenn auch „verhaltenes Plädoyer für Kaufhausbilderbücher" und billigt damit dem kindlichen Geschmack die „Wonnen der Gewöhnlichkeit“ (ebd., 23) zu.

Literaturtheoretische Betrachtungen zum Bilderbuch und kursorische Untersuchungen $\mathrm{zu}$ Einflüssen der bildenden Kunst und der Medienwelt auf die Ästhetik der Bilderbuchillustration liegen vor allem von Jens Thiele in

8 Hinweise auf vereinzelte Beiträge s. ebd.

9 „W]as hier an Bildheften und Kinderbilderbüchern der unteren Wertlage angeboten wird, muss erschrecken. Über die Wirkung dieser Konzentrate an Kitsch, Weltfremdheit und Gewaltverherrlichung auf Kinder gibt es nur Spekulationen, keine seriösen Untersuchungen." (Ramseger 1979, 165). 
zahlreichen Publikationen vor. Seine Monographie (Thiele 2003a) ist der bisher umfassendste Versuch einer theoretischen, interdisziplinäre Zusammenhänge berücksichtigenden Erfassung der Gattung Bilderbuch. ${ }^{10} \mathrm{Zu}$ den zahlreichen Forschungsdesideraten gehören neben den genannten auch die Konvergenzen und Divergenzen zwischen Bilderbuch, Comic und Graphic Novel, deren gemeinsame Wurzeln in den Bildgeschichten des 18. und 19. Jahrhunderts liegen (vgl. Dolle-Weinkauff 2013, 200). Für die Comicforschung ${ }^{11}$ wie für die Bilderbuchforschung stellt sich deshalb gleichermaßen die Frage: „Taugen herkömmliche narratologische Begrifflichkeiten als sinnvolle Analyseinstrumente“ (Brunken/ Giesa 2013, 9) und wie kann das Zusammenspiel der visuellen und der sprachlichen Ebene beschrieben werden? Die Suche nach einer Antwort fällt unweigerlich in die Zuständigkeiten der verschiedenen Bezugswissenschaften.

\section{II.1.3 Die wichtigsten Bezugswissenschaften}

In erster Linie ist das Bilderbuch Literatur. Eine Bilderbuch-Literaturtheorie hat aber aufgrund der konstitutiven Text-Bild-Kombination literaturwissenschaftliche wie dramentheoretische mit kunst- und bildwissenschaftlichen Ansätzen zu verknüpfen (vgl. z. B.: Halbey 1997; Tabbert 1999; Thiele 2007b). Denn im Bilderbuch mit seinem sprachlichen, bildlichen und „visuell wie semantisch arrangierten Text" (Lämmert 1999b, VII) sind mehrere Künste vereint, zu deren Gemeinsamkeiten ${ }^{12}$ vor allem die erzählerische Dimension zählt, die Hilmar und Tanja Frank $(1999,38)$ für das Bild in der Kunstwissenschaft so beschreiben:

[E]rst die Einsicht, dass Raum und Zeit in menschlicher Erfahrung und visueller Darstellung untrennbar verknüpft sind, [vermag] das Erzählen als eine genuine Möglichkeit bildender Kunst zu erweisen [...]. Könnte das Einzelbild nicht erzählen, wäre zyklische Narration nicht möglich.

Ein Vergleich mit dem Bild im Bilderbuch drängt sich hier förmlich auf. In den letzten Jahren mehren sich die Studien aus dem Bereich der Kunstwissenschaft, die sich mit dem „Phänomen der Narrativität in bildenden Kunstwerken“

10 Die wichtigsten amerikanischen Forschungen zum Bilderbuch: Nikolajeva/ Scott (2001); Nodelman (1988); Schwarcz (1982); Schwarcz/ Schwarcz (1991).

11 Vgl. zur wissenschaftlichen Erforschung von Comics im deutschsprachigen Raum: Gesellschaft für Comicforschung „ComFor“: http://www.comicgesellschaft.de/

12 Einen Überblick zum Forschungsstand in den Bereichen der Literaturwissenschaft, Kunstwissenschaft, Theater, Filmwissenschaft und Musik und eine Einführung zum Thema bietet die Aufsatzsammlung „Die erzählerische Dimension: eine Gemeinsamkeit der Künste“ (Lämmert 1999a). 
beschäftigen und die Annäherungen und Abgrenzungen zwischen „Kunstwissenschaft, der literaturtheoretisch begründeten Narratologie und der intermedial orientierten Erzähltheorie" (Scheuermann 2010, 191) aufgreifen. ${ }^{13}$ Und da „die kunstwissenschaftliche Erzählforschung aufs engste mit der Erforschung der Text-Bildbeziehungen verbunden ist" (Frank/ Frank 1999, 42), müsste sich umgekehrt eine Erzähltheorie des Bilderbuchs der Erkenntnisse kunstwissenschaftlicher Forschungen bedienen, um für das Gemeinsame der Künste, die Narrativität des Bildes, ein tragfähiges Beschreibungsmodell zu generieren. Zudem wären die komplexen Zusammenhänge zwischen Bilderbuch, Kindheit, Medien, Kommerz und Gesellschaft zu berücksichtigen, weshalb erzähltheoretische Untersuchungen zur Sprach- und Bildästhetik, einschließlich der Verbindungen zur bildenden Kunst, um Fragen nach dem Adressatenbezug und den Funktionen des Bilderbuches im literarischen bzw. medialen Sozialisationsprozess ergänzt werden müssen. Damit ist ein ganzes Bündel von Forschungsdesideraten umrissen, die aus der Perspektive der wichtigsten Bezugswissenschaften - Literaturwissenschaft und Literaturdidaktik, Bildwissenschaft und Kunstwissenschaft, Bildungs- und Erziehungswissenschaften - im Folgenden in Einzelaspekten angesprochen werden.

\section{II.1.3.1 Literaturwissenschaft und Literaturdidaktik}

Gemeinhin, d. h. durchaus nicht nur aus der Sicht des nicht-wissenschaftlichen Publikums, ist vom Bilderbuch heute noch immer die Rede als Literatur für (Klein-) Kinder. Mit Bilderbüchern werden pädagogische Intentionen und Erwartungen an eine freundlich-farbige, auf (vermeintlich) kindliche Bedürfnisse ausgerichtete Ausstattung in Text und Bild verbunden. Bar jeglicher wissenschaftlicher Beweisführung, steht hinter diesen Vorstellungen eine thematische und formalästhetische Reduzierung im Sinne einer trivialen Einfachheit, die getragen wird von

zwei hartnäckigen Vorurteilen: Kinder können nur einfache Bilder sehen (im physiologischen und kognitiven Sinne von erfassen, begreifen, verstehen). Und: Kinder dürfen nur einfache Bilder sehen (als pädagogische Forderung, die gerade im Medienzeitalter neue Nahrung erhält). (Thiele 1997, 151; H. i. O.)

Ursprünglich aber war das Bilderbuch nicht dem kindlichen Verständnis verpflichtet. Erst im Verlauf seiner Geschichte hat es sich „in seinem Selbstverständnis von

13 Einen Überblick über den Forschungsstand in den Kunstwissenschaften, der Narratologie und einer intermedial ausgerichteten Erzähltheorie bietet die Dissertation von Barbara J. Scheuermann (2005). 
freien künstlerischen Ideen abgekoppelt“ und zu einer „Spezialkunst für Kinder“ entwickelt (Thiele 2002, 228).

Die Geschichte des Bilderbuches ist untrennbar mit der Geschichte der Buchdruckkunst verbunden. Schon bald nach ihrer Erfindung und aufgrund der neuen Möglichkeiten der Verbreitung von Schrifttum um die Mitte des 15. Jahrhunderts kam man nicht umhin, Druckerzeugnisse mit Illustrationen $\mathrm{zu}$ versehen, um auch die noch große Zahl der Leseunkundigen erreichen $\mathrm{zu}$ können. Die frühe Form des Bilderbuchs mit seinen handwerklich-künstlerisch gestalteten Bildbeigaben galt also zunächst „dem ungeübten erwachsenen Leser, weniger dem Kind“ (Müller 1973, 1). Gleichwohl sind die reich bebilderten Bilderbibeln, Bilderfibeln und illustrierten Fabelbücher dieser Epoche als früher Anfang einer deutschsprachigen spezifischen Kinder- und Jugendliteratur und als Vorläufer des heutigen Bilderbuches anzusehen (vgl. ebd.). Zunächst war mit der Bezeichnung Bilderbuch, die sich schon in den Verlagsverzeichnissen des 18. und der ersten Hälfte des 19. Jahrhunderts findet, schlichtweg jedes bebilderte Buch gemeint; erst um die Mitte des 19. Jahrhunderts bildete sich das Verständnis vom unterhaltsamen, kaum oder keinen Text enthaltenden Bilderbuch als an das (Klein-) Kind adressierte, literarische Gattung heraus (vgl. ebd., 2). Bis dahin war der kinderliterarische Markt von drei Grundtypen des weltlichen Bilderbuchs bestimmt, die noch nicht darauf ausgelegt waren, Geschichten zu erzählen: das „Genre des belehrenden Anschauungsbilderbuchs“, das „Album [...] ohne erkennbare Storyline [...] [und] ein dritter Grundtypus, derjenige der illustrierten Gedichtsammlung“ (Dolle-Weinkauff 2013, 200ff.). Erst der 1845 in seiner Urform erschienene Struwwelpeter von Heinrich Hoffmann markiert die Anfänge des narrativen Kinder-Bilderbuchs: „Das Verdienst, die Bildergeschichte als Darstellungsform für das Kinderbilderbuch erobert zu haben, kommt Heinrich Hoffmann [...] zu.“" (Brunken et al. 2008, 167) In der zweiten Hälfte des 19. Jahrhunderts entwickelt sich dann eine spezifische Literatur für Kinder und Jugendliche und

auch das Bilderbuch beginnt einen altersspezifischen Zweig auszubilden, der sich bis zum Ende des 19. Jahrhunderts zum bestimmenden Phänomen auswächst: Von nun an ist das >Bilderbuch eigentlich nur noch als Bilderbuch ad usum delphini denkbar. (Dolle-Weinkauff 2013, 200; H. i. O.)

Erste Definitionen einer wissenschaftlichen Auseinandersetzung schreiben dem Bilderbuch als „Wesensmerkmale“ die Bilddominanz, ein ausgeprägtes Zusammenspiel von Bild und Text und einen ausgewiesenen Leserkreis zu, der sich auf einer Entwicklungsstufe befindet, „die noch viele Jahre vor der geistigen und literarischen Mündigkeit liegt“" (Maier 1964, 14). Demnach gelte es, diesem 
Adressatenkreis passgerechte, auf der inhaltlichen und formal-konzeptionellen Ebene kindgemäße Angebote zur Welterfahrung zu machen (vgl. ebd.). Diese Sicht auf das Bilderbuch und seinen aufgrund mangelnder Lesefertigkeit auf Bilder angewiesenen Rezipienten hat durchaus ihre Berechtigung, sie wird aber spätestens seit den 1990er-Jahren den ästhetisch und erzähltechnisch komplexer angelegten Bilderbuchkonzepten, die vermehrt auch ältere Kinder und Erwachsene ansprechen, nicht mehr gerecht. In den so genannten All-Age-Bilderbüchern ist eine „kreative Durchlässigkeit von Illustration, Kunst und Medien“ (Oetken 2008, 82) angelegt, die auf den erwachsenen Kennerblick ebenso zielt wie auf den jungen Leser, dessen grundsätzlich anzunehmende Offenheit für ästhetische Erfahrungen einen affektiven Zugang über die schiere Freude am Neuen zulässt. Jens Thiele, der sich seit den 1980er-Jahren intensiv mit der Ästhetik des Bilderbuches auseinandersetzt, fragt in diesem Zusammenhang jedoch auch zu Recht Ist das Kind noch im Bilde? (Thiele 2004; s. a. ders. 2005b) und stellt damit die intellektuelle Fassbarkeit aufgelöster linearer Erzählkonzepte für Kinder infrage. Für eine dichotomische gattungstheoretische Beschreibung des Bilderbuches im Sinne einer adressatenbezogenen Unterscheidung zwischen Erwachsenen-Bilderbuch und Kinder-Bilderbuch sprechen auf der normativen Ebene aber weniger die vielfach diskontinuierlichen Gestaltungs- und Erzählkonzepte, die hohe Ansprüche an die Fähigkeit zur Kohärenzbildung stellen, sondern vielmehr die Subtilität mancher Darstellungen und ihre fehlende Nähe zum kindlichen Erfahrungshorizont (vgl. ebd.). Die Heterogenität der gegenwärtigen Bilderbuchliteratur verlangt nach einer differenziert angelegten, gattungstheoretischen Neubestimmung des Bilderbuchs, jenseits der noch immer populärwissenschaftlich verbreiteten Verengung des Begriffs Bilderbuch „auf die Seite einer pädagogisch-psychologisch begründeten Gebrauchskunst" für Kinder (Thiele 2003a, 15).

Die Literaturwissenschaft hat sich zwar dem Wechselverhältnis von Schrift und Bild längst zugewandt, doch unter der mittlerweile umfangreichen Forschungsliteratur zu Bild-Text-Beziehungen ${ }^{14}$ finden sich nur wenige Beiträge, die das Bilderbuch fokussieren. ${ }^{15}$ Obwohl das Bilderbuch im Gattungsrepertoire der allgemeinen Literaturwissenschaft noch eine Randposition belegt, hat es sich

14 Z. B.: Wenzel 1995; Mergenthaler 2002; Horstkotte/ Leonhard 2006a; Fokus Bilderbuch z. B.: Grünewald 1991; Thiele 1991, 2005a; Ries 1992 u. a.

15 Auch das von der DFG geförderte wissenschaftliche Netzwerk, Literaturwissenschaftliche Visualitätsforschung/ Studies in Literary Visuality' (Ruhr-Universität Bochum 2011-2014) hat mit seinem Forschungsanliegen, ,literaturwissenschaftliche Theorien, Modelle, Methoden und Arbeitsgebiete mit jenen der sog. Visual Culture 
aber im Bereich der Kinder- und Jugendliteraturforschung emanzipiert und erfährt dort gegenwärtig große Beachtung.

Immer mehr Literaturwissenschaftler und Literaturdidaktiker stellen sich auf vielfältige Weise der Notwendigkeit, das literarästhetische Potenzial des Bilderbuchs sowohl theoretisch als auch empirisch zu erschließen, um z. B. Beziehungen zwischen der Komplexität von Bild-Text-Verbindungen, frühen literarischen Bild-Lese-Erfahrungen, dem Erwerb von Lesekompetenz und literarischer Kompetenz und letztlich Medienkompetenz aufzudecken. Die jüngst veröffentlichten Herausgeberschriften Fragwürdiges Bilderbuch (Kruse/ Sabisch 2013) und Text und Bild - Bild und Text (Jantzen/ Klenz 2013), beide hervorgegangen aus Veranstaltungen im Fachbereich Erziehungswissenschaft/ Didaktik der deutschen Sprache und Literatur der Universität Hamburg, weisen ebenso in diese Richtung wie der gerade erschienene Tagungsband (Scherer/ Volz/ Wiprächtiger-Geppert 2014) zum Forschungsprojekt „Zeitgenössische Bilderbücher in der Rezeption von Grundschulkindern“ an der Universität Koblenz-Landau, in dem Beiträge aus verschiedenen Disziplinen wie Kunstpädagogik, Kinder- und Jugendliteraturforschung, Literatur- und Sprachdidaktik versammelt sind. Und die gerade neu erschienene Reihe Deutschdidaktik für die Primarstufe bietet mit den ersten beiden Bänden zur Theorie und Praxis des Bilderbuchs (Knopf/ Abraham 2014) Impulse gebende Beiträge. Der Theorieband enthält unter anderem ein „fünfdimensionales Modell der Bilderbuchanalyse" (Staiger 2014), das auf vorwiegend aus dem angloamerikanischen Raum bekannte Ansätze (Nikolajewa/ Scott 2006; Nodelman 1988; Schwarcz 1982; u. a.) zurückgreift und „mehrere vorliegende Begriffslisten und Raster der Bilderbuchanalyse“ (Staiger 2014, 13), auch aus der deutschsprachigen Forschungsliteratur, impliziert. Einmal mehr belegt dieses Modell, ebenso wie die vorweg genannten Publikationen, dass das Bilderbuch sich einem einfachen, linearen Zugang verschließt und interdisziplinär erschlossen werden muss.

Davon geht auch die Verfasserin mit dem Entwurf des narratologischen Modells der Bilderbuchanalyse aus, das die Mehrfachcodierung des Bilderbuchs auf drei Ebenen, denen jeweils narratologische Dimensionen immanent sind, spiegelt und im vorliegenden Kapitel III ausführlich vorgestellt wird.

Studies (VCS) in einen Dialog zu bringen“ (GEPRIS-Eintrag), das Text-Bild-Medium Bilderbuch offenbar nicht mit erfasst. 


\section{II.1.3.2 Bildwissenschaft und Kunstwissenschaft}

Beim Bilderbuch liegen die Bezüge zur Bildwissenschaft und zur Kunstwissenschaft auf der Hand, denn es vereint mehrere ästhetische Kategorien der bildenden und darstellenden Künste und der Bildwissenschaft. Zunächst dürfte unstrittig sein, dass Bilderbuchkunst als ,angewandte Bildkunst“ (Thiele 1990b, $141)^{16}$ nie frei war von zeitgeschichtlichen Stil- und Formeinflüssen. Der Weg von den traditionellen, realitätsbetonten Kunststilen über expressionistische Gestaltungsformen bis hin zur abstrakten und medial beeinflussten Bildsprache ist auch im Bilderbuch nachvollziehbar, wenn auch auf eine eher subtile Weise und nicht in chronologischer Kongruenz (vgl. ebd, 141ff.). Thiele konstatiert: „Das Verhältnis von moderner Kunst und Bilderbuch zu definieren, ist ein schwieriges Unterfangen, denn jeder einzelne Partner in diesem Verhältnis ist für sich schon kompliziert genug." (Ebd., 141)

Ein Blick auf das Bilderbuchschaffen der 1960er- und 1970er-Jahre ${ }^{17}$ zeigt, dass der Anspruch an kindgerechte Gestaltung nicht mit der Banalität einer auf Idylle ausgerichteten Erzählweise und anspruchslos-kitschigen Bildkonzeptionen einhergehen muss, sondern auch Strömungen der Bildenden Kunst aufgreift (vgl. ebd.). Die abstrakte Kunst der freien Malerei, vor allem als Form des sogenannten abstrakten Expressionismus mit dem fleckenhaften, bewusst die Kontur ignorierenden Farbauftrag, hat in das Bilderbuch dieser Zeit Eingang gefunden (vgl. Bode 2004, 97). Eine weitere „Annäherung zwischen Kunst und Alltag und damit auch zwischen Kunst und Bilderbuch“ zeigt sich z. B. im Aufgreifen der „Motive und Ästhetik der Popart“ der 1960er-Jahre (Thiele 1990b, 167). Für die nachfolgenden Jahrzehnte gilt dann, dass das Bilderbuch nur noch unter gelegentlichem Rückgriff „auf mittlerweile historisch gewordene Kunststile“ die Kunstgeschichte zitiert und die aktuellen Kunstströmungen unbeachtet lässt (ebd., 169). Als bekannter Vertreter intertextueller Bilderbuchkunst sei Anthony Browne genannt, dessen Bildzitate auf die surreale Kunst Magrittes verweisen ${ }^{18}$.

16 Jens Thiele hat unter dem Titel Wurzelkinder und Honigpumpe (1990b; Titel bezieht sich auf Sibylle von Olfers' Etwas von den Wurzelkindern (1906) und Joseph Beuys' Honigpumpe (1977)) seine Überlegungen zum Verhältnis von Kunstmoderne und Bilderbuch zusammengefasst und die „Schwierigkeiten“ beleuchtet, „die freie Kunst und Gebrauchskunst miteinander hatten und haben" (ebd., 144).

17 Überblicke z. B. von Andreas Bode: Stilwandel im deutschen Bilderbuch 1950-2000 (2004) und Tendenzen im Bilderbuch von 1950 bis zur Gegenwart (2005).

18 Z. B. Annalena McAfee/ Anthony Browne 1984: Mein Papi, nur meiner! oder: Besucher die zum Bleiben kamen. 
Spätestens seit den 1990er-Jahren hat die Bilderbuchliteratur eigene Formen gefunden und ist heute vielfältig wie nie zuvor. Mediale Einflüsse, innovative, experimentelle Konzepte und traditionelle Gestaltungen bestimmen das Angebot mit, das in seiner Heterogenität ebenso für die Uneindeutigkeit der Moderne steht wie die Bildende Kunst, die sich kaum mehr auf Schwerpunkte festlegen lässt (vgl. ebd.). Das Nebeneinander verschiedenster Formen, Stile und medialer Gestaltungen - von der Malerei über die Fotografie, die Medienkunst und ihre begehbaren Installationen, die Konzeptkunst und andere visuelle Gestaltungen - zeichnet die Bildende Kunst als facettenreiches Spiegelbild der gegenwärtigen, bunten Welt aus, ist aber vielfach „ein Kunstprodukt, das sich nicht mehr aus der Anschauung erschließt“ (ebd., 172). Stand die Kunst bis etwa zur Mitte des 19. Jahrhunderts "noch im Dienste der Abbildhaftigkeit“, wurde sie zunehmend autonom und war nicht mehr dem mühelosen Verständnis verpflichtet wie noch die „auf handwerklich-technischer Fertigkeit basierende Naturdarstellung" (ebd., 144). Die Entfremdung von Kunst und Gesellschaft - womit nichts anderes gemeint ist als Kunst um der Kunst willen, dem individuellen Zugang anheimgestellt - findet ihre Entsprechung in den zunehmenden Entgrenzungen der Bilderbuchkunst seit der zweiten Hälfte der 1990er-Jahre als Nebenschauplatz einer Bilderbuchkultur, die weiterhin dem Kind und seiner Wahrnehmung verpflichtet und damit „Gebrauchskunst“ (ebd., 172) bleiben sollte.

Neben den literaturwissenschaftlichen und kunsthistorischen Anfragen müssen auch bildtechnische bzw. bildwissenschaftliche Disziplinen zum Entschlüsseln der Gestaltungskonzepte, Implikationen und Wirkungen von Bilderbüchern bemüht werden. Unter dem Begriff Bildwissenschaft sind zahlreiche Einzeldisziplinen zu einem ,integrative[n] Forschungsprogramm “19 zusammengefasst: Beiträge leisten die Kunstwissenschaft, die Kognitions- und Kommunikationswissenschaft, die Semiotik, die Medienwissenschaften, die Psychologie und Entwicklungspsychologie, die Erziehungswissenschaften, die Soziologie u. a. m. Es liegen unzählige Veröffentlichungen von Studien und Stellungnahmen zu Bild-Text-Konstellationen in medialen und intermedialen Zusammenhängen vor, denn die „Beziehung von Visualität und Verbalität, Bildern und Texten, ist eines der Schlüsselthemen der neueren Kulturwissenschaft" (Horstkotte/ Leonhard 2006b, 1). Die Schlagworte „,iconic turn“ (Boehm 1994) bzw. „pictorial turn“" (Mitchell 1994) stehen seit Mitte der 1990er-Jahre für die wachsende Bildhaftigkeit der Mediengesellschaft, deren Repräsentationen in Film, Fernsehen, Fotografie, Internet und anderen digitalen Formaten sowohl nach spezifischen

19 S. dazu ausführlich: Sachs-Hombach (2005). 
Rezeptionsformen als auch nach geeigneten Analysemethoden verlangen (vgl. Horstkotte/ Leonhard 2006b, 1).

So vielfältig die Erscheinungsweisen des Bildlichen und Sichtbaren, so vielseitig und komplex sind seine Interaktionen mit der Textualität. Entsprechend schwer überschaubar ist die neuere Forschungsliteratur zu Bild-Text-Beziehungen. [...] Umgekehrt, also von der Bildseite her - werden literarische bzw. narrative und narratologische Kategorien zunehmend auch auf visuelle Kunstwerke angewandt, ein Verfahren, das insbesondere für Fragen der Bild-Erzählung fruchtbar gemacht werden kann. (Ebd., 2ff.)

Die bildwissenschaftlichen Untersuchungen richten ihre Interessen an Text-BildGefügen hauptsächlich auf „das intermediale Mischgebiet von Bild und Text" (ebd., 8). Das Bild zum Text ist immer auch eine Überhöhung des Textes, wie der Text selbst ein sprachliches Mehr bietet. „In gleicher Weise wie die Illustration den Text konkretisiert, entfernt sie sich auch von ihm, entwirft in jedem Fall ihren eigenen Inhalt in ihrer eigenen Form“ (von Criegern 1996, 107), entfaltet aber nur gemeinsam mit dem Text die volle Aussagekraft. „Einseitige Aufmerksamkeit für Bild oder Wort führt zu Missverständnissen oder Bedeutungsverlust.“ (Abraham/ Sowa 2012,6) Die damit angesprochene, bei der Rezeption idealerweise sich vollziehende semiotische Verschmelzung von Bild und Text findet ihren Ausdruck im Begriff Ikonotext ${ }^{20}$, der in dem im Weiteren vorgestellten Erzählmodell des Bilderbuchs (Kap. III) Verwendung findet.

Mit dem ästhetischen Lernen an und mit Bilderbüchern in der Schnittmenge von Deutschunterricht und Kunstunterricht beschäftigt sich beispielsweise Dietrich Grünewald seit vielen Jahren und konstatiert:

Bilderbücher strukturieren und fördern grundlegend die visuelle Kompetenz. [...] Es geht nicht um Geschmackserziehung im Sinne einer Übertragung der Wertungen und Auswahl des Lehrers/der Lehrerin, sondern um die Möglichkeit, in vergleichender Auseinandersetzung mit unterschiedlichen Beispielen die Lesekompetenz mit der Wertungs- und Urteilskompetenz zu verbinden, nach Kriterien, die sich im kritischen Umgang mit Bilderbüchern entwickeln und - subjektiv - als sinnvoll erfahren werden. (Grünewald 1991, 40)

Diese Überlegungen liegen schon dem 1978 erschienenen Sonderheft KUNST + UNTERRICHT. PRAXIS DEUTSCH zugrunde, das deutschdidaktische und kunstdidaktische bzw. bildwissenschaftliche Anfragen an Text und Bild - Bild und Text zusammenbrachte. Die heute noch relevanten Beiträge besprechen die Funktion von Sprache in der kunstästhetischen Erziehung einerseits und die

20 S. Ausführungen zur Genese und Verwendung des Terminus' Ikonotext in: Horstkotte/ Leonhard 2006a. 
Funktion von Bildern im Deutschunterricht andererseits und leiten daraus Vorschläge für die Praxis ab.

Es liegt auf der Hand, dass bildwissenschaftliche Ansätze und Erkenntnisse hinsichtlich des Verstehens von Bildern - Visual Literacy, Bildkompetenz oder visuelle Kompetenz - auf das Bilderbuch übertragbar sind. Die Gesetze perspektivischer Gestaltung, Blickkonstruktionen und Farbwirkungen sowie andere bildtechnische Aspekte können am Bilderbuch-Bild und seiner Interaktion mit Sprache überprüft und für die Erforschung von literarischen Verstehensprozessen nutzbar gemacht werden. Welche Bedeutung der ästhetischen Bildung durch Wort und Bild, also dem Lesen-Lernen wie dem Bilder-lesen-Lernen für den Erwerb einer umfassenden Medienkompetenz zukommt, wurde bereits erkannt und bedarf weiterführender Konzepte in Lehr-Lern-Zusammenhängen, mit denen sich gerade die Bildungs- und Erziehungswissenschaften auseinandersetzen.

\section{II.1.3.3 Bildungs- und Erziehungswissenschaften}

Seinen unbestrittenen Platz im Leben behauptet das Bilderbuch vor allem durch seine zweifellos bildende Funktion im Prozess der literarischen Sozialisation von Kindern. Die Korrelationen zur Literaturdidaktik sind evident. Mit Bilderbüchern werden erste literarische Erfahrungen gemacht, die im Verbund mit den pädagogischen Implikationen psychologische und kognitive Entwicklungen in Gang setzen. 1977 erschien unter dem Titel Erziehungsziele in Bilderbüchern (Niermann 1977) ein der pädagogischen Perspektive verpflichtetes, höchst komplexes Analysemodell zur Untersuchung der offensichtlichen und impliziten Erziehungsziele in Bilderbüchern. Ein ähnliches Modell entwarf einige Jahre später Ottilie Dinges mit Fragestellungen zu einer umfassenden ästhetischen und didaktischen Analyse des Bilderbuches (Dinges 1984), das die zahlreichen Bildungsfunktionen von Bilderbüchern hinsichtlich einer literarischen, sprachlichen, ästhetischen, sozialen und emotionalen Entwicklung hervorhebt. Eine umfangreiche Analyse der Erfahrungswelt der Hauptpersonen legte Rüdiger von Hanxleden 1978 mit Bilderbücher für das Vorschulalter vor, womit er die damalige Vielschichtigkeit der Themen und Motive im Bilderbuch erfasste und für pädagogische Zwecke aufbereitete.

Für die Entwicklungspädagogik resp. Grundschulpädagogik konnte in verschiedenen Untersuchungsreihen zur Bilderbuchrezeption im familiären Kontext (Schneider 1995; Braun 1995; Wieler 1997) festgestellt werden, dass die i. d. R. vorlesenden Mütter die „Interaktionsstrukturierung beim gemeinsamen Bilderbuch-Lesen“ bestimmen und damit sowohl die Übernahme konventioneller Handlungsmuster als auch die Verstehensprozesse beim Kind nachhaltig 
beeinflussen (vgl. Blei-Hoch 2002, 70f.). Petra Wieler (1997) setzte in ihren Forschungen die Interaktionsstrukturen zwischen vorlesenden Müttern und ihren Kindern in Beziehung zum sozialen Milieu der Familien und stellte fest, dass die jeweilige soziale Herkunft bestimmte Handlungsmuster im Vorleseprozess bedingt und die Organisation des Vorlesedialogs maßgeblichen Einfluss auf die kindlichen Verstehensprozesse nimmt. Die bemerkenswerte Erkenntnis Wielers, dass dabei die Verstehensanforderungen der Bilderbücher selbst eine untergeordnete Rolle spielen, muss an anderer Stelle im Zusammenhang mit rezeptionsästhetischen Überlegungen und dem Anspruch an Kindgemäßheit diskutiert werden. Sicher aber ist daraus zu schließen, dass eine hohe literarästhetische Komplexität ebenso wenig ein grundsätzliches Ausschlussmerkmal für Rezeptionsvorhaben sein kann wie die Banalität von Kaufhausbilderbüchern. Dass im Kindesalter überhaupt gelesen wird, und das Wie des Lesens sind offenbar die wichtigsten Einflussfaktoren einer lebenslangen Lesekarriere.

In der Alltagspraxis ist das Bilderbuch „eingespannt in ein Netzwerk pädagogischer, entwicklungspsychologischer und kultureller Bildungsarbeit“" (Thiele $2007 c, 8)$. So verwundert es nicht, wenn Veröffentlichungen häufig auf eine pädagogisch-didaktische Instrumentalisierung des Bilderbuchs als Themenlieferant ausgerichtet sind (z. B. Oberhuemer et al. 1988; Schaufelberger 1990; Dietschi Keller 1995; Engelbert-Michel 1998; Kretschmer 2010; Hollstein/ Sonnenmoser 2006, 2007; Bardola et al. 2009). Die Monographien von Michael Sahr (1987 Problemorientierte Bilderbücher im Unterricht der Grundschule) und Heidi Rösch (1997 Bilderbücher zum interkulturellen Lernen) seien stellvertretend genannt. Dass aber mit Bilderbuchrezeption durchaus mehr als die Erschließung thematischer Inhalte verbunden wird, hat z. B. Hein Retter (1989) mit empirischen Befunden aus einer Befragung von insgesamt 223 Erzieherinnen und Lehrerinnen zu Beurteilungskriterien für Bilderbücher und ihren pädagogischen Zielsetzungen belegt. Die Ergebnisse bezeugen ein Bewusstsein der Pädagogen „für die Bedeutung des Kommunikationsaspektes"von Bilderbüchern (Retter 1989, 31). Auch die Aspekte der Phantasieförderung und die Entwicklung von Kritikfähigkeit rangieren demnach noch vor der Wissensvermittlung mit Bilderbüchern (vgl. ebd., 31ff.). Die Studie von Marie Luise Rau (2013) ist die gegenwärtig aufschlussreichste Darlegung von Wechselwirkungen zwischen Bilderbuchrezeption und kognitiver Entwicklung von Kindern im Alter von 1 bis 6 .

Neben den weiter oben genannten aktuellen Publikationen aus dem Bereich der Literaturdidaktik liegen z. B. Untersuchungen und Beispiele aus der Praxis mit dem Handbuch zur Bilddidaktik (Lieber 2013) vor, das die Vielfalt der Bildungschancen durch Bilderbuchrezeption (z. B. Hopp/ Lieber 2013) auffächert, 
und außerdem ein Sammelwerk über verschiedene empirische Miniaturstudien zum Einsatz von Bilderbüchern im Dienste medienpädagogischer Zielsetzungen (Lieber 2009). Darin werden die positiven Effekte einer gesteuerten Bilderbuchrezeption betont, umfassende, gesicherte Forschungsergebnisse zur Funktion und Wirkung des Umgangs mit Bilderbüchern in Bildungszusammenhängen sind jedoch noch rar. Auch die 2011 erschienene Rezeptionsstudie von Inge Rychener zur Entwicklung des Textverstehens von Zweitklässlern mit dem Bilderbuch Swimmy (Lionni 1963) ist nicht repräsentativ. Das Resümee, es sei „anspruchsvoller [...], ein Bilderbuch zu verstehen als ein bildloses Buch“" (Rychener 2011,345), ist so verallgemeinernd nicht haltbar.

Abschließend bleibt festzuhalten: Das wissenschaftliche Interesse am Bilderbuch ist deutlich geprägt durch Rezeptionsstudien im Bereich der Elementarund Grundschulpädagogik bzw. -didaktik. Die neuesten Veröffentlichungen zum literarästhetischen Potenzial des Bilderbuchs, vorwiegend hervorgegangen aus Forschungsinteressen an visuell-ästhetischen Lehr-/Lernzusammenhängen, bestätigen, dass eine gewinnbringende Auseinandersetzung mit den narrativen Konnotationen und wirkungsästhetischen Dimensionen des Bilderbuchs nur als interdisziplinäres Unterfangen denkbar ist. Dass das gegenwärtige Bilderbuchangebot teilweise auch hohen erwachsenen Ansprüchen an literarästhetische Komplexität gerecht wird und deshalb das Bilderbuch über die o. g. Ansätze hinaus in der allgemeinen literaturwissenschaftlichen Forschung mehr Beachtung verdient, wird im vorliegenden Kapitel III zur Theorie des Bilderbuchs deutlich gemacht.

\section{II.1.4 Exkurs: Das Bilderbuch in der DDR}

Die umfassendste bibliographische und literaturhistorische Aufbereitung der Gesamtheit der 1945 bis 1990 erschienenen intentionalen KJL der SBZ und DDR, darin das „sozialistische Bilderbuch“ (Bode 2006), dokumentiert Band 7 des Handbuchs zur Kinder- und Jugendliteratur (Steinlein/ Strobel/ Kramer 2006). Die wissenschaftliche Erkenntnislage zum Bilderbuch der DDR war während der Trennung der beiden deutschen Staaten ähnlich defizitär wie die der bundesrepublikanischen. So ist es „während der vierzig Jahre DDR nicht zu einer Erarbeitung einer grundlegenden Theorie des sozialistischen Bilderbuchs gekommen" (Bode 2006, 831). Eine Typologie des DDR-Bilderbuchs sucht man deshalb vergeblich; auch die Klassifizierung nach den Kategorien einer ideologischen Grundhaltung, wie Andreas Bode (ebd., 887ff.) sie in den Formen des „indoktrinierenden, des belehrenden und des kritischen Bilderbuchs" anbietet, ist nur der Ansatz eines Versuchs. Bode hat zwei maßgebliche „Zielrichtungen“ 
herausgearbeitet, die die sozialistische Bilderbuchkultur dem „sozialistischen Realismus" verpflichten:

1. Inhaltlich: Das sozialistische Bilderbuch hat den kindlichen Leser entsprechend den Prinzipien sozialistischer Erziehung zu einem sich der vorherbestimmten Gesellschaftsform einfügenden Menschen zu erziehen.

2. Künstlerisch: Die Art der künstlerischen Darstellung hat so zu erfolgen, dass sie die angestrebte sozialistische Wirklichkeit erkennbar wiedergibt. Von dieser Wirklichkeit wegführende oder sie aussparende Illustrationen sind nicht erwünscht; zum Abstrakten hin tendierende Illustrationen, die konkrete sozialistische Inhalte eo ipso nicht wiedergeben können, sogar streng verpönt. (Bode 2006, 831)

Bilderbücher der $\mathrm{DDR}^{21}$ waren hauptsächlich den Themen des Alltags verpflichtet und bemühten sich um eine möglichst realitätsnahe, selten (und dann nur subtil) auch kritisch gefärbte Darstellung (vgl. Feyerabend 1989, 54), die den Kindern die gesellschaftliche Wirklichkeit als Ort der sozialen Beziehungen vornehmlich zu Erwachsenen aufzeigte (vgl. Langenhahn 1993, 163).

Die Definitionsfrage stellt Heinz Kuhnert in seiner umfassenden Arbeit zum Bilderbuch der DDR bis 1975 und schreibt zum Begriff Bilderbuch:

Als Oberbegriff benennt er wohl einen Zweig der Kinderliteratur, dessen Inhalt und ideell-emotionaler Gehalt den gesellschaftlichen Erziehungszielen für zwei- bis achtjährige Kinder entspricht und überwiegend oder ausschließlich durch künstlerische Bilder ausgedrückt wird, aber als literarischer Terminus bleibt er für den Gesamtkomplex des Bilderbuchschaffens unpräzis und überaus allgemein. (Kuhnert 1976, 8)

Diese Einschätzung hindert ihn aber nicht daran, diesen Begriff weiterhin und synonym mit dem der „Bilderbuchgeschichte“ (ebd., 8) zu verwenden, ohne eine neue Explikation vorzunehmen. Er stellt allgemein fest, dass die „Entwicklung des Bilderbuches in der DDR gekennzeichnet [ist] durch Kunstsinn und Parteilichkeit, durch Kontinuität und wachsende Qualität", und hebt die besondere künstlerische Qualität des Bilderbuchschaffens hervor (ebd., 11ff.). Gleichzeitig moniert er, dass die „Möglichkeiten des Bilderbuches, frühzeitig gesellschaftliches Bewusstsein zu wecken und politische Einsichten und Impulse zu geben, [...] vielfach ungenutzt" blieben (ebd., 40).

Sandra Langenhahn fragt in ihrem retrospektiven Aufsatz nach den Unterschieden zwischen westdeutschen Bilderbüchern und denen der DDR und „welchen Niederschlag Uniformität und Heldenerziehung im Bilderbuch fanden“ (Langenhahn 1993, 162). Sie unterscheidet die Formen der phantastischen

21 Vgl. auch: Almanach zur Kinderliteratur der DDR (Deutsche Staatsbibliothek Berlin 1989). 
Erzählung, Kunstmärchen und Tiererzählung, die sich inhaltlich und ästhetisch, entgegen der bundesrepublikanischen „Tendenz zur Idylle und Realitätsferne“, den „Anforderungen, die der ,Sozialistische Realismus" vorgab, zu stellen" hatten (ebd., 163; H. i. O.). Kritisch geht Karin Richter (2002, 137f.) in ihrem Handbuchbeitrag Kinder- und Jugendliteratur der DDR mit den einschlägigen Arbeiten zur „kinderliterarische[n] Entwicklung im Osten Deutschlands“ ins Gericht, da diese, mitunter ohne das Material selbst aus objektiv distanzierter Sicht in Augenschein genommen zu haben, den sozialistisch gefärbten Blick auf das kinderliterarische Textkorpus übernommen hätten. Obwohl „die Bilderbuchgeschichte und die Literatur für jüngere Leser" nicht Gegenstand der Ausführungen Richters sind (ebd.), dürfte die Reichweite ihrer Erkenntnisse auch das Bilderbuch einschließen. Richter verweist auf eine "grundlegende Differenz, die in der Auffassung von Kindheit und deren literarischer Widerspiegelung in östlichen und westlichen Kinderliteraturen bestand“', denn in der DDR war Kindheit nie ein von der Erwachsenenwelt abgegrenzter Raum, sondern immer ein Teil der gesamtgesellschaftlichen Gegebenheiten und Entwicklungen (ebd., 157).

Zur im Rahmen der vorliegenden Dissertation relevanten Frage nach den thematischen Schwerpunkten im Bilderbuch der DDR stellt Wolfgang Feyerabend $(1989,56)$ fest, dass auch im Bilderbuch der DDR „Krankheit und Tod [...] zumeist ängstlich umgangen“" wurden. Zum gleichen Ergebnis kommt Heinz Kuhnert und resümiert:

Da gab es in beiden deutschen Literaturen Ähnlichkeiten der Tabuisierung: Tod, Altern, Sexualität, Krankheit, Behinderung u. a. Was in der BRD aber tradierter Schonraumpädagogik geschuldet war, folglich auch früher und konsequenter überwunden werden konnte, war in der DDR oft ein prinzipielles ideologisches Problem: Glück und Optimismus waren staatsbürgerliche Tugenden, also fanden Tod und Trauer in der Literatur fast niemals statt. (Kuhnert 1993, 127)

Aus diesem Grund umfasst das Textkorpus der vorliegenden Dissertation keine DDR-Bilderbücher, die einen Anlass zu Vergleichen hätten geben können.

\section{II.2 Sterben und Tod in der Kinder- und Jugendliteratur}

\section{II.2.1 Forschungslage zur Kinder- und Jugendliteratur}

Die wissenschaftliche Beschäftigung mit der Frage nach dem Vorkommen und der Darstellung der Trias Sterben, Tod und Trauer in der Kinder- und Jugendliteratur setzt im deutschsprachigen Raum erst in den 1980er-Jahren ein. Am Ende dieser Dekade „verdichtet sich die Auseinandersetzung mit der Thematik“ zunehmend (Krebs-Dijksma 1988, 109), ohne allerdings in der Folge größere 
literaturwissenschaftliche Untersuchungen hervorgebracht $\mathrm{zu}$ haben. Der Schwerpunkt liegt eindeutig im Bereich der Religionspädagogik, während die Jugendliteraturforschung bis heute zurückhaltend mit diesem Thema umgeht. Es lassen sich lediglich Erkenntnisfragmente aus verschiedenen Einführungen, Handbüchern und den wenigen, als Einzeluntersuchungen angelegten Arbeiten zum literarischen Tod im Kinder- und Jugendbuch herauslesen. Mehrheitlich sind die Veröffentlichungen kaum anderes als Ansammlungen von Rezensionen und Empfehlungslisten. Im Folgenden werden die wichtigsten Publikationen aufgeführt, die entweder literaturwissenschaftliche Aspekte berücksichtigen und/oder inhaltsanalytische Schwerpunkte setzen.

In Amerika veröffentlichte Francelia Butler bereits 1972 einen Aufsatz mit dem Titel Death in Children's Literature, mit dem sie auf die Zusammenhänge „Zwischen gesellschaftlicher Entwicklung, Kinder- und Jugendliteratur und der Thematik von Sterben und Tod“ hinweist, die sich in der zweiten Hälfte des 18. Jahrhunderts in der Herausbildung einer spezifischen Kinderliteratur mit nützlich-moralischen Anspruch in Verbindung mit einer "kommerziellen Ausbeutung " zeigten (Butler 1972, zit. in: Krebs-Dijksma 1988, 107). ${ }^{22}$ Während aber die untersuchten Märchen und Sagen eine „direkte Ermutigung zur Hoffnung auf ein Leben nach dem Tode und ein einfaches Annehmen des Todes" transportierten, werde das Thema Tod ,in der modernen Literatur für Kinder [...] tendenziell oberflächlich oder geringschätzig, erschreckend inhuman und unpersönlich abgehandelt" (ebd.) $)^{23}$. Für die deutschsprachige Kinderliteratur erschien 1978 der erste recherchierte Aufsatz zum Thema Tod mit dem Titel Begegnung mit dem Tod. Das Sterben ist kein Tabu in Kinderbüchern. Dort heißt es:

Im Kinder- und Jugendbuch, ja vereinzelt sogar im Bilderbuch, ist in den letzten Jahren das Thema Tod aufgegriffen worden, sei es, dass er im Handlungsablauf ein prägendes Ereignis darstellt oder aber gar zum zentralen Thema erhoben wird. (Jugendliteratur 1978, 7)

Dagegen spricht die Jury des Deutschen Jugendbuchpreises 1978 in ihrer Begründung für Elfie Donnellys ausgezeichnetes Werk Servus Opa, sagte ich leise (1977) vom Tod in der Kinderliteratur als „bisher verdrängtes, allenfalls umschriebenes, meist geleugnetes, [...] tabuisiertes Problem" (zit. in Rabl 1979, 122). Diese These bildete die Ausgangslage für die Dissertation von Josef Rabl

22 Ähnliche Ergebnisse führt die literaturhistorische Aufbereitung der deutschen Kinderliteratur an, auf die im folgenden Kapitel Bezug genommen wird.

23 Für die deutschsprachige Kinderliteratur konnten ähnliche Untersuchungsergebnisse nicht recherchiert werden. 
(1982), der sich als einer der ersten intensiv mit der Frage nach dem Ob und Wie der Darstellung von Sterben und Tod in der zeitgenössischen Kinderliteratur beschäftigte (Rabl 1979; 1981; 1982). Seine religionspädagogische Aufarbeitung derjenigen Werke, die auf den Auswahllisten des Deutschen Jugendbuchpreises von 1971 bis 1976 standen, widerlegt zwar die o. g. These vom Ausschluss der Todesthematik, denn etwa die Hälfte der 92 untersuchten Kinderbücher enthält Hinweise und Anspielungen auf den Tod, andererseits waren aber nur ,in etwa einem Dutzend“ Tod und Sterben „wenigstens teilweise zum handlungstragenden Element" erhoben worden (Rabl 1979, 122). In einer der wenigen deutschsprachigen Monographien zur Todesthematik im Kinderbuch kommt Ingun Spiecker-Verscharen zu dem Schluss, dass die untersuchten Texte (7 Kinderromane, 2 Bilderbücher) „das Thema mehr oder weniger verkürzt“ angehen, beim Leser ein bereits „fortgeschrittenes Todesverständnis“ voraussetzen und, „daß Empfindungen, die mit Tod und Sterben verbunden sind, nach wie vor weitgehend tabuisiert werden" (Spiecker-Verscharen 1982, 137ff.).

Sterben und Tod in der Kinderliteratur der 1970er und 1980er Jahre untersuchte Gundel Mattenklott (1994). Sie zeigt Variationen dieses „Erwachsenenthema[s]“ (ebd., 230) an ausgewählten Beispielen der kinderliterarischen Auseinandersetzung mit dem Tod auf und lässt angesichts der an Zahlen festzumachenden Bereitwilligkeit der Kinderbuchautoren, „vom Tod zu schreiben“, den immer wieder angeführten Tabustatus ${ }^{24}$ für die Kinderliteratur nicht mehr gelten (ebd., 237f.).

Für die religionspädagogische Praxis setzten sich Christoph Bodarwé (1989), Veronika Arens (1994) und Martina Plieth (2005; 2009), im Kontext der Elementarerziehung Kathleen Paul (2008) mit Alter und Tod ausführlich auseinander. Plieths Analysen sind hervorzuheben, weil sie auf einem komplexeren, auf literarästhetische Aspekte ausgerichteten Analysekonzept basieren, aufgrund der subjektiven Auswahl des schmalen Untersuchungskorpus' jedoch einer kritischen Überprüfung bedürfen, insbesondere hinsichtlich der Aussagen, „religiöschristliche Motive“ kämen „in den reinen Bilderbüchern eher selten und wenn überhaupt, dann nur am Rande vor“ (Plieth 2009, 155) und „das Lebensende von Kindern oder Jugendlichen sowie jungen Erwachsenen komm[e] nicht in den Blick“ (ebd., 154).

24 Die Rede vom Tod als Tabuthema hält sich trotz der unzählbaren einschlägigen Veröffentlichungen bis heute hartnäckig. Zur kulturwissenschaftlichen Diskursanalyse im Rahmen der Thanatologie formuliert Frank Kelleter: „Die Aussage, das Thema sei tabuisiert, wird nun gewissermaßen selbst zum konstitutiven Bestandteil des Diskurses." (Kelleter 2002, 7) 
Der Lexikonartikel von Claus Ensberg (2006) bezieht sich auf Tod und Sterben in der erzählenden Kinder- und Jugendliteratur der zurückliegenden etwa 30 Jahre und stellt die Auswahl einzelner Bilderbücher, Kinderbücher, Jugendbücher und Sachtexte in die Traditionslinien der Aufklärung und Romantik. Ensberg konstatiert, „dass die thematisch einschlägigen Texte mit zunehmendem Alter der Adressaten, an die sie sich wenden, vermehrt an die Tradition aufklärerischen Denkens anknüpfen“ und der Gottesglaube kaum noch eine Rolle spiele (ebd., 42).

Erwähnenswert sind außerdem die Tagungsbände der Katholischen Akademie DIE WOLFSBURG in Mülheim an der Ruhr, wo seit vielen Jahren immer wieder die Auseinandersetzung mit den religiösen Dimensionen in der Kinderliteratur in Rahmen vieler Veranstaltungen angeregt wird (Fährmann et al. 1997f.; Göcking/ Eckhold 1989; Born 1989, 2003; Kammhuber 1989), sowie der Sammelband von Jürgen Heumann (2005) mit dem Beitrag Religiöse Vorstellungen in neueren Kinderbüchern zum Thema ,Sterben, Tod und Traurigkeit' von Martina Plieth. Daneben versammelt die Herausgeberschrift Gestatten: Gott (Langenhorst 2011) verschiedene Aufsätze zur religiösen Ausrichtung von Kinder- und Jugendbüchern, die auch das Thema Tod und Sterben berühren.

Die 2010 veröffentlichte (medizinische) Dissertation von Katharina Betina Duhr trägt zwar den Titel Tod und Sterben in der modernen Kinder- und Jugendliteratur, bringt aber mit dreißig wenig differenzierten Kurzanalysen von Kinder- und Jugendbüchern (davon 15 Bilderbücher) keinerlei Erkenntnisgewinn hervor. Weitere kürzere, erwähnenswerte Abhandlungen liegen von folgenden Autoren vor: Schindler (1981), Sahr (1986), Fischer (1987), Dankert (1988), Raecke-Hauswedell (1988), Schmidt-Henkel (1990), Reil (1994), Schmidt-Dumont (1998). Ausgewählte Einzelanalysen von Kinder- und Bilderbüchern, in denen vorzugsweise die Lebensgeschichte und das Sterben eines alten Menschen Gegenstand des Erzählens sind, finden sich unter anderem bei Wülfing (1986), Pries-Kümmel (2005) und Wülfrath-Wiedenmann (1987, 1990, 1992). Veröffentlichungen, die sich explizit mit dem Thema in Bilderbüchern beschäftigen, werden im vorliegenden Kapitel II.2.3 aufgeführt.

Das wachsende Angebot der themenbezogenen Primärtexte griffen auch Zeitschriften mit ihren ausgewiesenen Themenheften zum Tod auf: Fundevogel 27/1986; Informationen des Arbeitskreises für Jugendliteratur 3/1988; Eselsohr 3/ 1988, 2/1998, 11/2000; 1000 und 1 Buch (TueB) 1/1990, 1/1991,4/2004; Bulletin Jugend + Literatur 5/1990; JuLit 1/09; kjl\&m 10.4,13.1.Zahlreiche Empfehlungslisten finden sich zudem in Broschüren und Online-Dateien von Hospizen, in Herausgeberschriften wie den Veröffentlichungen des Deutschen Verbandes Evangelischer 
Büchereien e.V. und den periodischen Katalogen Christliche Kinder- und Jugendbücher der Deutschen Akademie für Kinder- und Jugendliteratur e.V. Volkach. Weitere kommentierte Listen von Bilder-, Kinder- und Jugendbüchern sind z. B. vom Pädagogischen Zentrum Berlin (Brandt 1989, 1995), von der Studien- und Beratungsstelle für KJL in Wien (STUBE 1998) und zur Ausstellung Last minute des Stapferhauses Lenzburg/ Schweiz (Fassbind-Eigenheer 1999, 2005) veröffentlicht worden. Eine allgemeine systematische Erfassung der Kinderliteratur zum Tod, die mit literaturhistorischen wie literaturwissenschaftlichen Untersuchungen zu verbinden wäre, liegt bisher nicht vor.

\section{II.2.2 Historischer Rückblick}

Im folgenden historischen Abriss werden allgemeine Tendenzen des Auftretens von Tod und Sterben in der deutschsprachigen Kinderliteratur der vergangenen etwa 260 Jahre aufgezeigt und einzelne Werke exemplarisch hervorgehoben. Eine umfassende differenzierte Untersuchung bleibt weiteren kinderliteraturhistorischen Forschungen vorbehalten. Da das Bilderbuch im Fokus der vorliegenden Untersuchung steht, wird im Anschluss an das folgende in einem eigenen Kapitel darauf eingegangen.

Die notwendige Eingrenzung der infrage kommenden Texte ist aus literaturwissenschaftlicher Sicht allein schon durch die Frage nach dem Leitthema eines Textes begründet. Dennoch kann eine leitmotivisch verengte Sicht hier nicht zielführend sein, da der Tod seit jeher in vielerlei Erscheinungsformen in der Kinder- und Jugendliteratur auftritt, auch ohne ausgewiesenes zentrales Thema zu sein. Es werden schlaglichtartig Schwerpunkte der Darstellung des kinderliterarischen Todes nachgezeichnet, wie sie sich seit der zweiten Hälfte des 18. Jahrhunderts, dem, wie es oft heißt, Jahrhundert der Pädagogik, mit dem Entstehen eines eigenständigen Handlungssystems Kinder- und Jugendliteratur zeigen. ${ }^{25}$ Auch wenn dem Zeitalter der Aufklärung die Erfindung der Kindheit nicht zugeschrieben werden $\mathrm{kann}^{26}$, hat die deutschsprachige Kinder- und Jugendliteratur dem „Wandel in der Bewertung von Kindheit“ (Wild 2008a, 57) nachhaltige

25 Die vor dieser Zeit gebräuchlichen Bilderbibeln, Bilderfibeln, illustrierten Fabelbücher und ABC-Bücher für Kinder (vgl. Hurrelmann 2008) bleiben unberücksichtigt.

26 Dieter Richter vertritt die These, dass die „zunehmende Beachtung, die Kindern und dem Status Kindheit während der Jahrhunderte der Neuzeit geschenkt wird, [...] nicht wachsender Nähe, sondern wachsender Distanz zwischen Erwachsenen und Kindern geschuldet“ sei (Richter 1987, 25). Von einer fehlenden Sensibilität früherer Jahrhunderte für Kindheit und Kinder und der Auffassung, „Kindheit sei eine Erfindung der Neuzeit“, könne grundsätzlich nicht die Rede sein, und insofern 
Impulse hinsichtlich der Maxime ihrer inhalts- und formalästhetischen Adressatenangemessenheit bzw. Kindgemäßheit und ihrer pädagogisch-didaktischen Intentionen zu verdanken (vgl. ebd., 43), weshalb an dieser Stelle die weiteren Ausführungen ansetzen.

In der Kinderliteratur der Aufklärung ist das Todesthema „ein realistisches Moment" (ebd., 57). Allerdings bildete die literarische Wirklichkeit, abgesehen von den Warngeschichten (s. w. u.), nicht die tatsächlichen Gegebenheiten der immer noch hohen Sterblichkeit und insbesondere der Kindersterblichkeit dieses Zeitalters ab, sondern vielmehr das Wunschbild einer vom Tod nicht betroffenen bürgerlichen Familiensituation, in der in Gesprächen vom Sterben, auch vom Kindertod, zwar die Rede ist, jedoch nicht im eigenen Familienkreis (vgl. ebd.).

Im Zuge der neuen Wertigkeit des Kindes in der zweiten Hälfte des 18. Jahrhunderts, die sich auch in der veränderten Einstellung zur nicht mehr als gottgegeben hingenommenen Kindersterblichkeit zeigte, „wird Kindheit eines der zentralen Themen der Literatur" (Richter 1987, 28). Im Zeitalter der Aufklärung wurde das „Faszinosum der Kindheit“, gebunden an den „kindlichen, den rohen und unzivilisierten Status des Kindes“, zum Tätigkeitsfeld von erziehenden Erwachsenen, die Kinder als unverbildetes Rohmaterial betrachteten, wie „Wachs in des Schöpfers Hand“, das durch Erziehung zum zivilisierten Menschen geformt werden müsse (ebd., 26; H. i. O.). Es ging um mahnende Unterweisung und Anleitung zum tugendhaften, moralischen Grundsätzen folgenden Lebenswandel, ohne wirklich am Kind und seinem „Eigen-Sinn und Eigen-Leben“ interessiert zu sein (ebd.). Diese Sicht auf Kindheit spiegelt sich in den für die Kinderliteratur der Aufklärung bezeichnenden „moralischen Erzählungen oder Beispielgeschichten; ihre Ausgestaltung gehört zu den kinderliterarisch wichtigen Leistungen der Epoche“ (Wild 2008a, 73). In den Warn- oder Unglücksgeschichten wurde in pädagogisch-didaktischer Absicht von der Allgegenwärtigkeit des Todes im Erfahrungsbereich der Kinder erzählt, denn Kinderleben war vielfach bedroht: Krankheiten, mangelnde Hygiene und Armut führten dazu, dass nur "die Hälfte der Bevölkerung ein Alter von zehn Jahren“ (Weber-Kellermann 1997, 25f.) erreichte. Kindheit ist in diesen „Kinderunglücks-Geschichten “27

sei das „Bild, das Ariès (1973) von der Geschichte der Kindheit gezeichnet hat, [...] in manchem Punkt korrektur- und ergänzungsbedürftig“ (Richter 1987, 18f.).

27 Sie finden sich zum Beispiel in den 37 Bänden der Kleinen Kinderbibliothek von Joachim Heinrich Campe, die als das „das erste literarisch-pädagogische Monumentalprojekt der damals neu entstehenden Kinder- und Jugendliteratur" gelten (Richter 1987, 42). 
eine Phase der erhöhten Lebensgefahr, in der der Tod als ein zumindest temporär vermeidbares Risiko erscheint, das es durch Beachtung moralischer Grundsätze und Verhaltensregeln zu vermeiden gilt. ${ }^{28}$ Erstmals in der Geschichte der Kinderliteratur agierten Kinder als Helden, deren Schicksal, als drastische Folge eines (Fehl-) Verhaltens, ein oft tödliches war (Richter 1987, 43). Die „Todesdrohung" ist das Instrument der aufgeklärten Pädagogik, und zwar nicht im Sinne des Unabwendbaren, des Memento mori, sondern eben mehr als Vermittler von „Lebensangst", denn dem kindlichen Verhalten war die Gefahr des selbst verschuldeten Unglücks immanent (ebd., 81f.). Der Tod war nicht Ausdruck autoritärer Strafverhängung, sondern eine natürliche Folge, der ein „neuer Begriff von Strafe" (ebd., 52) zugrunde lag, wie er auch noch für heutige Erziehungsmodelle gilt. Die „Strafinstanz Natur“ (ebd., 53) ahndete z. B. den von Naschsucht getriebenen Griff nach dem mit Arsen versetzten Zucker mit dem Tod; allzu weites Hinauslehnen aus dem Fester zog ,natürlich' einen tödlichen Sturz nach sich, und wer sich trotz Warnung auf dünnes Eis begab, brach unweigerlich ein und ertrank (vgl. ebd., 43). Drastische Beschreibungen und bildliche Darstellungen führten den Schrecken im Wortsinne buchstäblich vor Augen.

Ein ganz anderes, konträr zur Aufklärung stehendes Kindheitsbild zeichnete die Romantik. Reiner Wild betrachtet die „neuen romantischen Kindheitsvorstellungen“ als „für die Kinderliteratur wohl folgenreichste Veränderung am Ende des 18. Jh.s" (Wild 2008a, 95). Bis heute ist die von der Romantik postulierte Nähe zwischen Kind und „Naturpoesie“29 für Teile der Kinder- und Jugendliteratur konstitutiv. Während das aufgeklärte Kindheitsbild „die Lebenslinie als

28 S. dazu ausführlich: Dieter Richter (1987); Richter geht auf vielfältige Facetten der Kinder- Unglücksgeschichten ein und zeigt Entwicklungen auf, die, kurz gefasst, von der warnenden Beispielgeschichte zum Kinder-Alltagsverhalten, zu dem das verbotene Naschen ebenso gehört wie das todbringende Onanieren (ebd., 51), über die „neue Version des seligen Sterbens“ (ebd., 100), die für die bekennende Erkenntnis der Verunglückten steht, sich selbst schuldig gemacht zu haben, bis zum bösen Kinderstreich der Wilhelm Busch- Geschichten reicht. Auf eine differenzierte Besprechung verzichtet die Verfasserin aus pragmatischen Gründen und vor dem Hintergrund der Tatsache, dass das warnende Erzählen vom Tod im untersuchten Textkorpus des 20. und 21. Jahrhunderts keine Rolle mehr spielt.

29 Synonym der Romantik für Volksliteratur: Sammlung der „vergessene[n] Lieder, Märchen, Sagen und Volksbücher, die den naiven, kindlichen Menschheitszustand widerspiegeln sollten“ (Doderer 1973, 99). Für die Märchen stehen besonders die Brüder Grimm ein: „Innerlich geht durch diese Dichtung dieselbe Reinheit, um deretwillen uns Kinder so wunderbar und seelig erscheinen." (Aus der Vorrede von 1812, zitiert in Ewers 2008, 112). 
wachsende Entfernung von der Kindheit“ zeichnet, steht das der romantischen Gegenbewegung für den „Versuch der Verschmelzung mit dem Verlorenen, als Rückkehr in die Kindheit" (Richter 1987, 27; H. i. O.). Kindheit erfuhr in der Romantik eine „immense Aufwertung“ dergestalt, dass das kindliche Gemüt „als ein ungetrübter Widerschein des Göttlichen begriffen“"wurde, wohin Erwachsene nur aufblicken konnten (Ewers 2008, 99). Sowohl für die Früh- als auch die Spätromantiker waren die „Nähe zum Unendlichen, Selbstverständlichkeit des Wunderbaren, Einblick in die Geheimnisse der Natur und Reichtum der Fantasie [...] die Kennzeichen der kindlichen Geistesart" (ebd., 103). Folglich wurden die aufgeklärten, moralisch-belehrenden Gattungen abgelehnt und stattdessen die ihrerseits von der Aufklärung verschmähten „folkloristischen Formen wie Ammenverse, Volkslieder, Märchen, Sagen, Legenden und Volksbücher“ im romantischen Literaturangebot favorisiert (Weinkauff/ von Glasenapp 2010, 44). Darin hatte der Schrecken des Todes nicht den Platz, der ihm von der aufklärerischen Literatur eingeräumt wurde. Für die Märchen gilt sogar, dass in ihnen, im Gegensatz zu den Kinderunglücksgeschichten, „der Tod auf verschiedene Weisen um- und hintergangen wird“ (Mattenklott 1994, 232), da sie „die herrschenden Bedingungen außer Kraft setzen. Und auch jene elementarste Bedingung der Welt, wie sie ist, wird in ihrem utopischen Spiegelbild außer Kraft gesetzt: daß die Menschen sterben“ (Richter 1982, 135). Der Tod ist in Märchen und Sagen nicht gänzlich ausgespart, aber vielfach als Scheintod und „Übergang zum Weiterleben" (Wülfing 1986, 76) auf den Sieg des Guten über das Böse ausgerichtet (z. B. Grimm: Schneewittchen); das Böse muss sterben, oftmals in drastische Szenarien gekleidet. Die Kinder- und Hausmärchen von Jacob und Wilhelm Grimm (1812-1815; 1819), zunächst ganz der „Idee einer absichtslosen, naturpoetischen Kinderliteratur" (Ewers 2008, 112) verschrieben ${ }^{30}$, erzählen auch von

30 Die Brüder Grimm lehnten zunächst alle Formen einer spezifischen Kinderliteratur ab, da die Ausrichtung auf einen Adressatenkreis ihrem Verständnis von „Naturpoesie“ widersprach. „Als wahre Kinderliteratur kann für Jacob Grimm nur eine Naturpoesie gelten, die bar aller kunstpoetischer Zutaten ist.“ (Ewers 2008, 107) Später war diese Position jedoch nicht mehr haltbar und die Grimms veränderten die aufgezeichneten „Volksmärchen“ z. B. durch Eliminierung nicht kindgerechter Ausdrücke und grausam-drastischer Beschreibungen nach und nach zu „Kindermärchen“ (Ewers 2008, 111ff.). Obwohl auch die Grimmschen Märchen „bestimmte Ideale, ein bestimmtes Bild vom Kind und vom Menschen“ vermitteln und also moralische Lehren enthalten, ,sind sie keine explizit moralischen Geschichten“ (Richter 1987, 228), da die Lehre „,wie eine gute Frucht aus einer gesunden Blüthe, ohne Zutun der Menschen“ (Wilhelm Grimm, zitiert in Richter 1987, 228) aus den Märchen erwachse. 
Versuchen, dem Tod auszuweichen (Grimm: Die Boten des Todes) oder ihn gar zu hintergehen, nachdem sich der Mensch auf einen Handel mit ihm eingelassen hatte (Grimm: Der Gevatter Tod).

Mit E. T. A. Hoffmanns Kindermärchen Nußknacker und Mausekönig (EA 1816) trat an die Seite der Volkspoesie ein weiteres „Erzählmodell romantischer Märchendichtung“, das „Wirklichkeitsmärchen“, das als „Ursprung der modernen fantastischen Kindererzählung“ gilt (Ewers 2008, 119). Mit der Uneindeutigkeit der Vermischung von Wirklichkeit und Phantasie, die in den fließenden Grenzen zwischen der realistischen Lebenswelt der Protagonistin Marie und der phantastischen Welt der belebten Spielzeugfiguren und der Heerscharen des Mausekönigs liegt, provozierte Hoffmann zwei mögliche Lesarten des Märchens: die des kindlichen, dem Wunderbaren sich überlassenden Lesers und die des erwachsenen Lesers, der den der Realität verpflichteten Blick der Eltern Maries übernimmt und die seltsamen nächtlichen Geschehnisse in der Spielzeugwelt dem Fieberwahn des Mädchens zuschreibt (vgl. ebd., 119f.). Besonders die Schlussszene, in der Marie vom jungen Drosselmeier zur Hochzeit in ein Wunderland geführt wird, zeigt diese Zweideutigkeit auf: Einerseits ist der Schluss als ein märchenhaft-glückliches Ende, andererseits aber auch „mit gutem Grund als euphemistische Umschreibung des Todes“ (ebd., 120) aufzufassen.

Im Biedermeier kamen als weitere Spielarten der „schillernden Vielfalt“ der Märchendichtung die Märchen von Wilhelm Hauff und die ins Deutsche übersetzten Mährchen und Erzählungen für Kinder des dänischen Dichters Hans Christian Andersen hinzu (ebd., 124). Eindeutiger als E.T.A. Hoffmanns Märchen sind diese Märchenerzählungen ,in einem geheimnisvollen Zwischenreich von Wirklichkeit und Zauberwelt“ angesiedelt (Schikorski 2003, 60) und ,in die Bahnen einer, sei es idyllischen, sei es sentimentalen Märchendichtung für Kinder" (Ewers 2008, 123) zurückgekehrt. Viele der Märchen, wie beispielsweise Der standhafte Zinnsoldat, ,thematisieren tiefes Leid und enden mit einem glorifizierten Tod" (Schikorski 2003, 60).

$\mathrm{Zu}$ einem „Hauptträger der biedermeierlichen Literatur für junge Leser“ wurde die „Moralische Geschichte“, die die „Exempeltradition“ der aufklärerischen Geschichten um „literarische Elemente wie Dialog, Naturschilderungen, Rahmenhandlungen oder überraschende Wendungen" erweiterte und damit „immer literarischer" wurde (Pech 2008, 134). Einer der wichtigsten Vertreter dieser biedermeierlichen Kinderliteratur war Christoph von Schmid, durch dessen Werke „die Entwicklung der Moralischen Geschichte zur langen Erzählung, gar zum Roman entscheidend forciert worden“ war (ebd., 137). Seine betont religiös-moralischen Geschichten trafen den Nerv der Zeit: die religiöse 
Grundstimmung wie auch das gewachsene Bedürfnis nach Unterhaltung. Das „schier unübersehbare Ausufern von Moralischen Geschichten à la Schmid“ wurde einerseits begünstigt durch den erhöhten Bedarf an Lesestoff aufgrund des starken Bevölkerungswachstums und steigender Lesefähigkeit, dem die technisch-gewerbliche Modernisierung des Buchmarktes entsprechen konnte, andererseits trug auch die Not der Autoren, niedrige Honorare mit Quantität auszugleichen, dazu bei (ebd., 139). Die „Schilderungen von Marterszenen, Blutvergießen, Mord, Durst- und Hungerqualen und kriegerischen Gräueln“, aus denen der tugendhafte Held siegreich hervorgeht, bestimmten die „neue Form unterhaltsamer Kinderliteratur“ (ebd., 141). Daneben leisteten auch die Tiergeschichten und Fabeln einen Beitrag zur Präsenz von Hässlichkeit, Gewalt und drastischen Todesszenarien in der Kinderliteratur (vgl. Hurrelmann 2008, 171).

1845 erschien dann ein Bilderbuch, das als eines der ersten im heutigen Sinne bezeichnet werden kann: Der Struwwelpeter von Heinrich Hoffmann. Als Reaktion auf das in seinen Augen unbefriedigende kinderliterarische Angebot entwarf der Frankfurter Nervenarzt für seinen dreijährigen Sohn zum Weihnachtsfest 1844 Bilder und Geschichten von ungehorsamen Kindern und den Folgen ihres Fehlverhaltens. Als Lustige Geschichten und drollige Bilder mit 15 schön kolorierten Tafeln für Kinder von 3 bis 6 Jahren erstmals unter Pseudonym veröffentlicht und 1847 mit dem endgültigen Titel Struwwelpeter (vgl. Pech 2008, 142) ) $^{31}$ versehen, zählen die Geschichten und Bilder vom Feuertod Paulinchens, vom Tod des Suppenkaspers und von anderen schrecklichen Vorkommnissen zu den wohl verbreitetesten literarischen Todesszenarien der Welt. Heute ist der Struwwelpeter das bekannteste Bilderbuch aller Zeiten. Viel und kontrovers diskutiert, ist dessen großer und überaus nachhaltiger Erfolg aber weniger dem moralisierenden Warncharakter der Geschichten zuzuschreiben, sondern mehr der seinerzeit neuen „Form der karikierenden Bildgeschichte“ (Richter 1987, 107), d. h. ihrer karikaturistischen Theatralik, die den Unglücksgeschichten einen neuen Unterhaltungswert verschaffte (vgl. Hurrelmann 2008b, 168).

In diesen unterschwelligen Tendenzen zu Subversion und Anarchie liegt das Erfolgsgeheimnis des Bilderbuchklassikers, der selbst die ideologiekritischen Angriffe in den siebziger Jahren des 20. Jhs. überstand. (Schikorsky 2003, 59)

Mit dem Aufkommen der Kinderstreich-Geschichten in der zweiten Hälfte des 19. Jahrhunderts, hauptsächlich Wilhelm Buschs Bildergeschichten (v. a. Max und Moritz 1865), wandelte sich „die moralische Unglücksgeschichte“ zur

31 Die bis heute übliche Form und Reihenfolge der Geschichten wurde erst mit der 29. Auflage im Jahr 1849 festgelegt (vgl. Hurrelmann 2008b, 167). 
unterhaltsamen Darstellung lustvoll inszenierter Normverstöße und moralischer Grenzüberschreitungen (Richter 1987, 107). Die oft sadistischen Strafen bzw. Todesszenarien der Bildergeschichten „können als Zugeständnis an die moralischen Anforderungen des gerade kritisierten und verspotteten Bürgertums angesehen werden" (Pech 2008, 144). Die Kinderstreiche sind darin ein einziger Angriff auf die spießige Bürgerlichkeit und in ihrer Boshaftigkeit gleichzeitig Ausdruck der Lust am Ausleben eines Machtgefühls, das der kindlichen Vitalität entspringt (vgl. Hurrelmann 2008b, 179ff.). Der Tod ist nicht allein die verdiente Strafe, sondern gleichzeitig der kalkulierte Preis für den Spaß, den die heimtückischen Verletzungen der Moral und tugendhaften Ordnung den bösen Buben Max und Moritz einbringen. Mit Hoffmanns und Buschs Werken, die „wie unter einem Brennglas“ (Pech 2008, 142) die Traditionslinien der Unglücks- und Warngeschichten der Aufklärung und der biedermeierlichen Moralgeschichten in Wort und Bild bündeln, wurden das aufklärerische und das romantische Kindheitsbild um das „Bild des bösen Kindes“ (ebd., 145) ergänzt.

Das parodistische Spiel mit der moralischen Beispielgeschichte, das er [Busch; M.H.] immer wieder betreibt, hat selbst einen doppelten Boden: Busch ergreift keineswegs Partei für seine `Helden`, er erhebt keinen Einspruch dagegen, dass sie wirklich als ১böse $`$ zu qualifizieren sind und dass ihrem Unwesen Einhalt geboten werden muss. (Hurrelmann 2008b, 184; H. i. O.)

Neben den verunglückten Kindern der aufklärerischen Warngeschichten und ihren Folgeformen, wie den mit dem Tod bestraften Kindern in den Kinderstreich-Geschichten, wurde im 19. Jahrhundert noch ein weiterer „Typus des sterbenden Kindes“ bedeutsam: „das schwindsüchtige Kind“ (Mattenklott 1994, 231). Der Tod ist dabei ein „sanftes Hinüberschlummern, ein Hinübergehen in eine bessere Welt; der Sterbende ergab sich demütig in sein Schicksal und war gar noch fähig, die Zurückbleibenden zu trösten und zu belehren“ (Rabl 1981b, 190). Beispiele für ein solch romantisch-unschuldiges Sterben auf einen Tod hin, der als „ein sanfter, blumiger Tod“ für ein (gott-) gefälliges und duldsames Leben belohnt, sind die Kinderschicksale in Johanna Spyris Geschichten (Gritlis Kinder 1883/ 1884) oder George MacDonalds Hinter dem Nordwind (1871) (vgl. Rabl 1981b, 190).

Im 20. Jahrhundert spielte die Verklärung des Todes „,weiterhin gern als sanfte Auszehrung, noch nach 1945", eine Rolle, ebenso wie auch der heldenhafte Tod (Mattenklott 1994,231).,Anders als die Märchen erzieht diese Kinderliteratur, in welch unterschiedlichen Bildern auch immer, zur widerspruchslosen Hinnahme des Todes." (Ebd., 233) Ganz anders geschieht Sterben in den Reise- und Abenteuerromanen und der „modernen Kriegsprosa“ des ausgehenden 19. bis zum 
ersten Drittel des 20. Jahrhunderts (Wilkending 2008, 236). Todesfälle sind entweder Unglücksfälle, Folge eines erhöhten Risikos in abenteuerlichen $\mathrm{Zu}$ sammenhängen oder die unvermeidbare Folge in Kampfes- und Verteidigungsszenarien.

\section{Nach 1945}

In den ersten Jahren nach dem Ersten Weltkrieg erschienen für das junge Publikum einige wenige Bücher, die die schrecklichen Erfahrungen der Kriegsjahre zu verarbeiten suchten und nichts beschönigten (vgl. Mattenklott 1994, 234). Als „das beste der Autorin und eines der gelungensten Bücher dieser Zeit“ (ebd.), das abwechselnd aus der Perspektive von sechs Kindern von ihren ambivalenten Emotionen angesichts des Todes erzählt, hebt Gundel Mattenklott Die Kinderwiese (Hertha von Gebhardt 1947) hervor. Insgesamt aber war die Nachkriegszeit geprägt von einer restriktiven Tendenz, die im stillschweigenden Konsens die „Flucht ins Harmlos-Idyllische“ (Steinlein 2008, 316) antrat und jegliche Bezüge zur jüngsten Vergangenheit, insbesondere zur Schuld an der nationalsozialistischen Katastrophe vermied.

Die 1950er- und 1960er-Jahre -

„Kinderliteratur der Kindheitsautonomie“ (Ewers)

In den 1950er-Jahren war dann der Literaturmarkt wieder „intakt“ (Steinlein 2008, 323). In der „Differenzierung und Diversifizierung der Themen, Genres und Schreibstile" hatten auch wieder Kampf und Eroberung einen Platz (ebd.). Herausragendes Merkmal der neuen Kinderliteratur der 1950er- und 1960erJahre ist die Entpädagogisierung des Erzählens, da nicht mehr moraldidaktische Ziele verfolgt wurden, sondern der Kindheit ein neuer Eigenwert zugebilligt wurde. Vorreiter bzw. Anstifter dieser „Kinderliteratur der Kindheitsautonomie“, des Prinzips der neuen "Gestaltung bevormundungsfreier kindlicher Lebens- und Spielräume“ (Ewers 1995, 17), ist Astrid Lindgren ${ }^{32}$, deren Pippi Langstrumpf (1949, OA S 1944) eine lustvoll-autonome Kinderfigur ist, die eine groteske Überlegenheit gegenüber Erwachsenen an den Tag legt und trotz moralischer Verfehlungen (Lügen etc.) Bewunderung hervorruft. Solche Konzeptionen, die dem „kindlichen Lustprinzip“ (Ewers 1992, 127) frönen, boten der

32 Der Erfolg der Werke Astrid Lindgrens legt es nahe, von einer „Lindgren- Ära“ in den 1950er-Jahren zu sprechen (Ewers 1995, 17). 
Problematik von Tod und Sterben keinen Raum. ${ }^{33}$ Die gegen Ende der 1950erJahre „auffallende[...] Zunahme von Kinder- und Jugendbüchern zum Thema >Judenverfolgung “" repräsentierte dann eine "Wiedergutmachungsliteratur", die als Reaktion auf antisemitische Schmierereien und das Erstarken rechtsradikaler Parteien wie auch auf die Erkenntnis, die politische und zeitgeschichtliche Bildung vernachlässigt zu haben, zu deuten ist (Steinlein 2008, 335; H. i. O.).

Ein Beispiel für das zunehmend kritische, realistische Erzählen in den 1960er-Jahren ist die auch in der DDR veröffentlichte pazifistische Erzählung Sadako will leben (1961) von Karl Bruckner, der als wichtigster der „wenigen Repräsentanten eines gesellschaftskritischen Realismus in der Jugendliteratur der 50er Jahre" (Steinlein 2008, 325) gilt. Erzählt wird vom tatsächlichen Schicksal des japanischen Mädchens Sadako Sasaki, das zehn Jahre nach dem Atombombenabwurf über Hiroshima infolge der atomaren Verstrahlung im Alter von 12 Jahren an Leukämie erkrankte und verstarb. ${ }^{34}$

Die 1970er-Jahre - Dualismus von realistischer und phantastischer Wende Der kinderliterarische Paradigmenwechsel, auch als realistische Wende bezeichnet, der um 1970 die Öffnung des Kinder- und Jugendbuches für alle Aspekte der kindlichen und jugendlichen Lebenswelt ${ }^{35}$ markiert, ist als literarische Reaktion auf die neuen gesellschaftlichen und pädagogischen Konzepte mit ihren Liberalisierungstendenzen in der Folge der 1968er-Bewegung anzusehen. Mit Beginn der 1970er-Jahre beschäftigte sich die "Literatur des Daseinsernstes“ (Ewers 1995, 25) mit dem Kindsein als problematischer Lebensphase, war „insgesamt einem sozialkritischen Realismus verpflichtet“ (Weinmann 2013, 314) und konfrontierte den kindlichen Leser auch mit dem Tod. Mit dem „Schritt von der Bewahrungs- zur Bewährungspädagogik“ (Rabl 1981b, 190) und der Aufnahme der zahlreichen unterschiedlichen Erscheinungsformen von Sterben und

33 Dass Pippi Langstrumpf mutterlos ist und fern vom Vater ihr Leben lebt, ist nicht mehr als eine Information, die die Autonomie des Kindes nur unterstreicht.

34 Diese Geschichte erschien 1995 als Bilderbuchfassung in der Bearbeitung von Eleanor Coerr (Text) und Ed Young (Ill.). S. a. das Bilderbuch von Heike Ellermann (1990): Papiervogel, flieg!

35 „Politik, Sozialkritik, familiäre und schulische Probleme, pubertäre und adoleszente Erfahrungen der Sexualität, Drogen, Kriminalität und Gewalt, die Umwelt, Atomkraft und Atomausstieg, Ausländerproblematik, die nationalsozialistische Vergangenheit etc." (Wild 2008b, 345). 
$\operatorname{Tod}^{36}$ in das kinderliterarische Themenrepertoire drückte sich eine so bestimmende „Hinwendung zur Realität“ (Wild 2008b, 345) aus, dass Ottilie Dinges (1974, 66; H. i. O.) feststellte:

Im Kinderbuch eine "heile Welt« darzustellen ist jedenfalls der schlimmste Vorwurf, den Autor und Verlag sich derzeit einhandeln können - Un-Heil und Un-Glück zu präsentieren scheint dagegen geboten zu sein.

Neben der realistischen und problemorientierten Kinder- und Jugendliteratur gewann - weniger in Konkurrenz als in Koexistenz - die phantastische Literatur für Kinder und Jugendliche immer mehr an Bedeutung und eine neue „Vielfalt und Diversität“ bestimmten das Angebot (Wild 2008b, 346). Der „einschneidende Themen- und Formenwandel" bezog auch ein wieder erwachtes Interesse an Märchen und Sagen mit ein, die sich um anthroposophische Motive, Totenreiche und paradiesische Wunschwelten ranken (Ewers 1995, 23). In deren Tradition stehen die zu Kultbüchern avancierten Bestseller der Phantastik: Der Herr der Ringe (Tolkien, 1969/70, OA GB 1954/55), Momo (Ende 1973), Die Brüder Löwenherz (Lindgren 1974, OA S 1973) und Die unendliche Geschichte (Ende 1979). Sie markierten eine neue Qualität kinderliterarischer Phantastik.

Astrid Lindgren, die mit ihren Geschichten schon die „Kinderliteratur der Kindheitsautonomie" (Ewers 1995, 17) maßgeblich bestimmte, hat mit Die Brüder Löwenherz (1974; OA S 1973) auch einen neuen Umgang mit thanatologischen Problemen und Fragestellungen angestoßen. Dieses Buch war Anlass für eine neue und intensive Diskussion über den Tod und darüber, was Kindern dazu erzählt werden darf. Die von Lindgren als Überschreiten phantastischer Grenzen dargestellten Todesszenarien haben neben der Anerkennung der komplexen Mehrdeutigkeit des Romans auch zu heftiger Kritik geführt. Die Geschichte sei „todessüchtig“ (Mattenklott 1994, 250), verharmlose bzw. verherrliche den Tod und animiere zum Suizid. Dem ist zweierlei entgegenzuhalten: zum einen die doppelte Lesart - als Geschichte der transzendentalen Erfahrung von Unsterblichkeit wie auch als phantastische Abenteuererzählung (vgl. Ensberg 2006, 5) -, zum anderen belegen die zahlreichen positiven Zuschriften kindlicher Leser, dass von dieser Erzählung offensichtlich keinerlei Gefahr ausgeht.

In der zweiten Hälfte der 1970er-Jahre entwickelte sich dann die „neuere Kinderliteratur über den Tod“ (Mattenklott 1994,238) mit märchenhaft-phantastischen wie auch realistischen Konzeptionen. Das Neue des kinderliterarischen

36 Als eine weitere kinderliterarische Variante gehören dazu auch die Werke der jüdischen Kinder- und Jugendliteratur (Völpel 2008), die Kinder- und Jugendliteratur der NS-Zeit (Josting 2008a) sowie die Exilliteratur (Josting 2008b). 
Erzählens drückte sich aber nicht nur thematisch, sondern auch formal im "Aufgreifen erwachsenenliterarischer Erzählmuster" aus, wodurch die Rezeptionsanforderungen „eklatant“ anstiegen (Ewers 1995, 24f.). Für die komplex angelegten Langformen der neuen KJL etablierte sich „der Oberbegriff ,moderner Kinderroman “" (Weinmann 2013, 318; H. i. O.), womit die Einstufung der Kinderliteratur als Einstiegsliteratur quasi aufgehoben war (vgl. Steinz/ Weinmann 2002, 125). Insbesondere der Wechsel der Erzählperspektive - an die Stelle des auktorialen erwachsenen Erzählers traten der kindliche Ich-Erzähler und das kindlich-personale Erzählen - ist für den Großteil der kinderliterarischen Werke des 20. Jahrhunderts und ihre Psychologisierung konstitutiv (vgl. Weinmann 2013, 318). Diese neue Form macht auch in den Erzählungen, die den Tod thematisieren, den hervorstechendsten erzähltechnischen Unterschied zu den Todes- und Unglücksgeschichten des 18. und 19. Jahrhunderts aus. Neben der Zurücknahme der pädagogisch-didaktischen Intentionen der Warngeschichten bestimmten mehr und mehr die Perspektive eines kindlichen Protagonisten und der „Blick ins Innere“ (Lypp 1989) das realistische Erzählen von Lebensumständen und Begebenheiten aus dem kindlichen Alltag, der sowohl mediale als auch reale Begegnungen mit dem Tod einschließt.

\section{Die 1980er-Jahre bis zur Gegenwart}

Dass Kinder sich mit Fragen zu Tod und Sterben beschäftigen, vor allem auch mit dem eigenen Tod, schlug sich im Laufe der 1980er-Jahre immer deutlicher in der Kinder- und Jugendliteratur nieder. Sterbeprozesse und Todesszenarien kamen ohne die Drastik der aufklärerischen Unglücksszenarien aus und unterlagen auch kaum mehr einer romantischen Verklärung (vgl. Mattenklott 1994, 238). Ein eindrucksvolles Beispiel für die neue Qualität und Komplexität kinderliterarischen Erzählens ist Erzähl mir von Oma von Guus Kuijer (1981) ${ }^{37}$, in dem die Erinnerungsgeschichte über Vergangenheit und Lebensumstände der verstorbenen Großmutter als angeregtes Gespräch zwischen Großvater und Enkelin angelegt ist. ${ }^{38}$

37 Altersempfehlung ab 8 Jahre; 1982 ausgezeichnet mit dem DJLP in der Sparte Kinderbuch.

38 Für die Erzählkonzepte dieser modernen Kinderromane spielen die Grundannahmen der in den 1970er-Jahren aufkommenden Rezeptionsforschung eine wesentliche Rolle. Die wichtigsten Vertreter, Wolfgang Iser und Robert Jauß, gehen von dynamischen Prozessen zwischen Text und Leser aus und weisen damit dem Leser eine gestaltende Funktion im Leseprozess zu. Gerade für die Auseinandersetzung mit den elementaren Fragen der menschlichen Existenz sind die komplexeren Erzählformen 
War das kindorientierte Erzählen vom Tod bis in die 1980er-Jahre noch wenig ausdifferenziert, hatte schon Ende der 1980er-Jahre „der Tod Konjunktur in der Kinderliteratur“ (Mattenklott 1994, 238), was mit geringer Verzögerung auch für das Bilderbuch gilt. Das Spektrum des Erzählens vom Tod erstreckt sich seitdem auf nahezu alle Facetten des Lebensendes: Tod durch eine Vielzahl verschiedener Anlässe und Ursachen, vom Alterstod über Suizid bis zum Mord; Tod von Großeltern, Freunden, Eltern, Geschwistern, anderen Verwandten und Bekannten, Sterben von Haustieren und anthropomorphisierten Tieren in Tiergeschichten. Auch das Erzählen vom Kindertod, z. B. aus der Perspektive betroffener Geschwister (Mebs 1982: Birgit; Zeevaert 1986: Max mein Bruder) oder selbst sterbender Kinder (z. B. Nicholls 2008: Wie man unsterblich wird) sowie philosophische Konzepte, die ohne ein konkretes Todesereignis auskommen, und Sachbücher zum Werden und Vergehen in der Natur haben ihren Platz. Entweder wird mit dem Tod die Vorstellung vom Übergang in eine neue Daseinsdimension markiert (z. B. Fessel 1999: Ein Stern namens Mama), oder der Unsterblichkeitsgedanke, das Nicht-hinnehmen-Wollen des absoluten und unumkehrbaren Endes drückt sich in Gedächtnisritualen aus, die vorgeben, den Verstorbenen durch symbolhafte Erinnerung lebendig halten zu können. Andere Konzepte bieten keine tröstende Antwort auf die Frage nach dem Danach, sondern lassen die letzte Frage offen und die Welt sich unbeeindruckt weiter drehen (z. B. Richter 2004: Hechtsommer).

Die Vermeidung der Darstellung kindlicher Todesängste scheint in der einschlägigen KJL lange „das wahre Tabu zu sein - man redet und schreibt zwar vom Tod, aber nicht von der Angst“ (Mattenklott 1994, 247). Neuere Werke lassen dagegen auch die Frage, ob sterben wehtue (Nicholls 2008: Wie man unsterblich wird), ebenso zu wie die bange Frage nach der Beschaffenheit des Danachs. Inwieweit Religiosität in der KJL zum Tod zum Ausdruck kommt, oder ob der „Glaube an Gott als die im Abendland für ,letzte Fragen` zuständige Instanz [...] in kaum einem Text mehr eine Rolle" (Ensberg 2006, 42; H. i. O.) spielt, muss an anderer Stelle näher untersucht werden. Insgesamt zeichnet sich in der KJL aber offenbar eine beschwichtigende Zuversicht hinsichtlich der Erträglichkeit des Todes ab (vgl. ebd.). Das derzeit wieder verstärkte Interesse an religiösen Inhalten der KJL belegt der Sammelband Gestatten: Gott (Langenhorst 2011) mit den wichtigsten Befunden der letzten Jahre. Gundel Mattenklott $(2011,27)$ spricht darin gar von Gott als einem "neuen Protagonisten“ in der KJL, eindeutige

der modernen Kinderliteratur geeignet, entsprechende Verständnis- und Verarbeitungsprozesse in Gang zu setzen. 
Tendenzen scheinen aber insgesamt nicht auszumachen zu sein, vielmehr zeigt sich eine Koexistenz verschiedener Facetten des Erzählens rund um die Todesthematik.

Außerhalb der familiären Kontexte, auf die sich die psychologischen Kinderromane beziehen, erhält der Tod in den 1980er-Jahren auch eine apokalyptische Dimension in den Katastrophengeschichten der Kinderliteratur, darunter als spektakulärste Gudrun Pausewangs Die Wolke (1987). Solche Konzeptionen spielen aber eine lediglich marginale Rolle (vgl. Mattenklott 1994, 239f.).

Im Bereich der phantastischen KJL dürften die Harry-Potter-Bände (Rowling 1997ff.), die Tintenwelt-Trilogie von Cornelia Funke (2003ff.) und auch die Eragon-Bände (Christopher Paolini 2004ff.) die vorläufigen literarischen Höhepunkte dieses Zweiges der KJL sein, der seit den 1970er-Jahren einen ungebrochenen Aufschwung verzeichnet. In diesen phantastischen Entwürfen ist der Tod zwar eine ständige Bedrohung, gleichzeitig aber vermögen die mit magischen Kräften ausgestatteten Protagonisten seine Wirkmacht auf die irdische Sterblichkeit aufzuheben oder zumindest einzuschränken. Neueste Ausprägungen sind derzeit die zahlreichen Geschichten über Vampire und andere Untote, die spätestens seit Stephenie Meyers Bis(s)-Bänden (2006ff.) und ihren medialen Adaptionen große, generationsübergreifende Aufmerksamkeit erzielten. Auch beispielsweise die Shonen Jump Mangas (Ohba/ Obata 2007) mit Serienmorden und mörderisch-selbstverliebten Besitzern von sogenannten Deathnotes, deren Gebrauch umgehend zum Tod der namentlich Verzeichneten führt, zählen dazu, ebenso wie aktuelle Comics und Graphic Novels ${ }^{39}$, womit jedoch das Bild vom Tod in der Kinder- und Jugendliteratur längst nicht vollständig gezeichnet ist.

\section{II.2.3 Die Enttabuisierung des Bilderbuchs und das kindliche Ich}

Der kinderliterarische Paradigmenwechsel zum Beginn der 1970er-Jahre mit seiner Öffnung für alle bis dahin tabuisierten Themen hat mit dem Thema Tod den Bilderbuchsektor erst viele Jahre später erreicht. Noch bis in die 1980er-Jahre spielten Bilderbücher über Sterben und Trauer nur eine marginale Rolle auf dem kinderliterarischen Markt (vgl. Murken 1983, 31). Erst danach wurden die bis dahin ausgeblendeten Themen und das Aufgreifen der künstlerischen, psychologischen und pädagogischen Tendenzen dieser Umbruchzeit bestimmend für das moderne Bilderbuch. Als herausragende Beispiele in der Anfangsphase der Bearbeitungen des Todesthemas haben Leb wohl, lieber Dachs (Varley 1984, OA GB 1984) und Abschied von Rune (Kaldhol/ Øyen 1987, OA N 1984) einen 
Klassikerstatus erreicht, der bis heute Maßstäbe setzt. Dass diese ersten Werke Übersetzungen aus dem europäischen Ausland waren, ist bezeichnend für die bis dahin der Bewahrpädagogik verpflichtete bundesrepublikanische Zurückhaltung im Bilderbuch. Wie gezeigt werden wird, hat jedoch die Ausweitung des genuin deutschen Angebotes nicht lange auf sich warten lassen.

Die Darstellungen des kindlichen Ichs im Bilderbuch sind eng verbunden mit den historisch sich wandelnden Vorstellungen von Kindheit. Die bis weit ins 20 . Jahrhundert reichende Utopie von Kindsein als einem Zustand unbeschwerten Daseins wich verstärkt seit den 1960er-Jahren der Erkenntnis, dass Kinder autonome Wesen mit ganz eigenen Gefühlswelten sind, die mit einer konfliktreichen und vielfach belasteten Umwelt umzugehen haben. Ein Klassiker und frühes Beispiel für die Psychologisierung des Bilderbuchs und ein die kindliche Innenwelt inszenierendes Darstellungskonzept ist Maurice Sendaks Wo die wilden Kerle wohnen (1967; OA USA 1963).

Die - zunächst zögerliche - Öffnung des Bilderbuchs für die gesellschaftskritischen Themen einer zwischen Kindern und Erwachsenen verhandelbaren Realität in den 1970er-Jahren erforderte auch neue Formen der Darstellung, besonders bezüglich der psychischen Konstitution von Kinderfiguren. Erst diese Psychologisierung des Bilderbuchs im Zuge des veränderten Blicks auf das Kind und seine spezifische Daseinsform, die mit zahlreichen Entwicklungsaufgaben und Problemen verbunden ist, schuf auch die Voraussetzungen für eine Beschäftigung mit Sterben und Tod, die mehr als eine Distanz haltende Außenperspektive zulässt. Seitdem ist in der Bilderbuchliteratur die „Auseinandersetzung mit dem kindlichen Ich-Bewusstsein" eines der zentralen Motive (von Stockar 2009, 59). Im vorliegenden Textkorpus bestätigen dies die Bearbeitungen existenzieller und zugleich kindlicher Fragestellungen zu den Bedingungen von Leben und Tod und im Speziellen das Teilkorpus zum Tod im Kindesalter (Kap. VII).

Selbstsuche [...] bleibt ein autonomer Akt. Er besteht aus einer Reihe von Aktivitäten, Begegnung mit dem Fremden, Vergleich mit dem Vertrauten, Subjekterweiterung durch Identifikation, Selbsterfahrung in der Realität, Erkenntnisgewinn. (Lypp 2009, 71)

In diesem Sinne entspricht gerade die Auseinandersetzung mit literarischen Stoffen und ihren Figuren einer Selbstsuche, die neue Perspektiven eröffnet und zur Identitätsfindung beiträgt.

Die Beschäftigung mit Bilderbüchern zur Trias Sterben, Tod und Trauer ist auch eng verbunden mit dem Bestreben, Material für Gespräche mit betroffenen Kindern und Erwachsenen zusammenzutragen. In den bereits genannten kurzen Abhandlungen mit ihrer Beschränkung auf inhaltliche Aspekte zeigt sich einmal mehr, dass Bilderbücher häufig auf ihre Funktion als Themenlieferant reduziert 
werden. Die Vielzahl der praxisorientierten Handreichungen und Empfehlungen mit (religions-) pädagogischer, didaktischer oder psychologischer Ausrichtung richten mit der Zusammenstellung von Titeln, teilweise mit Kurzangaben zum Inhalt, das Augenmerk hauptsächlich auf die Brauchbarkeit für einen präventiven oder unterstützenden Einsatz im Rahmen von Trauerbegleitung und Trauerverarbeitung. Einzelne hervorzuhebende Aufsätze mit didaktischem Schwerpunkt, die sowohl literarästhetische Kriterien als auch psychologische und pädagogische Überlegungen in ihre Analysen mit einbeziehen, liegen von Michael Sahr (1986, 1987, 2000), Ottilie Dinges (1990), Erika Fischer (1994), Gerlinde Unverzagt (2007) u. a. vor. Für die psychologische Praxis hat Barbara Cramer $(2008,2012)$ das bisher umfassendste Textkorpus von Bilderbüchern zu Sterben und Tod aufbereitet und mit Altersempfehlungen versehen. Die jüngst von Florinne Egli (2014) veröffentlichte Publikation zu „Sterben und Tod in ausgewählten Bilderbüchern der Gegenwart" (Untertitel) greift literaturwissenschaftliche Fragestellungen auf, geht aber über Einzelergebnisse aus Analysen von „33 zufällig ausgesuchten Bilderbüchern“ (ebd., 11) kaum hinaus. Dem Forschungsdesiderat der systematischen literaturwissenschaftlichen Erfassung und Analyse der deutschsprachigen Bilderbücher zur Trias Sterben, Tod und Trauer nach 1945 widmet sich die vorliegende Forschungsarbeit unter Anwendung des im Folgenden dargestellten narratologischen Modells der Bilderbuchanalyse. 



\section{Zur Theorie des Bilderbuchs}

\section{III.1 Das Verhältnis von Sprach- und Bildebene - der Ikonotext}

Das Bilderbuch ist ein „Genre der KJL, das durch die Wechselbeziehung von Bild und Text charakterisiert ist und sich durch ein Erzählen in bzw. mit Bildern auszeichnet" (Blei-Hoch 2006, 56f.; s. a. Nodelman 1988; Nikolajewa/ Scott 2001; Thiele 2011 u. a.)..$^{40}$ Eine Sonderform stellen die textfreien Bilderbücher dar, die ausschließlich in Bildern erzählen. Neben der quantitativen Bilddominanz (vgl. Grünewald 1991, 17) kann aber auch die „epische Narrativität“ (Zöhrer 2010, 101) der Bilder ${ }^{41}$ für eine Gattungszuweisung bestimmend sein. „Bild wird hier im erweiterten Sinne der Bildwissenschaft verstanden: ein Bild ist ein gestaltetes visuelles Angebot ästhetischen und geistigen Gehalts." (Grünewald 1989, 5) Der Begriff „Erzählbild“ (Zöhrer 2010, 103) impliziert den narrativen Charakter des Bilderbuchbildes und setzt sich damit deutlich von den Illustrationen im Kinderbuch $\mathrm{ab}$, die lediglich eine schmückende, entbehrliche Zugabe zur verbal erzählten Geschichte darstellen und entsprechend als Paratext oder „paratextuelle Illustration" (ebd., 102) bezeichnet werden können. Unscharf wird die Grenzziehung zwischen Bilderbuch und illustriertem Kinderbuch aber immer dann, wenn die Bilder eine eigene erzählerische Qualität aufweisen und einen Beitrag zum Erzählganzen leisten, obwohl der Verbaltext aufgrund seines Umfangs autonom wirkt. Diese Unschärfe ist für jeden Einzelfall zu klären. Auch die Fülle der Möglichkeiten, Geschichten in verschiedenen Bildstilen wie Collage, Graphik oder Malerei, Karikatur, Fotorealismus, Abstraktion etc. darzustellen, muss mitgedacht, kann aber hier nicht weiter aufgefächert werden, zumal „eine kunsthistorisch versierte Auseinandersetzung mit dem B. und die Entwicklung

40 Einen Vorschlag zur Verwendung der in der Fachliteratur nicht einheitlich gebrauchten Begriffe Genre und Gattung machen Ulf Abraham und Julia Knopf (2014,3ff.) im Theorieband der Reihe Deutschdidaktik für die Primarstufe (Bd. 1). Dieser entspricht nicht dem hier zitierten Genrebegriff von Claudia Blei-Hoch, was die Verfasserin dazu veranlasst hat, im Folgenden von der Gattung Bilderbuch und ihren Subgattungen zu sprechen. Der Begriff Genre wird lediglich zitierend verwendet.

41 Die verbreitete synonyme Verwendung der beiden Begriffe Bild und Illustration für den visuell erfahrbaren Teil des Erzählten im Bilderbuch wird deshalb im Folgenden weitgehend vermieden. Zur Bevorzugung des Begriffs Bild vgl. Thiele 2003a, 72f. 
einer fachsprachlichen Terminologie für die Analyse des B. bis heute aussteht" (Kümmerling-Meibauer 2012, 150; Abk. i. O.).

Die gängige, bildwissenschaftliche Typologie unterscheidet narrative Bilder formell nach „zwei Ordnungsprinzipien“: nach der Anzahl der auf einer Bildfläche dargestellten Szenen und der Anzahl der Bilder (Varga 1990, 360). Daraus ergeben sich vier Kategorien jeweils unterschiedlicher Komplexität: monoszenische und pluriszenische Einzelbilder und ebensolche Bilderreihen. Einzelbilder sind monoszenisch angelegt, wenn sie eine aus dem Handlungsverlauf herausgegriffene Momentaufnahme eines Einzelgeschehens darstellen, pluriszenische Einzelbilder (auch Simultanbilder genannt) zeigen dagegen mehrere Szenen, die oftmals auch in eine zeitliche Ordnung gebracht werden können und „dem Zuschauer eine ganze Geschichte suggerieren“ (ebd.); daneben gibt es Bilderreihen, in denen die Gesamtheit der Einzelbilder gemeinsam eine Geschichte erzählt. Diese Kompositionen sind für alle im Weiteren genannten „Bild-Text-Interdependenzen“ (Thiele 2003a, 65ff.) ebenso möglich wie die Bild-Bild-Montagen, deren Gesamtaussage sich aus dem AufeinanderBezogensein entweder nebeneinander oder ineinander montierter Bilder bildet. Die Bezeichnung „Bild-Bild-Montage“ ist der Filmwissenschaft entlehnt und meint das im Auge des Betrachters korrespondierende Zusammenwirken „getrennte[r], unterschiedliche[r] Bildinformationen zu einem übergeordneten Vorstellungsbild, wenn zwischen den Bildern bestimmte formalästhetische oder inhaltlich-symbolische Beziehungen bestehen“ (ebd., 68f.). Diese können auch miteinander kollidieren, wenn sich die „verbindende assoziative Kraft“ in der Montage ,zweier unterschiedlicher, aber zugleich analoger Bilder oder Bildmotive" zeigt $^{42}$ (ebd., 70).

Bild- und Sprachebene können einander gleichen, sich widersprechen oder ergänzen, sie können gleichberechtigt nebeneinander und mit wechselnden Rollen agieren, „aber sie können vielleicht auch miteinander konkurrieren. Der Text kann das Bild bereichern, aber auch profanieren und umgekehrt" (Bringeus 1995, 26). Für die Varianten der verschiedenen Bild-Text-Interdependenzen, die möglichen Bezüge und Rückwirkungen zwischen Text und Bild, werden von Jens Thiele

42 Thiele (2003a, 70) führt als Beispiel Die Kinder vom Meer von Solé Vendrell (1992) an. Die Buchmitte fungiert als Trennlinie zwischen zwei unterschiedlichen Vorstellungsbildern von einer Reise in die Unendlichkeit (ebd.): Auf der einen Seite ist eine märchenhafte Traumvorstellung abgebildet und auf der anderen der erwartbare Trip nach Drogenkonsum. 
(2002, 230ff.) drei zentrale Kompositionen definiert: Bild-Text-Parallelität ${ }^{43}$, die kontrapunktische Beziehung und der "geflochtene Zopf “, im Weiteren alternierendes Erzählen genannt. Der „Normalfall“ im Bilderbuch ist das parallele Erzählen, bei dem Sprach- und Bildebene sich in ihrer Aussage entsprechen, ohne sich einfach zu doppeln (ebd., 230), denn die Spezifik der beiden medialen Ebenen bedingt eine je eigene Darstellungsweise mit sich voneinander abhebenden Informationen (vgl. Nodelman 1991, 1).$^{44}$ Narrative Bilder gehen auf ihre je spezifische Weise über die Erfahrungsmöglichkeiten der Sprachebene hinaus, ebenso wie der Verbaltext Informationen bereithält, auch deiktische Aspekte, die auf der Bildebene keine Entsprechung finden können. Der Betrachter ist immer aufgefordert, die „produktive Korrespondenz beider Erzählschichten“ zu erfassen wie auch „Sprünge zwischen den Bildern und narrative Zwischenräume durch eigene assoziative Leistung abzudecken“ (Thiele 2003b, 70). Eine besondere Herausforderung stellen die kontrapunktisch konzipierten Bilderbücher dar, in denen Wort und Bild konträr zueinander stehen, wie z. B. dann, wenn das Bild nicht der gängigen Vorstellung vom sprachlich Beschriebenen entspricht. ${ }^{45}$ Text und Bild können aber auch abwechselnd die Aufgabe des Erzählens übernehmen und dabei jeweils die volle Aufmerksamkeit des Rezipienten für sich beanspruchen, in dessen Vorstellung sich dieses alternierende Zusammenspiel, ähnlich

43 Marlene Zöhrer unterscheidet in Ihrer Untersuchung der Transformationen von Weltliteratur ins Bilderbuch die Bild-Text-Parallelität („Bildebene konkretisiert lediglich die Vorstellung des Textinhalts, übernimmt somit eine illustrierende Funktion“), vom akzentuierenden Bild (Übertragung einzelner „Handlungselemente der Textebene [...] in den Bildtext") und dem amplifizierenden Bild (Hinzufügungen oder Ausschmückungen auf der inhaltlichen Ebene der Bildnarration). Sie geht davon aus, dass ein umfangreicher Verbaltext es nahezu unmöglich mache, „ihn umfassend auf die Bildebene zu übertragen“, weshalb von einem parallelen Erzählen nur im Fall einer Bilddominanz bzw. „einem ausgeglichenen Verhältnis von Bild- und Textumfang“ ausgegangen werde könne; Bilddominanz gelte nur für Bücher, „die den herkömmlichen Kriterien eines Bilderbuchs entsprechen (max. 32 Seiten, unter 1000 Worte)“, nicht für „Text-Bilderbücher“. (Zöhrer 2010, 139ff.) Diese an der Quantität ausgerichtete Begriffsexplikation widerspricht m. E. dem Charakter des Erzählbildes, dessen erzählerische Leistung eben nicht in der passgenauen Doppelung der verbalen Erzählebene zu finden ist, sondern in seinem spezifischen Beitrag zum Erzählganzen, der sich auch in der Ausgestaltung eines einzigen Moments der erzählten Geschichte findet.

44 " $[\mathrm{T}]$ he basic differences in the nature of the two media mean that pictures inevitably convey a different kind of information from words, and do it in different ways." (Nodelman 1991, 1).

45 Z. B.: Prinz Alfred (Heidelbach 2012). 
der Struktur eines geflochtenen Zopfes, zu einem Erzählganzen zusammenfügen muss (vgl. Thiele 2002, 232).

Die formale und inhaltliche Interaktion der beiden semiotischen Systeme, im Verbund mit einem „dritten, obgleich unsichtbaren Teilnehmer: [dem] Kontext“ (Bringeus 1995, 32), bestimmt in jedem Fall das gemeinsame Sinnkonstrukt, das mit dem Terminus Ikonotext ${ }^{46}$ erfasst werden kann. Demnach sind Ikonotexte das Ergebnis einer aufeinander bezogenen „Kopräsenz von Wörtern und Bildern" (Horstkotte/ Leonhard 2006b, 8), die von unterschiedlichen Rezipienten je unterschiedlich wahrgenommen und gedeutet werden kann und gerade im Bilderbuch vorzufinden ist. ${ }^{47} \mathrm{Da}$

zwischen Bild und Text narrative, dramaturgische und ästhetische Wechselbeziehungen in prinzipiell unbegrenzter Form stattfinden können, die weit über die konventionelle Beziehung von Text und Buchillustration hinausgehen (Thiele 2001,38),

ist für die Theoriebildung zum Bilderbuch der Begriff Ikonotext der gegenwärtig brauchbarste. Es gilt somit:

Das Erzählen im Bilderbuch ist definiert über die Unauflöslichkeit der Beziehungen zwischen Bildebene und Sprachebene und ihrer Synthese im Ikonotext.

Dieser Definition ist auch das besondere Format der textfreien Bilderbücher inhärent, obwohl diese auf der Oberfläche nur ein optisch wahrnehmbares Angebot machen. Denn eine sprachliche Dimension ist immer auch mitzudenken:

Das sprachliche Moment im Erzählen ist nie vollkommen ersetzbar. Wenn die Sprache nicht innerhalb oder neben den Bildern schriftlich in Erscheinung tritt, dann mag es ein Bildvorführer sein, der die Bilder mit Worten verlebendigt, oder der Bildbetrachter selbst, der sich eine Erzählung aus den Bildern still zusammenbuchstabiert. (Gerndt 2009, 313)

Damit liegt auf der Hand, dass für die Analyse des Bilderbuchs strukturalistische und formalästhetische Kategorien nicht ausreichen. In Anlehnung an Isers Wirkungsästhetik (1976) und das „Konzept des impliziten Lesers“ (Iser 1994, 50ff.), wonach jedem Text die Beteiligung des Lesers an der Sinnbildung

46 Der Begriff geht auf Roland Barthes, Julia Kristeva, Jacques Derrida u. a. zurück und wurde von Peter Wagner etabliert (vgl. Wagner 2006, 211). Vgl. dazu auch: Siegel 2006; Hallberg 2005.

47 „Da Bedeutung [...] zwar im Text angelegt ist, aber erst im Wechselspiel zwischen textuellen Signalen und ihrer Interpretation durch die Leser/innen realisiert und konkretisiert wird, richtet sich der Blick auf Prozesse der Rezeption und Kognition (kognitive Narratologie).“ (Sommer 2010, 95f.; H. i. O.). 
eingeschrieben ist, sind auch für die Bilderbucherschließung mentale Interaktionen mit der Bild- und der Sprachebene gefordert.

Der schöpferische Akt ist beim Erschaffen eines Werkes nur ein unvollständiges, abstraktes Moment; wenn der Autor allein existierte, könnte er schreiben, so viel er wollte - das Werk würde nie als Objekt das Licht der Welt erblicken, er müßte die Feder niederlegen oder verzweifeln. Aber der Vorgang des Schreibens schließt als dialektisches Korrelativ den Vorgang des Lesens ein, und diese beiden zusammenhängenden Akte verlangen zwei verschieden tätige Menschen, die vereinte Anstrengung des Autors und des Lesers läßt das konkrete und imaginäre Objekt erstehen, das das Werk des Geistes ist. Kunst gibt es nur für und durch den anderen. (Sartre 1958, S. 27f.; zit. in Iser 1994, 177)

Die Ganzheit einer Lektüre ist also „nur durch Synthesen zu gewinnen“, indem „sich die Gegenständlichkeit des Textes durch die Abfolge der Synthesen als ein Bewußtseinskorrelat aufzubauen beginnt" (Iser 1994, 178f.). Anders als bei der Wahrnehmung von „Wahrnehmungsobjekten“, demnach auch Bildern, die „als Ganzes im Blick“ stünden, sind „wir im Text immer mitten drin“, so Iser. "Als wandernder Blickpunkt innerhalb dessen zu sein, was es aufzufassen gilt", bedinge „die Eigenart ästhetischer Gegenständlichkeit fiktionaler Texte“ (ebd., 177f.). Ausgehend von einem weiten Textbegriff und einer gegebenen Narrativität von Bildern in Bilderbüchern, kann nun die Vorstellung vom „wandernden Blickpunkt" (ebd.) in fiktionalen Texten ebenso auf die Erschließungsakte von Bilderbuchbildern übertragen werden. Der „implizite Leser“ ist dann impliziter Betrachter, oder besser: impliziter Rezipient, der an der Sinnkonstruktion nicht nur maßgeblich beteiligt ist, sondern Sinn erst generiert. Außerdem gilt für fiktionale Texte: „Die Inhaltlichkeit solcher Vorstellungen bleibt vom Erfahrungshaushalt des jeweiligen Lesers gefärbt" (ebd., 66), so dass jeder Rezeptionsprozess in Abhängigkeit von den personenbezogenen Wahrnehmungs- und Deutungskompetenzen ein individuell ausgestalteter Vorgang ist, mit einem je eigenen Ergebnis. Für das Bilderbuch folgt daraus, dass Text und Bild zusammenzudenken sind und ihre Synthese im Rezeptionsvorgang den Ikonotext hervorbringt, dessen Gehalt und Qualität maßgeblich vom Rezeptionsvermögen des jeweiligen Rezipienten abhängen. Ebenso konstatiert Marion Bönnighausen $(2010,506)$ mit literaturdidaktischer Zielrichtung am Beispiel von Comics im Deutschunterricht,

dass der Gegensatz des Logozentrismus von Sprache und einer aisthesiologischen Prägung von Bildern nicht gerechtfertigt ist, sondern sich ein Text strukturierender und Verständnis fördernder Effekt erst aus der Gesamtheit aller Sinnbezüge ergibt, und zwar durch die aktive Sinnstiftung des Rezipienten. 
Demzufolge muss die oben formulierte Definition erweitert werden:

Der Ikonotext ist das Ergebnis der Sinnkonstruktion im Prozess der Wahrnehmung des Wechselspiels von Sprach- und Bildebene und ihrer im Layout sichtbaren formalen Komposition.

Gerade die innovativen Bilderbücher, die nicht die ungeschriebenen Gesetze der Kindgemäßheit einer naiv-betulichen Erzählform bedienen, die dem Rezipienten Brüche, Sprünge und Leerstellen zumuten, ungewöhnliche Perspektiven und Formen zeigen, intertextuelle Züge aufweisen und eher rätselhaft erscheinen, bedürfen einer entsprechend komplexen (methodischen) Herangehensweise, die an jedem Gegenstand immer wieder neu zu justieren ist. Auf der Grundlage dieser Überlegungen ist einem Erzähl-Modell des Bilderbuchs das hermeneutische Moment des individuellen Verstehens immer inhärent. Ein analytisches Instrumentarium dafür bietet das nachfolgend entwickelte Modell, welches erzähltheoretische Kategorien mit rezeptionsästhetischen Überlegungen verbindet.

\section{III.2 Das narratologische Modell der Bilderbuchanalyse}

Die narratologische Bilderbuchanalyse ist sicher kein Anliegen privater Bilderbuchrezeption, aber selbst im genussvollen Lesen und Betrachten sind analytische Prozesse im Gange, die implizit ablaufen und zu einem wertenden Urteil führen, das umso mehr subjektiv bestimmt ist, als es ungesteuert entsteht. Das Visuelle ist dabei oftmals unreflektierter, spontaner Auslöser von Ablehnung oder Interesse, selbst in fach- oder sachbezogenen Zusammenhängen, ohne dass das Sinnpotenzial erschlossen wurde. Die Erfahrung aber lehrt, dass vorschnell getroffene (Wert-) Urteile nach intensiverer Auseinandersetzung nicht selten wieder revidiert werden müssen. Um eine subjektiv bestimmte Engsichtigkeit zu vermeiden, ist deshalb einerseits der Erwerb analytischer Fähigkeiten - gerade für Literaturvermittler - von großer Bedeutung, andererseits muss ein wissenschaftlich begründetes Analysewerkzeug zur Verfügung stehen, um trotz der unvermeidbaren Einflüsse von Subjektivität zu dennoch objektivierbaren Ergebnissen kommen zu können.

Wie strukturalistische bzw. narratologische Ansätze nach der Ebene der story und der Ebene des discourse unterscheiden und dabei unter anderem nach den Figuren, den Handlungskonzepten und -räumen in Erzähltexten fragen, kann auch an Bildern untersucht werden, was und wie sie erzählen. Nodelman (1991, 2) geht darüber hinaus davon aus, dass in Bilderbüchern „three stories“ erzählt werden: 
Because words and pictures communicate different kinds of relationships in different ways, the doubleness of picture books is not simply the repetition of the same information in a different form. The pictures inevitably convey a different story from the words. As a result, any given picture book contains at least three stories: the one told by the words, the one implied by the pictures, and the one that results from the combination of the first two.

Diese Sicht auf das Bilderbuch liegt dem narratologischen Modell der Bilderbuchanalyse (Abb.1) zugrunde, denn nur ein auf einer ersten Stufe dichotomisch angelegter Analyseansatz kann der doppelten Medialitä $t^{48}$ von Bilderbüchern gerecht werden, bevor in einem zweiten Schritt beide Ebenen zusammengeführt werden.

Abb. 1: Das narratologische Modell der Bilderbuchanalyse.

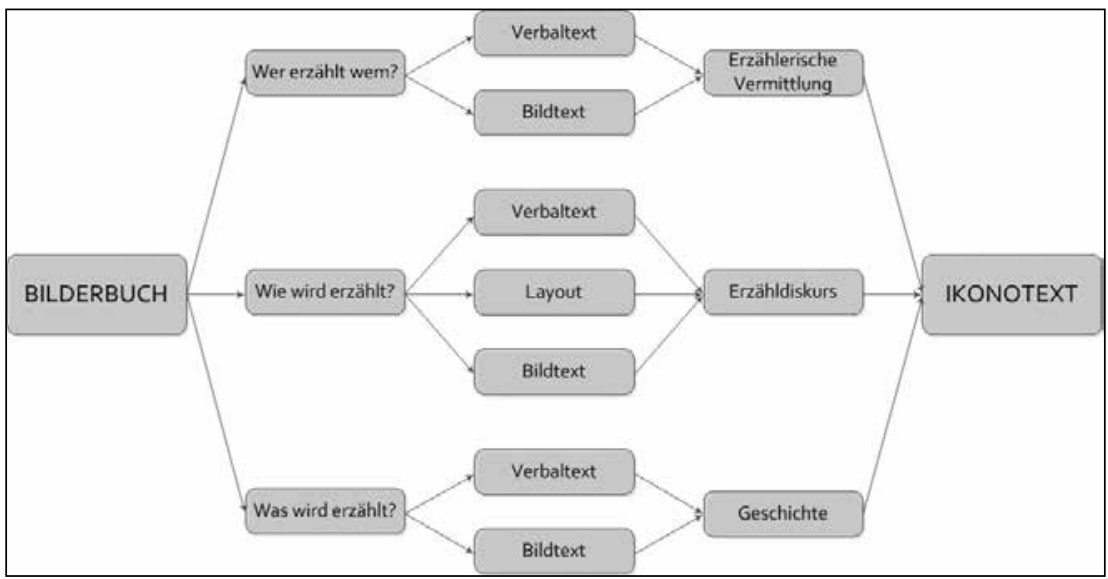

Wie die Aufmerksamkeit des autonomen Rezipienten ständig zwischen Bild- und Sprachtext pendelt und dabei Sinn konstruiert, muss dieses alternierende Vorgehen auch die analytische Herangehensweise bestimmen. Die im Modell dargestellte Trennung von Sprachtextebene und Bildtextebene legitimiert sich somit einerseits aufgrund der Unmöglichkeit einer simultanen Wahrnehmung beider Ebenen (vgl. Nodelman 1991, 1) und ist andererseits auch einer formalen Pragmatik geschuldet. Nur im spezifischen Fall der (dialogischen) Vorlesesituation,

48 Die Zweidimensionalität von Bilderbüchern tritt besonders in Bilderbüchern zutage, deren Erzähler in der 1. Person berichtet (vgl. Nodelman 1991, 2). Im Vorliegenden geht das Kap. VII.2 mit konkreten Beispielen darauf ein. 
die neben den zwei üblichen Beteiligten, Bilderbuch und Kind bzw. autonomer Rezipient, einen weiteren, den Vorlesenden, umfasst, ist die Vorstellung zutreffend, dass im Bilderbuch Bild und Text vom zuhörend betrachtenden Kind nahezu zeitdeckend erfasst werden können (vgl. ebd.). Das Hören und Betrachten verschmelzen für das nicht lesende Kind zu einer audiovisuellen Wahrnehmung, die sich grundlegend von der Rezeption audiovisueller Medien unterscheidet, insbesondere aufgrund der individuell gestaltbaren Rezeptionsgeschwindigkeit. Nodelman verweist in diesem Zusammenhang auch darauf, dass das nicht lesende Kind zusätzlich gefordert sei, weil es die beiden auf der Bilderbuchseite gleichzeitig dargebotenen Informationsquellen, Sprache und Bild, erst voneinander abgrenzen müsse, um den Sinngehalt der Bildebene erfassen zu können (vgl. ebd.). $\mathrm{Zu}$ erkennen, dass der Sprachtext nicht Bild ist und eine eigene Semantik birgt, mit typographischen Gestaltungsvarianten aber auch eine ikonische Ausdruckskraft transportieren kann, setzt somit bereits ein ganzes Bündel von Kompetenzen voraus, die in der Fähigkeit zur Generierung des Ikonotextes ihre höchste Ausprägung erreichen. Daraus folgt, dass das Bilderbuch in Gestalt der Bilder, des Sprachtextes und ihrer verbindenden Komposition, dem Layout, das Material zur Verfügung stellt, aus dem im Rezeptionsvorgang unter dem Einfluss verschiedener Rezeptionskompetenzen sein Sinnpotenzial - der Ikonotext - gebildet wird. Da diese Interdependenzen an jeder Stelle eines Bilderbuches auftreten, an der Text und Bild zusammentreffen, sind Ikonotexte sowohl auf der Ebene von Einzelbildern und ihrer Textbeigabe als auch als Gesamtheit des Bilderbuches zu bilden. ${ }^{49}$

Die Ausgangsfrage einer jeden Erzählanalyse lautet: Was wird von wem über wen oder was in welchen Zusammenhängen wie erzählt? Dahinter steht die Vorstellung vom Erzähler als dem „Urheber des Erzähltextes“ (Schmid 2008, 155), der „als unumgängliche Vermittlungsinstanz der Geschichte“ (Lahn/ Meister 2013, 59) dafür verantwortlich zeichnet. Dass der Erzähler nicht mit dem Autor gleichzusetzen ist, sondern eine von diesem geschaffene Instanz ist, erläutert Schmid $(2011,132)$ folgendermaßen:

Das Fingieren einer Geschichte und eines sie präsentierenden Erzählers ist Sache des realen Autors. In den Akten der Auswahl und Ausstattung eines Erzählers verweisen alle Indizes auf den Autor als verantwortliche Instanz. Die Auswahl der erzählten Geschehensmomente, ihre Verknüpfung zu einer Geschichte, ihre Bewertung und Benennung sind Operationen, die in die Kompetenz des Erzählers fallen, der sich in ihnen kundgibt. Im Einzelnen ist die Zuordnung der Symptome eine Sache der Interpretation. Alle Akte,

49 Aus Gründen der Übersichtlichkeit wurde in der Grafik auf den Zwischenebenen auf die Visualisierung dieser Prozesse verzichtet. 
die den Erzähler kundgeben, fungieren letztlich natürlich auch als Indizes für den Autor, dessen Schöpfung diese fiktive Instanz ist.

Dieser Auffassung folgend, steht dem Erzähler in der Analyse eines Erzählwerkes eine exponierte Stellung zu, welche sich im hier entwickelten Modell in der Erweiterung des Zwei-Ebenen-Modells (z. B. Chatman 1975) um die erzählerische Vermittlung zur Trias ${ }^{50}$ spiegelt. Auf der Ebene der erzählerischen Vermittlung geht es also um die Identifizierung des Erzählers und seines Adressaten. Der Autor ist als Schöpfer dieser fiktiven Erzähler-Instanz auch als Initiator der Wirkung mitzudenken, die die erzählerische Vermittlung einer Geschichte beim Rezipienten hervorruft. Der so verwendete Begriff Geschichte rekurriert auf das „,idealgenetische Vier-Ebenen-Modell“51 der narrativen Konstitution von Erzählwerken von Wolf Schmid (2008). Wenn von einer Geschichte die Rede ist, setze diese ein Geschehen voraus: „Das Geschehen ist die amorphe Gesamtheit der Situationen, Figuren und Handlungen, die im Erzählwerk explizit oder implizit dargestellt oder logisch impliziert sind." (Schmid 2008, 251) Die Geschichte konstituiert sich dann aus der vom Erzähler getroffenen Auswahl von Geschehensmomenten und deren „aus der unendlichen Menge der den gewählten Momenten im Geschehen zuschreibbaren Eigenschaften“ (ebd, 252). Damit ist der Erzähler in jedem Fall der „aktive Produzent des Diskurses“ (Lahn/ Meister 2013, 59), indem er die Erzählung generiert und für die Präsentation verantwortlich zeichnet (der „Erzählung“ und „Präsentation der Erzählung“ (Schmid 2008) entsprechend). Der Erzähler und seine Geschichte, der ihr eingeschriebene Adressat und die Art und Weise ihrer Präsentation sind deshalb im vorgestellten Modell (Abb. 1) auf drei Ebenen angelegt, deren Separierung eine Trennschärfe suggeriert, die insofern nicht gegeben ist, als sich die einzelnen Komponenten jeweils auf dasselbe Sprach- und Bildmaterial beziehen und immer

50 In Anlehnung an die Systematik der Einführung in die Erzähltextanalyse von Silke Lahn und Jan Christoph Meister (2013).

51 Schmid zieht aus dem Vergleich der Modelle des russischen Formalismus (Todorov 1966) und des französischen Strukturalismus (Genette 1972) „den Schluss, dass die Dichotomie oder Triade der Begriffe durch ein Modell mit vier Ebenen ersetzt werden sollte" (Schmid 2008, 251ff.). Er postuliert als Erweiterung der Dichotomie histoire und discours (Todorov 1966) bzw. story und discourse (Chatman 1975) und der drei Termini récit, histoire und narration (Genette 1972) die vier Ebenen Geschehen - Geschichte - Erzählung - Präsentation der Erzählung. Danach sind Geschehen und Geschichte dem Bereich der story, d. h. dem WAS des Erzählens zuzuschreiben, Erzählung und Präsentation der Erzählung dem Bereich des discourse, dem WIE des Erzählens. (Vgl. Schmid 2008, 251). 
in Zusammenhängen und Abhängigkeiten stehen. Das auf einer Metaebene vorausgesetzte Geschehen bleibt in der Darstellung unberücksichtigt.

Das wissenschaftliche Interesse der Bilderbuchanalyse richtet sich auf die Zusammenhänge zwischen Form und Inhalt, auf das Zusammenspiel von materiell-formaler, bildästhetischer und sprachästhetischer Ebene und damit auf eine Durchdringung des Ganzen, um ein möglichst nachvollziehbares und begründetes Analyseergebnis zu erhalten. Je nach Ausrichtung, ob literaturwissenschaftlich, pädagogisch, sozialwissenschaftlich o. a. orientiert, ändert sich zwar der Fokus, nicht aber die Notwendigkeit, alle Darstellungsebenen in die Analyse mit einzubeziehen.

Grundsätzlich gilt:

Die Analyse von Bilderbüchern ist heute nicht als geschlossenes Konzept denkbar. Nicht ein allumfassendes Super-Modell wird der Komplexität des Mediums und seiner narrativen Spezifik gerecht, sondern vielfältige, offene Wege des Zugangs. Die Vorstellung eines alleingültigen Analysemodells, das auf alle Bücher gleichermaßen ergiebig zu beziehen sei, löst sich in dem Maße auf, in dem sich die Gegenwartskultur, auch die Kinderkultur, selbst offen, unfertig, widersprüchlich und heterogen zeigt. (Thiele 2003a, 92)

Das narratologische Modell der Bilderbuchanalyse kann aber dennoch eine universelle Anwendbarkeit für sich reklamieren, weil es die konstituierenden Merkmale der Gattung Bilderbuch in ihrem Wirkungszusammenhang darstellt: die Untrennbarkeit der genuin angelegten Zweidimensionalität, die verbindende Funktion des Layouts für die Bild-Sprache-Beziehungen ${ }^{52}$ und ihre Symbiose im Ikonotext.

Die vorausgegangenen Überlegungen werden unter Rückgriff auf das aktuelle narratologische Begriffsspektrum (vgl. dazu: Schmid 2008; Lahn/ Meister 2013) und relevante Aspekte der Bezugswissenschaften im Folgenden in einen analytischen Fragenkatalog ${ }^{53}$ überführt, der die Trias des Modells spiegelt. Dieses Instrumentarium ermöglicht eine erzähltheoretisch begründete Erschließung von Bilderbuchliteratur, ohne Vollständigkeit für sich zu beanspruchen. ${ }^{54}$ Es stellt keineswegs ein allgemein applikables Raster dar, sondern fordert dazu auf, die Analysebereiche neben- und ineinander zu stellen, zusammenzudenken und,

52 Vgl. Nodelman 1991; vgl. auch: Staiger 2013.

53 Vgl. auch: Dinges 1984; Gansel 2010; Schmidt-Dumont 1997; Thiele 2003b.

54 Es werden die wichtigsten relevanten Aspekte der Erzähltheorie mit den Erfordernissen des Bilderbuchs zusammengebracht, was als Ansatz einer Erzähltheorie zum Bilderbuch verstanden sein will. 
orientiert am Gegenstand, jeweils neu zu modifizieren. „[E]in Schema muss immer offen bleiben" (Genette 2010, 271; H. i. O.).

\section{III.3 Die Trias des narratologischen Modells der Bilderbuchanalyse}

Das Modell fußt auf der Überzeugung, dass Bildtexte wie Sprachtexte eigene narrative Qualitäten haben, die anhand erzähltextanalytischer Fragestellungen erschlossen werden können.

\section{III.3.1 Die erzählerische Vermittlung}

Jeder Erzählung liegt per se die Existenz eines Erzählers zugrunde, denn das Erzählwerk ist die Manifestation dessen, was ein Erzähler für bedeutsam und erzählenswert hält (vgl. Schmid 2008, 138). „Der fiktive Erzähler ist eine Ins$\operatorname{tanz}$ der dargestellten Welt und kann auf zwei Weisen dargestellt werden, explizit oder implizit." (Schmid 2011, 131; H. i. O.) Die Erzählinstanz kann beispielsweise explizit auftreten, indem sie ihr eigenes Leben erzählt, sich namentlich präsentiert oder sich mit Kommentaren, Bewertungen und einer eigenen Weltsicht ins Spiel bringt. „Der implizit dargestellte Erzähler ist [dagegen; M.H.] ein Konstrukt (oder - genauer - ein Re-Konstrukt), das der Leser aus den Symptomen des Erzähltextes bildet.“" (Ebd.)

[Die] indizialen Zeichen [dafür sind; M.H.] [...] in folgenden Verfahren angelegt:

1. Auswahl von Momenten (Figuren, Situationen, Handlungen, auch Rede-, Gedanken und Bewusstseinshandlungen) aus dem Geschehen als dem narrativen Material zur Bildung einer Geschichte;

2. Konkretisierung und Detaillierung der ausgewählten Geschehensmomente durch bestimmte Eigenschaften;

3. Komposition des Erzähltextes, d. h. Zusammenstellung und Anordnung der ausgewählten Momente in einer bestimmten Ordnung;

4. Präsentation der Erzählung in einer lexikalisch, syntaktisch und grammatisch mehr oder weniger markierten Sprache;

5. Bewertung der ausgewählten Momente (diese kann in den vier oben aufgeführten Verfahren implizit enthalten sein, aber auch explizit gegeben werden);

6. Jegliche Art von `Einmischung` des Erzählers, d. h. Autothematisierungen, Reflexionen, Kommentare, Generalisierungen, die auf die erzählte Geschichte, das Erzählen oder den Weltlauf bezogen sind. (Ebd.; H. i. O.) 
Der Erzähler, bei Genette (2010, 137ff.) der „Stimme“ entsprechend, „umfasst [...] alle Spuren, die die Erzählinstanz im narrativen Diskurs hinterlassen hat, auch die Evokation eines 'narrativen Adressaten “", der jedem Erzählakt eingeschrieben ist (Schmid 2011, 131; H. i. O.). Dieser "fiktive Adressat ist nichts anderes als das Schema der Erwartungen und Vorahnungen des Erzählers" und kann wie der Erzähler explizit und implizit dargestellt sein (Schmid 2008, 101). Die explizite Darstellung zeigt sich in der Verwendung der „Pronomina und grammatischen Formen der zweiten Person oder der bekannten Anredeformeln“, die implizite Darstellung des fiktiven Lesers ${ }^{55}$ drückt sich in „denselben indizialen Zeichen wie die Darstellung des Erzählers“ aus (ebd., 105f.). „Während die explizite Darstellung fakultativen Status hat, ist die implizite Darstellung unvermeidbar.“ (Schmid 2011, 131)

Wolf Schmid (2011, 133; H. i. O.) ersetzt „die traditionelle, terminologisch problematische und in der Sache irreführende Dichotomie von `Ich- $<$ und `Er-Erzähler «", indem er „zwischen diegetischem und nichtdiegetischem Erzähler“ unterscheidet und damit „der von Genette eingeführten und nun weit verbreiteten Opposition >homodiegetisch vs. > heterodiegetisch`(Genette 1972, 253)“ entspricht. ${ }^{56}$

Diegetisch soll ein Erzähler heißen, der zur erzählten Geschichte (Diegesis) gehört, der folglich über sich selbst - genauer sein früheres Ich - als Figur der erzählten Geschichte erzählt. Der diegetische Erzähler figuriert auf zwei Ebenen: sowohl in der Exegesis als auch in der Diegesis. Der nichtdiegetische Erzähler gehört dagegen nur zur Exegesis und erzählt nicht über sich selbst als eine Figur der Diegesis, sondern ausschließlich über andere Personen. Diegetische Erzähler zerfallen in zwei nach Ebene und Funktion differenzierbare Instanzen, das erzählende und das erzählte Ich ([...] auch erlebendes Ich [...]). (Schmid 2011, 133)

Das erzählte Ich kann in der Diegesis als Nebenfigur in unterschiedlicher Funktion Teil der Geschichte sein. Ist das erzählte Ich als früheres Ich des Erzählers die „zentrale Figur der Diegesis“ (ebd.), trifft darauf der von Genette (1972, 253f.) geprägte Begriff des autodiegetischen Erzählers zu. Zu beachten ist, dass ein nichtdiegetischer Erzähler durchaus Formen der ersten Person gebrauchen kann, wie auch ein diegetischer Erzähler über sich selbst in der dritten Person schreiben kann (vgl. Schmid 2011, 133).

55 Schmid verwendet die Begriffe „fiktiver Leser“ und „fiktiver Adressat“ zwar synonym, weist aber gleichzeitig darauf hin, dass es „richtiger wäre [...], vom fiktiven Adressaten zu sprechen" (Schmid 2008, 100; H. i. O.).

56 Schmid postuliert außerdem, dass jeder Erzähler ein Ich-Erzähler sei und sich selbst benennen könne, ohne eine Figur der Diegesis zu sein, weshalb die Typologie der Erzählsituationen nach Stanzel wenig überzeugend sei. (Vgl. Schmid 2011, 133). 
Die im Text enthaltenen Symptome, die von Werk zu Werk unterschiedlich stark ausgeprägt sind, können am Erzähler und seinem Erzählen Züge unterschiedlicher Art anzeigen. Die wichtigsten davon sind: der Modus des Erzählens (mündlich oder schriftlich, spontan oder vorbereitet, umgangssprachlich oder rhetorisch), die narrative Kompetenz (die Präsenz in den Teilwelten, das Wissen um die zu erzählende Geschichte und ihre Hintergründe, die Fähigkeit zur Introspektion in das Innere der Figuren der erzählten Welt), der soziale Status, die Bildung und der geistige Horizont, die Weltanschauung. (Ebd., 131)

Folgende Kriterien können als Grundlage einer Typologie des Erzählers dienen (Abb. 2):

Abb. 2: Schmidt 2011, 132.

\begin{tabular}{|l|l|}
\hline Kriterien: & Typen des Erzählers: \\
\hline Darstellungsmodus & explizit - implizit \\
\hline Grad der Markiertheit & stark markiert - schwach markiert \\
\hline Personalität & persönlich - unpersönlich \\
\hline Homogenität der Symptome & kompakt - diffus \\
\hline Wertungshaltung & objektiv - subjektiv \\
\hline Kompetenz & allwissend - im Wissen begrenzt \\
\hline Räumliche Bindung & allgegenwärtig - an einen bestimmten Ort gebunden \\
\hline Introspektion & mit Introspektion - ohne Introspektion \\
\hline Zuverlässigkeit & unzuverlässig - zuverlässig \\
\hline
\end{tabular}

Die Spezifik einer sich über Bilder ausdrückenden Erzählinstanz erfordert eine erweiterte Handhabe dieser narratologischen Analysekategorien. Da Bildern immer eine räumlich-visuelle Perspektive inhärent ist, ist die Identifikation des visuellen Erzählers ohne den Einbezug der Kategorie Perspektive nicht zu leisten. Die Kategorien „Stimme“ und „Modus“, die bei Genette (2010) mit den Fragen Wer spricht? und Wer sieht? einhergehen und damit die Erzählstimme und die Perspektive des Erzählens meinen, müssen deshalb für die Bildebene modifiziert und zur Frage Wer zeigt, was er sieht? zusammengefasst werden. Der visuelle Erzähler zeigt im Bild seine (mehr oder weniger subjektiv gefärbte) Sicht auf das Geschehen, die er erzählerisch, d. h. vermittelnd auf einen Adressaten ausgerichtet, ausgestaltet. Seine Erzählmittel sind Farben, Formen, Stile, Oberflächen und räumliche Perspektiven, die eine mehr oder weniger deutliche räumlich-zeitliche Distanz zu den fiktiven Figuren oder auch deren Wahrnehmung ausdrücken und ebenso Träger von Symbolgehalten sein können. Wie der Erzähler der Sprachebene, kann auch der visuelle Erzähler mit der Fähigkeit zur Introspektion 
ausgestattet, allwissend oder in seinem Wissen beschränkt und demnach auch dazu in der Lage sein, die visuelle Wahrnehmungsebene einer Figur darzustellen. Unter Einbezug dieser Überlegungen muss die oben gestellte Frage deshalb lauten: Wer zeigt, wer was sieht? Ob das Dargestellte die Sicht des Erzählers auf die Dinge oder die Blickrichtung einer Figur präsentiert, kann nur unter Einbezug der Sprachebene erschlossen werden, um im Ikonotext zu einer Gesamtaussage zu gelangen. In jedem Fall ist ein Bild bzw. die gesamte Bildebene eines Bilderbuchs das Werk eines visuellen Erzählers, der darin sein Wissen über das Geschehen und die beteiligten Figuren anhand seiner Auswahl und Ausgestaltung einzelner Geschehensmomente zeigt. ${ }^{57}$

Eine besondere analytische Herausforderung stellen Bilderbücher dar, in denen der autodiegetische Erzähler der Sprachebene, in der Regel identifizierbar aufgrund der grammatischen Form der ersten Person, auf der Bildebene figural auftritt und eine Distanz zum erzählten Ich sichtbar macht. Es gibt zwei Möglichkeiten, diese Situation im Bilderbuch analytisch aufzuschlüsseln. ${ }^{58}$ Zum einen kann die Diskrepanz zwischen dem visuellen und dem sprachlichen Erzähler so gedeutet werden, dass die Figur quasi aus sich herausgetreten ist und sich selbst entweder retrospektiv oder gleichzeitig - im Sinne der Gleichzeitigkeit von Erzählen und Erleben - von außen zeigt. ${ }^{59}$ Vergleichbar ist diese Annahme mit der Unterscheidbarkeit der zwei Ichs eines autodiegetischen Erzählers auf der Sprachebene, dem erzählenden Ich und dem erzählten Ich. Für den Betrachter resp. Rezipienten geht diese Irritation aber im Verständnis der erzählten Situation auf, da die Bilder i. d. R. als Standbilder einzelner Geschehensmomente konzipiert sind und den Verbaltext durch ihnen eigene Darstellungsmodi ergänzen, sodass erzählendes und erzähltes Ich als „psychophysische Einheit“ (Schmid 2011, 134) wahrgenommen werden können. ${ }^{60}$ Voraussetzung dafür ist die Verwendung der grammatischen Form der ersten Person auf der Sprachebene, denn wäre der Sprachtext in der dritten Person verfasst, müsste dasselbe Bild in Analogie zur Sprachebene vom Rezipienten als Aussage eines nichtdiegetischen Erzählers

57 Dass demnach für die Identifizierung des des Erzählers immer auch die Frage nach der dargestellten Perspektive zu stellen ist, zeigt wiederum die Untrennbarkeit der einzelnen Analyseebenen auf, obwohl sie hier kapitelweise behandelt werden (zur Erzählperspektive Kap. III.3.2.2).

58 Die Kombination mehrerer Erzählebenen, wie Rahmen- und Binnenerzählungen, erfordert eine weitere theoretische Differenzierung, bleibt aber hier unberücksichtigt.

59 Die oben formulierte Frage Wer zeigt, was er sieht? müsste dann treffender lauten: Wer zeigt, wie er gesehen werden will?

Vgl. dazu auch: Rau 2013. 
gedeutet werden, der nicht seine eigene Geschichte erzählt. ${ }^{61}$ An dieser Stelle wird der sinnbildende Prozess des Zusammendenkens von Bild- und Sprachebene im Ikonotext evident.

Andererseits kann im Fall des autodiegetischen verbalen Erzählers die Bildebene aber auch als Mitteilung eines nichtdiegetischen Erzählers gedeutet werden, der dem Ich der Sprachebene eine Gestalt gibt und sein mehr oder weniger umfangreiches Wissen über diese Figur mit ikonischen Mitteln zeigt, selbst aber die Handlungsebene nicht mitbestimmt. Ausgehend von der Grundannahme eines übergeordneten Geschehens, aus dem von verschiedenen Erzählern auch unterschiedliche Geschehensmomente ausgewählt werden können, kann dieser Ansatz nicht nur für das parallele Erzählen derselben Geschichte auf beiden medialen Ebenen Erklärungen liefern, sondern gerade für das kontrapunktische und das alternierende Erzählen, das per se unterschiedliche Erzähler impliziert.

Die Erläuterungen zur Frage nach dem Erzähler auf der visuellen Ebene im Vergleich zum verbalen Ich-Erzähler sollen am Beispiel des Bilderbuchs ich von Philip Waechter (2004) verdeutlicht werden, das zu den ,vermeintlich einfachen Bilderbucherzählungen [gehört; M.H.], in denen Bild und Schrifttext parallel geführt werden" (Staiger 2013, 65). ${ }^{62}$

Abb. 3: Philip Waechter (2004): ich. Weinheim, Basel: Beltz \& Gelberg.

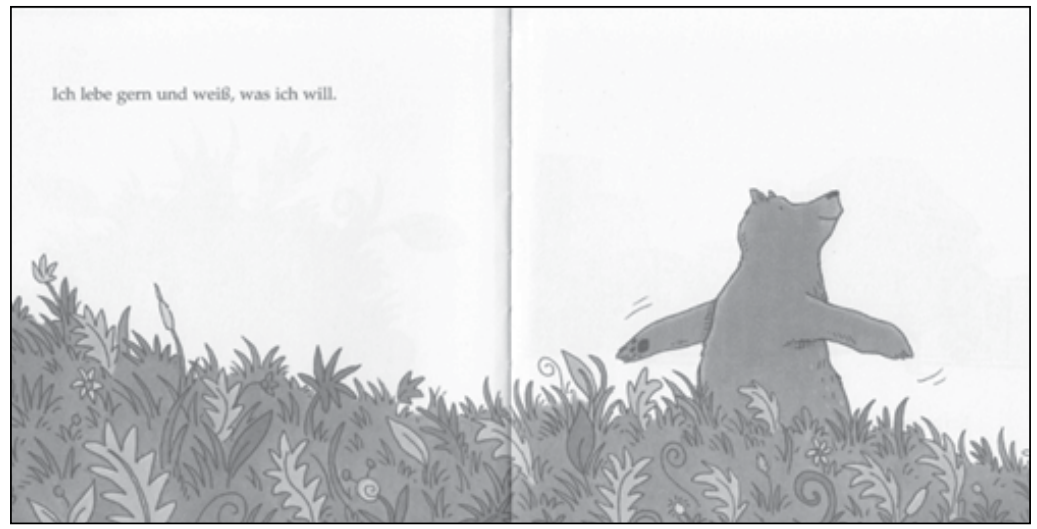

61 Der umgekehrte Fall, eine in der dritten Person erzählte Geschichte, deren Protagonist nicht gezeigt wird und deren visueller Erzähler quasi mit dessen Augen auf das Geschehen blickt, ist sicher möglich, aber kaum wahrscheinlich, ebenso wenig wie das Erzählen eines Ich, das von sich selbst in der dritten Person spricht.

62 „Das Bilderbuch bereitet Kindern in der Regel keine Verständnisschwierigkeiten, der Verlag empfiehlt es ab einem Alter von 3 Jahren." (Staiger 2013, 66). 
Staiger zeigt daran, „dass eine Kategorie wie die Fokalisierung nur bedingt geeignet ist, um die Erzählperspektive in einem Bilderbuch zu beschreiben" (ebd. 67). Dem ist zuzustimmen, die Verfasserin geht aber im Gegensatz zu Staiger nicht von einer externen, sondern von einer Form der internen Fokalisierung am Beispiel dieses Bildes (Abb. 3) aus, denn der visuelle Erzähler hat offenbar Kenntnis vom innerpsychischen Befinden der Figur. Der verbalsprachliche Text lautet Ich lebe gern und weiß, was ich will. Dass das sprechende Ich identisch ist mit dem abgebildeten Bären, dürfte unzweifelhaft sein. Die optimistische Selbstbeschreibung seiner Lebenshaltung drückt sich im aufrechten Gang und den weit ausholenden Schritten, sichtbar an den mithilfe von speed lines schwingend dargestellten Armen, sowie dessen hoch erhobenem, lächelndem Gesicht aus. Die Abbildung des Bären zeugt von Selbstsicherheit und Zielstrebigkeit, sodass dem visuellen Erzähler, dem Urheber des Bildes, dieses introspektive Wissen unterstellt werden kann, was einer visualisierten internen Fokalisierung entspricht. Hätte der Erzähler keine Kenntnis und wäre extern fokalisiert, müsste die Darstellung neutraler ausgestaltet sein und „der Held vor unseren Augen [handeln], ohne dass uns je Einblick in seine Gefühle oder Gedanken gewährt würde“ (Genette 2010, 121).

In der Wahrnehmung des Betrachters fließen die Informationen der Sprachund Bildebene, die parallel angelegt sind, zu einem Gesamteindruck zusammen, der auch von der Vorstellung gestützt sein kann, dass der Erzähler des Bildes mit der abgebildeten Figur und dem verbal auftretenden Ich identisch ist. Demnach wäre der visuelle Erzähler der erzählende Teil des autodiegetischen Ichs, das sich selbst präsentiert und mit ikonischen Mitteln eine bestimmte Wahrnehmung seiner selbst beim Rezipienten hervorrufen will, analog zur Verwendung sprachlicher Mittel des verbal im Präsens erzählenden Ichs. Parallelen zur Spezifik des Erzählens in „Handkamera- und Ich-Kamera-Filmen“ (Kuhn 2013, 167ff.) sind evident. Erzählvorgang und Erleben fallen hier ebenso zusammen wie das erzählende und das erzählte Ich, das dem Betrachter des Bildes gegenwärtig ist.

Wie beschrieben, wird in Abhängigkeit von einer unterschiedlich großen zeitlichen Distanz zwischen Erzählvorgang und fiktionalem Erleben eine Diskrepanz, die in der dichotomischen Betrachtung von Bild und Sprache angelegt ist, entweder im Rezeptionsvorgang mühelos aufgehoben, oder die Wahrnehmung zweier differenter Erzählinstanzen bleibt bestehen. Immer konstituiert der Ikonotext Sinn, der im Fall einer kontrapunktischen Beziehung der funktionalen Differenz zwischen Sprach- und Bildebene liegt innewohnt und beispielsweise Komik hervorruft. Das Problem der Erzähleridentifikation bzw. Erzählerdifferenzierung scheint demnach ein eher theoretisches zu sein und für 
die Sinnkonstruktion im Ikonotext eine untergeordnete Rolle zu spielen. Inwieweit sich daraus Grundsätzliches ableiten lässt, müsste an weiteren Beispielen untersucht werden.

Der nachstehende Fragenkatalog listet Anregungen zur Identifizierung des Erzählers bzw. der Erzählstimme und des fiktiven Adressaten auf beiden semiotischen Ebenen auf und erhebt dabei keinen Anspruch auf Vollständigkeit.

Anfragen an den Erzähler auf der Bildebene und auf der Sprachebene Zentrale Fragen: Wer erzählt, wer was sieht? und Wer erzählt, wer was spricht?

- Tritt der Erzähler explizit oder implizit auf?

- Ist der Erzähler eine agierende Figur im Handlungsgeschehen (diegetisch bzw. autodiegetisch vs. nichtdiegetisch)?

- In welcher zeitlichen Distanz befindet sich der Erzähler zum Erzählten (retrospektives, gleichzeitiges oder prospektives Erzählen)?

- Was weiß der Erzähler und was lässt er den Rezipienten wissen?

- Nimmt der Erzähler eine wertende Haltung ein?

- Ist ein Erzählanlass expliziert?

- Wie verhält sich der Erzähler zu seinem Adressaten? Wendet er sich direkt oder implizit an einen Adressaten?

- Ist das auf einen bestimmten Adressaten gerichtete Erzählen aufgrund formaler und/ oder inhaltlicher Aspekte nachweisbar (z. B.: parataktischer Sprachstil als Indiz für kindorientiertes Erzählen; kindlich konnotierte Bildelemente oder Bildstile)?

- Wo können ein erlebendes/erzähltes Erzähler-Ich und ein erzählendes Ich unterschieden werden?

- Wie ist es um die Glaubwürdigkeit des Erzählers bestellt?

Interdependenzen der sprachlichen und bildlichen

Realisierung des Erzählers

- Auf der Bildebene ist der Erzähler der Urheber der Auswahl der Bildelemente: Welche Indizien weisen auf die Kompetenz des Erzählers und den Zeitpunkt seines Erzählens hin?

- Welche Abhängigkeiten bestehen zwischen den Erzählern der beiden Ebenen?

- Bilden der Erzähler auf der Bildebene und der Erzähler auf der Sprachebene eine psychophysische Einheit?

- Stehen sie für zwei Bewusstseinszustände eines Ichs?

- Ergänzen oder widersprechen sich die beiden Erzählinstanzen? 


\section{III.3.2 Der Erzähldiskurs - Das WIE des Erzählens}

Die Art und Weise, wie die Geschichte in Sprach- und Bildtext gefasst ist, bestimmt die Ebene des Erzähldiskurses.

In der Präsentation der Erzählung wird die medial noch nicht manifestierte Erzählung in der spezifischen Sprache einer Kunstgattung ausgedrückt. Im literarischen Werk geschieht die Präsentation der Erzählung durch die Verbalisierung. [...] In der Verbalisierung kommt die sprachliche Perspektive zur Geltung. (Schmid 2008, 276)

Für das Bilderbuch heißt dies, dass neben die Verbalisierung der Erzählung als weitere Präsentationsebene die der Verbildlichung der Erzählung tritt. Im Modell steht der Erzähldiskurs für die Präsentation der Erzählung auf der Verbalebene und der Bildebene sowie ihrer Komposition im Layout, die als Gemeinsames im Ikonotext zusammenfließen.

\section{III.3.2.1 Layout}

Das Layout ist die dritte, neben die Erzähler der Verbal- und der Bildebene gestellte Instanz, die die Beziehung zwischen Bild und Wort formal gestaltet und der Geschichte den äußeren Rahmen gibt. Auf der Ebene des Layouts zeigt sich eine deutliche Abgrenzung, wenn Text und Bild sich auf je gegenüberliegenden Seiten befinden oder auch auf derselben Seite voneinander separiert angeordnet sind, manchmal in Rahmen gefasst, wobei der Text in der Regel unter dem Bild steht. Erscheinen Text und Bild miteinander verwoben, ist der Text ein mitgestaltendes Bildelement; oder der Text ist beispielsweise selbst Bild, wenn seine typographische Gestaltung ${ }^{63}$ mit der Textaussage visuell korreliert und eine weitere ästhetische Dimension eröffnet, die diejenige Sprachebene bestätigt oder um zusätzliche Deutungsmöglichkeiten ergänzt (vgl. Gerndt 2009, 312). In jedem Fall ist die Frage nach der Wirkung bzw. dem Beitrag der Form zur Bedeutungskonstitution zu stellen.

Dazu gehören:

- Format und Größe des Bilderbuchs

- Material (Hardcover, Papierqualität etc.)

- Seitenanzahl

- Welches quantitative Verhältnis besteht zwischen Text- und Bildangebot?

- Seitenarchitektur: Wie sind Text und Bild angeordnet? Ist der Text ins Bild integriert oder separiert? Länge der Druckzeilen? Etc. 
- Inwiefern korreliert das Design des Verbaltextes mit dessen Sinngehalt (z. B. onomatopoetische Ästhetik der Schriftgröße)?

- Sind Umfang und Typographie des Textes an kindlichem Lesevermögen orientiert?

\section{III.3.2.2 Die Erzählperspektive}

Was der Erzähler auswählt, was er weglässt, wo er sich befindet und welche zeitliche Distanz zwischen dem Erzählakt und den Geschehensmomenten besteht, ist für die Wirkung der Geschichte entscheidend. Der Erzähler ist entweder Teilnehmer am Geschehen oder zumindest Beobachter und blickt aus einer mehr oder minder distanzierten Position auf das Geschehen. Seiner Perspektive entsprechend, filtert er die Geschehensmomente und ordnet sie zu einer Erzählung (vgl. Schmid 2008, 129ff.). So sind von unterschiedlichen Perspektiven auf ein Geschehen jeweils unterschiedliche Geschichten zu erwarten, weshalb die Perspektive ein wesentlicher Indikator für die beabsichtigte Wirkung des Erzählten darstellt (vgl. ebd., 262). So ruft beispielsweise die kindliche Perspektive eines Protagonisten andere Identifikationsprozesse hervor als eine dasselbe Geschehen wahrnehmende erwachsene Figur.

Für eine Grunddefinition bietet sich an, Perspektive zu definieren als den von inneren wie äußeren Faktoren gebildeten Komplex von Bedingungen für das Erfassen und Darstellen eines Geschehens. Diese Definition impliziert, dass Perspektivierung kein fakultatives, sondern ein notwendiges Verfahren ist, das jede Darstellung eines Geschehens begleitet und ohne das es keine Geschichte gibt. (Schmid 2011, 138)

Der Erzähler kann

ein Geschehen von zwei verschiedenen »Standpunkten« aus darbieten, von seinem eigenen, dem Geschehen gegenüber "äußeren« Standpunkt oder von einem »inneren« Standpunkt, d. h. aus der Position einer oder mehrerer der erzählten Figuren. (Ebd., 140; H. i. O.)

Demnach ist die „Perspektive [...] entweder narratorial oder figural“ angelegt und jeweils anhand eines Modells mit 5 Parametern (ebd., 140f.) beschreibbar:

1. die 'perzeptiveく Perspektive, zu der man die Fragen stellen kann: Wer ist für die Auswahl dieser und nicht anderer Momente des Geschehens für die Geschichte verantwortlich? Mit wessen Augen blickt der Erzähler auf die Welt?;

2. die >ideologische` Perspektive, die unterschiedliche Faktoren umfasst, die bei Bedarf in der Analyse weiter differenziert werden können: das Wissen, die Denkweise, die Wertungshaltung; 
3. die >räumliche` Perspektive, die als einziger Parameter die ursprüngliche, nicht metaphorische Bedeutung von Perspektive erfüllt und durch den Ort konstituiert wird, von dem aus das Geschehen wahrgenommen wird, mit den Restriktionen des Gesichtsfelds, die sich aus diesem Standpunkt ergeben;

4. die >zeitliche` Perspektive, die den Abstand zwischen dem ursprünglichen Erfassen eines Geschehens und späteren Erfassens-, Erinnerungs- und Darstellungsakten betrifft und mit einer Veränderung im Wissen und Bewerten verbunden sein kann;

5. die `sprachliche` Perspektive, in der darüber entschieden wird, ob der Erzähler ein Geschehen in seinen eigenen Ausdrücken und Intonationen oder denen einer Figur (bzw. seines früheren Ich) darstellt.

Wer ein Bilderbuch liest, betrachtet es auch, womit zwei Zugangswege zur Geschichte beschritten und zwei sich voneinander unterscheidende Erzählebenen erschlossen werden müssen. Auf der Bildebene ist mit der Perspektive ganz konkret der auf die Situation gerichtete Blick gemeint, welcher sowohl als optische Perspektive als auch in narratologischen Kategorien beschrieben werden kann. Zum Erzählen aus der Perspektive eines Ichs konstatiert Perry Nodelman (1991, 2): „The doubleness of picture books is nowhere more apparent than in books containing texts with first-person narrators." Wenn ein Erzähler seine eigene Geschichte erzählt, ist das, was das Bild zeigt, üblicherweise nicht das, was das Ich des Erzählers im Moment des Geschehens sieht (vgl. ebd., 3), sondern das Bild zeigt das erzählte Ich als Teil der Szenerie. Die Bilder halten den Betrachter dann auf Abstand zur Erzählerfigur, während der Text dazu auffordern kann, die Introspektive anzunehmen, in ihre Gedanken- und Gefühlswelt einzutauchen und die Situation mit ihren Augen wahrzunehmen. Die Diskrepanz zwischen Sprachperspektive und Bildperspektive ist eine analytische Herausforderung, scheint aber gleichzeitig ein eher theoretisches Problem zu sein und kann schon von Kleinkindern mühelos überwunden werden, sobald sie beginnen, ein IchKonzept zu entwickeln und ein Du als ein Gegenüber davon abzugrenzen (vgl. Rau 2013, 97ff.). Etwa im Alter von 20 bis 24 Monaten können Kinder aufgrund ihrer kognitiven Entwicklung die „ich/du-Distinktion“ (ebd., 100) sprachlich korrekt anwenden und sind dazu in der Lage, eine Ich-Aussage einem Gegenüber zuzuordnen. Im Bilderbuch entspricht dieser Situation ein Bild, das vor Augen führt, wer von sich selbst in der 1. Person spricht (vgl. ebd., 103). Die Distinktion zwischen Bildperspektive und Sprachperspektive wird dabei aufgrund der Fähigkeit aufgehoben, sich selbst als Betrachter des Ichs des Sprechenden (des erzählten Ichs) abzugrenzen und die Ich-Form als dessen direkte Rede $\mathrm{zu}$ identifizieren. Es ist also davon auszugehen, dass die Ich-Perspektive keine 
Verstehenshürde darstellt (vgl. ebd.). ${ }^{64}$ Erzählt der Erzähler retrospektiv von dem Erleben seines früheren Ichs, d. h. in grammatischen Formen der Vergangenheit, hebt sich diese Diskrepanz automatisch auf, da der Erzähler im Erzählakt dann selbst als Betrachter früherer Geschehensmomente auftritt und den Rezipienten quasi an seine Seite holt. Wie sich auf der Sprachebene das erlebende Ich vom erzählenden Ich unterscheiden lässt, ist diese Distanz auf der Bildebene in der Blicklenkung des betrachtenden Rezipienten angelegt.

Die Möglichkeit eines mehrfachen Wechsels der verbal angelegten Perspektive ist gerade dann auch über die Bilder gegeben, wenn einmal der Blick des erzählenden Ichs dargestellt wird und ein anderes Mal der des erzählten/ erlebenden Ichs. Grundsätzlich ist es

deshalb ratsam, zwischen der Introspektion, dem Zugang eines Erzählers zur Innenwelt einer Figur, und seiner Darbietung der Welt aus der Sicht der Figur zu scheiden. Ersteres gehört wie Allwissenheit und Allgegenwärtigkeit zu den Kompetenzen des Erzählers, letzteres bezeichnet die Perspektive. Die Innenperspektive setzt die Kompetenz der Introspektion voraus. Die Umkehrung ist nicht zulässig. Introspektion ist durchaus ohne Innenperspektive möglich. Von einer Innensicht bei der Darstellung des inneren Zustandes einer Figur kann nur dann die Rede sein, wenn der Erzähler die Selbstwahrnehmung der Figur gestaltet. (Schmid 2011, 142)

Das Verständnis für die komponierte Situation entwickelt sich in jedem Fall im Zusammendenken der beiden ästhetischen Dimensionen, der visuellen und der sprachlichen, zum Ikonotext.

Leitfragen zur Analyse der narratorialen und figuralen Perspektive:

- Wie sieht der Erzähler auf das Geschehen? Nimmt er aus seiner eigenen, der narratiorialen Perspektive wahr oder gestaltet er die Sicht eines figuralen Standpunktes? (Vgl. Schmid 2008, 137)

- Nutzt der Erzähler seine Fähigkeit zur Introspektion, um Informationen über das Denken und Fühlen einer Figur kundzutun?

- Ist die Innenperspektive einer Figur auf solche Weise gestaltet, dass die Figur selbst über ihr Innerstes und ihre individuelle Sicht auf das Geschehen Auskunft gibt?

- Wechselt die Perspektive innerhalb des Erzählganzen?

- An welchen Stellen vermischen sich narratoriale und figurale Perspektive (z. B. in der erlebten Rede)?

64 Es gibt noch kaum gesicherte Ergebnisse darüber, wann ein Kind zu empathischen Empfindungen oder gar Identifikationsprozessen in der Lage ist, die an die Perspektive eines Ichs und den Einblick in seine Innenwelt geknüpft sind (vgl. ebd.). 


\section{III.3.2.3 Das WIE des Erzählens auf der Ebene des Verbaltextes}

Die Kategorien des discourse werden hier für die Verbalebene nur kurz gefasst.

Sprachliche Ästhetik

- Wie hoch ist die sprachliche Komplexität: Umfang, Wortschatz, Stil, syntaktische, grammatische und stilistische Strukturen (Parataxe, Hypotaxe, Reime, lyrischer Satzbau, Verwendung des Konjunktivs, umgangssprachliche Wendungen etc.)

- Sind traditionelle narrative Strukturen erkennbar (Exploration, Höhepunkt, Wendepunkt, Schluss/Auflösung)?

- Weist die semantische Ebene Vergleiche, Symbole oder Metaphern auf?

- Ist Komik ein gestalterisches Element?

- Wie ist die Mittelbarkeit der Figurenrede, wie die der Erzählerrede gestaltet?

- Werden Erzählebenen gewechselt (personale Ebenen, räumlich-zeitliche Verschiebungen, etc.)?

- Korrespondieren formale Aspekte der Sprachebene (z. B. Sprachvarietäten) mit der Anlage einer Figur oder eines Geschehensmoments?

Dimensionen der Zeit und dramaturgische Struktur bzw. Ordnung

- In welchem Verhältnis stehen Erzählzeit und erzählte Zeit zueinander?

- Erzählordnung: lineares, chronologisches, anachronistisches Erzählen, Analepse, Prolepse

- Erzähldauer: Zeitdeckung, Zeitraffung, Zeitdehnung, Ellipse, Pause

- Gibt es überraschende Momente/ Wendungen?

\section{III.3.2.4 Das WIE des Erzählens auf der Ebene des Bildtextes}

Welche Wirkungen werden durch die zugrunde liegenden ästhetischen Entscheidungen wie Farbwahl, Stil, künstlerische Technik, Material, Bildkomposition, Betrachterstandpunkt, medienaffine Anlehnungen (Nähe zu Film, Theater, bildender Kunst) und andere Gestaltungsmerkmale hervorgerufen und worin besteht ihr Beitrag zum Erzählganzen? Wie anspruchsvoll (hinsichtlich visueller Kompetenz und Kognition) sind die Darstellungsformate?

\section{Korrelate mit der Bildenden Kunst}

- Spiegelt die Bildästhetik eher traditionelle, malerisch-realitätsnahe bzw. naivrealistische Konzepte oder bietet sie mehr innovative Darstellungsformen im Sinne postmoderner, experimenteller Konzepte? Bildstile: traditionell 
im Ambiente des 19. Jahrhunderts, wirklichkeitsnah bzw. formgetreu, naturalistisch, abstrakt, experimentell, kindlich-naiv, magisch, futuristisch, surrealistisch, impressionistisch, expressionistisch, fotorealistisch, graphisch, stilisierend, plakativ, flächig, etc. (vgl. z. B.: Dehn/ Thiele 1985).

- Technik: „Künstlerische Drucktechniken, Technik des Plattenschnittes (z.B. Holzschnitt), Collagen (mit gefärbten Papieren, Fotocollage), Aquarelle, Tempera, Acryl, pasos oder lasierend aufgetragen, Airbrush, Mischtechnik, (z. B. Buntstift und Wasserfarbe, oder Acryl kombiniert mit der Spritzpistole), [...] Pastellkreide auf farbigem Tonpapier, Fotografie" (Schmidt-Dumont 1997, 102)

- Inwieweit spiegeln sich inhaltliche Aspekte in der Art und Weise der bildlichen Gestaltung, d. h. in der Strichführung, im Bildstil und in der Komposition der Bildelemente?

- Wird an kunsthistorisch belegbare Bildtraditionen angeknüpft?

- Sind intertextuelle Bezüge zu Stilen bekannter Maler und ihrer Werke nachweisbar?

- Bestehen Wechselbeziehungen zwischen Bildstil und Kindheitsbild? In welchen kultur- und kunstwissenschaftlichen Traditionen steht die ikonische Darstellung des Kindes?

Bildwissenschaftliche Aspekte zum Erzählbild

- Wie ist die Titelseite gestaltet? Spielen bildwissenschaftliche Aspekte hinsichtlich Blicklenkung durch Farbe, Form und Konstellation bzw. Komposition eine Rolle?

- Sind die Bilder monoszenisch oder pluriszenisch angelegt?

- Handelt es sich um eine komplexe, simultane Darstellung, in der die Auflösung der Einheit von Ort und Zeit ein Nebeneinander mehrerer Handlungsabläufe an verschiedenen Schauplätzen und u. U. in zeitlicher Abfolge möglich macht?

- Lädt das einzelne Bild aufgrund von Detailfülle, Ambiguität oder anderer gestalterischer Spezifika zum verweilenden Betrachten ein?

- Inwieweit ist die Farbsymbolik als Gestaltungsmerkmal in die Darstellungskonzepte einbezogen worden?

- Wie und worauf wird die Aufmerksamkeit des Betrachters gelenkt (Farbgebung, Licht- und Schattenspiele, Kameraperspektive, Bildaufbau)?

- Welche Wirkungen werden durch Beleuchtung, Kameraperspektive und Farbwahl beim Betrachter hervorgerufen? 
- Sind die Figuren in ruhender Haltung oder in Bewegung dargestellt und welche Funktion erfüllen sie damit?

- Weist die Bildgestaltung mediale Einflüsse (Film- und Fotokunst etc.) auf, wie z. B. Handlungsreihungen, Aufzeigen von Aktivität und Bewegung, KameraPerspektiven und Perspektivwechsel, im weitesten Sinne filmische Akzente?

- Inwieweit ist über die Bildkomposition die Erzählinstanz identifizierbar?

- Ist die Kameraperspektive überwiegend überschauend (Vogelperspektive), ebenbürtig (auf Augenhöhe) oder eine aufschauende (Untersicht/Froschperspektive)?

- Wird Distanz zum Betrachter gehalten (Vollbild oder Totale) oder durch Nahaufnahmen (Zoom) empathische oder gegenstandsbezogene Nähe evoziert?

- Wie ist der Hintergrund gestaltet? Raumtiefe, Flächigkeit oder fehlender Hintergrund?

- Regen ungewöhnliche Darstellungen und ihre Konnexionen zum Staunen an? Sind sie überraschend und machen sie neugierig oder gereichen sie eher zu Verwirrung und Ablehnung?

- Lassen ikonische Requisiten und Gestaltungselemente eine zeitgeschichtliche Situierung des Handlungsraumes zu?

- Weisen Requisiten auf einen bestimmten Lebensraum, ein soziokulturelles Milieu hin?

Dimensionen der Zeit und dramaturgische Struktur des Bilderzählens

- Liegt eine kohärente Darstellung im Sinne einer nachvollziehbaren Abfolge vor, evtl. unter Einbezug von Analepsen und Prolepsen?

- Werden räumlich-zeitliche Dimensionen bzw. Verschiebungen im Bild dargestellt (z. B. Altern, Jahreszeiten, Vorher-Nachher-Differenzierung etc.)?

- Gibt es eine visuelle Spannungskurve, die sich beispielsweise durch Farbsymbolik oder formale Aspekte wie die Bildgröße ausdrückt?

- Bei textfreien Bilderbüchern: Erzählen die Bilder eine Handlungsfolge oder gibt es eine Vielzahl einzelner Erzählanlässe? Ist inhaltliche und/oder formale Kohärenz gegeben? Inwiefern gehen die Bilder über Benennanreize hinaus und erzählen auf einer konnotativen Ebene? 


\section{III.3.2.5 Inszenierungen von Sprache und Bild}

und ihre Interdependenzen

- Entspricht das Erzählte den Ankündigungen von Titel und Titelbild oder gibt es irreführende Diskrepanzen? Welche Erwartungen werden geweckt, welche eingelöst?

- Wie verhalten sich Sprach- und Bildebene zueinander: parallel, alternierend oder kontrapunktisch?

- Bestehen Differenzen zwischen der Erzählinstanz der Bildebene und der der Verbalebene?

- Ist die Sprache erzählerisch (in Bezug auf Inhalt und erzählte Situation) und stilistisch im Einklang mit den Bildern oder gibt es Brüche? Welche Wirkung wird erzielt?

- An welchen Stellen gehen die Text- bzw. Bildebene über den narrativen Gehalt der jeweils anderen Ebene hinaus?

- Greift das Bild prägnante Aspekte/Situationen des Erzählten auf? Worin besteht der narrative Mehrwert der Bilder?

- Welche Ikonotexte generiert das Zusammenspiel der beiden semiotischen Systeme Sprache und Bild?

\section{III.3.3 Die Geschichte - Das WAS des Erzählens ${ }^{65}$}

Was erzählt der Erzähler, welche Informationen gibt er preis? Die Fragen zur Geschichte betreffen die „Aspekte Thematik, Handlung, Figur, räumliche und zeitliche Struktur sowie Regeln und Gesetzmäßigkeiten der Inhaltsdimension des Erzähltextes, die wir intuitiv als eine »erzählte Welt" wahrnehmen" (Burghardt 2013, 199; H. i. O.). Sofern nicht ausdrücklich differenziert, sind die nachfolgenden Fragen sowohl für die Erschließung der Bildebene als auch der Sprachebene anzuwenden.

Aspekte der Thematik: Stoff, Thema, Motiv

Hier ist zu klären, welcher Subgattung das Bilderbuch aufgrund des identifizierten Stoffes, Themas oder Motivs zuzuordnen ist. Dabei ist das „Leserbewusstsein“ gefordert, das aufgrund seines Wissenshorizontes und anderer persönlicher

65 Interferenzen aufgrund von Fragestellungen, die in die Ebene des discourse hineinreichen, sind unvermeidbar, da eine Trennschärfe der Analyseebenen der Gesamtwirkung und -deutung eines Textes zuwiderlaufen würde. 
Konstitutionen Sinn- und Bedeutungszuschreibungen der dargebotenen Handlungen, Geschehnissen und Ideen vornimmt (Hansen 2013, 207).

- „Gibt es konventionelle Indizien [...] (Gattungs- und Genrebezeichnungen, tradierte Stoffe und Motive, »sprechende Namen« etc.)“ (ebd., 209; H. i . O.)

- Gibt es intertextuelle Bezüge?

- Welche Hinweise geben Paratexte (Titel, Untertitel etc.) auf die thematische Ausrichtung?

\section{Handlung}

Es wird nach den Geschehnissen, Ereignissen und den durch Figuren hervorgebrachten Handlungen gefragt.

- Gibt es mehrere Handlungsebenen?

- Wie komplex sind die Handlungsabläufe konzipiert?

- Sind sie nach einem bestimmten Schema miteinander verbunden?

- Ist ein Spannungsbogen angelegt?

- Folgt das Handlungsgeschehen spezifischen narratologischen Mustern (Tragödie, Komödie, Krimi etc.)?

\section{Aspekte des Raumes}

- In welchem Raum findet das Geschehen statt (historische Zeit, Alltagswelt, Arbeitswelt, Natur, Stadt, etc.)?

- Wird eine realitätsnahe oder phantastische Welt dargeboten?

- Sind die Handlungsorte in der Tierwelt oder der Menschenwelt angesiedelt?

- Ist der Handlungsort einem bestimmten Milieu zuzuweisen? Wie ist er ausgestattet?

- Gibt es mehrere Handlungsräume und wie verhalten sie sich zueinander?

\section{Figuren}

Figuren sind Individuen einer fiktionalen Welt, hervorgebracht vom Verbaltext, der ihnen Aussehen, Eigenschaften, Gedanken, Wünsche, Verhalten und Handlungen einschreibt und damit eine Gestalt verleiht (vgl. Hansen 2013, 232ff.). Auf der Bildebene werden diese individuellen Konstitutionen teils sichtbar ausgestaltet, ergänzt oder konterkariert. Figuren sind aber nicht zwangsweise Menschen oder menschenähnlich, sondern können auch mit „mentale[n] Zustände[n] (Wahrnehmungen, Gedanken, Gefühle Wünsche, Absichten)“ (Schmid 2011, 145) ausgestattete Gegenstände einer fiktionalen Welt sein. 
- Welche Figuren treten auf und in welchen Beziehungen stehen sie zueinander?

- Ist die Figur ein runder oder ein flacher Charakter?

- Ist die Figur statisch oder dynamisch, eindimensional oder mehrdimensional angelegt?

- Welche Funktion übernimmt die Figur im Handlungszusammenhang: Protagonist, Antagonist, Nebenfigur?

- Werden die äußere Erscheinung der Figur und ihr Charakterbild mehr explizit, durch den Erzähler oder andere Figuren, oder implizit über ihr eigenes Verhalten und ihre Äußerungen erschließbar?

- Welches Alter kann der Figur zugeschrieben werden?

- Spielen genderspezifische Aspekte eine Rolle?

- Gehört die Figur der Tierwelt an? Ist sie anthropomorphisiert dargestellt?

- Ist das äußere Erscheinungsbild mit besonderen Attributen oder Eigenschaften versehen?

- Ist die Figur realistisch oder verfremdet, karikiert oder typisiert, skurril, bizarr oder verniedlicht dargestellt?

- Weist sie geschlechtstypische Merkmale auf?

- Verkörpert die Figur ein bestimmtes Rollenklischee?

- Ist die Figur in ein Beziehungsgeflecht eingebunden und welche emotionalen und funktionalen Bezüge bestehen zu Anderen, insbesondere in Familienkonstellationen?

- Verhält sich die Figur aktiv oder passiv zum Geschehen?

- Ist die Figur ein Held, hat sie mit Identitätsproblemen zu kämpfen, leidet sie an einem Mangel, benötigt/erhält sie Hilfe oder handelt sie autonom?

- Welche Gemütszustände durchlebt sie?

- Auf welche Weise werden innerpsychische Zustände der Figur deutlich (implizite bzw. explizite Darstellung auf der Bild- und Sprachebene; Figurenrede)?

- Welche Rückschlüsse auf den sozialen Status oder den Lebensstil der Figur lassen Bild oder Text zu? Werden sie auf der jeweils anderen Ebene bestätigt?

- Korreliert die Figurenkonzeption mit der Gestaltung ihrer Lebensumwelt?

Aspekte der Zeitstruktur

- Welchen Zeitraum umfasst die Geschichte insgesamt?

- Welche Dauer nehmen einzelne Ereignisse in Anspruch?

- Sind die Indizien für Zeitspannen implizit oder explizit auszumachen?

- Inwiefern hat der Zeitfaktor für Ereignisse eine bedeutungstragende Funktion? 
Interdependenzen zwischen Verbal- und Bildebene

- Spiegeln die Bildelemente die aus der Sprachebene herauszulesenden Themen und Motive?

- Besteht Kongruenz zwischen der bildnerischen und sprachlichen Anlage der Figur?

- Spiegeln sich auf nachvollziehbare Weise verbal vermittelte innerpsychische Zustände auf der Bildebene?

- Bestehen Korrelationen zwischen Raum- und Handlungsstruktur und wie sind sie auf der Sprach- und Bildebene realisiert?

- Werden zeitliche Dimensionen auf beiden Ebenen deckungsgleich wiedergegeben?

Der vorstehende Fragenkatalog zum narratologischen Modell der Bilderbuchanalyse zielt einerseits auf eine literaturwissenschaftliche Erschließung, andererseits lassen die daraus resultierenden Analyseergebnisse auch Rückschlüsse auf die Verstehensanforderungen eines untersuchten Bilderbuches zu. Diese werden u. a. mit den folgenden rezeptions- und wirkungsästhetischen Anfragen an den Ikonotext angesprochen.

\section{III.3.4 Rezeptions- und wirkungsästhetische Anfragen an den Ikonotext}

Aus rezeptionsästhetischer Perspektive entfaltet sich eine Geschichte bekanntlich erst dann, wenn die Präsentation einer Erzählung einen Rezipienten zur Wahrnehmung veranlasst. Somit ist die Konstitution des Ikonotextes wesentlich davon abhängig, über welche kognitiven, visuellen und sprachlichen Kompetenzen der jeweilige Rezipient verfügt. Das heißt: Auf einer abstrakten Ebene kann der Ikonotext zwar als gegebene Größe betrachtet werden, da aber der Leser bzw. Betrachter immer an der Generierung der Geschichte beteiligt ist, muss der Ikonotext als individuelles Rezeptions- und Analyseergebnis verstanden werden. Die folgenden Fragen sind deshalb nur im Bewusstsein dieser Subjektivität beantwortbar.

- Bietet die Fiktion Anknüpfungspunkte zur realen Kinderwelt, zu kindlichen Erfahrungs- und Gefühlswelten?

- Regen die Figuren zur Identifikation (Substitution, Projektion, Empathie) an?

- Welche Strategien der Sympathie- und Rezeptionslenkung, wie z. B. Farbgebung, Bildperspektive, Wortwahl u. a., sind mit welcher Wirkung verbunden?

- Ergänzen sich Text und Bild zu einem stimmigen Ganzen? Kann man von gelungenem Zusammenspiel (Gleichklang oder auch Kontrastierung) sprechen? 
- Welche Gratifikationen sind zu erwarten? Wie hoch ist der Unterhaltungswert, wie hoch der Informationswert einzuschätzen? (Weist die Geschichte informative und/oder unterhaltsame, spannende, überraschende oder komische Momente auf?)

- Welche Botschaft lässt sich aus dem Dargestellten ableiten?

- Werden Klischees bedient oder eher vermieden?

- Welche Leserbeteiligung fordert das Bilderbuch (Leerstellen, Leseransprache etc.)?

- Stellt das Bilderbuch besondere Verstehensanforderungen auf der sprachoder formalästhetischen Ebene?

- Stellt der Inhalt besondere Verstehensanforderungen, die Gespräche initiieren und in die Zone der nächsten Entwicklung weisen?

- An welchen Kriterien ist ggf. eine Doppeladressierung festzumachen?

- Gibt es (konkrete) Anknüpfungspunkte für Anschlusskommunikationen und Anschlusserzählungen (offenes Ende, offene Fragen, Problemorientierung)?

- Werden inhaltlich-pädagogische Anregungen für Handlungsmöglichkeiten geboten (Reflexion und Weiterentwicklung von Urteilskriterien, Erfahrungsbestätigung oder Anlass zur Korrektur, Bewältigung von Gefühlen und Konflikten, Bewältigung von Entwicklungsaufgaben)?

Da die leitmotivischen und konzeptionellen Spezifika einzelner Werke eine am Gegenstand je neu zu justierende Herangehensweise und somit eine Modifizierung bzw. Ergänzung des gesamten Kataloges erfordern, ist der im Kapitel V.2.3 vorgestellte thanatologisch-diskursanalytische Ansatz als solche zu verstehen. Grundlagen dieser Modifizierung sind die im folgenden Kapitel zusammengestellten Erkenntnisse der Sterbe- und Trauerforschung. 



\section{Thanatologische Grundlagen}

Die Thanatologie ist ein breit aufgestelltes, interdisziplinäres Forschungsgebiet, das sich mit den Fragen zu Tod und Sterben und den damit verbundenen Problemfeldern beschäftigt. Dazu gehören neben den medizinischen und soziologischen Disziplinen unter anderem die Psychologie und die Theologie, die im Folgenden in den Kontext der Trias Sterben, Tod und Trauer gestellt werden.

\section{IV.1 Thanatologie und Thanatopsychologie}

Es ist ein Gemeinplatz der modernen Thanatologie, dass der Tod für keinen Menschen ein beschreibbares Ereignis des eigenen Lebens sein kann. Wir wissen alle um unseren Tod, aber wir wissen nichts von ihm. Statt eines Todeswissens besitzen wir eine unbestimmte Todesgewissheit: Das Dass unseres Endes ist uns eine verbürgte Tatsache, ein Erfahrungsereignis wie der gesehene Tod anderer, aber über das Wann, Wie, Wo oder gar Warum dieses Ereignisses lässt sich zeitlebens nichts erfahren; mors certa, hora incerta $^{66}$. (Kelleter 2002, 1; H. u. Fußnote i. O.)

Wie kann der Mensch über das Unbekannte und Unerforschbare kommunizieren, wenn der Tod doch die absolute Grenze aller Sprache und Kommunikation ist? „Was sich überhaupt sagen läßt, läßt sich klar sagen; und wovon man nicht reden kann, darüber muß man schweigen", so formuliert Wittgenstein im Vorwort seiner Logisch-philosophischen Abhandlung (Tractatus Logico-Philosophicus 1921). Ist danach nicht jeder Gedanke über den Tod bar jeder Vernunft, da doch alle Sprache den Tod nur höchst spekulativ, bestenfalls metaphorisch angehen kann? Müsste der Mensch es nicht bei der Akzeptanz der unumstößlichen Tatsache bewenden lassen, dass alles Leben endlich ist und er kein Wissen davon erlangen kann, ob diese Begrenzung absolut oder eine Grenze zwischen zweierlei Welten ist?

Der Tod, ganz gleich was er ist, wird nichts mehr mit dem uns im Leben Bewussten zu tun haben. Deshalb könnten wir ihn, in Anlehnung an den Materialismus Epikurs ${ }^{67}$, als natürliches Ende unseres Bewusstseins schlicht

66 Vgl. Ariès 1976, 20.

67 Epikur (341-270 v. Chr.), zit. in Mischke 1996, 17: „Das angeblich schaurigste Übel also, der Tod, hat für uns keine Bedeutung; denn solange wir noch da sind, ist der Tod nicht da; stellt sich aber der Tod ein, so sind wir nicht mehr da. Er hat also weder für die Lebenden Bedeutung noch für die Abgeschiedenen, denn auf jene bezieht er sich nicht, diese aber sind nicht mehr da." 
hinnehmen - wenn dem nicht die Unwägbarkeiten des Sterbens vorausgingen und uns nicht die Ungewissheit umtreiben würde (vgl. Mischke 1996, 17ff.). Wo bleibt das Ich, wenn der Körper verfällt, oder ist der Mensch nur Körper? Werden wir neu nach dem Tod? Was haftet dem möglichweise neuen Ich vom vergangenen an? Für jeden, ob er sich diesen Fragen stellt oder sie vermeidet, ist der Tod eine latente Gefahr, die, wird man sich ihrer bewusst, Angst macht, weil sie in vielerlei Form plötzlich und unerwartet oder als Ende eines langen und qualvollen Prozesses über den Menschen hereinbrechen kann. Deshalb zieht der Mensch es gewöhnlich vor, die unaufhebbare Tatsache der Sterblichkeit aus dem aktiven Bewusstsein zu verdrängen. Bei Sigmund Freud findet man dazu Folgendes:

Wenn man uns anhörte, so waren wir natürlich bereit zu vertreten, daß der Tod der notwendige Ausgang alles Lebens sei, $[\ldots]$ daß der Tod natürlich sei, unleugbar und unvermeidlich. In Wirklichkeit pflegten wir uns aber zu benehmen, als ob es anders wäre. Wir haben die unverkennbare Tendenz gezeigt, den Tod beiseite zu schieben, ihn aus dem Leben zu eliminieren. Wir haben versucht, ihn totzuschweigen. [...] Der eigene Tod ist ja auch unvorstellbar, so oft wir den Versuch machen, können wir bemerken, daß wir eigentlich als Zuschauer weiter dabeibleiben. So konnte in der psychoanalytischen Schule der Anspruch gewagt werden: Im Grunde glaube niemand an seinen eigenen Tod, oder, was dasselbe ist: Im Unbewußten sei jeder von uns von seiner Unsterblichkeit überzeugt. (Freud 1915, 341)

Die natürliche Unmöglichkeit des Menschen, seine „Nicht-Existenz“ (Leist 2004, 15) zu denken, ist einer lebensbejahenden Lebensgestaltung ganz offensichtlich dienlicher, als besorgt jeden Tag für den letzten halten zu müssen. Solange die Relevanz des Todes für das eigene Leben ignoriert wird bzw. werden kann - die Situation eines Schwerkranken stellt selbstredend andere Bedingungen -, ist kein Anlass zur Auseinandersetzung gegeben. Gleichzeitig aber bleibt der Tod eine unumstößliche Tatsache, und diese Gewissheit der irreversiblen Vernichtung der Existenz scheint wiederum so unaushaltbar zu sein, dass der Mensch, „[u]m dem Tod zu entkommen, [...] sich in Phantasien von einer Nachwelt oder der Reinkarnation“ flüchtet (Mischke 1996, 7). Auch damit können Ängste verbunden sein; sind diese religiös motivierten Vorstellungen dagegen - im Sinne eines besseren Danach - positiv konnotiert, können sie durchaus mit einer Gelassenheit einhergehen, wie sie der von Epikur propagierten „Bedeutungslosigkeit des Todes“ für die „diesseitigen Freuden“ des Daseins entspringt (vgl. ebd., 17). Da der Tod „außerhalb des menschlichen Lebens“ steht, habe das Leben „nur an sich und für sich einen Sinn“ (ebd., 18). Die logische Konsequenz der antiken Auffassung, dass darüber zu schweigen sei, was keine Bedeutung im Leben hat, ist dagegen in der Neuzeit der Überzeugung gewichen, dass erst die 
Auseinandersetzung mit dem Tod dem Leben seine Bedeutsamkeit verleiht (vgl. ebd.). Die empirische Wirklichkeit des Todes

existiert als Anlass von Tröstungen, Schmerzensbekundungen, Autopsien, Erklärungsversuchen, Begräbnisritualen, Fitnessprogrammen, Rettungsbemühungen, Präventivmaßnahmen, Lebensmaximen, Lehrgebäuden, Glaubenssystemen, interdisziplinären Arbeitskreisen. (Kelleter 2002,7)

Wie nie zuvor wird heute über den Tod geredet. Die Anzahl der Publikationen des interdisziplinären thanatologischen Diskurses ist seit den 1970er-Jahren „lawinenartig angewachsen ${ }^{68 " ~(M i s c h k e ~ 1996, ~ 7) . ~ T h e o l o g e n, ~ P h i l o s o p h e n, ~ P s y c h o-~}$ logen, Soziologen, Pädagogen, Mediziner u. a. beschäftigen sich in unzählbaren Veröffentlichungen mit dem Tod. Besonders im Bereich der populärwissenschaftlichen Literatur scheint sich ein Bemühen um Entschärfung der „grausamen Realität des Sterbens im Krankenhaus“ auszudrücken: „Vorstellungen vom ewigen Leben, Auferstehung, Rebirthing, Seelenwanderung usw. waren und sind sehr verführerisch, um mit dem Tod fertig zu werden." (Ebd.) Aber wir müssen sterblich sein, um leben zu können, denn: „Es ist richtig, daß, was nicht lebt, nicht stirbt, aber doch nur, weil, was nicht stirbt, nicht lebt." (Jankélévitch et al. 2005, 541) Erst die gegenseitige Bedingtheit von Leben und Tod gibt dem Leben einen Sinn, nur die „Erkenntnis des Fristcharakters“ (Mischke 1996, 11) macht jedes Erleben in seiner zeitlichen Dimension so wertvoll, treibt den Menschen an, sein Leben zu gestalten. Ohne die Beschränktheit der Möglichkeiten gäbe es keinen Antrieb, denn ein $\mathrm{Zu}$-spät gäbe es nicht mehr, das Leben würde zu einem Dahindümpeln verkommen, beliebige Wiederholbarkeit nähme allem Tun seine prägnante Zielsetzung und Wirkung. Aber der Tod bleibt fremd und nicht fassbar, er kann nur als Tod der Anderen wahrgenommen werden, nie als der eigene. „Real ist der Tod nur auf der Ebene der Todesangst.“ (Ebd., 19) Aber wovor fürchtet sich der Mensch?

Der Tod ist nichts Schreckliches. [...] Schrecklich sind oft die kollektiven und individuellen Phantasien, die den Tod umgeben. Sie zu entgiften, ihnen die einfache Realität des endlichen Lebens gegenüberzustellen, ist eine Aufgabe, die noch vor uns liegt. (Elias 1982, 99)

Sollte der Mensch also nicht besser die Furcht ablegen und sich nicht sorgen um etwas, das keiner Sorge zugänglich ist, und sich dem Leben und seinen in aller Begrenztheit vorhandenen Möglichkeiten zuwenden? Und muss nicht schließlich positiv gesehen werden, dass das Leben unentrinnbar auf den Tod hinausläuft,

68 „Eine unvollständige Bibliographie aus dem Jahre 1976 nennt allein 3848 Titel.“ 
da „eine immerwährende Dauer, eine sich endlos hinziehende Existenz [...] in vielerlei Hinsicht die charakteristischste Form der Verdammnis" (Jankélévitch et al. 2005, 541) wäre? Diese Überlegungen wie auch die Beschäftigung mit den Ursachen und Formen der Angst sind Teil des komplexen Diskurses, für den die Thanatologie steht.

Die Thanatologie umfasst Sterbeforschung, Trauerforschung, historische Todesbildforschung, Suizidforschung usw. (vgl. Kelleter 2002, 5) und berührt in der Beschäftigung „mit dem Erleben und Verhalten gegenüber Sterben und Tod“ mehrere etablierte Teilgebiete der Psychologie, unter anderem die Entwicklungspsychologie und die Sozialpsychologie (Wittkowski 1990, 1). Dieses relativ neue Feld psychologischer Forschung wird mit dem Begriff der Thanatopsychologie umrissen. Erst Ende der 1970er-Jahre „wurden zum ersten Mal im deutschen Sprachraum Beiträge der Psychologie zu ausgewählten Aspekten der Todesthematik in einer Monographie vorgestellt (Wittkowski 1978)." (Wittkowski 1990, IX)

$\mathrm{Zu}$ den neuen Psychologien zählt auch die Thanatopsychologie. [...] Eine besondere Notwendigkeit zur wissenschaftlich-psychologischen Beschäftigung mit der Todesthematik ergibt sich in der zweiten Hälfte [...] [des 20. Jhs.; M.H.] durch das Zusammenwirken folgender Entwicklungen bzw. Umstände: (1) Die Zahl sehr alter, kranker und pflegebedürftiger Menschen, die sich mit der Endlichkeit ihres Dasein konfrontiert sehen, hat nicht zuletzt aufgrund moderner medizinischer Behandlungsmöglichkeiten zugenommen. (2) Eine gegenüber früher erheblich gestiegene Zahl von Krebskranken - Erwachsenen und Kindern - verbringt eine lange Zeitspanne zwischen der Diagnosestellung und dem Eintritt des Todes oder der (vorläufigen) Entlassung aus dem Krankenhaus. Dies ist für die Betroffenen selbst, aber auch für Ärzte, Betreuer und Angehörige mit erheblichen psychischen Belastungen verbunden. (3) Besonders plastisch treten psycho-soziale Probleme unheilbar Kranker und Sterbender, ihrer Betreuer und Angehörigen bei der erworbenen Immunschwächekrankheit AIDS zutage. [...] (4) Über den angemessenen Umgang mit Hochbetagten, unheilbar Kranken und Sterbenden wird unter den Schlagworten ,Sterbebeistand', ,Sterbehilfe` und ,Hospizbewegung' unter Medizinern, Juristen, Theologen und Sozialwissenschaftlern zunehmend heftiger diskutiert. Gerade sozialwissenschaftliche Erkenntnisse vermögen einerseits zur Differenzierung und andererseits zur Versachlichung dieser Diskussion beizutragen. (Ebd., 1f.; H. i. O.)

Vortoderfahrungen, die psychischen Prozesse in der letzten Lebensphase, Notwendigkeiten und Bedingungen von Sterbebeistand, Konstituenten professioneller und privater Interaktion mit Sterbenden, Sterben als psychosoziales Verhalten, Trauerprozesse, Suizid und Suizidprävention sind die Forschungsfelder der Thanatopsychologie (vgl. Ochsmann 1993, 14ff.). Es geht dabei um das Aufdecken und Verstehen von Gesetzmäßigkeiten im Umgang der Menschen 
mit Todesereignissen und Sterbeprozessen, auch, um präventiv wie akut begleitend Hilfestellungen anbieten zu können.

Ganz allgemein sind in der Annäherung an Sterben und Tod verschiedene Positionen der Betroffenheit zu unterscheiden, die einerseits individuell geprägt sind, andererseits aber auch überindividuelle Gemeinsamkeiten aufweisen. Es sind die Perspektiven von gesunden Menschen, die von lebensverkürzend erkrankten Erwachsenen und Kindern und ihrer Angehörigen und derjenigen Betroffenen, die bereits einen Verlust erlitten haben. „Das Wissen, dem Tod nicht entrinnen zu können, ist uns nicht angeboren, sondern eine soziale Erfahrung, Ergebnis und Lernprozess, dessen Basis die Erfahrung des Todes anderer ist.“ (Hahn 1968, 23)

Für das Verständnis der in den einschlägigen Bilderbüchern erzählten Erfahrungen mit Sterben und Tod sind vor allem die im Folgenden aufgeführten Ergebnisse psychologischer Studien zur Entwicklung kindlicher Todesvorstellungen einerseits und zu den verschiedenen Ausprägungen von Trauer andererseits von Bedeutung.

\section{IV.1.1 Das Kind in der Thanatopsychologie}

$\mathrm{Zu}$ den allgemeinen Problemen und Untersuchungsfeldern der Thanatopsychologie gehören die Fragen danach, wann Kinder beginnen, Vorstellungen vom Tod zu entwickeln und wie diese Vorstellungen auf unterschiedlichen Altersstufen aussehen, wann Kinder in der Lage sind, die eigene Sterblichkeit zu begreifen und welche Gefühle mit ihren Gedanken über Totsein und Tote verbunden sind (vgl. Wittkowski 1990, 44). „Mit dem Begriff, Death Education“ kann der Prozeß der Entwicklung einer individuellen Einstellung zur Tatsache der Endlichkeit des Lebens sowie der Deutung des Todes bezeichnet werden." (Reuter 1994, 102; H. i. O.) Kinder treffen auf Sterben und Tod in vielfältiger Weise in ihrer Erlebnis- und Erfahrungswelt, ohne dass ihnen die umfassende Dramatik des Todes bereits bewusst ist bzw. überhaupt bewusst werden kann, denn das Verständnis vom Tod, das sogenannte Todeskonzept, wird erst im Laufe der Sozialisation und ontogenetischen Entwicklung erworben.

Das Todeskonzept bezeichnet die Gesamtheit aller kognitiven Bewußtseinsinhalte (Begriffe, Vorstellungen, Bilder), die einem Kind oder einem Erwachsenen zur Beschreibung und Erklärung des Todes zur Verfügung stehen. Das Todeskonzept beinhaltet eine kognitive Komponente, an der primär Wahrnehmung und Denken beteiligt sind, sowie eine emotionale Komponente, welche die mit einzelnen kognitiven Inhalten des Todeskonzepts verbundenen Gefühle abdeckt. (Ebd.) 
Das Wissen über die Entwicklung von Todeskonzepten in der Kindheit stützt sich auf eine ganze Reihe von experimentellen Arbeiten, die sich bis in die 1980er-Jahre hauptsächlich mit dem Todeskonzept von gesunden Kindern beschäftigten. Seitdem sind „auf diesem Gebiet kaum neue Erkenntnisse hinzugekommen", da in den vergangenen drei Jahrzehnten immer mehr das kranke Kind in den Fokus rückte (Niethammer 2008, 139). Die bereits nachgewiesenen Unterschiede sind für die Erfordernisse im Umgang mit gesunden oder kranken Kindern zu bedenken.

\section{IV.1.1.1 Todeskonzepte des gesunden Kindes}

In der Begegnung bzw. im kindlichen Umgang mit dem Tod spielen von Anfang an und auf jeder Entwicklungsstufe mehr oder weniger ausgeprägt drei Aspekte eine Rolle: das Sachinteresse am Tod, der Tod als Spiel bzw. Fiktion und die synonyme Wirkung von vorübergehender Trennung und endgültigem Verlust (vgl. Mühle 1995, 59ff.). Meist sehr viel früher, als Erwachsene vermuten oder ihnen zugestehen wollen, beginnen Kinder über die Umstände des Lebens und des Sterbens nachzudenken (vgl. Brocher 1980, 10ff.; Bürgin 1981, 53). Wo komme ich her? Was wird aus mir, wenn ich tot bin? Diese Grundfragen menschlichen Daseins stellen sich schon Kinder ab dem dritten bis vierten Lebensjahr und erwarten darauf auch eine Antwort. Die Frage nach der Herkunft ist keine so schwierige mehr und dürfte heute wohl von den meisten Eltern auch angemessen beantwortet werden, Fragen nach der Begrenztheit des Lebens lösen jedoch nach wie vor Unsicherheit und Unbehagen aus und bleiben deshalb nicht selten unbeantwortet (vgl. ebd.). Die verbreitete Verweigerung von Aussagen und Gesprächen über Sterben und Tod spiegelt aber nicht nur die erwachsene Befangenheit angesichts der eigenen Sterblichkeit, sondern auch eine bewahrpädagogische Haltung, die davon ausgeht, dass Gespräche über den Tod zu einer Überforderung und unnötigen Belastung von Kindern führen. Dass Kinder mit ihren unbefangenen Fragen lediglich ihren Wissensdurst zum Ausdruck bringen, weil sie wissen wollen, wie die Welt funktioniert, dass die belastende Komplexität des Todesthemas den Kindern noch fremd ist und nur in den Köpfen der Erwachsenen existiert, wird dabei meist verkannt (vgl. Mühle 1995, 59). Die vermeintlich behütende Informationsverweigerung schlägt dann ins Gegenteil um, wenn die Kinder hinter der von ihnen wahrgenommenen Ablehnung des Themas Schreckliches vermuten und, damit allein gelassen, beängstigende Vorstellungen entwickeln. Zudem ist die Verwendung von Euphemismen wie ,die Oma ist entschlafen' oder, sie ist von uns gegangen' besonders problematisch, 
da Kinder solche Äußerungen wörtlich nehmen, was für die Entwicklung eines gesunden Todeskonzepts höchst hinderlich ist (vgl. Unverzagt 2004, 35ff.).

Erste Begegnungen mit dem Tod sind oftmals tote Tiere, entweder der tote Vogel im Garten, das überfahrene Kaninchen auf der Straße oder das tote Haustier, vielleicht auch Verstorbene im Lebensumfeld, wobei unterschiedliche Betroffenheiten hinsichtlich Mensch oder Tier zunächst noch eine eher untergeordnete Rolle spielen ${ }^{69}$. Wesentlich sind die Sachinformationen, nach denen Kinder in solchen Situationen verlangen und die ihnen helfen, schrittweise zu einem Todesverständnis zu gelangen, das für ihr Leben tragfähig ist. Sie lernen zunächst, dass mit dem Eintreten des Todes Bewegungsunfähigkeit, der Verlust von Seh- und Hörvermögen und insgesamt die Einbuße aller Körperfunktionen einhergehen. Dieses Wissen über die biologische Nonfunktionalität ist eine erste Stufe auf dem Weg zur Entwicklung eines reifen Todeskonzeptes (vgl. Wittkowski 1990, 47f.), dessen Dimensionen weiter unten näher beschrieben werden.

Neben dem Sachinteresse am Tod beschäftigt Kinder auch die phantastische Dimension des Todes, die ihnen in Geschichten und Märchen, in Film und Fernsehen begegnet und die sie im Spiel ausleben und nachvollziehen. Sie,fallen tot um' und stehen wieder auf, sie, erschießen' sich gegenseitig und verbünden sich wieder, sie wünschen im Streit ihrem Gegenüber den Tod und meinen doch nur, dass derjenige für eine Weile verschwinden soll. Das Spiel mit dem Tod in solchen Als-Ob-Szenarien hat eine entlastende Funktion für die Verarbeitung von Aggressionen und Angst und noch wenig zu tun mit einem Verständnis vom Tod als dem unabwendbaren Ende aller Existenz - auch der eigenen - und seinen psycho-sozialen Konsequenzen und emotionalen Dimensionen (vgl. Ramachers 1994, 29ff.).

Auch der dritte Aspekt der kindlichen Annäherung an den Tod ist eine Art Vorstufe zur Entwicklung eines reifen Todeskonzepts, spielt aber gleichzeitig in seinen Facetten zeitlebens eine wichtige Rolle: die Bedeutungsverwandtschaft von Trennung, Verlust und Tod (vgl. Bowlby 2006a, 44ff.). Ohne diese Synonymität erfassen zu können, ist schon die Verlusterfahrung einer vorübergehenden Abwesenheit von geliebten Bezugspersonen für Kinder eine ähnlich existenzielle Bedrohung, wie sie eine tatsächliche Trennung durch den Tod darstellt ${ }^{70}$.

69 Gewisse Unterschiede des Todesverständnisses in Bezug darauf, ob es sich um den Tod eines Tieres oder eines Menschen handelt, beschreiben Lazar, A./ Torney-Purta, J.: The development of the subconcept of death in young children: a short-term longitudinal study. Child Dev 1991; 62: 1321-33 (zit. in Niethammer 2008, 96).

70 Dieser Auffassung liegt die Bindungstheorie von J. Bowlby (2006a) zugrunde, worauf im Weiteren mehrfach Bezug genommen wird. 
Jeder kennt die Versteck-Spiele, die beim Kleinkind schnell ängstliche Verzweiflung hervorrufen, wenn die Bezugsperson nur einen Moment zu lange aus seinem Gesichtsfeld verschwunden bleibt, und das befreite Lachen, wenn wieder Blickkontakt hergestellt wird. Jede Trennung wird wie ein Verlust erfahren, der Unterschied zu dauerhaften Verlusten liegt nur in der Rückkehr des Abhandengeglaubten. Diese Erfahrungen von Getrennt- und Wieder-vereint-Sein sind Übungsfelder für das Erlangen eines Grundvertrauens (vgl. ebd.), das sich in der späteren erwachsenen Einstellung zum Tod in einer Form von Gelassenheit ausdrücken kann, die von Hoffnung und Trost getragen wäre.

Im Folgenden werden die kognitiven Anteile der Todeskonzepte von Kindern und Erwachsenen dargestellt, die gemeinsam mit den emotionalen Komponenten das gereifte Todeskonzept eines Menschen ausmachen (vgl. Wittkowski 1990, 71).

\section{Vom kindlichen zum reifen Todeskonzept}

Die Vergleichbarkeit der vorliegenden Studien zum Todeskonzept von gesunden Kindern ist aufgrund der Unterschiedlichkeit der Fragestellungen, Untersuchungsmethoden und der befragten Klientel nur bedingt gegeben, dennoch aber sind ähnliche Phasenfolgen für alle gesunden Kinder bis zum Erreichen eines umfassenden Todeskonzepts beschrieben worden (vgl. zusammenfassende Überblicke bei: Bürgin 1981; Fischer 1987; Iskenius-Emmler 1988; Wittkowski 1990; Ramachers 1994; Niethammer 2008; Grumbach-Wendt/ Zernikow 2013).

Einigkeit herrscht heute darüber, dass die Entwicklung von kindlichen und erwachsenen Vorstellungen vom Tod einer Vielzahl verschiedener äußerer und innerer Einflussfaktoren unterliegt. Maßgeblich sind „soziokulturelle, familiäre und individuelle Modalitäten“ (Plieth 2009,38), denn das Verständnis von Leben und Tod ist nicht angeboren und entwickelt ,sich auch nicht automatisch mit der intellektuellen Reifung" (Bodarwé 1989, 32; auch Arens 1994, 59). Parallelen zu den Entwicklungsstadien (chronologisches Alter und kognitiver Entwicklungs$\operatorname{stand}^{71}$ ), wie Piaget sie als aufeinander aufbauende Phasenfolge beschrieben hat, sind vielfach nachgewiesen worden, andere und neuere Studien aber belegen das

71 Vgl. Ausführungen zur Entwicklung des Todeskonzepts in Abhängigkeit vom kognitiven Entwicklungsstand z. B. bei Wittkowski (1990, 59ff.), Ramachers (1994, 142ff.), Niethammer (2008, 68ff.). „Entscheidende kognitive Entwicklungsschritte sind dabei der Übergang vom voroperatorischen Denken zum Denken in konkreten Operationen (5-6 Jahre) und der nachfolgende Übergang zum formal-operatorischen Stadium (ab ca. 12 Jahren). Im ersten Schritt erfolgt die Abkehr vom animistischen Denken und dadurch die verläßliche Unterscheidung zwischen lebend, unbelebt 
Ausbilden des Todeskonzepts vor allem in Abhängigkeit von den Interaktionen eines Kindes mit seiner Umgebung und den Informationen und Eindrücken, die es aus seinem Umfeld gewinnt (vgl. Ramachers 1994, 30). So macht es z. B. einen Unterschied, ob ein Kind bereits den Verlust eines Haustieres oder den Tod einer Bezugsperson erlebt hat, ob ein krankes oder gesundes Kind sich mit der Todesproblematik beschäftigt und welche Kommunikationsstrukturen in seinem Umfeld vorherrschen (vgl. Cramer 2008, 26). Seit den 1980er-Jahren hat sich in der Forschung immer mehr gezeigt, dass die von Piaget entworfenen Entwicklungsstufen nur tauglich sind für die Beschreibung von Todeskonzepten bei gesunden Kindern, dass aber „spätestens ab dem vierten Lebensjahr“ Kinder „unter dem Einfluss der eigenen Erfahrungen ein Konzept vom Tod entwickeln, das ihnen ermöglicht, mit diesem bedrohlichen Ereignis umzugehen“ (Niethammer 2008, 141). Das chronologische Alter und die jeweils zugewiesenen kognitiven Fähigkeiten nach Piaget sind als Indikatoren für die Beschreibung der Bereitschaft und Fähigkeit von Kindern, sich mit Tod und Vergehen oder Nicht-Vergehen auseinanderzusetzen, also allein nicht ausreichend, sondern immer relational zu äußeren Gegebenheiten und Einflussfaktoren zu sehen.

Die kognitiven Aspekte eines gereiften, erwachsenen Todeskonzeptes lassen sich mit vier Dimensionen erfassen: Nonfunktionalität, Irreversibilität, Universalität und Kausalität (vgl. Wittkowski 1990, 53f.). Die Nonfunktionalität steht für die Erkenntnis, dass mit dem Tod alle biologischen, lebensnotwendigen Körperfunktionen aussetzen. Dass dieser Vorgang die Grenze der menschlichen Existenz markiert und unumkehrbar ist, drückt der Begriff der Irreversibilität aus. Die Universalität betrifft ausnahmslos jedes Lebewesen, dessen Tod immer einer biologisch begründeten Kausalität unterliegt. Einerseits belegen Studien, dass die Subkonzepte dieses Gesamtkonzeptes in Abhängigkeit vom Alter und vom kognitiven Entwicklungsstand innerhalb des Altersbereichs von etwa 5 bis 7 Jahren „nahezu gleichzeitig erworben werden“ (Wittkowski 1990, 60), andererseits wird auch von einem noch unscharfen Erkenntnisstand und uneinheitlichen Ergebnissen berichtet, die von einem unterschiedlichen Schwierigkeitsgrad der Subkonzepte ausgehen, der die Reihenfolge des Erwerbs bestimmt (vgl. ebd., 69). Es zeigte sich aber auch, dass Kinder leichter die Tatsache des Todes verstehen, wenn nicht ein geliebter Mensch gestorben ist, sondern ein Tier; andererseits begreifen Kinder den Tod einer Beziehungsperson besser, wenn sie aufgrund von Erfahrungen mit toten Tieren bereits einen Todesbegriff haben (vgl. Furman

und tot, der zweite Schritt markiert das vollständige Verständnis des Todesbegriffs. “ (Ramachers 1994, 142). 
1977, 63). „Immerhin zeichnet sich ab, daß das Verständnis der Irreversibilität des Todes früh und dasjenige der Kausalität des Todes eher spät erworben wird.“ (Wittkowski 1990, 69) Insgesamt konstituieren diese kognitiven Komponenten gemeinsam mit emotionalen Aspekten das Todeskonzept eines Menschen (vgl. ebd., 71).

Auch wenn sich aus „Einzelbeobachtungen [...] eine deutlich frühere Ausbildung eines ,reifen` Todeskonzeptes“ ableiten lässt, was wiederum für die individuellen Aspekte der Erwerbsprozesse spricht, belegen die einschlägigen Studien mit gesunden Kindern zwischen 3 und 12 Jahren ähnliche Phasenfolgen bis zum Erreichen eines gereiften Todeskonzepts (vgl. Ramachers 1994, 53). Bedingt durch die je individuellen Erfahrungen und intellektuellen Entwicklungen, ist aber die Verweildauer der Kinder auf den beschriebenen Stufen sehr unterschiedlich, weshalb die nachfolgend aufgeführten Altersgrenzen nur ungefähre Angaben sind.

\section{0 bis 3 Jahre}

Für den Altersbereich der ersten Lebensjahre bis etwa zum dritten fehlen in qualitativer wie quantitativer Hinsicht befriedigende Befunde, „da strukturierte und elaborierte Erhebungsmethoden kaum einsetzbar sind“ (Wittkowski 1990, 57). Grundsätzlich kann man aber davon ausgehen, dass Kinder unter drei Jahren noch keine Vorstellungen vom Tod haben. Sie erleben jede Trennung als Verlust, einem Tod gleich, wie z. B. das Verschwinden einer Bezugsperson aus ihrem Gesichtsfeld, und reagieren entsprechend mit Trauer und Verzweiflung. Da Kleinkinder ausschließlich in der Gegenwart leben und aufgrund ihres fehlenden Zeitverständnisses nichts von einem Nachher und einem Zurückkommen wissen können, sind für sie,weggegangen' und, verloren' bedeutungsgleich.

\section{3 bis 6 Jahre}

In der Altersklasse der 3- bis 6-Jährigen beginnen die Kinder, ihr animistisches Weltbild abzulegen und unbelebte Objekte von belebten Objekten zu unterscheiden, ohne aber über Vorstufen des reifen Todeskonzeptes hinaus zu gelangen (vgl. ebd., 63). Bemerkenswert ist, dass die in der sensumotorischen Phase ${ }^{72}$

72 „Piaget unterscheidet vier Hauptstadien der kognitiven Entwicklung bei Kindern [...]:

1. Auf der Stufe der sensumotorischen Intelligenz (0-18/24 Monate; mit sechs Substadien) verfügt der Säugling zunächst nur über einige angeborene Reflexe. [...] Mit etwa 12 Monaten erkennt das Baby, dass Dinge auch da sind, wenn es sie nicht 
ausgebildete Objektkonstanz , der Entwicklung einer Vorstellung vom Tod in der nachfolgenden Phase des voroperatorischen Denkens sogar entgegen[steht]", da die Kinder lernen, dass ,ein Gegenstand auch dann noch existiert, wenn er nicht zu sehen ist" (Ramachers 1994, 37). Sie halten das Totsein deshalb für einen vorübergehenden Zustand, für ein Weggehen, dem ein Zurückkommen folgen kann. Oder sie stellen sich eine Art „reduziertes Weiterleben“ (ebd., 37), ähnlich dem Schlaf, vor und gehen davon aus, dass Unbelebtheit lediglich eine Einschränkung der Körperfunktionen bedeutet und ein Aufwachen möglich ist (vgl. Wittkowski 1990, 58).

Dass alte Menschen sterben, wissen die Kinder bald, dass aber die Sterblichkeit jeden betrifft, auch die Eltern und Geschwister und sogar sie selbst, nicht (vgl. ebd., 57). Der noch fehlende Zeitbegriff fixiert jegliches Erleben in der

sieht („Objektpermanenz"). Es beginnt, zwischen sich selbst (Subjekt) und seiner Umwelt (Objekte) zu unterscheiden. [...]

2. Das präoperationale Stadium beginnt mit der Stufe des symbolischen oder vorbegrifflichen Denkens (18/24 Monate - 4 Jahre): Das Kleinkind eignet sich die Sprache an und kann nun mit Vorbegriffen - Vorstellungen und Symbolen - umgehen. Ferner unterscheidet es jetzt zwischen einem Objekt (einer Situation, einem Verhalten etc.) und der mentalen Repräsentation desselben, was auch symbolische bzw. „Als ob-Spiele" ermöglicht (z. B. kann es mit einem Bauklotz spielen, als ob es ein Auto ist). [...]

Später folgt die Stufe des anschaulichen Denkens (4-7/8 Jahre): [...] Das Kind entwickelt nun echte Begriffe, wobei hauptsächlich wahrnehmungsmäßig herausragende Merkmale berücksichtigt werden. [...] Zugleicht entwickelt es ein Regelbewusstsein („Wenn heute Montag ist, ist überall Montag“). Das Denken ist aber noch eingleisig und ermöglicht nur die Ausführung einer einzigen inneren Handlung. Gegen Ende dieser Phase wird der frühkindliche Egozentrismus überwunden.

3. Stufe der konkreten Operationen (7/8-11/12 Jahre): Das Denken ist weiterhin an anschaulich erfahrbare Inhalte gebunden. Es werden aber nun verschiedene Merkmale eines Gegenstandes und Vorgangs gleichzeitig erfasst und zueinander in Beziehung gesetzt. Regeln beziehen sich jetzt auf die Relation zwischen zwei und mehr Begriffen. Das Kind denkt im Sinne verinnerlichten Handelns, kann vorausdenken und sein Handeln reflektierend steuern. Logische Schlussfolgerungen über Phänomene, die physische Objekte betreffen, und über konkrete Situationen werden möglich. Das Regelspiel wird zur vorherrschenden Spielform.

4. Stufe der formalen Operationen (ab 11/12 Jahre): Nun kann der Jugendliche mit abstrakten Inhalten wie Hypothesen gedanklich umgehen, Probleme theoretisch analysieren und (wissenschaftliche) Fragestellungen systematisch durchdenken. Er hat die höchste Form des logischen Denkens erreicht. [...] Literatur: Astington, J. W.: Wie Kinder das Denken entdecken. München, Basel: Reinhardt 2000“Quelle: http://www.kindergartenpaedagogik.de/1226.html; aufgerufen am 10.03.2011 
Gegenwart, weshalb das Altern und das Sterben, insbesondere geliebter Menschen und Tiere, für sie unvorstellbare Vorgänge sind (vgl. Bürgin 1981, 73). Gleichzeitig ist für Kinder dieses Alters die Vorstellung von der Heilbarkeit des Todes vorherrschend. Dass Tote ihre gesamten Körperfunktionen unwiederbringlich eingebüßt haben, dass der Körper nach dem Tod zerfällt und dieser Vorgang irreversibel ist, ist für sie noch nicht fassbar, ebenso wenig wie die Tatsache, dass auch sie selbst einmal sterben müssen (vgl. Wittkowski 1990, 57). Zudem sind Kinder im Vorschulalter noch dem Glauben verhaftet, man könne dem Tod durch bestimmte Verhaltensweisen ausweichen oder ihn gar durch magisches Denken beeinflussen, im positiven wie im negativen Sinne (vgl. ebd.). Tritt plötzlich ein emotional belastendes Todesereignis ein, ist es wichtig, dem Kind zu versichern, dass nichts, was es gesagt oder gedacht haben könnte, darauf einen Einfluss genommen hat, und dass auch magische Praktiken, wie Mutproben oder intensives Wünschen, den Verstorbenen nicht zurückbringen können. Als Ursache des Todes werden vornehmlich äußere Umstände wie Gewalteinwirkung oder andere Fremdeinwirkung angenommen, „intraorganismische Vorgänge“ (ebd.) als natürliche Todesursachen werden erst später mit dem Subkonzept der Kausalität begriffen und auch auf die eigene Person bezogen.

\section{6 bis 9 Jahre}

Die Fragen nach dem Sinn und dem, was dem Tod folgt, gewinnen zunehmend an Bedeutung. Die Kinder schwanken noch zwischen ihren vorschulischen Vorstellungen von der Umkehrbarkeit des Todes und einem realistischen Konzept von Sterben und Tod, das sie im Zuge ihrer kognitiven Entwicklung und steigenden Interesses an Umständen und Bedingungen des Todes gewinnen. Die prinzipielle Endlichkeit des Lebens wird denkbar, dass aber der irreversible Ausfall aller Körperfunktionen zu einem natürlichen Tod führt, „kann letzten Endes nicht realisiert und akzeptiert werden" (Plieth 2009, 71). Die Todeswirklichkeit manifestiert sich für Kinder ab etwa sechs Jahren vielmehr in der Auffassung, der Tod trete durch äußere Einwirkung ein, oftmals auch als personifizierte Imagination (vgl. ebd., 71f.). Indem der Tod in der Vorstellung vom schwarzen Mann, als Sensenmann oder Skelett Gestalt annimmt, wird er als (an-) greifbar und vermeidbar zugleich imaginiert. Die Vorstellung, einer Begegnung durch List, körperliche Vitalität oder Magie ausweichen zu können, hat dabei durchaus entlastenden Charakter.

Um das siebte Lebensjahr herum vollzieht sich die Wandlung des kindlichen Zeitverständnisses hin zum linearen Zeitverständnis der Erwachsenen und die Kinder lernen, zwischen Vergangenheit, Gegenwart und Zukunft zu 
unterscheiden. Sie verstehen langsam, dass der Tod eine dauerhafte Dysfunktion aller Körperfunktionen nach sich zieht, die unumkehrbar ist und alle Lebewesen betrifft (Wittkowski 1990, 58). In der Altersspanne zwischen etwa 6 und 9 Jahren wird

mindestens ein partielles Verständnis der konstituierenden Komponenten des reifen Todeskonzepts erworben. [...] Es hat den Anschein, als würden die Subkonzepte Universalität, Irreversibilität, Nonfunktionalität und Kausalität innerhalb der Jahre von etwa 6 bis 8 annähernd gleichzeitig verstanden werden. (Ebd.)

Dieser Altersgruppe ist eine große Affinität zum Thema Tod und allem, was damit zusammenhängt, gemein. Sterbevorgänge, Leichen, Friedhöfe, gefährliche Krankheiten u. a. sind von großem Interesse, das sich geradezu anbietet, im schulischen Kontext im Sinne einer nachhaltigen Entwicklung des reifen Todeskonzepts nutzbar gemacht zu werden - auch, um behutsam auf Todesängste angesichts der neuen Gewissheit eingehen zu können, dass das eigene Ich und auch die Eltern nicht vom Tod verschont bleiben (vgl. Bodarwé 1989, 35). Fragen nach dem Wie des Sterbens, nach dem Verbleib der Toten und ihrem weiteren Werdegang sind von drängender Wichtigkeit, ebenso wie mögliche Ängste angesichts der Universalität, die das eigene Ich und die Eltern einschließt. Es ist das Alter der Ambivalenz von Faszination und Fürchten, der „Übernahme magisch-religiöser Vorstellungen einerseits und realistisch-biologischer Informationen andererseits", das Alter der interessierten, oft sachlich-technischen Fragen und bildhaften Vorstellungen von einem möglichen Weiterleben in verschiedenen Daseinsformen und an verschiedenen Orten (Gebhard 1994, 183) ${ }^{73}$. Hinter den Unsterblichkeitsgedanken und Vorstellungen von einer endlosen Seelenwanderung verbirgt sich vermutlich bei Kindern - nicht anders als bei Erwachsenen - ein schützendes Konzept angesichts der beängstigenden Gewissheit der Irreversibilität und Universalität des Todes und des Wissens über den biologischen Verfall des toten Körpers (vgl. Wittkowski 1990, 75ff.).

\section{9 bis 12 Jahre}

Auch wenn man davon ausgehen kann, dass etwa ab dem Alter von neun Jahren das Wissen vom Tod dem Erwachsener entspricht, gibt es, wie in allen anderen Entwicklungsphasen, große interindividuelle Unterschiede. Das intellektuelle Wissen um die Endgültigkeit des Todes und seine Universalität sowie die Gewissheit über die unwiederbringlich verlorenen Körperfunktionen und die biologischen Gründe dafür rufen sehr unterschiedliche Assoziationen und Fragen

73 Vgl. auch: Cramer 2008, 2012; Plieth 2009. 
hervor, die sich kaum von denen der vorangegangenen Altersstufe unterscheiden und teils mit diffusen Ängsten einhergehen (vgl. Cramer 2008, 51f.). Diese Ängste stehen in Zusammenhang mit den vielfältigen realen und medialen Eindrücken aus der Lebensumwelt und sind auch noch für das Erwachsenenalter bestimmend. Denn die „emotionale Auseinandersetzung mit dem Tod ist mit Abschluss der Adoleszenz nicht beendet“ (Bürgin 1981, 69), sie ist ein andauernder Prozess, Teil des beim gesunden Menschen lebenslangen menschlichen Entwicklungsprozesses. Einzelne Untersuchungen belegen weitere Zusammenhänge zwischen dem Medienkonsum und dem Zeitpunkt und der Art der entwickelten Todesvorstellungen, welche umso unrealistischer werden, je größere Ausmaße der Medienkonsum annimmt (vgl. Gebhard 1994, 185). Gleichzeitig neigen Zehn- bis Elfährige weniger dazu, sich mit Fragen zum Tod auseinanderzusetzen, da sie mehr dem Leben und ihren Freizeitaktivitäten zugewandt sind der Tod kann warten (vgl. Spiecker-Verscharen 1982, 18). Mit bestimmend für die Einstellung zu Sterben und Tod ist in dieser Altersklasse auch die religiöse Sozialisation im Religionsunterricht, die jedoch bezüglich des christlichen Auferstehungsglaubens ins Leere läuft, wenn sie nicht von der Familie getragen wird. Neben dem materialistischen Nihilismus, der Ansicht, dass die Verwesung des Körpers das absolute Ende bedeutet, und unabhängig vom religiösen $\mathrm{Be}$ kenntnis haben die meisten Kinder dieser Altersstufe mehr oder weniger diffuse Vorstellungen von einem jenseitigen Dasein entwickelt, da ein endgültiges Verschwinden offenbar unaushaltbar scheint. ${ }^{74}$ Die Auffassungen vom „Totsein als Erholung“, „Sterben als Befreiung [...] oder als Abwesenheit von Problemen“ und die Vorstellung, „als Tote die Geschicke der Lebenden lenken zu können“ (Spiecker-Verscharen 1982, 19f.), dienen offenbar der Abmilderung der Unerbittlichkeit des Todes.

\section{Zusammenfassung}

Es kann festgehalten werden, dass zwar die vielfach beobachteten Korrelationen „Zwischen dem kognitiven Entwicklungsstand eines Kindes und seinem Verständnis der einzelnen Komponenten des Todeskonzepts in Einklang mit der Theorie PIAGETs“ stehen, dass aber neuere Forschungsergebnisse interindividuelle Unterschiede und einen schnelleren Verlauf der kognitiven Entwicklung von Kindern belegen, weshalb die von Piaget propagierte Universalität seines StufenModells nicht haltbar ist (Wittkowski 1990, 60f.; H. i. O.). Die vorliegenden Erkenntnisse über die Entwicklung kindlicher Todeskonzepte geben insgesamt ein 
eher uneinheitliches Bild ab und müssen noch immer als vorläufig betrachtet werden, auch aus Gründen der angewandten Untersuchungsmethodik, da sie auf Querschnittstudien beruhen und somit keinen Anspruch auf Validität erheben können (ebd.; s. a.: Bürgin 1981, 39f.; Gebhard 1994, 185ff.). Die nachgewiesenen großen individuellen Unterschiede innerhalb einer Altersgruppe aufgrund verschiedener innerer und äußerer Faktoren - Selbstkonzept, Beziehungs- und Verlusterfahrungen, gesellschaftliche und kulturelle Zugehörigkeit, die vorherrschenden Interaktionsstrukturen im direkten Umfeld u. a. m. - verlangen nach weiterführenden interdisziplinären Studien und bedingen auch die Notwendigkeit, zwischen den Todesvorstellungen gesunder und kranker Kinder zu differenzieren (vgl. Grumbach-Wendt/ Zernikow 2013, 85ff.).

\section{IV.1.1.2 Das sterbenskranke Kind und sein Todeskonzept $t^{75}$}

Die Verbindung von Krankheit und Sterben bedeutet für alle Betroffenen eine emotionale Verschärfung der Gewissheit, dass niemand dem Tod entkommen kann, insbesondere dann, wenn Kinder und Jugendliche von einer progressiven Erkrankung betroffen sind. Im Umgang damit tun sich Erwachsene, Familienangehörige wie professionelles Betreuungspersonal, schwer. Das von der eigenen Angst der Erwachsenen getragene Schweigen über den zu erwartenden Krankheitsverlauf und die Vermutung, Kinder könnten die belastende Wahrheit nicht verkraften und würden den Tod nicht verstehen, führen zu einer Verzerrung der Situation, die den Kindern und ihren Fähigkeiten zum Verständnis der Vorgänge um den Tod nicht gerecht werden (vgl. Matthews 1995, 150ff.). Dass Kinder oft sehr viel früher als angenommen ein Verständnis von Zusammenhängen zwischen ihrer Lebenswelt und dem Tod entwickeln und das oben beschriebene Phasenmodell deshalb nur bedingt anwendbar ist, fasst G. B. Matthews mit ironischem Zwischenton so zusammen:

[W]enn die zugrunde liegenden Beiträge auch nur einigermaßen korrekt sind, gibt es keinen hinreichenden Grund, mit Kindern über den Tod zu diskutieren, wenn sie jünger sind als neun Jahre, geschweige denn über die damit verknüpfte Thematik des >Bösen`. (Matthews 1995, 152; H. i. O.)

Diese Aussage fordert zum beabsichtigten Widerspruch auf. Matthews (1993), der selbst zahlreiche philosophische Gespräche mit Kindern geführt hat, belegt seine Position mit Forschungsergebnissen, die - wie bereits oben erwähnt - besagen,

75 Vgl. dazu: Bodarwé 1989; Bürgin 1981; Kübler-Ross 1983, 2004; Niethammer 2008; Plieth 2009; Varga 1991. 
dass drei- bis neunjährige Kinder zwar die verschiedenen Stadien der Entwicklung eines Todeskonzepts durchlaufen und damit in gewisser Weise das Piaget'sche Stufenmodell bestätigten, dass aber das chronologisch erfassbare Lebensalter keine Rolle spielt (vgl.: Matthews 1995, 156; Niethammer 2008, 100). Bestimmend sei vielmehr das Miterleben eines todbringenden Krankheitsverlaufs von Mitpatienten; so waren sich schon Drei- bis Vierjährige ihrer begrenzten Lebenserwartung bewusster als Neunjährige, wenn sie über mehr Erfahrungen mit Mitpatienten aufgrund häufigerer Klinikaufenthalte verfügten (vgl. Matthews 1995, 155f.). Todkranke Kinder

'reifen' häufig mit atemberaubendem Tempo und, erkennen' die bruta facta herannahender bzw. hereinbrechender Todeswirklichkeit mitunter schneller und klarer als die sie begleitenden Erwachsenen (Plieth 2009, 47; H. i. O.). ${ }^{76}$

Die Eltern oder andere erwachsene Bezugspersonen sind in solchen Situationen extrem gefordert, denn sie müssen die akute Lebensbedrohung des Kindes emotional aushalten, sich den Ängsten und Fragen des Kindes stellen und darüber auch die eigene Einstellung zum Tod reflektieren.

Wenn wir lernen, mit einer solchen Bedrohung ehrlich umzugehen und ebenso respektvoll wie liebevoll mit dem Kind, haben wir einen Meilenstein in unserer persönlichen Entwicklung zurückgelegt. (Matthews 1995, 158)

Kindern sollte die Wahrheit über ihre lebensverkürzende Krankheit nicht verweigert werden, zumal „Untersuchungen zeigten, daß sich damit ihre Chancen drastisch verbessern, psychisch stabil zu bleiben und keine schweren Depressionen zu haben" (ebd.). Dietrich Niethammer widmet sich der Problematik der Kommunikationsverweigerung ausführlich in der Monografie Das sprachlose Kind (Niethammer 2008), in der er seine Erfahrungen mit todkranken Kindern und ihrer ihnen bis ins letzte Drittel des 20. Jahrhundert weitgehend abgesprochenen Fähigkeit zur Auseinandersetzung mit dem Tod dokumentiert und wissenschaftlich verortet. Wie schon andere vor ihm, widerlegt er die Überzeugung Freuds, dass dem Kind jede Furcht vor dem Tod fremd sei, weil es vom Tod nichts verstehe, und wirbt nachdrücklich für einen ehrlichen Umgang mit der Schwere einer Erkrankung, gegen eine auferlegte Sprachlosigkeit und die damit einhergehende Isolation des Kranken (vgl. ebd., 65). Dass dies ebenso für Erwachsene gelten muss, liegt auf der Hand, ist aber längst nicht gängige Praxis.

Vgl. dazu: Kübler-Ross 2004, 70ff. (mit Beispielen aus der Praxis). 
Halten wir also fest: Es spricht alles dafür, dass auch schon kleine Kinder ein eigenes Todeskonzept und auch Furcht vor dem Tod entwickeln können. Diese Konzepte sind weniger alters- als erfahrungsabhängig und entsprechen daher nicht unbedingt den Konzepten, die Erwachsene haben. Sie reichen aber aus, um die Bedeutung einer lebensbedrohlichen Erkrankung zu verstehen und die damit verbundenen Probleme zu verarbeiten. Es ist heute nicht mehr akzeptabel, eine mangelhafte oder gar fehlende Kommunikation mit der Unwissenheit der Kinder zu begründen. Die Konsequenz ist die Abkehr vom protektiven Schweigen, an dem man in den ersten sieben Jahrzehnten des letzten Jahrhunderts festhielt, hin zu einer offenen und informativen Kommunikation, zu einem Konzept der offenen Wahrheit. (Ebd., 141)

Auf die wichtige Funktion von Literatur für eine gelingende Kommunikation über Sterben und Tod im Umgang mit betroffenen und interessierten Kindern (und Erwachsenen) wurde bereits hingewiesen. Sie wird im Hauptteil der vorliegenden Arbeit ausführlicher beleuchtet.

Wie wichtig Zuwendung und eine offene Interaktion für sterbenskranke Erwachsene und Kinder sind, hat Elisabeth Kübler-Ross bereits in den 1960er-Jahren betont und die Erforschung der psychischen Vorgänge in Sterbeprozessen zu ihrer Lebensaufgabe gemacht. Auf die Ergebnisse ihrer engagierten Arbeit nimmt das folgende Kapitel Bezug.

\section{IV.1.2 Die Sterbephasen nach E. Kübler-Ross}

Die Psychologin und Sterbeforscherin Elisabeth Kübler-Ross hatte in den 1960erJahren damit begonnen, in zahlreichen Interviews mit Sterbenden (Kübler-Ross 1969) den Gedanken, Gefühlen und Bedürfnissen sterbenskranker Patienten nachzuspüren, geleitet von dem Anliegen, die Sterbenden aus ihrer Isolation zu befreien und mit dem Wissen um ihre Ängste und Wünsche einen menschlicheren Umgang mit ihnen zu ermöglichen. Denn im Zuge der rasant sich entwickelnden medizinischen Fortschritte dieser Zeit war alle Aufmerksamkeit auf die Genesungsprozesse und medizinischen Erfolge gerichtet, die hoffnungslosen Fälle wurden flugs ausgesondert und oftmals isoliert ihrem Schicksal überlassen (vgl. ebd., 13f.). Ob sich allerdings die Situation alter und sterbenskranker Menschen in heutiger Zeit grundsätzlich besser darstellt, ist eine Frage, die die aktuellen Diskussionen über Altersvorsorge, Pflegestufen, Patientenverfügungen, Sterbehilfe usw. berührt, hier aber nicht diskutiert werden kann.

Elisabeth Kübler-Ross gilt mit ihren seinerzeit Tabu brechenden Befragungen als Begründerin der Sterbeforschung und hat mit ihren Erkenntnissen über die Gesetzmäßigkeiten von Sterbeprozessen den Weg bereitet für die Hospizbewegung, die ihre Aufgabe darin sieht, den Sterbenskranken in ihrem letzten Lebensabschnitt Hilfe und verständnisvolle Betreuung zuteilwerden zu lassen, 
denn menschenunwürdig ist das Sterben für einen Menschen immer dann, wenn er damit allein gelassen wird (vgl. ebd.). Eine Schwierigkeit des Sterbens ist nach Kübler-Ross darin begründet, dass die Sache der Ärzte das Leben ist, nicht das Sterben; Ärzte sind auf die maximale Verlängerung des Lebens fokussiert (vgl. ebd., 14). Kübler-Ross dagegen forderte ein Bewusstsein für das Sterben, dem als Bestandteil des Lebens eine ebensolche Aufmerksamkeit und Wertschätzung gebühre wie dem Leben selbst (vgl. ebd.).

Zur Beschreibung der psychischen Befindlichkeiten eines Menschen, seiner Ängste und Hoffnungen, die das Leben und Erleben im Sterbeprozess prägen, unterscheidet sie fünf Stadien (vgl. Kübler-Ross 1996, 16ff.; 2004, 35ff.) ${ }^{77}$ :

Die erste Phase: Nichtwahrhabenwollen und Isolierung

Die zweite Phase: Zorn

Die dritte Phase: Verhandeln

Die vierte Phase: Depression

Die fünfte Phase: Zustimmung

\section{Die Phase des Nichtwahrhabenwollens und der Isolierung}

Kübler-Ross nennt die erste Phase „die »Nein, nicht ich«-Stufe“ (Kübler-Ross 2004, 36; H. i. O.). Auf die Diagnose einer lebensbedrohenden Krankheit als auslösendem Moment folgt eine Schockreaktion, die dazu führt, die Information als Irrtum abzutun und sie weder emotional noch rational ins Bewusstsein dringen $\mathrm{zu}$ lassen. Diese Form der Verdrängung ist eine spontane Schutzreaktion der Psyche, um nicht von der geballten Wucht der Nachricht getroffen zu werden und Zeit zu gewinnen für eine allmähliche Annäherung an das Unfassbare. Oft geht mit der Leugnung eine Form von (scheinbarer) Empfindungslosigkeit einher, oder auf der Suche nach dem Beweis des erhofften Irrtums vergeht schon einmal viel Zeit mit Arztbesuchen, die die Annahme der Diagnose aufzuschieben helfen (vgl. Kübler-Ross 1996, 16). Betroffene Kinder, die entweder mit dem eigenen Sterben oder dem einer wichtigen Beziehungsperson konfrontiert werden, scheinen sich in eine andere Welt zurückzuziehen, sie verweigern sich der Katastrophe des drohenden Existenzverlusts und „neigen zu formelhafter Wiederholung signifikanter Muster“, begleitet von „Eß- und Schlafstörungen [...], die das Ausmaß der inneren Blockade äußerlich sichtbar werden lassen“ (Plieth 2009, 105). Die Dauer dieser Phase ist individuell unterschiedlich, meist aber recht kurz.

77 Vgl. Hinweise auf weitere Phasen-Lehren in: Wittkowski 1990, 122ff. 


\section{Die Phase des Zorns}

Auf dieser „»Warum-ich?«-Stufe“ (Kübler-Ross 2004, 49; H. i. O.) erkennt der Patient nun, dass die Diagnose tatsächlich ihn betrifft, aber er lehnt sich innerlich empört auf gegen das als ungerecht empfundene Schicksal oder gegen Gott. Er ist erfüllt von Wut und Frustration, die sich nicht selten gegen jene richtet, die nur helfen oder trösten wollen. Verständlich wird diese Wut auf alles und jeden, die diese Patienten oft zu schwierigen Zeitgenossen werden lässt, wenn man vergegenwärtigt, dass jeder Besuch dem Kranken vor Augen führt, worüber er selbst nicht mehr verfügt und was er auch nicht mehr erreichen wird: Vitalität und Gesundheit (vgl. ebd., 51). Bei Kindern kann diese Phase des Aufbäumens mitunter „im wahrsten Sinne des Wortes blindwütiges Toben und Um-sichSchlagen" auslösen (Plieth 2009, 107). Wenn dem Patienten oder dem betroffenen Kind die Gelegenheit gegeben wird, seinen heftigen Gefühlen Ausdruck zu verleihen, ohne dafür verurteilt zu werden, wird „sehr schnell ein merkwürdiges Stadium des Verhandelns“ (Kübler-Ross 2004, 53) erreicht.

\section{Die Phase des Verhandelns}

Der Patient hegt in dieser Phase insgeheim die Hoffnung, durch die Abgabe eines Versprechens oder Gelübdes das Unglück abwenden zu können. Für die Verlängerung seines Lebens tritt er in Verhandlungen mit dem Schicksal oder mit Gott und bietet seinerseits für eine Genesung an, z. B. Gutes zu tun oder sein Leben zu ändern (vgl. ebd.). Kinder erweisen sich dabei oft als äußerst erfinderisch, wobei sie ihre durchaus auch abstrusen Angebote in den Bereich der archaisch-magischen und mythologischen Vorstellungen verlegen und gar vor "Selbstopferungen“ nicht zurückschrecken, um den Tod abzuwenden (vgl. Plieth 2009, 108). In dieser Phase des Glaubens an eine Einflussnahme ist eine abgeklärte Akzeptanz der Wirklichkeit zu beobachten, die aber nicht mehr ist als eine Zeit des „Waffenstillstands“ in Erwartung des erfolgreichen Geschäfts mit dem Schicksal (Kübler-Ross 2004, 58). Es folgt die Phase der Depression, des Resignierens, wenn deutlich wird, dass alle Bemühungen ergebnislos bleiben. Die Auswirkungen der Vergeblichkeit sind von besonderer Schwere für solche Kinder, die als Miterlebende des Sterbens eines geliebten Menschen glauben, sich nicht genug angestrengt zu haben. Die Folge kann eine schuldbelastete Depression sein, die therapeutisch behandelt werden muss.

\section{Die Phase der Depression}

Dieses Stadium ist das des „stummen Schmerzes“ oder „Vorbereitungsschmerzes“, in dem der Patient eine tiefe Enttäuschung und Hoffnungslosigkeit 
empfindet (ebd.). Ihm ist bewusst, dass er sich von allem, was ihm bisher wichtig war, verabschieden muss. Dann braucht der Sterbende Gelegenheit und viel annehmendes Verständnis für seine Tränen und Traurigkeit (vgl. ebd., 60). Möglich ist aber auch eine reaktive Depression, die mit Lethargie einhergeht und es sehr schwierig macht, den Patienten in der Welt seiner dunklen Gedanken und Gefühle zu erreichen (vgl. Plieth 2009, 108; Kübler-Ross 1978, 57ff.)

\section{Die Phase der Annahme}

Das letzte Stadium des Sterbeprozesses ist das der Annahme der Unabwendbarkeit, die aber längst nicht von allen Sterbenden erreicht wird. Die Akzeptanz des bevorstehenden Endes hat sehr selbstbestimmte Züge, die von einem Ausdruck des inneren Friedens getragen sind, dem „Gefühl, einen Sieg errungen zu haben“ (ebd., 65). Dann sind oft keine Besuche mehr erwünscht und auch keine weiteren Behandlungen, der Sterbende scheint alles im Leben abschließend geregelt zu haben (vgl. ebd. 64). Darin unterscheidet sich das Annehmen deutlich von der Resignation, die für Niederlage, Bitterkeit und Aufgeben steht. Die Stufe des Annehmens kann aber auch schon früher erreicht werden, denn sie

bedeutet einfach, daß die Menschen sich damit abgefunden haben, daß sie endlich sind, daß sie dann ein Leben von neuer Qualität leben mit anderen Werten, daß sie lernen, das Heute zu genießen und sich nicht zu große Sorgen um das Morgen zu machen, und daß sie die Hoffnung haben, daß ihnen noch viel, viel Zeit bleibt, um diese Art des Lebens zu genießen. (Kübler-Ross 2004, 65) ${ }^{78}$

Nicht immer kann dieser auch äußerlich sichtbare innere Frieden im Sterbebett von Angehörigen angenommen werden, da sie den Kranken unbedingt im Leben halten wollen und noch nicht bereit sind, die Folgen des Verlusts für das eigene Leben anzunehmen. Berührende Beispiele schildet Elisabeth Kübler-Ross in ihren Büchern, die deutlich machen, wie individuell die Phasen des Sterbens erlebt werden und wie wichtig es ist, auf die Sterbenden und ihre (Gesprächs-) Bedürfnisse sensibel einzugehen.

Auf der Basis dieser von E. Kübler-Ross erstmals beschriebenen Sterbephasen, für die jedoch eine lineare Abfolge keinesfalls erwartet werden kann (vgl. ebd.), haben eine Reihe von Wissenschaftlern weitere Überlegungen und Forschungen zur psychischen Verarbeitung von Verlusterfahrungen angestellt und ihre Erkenntnisse in Konzepte gefasst, die deutliche Parallelen aufweisen. Sie beschreiben „- trotz deutlicher Unterschiede in Struktur und 
Begrifflichkeit - Reaktionen Trauernder übereinstimmend als Elemente eines überaus komplexen Vorgangs trauerbedingter Dekonstruktion und Rekonstruktion" (Plieth 2009, 105; H. i. O.). Das Wissen über die Sterbephasen ist deshalb nicht nur für Sterbende oder ihre Betreuer wichtig, sondern in abgeschwächter Form auch bedeutsam für das Verständnis von alltäglichen Verlusten, die ähnliche Trauerreaktionen auslösen (vgl. Kast 1999, 65). Sei es der Verlust des Arbeitsplatzes, eines bedeutsamen Gegenstandes oder der Verlust eines nahestehenden Menschen ${ }^{79}$, immer lösen solche Krisensituationen Reaktionen aus, die in mehr oder weniger ausgeprägter Form und in variabler Reihenfolge ablaufen, dennoch aber signifikante Gesetzmäßigkeiten aufweisen (vgl. Plieth 2009, 104). Für die vorliegende Dissertation sind nur die Schlussfolgerungen aus Untersuchungen psychischer Verarbeitungsprozesse relevant, die sich auf die Trauer nach dem Verlust einer wichtigen Bezugsperson beziehen.

\section{IV.1.3 Angst vor Tod und Sterben}

Zunächst muss eine begriffliche Unterscheidung zwischen der Todesangst und der Angst vor dem Tod vorgenommen werden, die deshalb von Bedeutung ist, weil beide Begriffe häufig synonym verwendet werden, jedoch für zwei sehr unterschiedliche Entwürfe von Angst stehen (vgl. Wittkowski 1990, 76). Die Todesangst wird durch eine akut lebensbedrohliche Situation hervorgerufen, wie sie beispielsweise die Bedrohung mit einer Waffe oder ein Flugzeugabsturz darstellt, und geht „mit einem sehr viel höheren Erregungsniveau“ als die Angst vor dem Tod einher, bei der es sich „um die antizipierende Auseinandersetzung“ mit der zeitlich nicht näher zu bestimmenden, nicht akuten Bedrohung des Lebens durch den Tod handelt (ebd.). Mit der Definition von Kübler-Ross, Todesangst sei nichts anderes „als eine Angst vor einer katastrophalen, destruktiven Macht, die einen überfällt und der man ohnmächtig gegenübersteht“ (KüblerRoss 2004, 30), müssen beide Varianten von Angst zusammengedacht werden. Dies erklärt sich aus der besonderen Situation der in ihrer letzten Lebensphase von Kübler-Ross begleiteten Patienten: Todesangst entsteht sicher angesichts der akuten Lebensbedrohung durch Krankheitsschübe, andererseits wird die Sterbephase durchgehend von der Angst vor dem Tod geprägt sein, da nicht von einem andauernden „erhöhten Erregungsniveau“ (Wittkowski 1990, 76), wie es der Todesangst zugeschrieben wird, ausgegangen werden kann.

79 Zum wissenschaftlichen Diskurs, ob Trauer mehr und anderes umfasst als den Verlust eines Liebesobjektes durch Tod, vgl. z. B.: Furman 1977, 47ff. 
Wenn im Folgenden von Angst die Rede ist, ist damit die Angst vor dem Tod gemeint, die im Gegensatz zur Todesangst ein „multidimensionales Konstrukt“ ist, das sowohl auf die eigene Person als auch auf andere Menschen gerichtet ist (vgl. ebd., 77f.). Die verschiedenen Ausprägungen zeigt die folgende Übersicht:

\begin{tabular}{|c|c|c|}
\hline & \multicolumn{2}{|c|}{ Bezug auf } \\
\hline & die eigene Person & andere(n) Menschen \\
\hline Sterben & $\begin{array}{l}\text { Angst vor dem eigenen Sterben } \\
\text { a) Angst vor körperlichen Leiden } \\
\text { b) Angst vor Demütigung } \\
\text { c) Angst vor dem Verlust persönlicher } \\
\text { Würde } \\
\text { d) Angst vor der Einsamkeit }\end{array}$ & $\begin{array}{l}\text { Angst vor dem Sterben anderer } \\
\text { Personen } \\
\text { j) Angst vor der eigenen Hilflosigkeit } \\
\text { angesichts fremden Leidens }\end{array}$ \\
\hline Tod & $\begin{array}{l}\text { Angst vor dem eigenen Tod } \\
\text { e) Angst vor Aufgabe wichtiger Ziele } \\
\text { f) Angst vor den Folgen des eigenen } \\
\text { Todes für die Angehörigen } \\
\text { g) Angst vor Bestrafung im Jenseits } \\
\text { h) Angst vor dem Unbekannten } \\
\text { i) Angst vor Vernichtung des eigenen } \\
\text { Körpers }\end{array}$ & $\begin{array}{l}\text { Angst vor dem Tod anderer } \\
\text { Personen } \\
\text { k) Angst vor dem Verlust wichtiger } \\
\text { Bezugspersonen } \\
\text { 1) Angst vor Toten }\end{array}$ \\
\hline
\end{tabular}

Vier Aspekte der Angst vor Tod und Sterben in Anlehnung an Collett \& Lester (1969) (aus: Wittkowski 1990, 80).

Wir reden über den Tod, aber wir wissen nichts von ihm, weshalb alle Fragen, Befürchtungen und Einstellungen zum Tod etwas zu tun haben mit dem Gefühl latenter existenzieller Bedrohung, das mehr oder minder bewusst erlebt wird oder einen Verdrängungsmechanismus auslöst.

Niemand ist wirklich frei von Todesangst. Wäre sie aber dauernd bewusst, so könnten wir nicht normal funktionieren. Sie muss vehement abgewehrt werden. Dass wir in normalen Zeiten so tun, als glaubten wir nicht an unseren eigenen Tod, als wären wir von unserer Immortalität überzeugt, als stellten wir die Ausnahmen dar, welche die Regel bestätigen, kann als Auswirkung dieser maniformen Abwehr der eigenen Angst vor dem Tode angesehen werden. (Bürgin 1981, 79)

Deshalb rückt erst in der direkten Konfrontation mit dem Tod eines Anderen die eigene Sterblichkeit wieder ins Bewusstsein. Und es gilt offenbar: „Akute Angst vor dem Tode entsteht dort, wo sich ein Todeskonzept entwickelt hat und die Verbindung mit der eigenen Person unabweisbar wird." (Anthony 1940, zit. in 
Bürgin 1981, 59) Die positiven wie negativen Attribute, die Menschen dem Tod zuweisen, sind eine Konsequenz aus gesellschaftlichen Interaktionen (vgl. Ochsmann 1993, 87). Bemerkenswert ist aber, dass auch gegenteilige Ergebnisse von Untersuchungen vorliegen, die Todesangst schon für Kinder von 30 Monaten diagnostizieren und darauf hinweisen, dass Todesangst auch ohne klare Vorstellungen vom Tod möglich ist (vgl. Gebhard 1994, 190). Noch immer weiß man zu wenig über den Einfluss von Variablen, die im Kontext verschiedener Untersuchungsansätze und -methoden zu uneinheitlichen Ergebnissen führen, wozu die noch nicht ausgebildete verbale Ausdrucksfähigkeit der kindlichen Probanden erheblich beiträgt.

Bis weit in die zweite Hälfte des 20. Jahrhunderts blieb die Behauptung Sigmund Freuds so gut wie unwidersprochen, Kinder verfügten über keinerlei Fähigkeiten, sich mit dem Tod auseinanderzusetzen und sie wüssten nichts „,von den Greueln der Verwesung, vom Frieren im kalten Grab, vom Schrecken des endlosen Nichts", weshalb ihnen „die Furcht vor dem Tod [...] fremd“ sei (Freud 1900, zit. in Gebhard 1994, 180; vgl. a.: Niethammer 2008, 96f.). Wie bereits dargelegt wurde, beginnen aber sehr wohl schon kleine Kinder über Sterben und Tod nachzudenken und Vorstellungen dazu zu entwickeln, wenn äußere Bedingungen sie dazu veranlassen. Gefürchtet wird die Konsequenz des Todes: der unaufhebbare Beziehungsverlust. Angst vor dem Tod „wäre somit in der Substanz eine Angst vor Liebesverlust und absoluter Einsamkeit“ (Gebhard 1994, 188). Für kleine Kinder ist, da sie existenziell auf die Betreuung und Fürsorge der Eltern angewiesen sind, schon die Trennungsangst von größter Bedeutung und deshalb von gleicher Qualität wie die Todesangst, da eine auch nur kurze Abwesenheit als akute Bedrohung wahrgenommen wird und sichtbare Verzweiflung hervorruft, sie kann aber als Angst vor dem Sterben nur in der synonymen Wirkung des Beziehungsverlusts angenommen werden (vgl. Bowlby 1983, 32ff.). Im Alter von etwa 3 oder 4 Jahren „kommt zur Trennungsangst noch die Angst vor Verstümmelung", wenn Kindern erste Bilder vom Tod in Form von überfahrenen, gerissenen oder auch geschlachteten Tieren begegnen (Kübler-Ross 2004, 68). Ab etwa dem 7. Lebensjahr werden die Todesgedanken „emotional bedeutsam" und mit Angst vor dem Tod verknüpft, wofür die sich langsam breit machende Erkenntnis von der Möglichkeit des eigenen Todes und des Todes der Eltern und anderer Nahestehender verantwortlich ist (vgl. Gebhard 1994, 182). Es wird bewusst, dass nicht nur alte Menschen vom Tod betroffen sind und natürliche biologische Prozesse wie Krankheiten mit dem Tod einhergehen (vgl. ebd., 183). Elfährige schließlich wissen vom Vorgang der Verwesung und 
fürchten ihn auch (vgl. Stern 1957, 140f.), sind aber dennoch in der Lage, dieses Wissen nicht gegenwartswirksam und belastend werden zu lassen.

Die Angst vor dem Tod und vor dem Sterben ist allen Kindern dieser Altersstufe bekannt, aber viele weisen sie von sich, indem sie sich sagen, der Tod liege sehr fern, er betreffe sie nicht, er gehe nur die ,Alten' an. Religiöse Vorstellungen bringen, wo sie vorhanden sind, wenig Trost. (Ebd., 142f.; H. i. O.)

Hinsichtlich der Korrelation zwischen Angst vor Tod und Sterben und Religiosität kann man dagegen für den erwachsenen Gläubigen davon ausgehen, dass religiöse Trostbilder entlastend wirken können (vgl. Wittkowski 1990, 90ff.). Die empirischen Befunde sind aber auch hier nicht eindeutig.

Erna Furman (1977) beschreibt ausführlich den Tod der Eltern oder eines Elternteils als Auslöser für eine ausgeprägte Angst vor dem eigenen Sterben. Besonders der Bedeutungszusammenhang Krankheit und Tod geht unweigerlich mit Ängsten und Befürchtungen einher, wenn diesbezügliche Erfahrungen mit dem Tod geliebter Bezugspersonen gemacht wurden. Dann wird jede Krankheit für das Kind zur existenziellen Bedrohung. Die Angst vor dem Tod wird dann oft auch auf den überlebenden Elternteil gerichtet (vgl. Bowlby 1983, 456f.).

\section{Sterbende Kinder}

Elisabeth Kübler-Ross hat aus ihren Erfahrungen mit sterbenden Kindern folgenden Schluss gezogen:

Ich glaube, daß Kinder im allgemeinen viel leichter sterben würden als Erwachsene, wenn wir Erwachsenen aus dem Sterben nicht ein solches Mysterium machten. [...] Wir werden mit nur zwei natürlichen Ängsten geboren, der Angst des Fallens und der Angst vor lauten Geräuschen. Alle anderen Ängste sind unnatürlich und werden von ängstlichen Erwachsenen auf Kinder übertragen. (Kübler-Ross 2004, 68)

Diese Annahme muss relativiert werden angesichts der Kenntnisse über die natürlichen Trennungsängste, die Kinder bei Abwesenheit ihrer Eltern befallen, umso mehr, wenn sie z. B. wegen eines Krankenhausaufenthaltes ihr gewohntes Lebensumfeld verlassen und die Eltern zurücklassen müssen. Gleichwohl legen manche kranke Kinder eine für den Erwachsenen unverständliche Unbekümmertheit an den Tag und können über den bevorstehenden Tod reden, während Erwachsene noch nach Worten ringen (vgl. ebd., 70). Todesangst bzw. Angst vor dem Tod scheinen Kinder unter fünf Jahren kaum zu haben, erst im Alter von sechs bis zehn Jahren erfassen Kinder mehr und mehr „die Ernsthaftigkeit und Bedrohlichkeit ihrer Erkrankung“ und entwickeln „auch Angst vor ihrem eigenen Tod" (vgl. Wittkowski 1990, 134). Zu bedenken ist, da die Angst von jüngeren Kindern nicht verbalisiert und daher leicht übersehen werden kann, 
dass eine sehr viel frühere Ausbildung von Ängsten nicht auszuschließen ist (vgl. Bürgin 1981, 83f.). Bereits nachgewiesen ist, dass sterbenskranke „6- bis 10jährige mit einer infausten Prognose sich nicht nur ihres bevorstehenden Todes bewußt sind, sondern dieses Bewußtsein auch artikulieren können" (Wittkowski 1990, 137). Georg Wolff (1979, 50ff.) zufolge liegt die Ursache für Ängste sterbenskranker Kinder mindestens teilweise im Verhalten der erwachsenen Bezugspersonen und in den für sie undurchschaubaren Prozessen der Diagniostik und Behandlung begründet.

Wenn lebensbedrohlich erkrankte Kinder in Heimen, Krankenhäusern oder Hospizen den Tod von kranken Mitpatienten miterleben, ziehen sie daraus Schlüsse für den eigenen Krankheitsverlauf und erkennen, „daß der Wechsel von Besserung und Verschlechterung nicht ad finitum andauern kann, sondern daß an seinem Ende der Tod steht" (ebd., 136). Mitunter verleugnen sie dann Trauer und Angst, was, ebenso wie die strikte Verweigerung von Gesprächen über den Tod eines Gefährten, auch als „Versuch der Realitätsbewältigung“ angesichts der ständigen Gegenwärtigkeit des Todes gesehen werden muss (vgl. Leist 1979, 40). Von Studien an todkranken Kindern und ihren Müttern weiß man,

dass sich zur psychischen Belastung durch die Krankheit drei Stressfaktoren aus der Umwelt gesellen, die sich in der Verstärkung bestimmter Angstformen der Kinder zu erkennen geben:

- die Trennung von der Mutter durch die Hospitalisation: Trennungsangst;

- die medizinisch-chirurgischen Eingriffe: Verstümmelungs- und Kastrationsangst;

- der Tod anderer Kinder: Todesangst (J.M. Natterson u. a., 1960; J.M. Natterson, 1973).

Die Reaktionen auf Trennung sind am größten bei den bis zu Fünfjährigen, diese auf Eingriffe bei den Fünf- bis Zehnjährigen und diese auf den Tod anderer Kinder bei den über Zehnjährigen. (Bürgin 1981, 83)

Das Problem der erhöhten Trennungsangst wird heute glücklicherweise vielfach durch die Möglichkeit der ständigen Anwesenheit von Mutter und/oder Vater im Krankenhaus, auch über mehrere Tage, gemildert. Wenn die Eltern aber aus verschiedenen Gründen nicht bei dem Kind bleiben können, weil sie z. B. andere Kinder zu betreuen haben, ist Ehrlichkeit dem Kind gegenüber unbedingt geboten $^{80}$, wie überhaupt in allen Gesprächen mit Kindern, die sich mit ihren Ängsten auseinandersetzen und nicht betrogen werden wollen.

80 Verlässt beispielsweise die Mutter das Kind erst nach dem Einschlafen, ohne sich vorher verabschiedet zu haben, wertet das Kind dies nach dem Erwachen als Betrug, 
Es ist deutlich geworden, dass die Angst vor Tod und Sterben mit dem kognitiven Wissen über den Tod und die Umstände, die zum Tod führen, einhergeht, dass aber die „Angst vor dem Tod [...] kein Bestandteil der alltäglichen Erfahrung“ sein kann, da die „ständige Erfahrung von Angst vor dem Tod [...] die Funktionsfähigkeit des Individuums bedrohen“ würde (Ochsmann 1993, 125). Auch wenn die Angst vor dem Tod angesichts einer Erkrankung einen konkreten Anlass hat, ist es möglich und notwendig, das Leben nicht von dieser Angst bestimmen zu lassen. Kinder scheinen dazu oft besser in der Lage zu sein als Erwachsene.

\section{IV.1.4 Trauer}

\section{IV.1.4.1 Die erwachsene Trauer}

„Die Trauer ist die subjektive Reaktion auf den Verlust von als unersetzlich Empfundenem." (Hahn 1968,7) Damit sind sowohl die nach außen bekundeten Affekte wie auch die innerpsychischen Vorgänge gemeint, die der Bekundung vorausgehen bzw. sie begleiten (vgl. Furman 1977, 47). Diese psychoanalytische Belegung des Begriffs geht auf Trauer und Melancholie (1915) von Sigmund Freud zurück, der mit seiner Hauptthese, „dass ein Großteil der psychischen Erkrankungen ein Ausdruck pathologischen Trauerns ist", vor fast 100 Jahren ein „weites und vielversprechendes Untersuchungsfeld“ eröffnete (Bowlby 2006b, 31). Mit den verschiedenen Explikationen von Trauerprozessen haben sich seitdem Wissenschaftler in unzähligen Untersuchungen auseinandergesetzt, wobei sich

Vorstellungen zu zwei verschiedenen Typen von Problemen entwickelt haben:

- Vorstellungen in Bezug auf das Wesen von Trauerprozessen selbst und darüber, wie sich gesunde und pathologische Prozesse unterscheiden;

- Vorstellungen in Bezug darauf, weshalb manche Menschen in pathologischer Weise auf Verlust reagieren und andere nicht. (Ebd.)

Der dazu geführte wissenschaftliche Diskurs ist zu komplex, als dass er hier dezidiert aufgefächert werden könnte. Die Unterscheidung zwischen gesunder und pathologischer Trauer findet in den nachfolgenden Ausführungen zu Formen erwachsener und kindlicher Trauer zwar Berücksichtigung, wird aus dem genannten Grund aber nicht explizit herausgearbeitet. Ausgangslage für das grundlegende Verständnis und die Beschreibung der psychischen Vorgänge im

der in Verbindung mit dem Zustand des Verlassenseins als traumatisches Erlebnis nachhaltig negativ wirken wird. (Vgl. dazu ausführlich: Niethammer 2008, 17ff.). 
Zusammenhang mit der Verarbeitung von Verlusten ist das Vier-Phasenmodell nach Verena Kast (1999). Dem werden einige wenige Aspekte zur Trauer aus historischer Perspektive vorangestellt.

\section{Zur Geschichte der Trauer}

Der Ausdruck von Trauer war immer schon mit Emotionalität verbunden, dass aber „Trauer als persönlicher Schmerz und als individuell einzigartiges Leid erlebt" wird, das aus dem Verlust eines einzelnen, als unersetzlich empfundenen Menschen erwächst, ist erst eine Erscheinung seit dem 18. Jahrhundert und insbesondere des 19. Jahrhunderts (Winkel 2002, 75). Davor war die „Affektivität auf eine größere Zahl von Personen verteilt" und weniger auf ein einzelnes Mitglied der betreffenden Sozialgemeinschaft gerichtet (Ariès 1982, 600). In „vormodernen Gesellschaften" war Trauer eine Gemeinschaftssache, das moderne Trauergefühl dagegen ist ein individualisiertes, für das selbstreferentielle Aspekte und damit die Fokussierung auf das Ich eine Rolle spielen (vgl. ebd., 18f.).

Indem Trauer in erster Linie als emotionales, im psychischen System zu verortendes Phänomen begriffen wird, wird auch die Verantwortung für den Ausdruck von Trauer auf die personale Ebene verlagert. (Winkel 2002, 19)

Ariès (1982, 18; H. i. O.) spricht im Zusammenhang mit der Individualisierung von Trauer vom "gegenwärtigen Phänomen[...] der Revolution des Gefühls", womit die „Betonung der inneren Befindlichkeit“ gemeint ist respektive die Konzentration auf das individuelle Verlusterleben, das nicht mehr öffentlich zelebriert, sondern der „gesellschaftlich erwarteten Regulierung und Kontrolle“ unterworfen wird (Winkel 2002, 18). Trauern ist zur Privatsache geworden, mit der möglichst kein Außenstehender belästigt werden will und soll. Begegnungen mit trauernden Menschen werden heute eher vermieden oder geraten aufgrund von unbeholfener Hilflosigkeit zu fast peinlich berührenden Situationen. Was darf man sagen, fragen, wie soll man über den Tod reden? Je weniger Platz Trauer und Tod in unserer Gesellschaft haben, desto schwieriger ist der Umgang mit Trauernden und umso größer das Problem der Isolierung, das der Trauernde selbst noch dadurch forciert, dass ihm in seinem Kummer selbst die Kraft fehlt, auf andere hilfesuchend zuzugehen (vgl. Kast 1999, 22f.). Trauer, Trauerempfinden und Konfrontation mit Trauer stören den positiv konnotierten Erlebnisalltag der Nicht-Betroffenen, weshalb eine möglichst schnelle Rückkehr zur Normalität gefordert wird (vgl. Pennington 156ff.). Die heute sozial standardisierte „Affektkontrolle“ ist aber keine Erscheinung der Neuzeit (Winkel 2002, 78). Das Wehklagen einer ehedem überschwänglichen Totenklage ist schon seit 
dem 14. und 15. Jahrhundert verstummt ${ }^{81}$, schon das 16. und 17. Jahrhundert beschreibt Ariès $(1982,211)$ als ersten Höhepunkt der Beschränkung und Kontrolle des gefühlsmäßigen Ausdrucks:

Die sozialen Konventionen gaben dem offenen Ausdruck der Gewalt des Schmerzes nicht mehr statt, sie drängten künftig eher auf Würde und Selbstkontrolle. Was man mit Worten und Gebärden nicht mehr ausdrücken wollte, stellte man [...] durch die Kleidung und deren Farbe zur Schau.

Das Tragen bestimmter Kleidung, ,in Farben, die an bleiche Gebeine erinnerten oder in Schwarz ${ }^{82 “}$, machte die Trauer von wohlhabenden Hinterbliebenen für ein Jahr, von Ärmeren dagegen für nur 30 Tage sichtbar (Mischke 1996, 50; Fußnote i. O.). Trauerkleidung ${ }^{83}$ und schon gar das Ritual der Männer, sich in der Trauerzeit das Haupt zu verhüllen und Haare und Bart wachsen zu lassen (vgl. ebd.), haben heute in europäischen Gesellschaften ihre Bedeutung für den Ausdruck von Trauer weitestgehend verloren, nicht zuletzt auch deshalb, weil niemand mehr ständig an den Tod erinnert werden will.

\section{Die Psychologisierung der Trauer}

Die Konfrontation mit dem Tod eines geliebten Menschen stellt den Hinterbliebenen vor

eine dreifache Aufgabe [...]: er muß mit den unmittelbaren Veränderungen fertig werden, er muß Trauerarbeit leisten, und er muß danach je nach seinem Reifungsstand seine psychische Entwicklung wiederaufnehmen und fortsetzen (Furman 1977, 159).

81 Dass die Zurschaustellung von Trauer als „unschicklich“ $\mathrm{zu}$ vermeiden sei, kommt schon „in der Verfassung von Bolgna aus dem Jahre 1288 zum Ausdruck: »Kein Bewohner der Stadt darf zu einem Begräbnis und zum Trauern Leute vom Land in sein Haus kommen lassen. [...] Ausgenommen sind die Verwandten bis zum fünften Grad, vorausgesetzt, daß sie sich an die vorgeschriebenen Regeln halten, nicht laut weinen und nicht mit den Händen gegen die Brust schlagen. « [...] Damit wurde der Weg für eine institutionelle Trennung der Toten von den Lebenden geebnet und die Trauerbekundungen aus dem öffentlichen Leben der Stadt verbannt." (Mischke 1996, 55; H. i. O.).

82 „Schwarze Stoffe waren teuer, deshalb setzte sich Schwarz als Trauerfarbe erst seit dem Spätmittelalter durch.“

83 Das „Schwarz als Trauerfarbe [...] hat zwei Bedeutungen: Es bezeichnet das düstere Wesen des Todes, wie es sich mit der makabren Ikonographie entwickelt, und vor allem die ältere Ritualisierung der Trauer. Die schwarze Trauerkleidung bringt aber auch die Trauer zum Ausdruck und entbindet von einer persönlicheren und dramatischeren Gebärdensprache." (Ariès 1982, 211). 
Mit der Psychologisierung der Trauer als Ausdruck der emotionalen Bewältigung von Beziehungsabbrüchen und einer Neuorientierung etablierte sich im 20. Jahrhundert eine institutionalisierte Trauerbegleitung und -beratung (vgl. Winkel 2002, 78f.), die sich auf die Erkenntnisse verschiedener psychologischer Untersuchungen (z. B. Bowlby 2006a; Brocher 1980; Furman 1977; Kast 1999; Leist 2004; Raimbault 1981) stützt. Im Vordergrund steht dabei das Individuum, dessen „Trauer zu einer modernen Form von Selbsterfahrung wird“ (Winkel 2002, 66). Die Bemühungen zielen darauf, „Autonomie zu erlangen und der symbiotischen Beziehung zu entwachsen“ (ebd.). Der Rollenverlust, das durch den Tod erzwungene Aufheben z. B. der Rolle als Vater, Mutter, Ehemann, Ehefrau etc., stellt „eine der entscheidenden soziokulturellen Determinanten“ dar, die eine Neuorientierung und Umgestaltung des eigenen Lebenskonzeptes erfordern (Mischke 1996, 155). John Bowlbys Bindungstheorie aus den 1960er-Jahren, die die prägende Wirkung der frühen Beziehung zur Mutter oder anderen Bezugspersonen für die Gestaltung späterer Beziehungen und die Folgen von Beziehungsverlust erfasst, war wegbereitend für viele weitere psychologische Forschungen. Trauern ist für Bowlby $(1980,68)$ ein

Schlüsselbegriff. Es gibt tatsächlich gute Gründe für die Annahme, daß die Abfolge der beschriebenen Reaktionen [auf die Trennung von der Mutter; M.H.] - Auflehnung, Verzweiflung und Loslösung - eine Abfolge ist, die in der einen oder anderen Variante für alle Formen des Trauerns charakteristisch ist.

Je nach Nähe zum und Betroffenheit vom erwarteten oder bereits eingetretenen Todesereignis ist eine unterschiedliche Intensität der Trauerreaktionen und eine individuelle Verarbeitung zu erwarten, gleichzeitig aber sind die Erscheinungsformen ähnlich. Weinen, Aggressivität, Unruhe, Depression, Schweigen - Art, Ausdruck und Dauer der Gefühlsäußerungen auf einen nahegehenden Tod sind individuell, sie können aber als mögliche Verhaltensmuster einer Phasenfolge, wie sie von Verena Kast mit ihrem Vier-Phasenmodell zum Trauerkonzept Erwachsener beschrieben wird (Kast 1999, 71ff.), verstanden werden. Dieses im Folgenden vorgestellte Modell von Trauer steht stellvertretend für die die grundlegenden Übereinstimmungen verschiedener Phasenmodelle ${ }^{84}$, die sowohl für die Beschreibung erwachsener als auch kindlicher Trauerbewältigung ${ }^{85}$ Anwendung finden.

84 Vgl. dazu: Bowlby 1983, 32ff.; Spiegel 1989; Kast 1999; zusammenfassend: Plieth 2009, 101ff.

$85 \mathrm{Zu}$ den Unterschieden und Gemeinsamkeiten erwachsener und kindlicher Trauer s. hier Kap. IV.1.4. 


\section{Das Vier-Phasenmodell nach Verena Kast}

1. Die Phase des Nicht-wahrhaben-Wollens

2. Die Phase der aufbrechenden Emotionen

3. Die Phase des Suchens und Sich-Trennens

4. Die Phase des neuen Selbst- und Weltbezugs

Die erste Phase ist die der Ablehnung der Realität des Todes, die nur kurze Zeit oder auch mehrere Tage andauern kann. Die schreckliche Nachricht vom Tod einer Beziehungsfigur löst einen "Gefühlsschock“ aus, der sich in scheinbarer Emotionslosigkeit ausdrückt und nicht mit „Gefühlslosigkeit“ verwechselt werden darf (Kast 1999, 71f.). Die Gefühlsstarre ist vielmehr als Reaktion auf die Mächtigkeit des nicht zu bewältigenden Verlustempfindens zu werten, die die Tatsache des Verlustes nicht ins Bewusstsein dringen lässt. Vom sozialen Umfeld ist in dieser Phase praktische Hilfe und wohl dosierte Nähe gefordert, die die Starre aufzulösen hilft.

In der Phase der aufbrechenden Emotionen wird sich der Hinterbliebene des Verlusts bewusst und fällt in ein regelrechtes Gefühlschaos ambivalenter Empfindungen, in denen sich die Macht des Verlusts von Sicherheit und Halt spiegelt (vgl. ebd., 73ff.). Heftige Gefühlsausbrüche von Angst, Schmerz, Wut, Enttäuschung, Hilflosigkeit, Schuldgefühlen und Schuldzuweisungen wechseln einander ab. Manche Trauernde suchen zornig einen Schuldigen bei Dritten, andere richten ihre Wut und ihren Zorn (seltener) auf den Verstorbenen selbst, der sie verlassen hat (vgl. Bowlby 1980, 71). Weil das wütende Auflehnen gegen die Hinnahme des Verlassenseins und die nicht selten nicht nur von Kindern geforderte Rückkehr der verlorenen Person sinnlose Anwandlungen sind, wurden sie „lange Zeit für pathologisch gehalten“ (ebd.). Heute aber gilt die Erkenntnis, dass der "offene Ausdruck dieses mächtigen Dranges [...] eine notwendige Bedingung" für einen gesunden Trauerverlauf von Kindern und Erwachsenen ist (ebd.). ${ }^{86}$ Auch eigene Schuldgefühle können eine Rolle spielen, wobei die gelungene oder weniger gelungene Kommunikation zu Lebzeiten des Verstorbenen einen

86 „Die Untersuchung des klinischen Materials legt den Schluß nahe, dass eines der Hauptmerkmale pathologischer Trauer die Unfähigkeit ist, den Drang, die verlorene Person wiederzugewinnen und auszuschimpfen, mit all der damit verbundenen Sehnsucht und Wut offen zum Ausdruck zu bringen. Statt dessen wird dieser Drang mit seiner ganzen Gefühlsamivalenz abgespalten und verdrängt und existiert als aktives System in der Persönlichkeit weiter, wodurch Gefühle und Verhalten beeinflusst und merkwürdig verzerrt werden. So entstehen viele Formen der Persönlichkeitsstörung und neurotischer Erkrankungen." (Bowlby 1980, 73). 
entscheidenden Einfluss auf die Intensität der Schuldgefühle und die Dauer der Trauerperiode nimmt (vgl. Kast 1999, 75). Was nach dem Verlust bleibt, sind die Erinnerungen an gemeinsam Erlebtes und gemeinsam Geschaffenes, aber auch alles Unausgesprochene und Ungeklärte bleibt offen, womit die Verarbeitung des Verlusts erschwert ist (vgl. ebd.). Unverarbeitete Konflikte, z. B. Geschwisterrivalität, können sich nachhaltig pathologisch auf die Lebensbewältigung auswirken; manche Kinder glauben gar, das Unglück dadurch herbeigeführt zu haben, dass sie dem Verstorbenen im Streit einmal den Tod gewünscht hatten (vgl. ebd.). Dass darin die Ursache für oft auch noch im späteren Verlauf der Ontogenese auftretende Verhaltensauffälligkeiten liegt, bleibt in manchen Fällen lange verborgen und muss therapeutisch aufgearbeitet werden (vgl. ebd., 77). Es ist aber auch immer wieder zu beobachten, dass Trauernde eine tiefe Dankbarkeit und Freude an den Tag legen angesichts der Tatsache, dass die verlorene Beziehung überhaupt bestanden hat und die Erinnerungen daran nicht genommen werden können (vgl. ebd.).

Ist das heftige Gefühlschaos der zweiten Phase des Trauerns überwunden, schließt daran die Phase des Suchens und Sich-Trennens an. Das Suchen des Verstorbenen äußert sich beispielsweise darin, dass Lieblingsorte besucht, Gewohnheiten des Verstorbenen übernommen oder innere Zwiegespräche mit dem Toten geführt werden. Dies kann als Versuch gesehen werden, sich dem Verlust zu widersetzen oder wenigstens einen Teil der verlorenen „Beziehungsintensität“ lebendig zu halten (ebd., 80). Kast sieht „dieses Suchen nicht nur als Verdrängung des Todes, sondern als Versuch, das, was der Tote bedeutet hat, ins neu entstehende Lebensgefüge mit einzubringen“" (ebd., 78). Wenn aber Gewohnheiten und Charaktereigenschaften des Verstorbenen in das eigene Verhaltensrepertoire übernommen werden, obwohl sie den eigenen entgegenstehen, wird diese Identifizierung mit dem Toten die eigene Identitätsentwicklung überlagern und eine abschließende Verarbeitung des Verlusts behindern (vgl. ebd.).

Die Phase des Suchens und Sich-Trennens ist ebenso wie die Phase des Zorns von ambivalenten Emotionen geprägt. Akzeptanz und die Gefühle der verzweifelten Hilflosigkeit wechseln einander immer wieder ab und brauchen in ihrer Ambivalenz Raum und Zeit. Möglicherweise dauert diese Phase Jahre an, in der der Trauernde nur allmählich seine Traurigkeit überwindet und zu einem Akzeptieren des endgültigen Verlusts findet (vgl. ebd.). Nur wenn dem Suchen und „Finden immer wieder auch der Aspekt des Sich-trennen-Müssens, des Verlassen-Müssens folgt und [...] diese Trennung akzeptiert wird“ (ebd., 81), kann die Trauerarbeit in einen neuen Selbst- und Weltbezug übergehen. 
Die Phase des neuen Selbst- und Weltbezugs folgt erst dann, wenn Gedanken und Gefühle nicht mehr auf den Verlust fokussiert sind, sondern „der Verstorbene nun eine ,innere Figur' geworden ist" (ebd., 83; H. i. O.), die der Hinterbliebene als wichtigen Bestandteil seiner Lebens- und Erfahrungsfülle auf dem Weg zu einem neuen Platz im Leben in sich trägt. Kinder wie Erwachsene, die die Gelegenheit haben, die Sterbephasen einer geliebten Beziehungsperson mitzuerleben und selbst die Phase des Annehmens erreichen,

sind in der Lage, neue tragfähige Kontakte zu Außenstehenden herzustellen und/oder solche bei Menschen in ihrer nächsten Nähe zuzulassen [...]. Sie sind in diesem Zustand Menschen, die Hoffnungen sterben sehen und doch darin einwilligen, neue hervorzubringen. (Plieth 2009, 109)

Rückfälle in die Traurigkeit sind auch in bzw. nach dieser Phase der Neuorientierung immer wieder zu erwarten, selbst dann noch, wenn neu erwachte Lebensfreude bereits zu neuen Beziehungen geführt hat und damit der Trauerprozess als abgeschlossen gelten kann (vgl. Kast 1999, 83).

Von einer regelmäßigen Abfolge dieser Phasen der psychischen Bewältigung des Verlusts einer geliebten Person kann also keinesfalls ausgegangen werden, vielmehr können sie „über lange Zeit hinweg in heftiger Widersprüchlichkeit nebeneinanderher bestehen“ (Leist 2004, 164). Als „Quintessenz psychologischer Trauertheorien" gilt die Erkenntnis, dass das Zulassen und Ausleben des „Verlustschmerzes“ die Voraussetzungen dafür sind, die „Trauer zu überwinden, um sich schließlich ganz von der Bindung an die tote Person lösen zu können“ (Winkel 2002, 11). Trauern heißt, „der Seele Zeit lassen, auf den Verlust zu antworten“ (Wilkening 1997, 82), pathologische Formen der Trauer liegen dann aber vor, wenn die Phase der Loslösung und der neuen, positiven Zuwendung zum Leben dauerhaft nicht gelingt. Das Trauern sollte also nicht grundsätzlich als etwas Pathologisches gesehen werden, sondern als notwendiger Teil menschlichen Erlebens, als Prozess, der Zeit braucht und Zeit gibt, das eigene Leben neu zu überdenken, eine neue Ordnung zu schaffen und aus der Krise verändert, d. h. erneuert und gestärkt hervorzugehen. ${ }^{87}$

87 Zum Diskurs über normale und pathologische Ausprägungen von Trauer vgl. Winkel (2002, 61ff.): Heidemarie Winkel führt an, dass neuere Studien auf einen „Paradigmenwechsel“ in der Psychologie hinweisen, der die Abwendung von der Auffassung postuliere, „das primäre Ziel von Trauer [liege] in der Ablösung der Beziehung von den Toten“, dass aber daneben das „normative[...] Paradigma pathologischer Trauer“ weiterhin Bestand habe (ebd., 62ff.). Gegenwärtig gilt für die einen, „erfolgreiche Verarbeitung von Trauer [bestehe] in der Identifizierung und Inkorporierung mit den Toten. Es wird nicht mehr länger davon ausgegangen, daß die Beziehung mit den 
Wissenschaftlicher Konsens ist außerdem, dass „die Einleitung des Trauervorgangs davon abhängt, daß der Beraubte den Verlust wahrnimmt und ihn innerlich als dauernd und unwiederbringlich erfaßt" (Furman 1977, 240), wofür ein Verständnis von tot sein, also ein verinnerlichtes Todeskonzept, Grundvoraussetzung ist. Parallel dazu ist auch in der kindlichen Trauerarbeit „das kognitive Verständnis der Irreversibilität des Todes Voraussetzung dafür, daß das Kind zur emotionalen Ablösung vom Verstorbenen, der ,Dekathexis fähig ist“ (Ramachers 1994, 56). Die Frage, wann Kinder beginnen, ein Todeskonzept ausbilden, und die Frage, wann Kinder zur Trauer fähig sind, gehören also eng zusammen. Die Vielzahl der Arbeiten über verwaiste Kinder und ihre Trauerarbeit belegen dies wie auch die Kenntnis, dass sowohl Gemeinsamkeiten als auch gravierende Unterschiede zur Trauerarbeit Erwachsener bestehen (vgl. Strasser/ Petzold 2000, 33).

\section{IV.1.4.2 Die Trauer von Kindern}

Ein Todesereignis, das uns nahegeht, führt uns unweigerlich auf uns selbst zurück. Der Tod eines geliebten Menschen erschüttert und macht auf radikale Weise deutlich, in welchem Maße wir uns und unser Lebensglück über die Beziehung zu anderen Menschen definieren, was für Kinder und ihre Angst vor Beziehungsverlusten ganz besonders gilt (vgl. Leist 2004, 22). John Bowlby (2006a, 44ff.) hat dies mit der bereits erwähnten Bindungstheorie wegweisend dargelegt. Seit seine Untersuchungen enge Zusammenhänge zwischen Trennungsangst und Trauer offengelegt haben, kann nicht mehr ernsthaft angezweifelt werden,

Toten, die Bindung an sie, überwunden werden müsse.“ (Vgl. ebd., 63) Der Trauerprozess könne diskontinuierlich verlaufen und ein Leben lang dauern (vgl. Rosenblatt 1996, zit. in Winkel 2002, 64). Andere vertreten die ältere Auffassung, dass der Verbleib in der Phase der „Internalisierung der Toten ins Innere“ eine pathologische Form der Trauer sei (Winkel 2002, 62). „Obwohl es wissenschaftlich ungenau ist, von Trauer als Krankheit [...] zu sprechen, hat sich dieses Bild von den pathologischen Tendenzen der Trauer verselbständigt.“ (Ebd.) Das „Konzept der Phasentheorien“ scheint nun das wichtigste Instrumentarium zu sein, „sogenannte normale bzw. hiervon abweichende Trauerverläufe zu erfassen“ (ebd., 62). Grundsätzlich stehen die „Idee der Subjektivierung und Emotionalisierung von Trauer" und die damit einhergehenden psychischen Veränderungen und Entwicklungsprozesse im Vordergrund, „, wobei Trauer zu einer modernen Form von Selbsterfahrung wird“ (ebd., 66). „Identifikation“, „Introjektion“ und „Erinnerungs- und Gedächtnisvorgänge als weitere Form der inneren Repräsentanz" sind dabei die drei Varianten innerlicher Veränderung (ebd., 65). 
dass schon bei Kleinkindern Verlustempfindungen Formen von Trauer hervorrufen $^{88}$. Voraussetzung dafür ist:

Das Kind muß wenigstens den Beginn der Objektkonstanz [...] erreicht haben, um sich nach einem verlorenen Liebesobjekt zu sehnen [...]. In dieser Phase wird die kontinuierliche Besetzung seiner Objektrepräsentanz vorgenommen, und dies ist die Voraussetzung für den Prozeß des Besetzungsabzugs, den wir als einen wesentlichen Teil der Trauerarbeit betrachten. Üblicherweise wird diese Phase in der zweiten Hälfte des ersten Lebensjahrs erreicht. (Furman 1977, 115)

Gewiss scheint zu sein, dass die Verarbeitung des Beziehungsverlustes ohne eine realistische Vorstellung vom Tod nicht möglich ist, wie Furman (Ebd., 62) resümiert:

Wir kamen zu dem Schluß, daß die Realität des Todes das sine qua non der Trauerarbeit war, weil diese Realität eine spezifische Finalität hat. Für das verwaiste Kind war Trauerarbeit nur möglich, wenn diese Realität wahrgenommen, verstanden und geglaubt werden konnte.

Mit diesem Ergebnis, dass also Trauerarbeit, verstanden als abschließende Verarbeitung des Beziehungsverlusts, ohne ein ausgebildetes, realistisches Todeskonzept nicht geleistet werden kann, bestätigt sich die erstmals von Bowlby Ende der 1960er-Jahre vertretene, kontrovers diskutierte Auffassung, dass die Reaktionen kleiner Kinder auf Trennung und Beziehungsverlust viele der Züge aufweisen, die bei Erwachsenen Zeichen pathologischen Trauerns sind (vgl. Bowlby 1983, 504). Die Schlussfolgerung aus den Beobachtungen kleiner Kinder, „daß die Trennung eines Kindes von seiner geliebten Mutterfigur im allgemeinen pathologisch zu nennende Trauerprozesse auslöst“ (Bowlby 1980, 69), machte es möglich, diese Forschungsergebnisse mit denjenigen Studien in Beziehung zu setzen, die sich mit Ursachen psychischer Erkrankungen von Erwachsenen, „wie zum Beispiel Angstzustände, depressive Erkrankungen oder Hysterie“ (ebd., 70), beschäftigen. Bowlby (2006b, 24) benennt in diesem Zusammenhang

vier pathologische Varianten des Trauerns von Erwachsenen [...]:

- unbewusste Sehnsucht nach der verlorenen Person;

- unbewusste Vorwürfe gegenüber der verlorenen Person im Verein mit bewussten und oft erbarmungslosen Selbstvorwürfen;

- zwanghafte Sorge um andere Personen;

- hartnäckiges Nicht-glauben-Können, dass der Verlust bleibend ist (was oft als Leugnung bezeichnet wird).

88 Zur kontroversen Diskussion, ob Kinder zur Trauer fähig sind, s. Bowlby 2006b, 23ff. 
Bowlby (ebd., 276) geht davon aus, dass „das, was während der kindlichen Trauer geschieht, sich im Prinzip nicht von dem unterscheidet, was bei der Trauer Erwachsener geschieht“. Dabei spielen die Lebensumstände und persönlichen Bedingungen Trauernder eine wichtige Rolle, wobei in der Kindheit die „Macht dieser Bedingungen, den Verlauf der Trauer zu beeinflussen, vermutlich sogar noch größer [ist] als bei Erwachsenen“ (ebd., 277; Furman 1977, 160f.). Der Verlust der Sicherheit und Geborgenheit nach dem Tod eines oder beider Elternteile potenziert sich in seiner traumatischen Wirkung, wenn zusätzlich zum Trauma des Verlusts ein Wohnortwechsel notwendig wird oder gar Geschwister voneinander getrennt werden müssen und das bekannte soziale Umfeld abhandenkommt (Bowlby 2006b, 277).

Weitere Studien haben gezeigt, „daß bei Personen, die psychisch erkranken, in der Kindheit häufiger Todesfälle auftraten als bei anderen" (ebd., 70), was den Schluss zulässt, dass Verlusterfahrungen, die aufgrund verschiedenster intraindividueller und äußerer Bedingungen nicht abschließend psychisch verarbeitet werden konnten, sich nachhaltig negativ auf die psychische Gesundheit und damit den gesamten Lebenslauf auswirken können (vgl. Furman 1977, 161f., 178f.).

\section{Unterschiede zwischen kindlicher und erwachsener Trauer}

Der elementarste Unterschied ist der, dass Kinder allein nicht trauern können, sondern der erklärenden Zuwendung Erwachsener bedürfen, um die Realität des Todes verstehen und akzeptieren zu können. Einige Unterschiede des kindlichen Trauerns sind darauf zurückzuführen, „,dass ein Kind noch weniger Kontrolle über sein eigenes Leben hat als ein Erwachsener" (Bowlby 2006b, 277). Kinder haben noch keine Erfahrung damit, „dass sie ohne die ständige Gegenwart einer Bindungsfigur leben können" und sind gerade deshalb besonders auf ein verständnisvolles und tröstendes Gegenüber in ihrem Umfeld angewiesen, weil sie im Gegensatz zu Erwachsenen in der Regel nicht dazu in der Lage sind, Hilfe von außen anzufordern (ebd.). Werden sie allein gelassen, kann ihr Trauern schnell pathologische Züge annehmen, was sich z. B. in besonderer Furcht vor weiteren Beziehungsverlusten ausdrücken kann. Auch hinsichtlich der Informationen über das Todesereignis sind Kinder abhängig von der Bereitschaft der erwachsenen Hinterbliebenen, mit ihnen zu kommunizieren. Werden sie im Unklaren gelassen und haben sie keine Möglichkeit, ihre Fragen andernorts zu klären, entwickeln sie aufgrund ihres fehlenden bzw. noch unvollständigen Todeskonzepts oft falsche Vorstellungen, die abstruse Ausmaße annehmen können, wenn miterlebte Begebenheiten, Bemerkungen und Redewendungen zu Fehlinterpretationen führen (vgl. ebd.). Umso mehr sind Gesprächsangebote 
und ehrliche Antworten auf existenzielle und manchmal unbequeme Fragen wichtig, die Kinder ernst nehmen, einen Austausch ermöglichen und die Ausbildung eines Todeskonzepts unterstützen.

Die gesunde emotionale Entwicklung des verwaisten Kindes hängt davon ab, ob es die Umstände des Todesfalls verarbeiten und die Trauerarbeit leisten kann. Sie hängt auch davon ab, ob rechtzeitig eine neue Elternfigur zur Verfügung steht, um eine Beziehung zu ermöglichen, die [...] »ausreichend gut« ist. (Furman 1977, 165; H. i. O.)

Das Ausgeliefertsein und die Hilflosigkeit von Kindern im Fall des Verlusts eines Elternteils besteht wieder auch darin, dass sie anders als Erwachsene keine Möglichkeit haben, sich aktiv um einen Ersatz des Liebesobjektes zu bemühen (vgl. ebd, 166). Die Verzweiflung der Kinder kann sich dann in vielerlei Symptomen, wie z. B. Schlafstörungen, Lernhemmungen, Apathie u. a., äußern, die ihre Ursachen in der „Unterdrückung affektiver Reaktionen und Schweigen über den Todesfall" haben (ebd., 164). Oft fällt es schwer, kindliche Reaktionen richtig einzuschätzen, zumal das Alter und der individuelle Entwicklungs- und Wissensstand dabei eine Rolle spielen.

In der großen Mehrzahl der Fälle, in denen es heißt, Kinder hätten in keiner Weise auf die Nachricht vom Tode eines Elternteils reagiert, ist es wahrscheinlicher, dass sowohl die gegebenen Informationen als auch die Gelegenheit, über deren Bedeutung zu sprechen, so unzulänglich waren, dass es dem Kind nicht gelungen ist, die Bedeutung des Geschehens zu begreifen. (Bowlby 2006b, 278)

Der mangelnde Wissenstand in Kombination mit Desinformation oder Informationsverweigerung seitens der Erwachsenen wirkt sich demnach äußerst erschwerend auf die Trauerarbeit von Kindern aus. Auch wechseln bei Kindern aufgrund ihrer starken Gegenwartsorientierung Spiel und Traurigkeit in für Erwachsene manchmal nicht nachvollziehbaren Rhythmen, was ihnen oftmals als Oberflächlichkeit oder Unfähigkeit zu trauern ausgelegt wurde und wird (vgl. ebd.).

Kinder müssen nicht trauern, sie sollen trauern dürfen. Wir müssen ihnen Raum geben, ihre Gefühle auszudrücken, sie jedoch nicht zwingen, nach den Maßstäben Erwachsener ihren Schmerz zu offenbaren. (Wilkening 1997, 91f.; H. i. O.)

Kinder sind leichter abgelenkt, aber keinesfalls ist daraus eine Trauerunfähigkeit oder eine auch nur partielle Trauerbewältigung abzuleiten (vgl. Iskenius-Emmler 1988, 132). Zudem gehen jüngere Kinder, deren Todeskonzept noch unvollständig ist, von einer nur vorläufigen Abwesenheit des Verstorbenen aus, da sie doch gerade gelernt haben, zeitweise, z. B. im Kindergarten, ohne die wichtigste Beziehungsfigur auszukommen und in Erwartung der verlässlichen Rückkehr 
ruhig zu bleiben. Viele Beobachtungen zeigen, dass sich oft noch nach größeren Zeitspannen bei hinterbliebenen Kindern Traurigkeit über den erlittenen Verlust zeigt. Unter günstigen Voraussetzungen, zu denen eine offene, emotional durchdrungene Umgangs- und Kommunikationsweise gehört, die den durchaus auch widersprüchlichen Gefühlen Raum gibt, spricht dies für einen heilenden, den Schmerz überwindenden, gesunden Trauerprozess ${ }^{89}$. Ein günstiger Verlauf von kindlicher Trauer scheint nicht weniger als die Trauer von Erwachsenen von Erinnerungsbildern und immer wieder vom Auftreten von Traurigkeit und Sehnsucht geprägt zu sein, was den Schluss zulässt, dass für das Eingehen neuer Beziehungen das Verblassen der Erinnerung an den Verstorbenen nicht notwendig ist, „sondern dass die neue Beziehung wahrscheinlich desto besser gedeiht, je deutlicher die beiden Beziehungen unterschieden werden können“ (Bowlby 2006b, 274).

In Abhängigkeit von unterschiedlichen und unterschiedlich stark belastenden Verlusterfahrungen besonders im engsten Familienkreis weist kindliche Trauer einige Besonderheiten auf.

\section{IV.1.4.2.1 Elternverlust}

Der Verlust eines oder gar beider Elternteile ist die größtmögliche existenzielle Bedrohung für ein Kind, weil es seine gesamten Gefühle in die Elternbeziehung investiert und der „Tod alle Möglichkeiten des Lebens und Geliebtwerdens auf einmal vernichten“ kann (Furman 1977, 23).

Hinterbliebene Kinder sind ebenso Hinterbliebene wie Erwachsene, bedürfen aber einer besonderen Zuwendung, da nicht nur der Verlust der/einer der wichtigsten Beziehungsfigur(en) verkraftet werden muss, sondern durch diesen Einbruch in die Sicherheit des Daseins auch Ängste vor weiteren möglichen Veränderungen entstehen können (vgl. ebd., 274). Unweigerlich drängen sich dem betroffenen Kind dann Fragen auf, die die Befürchtung ausdrücken, weitere vertraute Menschen könnten plötzlich aus seinem Umfeld verschwinden, insbesondere dann, wenn das Kind von einem ggfs. vorausgehenden Sterbeprozess und entsprechenden Informationen ausgeschlossen war (vgl. ebd.). Werden solche kindlichen Nöte, die der Realität oft näher sind als die Beschwichtigungen, mit denen Kinder gerne vorschnell abgespeist werden, nicht ernst genommen und in einem offenen Gespräch aufgefangen, können sie nachhaltig bis weit ins

$89 \mathrm{Zu}$ den verschiedenen Formen nicht gelingender Trauer und ihren pathologischen Folgen s. ausführlich Bowlby 2006b, 281ff. 
Erwachsenenalter hinein als Verlustängste wirksam sein und die Gestaltung späterer Beziehungen stark beeinträchtigen..$^{90}$

Das Kind ist beim Verlust des Liebesobjektes mehreren seelischen Belastungen ausgesetzt: „Todesfurcht, Differenzierung vom Toten, Angst im Zusammenhang mit den besonderen Umständen des Todesfalls, Sorge um die Befriedigung der körperlichen und seelischen Bedürfnisse" (Furman 1977, 160). Kinder erleben den Verlust des Vaters oder der Mutter als doppelten Verlust, wenn der überlebende Elternteil ganz in der eigenen Trauer aufgeht und dem Kind den Eindruck unüberwindbaren Schmerzes vermittelt, der im Kind Zweifel am Wert der eigenen Anwesenheit aufkommen lässt (vgl. Bowlby 2006b, 278f.). Dann steht auf der einen Seite der Verlust des Verstorbenen und auf der anderen Seite ist der verbliebene Elternteil an die Trauer verloren gegangen. Auch für den Erwachsenen stellt sich die Situation zweifach belastend dar, denn er ist gefordert, einerseits das trauernde Kind zu trösten, andererseits den eigenen Trauerschmerz auszuhalten und zu verarbeiten. Ein Zugehen auf das Kind kann jedoch für beide eine entlastende und tröstende Wirkung haben (vgl. Leist 2004, 167). Kinder mit ihrer Unsicherheit nicht allein zu lassen, sich ihnen zuzuwenden, ihnen gleichzeitig ihre eigene Art zu trauern zuzugestehen und sie an der persönlichen Traurigkeit teilhaben zu lassen, ist immer ein „Balanceakt" (Wilkening 1997, 90), der viel Einfühlungsvermögen und Kraft erfordert. Denn Kinder trauern anders. Manchmal entsteht der falsche Eindruck, das Kind könne nicht trauern. Die scheinbare Teilnahmslosigkeit ist jedoch oft nur das Ergebnis des erfolglosen Versuchs, mit den den Tod begleitenden Umständen allein fertig zu werden, da „ihm von seinen Nächsten keine Hilfe zuteil wurde“ (Furman 1977, 160). Häufig reagieren Kinder auch mit Schuldgefühlen und suchen die Ursache für den Tod bei sich selbst: Sie vermuten, entweder nicht lieb genug oder überhaupt nicht liebenswert gewesen zu sein und deshalb diese Strafe erhalten zu haben (vgl. Leist 1981, 46). Andere entwickeln aggressive Gefühle gegen den überlebenden Elternteil, weil sie ihre Wut und Frustration, die demjenigen gilt, der sie verlassen hat, auf die verfügbare Beziehungsperson projizieren (vgl. Furman 1977, 165). In der Erinnerung wird der verlorene Elternteil oftmals auch überidealisiert. Alle positiven Gefühle werden dabei auf diesen konzentriert, während die negativen Gefühle auf den verfügbaren lebenden Elternteil gerichtet sind. Im Fall einer neuen Paarbeziehung trägt dieses Verhalten zum Problem

90 Vgl. dazu z. B.: Bowlby 2006b, 281ff.; Furman 1977, 159ff., Kast 1999, 93ff.; KüblerRoss 1998; Leist 1990, 54ff. 
der ausgeprägten Feindseligkeit gegenüber dem Elternteil und dessen neuem Partner bei (vgl. Raimbault 1981, 158).

Als gesichert gilt: Wenn Eltern sterben, bleibt diese Erfahrung nie ohne Spuren für die Entwicklung der Persönlichkeit eines Kindes. Die Auswirkungen können negative wie auch positive Züge haben, beeinflusst durch die individuelle Konstitution des Kindes und die äußeren Umstände. Insgesamt kann aber nach angemessener Trauerarbeit wohl nicht von einer Stärkung der Persönlichkeit die Rede sein, sondern lediglich von einer Erfahrung als Teil der Lebensgeschichte (vgl. Furman 1977, 178).

\section{IV.1.4.2.2 Geschwisterverlust}

Geschwister sind füreinander Bündnispartner, Rivalen, Vertraute, Spielgefährten, Beschützer oder Lehrer, in jedem Fall sind „Geschwisterbeziehungen [...] einzigartig unter den menschlichen Beziehungen, da Geschwister sowohl genetische als auch familiäre Charakteristika, Werte und Erfahrungen miteinander teilen" (Gözütok et al. 2000, 45ff.). Der Tod eines Geschwisterkindes ist zweifellos für jedes einzelne Familienmitglied ein einschneidendes Ereignis, das die bestehende Familienstruktur zerstört und weitgreifende emotionale wie psychosoziale Reaktionen und Wirkungen auslöst. Die zurückgebliebenen Geschwister aber haben es dabei „schwerer als irgendjemand sonst“ (Leist 2004, 43) und zeigen teilweise erhebliche körperliche und psychische Auffälligkeiten (vgl. Nitsche 2010, 149ff.). Diese Erkenntnis ist nicht neu, ihr wird aber bis heute in der Literatur wie auch in soziokulturellen Kontexten nur wenig Rechnung getragen.

Die Ursachen für die besondere Belastung der überlebenden Geschwisterkinder sind vielschichtig. Eine davon beschreibt Ginette Raimbault $(1981,160)$ als den Effekt der „narzißtischen Wunde“, die der Tod eines etwa gleichaltrigen Geschwisters, im Extremfall des Zwillings, dem Kind zufügt. „[J]e mehr jeder der andere ist", desto mehr „,verliert das Kind sich selbst“ und identifiziert sich „mit dem Toten als Toten“ (ebd.). Gleichzeitig verändert sich das Bild, das das Kind von den Eltern hat. Der "Zerfall der Allmacht, die es seinen Eltern zuschrieb“, ruft ambivalente Gefühle hervor: Kinder schwanken zwischen der Akzeptanz der Ohnmacht der Eltern und der Unterstellung einer elterlichen Schuld am Tod des Geschwisters (ebd., 161).

Es ist aber nicht nur der Verlust der engen emotionalen Bindung zu Bruder oder Schwester zu verkraften, es spielen auch Schuldgefühle ${ }^{91}$ eine Rolle, da Geschwisterliebe zeitweise auch Neid, Rivalität und Eifersucht impliziert, besonders

91 Berichte aus der Praxis z. B. von Leist 1990, $45 \mathrm{ff}$. 
dann, wenn dem Tod ein längerer Krankheitsverlauf vorausgegangen ist und die Fürsorge und emotionale Zuwendung der Eltern ganz dem kranken Kind galt. Geschwister fühlen sich dann vernachlässigt, allein gelassen und weniger wert (vgl. ebd.). Zudem geschieht es allzu oft, dass die Eltern nach dem Tod eines Kindes so sehr in der eigenen Trauer gefangen sind, dass sie ihrer Aufgabe als Eltern dem oder den hinterbliebenen Kind/ern gegenüber nicht mehr gerecht werden können. Sie bedürfen selbst so sehr des Trostes, dass sie, die eigentlich Trost spenden sollten, sich nicht auf die Gefühle ihrer Kinder einlassen können, was für die Kinder an die existenzielle Bedrohung durch Verlassensein grenzt. So wird der Verlust eines Geschwisters für ein Kind zu einem doppelten Verlust, da es auch der elterlichen Zuwendung verlustig ist (vgl. Brocher 1980, 112f.). Kinder brauchen in solchen Situationen aber schon allein deshalb besonders viel Liebe und Aufmerksamkeit, weil sie oft noch keine Worte für ihre Trauer haben und durch ihre ohnehin ambivalenten Gefühle zusätzlich belastet werden, wenn ihnen die extreme Trauer der Eltern als Indiz für den besonderen Wert des verstorbenen Geschwisters erscheinen muss (vgl. ebd.). Neigen Eltern dann noch dazu, das verstorbene Kind zu idealisieren, kann sich beim lebenden eine „Überlebensschuld“ (Leist 2004, 53) entwickeln, die den Selbstwert untergräbt und Gedanken wie, Wäre doch bloß ich gestorben, dann wären sie nicht so traurig' hervorrufen. Viele Kinder versuchen dann gar, ihren „Wiedergutmachungswunsch" (Raimbault 1981, 161) umzusetzen, indem sie sich selbst ganz zurücknehmen und die Traurigkeit der Eltern zur eigenen Sache machen. „Sie möchten den unglücklichen oder einsamen, verlassenen Elternteil wiederaufrichten, ihn vor dem Leid retten, das er erfahren hat, und ihn gegen weiteres Leid schützen." (Ebd.)

Der nachhaltig negative Einfluss solcher Reaktionen auf das Selbstkonzept und die Identitätsentwicklung insgesamt kann oft nur therapeutisch aufgefangen werden. Wenn aber Gefühle der eigenen Minderwertigkeit gepaart sind mit Wut darüber, dass die Eltern dem Verstorbenen „selbst im Tod mehr Aufmerksamkeit widmen“, äußern sie sich häufig in aggressivem Verhalten, in Erkrankungen oder auch (Selbst-) Verletzungen, wobei Zusammenhänge mit dem Todesereignis nicht selten erst spät erkannt werden (vgl. Blum 2000, 161; Raimbault 1981, 155f.).

Manche Eltern projizieren ihre Wünsche und Hoffnungen, die sie mit dem verstorbenen Kind verbunden hatten, auf das Geschwisterkind oder versuchen, durch eine erneute Elternschaft Ersatz zu schaffen (vgl. Leist 2004, 48ff.). Dass dies den Kindern nicht gerecht wird und eine Verarbeitung der Trauer wie eine gesunde und individuelle Entwicklung erschwert, wenn nicht gar unmöglich 
macht, liegt auf der Hand. Wenn „hinterbleibende Geschwister“ (Plieth 2009, 129) nicht mehr ihre eigene Identität ausbilden können, sondern als Ersatz für das verlorene Kind herhalten müssen, leben sie ein „uneigentliches Leben“ (Leist 2004, 50), das die Lösung vom verstorbenen Geschwister unmöglich macht und „identitäts-verbildend und somit zerstörend, statt aufbauend“ (Plieth 2009, 129) wirkt.

Ein weiteres, durchaus verbreitetes problematisches Phänomen ist die Rollenübernahme. Nicht selten bemühen sich Kinder selbst, den Platz des verstorbenen Geschwisters in der Familie einzunehmen, seine Aufgaben und Gewohnheiten zu übernehmen, um den Verlust auszugleichen, manchmal aus dem Bedürfnis heraus, „das Getrenntsein aufzuheben“ oder auch, um den Schuldgefühlen, mit denen sie sich eine irgendwie geartete Mitverantwortung am Tod zuschreiben, etwas entgegenzusetzen (Blum 2000, 162). Eltern sollten aufmerksam für solche Prozesse sein, liebevolle Fürsorge walten lassen und Kommunikationsstrukturen pflegen, die dem Kind eine Bewältigung und Umwandlung der destruktiven Gefühle ermöglichen. ${ }^{92}$

Die Fähigkeit zur Trauerbewältigung von Geschwistern ist also nicht nur von entwicklungspsychologischen Reifestadien beeinflusst, sondern hängt maßgeblich von innerfamiliären Beziehungen, den Interaktionen zwischen Eltern und Kind, dem Trauerverhalten der Eltern und der „Qualität der Beziehung des Geschwisters zum gestorbenen Kind“ ab (ebd., 161).

\section{IV.1.4.2.3 Verlust eines Freundes}

Erleben Kinder z. B. den Unfalltod eines etwa gleichaltrigen Kindes oder Freundes mit, reagieren sie häufig spontan ohne besonderes Mitleid und verbinden mit dem Erlebnis eher Angst vor der Möglichkeit des eigenen Todes oder von Angehörigen (vgl. Leist 1979, 36f.). „Offensichtlich ist die eigene Reaktion an Angst, Furcht, Betroffenheit und Verunsicherung zu groß", als dass sie sich empathisch auf ein Gegenüber einlassen können, möglicherweise auch aufgrund der noch nicht entsprechend ausgebildeten Empathiefähigkeit (ebd., 37). Was ihre Trauer ausmacht, ist die Lücke, die der Verstorbene in ihr Leben gerissen hat, und weniger das mitfühlende Entsetzen über das Unglück des frühen Todes (vgl. ebd.).

Es kann sogar sein, daß Kinder um den Verlust eines Freundes tiefer trauern als um den Tod von Geschwistern. Offensichtlich spielen bei dem Tod von Geschwistern eine

92 Ratschläge und praktische Hilfestellungen z. B. bei: Brocher 1981; Tausch-Flammer/ Bickel 1998; Ennulat 2003; Cramer 2008, 2012. 
stärkere Ambivalenz, alte Geschwisterrivalität und intensivere Schuldgefühle mit als bei dem Tod von Freunden, zu denen das Verhältnis vielleicht unbelasteter war. (Ebd., 38)

Manche Kinder können ihrer Trauer keinen Ausdruck verleihen, wollen sie sich und anderen nicht eingestehen und kommen erst sehr viel später dazu, ausgelöst durch ein anderes Ereignis, die unterdrückten Gefühle auszuleben (vgl. ebd., 40). Grundsätzlich gilt auch hier: Die unterstützende und einfühlende Begleitung erwachsener Bezugspersonen, die Kinder ernst nehmen, ihre emotionalen Widersprüchlichkeiten annehmen und mit den eigenen Gefühlen und Gedanken in für Kinder verständlicher Form offen umgehen, ist entscheidend für die gesunde kognitive und emotionale Entwicklung der Kinder.

\section{IV.1.4.2.4 Verlust eines Tieres}

Erste Erfahrungen mit dem Tod sind für Kinder oft mit dem Sterben von Tieren verbunden, wobei fremde Tiere und bekannte bzw. geliebte Haustiere in der Betroffenheit einen Unterschied machen. Für Erwachsene ist es durchaus entlastend, wenn Kinder z. B. beim Anblick von überfahrenen Tieren lediglich nüchternes Sachinteresse zeigen, es kann aber auch mindestens irritierend sein, wenn Kinder in Unkenntnis und ohne ein ausgebildetes Todesverständnis nicht angerührt sind oder grausam und unvernünftig mit Tieren umgehen (vgl. Leist 2004, 25). Das Ausreißen von Spinnenbeinen, Vernichten von Ameisenkolonnen und andere Quälereien scheinen „keine wesentliche Erfahrung über Tod und Sterben“ zu evozieren, sondern werden „als folgerichtiges Ergebnis aus dem Kampf des Stärkeren gengenüber dem Schwächeren angesehen“, vielleicht sind sie aber auch "ein Versuch, mit der eigenen uneingestandenen Todesangst fertig zu werden“ (ebd., 26). Als „erste wesentliche Erfahrung mit dem Tod, die das Kind machen kann", sind Funde von toten Tieren in der Natur anzusehen, deren Unbeweglichkeit und Totsein auch nicht durch die Eltern aufgehoben werden kann (ebd.).

Anders wird das Kind den Tod eines geliebten Haustieres erleben, das, gemessen am kindlichen Leben, für lange Zeit zur Familie gehörte. Die Kenntnis aus der Natur, dass tot sein unbelebt und starr zu sein heißt, wird durch den Tod des Haustieres um die Erfahrung erweitert, dass mit dem Tod „Verlust, Trennung und Abschied auf immer" und somit auch Schmerz einhergehen (ebd., 27). Dieser Verlustschmerz sollte dem Kind zugebilligt werden, denn ein allzu schneller Ersatz durch ein neues Tier wertet das verstorbene und die berechtigte Trauer darum ab. Hilfreich, auch im Sinne eines Lernprozesses, ist es vielmehr, Trauerrituale und eine Beerdigungs- und Erinnerungskultur zu zelebrieren, die die Achtung vor dem Tier als Lebewesen zum Grundsatz erhebt. Dass aber der Tod 
von Tieren, der auch als Gnadentod durch Menschenhand herbeigeführt werden kann, sich von dem Sterben, das dem Menschen zugedacht ist, gravierend unterscheidet, wird das Kind erst später erfahren (vgl. ebd., 29).

\section{IV.1.5 Zusammenfassung}

Kinder entwickeln in Abhängigkeit von kognitiven und psychischen Dispositionen ein Todeskonzept, das auch ihr Trauerverhalten beeinflusst und wesentlich von einer Vielzahl von Konstituenten in ihrer Umgebung geprägt wird. Dass die Schlussfolgerungen aus verschiedenen Studien zur Frage nach dem Wann und Wie der Ausbildung einer kindlichen Trauerfähigkeit widersprüchlich sind, bestätigt imgrunde die Unzulässigkeit einer Verallgemeinerung, da die jedem Menschen eigene Individualität das Ergebnis verschiedenster interpersoneller und soziokultureller Einflussfaktoren darstellt. Die Fähigkeit zur Trauer ist offenbar nicht altersabhängig, grundsätzlich aber müssen drei Prämissen erfüllt sein, damit Trauerverarbeitung in der Kindheit gelingen kann:

Erstens sollte sich das Kind vor dem Verlust einer ziemlich sicheren Beziehung zu seinen Eltern erfreut haben; zweitens sollte es rasch und zutreffend informiert werden, und es sollte Fragen stellen und an der Trauer der Familie teilhaben dürfen; drittens sollte ihm die tröstliche Gegenwart seines überlebenden Elternteils oder einer bekannten Ersatzperson zur Verfügung stehen, zu der es Vertrauen hat. (Bowlby 2006b, 305)

Studien belegen das erhöhte Risiko, nach einem in der Kindheit erlebten Todesfall psychisch zu erkranken, wenn diese Voraussetzungen nicht gegeben sind (vgl. ebd. 281). Mehr, als Erwachsene gemeinhin glauben, und mehr noch als Erwachsene selbst bedürfen Kinder einer einfühlsamen und ernsthaften Zuwendung, wobei grundsätzlich gilt, dass bei einem Beziehungsverlust die Auswirkungen der Verletzung umso größer sind, je jünger das Kind ist (vgl. Raimbault 1981, 154). Störungen treten dann auf, wenn das Kind seine Trauer nicht leben kann, weil Erwachsene ihm die Fähigkeit zum Trauern nicht zubilligen oder in der Absicht, das Kind zu schonen, die eigenen Trauergefühle verbergen und eine Atmosphäre der Negierung und Verleugnung schaffen, in der sich das Kind mit seiner Trauer nicht positionieren kann. Wenn Trauer im Sinne eines gesunden, abschließenden Verlaufs gelingen soll, dürfen Kinder nicht mit lapidaren oder gar unehrlichen Phrasen abgespeist werden. Überaus belastend wird die Situation für das Kind, wenn die trauernden Eltern bzw. der hinterbliebene Elternteil so sehr der eigenen „Trauerdepression“ (ebd. 1981, 161) verfallen, dass es sich aufgefordert fühlen muss, die Rolle eines Trösters zu übernehmen. Dann verstummt es fatalerweise in der eigenen Trauer und unterdrückt das Gespür für das Eigene, um nicht selbst zusätzlich zur Last zu fallen; das noch im Aufbau 
befindliche Selbstkonzept wird dabei nachhaltig beschädigt (vgl. ebd., 161f.). Diese Erkenntnisse verlangen nach einem Bewusstsein für die Verantwortung, die mit dem Trauerverhalten hinterbliebener Bezugspersonen einhergeht. Der offene Umgang mit ggfs. religiösen Vorstellungen und Trostbildern kann dabei hilfreich sein.

\section{IV.2 Religiöse Perspektiven auf den Tod}

Das unergründbare Geheimnis des Todes ist seit Menschengedenken Auslöser für unzählige Fragen, Ungewissheiten, Hoffnungen und Befürchtungen und nimmt in den Jenseitstheorien der verschiedenen religiösen Glaubensrichtungen Gestalt an. Dass dabei „der Jenseitsglaube keine angeborene anthropologische Konstante sein kann", sondern gesellschaftlich-kulturell bedingt ist, gilt als sicher (Hahn 2002, 575). Der moderne Begriff Jenseits, „, seit etwa 1800 als Gegenbegriff zu dem das moderne Daseinsgefühl bestimmenden,Diesseits' geläufig" (Kremer 1996, 769; H. i. O.), steht für alles, was nicht dem irdischen Lebensumfeld des Menschen zugerechnet werden kann: Himmel, Hölle, Fegefeuer, Unterwelt u. a. Im Zentrum des menschlichen Bedürfnisses nach Gewissheit stehen vor allem zwei Fragen: Was ist der Tod und was kommt danach? und Wenn es ein Danach gibt, wie wird es sein und wie lange dauert es? Vier Varianten einer Antwort sind möglich:

1. Der Tod ist das absolute Ende, das endgültige Verlöschen jeglicher Form von Existenz - danach kommt nichts. Vertreter dieser Ansicht sind „materialistische und marxistische Philosophen“ (Klug 1997, 12) und all die „rationalen, wissenschaftlich aufgeklärten Menschen“ (Fischer 1987, 20) einer säkularisierten Gesellschaft, deren Lebensformen und Weltanschauungen kaum noch von Kirche und Religion bestimmt sind.

2. Der Tod ist Ende und Anfang zugleich, ein einziger Moment, in dem die irdische Existenzform verlöscht und in veränderter, auch nicht-menschlicher Gestalt wiedergeboren wird. Diese Auffassung von der Reinkarnation wird z.B. von Buddhismus und Hinduismus vertreten.

3. Der Tod ist eine Durchgangsstation, ein Übergang in eine transzendentale oder erneuerte Form ewigen Daseins. Manche Vorstellungen gehen davon aus, dass sich im Tod ein Heilungsprozess vollzieht, der zur Unversehrtheit der ehemals beschädigten physisch-biologischen Existenz führt und ein unbelastetes, ewig glückliches, überirdisches Leben in einem paradiesischen Garten ermöglicht. Im Grundsatz ähnlich, vertreten die drei monotheistischen Weltreligionen, Christentum, Judentum und Islam, diese Auffassung 
vom Tod, fundamentale Unterschiede bestehen allerdings im Glauben an die Ausgestaltung der nachirdischen Welt (vgl. Hoheisel 1993, 1191).

In alttestamentarischer und jüdischer Überlieferung findet sich zunächst keine entsprechende Bezeichnung für einen jenseits des Erdenlebens liegenden Ort oder Zustand, wohl aber wird der Himmel als Wohnort Gottes genannt (vgl. Schmid 1960, 890). Erst viele Jahrhunderte später, im zweiten vorchristlichen Jahrhundert, entwickelte sich allmählich die Hoffnung auf eine individuelle Weiterexistenz über die Todesgrenze hinaus (vgl. Pennington 2001, 43), verbunden mit einem "Vergeltungsglauben“ (Schmid 1960, 891), der nach dem Tod Lohn oder Strafe für irdische Taten vorsieht. Damit wurde die Vorstellung von dem glücklichen Los einer unmittelbar nach dem Tod erfolgenden Auferstehung der Gerechten ,in die Gemeinschaft mit Gott im Himmel“ verbunden, dem das Bild von der „Hölle als Ort der Verdammnis der Gottlosen“ gegenübersteht (ebd.).

Im christlichen Glauben des Neuen Testaments manifestiert sich die Vorstellung vom Jenseits als einem Leben nach dem Tod bei Gott, der der Glaube an die Unsterblichkeit der Seele und der Auferstehung des Körpers inhärent ist. Das Sprechen vom Jenseits „reicht von konkreten Bildern und Vorstellungen bis zur absoluten Transzendenz“ (Schreiber/ Siemons 2003, 12) und nennt „den Himmel (das Paradies) als Ort des Heils für die Auserwählten, u. zwar offenbar sogleich nach dem Tod [...], und die Hölle als Stätte der ewigen Bestrafung der Gottlosen“ (Schmid 1960, 891). Die darauf gerichtete Hoffnung stützt sich auf den Glauben an die Auferstehung der geschichtlichen Person Jesus von Nazareth, begründet und regelmäßig erneuert im österlichen Geschehen. Die Vorstellungen vom Tod als Trennung von Leib und Seele und einem Neuwerden an einem paradiesischen Ort, den die Offenbarung des Johannes in großartigen Bildern von einem himmlischen Jerusalem entwirft und dessen Herrlichkeiten an die Paradiesbeschreibung des Alten Testaments (Genesis 2/3) erinnern, sind für Christen fester Bestandteil ihres gläubigen Vertrauens auf eine unvergleichlich bessere Daseinsform nach der irdischen, die sich als „Teilhabe an einem heilvollen Jenseits ganz als Ergebnis des gnadenhaften, schöpferischen Tuns Gottes präsentiert" (Schreiber/ Siemons 2003, 13).

In der $622 \mathrm{n}$. Chr. vom Propheten Mohammed begründeten islamistischen Glaubenslehre ruht, wer der Offenbarung des Koran „gläubig folgt, [...] nach dem Tod bis z. Auferstehung bewußtlos im Grab u. soll nach dem Jüngsten Gericht himmlischen Lohn empfangen“" (Köbert/ Schatz 1967, 793; Abk. i. O.); 
dem, der im Kampf ${ }^{93}$ für den Islam fällt, wird als Märtyrer besondere Ehre zuteil, indem er unmittelbar ins Paradies eingeht (vgl. ebd.). Insgesamt aber bleibt der jenseitige Daseinszustand den Menschen verborgen, „wird verschlüsselt in Sinnbildern, in den reichen volkstümlichen Überlieferungen [...] und in der blumigen Gefühlswelt der Bildersprache" (Pennington 2001, 47). Der Tod ist nicht Bestrafung, sondern „eingeplanter Bestandteil des Schöpfungszieles“ und wird damit auch in der islamischen Glaubenslehre als Übergang in eine andere, unvergleichlich bessere Welt bei Gott verstanden (ebd., 46).

4. Eine weitere Vorstellungsvariante einer postmortalen Existenz ist das „Weiterleben im Diesseits" (Hahn 2002, 576), das Lebendighalten des Verstorbenen im Gedächtnis bzw. der Erinnerung der Überlebenden.

Der Tote lebt in den Überlebenden weiter. [...] Jedes Ich enthält als Element seiner selbst die anderen in verinnerlichter Gestalt. [...] Nach unserem Tod existiert unser eigenes Bewußtsein nicht mehr. Für uns selbst haben wir folglich unsere Identität verloren. Das gilt aber nicht für das Bild, das andere von uns in ihrem Bewußtsein tragen. [...] Unsere Identität überlebt uns als Thema, sei es fremder Vorstellungen, sei es fremder Kommunikation. Seit es Schrift gibt, seit es Portraits gibt, seien es gemalte, in Stein gehauene oder photographierte [...], heißt das, daß unsere Identität virtuell immerwährend ist. (Hahn 2002, 577)

Hahn formuliert für alle Formen des Jenseitsglaubens, unabhängig von religiöser Motivierung, die „soziologische Hypothese [...]: Wir verdanken die Unterstellung eines Lebens nach dem Tode dieser realen Weiterexistenz in den Vorstellungen von alter ego" (ebd., 578). Ein absolutes Verlöschen der Existenz scheint den meisten Menschen eine unaushaltbare Vorstellung zu sein, da selbst diejenigen Hinterbliebenen, die nach eigener Aussage nicht an ein Weiterleben nach dem Tode glauben, sich der Erinnerung und manchmal auch der inneren Zwiesprache mit den Verstorbenen nicht erwehren können (vgl. ebd., 578f.). Der Glaube an diese „postmortale Existenz im Diesseits“ zeichnet gerade die säkularisierten Gesellschaften aus, in denen manche Menschen größte Anstrengungen unternehmen, um z. B. in ihren Kindern ihre „biologische[...] Überlebenschance“ zu sichern oder in ihrem Nachlass eine Stätte der „sozialen Fortdauer“ resp. eine in die Zukunft reichende Wirkkraft im Gedenken anzulegen (ebd., 579f.). Dieses Phänomen der Weiterexistenz im Gedächtnis der Lebenden ist

93 „Die Verpflichtung z. (eigentl. jährlich zu führenden, dann aber notfalls auch durch bloße Rüstung ersetzbaren) Hl. Krieg ( $\square$ ihād) z. Unterwerfung der Welt unter den I. als Gottes Ordnung lastet auf einer islam. Gemeinschaft, sobald sie dazu in der Lage ist, nicht dagegen auf dem einzelnen Muslim." (Köbert/Schatz 1967, 794; Abk. i. O.). 
im kulturwissenschaftlichen Diskurs der Erinnerungstheorie ${ }^{94}$ inhärent und umfasst eine Erinnerungskultur, die im Fall eines Beziehungsverlusts zweifach gerichtet ist: einerseits affektiv auf ihre Trost spendende Funktion für den Trauernden als Träger einer dankbaren, liebevollen Erinnerung, andererseits auf die Fortdauer des In-der-Welt-Seins mittels Hinterlassenschaften unterschiedlichster Form (vgl. ebd.).

\section{IV.2.1 Vorstellungen nachtodlicher Existenz}

Die Vorstellung, dass nach dem Tod des biologisch-funktionalen Organismus vom Menschen der Teil bleibt, der das Geistige, nicht Physische des menschlichen Seins ausmacht, ist verbunden mit dem Leib-Seele-Dualismus, der seinen Ursprung in der platonischen Philosophie der Antike hat (vgl. Vorgrimler 2000, 565f.). Im Gegensatz zum krassen Dualismus Platons, der die „Seele als das geistige Selbst“ des Menschen sieht, „das in den Körper gleichsam wie in ein Gefängnis oder Grab [...] hineingebannt sei“, und das Materiell-Körperliche damit abwertet, geht die katholische Lehre von zwei Seinsprinzipien des Menschen aus: von der Seele und dem Materiellen als je einem „Seinsprinzip“, die gemeinsam „den einen Menschen in substanzieller Einheit bilden." (Ebd.) Diese Ganzheitlichkeit des Menschen macht seine „unvertauschbare Individualität“ aus: Der Tod wirkt nur auf das "physisch-biologische Bewußtsein des Menschen“, die Individualität und damit das Unverwechselbare einer Lebensgeschichte dagegen „hören bei Gott nicht auf zu sein.“ (Ebd., 567)

$[D]$ aher spricht die kath. Lehre der Seele Unsterblichkeit zu, die in der neueren Theologie nicht als »Weiterleben « in der gleichen Art wie im früheren Leben gedacht wird, sondern als überzeitliche Vollendung dessen verstanden wird, was im irdischen Leben vielleicht nur keimhaft angelegt, vielleicht in fragmentarischen Freiheitsentscheidungen nur begonnen war. (Ebd.; H. i. O.)

Die Unüberschaubarkeit der philosophischen und theologischen Diskurse, Betrachtungen und Erkenntnisansätze zum Leib-Seele-Verhältnis zwingt im Rahmen der vorliegenden Untersuchung dazu, es "umgangssprachlich-unscharf“ bei der Vorstellung von der Seele als „das Innere oder das Selbst des Menschen, als Organ der Einsicht von Sünde u. Vergebung, als Ort der Liebe u. der Hoffnung" zu belassen und ihre Unsterblichkeit darin zu sehen, dass sie nach dem biologisch-materiellen Tod den physischen Leib verlässt und als transzendentales

Vgl. dazu: A. Assmann 2009; J. Assmann 2007. 
Sein für ein Nicht-Verlöschen der menschlichen Individualität steht, die ewig existiert (ebd., 566f.).

Gemeinhin wird mit dem ,ewigen Leben' die Vorstellung von unendlich andauernder Zeit verbunden, die sich an die begrenzte irdische Lebenszeit anschließt, wobei mit dem sich ins Unendliche ausdehnenden Zeiterleben durchaus auch eine belastende Drohung verbunden sein kann, gerade dann, wenn schon das gegenwärtige Leben als Last empfunden wird (vgl. Nocke 2005, 150). Nach "Schrift und Tradition“ bezieht sich ,ewiges Leben' jedoch nicht auf die Kategorien Raum und Zeit, es „meint vielmehr Fülle des Lebens, Grenzenlosigkeit eines Glücks", das schon in Momenten des irdischen Lebens erfahrbar ist und im Einssein mit Gott den Zustand höchster Glückseligkeit erreicht (ebd.).

„Gott ist nicht der Himmel“, aber die „Rede von Gott [ist] eng mit der Rede vom Himmel verknüpft“, weshalb J. E. Hafner (2003, 143f.) von der „Notwendigkeit einer nichtgöttlichen Transzendenz“ spricht. Weiter sei es „theologisch unproblematisch, dass Gott das absolute Gegenüber zur Welt darstellt; wo aber der Himmel dazwischen zu platzieren ist, bedarf einer eingehenden Begriffsbestimmung“ (ebd., 145). Zunächst muss eine „Unterscheidung in kosmologische und theologische Himmel“ erfolgen, also der "religiöse Himmel (Paradies)“ vom "natürlichen Himmel (Atmosphäre)“ systematisch abgegrenzt werden, wie es im Christentum erstmals durch Augustinus geschehen ist (ebd., 145f.). Der Himmel als Ort und der „Zustand des Im-Himmel-Seins sind fast identisch. Augustinus hält seine Vorstellung vom Himmelshimmel so nah zu Gott wie möglich und so distanziert wie notwendig“ (ebd., 148). Aber er "positioniert den Himmel sowohl in deutlicher Differenz zu Gott als auch in Differenz zur Erde“, wonach drei Ebenen in Relation zueinander stehen (ebd., 149). Im Judentum steht das Wort Himmel als Synonym für den „Gottesnamen, den man aus Ehrfurcht nicht nennen möchte. [...] »In den Himmel kommen« heißt demnach nichts anderes als »zu Gott kommen«." (Nocke 2005, 145; H. i. O.) Als christlich-eschatologisches „Hoffnungswort [...] umfaßt das Wort »Himmel» das gesamte Glück, das dem Bei-Gott-sein mitgegeben ist" (ebd.; H. i. O.). Die genannten Vorstellungen verschmelzen in der geläufigen, umgangssprachlich konnotierten Bedeutung des Himmelsbegriffs als transzendentes Gegenteil von Diesseits, als jenseits des Erdenlebens angelegten paradiesischen Zustand des Wohlergehens, wie er sich auch in Kindertexten und in Texten für Kinder finden lässt. ${ }^{95}$

$95 \mathrm{Zu}$ ausführlicheren systemtheoretischen Begründungen der Vieldimensionalität des Himmelsbegriffs vgl. z. B.: Berger 1997; Herzog/ Gerl-Falkovitz 2001; Schreiber/ Siemons 2003. 
Mit dem Paradies ist im engeren Sinn die Assoziation eines Gartens (Eden) als Ort größter Seligkeit verbunden, im weiteren Sinn jede Form metaphorischer Entwürfe immerwährender Glücks- und Harmoniezustände (vgl. Paus 1998, 1359). Die meisten Volkskulturen kennen Paradiesvorstellungen, die aber eine große Uneinheitlichkeit und Vielschichtigkeit aufweisen. Auch aus biblischtheologischer Sicht lässt sich „[w]eder begrifflich noch sachlich“ eine eindeutige Paradiesvorstellung beschreiben (vgl. Dohmen 1998, 1360), allen Vorstellungen gemeinsam ist nur die Idee von größter Nähe zu Gott und einer umfassenden Heilsbringung (vgl. Lautenschläger 1998, 1362), weshalb auch der Begriff Himmel äquivalent verwendet wird. Ikonographisch gehen die christlichen Paradiesvorstellungen auf die Schilderungen vom Garten Eden als einer wasserreichen, blühenden Landschaft in Genesis 2 und auf Offb 21-22 zurück (vgl. Nitz 1998, 1363). Diesen im ursprünglichsten Sinne paradiesischen Bildern stehen die Schreckensvisionen der Hölle gegenüber.

Die Vorstellung von der Hölle als einem Ort der Vergeltung für begangene Untaten als Gegenpol zum Paradies der Seligen ist eng mit der jüdischen ScheolVorstellung verbunden, die nach dem Aufkommen des Auferstehungsglaubens in nachexilischer Zeit als zweigeteilt gedacht wurde: eine Seite für die Guten und eine Seite für die Bösen (vgl. Beitl 1967, 449). Mit dem Christentum wurde diese Zweiteilung in der Vorstellung von Himmel und Hölle zum „Allgemeingut“ (ebd.). Höllenqualen stehen für die Erfahrung des absoluten Ausschlusses aus jeglicher Gemeinschaft, vor allem aber für „den Ausschluß aus der liebenden Beziehung zu Gott“ (Nocke 2005, 137). Zum Höllendasein verdammt zu sein, heißt also ewig ohne Liebe und unfähig zur Liebe zu sein (vgl. ebd.). „Weil der Mensch durch und durch zur Liebe bestimmt ist, bedeutet eine solche Situation den größten denkbaren Schmerz." (Ebd.)

Der Glaube an Himmel oder Hölle in der Folge eines mehr oder weniger gottgefälligen Lebens war und ist untrennbar mit dem Memento-mori-Motiv verbunden, das besonders deutlich in den Totentanz-Darstellungen des Mittelalters Gestalt angenommen hat.

\section{IV.2.2 Das Memento-mori-Motiv und der Totentanz}

Memento mori! - Gedenke, dass du sterblich bist! Die große Pest-Epidemie von 1348 führte den Menschen diese Aufforderung täglich in größter Eindringlichkeit vor Augen und löste eine „wahre Flut der Ars-moriendi-Literatur“ aus (Mischke 1996, 74). Dabei handelte es sich um „Anleitungen zur Kunst des richtigen Sterbens" in Form von sogenannten Sterbebüchlein, die „ursprünglich als seelsorgerischer Leitfaden für junge Geistliche gedacht “ waren, um die Menschen 
zu lehren, auf eine gottgefällige Weise zu sterben (ebd., 74f.). Die Furcht vor dem plötzlichen Pest-Tod, der zwischen 1348 und 1350 etwa ein Drittel der Bevölkerung des damaligen Europas (ca. 25 Millionen Menschen) dahinraffte (vgl. ebd., 62) und keine Zeit mehr ließ für Bußehandlungen und abschließende Rituale, erhöhte das Interesse auch von Laien an diesen Sterbebüchlein, mithilfe derer sie die Kunst des Sterbens beizeiten üben konnten, „um nicht in der Todesstunde den Versuchungen der höllischen Mächte“ ausgeliefert zu sein (ebd., 74).

Das »memento mori« führte zu einem verstärkten Lebensgefühl und bildete einen der Faktoren, aus denen das säkularisierte Weltbild unserer Gegenwart erwachsen sollte. Der Mensch entdeckte seine Individualität auch in seinem eigenen Tod. Der Tod wurde zunehmend als individuelles Schicksal begriffen. (Ebd., 55)

Als Mahnung an den Tod verbreiteten sich zur selben Zeit auch die Totentanzdarstellungen, die als Bilderbogen und Bildertafeln den Seelsorgern für die Bußpredigt dienten (vgl. Zoepfl 1966, 278). In Anlehnung an den alten Volksglauben, wonach die Toten um Mitternacht den Gräbern entsteigen und auf dem Friedhof oder an Kreuzwegen Tänze aufführen und „Lebende in ihren Reigen zu ziehen trachten“" (ebd., 277), wurde der strafende Charakter des Totentanzes denjenigen vor Augen geführt, die sich in einem unbußfertigen Zustand befanden und deshalb den plötzlichen Tod besonders zu fürchten hätten (vgl. ebd.). Im Totentanzmotiv offenbarte sich die Angst der Menschen vor der Heimtücke des jähen Todes, der keine Möglichkeit mehr für notwenige Buße und „Gnadenmittel der Kirche" bot und die Menschen den Höllenqualen der mittelalterlichen Jenseitsvisionen auslieferte (vgl. Mischke 1996, 78). Die Totentänze

enthielten fromme Hinweise auf die Vergänglichkeit des menschlichen Lebens, sie waren Lektion für die menschliche Gleichheit vor dem Tod und Aufforderung, sich durch entsprechendes Verhalten im irdischen Dasein nicht das ewige Leben zu verscherzen. (Ebd.)

Der Tod war „der große Gleichmacher“, der in Gestalt eines Skeletts, als Sensenmann, schwarzer Mann, Spielmann und in anderen Erscheinungsformen alle sozialen Unterschiede nivellierte, da er niemanden, gleich welchen Standes oder Alters, Rasse oder Geschlechts, verschonte (vgl. ebd., 79). Mit der Darstellung des Todes als Spielmann „erweist sich das tragende Element des Totentanzes als typisch deutsch“ (Rosenfeld 1974, 302). Deutschland blieb sein

Hauptverbreitungsgebiet. Hier vor allem entfaltete er sich in knapp zwei Jahrhunderten von schlichtester Form zu den mannigfaltigsten Kunstformen, wuchs er von der Kleinform des Bilderbogens zu Monumentalgemälden und illustrierten Büchern an, fand er im Buchdruck ein Mittel weitester Verbreitung [...]. (Ebd., 306) 
Das immer wieder aufflackernde Pest-Sterben, die kämpferischen Unruhen, Aufstände und Hungersnöte des 14. und 15. Jahrhunderts führten dazu, dass sich der Blick der Menschen auf den Tod veränderte: „Der Tod war nicht länger ein heilsgeschichtliches Ereignis, ein Übergang zum wirklichen Leben. Es kam vielmehr die düstere Ahnung auf, daß er das endgültige Ende sei." (Mischke 1996, 58) Die Kirche nutzte die Totentanzdarstellungen zur Ermahnung, das Diesseits duldsam anzunehmen und sich wieder dem Glauben an ein heilvolles Jenseits zuzuwenden, bis sie sich während der Reformationszeit von der zunehmend kritischen und kirchenfeindlichen Gestaltung der Totentänze, die den „Kampf des Todes gegen eine in Ständen organisierte Gesellschaft“ ins Bild setzten, distanzierte (ebd., 80).

\section{IV.2.3 Engel}

Religionsgeschichtlich ist die Gestalt des Engels in fast allen Religionen nachzuweisen (vgl. Paus 1995, 646).

Allgemein bedeutet E. ein außerirdisches, menschenähnlich od. tierartig erscheinendes ,numinoses' Geistwesen, an sich leibfrei, mit begrenzter Willenskraft, Selbstbewußtsein u. Emotionsfähigkeit ausgestattet u. fähig, aus seiner kosmischen Verborgenheit herauszutreten, um in den raum-zeitl. Aktionsrahmen der Menschen bis hinein in ihr Traumleben wirksam einzugreifen. (Ebd.; Abk. i. O.)

Engel wurden und werden heute noch in ihrer Funktion vor allem als den Menschen „individuell zugeordnete Schutzmächte“ (ebd.), als Boten Gottes oder Mittler zwischen Mensch und Gott verehrt, spielen aber „im Leben der Kirche sowie in der Spiritualität eine marginale Rolle" (vgl. Kunzler 1995, 651). Als „personale Geistwesen“ werden Engel seit „ihrer christentüml. Verkitschung im 19. Jh.“ nicht mehr ernst genommen (vgl. ebd.). In der gegenwärtigen Wahrnehmung sind mit dem Begriff Engel eher Metaphern im Bereich der Werbung („Blauer Engel“) oder z. B. alltagssprachlich bekundete Hilfsbereitschaft („Gelber Engel“, Engel der Straße u. a.) verbunden, als dass Engel mit dem Willen Gottes und dessen schützendem Auftrag in Verbindung gebracht werden (vgl. ebd.). Solche Vorstellungen sind den Mythen und Märchen zugeordnet, deren Bedeutung als „Ausdrucksweisen v. Sehnsuchtsbildern der Seele“ (ebd., 652) den Engelsgestalten eine neue Wertigkeit zuerkannte.

Ikonographisch sind Engeldarstellungen schon bald nach „Beginn einer eigenständigen Kunst des Christentums" nachzuweisen (vgl. Koch 1995, 653). Zunächst sind sie noch flügellos, teilweise auch noch im 9./10. Jahrhundert und in der Renaissance, später mit doppelten, vereinzelt vier- oder sechsfachen Flügeln ausgestattet, mit meist knabenhaften, dann auch weiblichen Zügen bis hin zu 
schwebenden, wesenlosen Gestalten (vgl. ebd.). Auch in der Literatur sind die Engel seit vielen Jahrhunderten in „vielfältigen metaphor. u. symbolisch-figurativen Verwendungen“ vertreten (vgl. Schmitz 1995, 653f.; Abk. i. O.). Gegenwärtig zeichnet sich ein deutlicher Trend ab, der einem Engelskult gleichkommt, wie die spirituell bzw. okkultistisch ausgerichteten Internetforen, Buchveröffentlichungen ${ }^{96}$ und die Angebote des Konsumgütermarktes (z. B. die Flut verschiedenster Schutzengelfiguren als Schlüsselanhänger, Bücherstützen, Seifen- und Kerzenformen u.v.a.m.) vielfach aufzeigen.

\section{IV.2.4 Christliche Ritual- und Begräbniskultur}

Anlass und Anliegen von ritueller Totenbehandlung und Bestattungsriten ist im Ursprung sicher die Vorstellung von einer postmortalen Weiterexistenz, wofür der Verstorbene entsprechend ausgestattet sein sollte, verbunden mit der Hoffnung auf eine fortdauernde Kommunikation zwischen Lebenden und Verstorbenen. In der modernen, verbreitet säkularisierten Gesellschaft stehen jedoch weniger die Toten im Zentrum der Aufmerksamkeit, sondern mehr die Hinterbliebenen, deren rituelles Handeln ebenso ihre Wertschätzung gegenüber dem Verstorbenen ausdrückt, wie ritualisiertes Abschiednehmen auch ein Teil der eigenen Trauerbewältigung ist (vgl. Heller/ Winter 2009, Vorwort). Zudem wissen

[i]mmer mehr Menschen [...] nicht (mehr), wo ihre Toten hingehen. In den neuen Formen zeitgenössischer Bestattungskultur - angefangen vom Verstreuen der Asche bis zum Weltraumbegräbnis - spiegelt sich diese zunehmende Tendenz zur Ortlosigkeit. (Ebd.)

Das war in vorangegangenen Jahrhunderten anders. Eine Rückschau auf die verschiedenen abendländischen Umgangsweisen mit dem Tod und ihre epochalen Veränderungen ${ }^{97}$ zeigt aber auch, dass einige traditionelle Akzente in der gegenwärtigen Ritualkultur wieder aufblühen (vgl. Heller 2009, 12). Diese neue „Wertschätzung traditionaler und teilweise adaptierter Rituale“ (ebd.) ist Teil einer ambivalenten Haltung dem Tod gegenüber in einer Gesellschaft, die geprägt ist von vielen Widersprüchen.

Anonyme Bestattungen, Verleugnung des Todes, Jenseitsverlust und medizinischtechnischer Unsterblichkeitswahn stehen unvermittelt neben einem neuen spirituellen

Interesse, das in der Auseinandersetzung mit dem Tod wieder die alten religiösen Fragen

96 Der Katalog der Deutschen Nationalbibliothek verzeichnete im Mai 2011 mehrere Hundert Verlagsankündigungen zum Schlagwort Engel.

97 Vgl. zur Sozialgeschichte des Todes und zu Veränderungen des Todesbewusstseins und der Todesideologie: Feldmann 2004, 42ff. 
entdeckt, den Bemühungen um eine angemessene Versorgung der Sterbenden und einer neuen Trauerkultur, die die Beziehungen zu den Toten aufrecht hält. (Ebd., 17)

Bis in die Neuzeit war das „Sterben [...] eine bewußte, vom Sterbenden eingeleitete öffentliche Zeremonie, die letzte und feierlichste seines Lebens, und ihr Verlauf wurde vom Sterbenden selbst wesentlich mitbestimmt" (Mischke 1996, 41). Die Teilhabe und die Zuständigkeit für den korrekten Ablauf des Sterberitus, der Bestattungsfeierlichkeiten und Trauerbekundungen unterlag einer Reihe von Vorschriften, die nicht nur die gesamte Familie, sondern auch das Hauspersonal, die Freunde und Nachbarn und ausdrücklich auch die Kinder betrafen (vgl. Ariès 1976, 24f.). Der Sterbende wurde bis zum letzten Atemzug begleitet; er nahm von allen Anwesenden Abschied, traf seine letzten Verfügungen, betete mit ihnen, gestand seine Schuld als reuiger Sünder und empfing die Sterbesakramente (vgl. Mischke 1996, 42).

Das hervorstechendste Merkmal des Sterbevorganges war die Einfachheit und Selbstverständlichkeit, mit der er geschah, ohne dramatischen Charakter, ohne exzessive emotionale Regung, sondern auf zeremonielle Weise, eingebunden in die Gemeinschaft und ohne Furcht. Die Vertrautheit mit dem Tod als Teil des Daseins beruhte auf der Anerkennung der natürlichen Ordnung. Der Mensch verstand seinen Tod als Etappe auf dem Weg zum ewigen Leben. (Ebd., 42f.)

Das anschließende Zeremoniell mit „Aufbahrung, Totenmesse und Beerdigung wurde als Christenpflicht empfunden“, deren Missachtung zu sozialer Ächtung führte (vgl. ebd.). Mit dem Entstehen der Industriegesellschaften des 18. und 19. Jahrhunderts wurden die Sterbe- und Totenrituale dann „ersetzt durch medizinische, rechtliche und administrative Maßnahmen; das traditionelle Betreuungspersonal (Verwandte, Nachbarn, Priester) wurde teilweise aus dem Feld gedrängt oder marginalisiert" (Feldmann 2004, 55). Heute sterben rund 80\% aller Menschen in Deutschland im Krankenhaus oder Pflegeheim. ${ }^{98}$ Auch die Begräbniskultur hat sich gewandelt. Im 17. Und 18. Jahrhundert war die Gestaltung der christlichen Grabstätten nur der Oberschicht ein Anliegen, meist waren die Gräber schmucklos und häufig der Verwahrlosung überlassen (vgl. ebd., 52). Das „Interesse an Gräbergestaltung, Grabsteinen und Mausoleen etc." des aufsteigenden Bürgertums des 19. Jahrhunderts weist dann schon auf eine "Säkularisierung des Todesbewusstseins" hin, da ein Grabmal der öffentlichen Darstellung des gesellschaftlichen Ansehens des Toten respektive seiner Familie diente und „nicht mehr mit einer vorgezeichneten Karriere des Toten im Jenseits in Verbindung gebracht“ wurde (ebd., 53). Der „Niedergang dieser

98 Quelle unter Aktuelles auf: http://www.christoph-student.de/ (Aufruf 13.07.2012). 
Sepulkralkultur des 19. Jahrhunderts“ ist vor dem Hintergrund der Tatsache, dass in der heutigen Zeit die Grabkultur für die Betonung eines gesellschaftlichen Status' so gut wie keine Bedeutung mehr hat, eine nachvollziehbare Entwicklung (vgl. ebd.). „Der moderne Friedhof gibt keine Auskunft mehr, [...] [ist; M.H.] nur noch ein Ort der »Entsorgung " (Mischke 1996, 109; H. i. O.). Daneben haben „[a]ndere Formen der Bewahrung der sozialen Erinnerung an Tote und der die eigene physische Existenz überdauernden Selbstdarstellung [...] an Bedeutung gewonnen: Fotografie, Film, Ton- und Videoaufzeichnungen." (Feldmann 2004, 53f.)

In christlichen Gemeinden des 21. Jahrhunderts ist die Begräbniskultur der vergangenen Jahrhunderte durchaus noch spürbar. So gibt es noch immer die Möglichkeit des Aufbahrens, allerdings nur äußerst selten im eigenen Haus, sondern in eigens dafür errichteten Leichenhallen auf dem Gelände der Friedhöfe, wie sie schon allein aus hygienischen Gründen seit dem 19. Jahrhundert gebräuchlich wurden. Das starre rituelle Regelwerk ist heute aufgehoben, die Choreographie der Beerdigungszeremonie und die anschließende Trauerphase sind ganz individuelle Angelegenheiten und nicht selten sehr private, sich der Öffentlichkeit weitestgehend entziehende Vorgänge, deren Ausgestaltung oft in die Hände von professionellen Bestattern gelegt wird. Die Öffentlichkeit wird häufig ganz explizit des persönlichen Ausdrucks von Anteilnahme enthoben, indem in Zeitungsanzeigen über die bereits erfolgte Beisetzung im engsten Familienkreis informiert oder darum gebeten wird, von Beileidsbekundungen am Grab abzusehen. Das Annehmen wie auch das Ausdrücken von Kondolenz über

herkömmliche[...] Verhaltensroutinen, darunter auch der Gebrauch ritueller Floskeln, [ist] in den großen Krisensituationen des menschlichen Lebens für viele Menschen suspekt und zum Teil peinlich geworden [...]. Die Aufgabe, das richtige Wort und die richtige Geste zu finden, fällt also [...] auf den Einzelnen zurück. Das Bemühen, gesellschaftlich vorgegebene Rituale und Formen zu vermeiden, vergrößert die Anforderung an die persönliche Erfindungs- und Ausdruckskraft des Individuums. Dieser Aufgabe aber sind Menschen derzeit gerade im Zusammenhang mit einer Eigentümlichkeit der gegenwärtigen Zivilisationsstufe nicht recht gewachsen. (Elias 1995, 45)

Der zunehmende „Modernisierungstrend“ spiegelt sich auch in der wachsenden Anzahl von Leichenverbrennungen ${ }^{99}$ und anonymen Urnenbestattungen, dem Trend zur Vermeidung von Kosten, der ablehnenden Haltung dem Leichnam gegenüber und im Verschwinden der Trauerkleidung wider (vgl. Feldmann

99 Das erste Krematorium wurde im Dezember 1878 in Gotha in Betrieb genommen (vgl. Mischke 1996, 107). 
2004, 54f.). Gleichzeitig aber wird immer mehr „der Verlust der Riten als negative Erscheinung mit katastrophalen Auswirkungen für die Sterbenden und ihre Angehörigen beklagt“, dem schon eine „Wiederbelebung alter Ritualtraditionen“ entgegenzustehen scheint (Heller 2009, 12). Ansätze einer neuen Ritualkultur in der christlich geprägten westlichen Welt zeugen von dem Bedürfnis vieler Menschen nach Orientierung (vgl. ebd.). Diese Ambivalenz im Umgang mit dem Sterben wird wesentlich bestimmt von der Tatsache, dass sich Lebensqualität maßgeblich über gelingende zwischenmenschliche Beziehungen definiert, deren Aufrechterhaltung noch über den Tod hinaus für das Leben des Hinterbliebenen bedeutsam ist. Bei aller Nüchternheit der säkularisierten Einstellung zum Tod bedarf es dazu offensichtlich einer Erinnerungskultur, die ohne Rituale nicht auskommt (vgl. ebd., 16). Wird aber der Tod nicht als Übergang in eine andere Existenzform angesehen, sondern als das alles auslöschende Ende, „sind die Rituale letztlich Selbstzweck und haben neben dem Stabilisierungseffekt für die Gesellschaft bestenfalls noch einen therapeutischen Nutzen für die Trauernden" (Heller 2009, 21).

\section{IV.2.5 Religionspädagogische Aspekte}

Wer sein Leben als sinn- und gehaltvoll erlebt und in allen Vorkommnissen und Umständen, auch in den nicht erwünschten, ein erfülltes Dasein sehen kann, zeigt dem Tod gegenüber eine größere Annahmebereitschaft, wie Befunde zu Befragungen älterer Menschen belegen (vgl. Munnichs 1972, 591ff.). „Wer [zudem; M.H.] sein Leben vom Willen Gottes bestimmen lässt und seine Lebenserfüllung als Mitarbeiter Gottes gefunden hat, ringt nicht mehr um den Sinn des Daseins." (Klempnauer 1977, 80)

Mit dem Tod sind alle menschlichen Beziehungen und weltlichen Bezüge befristet und können jederzeit radikal abgebrochen werden. Theologischem Todesverständnis sollte es fernliegen, in dieser Radikalität einen Sinn zu sehen oder auch nur die Andeutung einer Antwort auf die Fragwürdigkeit zu versuchen. Ihr Angebot und ihre Möglichkeit kann allein darin bestehen, die Hoffnung wecken zu dürfen, daß es über die menschlichen Beziehungen und weltlichen Bezüge hinaus ein Verhältnis gibt, daß auch der Tod nicht unterbrechen kann: den Glauben an den die Menschen annehmenden Gott. (Hennecke 1987, 47)

Die christliche Theologie bietet dem Gläubigen an, über den Tod hinaus zu denken und seine Existenz dem tröstlichen Hoffnungsgedanken an eine Fortsetzung des Lebens bei Gott anheim zu stellen. Die ars moriendi, die Kunst des Sterbens, wie sie als gottgefällige Gestaltung von den von Furcht vor den teuflischen Mächten geprägten mittelalterlichen Menschen verstanden und geübt 
wurde, ist damit auch eine Anleitung zur ars vivendi, der Kunst des Lebens. Die Philosophie des 20. Jahrhunderts hat dagegen "mit erheblichen erkenntnistheoretischen Schwierigkeiten zu kämpfen“ (Wildfeuer 2005, 86), da weder zum Wesen des Todes noch zur unbewiesenen Möglichkeit einer postmortalen Existenz vor dem Erreichen der Todesgrenze etwas in Erfahrung gebracht werden kann. Aus religionspädagogischer Perspektive müssen die Fragen nach dem Selbstverständnis des Menschen in Anbetracht des memento mori und seiner Bereitschaft, sich den Möglichkeiten einer postmortalen Existenz jenseits des durch Vernunft Erschließbaren zu öffnen, deshalb zusammengedacht werden, um einerseits die Hoffnung des Perspektiven aufzeigenden Glaubens an die Heilswirkung des Todes Jesu anzuschieben und anderseits die anthroposophische Perspektive der in einer säkularisierten Gesellschaft aufwachsenden Kinder und Jugendlichen nicht aus den Augen zu verlieren (vgl. Hennecke 1987, 45ff.). Da der gläubigen Hoffnung auf ein Aufgefangen-Werden von der Gnade Gottes, die mit christlichem Verständnis schon im Leben wirksam ist, aus theologischer Sicht eine Erleichterung der Radikalität des biologischen Endes zugeschrieben wird, muss die Auseinandersetzung mit den existenziellen Fragen menschlichen Seins und Werdens aus christlich-theologischer Perspektive gerade deshalb Gegenstand des Religionsunterrichts sein, weil Kinder und Jugendliche in die Lage versetzt werden müssen, verschiedene Positionen zu reflektieren und darüber eine eigene, Lebenssinn stiftende Haltung zum Tod einzunehmen (vgl. ebd.). ${ }^{100}$ Damit kann auch eine „Neudefinition“ der mittelalterlichen ars moriendi auf mehreren Ebenen verbunden sein:

- auf der biologisch-medizinischen Ebene (keine falschen Hoffnungen auf die Medizin setzen);

- auf der kulturellen Ebene (nicht dem Jugendlichkeitswahn erliegen);

- auf der Beziehungsebene (Freundschaft, Partnerschaft, Liebe entziehen sich menschlicher Machbarkeit);

- auf der Ebene der Umwelt (ein angemessenes Bewusstsein für Fragen der Ökologie und des Umweltschutzes entwickeln);

- auf der Ebene der Wirtschaft (nicht nur an den eigenen Nutzen denken);

- auf der persönlichen Ebene (reflektierte Einschätzung der eigenen Fähigkeiten und Kompetenzen). (Wuckelt 2005, 131ff.)

Der Tod gehört zum Leben. Dies ist ein Satz, der im Religionsunterricht seinen Platz haben muss. Die Schule hat hier Mittlerfunktionen zu übernehmen und sollte ein Forum bereitstellen, das dem verbreiteten, ausweichenden

$100 \mathrm{Zu}$ den Möglichkeiten und Grenzen des Religionsunterrichts im Umgang mit dem Verwaisen von Schülern vgl. ebd. 
Schweigen zum Tod mit kommunikativen Anstößen begegnet. Darin liegt der Anknüpfungspunkt für religionspädagogisches Handeln: dem Glauben an die Auferstehung als Zentrales der christlichen Botschaft gerade mit Blick auf die trotz Konfessionszugehörigkeit nicht mehr im christlichen Milieu sozialisierten Kinder und Jugendlichen Raum zu geben und gleichzeitig Ausdrucksmöglichkeiten für individuelle Haltungen zu schaffen. Dies gilt insbesondere für solche Situationen im Schulalltag, in denen Schulkinder einen Todesfall im engsten Familienkreis zu verkraften haben oder mit der Krankheit und dem Tod eines Schulkameraden konfrontiert werden (vgl. Nitsche 2010, 72ff.). ${ }^{101}$ Solidarität mit Sterbenden, Toten und Trauernden zu zeigen, ist dabei ebenso eine Aufgabe, wie mit der eigenen Betroffenheit und der möglicherweise angstbehafteten Einstellung zum Tod zurechtzukommen.

\section{IV.2.6 Zusammenfassung}

Die vorstehenden Ausführungen legen nahe, die Ursache für die in unserer Gesellschaft verbreitete Verdrängung von Fragen zu Alter und Tod in der schwindenden Religiosität zu sehen, da der größte aller Verluste, der Verlust des eigenen Lebens, ohne tröstende Hoffnungsperspektive auf eine Weiterexistenz unausweichlich erwartet werden muss und diese Perspektive nur mit Ignoranz erträglich scheint. Die Angst vor dem (eigenen) Tod geht offenbar durchaus mit Ungläubigkeit einher, denn Bezeugungen tief gläubiger Menschen lassen vermuten, dass im Glauben an den behütenden Gott und sein ewiges Reich Angst keine Rolle spielt oder sich in zuversichtliche Akzeptanz - oder gar Erwartung wandeln kann. Auch mit dem Blick auf die Tragik eines Beziehungsverlusts lässt sich mit Ariès $(1982,600)$ resümieren:

Die verschiedenen Arten des Glaubens an ein künftiges Leben oder an das Leben in der Erinnerung sind in der Tat Antworten auf die Unmöglichkeit, den Tod des geliebten Menschen zu akzeptieren.

Ob und wie aber der Glaube an das Heil bei Gott auf die Psyche des Einzelnen tatsächlich entlastend, tröstend oder Angst aufhebend wirken mag, ist für jeden Menschen nur mit sich selbst auszumachen. Wie mit der finalen Bedrohung des

101 Dass Schulen über ausreichende und angemessene Handlungsstrategien für die Trauerbegleitung von Schulklassen verfügen, resümiert Martin Nitsche (2010) in seiner Dissertation, einer empirischen Untersuchung der Trauerarbeit von Eltern und Geschwistern nach dem Tod eines Schulkindes. Er stellt aber auch den dringenden Handlungsbedarf für die Betreuung der hinterbliebenen Geschwisterkinder heraus, deren spezifische Trauerproblematik noch zu selten Beachtung findet. 
Lebens umzugehen sich empfiehlt, entzieht sich jeder Verallgemeinerung. Die Entscheidung, sich mit dem Tod auseinanderzusetzen, ihn zu akzeptieren oder mehr zu fürchten, ihn weitestgehend zu ignorieren oder das Lebensgeschick einer irgendwie gearteten religiösen Dimension zu überantworten, ist von jedem Menschen je individuell zu treffen, ist eine Aufgabe, die das Leben jedem Einzelnen stellt.

Dass Literatur für die Auseinandersetzung mit dem Tod und in Trauerzusammenhängen wichtige Funktionen übernehmen kann - als kommunikativer Mittler, als fiktionaler Entwurf erfolgreicher Trauerbewältigung u. a. m. -, liegt in der Natur des Gegenstands. Der gesamte Literaturmarkt setzt sich derzeit in unzähligen Titeln mit diesem Thema auseinander, wozu auch das Bilderbuch einen nicht unerheblichen Beitrag leistet. 


\section{Forschungskonzeption}

\section{V.1 Das Textkorpus}

Das Forschungsinteresse ist auf die Gesamtheit der deutschsprachigen, in das Verzeichnis der Deutschen Nationalbibliothek aufgenommenen Bilderbücher ${ }^{102}$ gerichtet, die in ihrer Entstehungszeit nach 1945 thanatologische Fragen berühren, also ein Todesereignis und/oder einen Trauerprozess, philosophische Fragen zur Trias Sterben, Tod und Trauer oder den natürlichen Lebenskreislauf vom Werden und Vergehen thematisieren.

Die Recherche erstreckte sich auf die Kataloge und archivierten Verzeichnisse der Deutschen Nationalbibliothek Frankfurt am Main und Leipzig, der Internationalen Jugendbibliothek München und der Staatsbibliothek Berlin, die Kataloge verschiedener Universitätsbibliotheken und Stadtbibliotheken, diverse Empfehlungslisten verschiedener Arbeitskreise und Hospize sowie die Primärliteraturverzeichnisse der einschlägigen Sekundärliteratur. Letztere waren besonders für die Jahre vor 1990 die ergiebigste Quelle, da bis zum Anfang der 1990er-Jahre in kaum einer Bibliothek die Bestände inhaltlich erschlossen wurden und auch nicht alle Titel, die seitdem katalogisiert werden (einschließlich die früherer Jahre), durchgängig beschlagwortet werden. ${ }^{103}$ Zudem gelten dafür keine einheitlichen Kriterien und es werden dabei auch nicht alle Motive ${ }^{104}$ eines Werkes berücksichtigt. Naturgemäß ist auch eine Suche über die Titelei hinsichtlich erwartbarer Inhalte kaum zielführend. Der sehr beachtenswerte Katalog der deutschsprachigen Bilderbücher der Bundesrepublik, der DDR, Schweiz und Österreich von 1945 bis 1975 (Weismann/ Jansen/ Stegner 1980) konnte aufgrund der fehlenden Erfassung der Inhalte als Ressource deshalb nicht genutzt werden.

102 Es sind drei Kinderbücher in das Korpus mit aufgenommen worden, deren hybrider Charakter aufgrund des hohen, wenn auch mehr illustrativen Bildanteils diskutabel ist: Wegenast/ Meyer 2008; Nilsson/ Eriksson 2006; Hermann/ Solé-Vendrell 1999.

103 Für diese Hinweise dankt die Verfasserin Herrn Werner Küffner von der Internationalen Jugendbibliothek München (Reference Library, International Youth Library, Schloss Blutenburg/ München).

104 Das Problem der unzureichenden Verlässlichkeit von Beschlagwortungen zeigt sich beispielsweise am Bilderbuch Franka \& Nonno auf den Spuren des Bären Ludewig (Blüm/Göbel 2001), dem einzig das Schlagwort ,Freundschaft‘ zugeordnet ist, obwohl ein Verlusterlebnis dem emotionalen Aufgefangensein in der Freundschaft seine Bedeutung verleiht. 
Die Recherche hat für den untersuchten Zeitraum ab 1945 bis 2011 ein Textkorpus von insgesamt 287 deutschsprachigen Bilderbüchern hervorgebracht, die konkret „die Begegnung mit dem Tod und die damit einhergehende Erfahrung des Leidens an der Vergänglichkeit des Lebens zu ihrem Gegenstand haben“ (Ensberg 2006, 2) ${ }^{105}$ sowie solche, die Sterben und Abschiednehmen als nur einen von mehreren Aspekten der Lebensgeschichte eines Menschen oder einer Lebensphase darstellen oder zentrale, existenzielle Lebensfragen aufgreifen. Ausdrücklich davon ausgenommen sind die Märchen-Klassiker, da sie aufgrund ihrer gattungsgeschichtlichen Traditionen eines eigenen Untersuchungsansatzes bedürften. Daneben bilden einige Titel mit märchenhaftem Charakter eine eigene Kategorie, der der Einfachheit halber auch Legenden, Parabeln und mythologische Erzählungen zugeordnet sind.

\section{V.2 Forschungsansatz und methodische Entscheidungen}

\section{V.2.1 Forschungshypothesen}

Dem Ziel, die Schwerpunkte und Entwicklungslinien literarästhetischen Umgangs mit Sterben, Tod und Trauer im Bilderbuch nach 1945 nachzuzeichnen, gehen folgende Hypothesen voraus:

1. In Abhängigkeit vom Erscheinungszeitraum hat sich das Bilderbuchangebot zur Trias Sterben, Tod und Trauer sowohl quantitativ als auch motivbezogen bis in die Gegenwart stetig erweitert.

2. Die Bilderbücher spiegeln verstärkt die Einstellungen einer säkularisierten Gesellschaft, in der religiöse Auffassungen kaum mehr eine Rolle spielen.

105 Zur leitmotivischen Einschränkung vgl. Ensberg (2006). Die einschlägige Kinderliteratur nach Lindgrens Die Brüder Löwenherz wurde, wie erwähnt, von Ensberg (2006) in die literarischen Traditionslinien der Aufklärung und Romantik gestellt. Er unterscheidet in den Texten der neueren Kinder- und Jugendliteratur die aufklärerischen Protagonisten, die mehr oder weniger subtile Unterweisungen hinsichtlich eines werteorientierten und gesellschaftlich-kulturell begründeten vernünftigen Verhaltens erführen und verinnerlichten, von den romantisch angelegten Figuren, die unbelehrt blieben und für „das Empfinden einer Urgeborgenheit im Sein, einer Aufgehobenheit des Ich in wechselseitig im eigenen Innern konstituierten und in der Natur sich widerspiegelnden kosmischen Bezügen und Zusammenhängen“ stünden (ebd., 4). Dieser Ansatz erscheint angesichts der Textauswahl vertretbar, aber mit seiner Dichotomie bei gleichzeitiger Definitionsunschärfe zu eng gefasst und für das vorliegende Material ungeeignet. 
3. Dem zeitlichen Moment und der Emotionalität von Trauer wird in den Bilderbüchern seit der Jahrtausendwende zunehmend mehr Raum gegeben.

4. Kindern wird eine gleichberechtigte und gleichzeitig spezifische Teilhabe an Todesgeschehen und Trauerprozessen zugebilligt, die sich insbesondere in der Auseinandersetzung mit dem Kindertod und ihren erzähltechnischen Darstellungsformen zeigt.

5. Die besondere Problematik des Geschwisterverlusts wird nur selten aufgegriffen.

Folgende Leitfragen sind damit verbunden:

$\mathrm{Zu} 1$ und 2: Welche inhaltlichen Aspekte der Auseinandersetzung mit Tod und Sterben lassen sich - ggf. auf einer Zeitleiste als Entwicklungslinien bestimmende Schwerpunkte - nachweisen? Von welchen Todesfällen wird erzählt? Trifft beispielsweise die verbreitete Annahme zu, in Bilderbüchern werde mehrheitlich der Tod von Großeltern betrauert? Welche Rolle spielen Krieg und Gewalt als Todesursachen? Wie hoch ist der Anteil der Bilderbücher über Kindersterben? Welche Bilderbücher konzentrieren sich auf eine philosophische Auseinandersetzung mit Tod und Sterben, ggf. im Kontext von Naturphänomenen? Wie hoch ist der Anteil christlichreligiöser Bilderbücher am Gesamtkorpus? Welche Nachtodtheorien werden angesprochen?

$\mathrm{Zu}$ 3: Wie viele Bilderbücher erzählen von Sterbeprozessen? Wie viele Bilderbücher erzählen von Trauerprozessen? Inwiefern sind die aus der Thanatologie bekannten, verschiedenen Phasen des Sterbens bzw. des Trauerns ausgestaltet und wie zeigen sie sich ggfs. in ihrer zeitlichen Ausdehnung?

$\mathrm{Zu}$ 4: In welchem Umfang und mit welcher Qualität bzw. Authentizität wird die Problematik des Todes und der Trauer im kindlichen Alter aufgegriffen und welche Funktionen sind damit verbunden? In welchem Maße werden Kinderfragen, belastende Aspekte und negative Gefühle zugelassen? Welche Dimensionen eines kognitiven Todeskonzepts sind ausgeprägt? Wie wird die kindliche Perspektive auf den eigenen Tod, der Umgang mit einer eigenen, krankheitsbedingten Todesgewissheit dargestellt? Welche funktionale Bedeutung hat in diesem Zusammenhang insbesondere die Erzählperspektive? In welcher Form ist Emotionalität auf der Bild- und auf der Textebene bzw. aufgrund der wechselseitigen Bezugnahme gestaltet?

$\mathrm{Zu}$ 5: Inwieweit gehen die Bilderbücher auf die besondere, aus der Thanatopsychologie bekannte Problematik kindlicher Trauerprozesse beim Verlust von Geschwistern oder Gleichaltrigen ein? Spielen negative Gefühle wie 
Schuldgefühle, ein minderer Selbstwert oder Isolation aufgrund des elterlichen Trauerverhaltens eine Rolle?

\section{V.2.2 Methodisches Konzept}

Die Untersuchung gliedert sich in zwei Abschnitte. Die Reihenfolge ergibt sich aus dem Anliegen, in der Betrachtung des Gesamtkorpus' einzelne Entwicklungslinien aufzuzeigen und diesen zunächst weiten Blick auf die konkrete Problematik des Sterbens im Kindesalter zu fokussieren. Im ersten Teil (Kap. VI) werden zunächst gattungsspezifische Häufigkeiten des gesamten Korpusmaterials erfasst. Datenerhebung und Analyse bedienen sich der Methoden der quantitativen Inhaltsanalyse ${ }^{106}$, ohne im Detail auf die spezifische Ästhetik der einzelnen Bilderbücher einzugehen. Weiterhin werden inhaltliche Kategorisierungen vorgenommen, deren Besonderheiten an einzelnen Beispielen exemplarisch herausgestellt werden. Im zweiten Teil (Kap. VII) kommt das von der Verfasserin entwickelte narratologische Modell der Bilderbuchanalyse (Kap. III) zur Anwendung. Mittels einer narratologischen Diskursanalyse ${ }^{107}$ werden die spezifischen Dimensionen des Erzählens vom Kindertod aufgefächert, an Einzelanalysen verdeutlicht und es wird der Bogen zu rezeptionsästhetischen Überlegungen gespannt.

Im ersten Abschnitt erfolgt die Kategorisierung der Bilderbücher hinsichtlich ihrer Themen- und Formenvielfalt nach inhaltlichen, ästhetisch-stilistischen und gattungsspezifischen Gesichtspunkten. Obwohl „das dichotomische Modell

106 Die vorliegende Untersuchung lässt die Debatte zur Dichotomie von qualitativ und quantitativ hinter sich und geht davon aus, dass eine „unauflösbare dialektische Wechselbeziehung“ zwischen „qualifizierenden und quantifizierenden Analyseschritten besteht“ (Früh 2007, 140; vgl. auch: ebd., 67ff.; Mayring 2007, 19f.). Die Begründung des notwendigen Ineinandergreifens qualitativer und quantitativer Analyseschritte fußt auf der Überzeugung, dass quantitative Operationen nicht für sich stehen können, sondern „wieder rückgeführt werden müssen an ihren Ausgangspunkt. Sie müssen interpretiert werden, auf die vorausgehende Fragestellung bezogen werden.“ (Mayring 2007, 21) In dem „Phasenmodell zum Verhältnis qualitativer und quantitativer Analyse“ (ebd., 20) steht die qualitative Analyse mit dem Entwurf der Fragestellung, der Begriffs- und Kategorienfindung und dem Analyseinstrumentarium am Anfang. Daran schließt die „Anwendung des Analyseinstrumentariums je nach Gegenstand und Ziel der Analyse unter Zuhilfenahme quantitativer Verfahren“ an; abschließend erfolgt mit der „Interpretation“ der „Rückbezug der Ergebnisse auf die Fragestellung“. (Ebd.).

107 Vgl. dazu: Neumeyer 2010. 
von realistischem und phantastischem Erzählen zu kurz greift“ (Weinkauff/ von Glasenapp 2010, 91) und der Hybridcharakter bei Gattungsfragen immer mitzudenken ist, wird hier dennoch der Versuch unternommen, das gesamte Material dichotom abzubilden, um auf diesem Weg mögliche Konzentrationen sichtbar zu machen. Auf der ersten Stufe wird das erzählende Bilderbuch vom Sachbilderbuch unterschieden, wobei das erzählende Bilderbuch hinsichtlich des Realitätsbezugs entweder ein phantastisches oder realitätsnahes Bilderbuch ist (vgl. Thiele 2011, 222). Dem Sachbilderbuch liegt die „Idee [zugrunde; M.H.], Bild und Lernen miteinander zu verbinden" (Maier 1995, 17), da aber die Übergänge vom Erzählen zum Informieren oftmals fließend sind, lässt sich die Frage der Abgrenzung weder für das Bilderbuch noch allgemein für das Kinder- und Jugendbuch eindeutig klären. Tierbilderbücher werden wegen ihrer spezifischen Gesetzmäßigkeiten gesondert betrachtet und sind wiederum, ihrem Realitätsgehalt entsprechend, den beiden Formen des erzählenden Bilderbuchs zuzurechnen oder auch als Sachbilderbuch zu behandeln. Weitere Subgattungen motiv- bzw. inhaltsbezogener Differenzierungen sind das religiöse Bilderbuch und das philosophische Bilderbuch, deren Hauptmotive in religiösen bzw. existentiell-anthroposophischen Belangen liegen. Daneben werden Teilkorpora der Menschenwelt und Tierwelt bestimmt und nach thematischen Schwerpunkten weiter ausdifferenziert. Auf der formalen Bildebene grenzt sich das Fotobilderbuch vom malerischen oder künstlerischen Bilderbuch ab, ohne damit den Kunstanspruch von Fotos in Abrede stellen zu wollen. ${ }^{108} \mathrm{Zudem}$ finden sich auch seltene Mischformen, die Zeichnungen und Fotos nebeneinander stellen oder collagieren. Im vorliegenden Textkorpus sind diese formalen Varianten, ebenso wie Fotobilderbücher, jedoch nur selten verteten und bleiben analytisch weitgehend unberücksichtigt. ${ }^{109}$ Auf eine Differenzierung „gestalterischer Sondertypen des Bilderbuchs" (Thiele 2002, 237), wie Pop-up-Bilderbücher, Malbücher, Spielbücher, Verwandlungsbilderbücher etc. (vgl. Ries 1992, 46ff.), wird hier aufgrund der Irrelevanz für das ausgewählte Textkorpus verzichtet.

Im Zentrum des zweiten Teils steht die Untersuchung des Subkorpus' der Bilderbücher, in denen kindliches Sterben thematisiert wird. Die narratologische

108 Der Einfachheit halber werden hier alle Bildkonzepte als künstlerische erfasst, die nicht Fotos sind.

109 Gleichwohl dürfte es vor dem Hintergrund bildwissenschaftlicher Fragestellungen durchaus interessant sein, gerade im vorliegenden thematischen Kontext die vermeintlich wahre Abbildung von Wirklichkeit, wie sie Fotografien suggerieren, näher zu untersuchen. Ein lohnenswertes Objekt: Tante Lotti geht in den Himmel (Feile/ Feile 2008). 
Analyse erfolgt unter Einbezug von Anfragen an die narratologischen Dimensionen der Sprach- und Bildebene und folgt dem Ansatz „postklassischer Narratologien“, wie er von Sommer (Sommer 2010, 95; H. i. O.) beschrieben wird:

Die narratologische Analyse ist eine textimmanente Methode zur Untersuchung narrativer Darstellungsverfahren und Erzählstrategien. Alle `Texte`, die eine Geschichte erzählen, lassen sich narratologisch analysieren, also neben Romanen u. a. auch Alltagserzählungen, Comics, Hörspiele oder Filme. Postklassische Narratologien gehen über die Untersuchung textueller Strukturen hinaus und beziehen kognitive und kulturelle Aspekte in die Erzähltextanalyse ein.

Aufgrund seiner „Kontextorientierung“ (Sommer 2010, 96), d. h. unter Einbezug narratologischer, psychologischer, pädagogischer, theologischer und hermeneutischer Aspekte, entspricht das Vorgehen einer narratologischen Diskursanalyse. Es geht darum, auf der Basis des in Kap. III vorgestellten Erzähl-Modells den Umgang mit den Anforderungen, die dieser besonders emotionsbelastete Themenkreis an die formale und inhaltliche Gestaltung stellt, zu untersuchen und mögliche Korrelationen zwischen narratologischen Besonderheiten und der Authentizität ${ }^{110}$ des Erzählten aufzudecken. Über mögliche Zusammenhänge zwischen dem Grad der Authentizität der Darstellungen und ihrer Verwendbarkeit für die Trauerbegleitung betroffener Kinder können dann abschließend nur Vermutungen angestellt werden.

\section{V.2.3 Der thanatologisch-diskursanalytische Ansatz}

Der nachstehende Fragenkatalog versteht sich als Erweiterung des „erzähltextanalytische[n] Werkzeugkasten[s]" (Sommer 2010, 96), hier vorliegend in Gestalt des narratologischen Modells der Bilderbuchanalyse (Kap. III), als thanatologisch-diskursanalytischer Ansatz. Im Rekurs auf die "tool-kit-Metapher" (ebd., 98) werden die Analyse-Werkzeuge den korpusbezogenen Fragestellungen und Gegebenheiten entsprechend angewandt und nur die signifikanten Kategorien bedient.

\section{Erzählerische Vermittlung}

- Ist der Erzähler selbst primär vom Tod betroffen oder ein trauerndes Ich?

- In welcher räumlichen und zeitlichen Distanz zur Geschichte befindet er sich?

- Richtet sich der Erzähler in seiner Rede an den Leser?

110 Unter Authentizität eines Textes ist hier die Stimmigkeit des Ausdrucks fiktionaler Wirklichkeit, orientiert an den Erkenntnissen der Thanatopsychologie (vgl. Kap. IV.1), zu verstehen. 
Todesvorstellungen und Nachtodtheorien

- Welche Vorstellungen vom Tod (Dimensionen des Todeskonzepts) werden vermittelt?

- Orientieren sich die inhaltlichen Konzeptionen an den Erkenntnissen der Entwicklungspsychologie hinsichtlich kindlicher Todeskonzepte und Trauerprozesse bzw. wie nah steht das Vermittelte der unterstellten kognitiven Konstitution der kindlichen Adressaten?

- Werden Vorstellungen vom Danach verbalisiert und/oder bildhaft dargestellt?

- Sind sie als Konkretisierungen fragwürdiger Behauptungen einer physischen Verwandlung oder Rückkehr von Verstorbenen angelegt, die unerfüllbare Hoffnungen oder beunruhigende Erwartungen wecken können?

Umgang mit Zeit und Dramaturgie der Handlungselemente

- Beginnt das Erzählte mit einem Todesereignis oder läuft es darauf zu?

- Stehen das Sterben oder das Trauern im Mittelpunkt?

- Werden erzählerische Mittel, wie z. B. Prolepse und Analepse, im Dienste der Darstellung einer gelingenden Verarbeitung von Trauer verwendet?

Figuren

- Wer stirbt, wo und woran?

- Wer trauert?

- In welcher physisch-psychischen Konstitution befindet sich der kindliche Protagonist?

- Wie authentisch ist die Darstellung im Hinblick auf die thanatopsychologisch begründeten Konstitutionen von trauernden oder sterbenden Kindern?

- In welcher Beziehung stehen die kindliche Figur und der Sterbende zueinander?

- Werden negative Gefühle oder Schuldgefühle bei Beziehungsverlust thematisiert?

- Inwieweit wird ggfs. auf die besondere Problematik eines Geschwisterverlusts eingegangen?

- Welche Emotionen prägen die Haltung des Trauernden und/ oder des Sterbenden zum Tod?

- Wie verhalten sich progressiv erkrankte Protagonisten zum Tod?

- Spielen Kinderängste oder die Todesfurcht Sterbender eine Rolle?

- Werden Einstellungen zu Sterben und Tod verbal und/ oder visuell expliziert? 
Kommunikationsstrukturen

- Wie wird über den Tod kommuniziert? Ist das Sprechen vom Tod offen und direkt oder werden Euphemismen und Verklausulierungen gebraucht?

- Welcher Raum wird existenziellen kindlichen Fragen eingeräumt: Sind Kinderfragen in einen dialogischen Austausch eingebettet und mit welcher Offenheit bzw. Ernsthaftigkeit gehen die beteiligten erwachsenen Bezugspersonen damit um?

- Spielt das Problem der Verheimlichung eine Rolle? Werden Wahrheiten über den (ggfs. bevorstehenden) Tod den Kindern vorenthalten?

- In welchem Maße und in welcher Form nimmt das Kommunikationsverhalten des sozialen Umfeldes Einfluss auf den Verlauf von kindlichen Trauerprozessen?

- Welche Schlussfolgerungen lassen sich aus thanatologischer/ kulturwissenschaftlicher Perspektive aus einer Gesprächsbereitschaft oder -verweigerung ziehen?

Trauerprozesse und Bewältigungsstrategien

- In welchem zeitlichen Rahmen und in welchen Phasen vollzieht sich der Trauerprozess?

- Welchen Einfluss hat das familiäre Umfeld auf die Bewältigung von Trauer?

- Welche Trosthilfen ergeben sich aus anderen Beziehungsstrukturen?

- Welche weiteren Konsolationsdeterminanten, z. B. religiöse Trostbilder, Symbolsprache oder Erinnerungsbilder, helfen bei der psychischen Verarbeitung des Verlusts?

- Welche Bedeutung hat Religiosität für den psychischen Bewältigungsprozess?

- Wenn Überzeugungen von nachtodlicher Existenz bzw. religiös-konfessionelle Überzeugungen eine Rolle spielen: Sind sie ein optionales Angebot? Wirken sie belehrend oder gar dogmatisch?

- Wird eine mit dem Beziehungsverlust ggf. verbundene Bedrohung der Lebensumstände des Kindes thematisiert (Verwaisung) und wird eine Lösung angeboten?

- Wird auf die besondere Problematik der Geschwistertrauer eingegangen?

Traditionen und Rituale

- Sind Traditionen und Rituale von Bedeutung? Welche?

- Inwieweit werden Kinder in rituelle Gepflogenheiten einbezogen oder davon ausgeschlossen? 
- Wird ein Abschied vom Sterbenden oder Verstorbenen (Aufbahrung) ermöglicht?

Bildästhetik des Todes und der Trauer

- Wird das Sterben ins Bild gesetzt? Wenn ja, wie (Abbildung des Sterbenden, der Zeichen körperlichen Verfalls)?

- Tritt der Tod als Personifikation auf?

- Sind Imaginationen nachtodlicher Zustände visualisiert?

- Inwieweit bildet die bildästhetische Gestaltung den kindlichen Blick, das kindliche Verständnis ab?

- Wo sind Leerstellen angelegt?

- Welche Symbole und Metaphern (ikonographische und sprachliche) sind auf der Bildebene identifizierbar?

- Werden Stimmungen und Gemütszustände über Bildarrangements, Perspektiven, Lichtverhältnisse oder Farben dargestellt?

- Erhält Emotionalität Ausdruck in der Körpersprache (Mimik und Gestik) der Figuren?

Inszenierung von Verbaltext und Bildtext

- Inwieweit ergänzen sich Verbal- und Bildtext hinsichtlich der Darstellung emotionaler Konstitutionen und Prozesse einer Figur oder Motivik (Parallelität o. a., Korrelationen von Wortwahl und Mimik, Gestik, Körperhaltung, Fehlen von Korrelationen)?

- Wie wird einem vom Verbaltext geweckten Bedürfnis nach Anschauung genüge getan?

Rezeptions- und wirkungsästhetische Fragen - Gesamtbeurteilung

- Welchen Adressatenkreis spricht das Bilderbuch implizit oder explizit an: Trauernde, Sterbende, Trauerbegleiter, Erwachsene, Kinder?

- Wie viel Tod wird dem rezipierenden Kind zugemutet, d. h., welche Nähe zu den Geschehnissen und Ritualen im Zusammenhang mit Sterbeprozessen und Trauerbewältigung wird ermöglicht?

- Ist die Darstellung von Emotionalität auf Plausibilität und Authentizität und ihre Wirkung damit auf Identifikation angelegt (Nähe zur kindlichen Lebenswelt; Berücksichtigung von Erkenntnissen aus der Psychologie)?

- Welches Kindheitsbild wird darüber ausgedrückt?

- Ist dem Erzählkonzept ein offensichtlich pädagogisch-didaktisches Anliegen inhärent? 
- Fordert das Erzählte dazu auf, Einstellungen zu überdenken und ggf. zu verändern?

- Sind Leerstellen zur Entwicklung eigener Vorstellungen vorhanden?

- Wird zur Annahme einer einzigen Lösung aufgefordert?

- Welcher Gesamteindruck ist entstanden? Wird eine positive, optimistische Grundhaltung vermittelt? Ist eine entlastende, tröstende Rezeptionswirkung zu erwarten?

- Welche Fragen und Probleme bleiben offen bzw. unbesprochen?

- Welchen Beitrag kann das Bilderbuch zur Entwicklung eines reifen resp. altersgemäßen Todeskonzeptes leisten?

- Wie ist insgesamt die Tauglichkeit des Bilderbuchs als begleitendes Medium in Trauerprozessen einzuschätzen?

Die Realisierung dieser Forschungskonzeption hat zu den nachfolgend dargestellten Ergebnissen geführt. 


\section{Auswertungen}

Von den insgesamt 287 recherchierten deutschsprachigen, in der Deutschen Nationalbibliothek verzeichneten Bilderbüchern entfallen auf die Jahre bis 1971 lediglich zehn Titel (davon vier in 1971), die als erste zaghafte Bearbeitungen des Themas fast ausnahmslos entweder in der Natur- oder Tierwelt angesiedelt waren oder phantastische Grenzen überschritten. Und auch auf die realistische Wende um 1970 hat das Bilderbuch zum Tod erst mit zeitlicher Verzögerung reagiert (Abb. 4). 1972 und 1973 blieb das Thema gänzlich unberücksichtigt und war dann ab 1974 zunächst noch marginal, oft mit nur einem Titel jährlich vertreten. Erst das Jahr 1984 markiert mit insgesamt sechs Bilderbüchern den Beginn einer kontinuierlich zunehmenden thematischen Bearbeitung, die 1995 erstmals, ab 2001 regelmäßig jährlich eine zweistellige Anzahl aufweist. ${ }^{111}$

Abb. 4: Anzahl aller recherchierten Bilderbücher in Abhängigkeit vom Jahr der deutschen Erstveröffentlichung.

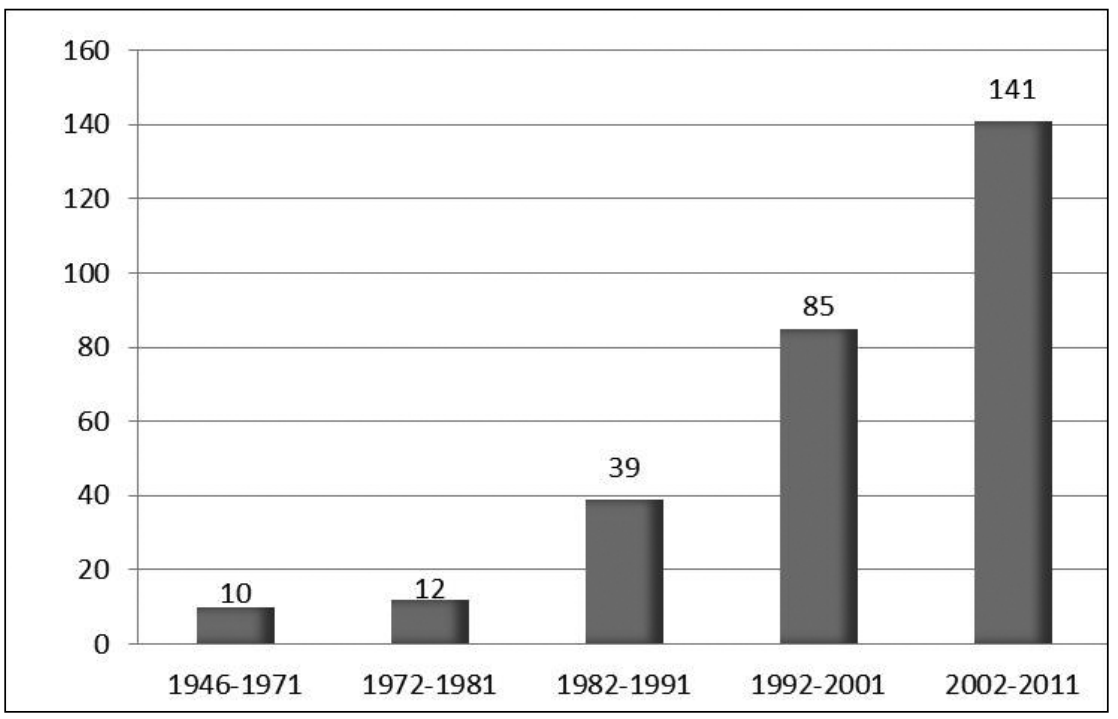

111 Die tabellarische Übersicht im Anhang (X.2) macht explizite Angaben zur quantitativen, gattungs- und inhaltsbezogenen Kategorisierung des Gesamtkorpus' in Abhängigkeit vom Jahr der dt. Erstveröffentlichung. 
Seit der Jahrtausendwende boomt das Thema und erreichte 2010 mit 18 Titeln und einem breit aufgestellten motivischen Spektrum, 2011 mit noch 17 Veröffentlichungen, seinen vorläufigen Höhepunkt, möglicherweise auch Scheitelpunkt, was aber die folgenden Jahre erst zeigen werden. ${ }^{112}$ Ein weiteres Indiz für die erhöhte Präsenz des Themas sind die Nominierungs- und Preisträgerlisten des Deutschen Jugendliteraturpreises in allen Sparten, wobei seit 2000 in kaum einem Jahr ein Bilderbuch zum Thema Tod fehlt. Insgesamt wurden seit Swimmy von Leo Lionni (1964) 26 Bilderbücher ${ }^{113}$ nominiert (acht Preisträger), die teilweise bis heute in mehrfachen Auflagen vorliegen und Klassikerstatus erlangten. Dem vergleichsweise kleinen Korpus von Bilderbüchern zum Thema Tod ist damit angesichts des quantitativ wie thematisch stetig ansteigenden Gesamt-Jahresaufkommens an Papierausgaben von Bilderbüchern - mit geringen Schwankungen zwischen 2000 und 2011 von 728 auf 1481 Papierausgaben $^{114}-$ große Aufmerksamkeit zuteil geworden, was auch für die literarästhetische Qualität der Bearbeitungen spricht.

Das untersuchte Textmaterial umfasst 140 deutsche Originalausgaben, 36 Erstveröffentlichungen aus dem deutschsprachigen Ausland und 111 Übersetzungen aus dem fremdsprachigen Ausland (Abb. 5). Ergänzend kann ebenso wie für den Gesamtzeitraum konstatiert werden, dass das Aufkommen pro Jahr in etwa gleiche Anteile von ausländischen und genuin deutschsprachigen Bilderbüchern umfasst.

112 Stand 31.05.2014: Die Deutsche Nationalbibliothek listet für 2012 und 2013 insgesamt kaum 20 entsprechend beschlagwortete Erstauflagen.

113 Fettdruck = Preisträger: Lunde/ Torseter 2010; Schins/ Mueller 2008; Duda/ Friese 2007; Erlbruch 2007; Schulz/ Krejtschi 2007; Nilsson/ Eriksson 2006; Janisch/ Blau 2005; Schössow 2005; Verroen/ Erlbruch 2003; Bauer 2001; Stalfelt 2000; Waechter 1998; Fried/ Gleich 1997; Stark/ Höglund 1997; Lemieux 1996; Tejima 1996; Geelen 1993; Heymans/ Heymans 1993; Dros/ Geelen 1992; Tidholm/ Tidholm 1990; Kaldhol/ Øyen 1987; Burningham/ Korschunow 1984; Becker/ Niggemeyer 1979; Gydal/ Danielsson/ Andersson 1974; Carle 1971; Lionni 1964.

114 Das von der Deutschen Nationalbibliothek in Frankfurt ermittelte Zahlenmaterial wurde der Verfasserin auf Anfrage im März 2014 zur Verfügung gestellt. 
Abb. 5: Die deutschsprachigen Erstveröffentlichungen und Übersetzungen nach Herkunftsländern.

\begin{tabular}{|lr|}
\hline Anzahl der Erstveröffentlichungen und Übersetzungen nach Herkunftsländern & \\
\hline Deutschsprachiges Europa & $\mathbf{1 7 6}$ \\
\hline Deutschland & 140 \\
\hline Schweiz & 25 \\
\hline Österreich & 11 \\
\hline Fremdsprachiges Europa & $\mathbf{8 0}$ \\
\hline Großbritannien & 24 \\
\hline Skandinavische Länder: & 23 \\
\hline - Schweden & 11 \\
\hline - Norwegen & 7 \\
\hline - Dänemark & 4 \\
\hline - Finnland & 1 \\
\hline Niederlande & 16 \\
\hline Frankreich & 13 \\
\hline Belgien & 3 \\
\hline Spanien & 1 \\
\hline Außereuropäisches Ausland & $\mathbf{3 1}$ \\
\hline USA & 20 \\
\hline Australien & 4 \\
\hline Japan & 5 \\
\hline Korea & 1 \\
\hline Russland & 2 \\
\hline
\end{tabular}

Hervorzuheben ist, dass die Bilderbücher aus der Schweiz, Großbritannien und den skandinavischen Ländern zahlenmäßig am stärksten vertreten sind. Auch hier kommt, wie so oft, „der skandinavischen Kinderliteratur eine Vorreiterrolle zu" (Daubert 2011,91), die vor allem die Kategorie der menschlichen Trauerfälle betrifft. ${ }^{115}$ Eine Beschränkung auf das Ursprungsland Deutschland brächte vermutlich andere Untersuchungsergebnisse hervor, widerspräche aber dem Anliegen, das insgesamt auf dem deutschen Markt verfügbare Bilderbuchangebot

115 S. dazu Kap. VI.2 und VII.1. 
zum Thema Tod zu erfassen. Eine Unterscheidung nach Herkunftsländern wird hier insgesamt und ebenso für das Teilkorpus zum Kindersterben (Kap. VII, Abb. 32) lediglich quantitativ vorgenommen. Auf internationale Vergleiche bzw. eine Untersuchung von Einflüssen wurde verzichtet.

Mit Bezug auf die ersten drei der eingangs aufgestellten Forschungshypothesen werden im Folgenden zunächst gattungsspezifische Differenzierungen vorgenommen, bevor einzelne Inhaltskategorien aufgefächert und anhand von Beispielen beschrieben werden. Eine Zusammenfassung der Ergebnisse gibt abschließend Antworten auf die vorausgegangenen Forschungsfragen.

\section{VI.1 Gattungsspezifische Differenzierungen}

Die Verteilung des untersuchten Bilderbuchmaterials von insgesamt 287 Bilderbüchern auf die Subgattungen der erzählenden Bilderbücher, inklusive der Tierbilderbücher, märchenhaften Bilderbücher und Sachbilderbücher (Abb. 6a) zeigt ein relativ ausgewogenes Verhältnis von realistischen und phantastischen Werken, wenn jeweils weit gefasste Begriffsexplikationen zugrunde gelegt werden.

Abb. 6a: Gattungsspezifische Differenzierung des Gesamtkorpus' in Prozent (N=287).

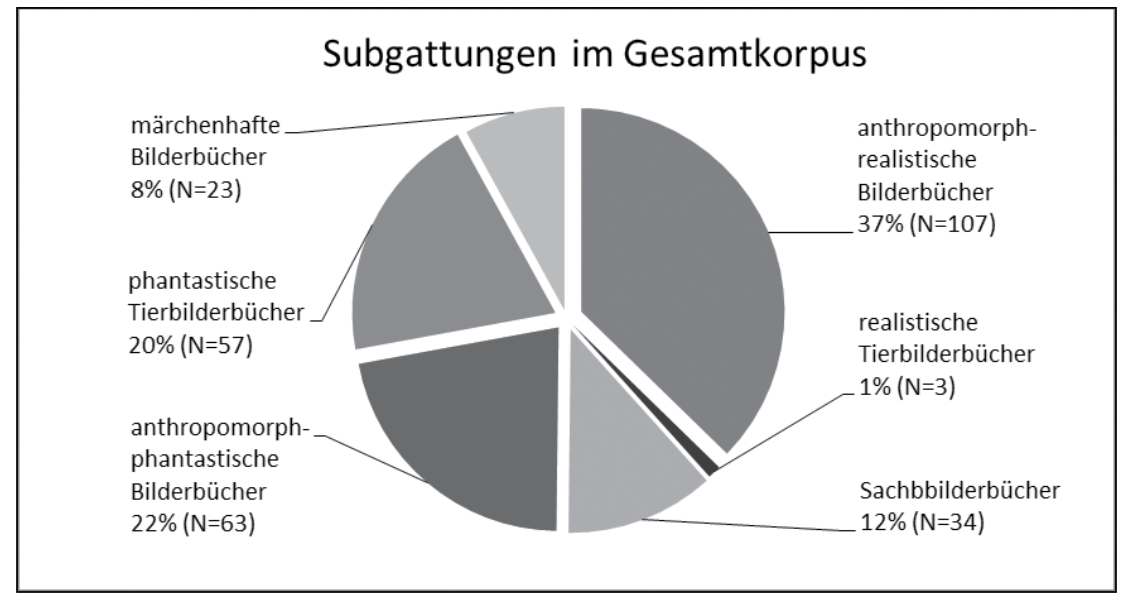


Abb. 6b: Verteilung der Subgattungen im Gesamtkorpus in Abhängigkeit vom Erscheinungsdatum.

\begin{tabular}{|c|c|c|c|c|c|c|c|}
\hline \multirow[b]{3}{*}{ Zeitraum } & \multirow[b]{3}{*}{$\begin{array}{c}\text { Gesamt- } \\
\text { korpus }\end{array}$} & \multicolumn{6}{|c|}{ Subgattungen } \\
\hline & & \multicolumn{3}{|c|}{ Realistisch } & \multicolumn{3}{|c|}{ Phantastisch } \\
\hline & & $\begin{array}{c}\text { Anthro- } \\
\text { pomorph- } \\
\text { realisti- } \\
\text { sches } \\
\text { Bilder- } \\
\text { buch }\end{array}$ & $\begin{array}{l}\text { Realis- } \\
\text { tisches } \\
\text { Tierbil- } \\
\text { derbuch }\end{array}$ & $\begin{array}{l}\text { Sachbil- } \\
\text { derbuch }\end{array}$ & $\begin{array}{c}\text { Anthro- } \\
\text { pomorph- } \\
\text { phantasti- } \\
\text { sches } \\
\text { Bilder- } \\
\text { buch }\end{array}$ & $\begin{array}{c}\text { Phantasti- } \\
\text { sches } \\
\text { Tierbil- } \\
\text { derbuch }\end{array}$ & $\begin{array}{c}\text { Märchen- } \\
\text { haftes } \\
\text { Bilder- } \\
\text { buch }\end{array}$ \\
\hline $\begin{array}{l}1946- \\
1971\end{array}$ & 10 & 1 & - & 3 & - & 3 & 2 \\
\hline $\begin{array}{l}1972- \\
1981\end{array}$ & 12 & 5 & - & 4 & 2 & - & 3 \\
\hline $\begin{array}{l}1982- \\
1991\end{array}$ & 39 & 10 & - & 9 & 10 & 5 & 5 \\
\hline $\begin{array}{l}1992- \\
2001\end{array}$ & 85 & 34 & 1 & 8 & 17 & 21 & 3 \\
\hline $\begin{array}{l}2002- \\
2011\end{array}$ & 141 & 57 & 2 & 10 & 34 & 28 & 10 \\
\hline Gesamt & 287 & 107 & 3 & 34 & 63 & 57 & 23 \\
\hline
\end{tabular}

Auf der Figurenebene werden die realistisch bzw. phantastisch erzählenden Bilderbücher nach ihren anthropomorphen und tierischen Protagonisten unterschieden (Abb. 6a u. 6b), auch wenn für das Tierbilderbuch ${ }^{116}$ darüber hinaus die Gattungsspezifika längst nicht eindeutig definiert sind. Die Differenzierung hinsichtlich der Handlungsebenen und ihrer Protagonisten ist im gegebenen thematischen Kontext besonders deshalb bedeutsam, weil das Reflektieren über Sterben, Tod und Trauer eine genuin menschliche Angelegenheit ist. Dementsprechend dominiert das anthropomorph-realistisch erzählende Bilderbuch, während das realistische Tierbilderbuch mit nur drei Exemplaren vertreten ist. Das einschlägige Bilderbuch zeigt sich demnach weniger als „bevorzugte Domäne" für "Tiererzählungen“" (Haas 2003, 127) als allgemein angenommen, denn auch in der Kategorie der phantastisch erzählenden Bilderbücher (42\%, excl. märchenhaftes Erzählen) stellt das Tierbilderbuch weniger als die Hälfte der recherchierten Titel (Abb. 6a u. 6b).

116 S. dazu Kap. VI.1.3. 


\section{VI.1.1 Das anthropomorph-realistische Bilderbuch}

Der dieser Subgattung zugrunde gelegte Realitätsbegriff meint „eine Darstellungsweise, welche die Welt ohne idealistische oder phantastische Überhöhungen zeigen möchte, nämlich so, wie sie ist.“ Literatur ,ist nicht selbst Wirklichkeit, sondern ästhetisch gestaltete Wirklichkeit", die sich in der KJL durch eine Nähe zur erfahrbaren sozialen und umweltbezogenen Lebenswirklichkeit von Kindern und Jugendlichen auszeichnet. (Payrhuber 2011, 106)

Mit 37\% $(\mathrm{N}=107)^{117}$ ist das in der Menschenwelt verortete realistische Bilderbuch das größte Teilkorpus, in dem den Figuren durchaus irreale Glaubensbzw. Jenseitsvorstellungen in den Mund gelegt sein können, ohne jedoch auf der Handlungs- oder Darstellungsebene eine Grenze zum Phantastischen zu überschreiten. Das realistische Erzählen von Tod, Sterben und Trauer ist an die kindliche Lebenswirklichkeit angelehnt und erstreckt sich mit je unterschiedlich ausgeprägter Direktheit auf die Darstellung von Sterbe- und Trauerprozessen, thematisiert Dimensionen eines reifen Todeskonzeptes und Aspekte einer Trauerkultur. Inhaltliche Kategorien dieses Teilkorpus' sind in nennenswertem Umfang mit 50\% die religiösen Bilderbücher, zu zwei Dritteln christlich-konnotiert, 35 Sterbefälle von Großeltern, 19 Texte zu kindlichem Sterben ${ }^{118}$, acht Verluste von Vätern und drei Verluste von Müttern, wobei im einzelnen Bilderbuch mehr als eine Kategorie angesprochen sein kann.

Das realistische Textkorpus zeigt ein ausgewogenes Verhältnis von religiösen Bilderbüchern (bis 1994 mit zwei Titeln noch eine marginale Erscheinung) ${ }^{119}$ und säkularisierten Bilderbüchern, die eine fatalistische Sicht auf das Leben vertreten, ohne jegliche Andeutungen einer Hoffnung auf Transzendenz. Wenn nicht der Glaube an eine christliche oder transzendental-religiöse Dimension Trost spendet, hält aber doch meist eine Kultur des Erinnerns und Festhaltens an Erinnerungsstücken die Beziehung zum Verstorbenen aufrecht und spendet Trost $^{120}$. Auch die religiösen Bilderbücher bleiben selten ohne Hinweise auf eine Erinnerungspraxis ${ }^{121}$. In nur wenigen Bilderbüchern, die weltliche Perspektiven einnehmen, steht nicht einmal die Möglichkeit der Erinnerung als Trauerpraxis zur Disposition ${ }^{122}$.

117 S. Abb. 6a u. 6b sowie die tabellarische Übersicht im Anhang (X.2).

118 Vgl. Kap. VII.

119 Tsurumi/ Suzuki 1984; Nystrom/ Large 1991.

120 z. B.: Carnavas 2011; Fortier/ Legendre 2008; Barth/ Wünsch 2003.

121 z. B.: Schneider/ Gotzen-Beek 2010; Stellmacher/ Lieffering 2005; Fried/ Gleich 1997.

122 Lunde/ Torseter 2010; Kaufmann 1999. 
Das realistische Erzählgeschehen in anthropomorphen Zusammenhängen wird von jeweils ca. der Hälfte aller Trauerprozesse und Sterbeprozesse ${ }^{123}$ bestimmt. Bemerkenswert ist dabei, dass sich davon wiederum jeweils etwa die Hälfte durch ein ausgeprägtes Kommunikationsverhalten zwischen Kindern und Erwachsenen auszeichnet. Insgesamt ist in den realistischen Bilderbüchern eine im Vergleich zum übrigen Gattungsspektrum deutlich erhöhte Bereitschaft auszumachen, mit Kinderfragen ernsthaft umzugehen und nach Antworten zu suchen. ${ }^{124}$ Ebenso ist die Anzahl der im realistischen Teilkorpus aus der kindlichen Ich-Perspektive erzählenden autodiegetischen Erzähler (21 von 39 autodiegtischen Erzählern) zu deuten, auch wenn dort auf der Inhaltsebene nur zu einem Drittel kommunikative Interaktionen eine Rolle spielen. Allein die Tatsache, dass kindliche Protagonisten selbst zu Wort kommen und ihre Wahrnehmungs- und Denkmuster das Erzählkonzept bestimmen, weist auf das seit den 1970er-Jahren veränderte, emanzipatorische Kindheitsbild hin (hier zuerst: Burningham/ Korschunow 1984). Nur selten wird die Universalität des Todes direkt angesprochen (9 von $14 \mathrm{Mal}$ im Gesamtkorpus) ${ }^{125}$, und dann meist verbunden mit religiös begründeten Aussichten auf ein neues Sein nach dem Tod. Beispielsweise in Erzähl mir vom Himmel (Godfrey/ Corke 2011) ${ }^{126}$, in dem ein Großvater das Werden und Vergehen in seinem Garten mit der christlichen Glaubenslehre verknüpft und seiner Enkelin erklärt:

„Alles was lebt, muss irgendwann auch sterben“, sagte Opa. „Wir finden das traurig. Aber der Tod ist ein neuer Anfang, so, als wenn man nach einem langen Schlaf aufwacht. Gott liebt uns so sehr, daß er uns für immer bei sich haben möchte, auch wenn unser Körper keine Kraft mehr hat zu leben. " [...] „Dort, bei Gott, ist alles neu und ganz anders als hier", sagte Opa. „Wir nennen das den Himmel. Jeder, der Gott liebt, kann dort bei ihm leben, wenn er gestorben ist."

123 Mit Trauerprozessen und Sterbeprozessen sind zeitliche Ausdehnungen der Geschehensmomente gemeint, nicht lediglich das Auftreten eines Ereignisses (s. dazu Kap. VI.2.5).

124 Wie authentisch die kindlichen Fragen sind, oder ob sie mehr von Erwachsenen her gedacht sind, muss am Einzelfall überprüft und zudem mit entwicklungspsychologischen Erkenntnissen abgeglichen werden.

125 Godfrey/ Corke 2011; Rohner/ Wünsch 2011; Langen/ Bohnstedt 2008; Nilsson/ Eriksson 2006; Cole 1997; Fried/ Gleich 1996; Godfrey/ Cope 1996; Wolf/ Duroussy 1992; Egger/ Jucker 1986.

126 Neuauflage mit verändertem Design und neuem Titel von: Godfrey, Jan; Cope, Jane (1996): Opas Kirschbaum. Die mit Wasserfarben colorierten, realistischen Abbildungen der Ausgabe von 1996 wurden ersetzt durch leuchtende Farben und verniedlichtstilisierte Formen (Gouache-Technik). 
Ein Bilderbuch, das diese Eindeutigkeit einer christlichen Einstellung umgeht, indem zahlreiche Fragen zwar vage, aber ehrlich beantwortet werden und dennoch zu einem Glauben an eine christlich konnotierte, transzendente Dimension Anlass gegeben wird, ist Hat Opa einen Anzug an? (Fried/ Gleich 1996). Dieses Bilderbuch, dessen literarische Ästhetik im Zusammenspiel von Sprach- und Bildebene von herausragender Qualität ist, greift ein breites Spektrum dessen auf, was Kindern im Zusammenhang mit dem Tod (nicht nur) im gutbürgerlichchristlichen, dörflichen Milieu begegnet, was sie bewegt und was sie verstehen wollen und wie es ihnen gelingen kann, den Verlust eines geliebten Menschen zu verwinden. Der kindliche Protagonist Bruno besteht auf der Teilnahme an der Beerdigung des Großvaters, er erlebt das Aufbahren und die Begräbnisrituale, das unverständliche Verhalten der Erwachsenen und ihre unklaren Antworten auf seine Fragen: „Wo ist der Opa jetzt?", „Was ist die Seele?", „Ist die Seele das, was ich am Opa lieb habe?" „Wie viele Seelen passen in den Himmel?" „Wann muss ich sterben?". Manches erklärt er sich selbst, durchleidet alle Phasen der Trauer und kommt schließlich zu der Erkenntnis: [W]enn Opa glücklich war dort, wo er jetzt war, dann durfte auch er, Bruno, wieder ein kleines bisschen glücklich sein. (Fried/ Gleich 1996) Das äußere Erscheinungsbild des Buches wirkt durch die düstere Farbwahl zunächst nicht einladend, denn in den durchgängig in Sepia-Braun gehaltenen Bildern treten nur Brunos rote Kleidung und Haare optisch hervor, doch die eindringliche Erzählkraft der Bilder liegt in den perspektivischen Verzerrungen und außergewöhnlichen Größenverhältnissen, die die ,Schräglage der kindlichen Psyche im wörtlichen Sinne sichtbar machen. Der visuelle Erzähler spiegelt damit die personale Erzählsituation der Sprachebene und erweitert sie gleichzeitig, indem er sich Brunos Wahrnehmung der Umwelt zu eigen macht, wie beispielsweise schon auf dem Titelbild (Abb. 7) zu sehen.

Abb. 7: Amelie Fried; Jacky Gleich (1997): Hat Opa einen Anzug an? München, Wien: Hanser.

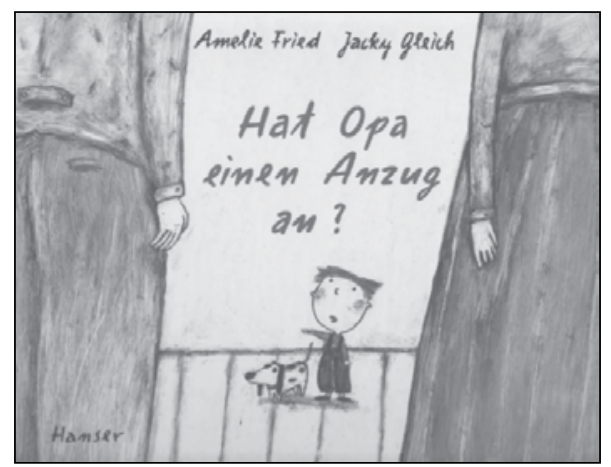


Obwohl der Blick auf Bruno gerichtet ist, entspricht die Perspektive hinsichtlich der Größenverhältnisse zwischen dem Jungen und seinen überdimensional großen Eltern der Untersicht des Kindes. An diesem Bilderbuch lässt sich beispielhaft die Funktion formal-stilistischer Bildgestaltung für das Erzählganze nachweisen, dessen zentrales Motiv hier die psychischen Dimensionen der Trauerverarbeitung eines Kindes sind.

Ein ganz anderes Anliegen als den oben aufgeführten Texten scheint der Geschichte von Jonas und Oma (Meinderts/ Fienieg 2007) zugrunde zu liegen, in der sich alles um Lebenswege dreht. Von der Geburt, vom ersten Verlieben über das Elternwerden bis zum Tod wiederholt sich alles Geschehen über drei Generationen in den männlichen Nachkommen, bis hin zu physiognomischen Ähnlichkeiten und der Weitergabe des Vornamens. Das fehlende Eingehen auf die in der Vergangenheit liegenden Todesfälle und die Darstellung des stillen, hinnehmenden Lebens und Sterbens (angedeuteter Suizid) der dementen, vom letzten Namensträger Jonas betreuten Großmutter weisen mehr auf eine erwachsene Wunschvorstellung von einem erfüllten und an seinem Ende nicht einsamen Leben hin, als dass Kindern dieses Szenario eine Verständnishilfe für ihre Fragen zu Sterben und Tod sein könnte.

Neue Töne des realistischen Erzählens vom Lebensende schlägt dagegen das Bilderbuch Wie Großvater schwimmen lernte (Rohner/ Wünsch 2011) an.

Abb. 8: Viola Rohner; Dorota Wünsch (2011): Wie Großvater schwimmen lernte. Wuppertal: Hammer.

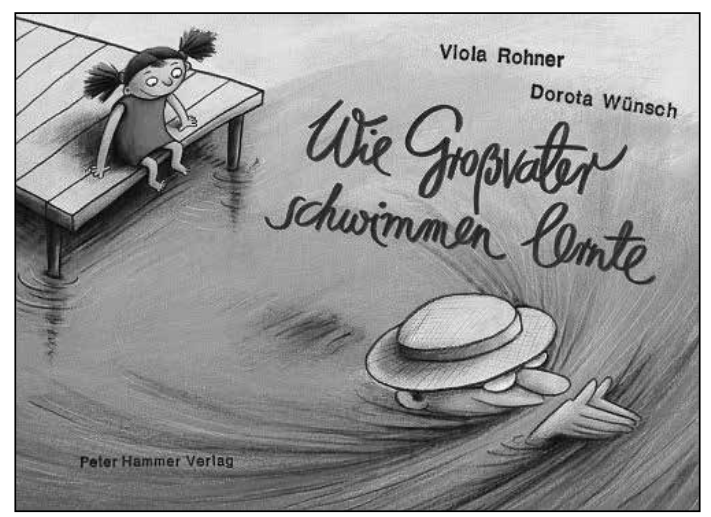

Dies ist ein Buch, das Lebensfreude spiegelt (Abb. 8), trotz oder vielleicht wegen des aus Altersgründen erwarteten Lebensendes. In dem proklamierten Bewusstsein, jede Unternehmung mit der Enkelin könnte für ihn das letzte Mal sein, 
macht der Großvater mit ihr Ausflüge und besucht auch ganz selbstverständlich eine Beerdigung. Schließlich schlägt die Kleine vor, schwimmen zu gehen, womit sie dem Großvater, da er nicht schwimmen kann, ein erstes, aber ganz offensichtlich nicht letztes Mal beschert, denn er findet Freude daran. Unter dem Motto ,Lebe jeden Tag, als sei er der letzte' können sich sicher täglich neue Perspektiven auf das Leben eröffnen, es kann auch dem Blick auf das Lebensende, frei nach Hermann Hesse, noch ein neuer irdischer Anfang innewohnen. $\mathrm{Ob}$ sich aber kindliche Leser damit dentifizieren können, sei dahingestellt. In jedem Fall bleibt nach dem offenen Ende dieses Bilderbuchs, da der Großvater schließlich so weit in den See hinaus schwamm [...], bis ihn das kleine Mädchen vom Ufer aus gar nicht mehr sah, die Frage ungeklärt, wohin er entschwunden sein kann, wenn dieses Schwimmen ein letztes war. Eine erwachsene Lesebegleitung ist da unbedingt wünschenswert, denn hier wird, wie auch in der Geschichte von Jonas und Oma (Meinderts/ Fienieg 2007), die Möglichkeit des selbst verantworteten Lebensendes angedeutet.

Die genannten Beispiele zeigen nur einige wenige inhaltliche Facetten des realistischen Erzählens vom Tod auf ${ }^{127}$ und belegen, da sie im Kapitel VI.2 ff. teilweise auch wieder aufgegriffen werden, dass thematische Interferenzen eine Trennschärfe ausschließen und die Kategorien sich entsprechend durchmischen. Auch das Folgende bildet die Vielfalt der Erzählvarianten nur exemplarisch ab.

\section{VI.1.2 Das anthropomorph-phantastische Bilderbuch}

„Mit Blick auf die kindliche Weltsicht vermischen sich im erzählenden Bilderbuch realitätsbezogene und fantastische Ebenen auffallend häufig“ (Thiele 2011, 222). Diese Feststellung erstaunt nicht angesichts der Kenntnis darüber,

dass Fantasmen von unsichtbaren Gefährten, Gestaltwandlungen oder nichtmimetischen Wesen in der Entwicklung des Menschen sowohl phylo- als auch ontogenetisch (also in der Entwicklung der Menschheit und des Kindes) sehr früh auftreten und einen anthropologischen Nährboden für die Literarische Fantastik bilden (Abraham 2012, 64; H. i. O.).

Als Beleg dafür scheint das vorliegende Textmaterial geradezu prädestiniert, denn alle Vorstellungen und Überlegungen zum unbeweisbaren Möglichen nach dem Tod können nichts anderes als Phantasmen sein und kommen im Bilderbuch gleichzeitig der Vorliebe von Kindern für Magisches entgegen. Da aber der Begriff der Phantastik nicht eindeutig konturiert und „seit der Einführung von

127 Realistische Bilderbücher, in denen der Tod von Haustieren eine Rolle spielt, werden im Kap. VI.2.4.5 mit erfasst. 
Tzvetan Todorov notorisch strittig ist" (Abraham 2012, 64), konzentriert sich das literaturwissenschaftliche Anliegen hier auf die Abgrenzung des phantastischen Bilderbuchs vom realistischen und märchenhaften Bilderbuch in quantitativen Kategorien. ${ }^{128}$ Dass dieses Teilkorpus sehr viel weniger umfangreich ist als das der realistisch erzählenden Bilderbücher, ist möglicherweise darauf zurückzuführen, dass es ein gewagtes Unterfangen ist, irrationale Vorstellungen eines jenseitigen Zustands zu visualisieren, weil mit der Konkretisierung auch immer die Gefahr einer Verklärung oder unzulässigen Vortäuschung von Tatsachen einhergehen kann, wie noch gezeigt werden wird.

Im Zusammenhang mit den Vorstellungen von einer nachtodlichen Existenz ist immer dann von einem phantastischen Bilderbuch die Rede, wenn das Erzählte die Grenze der empirisch erfahrbaren Wirklichkeit überschreitet und eine weitere Handlungsebene eröffnet. Dem liegt der strukturalistische Phantastikbegriff des „Zwei-Welten-Modells“ von Maria Nikolajeva (1988) zugrunde. Wesentliches Charakteristikum phantastischen Erzählens ist demnach das Vorhandensein einer primären, realistischen Welt und einer sekundären, magischen Welt, deren unterschiedliches Verhältnis zueinander drei Formen bildet: die offene sekundäre Welt, die implizite sekundäre Welt und die geschlossene sekundäre Welt (vgl.: Tabbert 2006, 119; Rank 2011, 171f.; Haas 2005, 121). Primäre und sekundäre Welt existieren entweder nebeneinander, durch eine Grenzlinie eindeutig voneinander getrennt, oder phantastische Elemente sind in die primäre Welt eingebettet und z. B. am Auftreten einer Figur oder eines Gegenstandes festzumachen. Außerdem kann das Geschehen gänzlich außerhalb einer (nach gültigem Wirklichkeitsmodell) real möglichen, vernunftorientierten Gestaltung von Wirklichkeit stattfinden (vgl. ebd.). Daraus ergeben sich im stofflich-motivischen Kontext des Sterbens drei Subkategorien des phantastischen Bilderbuchs:

1. Das geschlossen-phantastische Bilderbuch: Das gesamte Geschehen vollzieht sich in phantastischen Erlebniswelten im Sinne irrealer, empirisch nicht erfahrbarer Wirklichkeitsentwürfe.

2. Das offen-phantastische Bilderbuch: Der Tod markiert den Moment der Grenzüberschreitung von der empirisch erfahrbaren Wirklichkeit in eine jenseits liegende Welt, die als transzendental erfahrbare Dimension ausgestaltet ist. Das verstorbene Lebewesen vollzieht dabei eine Verwandlung, die sich entweder als neue Existenzform oder als wieder hergestellte Unversehrtheit in alter Gestalt zeigt. Vorausgesetzt ist, dass diese phantastischen Elemente

128 Das Tierbilderbuch wird in Kap. VI.1.3 gesondert betrachtet und ist an dieser Stelle nicht mit gemeint. 
das die Gesamtstruktur des Erzähltextes prägende Charakteristikum sind, womit das intradiegetische Reden über Transzendenz und das gedankliche Imaginieren ausgeschlossen sind.

3. Das implizit-phantastische Bilderbuch: In irdischen, realistischen Zusammenhängen treten Figuren auf, die mit einer übernatürlichen Konstitution ausgestattet sind, z. B. Engel, andere transzendente oder transpsychologische Gestalten oder der personifizierte Tod.

Grundsätzlich wurden alle Bilderbücher als phantastische erfasst, wenn entweder auf der Textebene oder auf der Bildebene oder im Zusammenspiel beider Ebenen phantastisches Erzählen im oben beschriebenen Sinne verwirklicht ist. Die insgesamt 63 phantastisch erzählenden Bilderbücher ${ }^{129}$ verteilen sich auf die o. g. Kategorien wie folgt: offen-phantastisch: 35; implizit-phantastisch: 16; geschlossen-phantastisch: 12. Der Anteil der religiösen Bilderbücher ist mit $62 \%$ $(\mathrm{N}=39)$ relativ hoch, bedingt durch die grenzüberschreitenden Vorstellungen von einer jenseitigen, nicht irdischen Dimension, die das Handlungsgeschehen mit bestimmen. Oft sind dabei Engel die Begleiter, die teils schon auf Erden als Schutzengel auftreten, oder Verstorbene selbst verwandeln sich in Engel.

In einigen Texten hat sich das magisch-esoterische Gedankengut der Autoren in einer Weise verwirklicht, die als kitschige Verherrlichung bezeichnet werden muss. Dass ausgerechnet die anerkannte Sterbeforscherin Elisabeth Kübler-Ross sich dieser Form von überhöhter Wirklichkeitsverdrängung verschrieben hat, mutet befremdlich an angesichts ihrer Anstöße für die Hospizarbeit, die dem Sterben einen Platz im Leben zuweist. In Die unsichtbaren Freunde (Kübler-Ross/ Rothmayr 1985) wird die Freundschaft zwischen Engeln und zwei Kindern, von denen eines verstirbt, mit so viel Sehnsucht nach Beisammensein belegt - zusätzlich verstärkt durch die in Wort und Bild glorifizierte Darstellung des in Aussicht gestellten Paradieses -, dass darin Todessehnsucht gesehen werden muss. Dazu trägt noch bei, dass die Kinder in einer Traumsequenz, die kaum als solche auszumachen ist, von den Engeln in eine überirdische Dimension geleitet werden, die sie als physisch erreichbaren Ort erfahren und worüber zu schweigen die Engel sie ermahnen. Ob solche esoterischen Überhöhungen für ein gesundes Verhältnis zum Tod bzw. zum Leben hilfreich sein können, ist mehr als zweifelhaft. Kinder im sogenannten Bilderbuchalter halten für real, was sie sehen und

129 S. Abb. 6a u. 6b sowie die tabellarische Übersicht im Anhang (X.2). 
hören und werden irregeleitet ${ }^{130}$, wenn ihnen konkrete Bilder vom nachtodlichen Weiterexistieren und seiner räumlichen Ausgestaltung präsentiert werden.

Esoterisch verklärende Illustrationen behindern Kinder in diesem Fall in ihrem Entwicklungsprozeß der zunehmend rationaleren Erfassung der Welt, können sie auch in Richtung einer irrationalen Abhängigkeit manipulieren. (Schmidt-Dumont 1998, 89)

In die Rubrik kitschiger Überhöhung gehört auch das Bilderbuch Als Papa in den Himmel flog (Paffrath 2010), das eine unzulässige Gewissheit von der Ausgestaltung eines Lebens nach dem Tod behauptet und diese auch ins Bild setzt. Das irdische Dasein scheint dort nur ein Intermezzo zu sein, bewacht von einem Schutzengel, der versichert: „Ich werde immer bei dir sein, ich habe dich vom Licht auf die Erde begleitet und ich werde dich auch wieder zurück ins Licht begleiten." (Paffrath 2010) Man mag Stefanie Paffrath ihre bekundet autobiographischen Vorstellungen (vgl. Prätext) zugestehen, unzulässig ist es aber, sowohl auf der Text- als auch der Bildebene Wahrhaftigkeit vorzutäuschen: Als die Protagonistin Steffi aus ihrem Traum erwacht, erlebt sie ihre Mutter verwirrt, da diese ein helles Licht gesehen hat, und ruft aus: „Dann ist es wirklich wahr!“Sehr viel ehrlicher und umso hilfreicher sind Bilderbücher, die von Glaubensvorstellungen ${ }^{131}$ erzählen, von unbehaupteten Möglichkeiten und Hoffnungen, ohne zu indoktrinieren. Dass dies auch auf einer phantastischen Ebene gelingen kann, zeigt das Pappbilderbuch Honiggelb und Steingrau. Eine Geschichte vom Sterben und Abschiednehmen (Heinrichsdorf 1995). Onkel Steingrau und ein kleines Honiggelb, Figuren als geometrisch gestaltete Farbflächen, setzen sich angesichts des bevorstehenden Todes des Onkels mit der Frage auseinander, was das bedeutete, Sterben und Totsein. In dem offen geführten Gespräch versucht der Onkel Antworten auf die vielen Fragen des kleinen Honiggelb zu finden, ohne Gewissheit zu behaupten. Nur eines scheint fraglos: [S]eine Seele würde bestimmt zu Gott in den Himmel kommen und dort weiterleben. Mit dem mehrfach gebrauchten vielleicht lassen seine Vermutungen und Hoffnungen Raum für kindliche Vorstellungen und Phantasien von einem möglichen Wiedersehen bereits Verstorbener, die auch der kindliche Ich-Erzähler Honiggelb in Erwägung zieht. Bemerkenswert ist dabei, dass alle vier Dimensionen eines reifen Todeskonzepts zur Sprache

130 Hier sei der Hinweis erlaubt, dass die Praktiken religiöser Sekten eben darauf abzielen, indem sie weltfremde, unhaltbare Versprechungen machen und irrationale Hoffnungen wecken, um ihre eigentlichen Motive, die zu erläutern hier nicht der Platz ist, zu verschleiern.

131 S. dazu Kap. VI.2.2. 
kommen, welches die Universalität des altersbedingten Sterbens impliziert, ohne explizit auf die Möglichkeit auch kindlichen Sterbens hinzuweisen.

Das Wissen darum, dass Kinder dazu neigen, ihre Realität mit Phantasie anzureichern, bestimmt in acht offen-phantastischen Bilderbüchern das Erzählen von Trauerprozessen aus der kindlichen Ich-Perspektive ohne kommunikative Interaktionen mit Erwachsenen. ${ }^{132}$ Diese Bilderbücher bieten besonders den Kindern Identifikationsangebote, die mehr oder weniger auf sich allein gestellt sind oder sogar offen mit Zurückweisung ${ }^{133}$ konfrontiert werden, wie z. B. in Julia bei den Lebenslichtern (Sommer-Bodenburg/ Tiong-King 1989), dem einzigen Bilderbuch, das diese Problematik in aller Deutlichkeit aufgreift. ${ }^{134} \mathrm{Kom}$ men Disharmonien in menschlichen Kommunikationszusammenhängen schon kaum vor, in Tierbilderbüchern spielen sie keinerlei Rolle.

\section{VI.1.3 Das Tierbilderbuch}

Ohne auf den wissenschaftlichen Diskurs zur Definitionsfrage näher einzugehen, handelt es sich allgemein immer dann um ein Tierbuch resp. Tierbilderbuch, „wenn Tiere allein oder zusammen mit Menschen den Mittelpunkt der Handlung ausmachen und in (erzählerischen Texten) zum Subjekt dieser Handlung werden" (Haas 2002, 287). Für die Bestimmungen von Subgattungen sind die Fragen nach der Stellung und Funktion des Tieres im Handlungsgeschehen und nach der Beschaffenheit des Verhältnisses zwischen Mensch und Tier ausschlaggebend. Haas unterscheidet die in einem realistischen oder phantastischen Milieu spielende Tiergeschichte, Tiermythen und Tiermärchen, die Fabel und das Tierepos. Eine weitere Differenzierung erfolgt danach, ob entweder ausschließlich Tiere auftreten oder Tiere und Menschen gemeinsam und gleichwertig den Handlungsverlauf bestimmen und ob die Tiere jeweils in ihrer biologischen Natur unverfälscht oder anthropomorphisiert dargestellt werden (vgl. ebd., 290). Die Untersuchung des vorliegenden Materials hat deutliche Tendenzen gezeigt, die eine fünffache Differenzierung hinsichtlich der Figurenkonstellationen, ihrer Handlungswelten und der Sachzusammenhänge nahelegen:

132 Tidholm/ Tidholm 1990; Heymans/ Heymans 1993; Geelen 1993; Stark/ Höglund 1997; Steiner 1999; Janisch/ Blau 2005; Treiber/ Rassmus 2006; Weigelt/ Haas 2011.

133 Wenn den Kindern ihnen zugewandte Bezugspersonen fehlen, stellt sich allerdings die Frage nach dem Zugang zur Literatur.

134 Weitere Titel zum Problem Sprachlosigkeit oder Kommunikationsverweigerung von Bezugspersonen: Tidholm/ Tidholm 1990; Davids/ Münzer 2000; Treiber/ Blazejovsky 2001. 
1. Die geschlossen-phantastische Tiergeschichte: Anthropomorphisierte Tiere sind alleinige Handlungsträger und bewegen sich in einem adaptierten Lebensumfeld ohne menschliche Gegen-/Mitspieler.

2. Die implizit-phantastische Tiergeschichte: Tiere sind als selbstständige, in menschlicher Manier handelnde und sprechende Figuren in die Menschenwelt integriert.

3. Die offen-phantastische Tiergeschichte: Innerhalb eines realistischen Umfeldes findet ein Überschreiten der Grenze zum Phantastischen statt, wobei ein Wechsel zwischen diesen beiden Dimensionen möglich ist.

4. Realistische Tiergeschichte: Tiere treten in ihrer biologisch unveränderten Natur als Protagonisten auf.

5. Das Sach-Tierbilderbuch: Biologisch korrekte Informationen über Tiere, ihre natürlichen Lebensprozesse und Existenzbedingungen stehen im Mittelpunkt.

„Tiergeschichten sind immer Menschengeschichten“, das wissen wir, seit es Fabeln gibt, weshalb Tiere in Menschenkleidern im Zusammenhang mit Sterben und Tod einerseits der Herstellung von Distanz dienen, andererseits dem Menschen einen Spiegel vorhalten, indem die Figur des Tieres als „Chiffre für den Menschen“ wahrgenommen werden kann (Schaufelberger 1990, 24).

Die stabile Verankerung des Tiers in der Kinderliteratur basiert auf dem Zusammentreffen von poetischen, tierphysiologischen und kinderpsychologischen Elementen, die - bildlich gesprochen - durch Verschlüsselung und Verschlossenheit aufeinander einwirken. (Lypp 2009, 69)

Da das Nachdenken und Stellungnehmen zum Tod eine genuin menschliche Fähigkeit ist und das „Grundmuster des Verweises vom Tier auf den Menschen und des Identisch-Setzens von Tier und Mensch“ (ebd.) außerordentlich häufig in Bilderbuchgeschichten anzutreffen ist, verwundert es nicht, dass die phantastischen Tierbilderbücher mit ihren Anthropomorphisierungen gegenüber den realistischen Tierbilderbüchern $(\mathrm{N}=3)^{135}$ hier überaus deutlich dominieren. Trauerreaktionen wie z. B. Nahrungsverweigerung, Arbeitsverweigerung und Rückzug, die aus der Tierwelt bekannt sind, wurden im realistischen Bilderbuch nur einmal aufgefunden (Güdel 2009: Apollo, das Maultier). ${ }^{136}$ Die weiteren Ausführungen beziehen sich deshalb ausschließlich auf phantastische Tierbilderbücher.

135 S. Abb. 6a u. 6b sowie die tabellarische Übersicht im Anhang (X.2).

136 Realistische Tierbilderbücher insgesamt: Güdel 2009; Goodall/ Marks 2004; Tejima 1996. 
Das phantastische Tierbilderbuch $(\mathrm{N}=57)^{137}$ liegt mit 37 Titeln als geschlossen-phantastische Variante vor, 18 Titel sind implizit-phantastisch, zwei offen-phantastisch ${ }^{138}$. Häufig vertreten sind alt und weise erscheinende Bären ${ }^{139}$, Elefanten ${ }^{140}$ und Füchse ${ }^{141}$, die mit großer Gelassenheit und Akzeptanz ihrem Ende entgegengehen und meist ihre tierischen Freunde darauf auch vorbereiten (z. B. Bourguignon/ D'Heur 2004). Fast immer wird dann ein späteres Wiedersehen in Aussicht gestellt. Trost finden die Trauernden dabei oft auch in einer Gedächtniskultur, im Festhalten an Erinnerungen und Erinnerungsobjekten. Anfängliches Ungehaltensein besonders jüngster Tiere wandelt sich aber zuverlässig in eine Akzeptanz des Todes, auf dessen Unabänderlichkeit manchmal schon der Titel verweist: Der alte Bär muss Abschied nehmen (Weigelt/ Kadmon 2003). Dort spricht der alte Bär zu seinen Freunden: Ich mache mich auf eine ganz besondere Reise, die jeder Bär und jedes Tier am Ende seines Lebens macht. Und er glaubt, dass man in den Himmel komme.

Eine Differenzierung des phantastischen Teilkorpus' hinsichtlich religiöser Merkmale bzw. fehlender Hinweise auf Transzendenz zeigt, dass eine hälftige Verteilung vorliegt und der Himmel ${ }^{142}$ als religiöser Aufenthaltsort einer nachtodlichen Existenz elf Mal in Aussicht gestellt wird. Meist auch verbunden mit mnestischen Troststrategien, übernimmt das „Tier als Medium des menschlichen Selbstverständnisses“ (Lypp 2009, 69) hier die Aufgabe des Mittlers zwischen säkularen Gewissheiten und religiösen Hoffnungen. In den Bilderbüchern ohne transzendente Aspekte ist selbst eine Erinnerungskultur verhältnismäßig weniger von Bedeutung für die Trauerverarbeitung.

137 S. Abb. 6a u. 6b sowie die tabellarische Übersicht im Anhang (X.2).

138 Missfeldt/ Schübel 1990: Der Rapskönig; der kindliche Protagonist trauert um seinen toten Hund, macht mit dem Rapskönig einen Ausflug ins All und erfährt von einer tröstlichen Nachtodexistenz; Imbsweiler/ Rappo 2003: Schildkrötenträume; eine Schildkröte imaginiert ihre Befreiung von allem Einschränkenden in einem Traumgeschehen und legt sogar ihren Panzer ab, kehrt aber in die Realität ihres Haustierdaseins wieder zurück.

139 Mürmann/ Meis 2004; Verroen/ Erlbruch 2003; Weigelt/ Kadmon 2003; Kinder 2001; Grey/ Cabban 2000.

140 Usatschow/ Junge 2008; Abedi/ Cordes 2008; Bourguignon/ D’Heur 2005; Heine 1976.

141 Durant/ Gliori 2004; Wickli/ Villiger 1997.

142 Reinheimer/ Wenz-Vietor 2008; Abedi/ Cordes 2006; Bourguignon/ D’Heur 2005; Doray 2003; van Ommen/ de Wanten 2003; Verroen/ Erlbruch 2003; Weigelt/ Kadmon 2003; Recheis/ Kaufmann 1998; Rylant 1998; Allan 1996; Velthuijs 1992. 
Das erste recherchierte, bis heute im Buchhandel verfügbare Tierbilderbuch, das mit dem Tod einen befreienden Vorgang und eine vorsichtige Hoffnung auf ein Weiterexistieren verbindet, ist Leb wohl, lieber Dachs (Varley 1984) (Abb. 9). Sowohl im Text als auch im Bild spiegelt sich in der Figur des Dachses der Idealtypus eines alten Menschen, der sich am Ende eines erfüllten Lebens gelassen auf seinen letzten Weg begibt. Der Dachs hat offenbar ein Gespür für sein nahes Ende und nimmt es ohne Furcht an, da seine Vorstellung vom Tod die eines unbeschwerlichen Vorganges ist, der ihn von seinem alten und gebrechlichen Körper befreien wird. Nur um seine Freunde sorgt er sich, die seinen bevorstehenden Tod nicht zu schwer nehmen sollen. Deshalb hatte er sie schon vorbereitet und ihnen gesagt, irgendwann einmal werde er durch den Langen Tunnel gehen.

Abb. 9: Susan Varley (1984): Leb wohl, lieber Dachs. München: Betz.

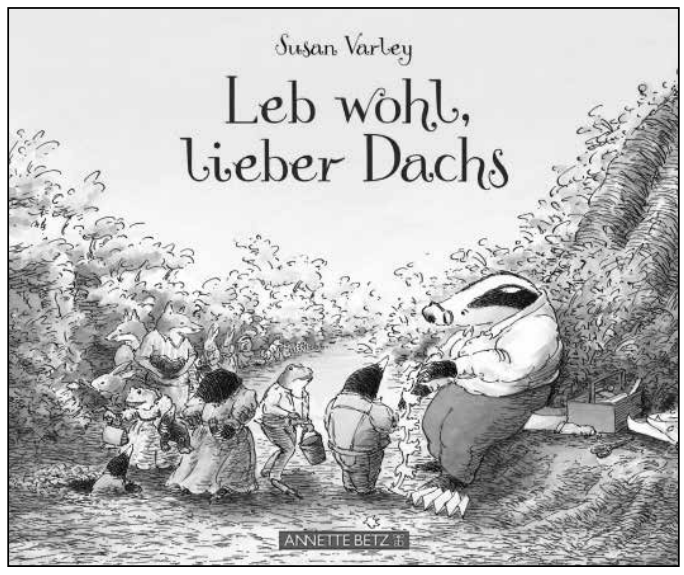

Susan Varley hat das Geschehen in drei Etappen angelegt: Im ersten Drittel des Buches werden in auktorialem Erzählstil die Vorbereitungen des Dachses auf seinen Tod (buchstäblich an seinem Lebensabend zieht er sich zurück, schreibt einen letzten Brief, schließt die Vorhänge etc.) und den Sterbevorgang als eingeschobene Traumsequenz geschildert; den mit zwei Dritteln größten Umfang beansprucht im Anschluss daran die Ausgestaltung des Trauerprozesses der Tiere und macht damit auch formal deutlich, dass Trauerarbeit Zeit braucht. Nachdem der Dachs tot ist, fühlen sich seine Freunde verlassen und furchtbar unglücklich, erst zum Frühlingsbeginn wird die Gemeinschaft der Tiere wieder lebendig. Sie erinnern sich der schönen gemeinsamen Erlebnisse mit dem Dachs und empfinden Dankbarkeit für die Fertigkeiten, die er jeden Einzelnen gelehrt 
hat und ihnen eine Hilfe im Miteinander sind. So wird eine Erinnerungskultur gepflegt und die Trauer überwunden, deren Zeit beanspruchende Prozesshaftigkeit sich im Wandel der Jahreszeiten widerspiegelt.

In kaum einem anderen Bilderbuch ist der Vorgang des Sterbens auf solch subtil-nachvollziehbare Weise und mit einer Offenheit für eigene Imaginationen ins Bild gesetzt worden wie hier. ${ }^{143}$ Sowohl auf der Textebene als auch auf der Bildebene geben die Traumvisionen des Dachses Anlass zu der Annahme, dass der Weg durch den langen Tunnel befreiend ist und auf ein Ziel hinführt, an dem Körperlichkeit keine Rolle mehr spielt:

Dachs lief. Zu seiner größten Überraschung lief er munter dahin. Vor ihm öffnete sich ein langer Tunnel. Seine Beine trugen ihn kräftig und sicher dem Tunnel entgegen. Er brauchte keinen Spazierstock mehr, also ließ er ihn liegen. Dachs lief leicht und behende, schneller und immer schneller durch den langen Gang, bis seine Pfoten den Boden gar nicht mehr berührten. Er fühlte, wie er kopfüber stürzte, wie er hinfiel und sich überschlug, aber er tat sich überhaupt nicht weh. Er fühlte sich frei. Es war, als wäre aus seinem Körper herausgefallen. (Varley 1984, o.S.)

Diese Transzendenz wird am Schluss wieder aufgegriffen, als die Trauer des besten Freundes, des Maulwurfs, einer Dankbarkeit für die gemeinsame Zeit Platz macht: „Danke, Dachs“, sagte er leise. Er war überzeugt, dass ihn der Dachs hörte. Und - vielleicht war es auch so. Die Verbalebene impliziert mit dem vielleicht, wie auf der Bildebene der in die Weite des Himmels gerichtete Blick des Maulwurfs, eine Sicht auf den Tod, die mehr Hoffnung und Glaube ist und eben keine Gewissheit, die im Leben nicht zu erlangen ist. ${ }^{144}$

Adieu, Herr Muffin (Nilsson/ Tidholm 2007) changiert dagegen zwischen Tierund Menschenwelt. Der auktoriale Erzähler erzählt die Geschichte vom Sterben eines Meerschweinchens, das auf ein erfülltes Leben mit einer Ehefrau (Viktoria, schwarz wie die Nacht, schön wie der Tag) und sechs kuscheligen kleinen Kindern zurückblickt, und wechselt dabei immer wieder von der Innenperspektive des Protagonisten zur Perspektive eines nur durch Briefe an das Meerschweinchen in Erscheinung tretenden Kindes. In diesen Briefen, Medium der Kommunikation mit dem Meerschweinchen und regelmäßig von diesem erwartet, setzt sich das Mädchen mit seinen Fragen und Gedanken zum Tod auseinander. Nachdem

143 Nicht von ungefähr liegt das Bilderbuch als Animationsfilm, ausgestrahlt in der Sendung mit der Maus, vor.

144 Die Übersetzung des Original-Titels Badger's Parting Gifts in Leb wohl, lieber Dachs setzt einen entsprechenden Akzent: Während der Original-Titel die Spuren des Verstorbenen im Diesseits der Trauernden verortet, ist der Abschiedsgruß der deutschen Ausgabe auf eine jenseitige Weiterexistenz gerichtet. 
das Tier schließlich in einer feierlichen Zeremonie zu Grabe getragen wurde, endet die Erzählung mit einer letzten Mitteilung, die die wichtigen Fragen zum Tod zusammenfasst und Glaubensvorstellungen Raum gibt:

Jetzt weißt Du mehr als wir, Herr Muffin.

Jetzt weißt Du, was passiert, wenn man stirbt.

Der Tod ist doch ein Ausruhen, oder? Und dann ist der Tod nichts, wovor man

Angst haben muss.

Oder man kommt irgendwohin, zu einem ewigen Leben, und da ist man glücklich.

Und dann ist der Tod etwas, worauf man sich freut.

Warum sollte man vor dem Tod Angst haben?

So ist es doch, Herr Muffin, oder?

$\mathrm{Du}$ weißt es doch?

In der weiteren Kommunikation über den Tod hinaus drückt sich die Hoffnung auf eine nachtodliche Wahrnehmung aus, dass ein friedlicher Ort oder zumindest Zustand erreicht wird, der nicht gefürchtet werden muss. Die abschließenden Fragen drücken die Unsicherheit aus und müssen im Raum stehen bleiben.

Was dem fiktionalen Tod aus der Perspektive eines Hundes folgen kann, ist in Gibt's im Himmel Schokolade? (Allan 1996) in ein amüsantes Setting eingebettet: Eines Morgens trifft Lili ihren Hund Rufus mit gepackten Koffern an. Zwei Engel sind gekommen, um ihn in den Himmel mitzunehmen. Es heißt also Abschied nehmen, aber wie darf man sich den Himmel vorstellen? Zwischen Lili und Rufus herrscht vergnügliche Uneinigkeit über die Ausgestaltung des Himmels, denn Rufus mag keine Süßigkeiten, Lili dagegen keine rohen Knochen und schon gar nicht an Hundehaufen schnuppern. Aber da Lili nun erfahren hat, was Hunde sich für ein paradiesisches Leben wünschen, gestaltet sie einem neuen Hundefreund den Himmel auf Erden.

In zwei Bilderbüchern ${ }^{145}$ wird die ungewöhnliche Perspektive trauernder Haustiere nach dem Verlust ihrer menschlich-kindlichen Bezugspersonen mit einer autodiegetischen Erzählstimme umgesetzt, die trotz der prägnant-knappen Sprache von besonderer Emotionalität geprägt ist und zu Empathie anregt. Die Distanz aber, die der zwar vermenschlichte, aber individuell tierische Verlustschmerz schafft, kann ohne Adaptionsleistungen nicht aufgehoben werden und wird möglicherweise nur bedingt zu Identifikationsprozessen anregen. Das Trostkonzept ist wie in vielen anderen Büchern das erinnernde Gedenken, das die Verstorbenen gegenwärtig erscheinen lässt, das aber gleichzeitig auch offen

145 Loske 2011: Sadakos Kraniche (ausführliche Besprechung in Kap. VII.3.2); Kikuta 2003: Du bist immer noch bei mir. 
ist für weitergehende Phantasien, wie sie z. B. in Du bist immer noch bei mir (Kikuta 2003) ganz subtil von der Bildebene - im minimalistischen Comic-Stil angestoßen werden.

Abb. 10: Mariko Kikuta (2003): Du bist immer noch bei mir. Hamburg: Carlsen.

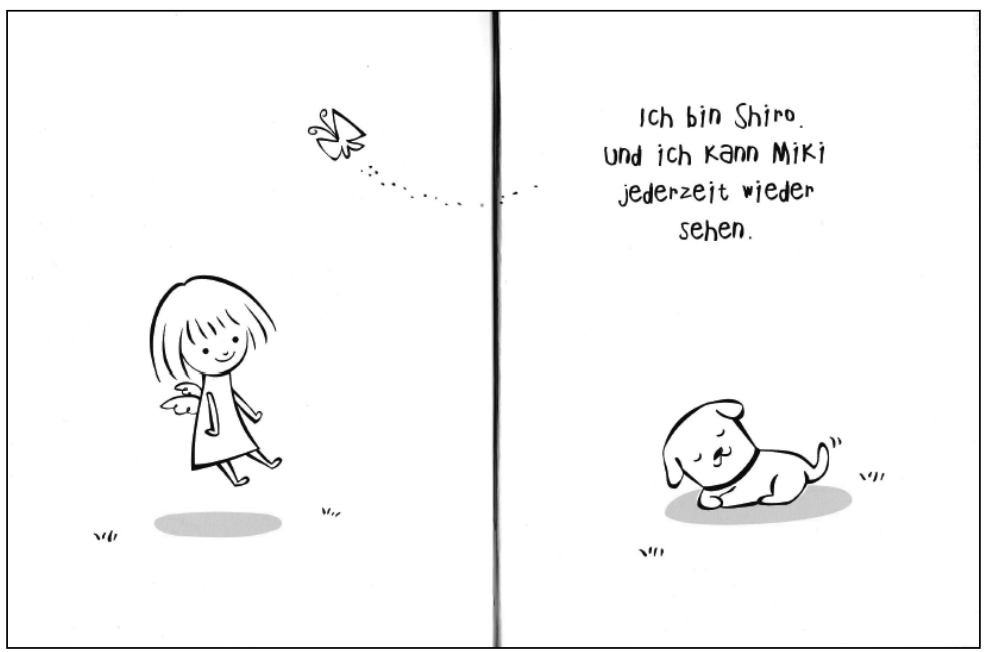

Dort gesellt sich auf den letzten beiden Seiten ein Schmetterling als Symbol des Todes zum Engelwesen, das als Imagination Shiros, des trauernden Hundes, zu verstehen ist und eine mögliche Weiterexistenz des verstorbenen Mädchens andeutet (Abb. 10).

Ein Bilderbuch, das im vorliegenden Textkorpus aus dem Rahmen fällt, ist Wenn ich an meine Oma denk... (Doray 2003), und zwar insofern, als sprachlich mit keinem Wort auf die stilisierte und anthropomorphe Katzengestalt der Figuren hingewiesen wird und das Erzählen aus der kindlichen Ich-Perspektive eine einzige große Erinnerung ist: eine Retrospektive auf die gemeinsam mit der Oma glücklich verbrachte Zeit, die Geschehnisse rund um die Todesnachricht und die Zeit der Trauer, die ihren Abschluss längst gefunden hat. Der Trost liegt, wie so häufig, weniger in Glaubensvorstellungen, obwohl sie hier zumindest verbalisiert werden, sondern mehr in der Pflege einer Erinnerungskultur: Oma [...] ist immer noch ein wenig da, weil sie eine große Erinnerung ist. Die Qualität des Buches liegt in seiner reduzierten Darstellungsweise: Die comicartigen Zeichnungen mit schwungvollem schwarzem Strich und wenigen Farbakzenten lassen viel Raum für eigene Assoziationen und bieten in der Kombination mit den kurzen Sätzen aus dem Mund eines kindlichen Protagonisten Identifikationsmöglichkeiten, die 
bei den im folgenden Kapitel thematisierten Sachbilderbüchern zwar weniger, aber dennoch teils gegeben sind.

\section{VI.1.4 Das Sachbilderbuch}

„Eine allgemeingültige Definition des Begriffs Sachbuch lässt sich bis heute der Fachliteratur nicht entnehmen." (Ossowski/ Ossowski 2011, 364) Eine der Ursachen ist das grundsätzliche Problem der Abgrenzung des Sachbuchs zum episch-narrativen Text (vgl. Franz 2011, 9). Obwohl „Einigkeit - im weitesten Sinne - herrscht darin, dass ein Sachbuch der non-fiction-Literatur zuzuordnen sei“ (Ossowski/ Ossowski 2011,364), liegen Überschneidungen mit vielen anderen Gattungen, beispielsweise der geschichtserzählenden Literatur, auf der Hand (vgl. Steitz-Kallenbach 2006, 647). Umso schwieriger ist es, das Sachbilderbuch zum Thema Tod zu definieren, weil besonders für die Kinderliteratur mit ihrem Anliegen, unterhaltsam-erzählend zu informieren, die Grenzen zum Fiktionalen fließende sind. Zum anderen ist der thematische Gegenstand selbst kaum fassbar, weshalb Informationen zu Sterben und Tod, sofern sie über die Erklärung biologischer Zusammenhänge hinausgehen, immer auch eine fiktive Dimension implizieren. Jörg Steitz-Kallenbach (ebd.) greift diese Aspekte in seiner Definition auf:

Sachbücher vermitteln Kindern Wissen über die Welt und das Handeln in der Welt. Der Bezug auf die Wirklichkeit der kindlichen Lebensräume steht dabei im Vordergrund. Sachbücher verwenden bei ihren Darstellungen Bilder und Texte sowie verschiedene Formen der Text-Bild-Kombination. Ansätze zur Fiktionalisierung sowohl auf der Bildebene wie auf der Textebene dienen der Motivierung der Leser/-innen bzw. Betrachter/-innen und sind der zu vermittelnden Wirklichkeit und den darzustellenden Handlungen verpflichtet.

Dementsprechend liegt dann ein Sachbilderbuch vor, wenn der Schwerpunkt auf der Vermittlung von real-sachlichen Informationen $\mathrm{zu}$ (möglichen) Todesumständen, zu religiösen Erklärungsmustern oder zu den Zusammenhängen zwischen Entstehen und Vergehen in einem natürlichen Kreislauf liegt. Nicht hinzuzurechnen sind solche Texte, die wissenswerte, aber mehr beiläufige Informationen zu Krankheiten und Jenseitsvorstellungen, zum Beerdigungsprocedere oder sonstigen Ritualen geben. Das Spektrum des sachorientierten Erzählens in insgesamt 34 Bilderbüchern ${ }^{146}$ wird hier mittels einer inhaltsorientierten Typologie ausdifferenziert: das naturwissenschaftliche, das religiöse, das geschichtserzählende und das faktuale Sachbilderbuch.

146 S. Abb. 6a u. 6b sowie die tabellarische Übersicht im Anhang (X.2). 
Die insgesamt neun naturwissenschaftlichen Sachbilderbücher gehen in den Kategorien Flora und Fauna wissenschaftlich korrekt auf biologische Zerfallsprozesse und zyklische Vorgänge in der Natur ein. Das Tier-Sachbilderbuch „ist nur in relativ wenigen Fällen völlig vom erzählenden Tierbuch zu trennen“ (Haas 2002, 302). Bilderbücher wie Das Bärenkind „kleiden sich erzählerisch ein, wollen aber primär informieren und zum Handeln anregen" (Haas 2002, 302). Dagegen stellt das Sachbilderbuch Wo bleibt die Maus? (Benecke/ Fuss 2008) den Verwesungsprozess einer toten Maus in nüchternen Zeichnungen und informierendem Sprachduktus völlig emotionslos dar und erklärt den Tod als Teil des biologischen Kreislaufs, ebenso wie das Fotobilderbuch Wenn Tiere sterben (Hansen 1981) mit Bildern von der natürlichen Aas-Verwertung und des Wandels in neue organische Stoffe, womit die Funktion des Todes für einen verlässlichen Naturkreislauf deutlich wird. Die natürlichen Lebensprozesse von Raupe und Schmetterling werden in Die kleine Raupe Nimmersatt (Carle 1969) und Raupengeschichte (Bröger/ Brandt 1971) beschrieben, über das Naturwissenschaftliche hinaus werden diese Vorgänge aber schon seit der Antike metaphorisch als scheinbares Sterben und Übergang in eine andere Existenzform betrachtet. Im Bilderbuch Das Apfelbaumjahr (Sturm/ Schleer 1988) sind mit dem Schlaf des Apfelbaumes, der „seinen langen Wintertraum“ träumt, „zwei nur vorübergehende [...] Todesformen“ (Schmidt-Dumont 1998, 78) genannt, die auf ein Wiedererwachen bzw. Neuwerden hinweisen, ähnlich dem Wandel von der Raupe zum Schmetterling. Die Grenzen zum religiösen (Sach-) Bilderbuch sind vor dem Hintergrund der ungeklärten Frage „Wonach sucht eigentlich, wer nach Religion in der Literatur sucht?" (Wittekind 2009, 11) auch hier fließend.

Die religiösen Sachbilderbücher (N=16) präsentieren, eng gefasst, wissensbasierte Informationen zu religiösen Auffassungen und einem rituellen Procedere und sind mehrheitlich ab 1995 erschienen.

[D]ie Zunahme dieser informierenden Literatur [ist] ein Beleg dafür, dass das unmittelbare Vorkommen von Religion im Leben des Kindes abgenommen hat, dass Kenntnis über Religion durch Wissen vermittelt werden muss. (Wittekind 2009, 12)

Die Dominanz des christlichen Auferstehungsglaubens wird in nur fünf Bilderbüchern des hier ausgewählten Sachbuchkorpus' aufgebrochen. Interreligiöses Herangehen bestimmt beispielsweise das Bilderbuch Was ist Tod? (Boritzer/ Forrest 2007), in dem auf die kindliche Neugier sachorientiert mit verschiedenen welt-religiösen Auffassungen von Tod, Verlust und Trauer geantwortet und gleichzeitig „die Hoffnung und die Ermutigung, das Leben zu umarmen“ (Klappentext) transportiert wird. Deutlich wird an dieser Stelle die Unmöglichkeit 
einer Abgrenzung von philosophischen Bilderbüchern. ${ }^{147}$ Das bereits 1979 erschienene Fotobilderbuch Ich will etwas vom Tod wissen (Becker/ Niggemeyer 1979) macht in kurzen, alltagsnahen Geschichten vertraut mit der natürlichen Regelhaftigkeit von Jahresabläufen, Altern und Tod, auch mit dem Verhältnis von Todesangst und verschieden ausgeprägtem Todesbewusstsein in Verbindung mit unterschiedlichen Jenseitsvorstellungen, jeweils eingebettet in ein kommunikatives Handlungsgeschehen zwischen Kindern und Erwachsenen. Die Antworten auf zahlreiche Kinderfragen lassen Raum für weltanschauliche oder religiöse Auffassungen, ohne festzulegen. Ähnlich breit gefächert ist die Herangehensweise in Wie ist das mit dem Tod? Willi wills wissen (Gätjen/ Kauss 2007), in dem der Reporter Willi Menschen befragt, die entweder beruflich oder privat mit dem Tod zu tun haben. Auch Pernilla Stalfelt (2000: Und was kommt dann?) nähert sich vielschichtig den Möglichkeiten, den Tod, seine Ursachen und Folgen sowie verschiedene Varianten des Totenkults zu erklären. In komisch-naiven, unsentimental-frechen Zeichnungen und Bildkommentaren, teils in Sprechblasen, gibt dieses Buch unprätentiöse und manchmal kuriose Antworten auf die detailverliebte Wissbegierde von Kindern und fängt ebenso z. B. das wörtliche Verständnis von Euphemismen (ins Gras gebissen) mit den Zeichnungen ein. Da Stalfelt nicht nur pragmatische Aspekte von Todesgeschehen aufgreift, sondern auch existenzielle Fragen stellt, ist dieses Bilderbuch auch als philosophisches anzusehen, was aber nur ein weiteres Mal die hybride Kategorienstruktur bestätigt. Zu bedenken ist jedenfalls, dass in den genannten Bilderbüchern die Antworten so zahlreich sind, dass ein lesendes Kind nur ratlos zurückbleiben kann, wenn ihm kein erwachsener Lesebegleiter - der immer verfügbar sein sollte - Orientierungshilfen bietet.

Zur Kategorie der faktualen Sachbilderbücher gehören vier Texte, die von realen Erfahrungen berichten bzw. als Mitteilungen eines real-weltlichen Autors gelesen werden können. ${ }^{148}$ Der Tod spielt dort auf verschiedene Weise eine Rolle,

147 Dass ein entsprechendes Teilkorpus dennoch gebildet wurde, wird im Kap. VI.2.3 begründet.

148 Angelehnt an das den Forschungsarbeiten des GRK „Faktuales und fiktionales Erzählen“ zugrunde gelegte Verständnis von Faktualität: „In diesem Kolleg wird unter Faktualität nicht etwa, Wahrheit' verstanden, sondern aus rezeptionspragmatischer Perspektive die text- bzw. gattungsspezifische Absicht, eine Kommunikation innerhalb eines realen Kontextes zu tätigen, in dem der Sprecher oder Autor mit Hilfe seiner Erzählung bestimmte Ziele verfolgt, wie auch der Adressat oder Leser bzw. Zuhörer gewisse Ansprüche an die Erzählung und den Erzähler stellen. Auch wenn der Erzähldiskurs nicht unbedingt wahr ist, setzt er sich einer Überprüfung oder 
entweder als Verlusterfahrung (Jianghong 2009: An Großvaters Hand; Verlust des Großvaters zur Zeit der Kulturrevolution unter Mao; Wikland/ Lagercrantz 1996: Die lange, lange Reise; Ilon Wikland erzählt ihre eigene Kindheitsgeschichte in Bildern) oder als lebensbedrohliche Leukämieerkrankung (Bergmann 1989; Gaes/ Gaes 1989).

Fünf Titel sind geschichtserzählende Sachbilderbücher, in denen vom gewaltsamen Tod von Kindern bzw. Jugendlichen erzählt wird: vom Tod Anne Franks und ihrer Angehörigen, vom gewaltsamen Tod eines Mädchens in den letzten Tagen der NS-Diktatur und vom Sterben des Atombombenopfers Sadako Sasaki. Auf diese Titel wird im Kapitel VII.3.2 näher eingegangen.

\section{VI.1.5 Das märchenhafte Bilderbuch}

In dieser Kategorie sind alle Titel zusammengefasst, die märchenhafte Merkmale aufweisen oder auch den Textsorten Parabel, Mythos, Legende zugerechnet werden können. Das ist diskutabel, aber pragmatischen Überlegungen geschuldet, wonach hier alle Titel aufgrund des literaturwissenschaftlich noch nicht abschließend geklärten Problems der Differenzierung zwischen den genannten epischen Formen und der Phantastik zusammengebracht werden. Die insgesamt 23 Bilderbücher dieser Subsumierung verteilen sich unregelmäßig und ohne herausstechende Häufung auf den Zeitraum von 1968 bis 2011, wobei, dem allgemeinen Anstieg entsprechend, in der letzten Dekade die relativ meisten Titel zu verzeichnen sind. ${ }^{149}$ Es liegen Interferenzen mit den Kategorien religiöstranszendentales Bilderbuch $(\mathrm{N}=10)$, philosophisches Bilderbuch $(\mathrm{N}=5)$, Totentanzadaptionen $(\mathrm{N}=6)$ und Kindertod $(\mathrm{N}=4)$ vor, die durchaus auch andere Verteilungen begründen könnten, insbesondere hinsichtlich der Kategorie der philosophischen Bilderbücher, worauf bereits hingewiesen wurde.

Im Märchen zieht der junge Bodkin (Hastings/ Cartwright 1994) aus, um nach dem ewigen Leben zu suchen, das er auch findet: auf einem Berg bei einem alten Mann. Doch im Laufe vieler Jahre wird ihm das Leben dort fad und als er sich zurück in sein Heimatdorf aufmacht, trifft er auf einen gebrechlichen Mann: „Ich bin der Tod. Und dies sind all die Schuhe, die ich durchgelaufen habe, um dich

Falsifizierung im Vergleich mit anderen bekannten Tatsachen aus und wird vom Adressaten als ein Text gewertet, der sich auf seine Wirklichkeit oder Welt bezieht, in der auch er selbst lokalisiert ist." (Graduiertenkolleg Uni Freiburg 2012).

149 S. Abb. 6a u. 6b sowie die tabellarische Übersicht im Anhang (X.2); möglicherweise ist die ungeklärte Definitionsfrage für die großen Lücken im Zeitraum zwischen 1987 und 1998 ursächlich. 
zu finden. Komm mit mir, denn zum Leben gehört auch der Tod. "In allen Bilderbüchern, die eine Begegnung mit dem Tod ermöglichen, ist dies die zentrale Botschaft. Im Märchen von Susann Hesselbarth (2011) geht es genauer darum: Das Leben leben! Und das heißt, dem Leben möglichst viel abzugewinnen und sich seine Kostbarkeit zu erhalten: mit gutem Essen, Gastfreundschaft, Geselligkeit und interessanten Gesprächen. Bei Hesselbarth zieht ein altes Ehepaar alle Register dieser lebensbejahenden Lebensführung und überlistet den mit Sense und Stundenglas bewehrten Tod, der Tag für Tag als erschöpfter Reisender Einlass in ihr Haus begehrt. Allnächtlich wird das Stundenglas umgedreht, sobald der Tod nach einem üppigen Mahl und geselligen Abend eingeschlafen ist. Und wenn sie nicht gestorben sind, so haben sie noch heute jeden Abend den Tod zu Gast und müssen ihn nicht fürchten, solange sie ihr Leben auf diese Weise gestalten.

Ebenfalls 2011 ist die Parabel vom Herz in der Flasche (Jeffers 2011) erschienen. Darin beschließt ein kleines Mädchen, das [...] ziemlich genauso [war] wie alle Mädchen, mit einem Kopf voller Fragen nach dem Wesen dieser Welt, nach dem Tod des (vermutlich) Großvaters sein Herz an einem sicheren Ort aufzubewahren. Es verschließt es in einer Flasche (ein stilisiertes Röntgenbild zeigt, wo sich das Herz im Körper befindet, der Vorgang des Entfernens bleibt der Phantasie überlassen) und hängt sich diese um den Hals. Mit dieser Last verliert das Mädchen sein früher so ausgeprägtes Interesse an der Welt, wächst heran und trifft schließlich auf jemanden, der viel kleiner und immer noch neugierig auf das Wesen dieser Welt ist. Erst da wird ihm bewusst, dass es eines Herzes bedarf, um sich dem kleinen Mädchens und all seinen Fragen zuwenden zu können. Doch die Flasche scheint unzerstörbar, an das Herz ist mit physischen Kräften nicht heranzukommen. Erst dem fremden Mädchen gelingt es mit seinen kleinen Händen, das Herz aus der Flasche zu befreien. Die Metaphorik des schweren Herzens ist in diesem märchenhaften Bilderbuch sowohl auf der Sprachebene als auch auf der Bildebene auf eine sehr eingängige Weise umgesetzt, obwohl der sparsame Text meist nicht mehr als einen kurzen Satz pro Blatt umfasst. Die zahlreichen Leerstellen erschließen sich über die Bilder, die das Ungesagte erfahrbar machen: Der Tod des Großvaters ist im Symbol des leeren Stuhls ins Bild gesetzt und die lange Zeit der Trauer ist am Wachstum des erst sehr kleinen Mädchens abzulesen. Das Erzählen des auktorialen Erzählers ist auf das Wesentliche beschränkt und ausschließlich auf die innerpsychischen Vorgänge des Mädchens ausgerichtet, ohne sie explizit zu beschreiben. Die entsprechenden Leerstellen machen es möglich oder erfordern vielmehr, eigenes Empfinden und eigene Erfahrungen in die Geschichte einzubringen und auf dem Weg der Identifikation mit der Protagonistin nachzuvollziehen, um wie sie sich des eigenen 
Verhaltens bewusst zu werden. Vielleicht empfiehlt sich dieses Bilderbuch deshalb doch mehr den Erwachsenen, die ihren eigenen Trauerprozess noch nicht abgeschlossen haben und sich darin wiederfinden können.

\section{VI.2 Inhaltskategorien}

Auch für das Bilderbuch gilt: „Je differenzierter im Inhalt und je komplexer in der Form [...], um so (sic!) schwieriger ist es, eindeutig bestimmte Typologien auszumachen und voneinander abzugrenzen." (Payrhuber 2011, 114) Die bereits vorgestellten Ausgangshypothesen und Leitfragen dienen deshalb als Orientierungsrahmen, der einen probaten Zugang zum Untersuchungsmaterial und seiner inhaltlichen Vielfalt ermöglicht. Sie werden an dieser Stelle der Übersichtlichkeit halber erneut aufgeführt, im Weiteren mit dem ermittelten Datenmaterial abgeglichen und in qualitative Analyseergebnisse überführt.

1. In Abhängigkeit vom Erscheinungszeitraum hat sich das Bilderbuchangebot zur Trias Sterben, Tod und Trauer sowohl quantitativ als auch motivbezogen bis in die Gegenwart stetig erweitert.

2. Die Bilderbücher spiegeln verstärkt die Einstellungen einer säkularisierten Gesellschaft, in der religiöse Auffassungen kaum mehr eine Rolle spielen.

3. Dem zeitlichen Moment und der Emotionalität von Trauer wird in den Bilderbüchern seit der Jahrtausendwende zunehmend mehr Raum gegeben.

Folgende Leitfragen sind damit verbunden:

$\mathrm{Zu} 1$ und 2: Welche inhaltlichen Aspekte der Auseinandersetzung mit Tod und Sterben lassen sich - ggf. auf einer Zeitleiste als Entwicklungslinien bestimmende Schwerpunkte - nachweisen? Von welchen Todesfällen wird erzählt? Trifft beispielsweise die verbreitete Annahme zu, in Bilderbüchern werde mehrheitlich der Tod von Großeltern betrauert? Welche Rolle spielen Krieg und Gewalt als Todesursachen? Wie hoch ist der Anteil der Bilderbücher über Kindersterben? Welche Bilderbücher konzentrieren sich auf eine philosophische Auseinandersetzung mit Tod und Sterben, ggf. im Kontext von Naturphänomenen? Wie hoch ist der Anteil christlich-religiöser Bilderbücher am Gesamtkorpus? Welche Nachtodtheorien werden angesprochen?

$\mathrm{Zu}$ 3: Wie viele Bilderbücher erzählen von Sterbeprozessen? Wie viele Bilderbücher erzählen von Trauerprozessen? Inwiefern sind die aus der Thanatologie bekannten, verschiedenen Phasen des Sterbens bzw. des Trauerns ausgestaltet und wie zeigen sie sich ggf. in ihrer zeitlichen Ausdehnung? 
Im folgenden Kapitel wird zunächst ein Überblick über die Ergebnisse für den Zeitraum bis 1981 gegeben, der sich aufgrund der geringen Anzahl der recherchierten Bilderbücher als Anfangsphase des Erzählens vom Tod im Bilderbuch bezeichnen lässt.

\section{VI.2.1 Die ersten Bearbeitungen des Themas im Bilderbuch zwischen 1945 und 1981}

Als symptomatisch für die Bilderbuchkonzepte der Jahre von 1945 bis 1981 können zwei Bilderbücher angesehen werden, die zwar von Todesereignissen berichten, jedoch weder den Tod noch die Trauer zu handlungstragenden Motiven erheben. In Die Geschichte von Babar, dem kleinen Elefanten (de Brunhoff 1946; OA F 1931) heißt es lapidar: Der Jäger hat die Mami totgeschossen. [...] Das ist ein großes Unglück. Nach der Beerdigung versammeln sich die ältesten Elefanten, um einen neuen König zu wählen. Das Elefantenkind Babar findet sich daraufhin schnell in seine neue Rolle als Elefantenkönig ein und zeigt kaum eine Spur von Trauer. Ähnlich verfährt Swimmy (Lionni 1964; OA USA 1963), ein kleiner Salzwasserfisch, als einziger Überlebender seiner Familie ${ }^{150}$ bzw. seines gesamten Schwarmes: Erschrocken, traurig und einsam wedelte der kleine Swimmy hinaus ins große, große Meer. Ohne sich mit Trauern aufzuhalten und mit dem Willen zum Überleben und einem klugen Pragmatismus ausgestattet, stellt er sich den Gefahren des Ozeans, schließt sich einem anderen Fischschwarm an und avanciert zum Helden. Herauszulesen ist eine Botschaft, die für alle Altersgruppen gedacht ist: Besinne dich auf deine Stärke, wenn dich ein schweres Schicksal trifft, denn das Leben geht weiter und wird auch wieder gut, wenn du es selbst gestaltest.

Das erste recherchierte Bilderbuch, in dem ein Todesfall erlebt und die Trauer um ein geliebtes Tier ausgelebt wird, ist Atuk, der Eskimojunge (Damjan/ Casty 1965; OA CH 1964) ${ }^{151}$. Erzählt wird von der Liebe zu einem Hund und dem unerträglichen Schmerz des Verlustes, den der kleine Atuk mit Rachegelüsten zu kompensieren sucht. In seinem Streben nach Vergeltung an dem Wolf, der seinen Hund getötet hat, wächst er zu einem von allen und allem gefürchteten

150 Kindliche Trauerprozesse nach dem Verlust eines Elternteils treten als zentrales Erzählmotiv erstmals 1993 (Tod der Mutter) bzw. 1994 (Tod von Vätern) auf (Heymans/ Heymans 1993: Die Prinzessin im Gemüsegarten; Wolf/ Sopko 1994: Weihnachten bei Großvater; Becker/ Mocka 1994: Roberts alter Freund).

151 Neuauflage 2008 bei NordSüd mit dem Titel Atuk und neu illustriert von Józef Wilkoń 
jungen Jäger heran und erlegt schließlich den Gejagten. Doch die erhoffte entlastende Wirkung bleibt aus, die Sinnlosigkeit des Tötens wird offenbar. Das Bild dazu zeigt aus der überschauenden Perspektive eines auktorialen Erzählers den tot im Schnee liegenden, wie aus sich selbst heraus leuchtenden Wolf, was anrührt, gleichzeitig Distanz schafft und den Betrachter unweigerlich auf die Sinnfrage verweist. Im Text, der die personale Perspektive einnimmt, heißt es:

Nun lag der Wolf tot vor ihm. Aber Atuk war nicht glücklich. Er war noch trauriger als zuvor. Sein Taruk war tot. Der Wolf war tot. Die Tundra lag leer und stumm vor ihm. Nichts hatte sich geändert! Wohl hatte er den Wolf getötet, aber Taruk war nicht zu ihm zurückgekommen.

In der Verschmelzung von Wort und Bild kommt die Botschaft, dass Hass und Rache weder Lebenszweck noch Ausgleich sein können, ebenso zum Ausdruck wie die Unabgeschlossenheit des Trauerprozesses. Erst als Atuk Freundschaft und Liebe in Gestalt eines weisen Blaufuchses und einer sprechenden Blume erfährt, wendet er sich wieder dem Leben zu. Es ist eine Geschichte, die drei existenzielle menschliche Erfahrungswerte anspricht: die Unumkehrbarkeit des Todes, die Sinnlosigkeit von Rache und die Bedeutung liebevoller Beziehungen.

Die Sinnlosigkeit des Kriegführens ist das Thema in der ersten recherchierten deutschen Originalausgabe eines Bilderbuchs zum Thema und datiert auf das Jahr 1968 von Janosch (Horst Eckert) mit dem Titel Böllerbam und der Vogel. Darin erzählt Janosch, dem kritischen Zeitgeist der 1968er-Jahre entsprechend, die Geschichte vom schießwütigen Soldaten Böllerbam, dessen Lebenszweck das Schießen ist, bis es ihm selbst zum Verhängnis wird und seine Inhaftierung der Welt den ersehnten Frieden bringt. ${ }^{152}$

Die vorliegende Untersuchung belegt, dass bis in die 1980er-Jahre das Bilderbuchschaffen in Deutschland noch weit davon entfernt war, die Realität menschlichen Sterbens aufzugreifen und sich mit den emotionalen Dimensionen dieser Grenzerfahrungen auseinanderzusetzen. ${ }^{153}$ In lediglich vier von insgesamt 21 Titeln dieses Zeitraums, davon drei Übersetzungen aus skandinavischen Ländern und ein deutsches Sachbilderbuch, sind Beziehungsverluste an kindliche Erfahrungshorizonte geknüpft. Oles Großvater (Gydal/ Danielsson/ Andersson 1974; OA S 1974) stirbt am Ende eines erfüllten Lebens im Einklang mit der Welt und sich selbst und antwortet auf die Fragen seines fünfährigen Enkels folgendermaßen: Wenn man alt ist und alles getan hat, was man gerne tun wollte, dann hat man keine Angst mehr vor dem Sterben. Ole selbst weiß sich in seiner Familie

152 S. a. Kap. VI.2.5.4.

153 S. die tabellarische Übersicht im Anhang (X.2). 
aufgehoben und tröstet sich nach dem Tod des geliebten Opas mit der Gewissheit: Großvater ist in meinen Gedanken. Also ist er da. Religiöse Aspekte spielen keine Rolle. Anders im Fotobilderbuch Johanna und der Tod (Melin 1977; OA S 1977). Dort sieht der alte Nachbar und Freund der etwa fünfährigen Johanna seinem Lebensende, das für ihn Erlösung von Krankheit und Gebrechen bedeutet, mit dem Glauben an Gott entgegen: Ich will lieber heimkommen zu Gott. (23) Auf die Frage Johannas, wo das sei, antwortet er: Das kann man nicht wissen, aber ich weiß, daß Gott sich um mich kümmert, wenn ich sterbe. (23) Und als die Nachricht von seinem Tod eintrifft, beschließt Johanna das gemeinsame Gebet mit ihrer Mutter mit den Worten: Weißt du, was ich glaube? Ja, wenn man tot ist, da ist man lebendig bei Gott. (24) Neue Spielkameraden füllen dann schnell die Lücke, die der Tod des Freundes in ihrem Alltag hinterlassen hat. Beiden Bilderbüchern gemeinsam ist die realistische und gesprächsoffene Atmosphäre, die es Kindern ermöglicht, den Tod als natürliche Erscheinung am Ende eines langen Lebens zu akzeptieren, ohne auf die eigene Sterblichkeit verwiesen zu werden, was den thanatopsychologischen Kenntnissen über Verstehensfähigkeiten der Altersgruppe der kindlichen Protagonisten entspricht.

Welchen Wert offene Gespräche zwischen Erwachsenen und Kindern für ein entlastendes Umgehen mit dem Tod haben, wird ebenso in dem Sachbilderbuch Ich will etwas vom Tod wissen (Becker/ Niggemeyer 1979) ${ }^{154}$ deutlich, in dem es in 28 alltagsnahen Geschichten und Kommunikationssituationen um den natürlichen Rhythmus von Natur und Jahreslauf, die Natürlichkeit von Alter und Tod, um persönliches Todesbewusstsein, die Frage nach Jenseitsvorstellungen, um belastende Aspekte wie Todesangst oder Schuldgefühle und selbst den Tod von Kindern geht. Dieses Fotobilderbuch ${ }^{155}$ steht ganz im Zeichen des

154 Ausführlicher in Kap. VI.1.4.

155 Von den insgesamt elf Fotobilderbüchern sind sechs in den Jahren 1976 bis 1983 erschienen, was als Indiz für das seinerzeit neue, auf Realitätsnähe ausgelegte Erzählen für Kinder in Wort und Bild gedeutet werden kann. Die Fotos geben vor, auf dem Weg der literarischen Verarbeitung wirkliches Leben abzubilden und die Welt erklären zu können. Eben diese Problematik der Fiktionalität von Medienbildern wird In Tobis böser Traum (Haerdter/ Redl 1976) aufgegriffen. Das textfreie Fotobilderbuch setzt die Angst eines etwa Siebenjährigen ins Bild, der nach dem Anschauen eines Westerns von Albträumen geplagt aufwacht und offenbar von seinem Vater getröstet wird. Die Fotos zeigen in wechselnder Perspektive den Jungen und das filmische Geschehen, dessen Fiktionalität im Weiteren mit Fotos entlarvt wird, die augenscheinlich am Set nach dem Abdrehen des Films entstanden sind: Der vermeintliche Tote steht auf und gibt sich als Schauspieler zu erkennen, das verwendete Mordinstrument ist ein Gummimesser etc. Diese Bilder ersetzen eine 
„Daseinsernstes“ (Ewers 1995, 25) der 1970er-Jahre, der sich auch auf der formalen Seite in den Schwarz-Weiß-Fotos ausdrückt, welche, ebenso wie im oben beschriebenen Johanna und der Tod (Melin 1977; OA S 1977), als vermeintlich reale Momentaufnahmen Wahrheit suggerieren.

Ein herausragendes, inhaltlich und formal an der Realität orientiertes Bilderbuch, für dessen Konzeption keine weitere Entsprechung gefunden wurde, stellt Christoph verliert seinen Freund (Carrick/ Carrick 1980, 1-23) inklusive der Fortsetzungsgeschichte Christoph und Ben (ebd., 23-46) dar. Die Geschichte lässt sich ganz auf die Gefühlswelt des 6-8-jährigen Protagonisten ein, der um seinen von einem Laster überfahrenen Hund trauert. Nicht-wahrhaben-Wollen, Schuldgefühle und Wut angesichts der vom Vater heimlich vorgenommenen Beerdigung des Hundes wandeln sich im ersten Teil des Buches in Traurigkeit: „Aber es tut gut, zu weinen." (22) An dieser Stelle fordert die doppelte Konzeption des Buches ein Innehalten, am Layout auszumachen in Gestalt der Titelseite der Anschlussgeschichte auf Seite 23, welches Raum für ein empathisches Nachspüren gibt. Der Trauerprozess, der sich in der dritten Phase, der des Suchens und Sich-Trennens befindet, wird im zweiten Teil des Buches fortgesetzt und zu einem überaus nachvollziehbaren, positiven Abschluss gebracht: Nachdem Christoph den gut gemeinten Vorschlag seiner Eltern ablehnt, sich mit einem Ersatzhund aus dem Tierheim zu trösten, geht die anfängliche Ambivalenz seiner Gefühle in die Bereitschaft über, eine neue Freundschaft mit einem Findelhund zu schließen, dem er den Namen seines alten Teddybären Ben gibt. Dieses Buch spiegelt in seiner Doppelstruktur alle bekannten Trauerphasen und greift den Wendepunkt, die beginnende Bereitschaft, sich wieder dem Leben zuzuwenden, in kongenialer Weise auf.

Eine solitäre Erscheinung in gestalterischer wie thematischer Hinsicht ist Das unglückselige Kind von Edward Gorey (1967; OA USA 1961), dessen Szenario an Grauen und Tragik kaum zu überbieten ist. Ein Mädchen aus wohlhabendem Hause verliert erst den Vater, dann die Mutter und in der Folge jeden menschlichen Rückhalt, gerät an zwielichtige Gestalten und in schreckliches Elend und stirbt schließlich, als der tot geglaubte Vater es unwissentlich überfährt. Erschienen im Verlag Diogenes, ist dies kein Bilderbuch für Kinder. Die kausale Abfolge der Schreckensszenarien und die Intensität der Darstellung des kindlichen Leides sind selbst für Erwachsene kaum aushaltbar. Als Gegenentwurf zu aller

Sprachebene und repräsentieren quasi die Erklärungen des Vaters zum Unterschied zwischen Fiktion und Wirklichkeit, erfordern aber eine Bildlesekompetenz, die damit in doppelter Weise auf der formalen und inhaltlichen Ebene thematisiert wird. 
kinderliterarischen Idylle ist dies eine düstere Bilderbuchgeschichte, die den Tod nicht als natürliches Lebensende in den Blick nimmt, sondern ihn als das Leben ständig bedrohendes Schreckensgespenst buchstäblich ins Bild setzt. ${ }^{156}$

Zusammenfassend kann für die 21 untersuchten Bilderbücher der Jahre bis 1981 konstatiert werden, dass sie sich einerseits durch Realitätsbezüge mit der Tendenz zum informierenden Erzählen auszeichnen und andererseits das Handlungsgeschehen fast ausschließlich in den Kontext von Tierschicksalen legen. Die weiteren Untersuchungsergebnisse werden in Abhängigkeit von gattungsspezifischen und inhaltsbezogenen Dimensionen im Folgenden kategorisiert und beschrieben.

\section{VI.2.2 Das religiöse Bilderbuch ${ }^{157}$}

Nachdem für die Gesamtheit der Kinderliteratur seit den 1960er-Jahren, abgesehen von der konfessionellen Gebrauchsliteratur, insgesamt eine Marginalisierung religiöser Inhalte festzustellen war (vgl. Mattenklott 1994, 242), „, folgt 1997 und 1998 ein regelrechter Boom der Religion in der Kinder- und Jugendliteratur" (Mattenklott 1998, 33), der auch messbar auf das Bilderbuchangebot abfärbte. Was aber ist religiöse Kinderliteratur? In jedem Fall sind es solche Texte, die explizit christlich-biblische Glaubensgrundsätze oder die anderer Religionsgemeinschaften thematisieren, „wo also in der Tat von Glaube, Gebet und Gottvertrauen, von Heil und Erlösung die Rede ist" (Wittekind 2009, 11). Dieser engen Auslegung von Religion in der Literatur steht ein „hermeneutisch-theologischer Grundsatz [gegenüber; M.H.]: Alle Literatur, alle Kunst, jeder schöpferische Umgang des Menschen mit sich selbst und jede Bemühung um Selbstdeutung ist religiös imprägniert.“ (Ebd.) Zwischen diesen beiden Polen, der sehr engen

156 Der aufmerksame Betrachter findet auf allen Blättern, mehr oder weniger verborgen, das auf dem Einband abgebildete Wesen wieder, ein kleines Ungeheuer, das als Unheilbringer überall lauert, das zunächst hell schraffiert auf dem 4. Blatt hinter der geöffneten Tür hervorlugt und dann sowohl seine Farbe ins Schwarze als auch seine Physiognomie wechselt, mal froschähnlich erscheint, mal lurchähnlich mit Hörnern, mal als Fledermaus. Die Kunstfertigkeit Goreys zeigt sich wie in allen seinen Werken in der Parallelität des Ausdrucks in Bild und Sprache, hier in den schwarz-weißen Zeichnungen und dem lakonischen Sprachstil, worin sich die erbarmungslose Kälte der Lebenswelt des Mädchens spiegelt.

157 Die hier nicht erfassten Titel implizieren eine „ethisch-existenzielle Ebene“, ohne in irgendeiner Form auf eine über das Irdische hinausgehende Dimension zu verweisen (vgl. Motté 1997, 28), und werden aufgrund dessen im Folgenden als säkularisierte Bilderbücher bezeichnet. 
und der sehr weiten Auffassung des Religionsbegriffs, liegt der "gegenwärtige Mainstream der katholischen Literaturtheologie“, wonach jede „Form von Sinnsuche, alle Artikulationen von letzten Fragen [...] als Ausdruck von Religion im Sinne eines Bezogenseins auf den unverfügbaren göttlichen Grund behandelt werden" können (ebd.). Demnach tut sich immer dann eine religiöse Dimension auf, wenn Gedanken und Vorstellungen über das Materialistisch-Naturwissenschaftliche hinausgehen, wenn

der Mensch in der Erfahrung von Liebe und Gemeinsamkeit, von Angst und Einsamkeit, von Leid und Tod an die Grenzen seiner Erkenntnis- und Erlebnisfähigkeit geführt wird, wenn er [...] das Ich nicht zum Mittel- und Zielpunkt des Universums stilisiert, sondern diese Erfahrungen transzendiert, das heißt, sich auf einen letzten, alles umfassenden Sinngrund verwiesen fühlt, von dem er sich abhängig weiß und dem er sein Leben verdankt (Motté 2011, 147).

Die Problematik einer Diagnostik religiöser Literatur liegt auf der Hand, zumal die Beschäftigung mit dem nach dem Tod Möglichen eine Glaubensfrage ist, die individuell und intersubjektiv verhandelt wird, auch ohne damit konfessionellreligiöse Momente zu implizieren. Sterbeprozesse und Todeserfahrungen können religiöse Haltungen anstoßen und zu einem Glaubensbekenntnis anregen, sie erfordern es aber nicht, was ebenso für literarische Bearbeitungen gilt. Bei Langenhorst (2011, 14; H. i. O.) findet sich folgende Kategorisierung, die auf Magda Motté $(1989,1997,2011)^{158}$ rekurriert:

- Werke der ,nicht intentional religiösen Literatur, die in erster Linie die ,ethisch-existenzielle Ebene' betreffen;

- Werke der ,religiösen Literatur, die eine allgemeine, nicht spezifisch konfessionell oder auf eine bestimmte Religion festgelegte, transzendental-religiöse Dimension' aufrufen;

- Werke der explizit ,christlichen Jugendliteratur, in denen die ,christliche Botschaft' direkt und unmittelbar erkennbar im Mittelpunkt steht.

Diese Kategorien wurden für das vorliegende Textkorpus modifiziert:

1. Das transzendental-religiöse Bilderbuch konkretisiert Entwürfe von Jenseitsorten oder Dimensionen einer nachtodlichen Weiterexistenz, die nicht explizit christlichen Glaubensvorstellungen folgen. Dazu gehören auch die Vorstellungen von einer Leib-Seele-Trennung, die eine unsterbliche Existenz außerhalb der sterblichen Leibhülle implizieren.

158 Vgl. dazu auch Born 2007. 
2. Das christlich-religiöse Bilderbuch erzählt von der im christlichen Glauben verankerten Überzeugung von der unversehrten Auferstehung und einem Bei-Gott-Sein. Die Vorstellungen einer Weiterexistenz nach dem Tod greifen das Symbol des Himmels auf, der implizit oder explizit für andauernde, ewige Seligkeit bei Gott steht und das anschlussfähige Indiz für eine Verortung in der christlichen Glaubenskultur darstellt.

Die Verfasserin beschränkt sich auf diese zwei Kategorien in dem Bewusstsein, dass die Unterscheidung zwischen Christlichem und Transzendental-Religiösem ohne eine fundierte Anbindung an theologische Theorien und Modelle hier nur eine vorläufige sein kann. ${ }^{159} \mathrm{Da}$ es "gegenwärtig kein allgemein akzeptiertes methodisches Instrumentarium“ zur Differenzierung von religiöser und nicht religiöser (Kinder- und Jugend-) Literatur gibt (Wittekind 2009, 11), können nur jene Bilderbücher, in denen Tod und Trauer mit einem expliziten Hinweis auf christliche Glaubensgrundsätze oder transzendental-religiöse Vorstellungen verbunden sind, von den säkularisierten Bilderbüchern abgegrenzt werden, die den Tod als absolutes Ende beschreiben bzw. darüber hinaus keine Überlegungen anstellen.

In der Übersicht (Abb. 11) sind alle Bilderbücher erfasst, welche die oben erläuterten Merkmale der ausgewählten Kategorien aufweisen, womit auch Interferenzen berücksichtigt sind. Insgesamt liegen auf der Basis der oben genannten Definitionen 147 Bilderbücher vor, die auf philosophische bzw. existenzielle Fragen mit religiösen Erklärungsmustern reagieren, davon 60 christlich-religiös und 87 transzendental-religiös konnotierte. ${ }^{160}$ Darunter wiederum befinden sich nur acht Titel ${ }^{161}$ mit explizit interreligiösen Aspekten, die neben christlichen Jenseitsvorstellungen auch die anderer Kulturen oder Weltreligionen ansprechen. Damit bestätigt sich Feststellung von Gundel Mattenklott (1994, 243; H. i. O.), „die Annäherung an das Thema ,Tod‘ im Kinderbuch [vollziehe sich; M.H.] häufig in einem Grenzbereich undefinierbar vager Religiosität.“

159 Vgl. dazu ausführlicher: Dreßing 2004.

160 S. a. die tabellarische Übersicht im Anhang (X.2).

161 Galeano/ Santos 2010; Schins/ Müller 2008; Schulz/ Krejtschi 2007; Schins/ Müller 2005; Müller 2003; Gerstein 2000; Coerr/ Young 1995; Lundgren/ Jacobsson 1983. 
Abb. 11: Inhaltsbezogene Kategorisierung - religiöse und philosophische Bilderbücher.

\begin{tabular}{|c|c|c|c|c|c|c|}
\hline \multirow[b]{2}{*}{ Zeitraum } & \multirow[b]{2}{*}{$\begin{array}{c}\text { Gesamt- } \\
\text { korpus }\end{array}$} & \multicolumn{5}{|c|}{ Religiöse und philosophische Bilderbücher } \\
\hline & & $\begin{array}{c}\text { Religiöse } \\
\text { Bilderbü- } \\
\text { cher } \\
\text { - gesamt }\end{array}$ & $\begin{array}{l}\text { christliche } \\
\text { Bilderbü- } \\
\text { cher } \\
\text { - anteilig }\end{array}$ & $\begin{array}{c}\text { transzen- } \\
\text { dentale } \\
\text { Bilderbü- } \\
\text { cher } \\
\text { - anteilig }\end{array}$ & $\begin{array}{c}\text { Philoso- } \\
\text { phische } \\
\text { Bilderbü- } \\
\text { cher }\end{array}$ & $\begin{array}{l}\text { Motiv: } \\
\text { Natur- } \\
\text { kreislauf }\end{array}$ \\
\hline $1946-1971$ & 10 & 1 & 1 & - & 2 & 2 \\
\hline $1972-1981$ & 12 & 5 & 3 & 2 & 1 & 2 \\
\hline $1982-1991$ & 39 & 16 & 6 & 11 & 7 & 4 \\
\hline 1992-2001 & 85 & 49 & 21 & 28 & 14 & 7 \\
\hline $2002-2011$ & 141 & 76 & 30 & 46 & 17 & 4 \\
\hline Gesamt & 287 & 147 & 60 & 87 & 41 & 19 \\
\hline
\end{tabular}

Abb. 12: Darstellung des prozentualen Anteils religiöser Bilderbücher am Gesamtkorpus.

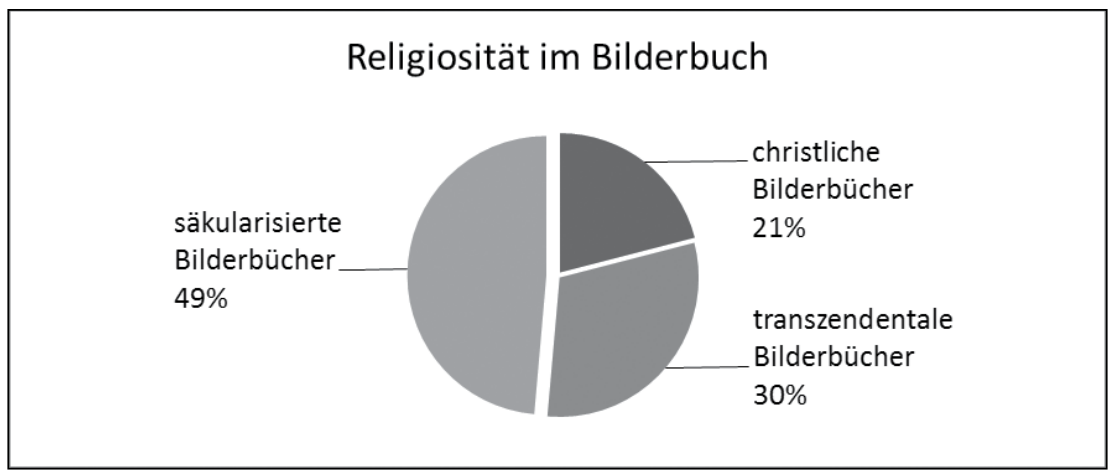

Obwohl mit den Minimal-Kriterien für christlich-religiöse Bilderbücher - die Erwähnung des Himmels als neuer Aufenthaltsort und Hinweise auf eine christliche Bestattungskultur (Besuch auf dem Friedhof, Teilnahme am Begräbnis, Särge und Kreuze) - die Kategorie breit aufgestellt ist, ist der Anteil von 21\% $(\mathrm{N}=60)$ am Gesamtkorpus als niedrig einzuschätzen (Abb. 12). Enger gefasst und beschränkt auf die Veröffentlichungen, die auf der Sprachebene von Gott künden und damit als konkret-religiös bezeichnet werden können ${ }^{162}$, reduziert sich der Anteil nochmals auf 13\% ( $\mathrm{N}=38)$. Noch deutlicher stellt sich die

162 Es muss darauf hingewiesen werden, dass hier lediglich eine quantitative Aussage getroffen wird, bezogen auf die Häufigkeit der Verwendung der Vokabel Gott. Welche Glaubensbekundung damit tatsächlich einhergeht, muss am Einzelfall geprüft werden. 
Marginalisierung konkret-neutestamentlicher Glaubensvorstellungen dar, wenn man nur die fünf Bilderbücher berücksichtigt, die den Auferstehungsgedanken explizit mit Jesus in Verbindung bringen. ${ }^{163}$ Mehrheitlich drücken sich dagegen diffuse Hoffnungen auf ein Weiterexistieren nach dem Tod aus, ohne dass sie sich auf eine größere, göttliche Macht stützten. Die vorangestellte Hypothese, die Bilderbücher spiegelten die Einstellungen einer säkularisierten Gesellschaft, in der konkret-religiöse Auffassungen vom Tod kaum mehr eine Rolle spielten, kann damit bestätigt werden. Festzuhalten ist daneben, wenn, wie hier vorgeschlagen, das Spektrum religiöser Aspekte weit gefasst wird, dass die dekadisch aufbereiteten Zahlen (Abb. 11) eine mit dem wachsenden Bilderbuchangebot nahezu gleichziehende Zunahme religiöser, nicht konfessionsgebundener Bilderbücher belegen. Dieses Ergebnis kann trotz der beschriebenen Unschärfe als Tendenz einer vielleicht sogar zunehmenden „Religionsbedürftigkeit“ (Wagerer 1997, 35) im gegebenen thematischen Kontext gedeutet werden.

Die säkularisierten Bilderbücher implizieren insgesamt eine „ethisch-existenzielle Ebene“ hinsichtlich „ihrer allgemein menschlichen Themen, wie die Frage nach dem Ich und Du, [...], der Krankheit und dem Tod. Sie [...] gehen aber nicht über das Sichtbare hinaus, öffnen kein Fenster mit Blick auf eine andere, größere Welt." (Motté 1997, 28) Dazu gehören philosophische Bilderbücher im hier definierten Sinne (Kap. VI.2.3) ebenso wie Sachbilderbücher und erzählende Bilderbücher, trennscharfe Abgrenzungen sind aber auch hier nicht geboten. Wie also die so zusammengestellten Teilkorpora des gesamten, aufgrund des Todesthemas religionsaffinen Textmaterials vor dem Hintergrund theologischer, religionspädagogischer, soziologischer und anderer Forschungsansätze neu und anders zu kategorisieren bzw. zu bewerten wären, muss diesen Disziplinen überlassen werden.

In der hier vorgenommenen Differenzierung wird außerdem deutlich, dass die kommunikative Auseinandersetzung mit dem Tod in einem religiösen Umfeld offenbar eine größere Rolle spielt als in einem säkularisierten. Dies ist an der Anzahl der christlich geprägten Bilderbücher festzumachen, die sich durch eine verhältnismäßig höhere Kommunikationsbereitschaft der Protagonisten und ihrer Bezugspersonen auszeichnen. Häufiger als in den transzendental-religiösen Texten wird explizit die Frage nach dem Verbleib der/des Verstorbenen gestellt, worauf mit Glaubensüberzeugungen geantwortet wird. Die dazu geäußerten Erwartungen an ein ,erlebbares' Danach lassen eine Furcht vor dem Tod gar nicht

163 Hubka/ Hammerle 2004; Vinje/ Zahl-Olsen 2000; Essen/ Schuler/ Bernard-Kress 1999; Waldman-Brun 1995; Nystrom/ Large 1991. 
erst aufkommen oder räumen Befürchtungen gleich aus, wie sie z. B. in Garmans Sommer (Hole/ Kronenberger 2009) hinter den Fragen an die alten Tanten stehen und in erheiternde Vorstellungen gewandelt werden.

Bemerkenswert ist, dass im gesamten Textkorpus überhaupt nur sieben Bilderbücher mehr oder weniger deutlich die Angst vor dem eigenen Tod thematisieren oder zumindest ungute Gefühle damit verbinden. ${ }^{164}$ Für die kleine Schnecke im gleichnamigen Bilderbuch (Ghazinoor 1993) ist es die Angst vor dem Gefressenwerden, die sie ans Haus fesselt, weshalb es vielleicht mehr eine Angst vor dem Leben ist, zu dem doch beides gehört: das Fressen und das Gefressenwerden. Erst ein anderer Schneck kann die kleine Schnecke davon überzeugen, dass das Leben nur lebenswert ist, wenn man es auch wagt. Die Angst vor dem Tod wird aber dann konkret, wenn er das absolute Ende markiert, wie in Marianne denkt an ihre Großmutter (Egger/ Jucker 1986). Dass dagegen die Rede vom Reich Gottes in christlich geprägten Familien eine sehr tröstliche sein kann, zeigt sich z. B. deutlich in Lara's Schmetterlinge (sic; Blumentritt 2003) oder in Franziska und der alte Gärtner (Marx/ Herrmann 1998). Die Protagonistin Franziska im letztgenannten Bilderbuch ist traurig über den Tod ihres alten Freundes - und sie darf traurig sein. Die Mutter erzählt ihr von der tröstenden Vorstellung eines neuen Lebens bei Gott, das alle erwartet und nicht zu fürchten sei:

„Eines Tages darfst du selbst bei Gott sein, Franziska. Dann wirst du Jakob vielleicht wiedersehen. Und bis dahin kannst du die Erinnerung an ihn lebendig halten. Dann lebt Jakob in deinem Herzen weiter und bleibt immer bei dir."

Das Kind säht Vergissmeinnicht auf Jakobs Grab aus und ist manchmal, wenn es den Blumen Wasser gibt, traurig, manchmal fröhlich, womit ein authentisches Identifikationspotenzial dargeboten wird. Die realistisch-malerischen Bilder tragen ein Übriges dazu bei.

Auch die im Gebet verbalisierte Gedankenrede ist ein probates Mittel, eine durch den christlichen Glauben gestützte Trauerverarbeitung deutlich zu machen. In Bernis Opa (Witt 2010, 28) findet der trauernde Enkel beispielsweise Trost in der beeindruckend schlichten und nachvollziehbaren Schlussfolgerung: Lieber Gott, wenn der Opa jetzt auch tot ist, hast du ihn ja doch gesund gemacht, weil ihm nun nichts mehr wehtut. Das finde ich gut. Amen. Angesichts dieser Erkenntnis verliert der eigene Verlustschmerz an Bedeutung. Gleichsam überhöhend und bestätigend spielt zusätzlich die gedankliche Vergegenwärtigung des

164 Crowther 2011; Hole/ Kronenberger 2009; Lemieux 1996; Ghazinoor 1993; Egger/ Jucker 1986; Haerdter/ Redl 1976; Gydal/ Danielsson 1975. 
Verstorbenen eine wichtige Rolle, indem an die aus der Vergangenheit bekannten, positiven Interaktionsmuster angeknüpft (gemeinsame Pflege des Grabes der verstorbenen Großmutter) und eine Verbindung über den Tod hinaus herstellt wird: Und dann dachte er wieder an seinen Opa und hörte genau, wie der wieder zu ihm sprechen konnte: „Nicht wahr, mein Kleiner, jetzt geht's uns beiden gut! Und wenn du mir eine Freude machen willst, legst du auf mein Grab auch ein paar Gänseblümchen. "Der Leser darf es Berni getrost gleichtun: sich erinnernd der Gegenwärtigkeit des Verstorbenen vergewissern und getröstet sein. Zu kurz kommt wie in fast allen Bilderbüchern auch hier das Zulassen negativer Emotionen, die sich z. B. in frustriertem Unmut über die Undurchführbarkeit der geplanten Unternehmungen mit dem Opa ausdrücken könnten. Möglicherweise ist aber eben diese Sicht auf den Tod als Befreier von Schmerzen und Leid - unabhängig von Glaubensbekenntnissen oder der Negierung eines Gotteswirkens die trostreichste, weil Sinn gebende. Ganz anders stellt sich der Tod dagegen für diejenigen Trauernden dar, deren geliebte Angehörige oder Freunde durch einen Unfall plötzlich aus dem Leben gerissen werden. Monika Born $(2007,17)$ fordert deshalb von religiösen Büchern:

Junge Kinder müssen durch religiöse Bücher eine grundlegende Geborgenheit erfahren, die durch schlimme Erfahrungen nicht so leicht zu erschüttern ist. Sie müssen sehen können, dass ihre Fragen ernst genommen und - vielleicht zunächst sehr vorläufig, aber wahrhaftig - beantwortet werden.

Ob dafür das Erzählen über das Wirken von Engeln, die geliebte Bezugspersonen abholen und an einen unerreichbaren Ort bringen, hilfreich sein kann, kann und sollte hinterfragt werden. Unbedachte Äußerungen von Erwachsenen über die nachtodliche Gestaltwerdung als Engel rufen bei jüngeren Kindern sicher dann Enttäuschung und Verwirrung hervor, wenn ihnen solche Begegnungen in Aussicht gestellt werden und sich diese Erwartungen nicht erfüllen. Diese Reaktion zeigt der kindliche Protagonist Jannik in Opa ist überall (Ellsworthy/ BenArab 2009). Jannik darf bei der Beerdigung dabei sein und sieht, wie der Sarg mit dem Großvater ins Grab hinabgelassen wird. Die Mutter teilt ihm dazu mit, der Opa sitze nun als Engel auf einer Wolke und schaue auf sie herab. Während eines Fluges in den Urlaub hält Jannik dann vergeblich in den Wolken nach dem Opa Ausschau und verlangt enttäuscht und immer trauriger nach einer Antwort auf die Frage Was passiert, wenn man tot ist?. Dass sich die Mutter daraufhin für ihre unüberlegte Äußerung entschuldigt und ihm den Trost der christlichen Botschaft nahebringt, mag vorlesenden Eltern ein Signal sein, auf verwirrende Behauptungen zu verzichten. 


\section{Engelfiguren}

Engelfiguren sind im „Zuge des Säkularisierungsprozesses [...] zu interessanten Flügelwesen eines jahrhundertealten Kulturrepertoires geworden" und in ihren ästhetischen Adaptionen der Gefahr des Kitsches besonders ausgesetzt (Tabbert 2005, 135f.). Die unmittelbar wahrnehmbare Verkörperung des Übernatürlichen in Gestalt von Engeln präsentieren 20 Bilderbücher ${ }^{165}$ des Gesamtkorpus', zwischen 1985 und 2000 sind es sieben, ab 2000 dreizehn Exemplare, die auf sehr unterschiedliche Weise und in verschiedenen Kontexten von Engelwesen und ihrer verantwortlichen Einflussnahme auf Verstorbene oder von der im Tod angelegten Verwandlung in Engel erzählen. Ein Drittel davon betrifft die Kategorie des Kindertodes und wird in Kapitel VII in die Analyse einbezogen.

Bilderbücher, die Engelsfiguren visualisieren, erreichen bzw. überschreiten mitunter die Grenze zum Kitsch, die von Kindern aber schwerlich als solche erkannt werden kann. In Das Mädchen Jane und die blaue Wolke (Matzen/ Grundmann 2003) vermittelt ein Schutzengel im Zwiegespräch dem fragenden Kind, das Ziel sei ein goldenes Licht, in dem der verstorbene Großvater schon auf die Großmutter warte. Das Geschehen gipfelt in der vom Mädchen mit ungeheurer Souveränität gestalteten Sterbebegleitung, die völlig ohne Verlustschmerz auf das Wunderbare nach dem Tod hinführt:

Jane fühlte sich glücklich und geborgen. Sie war ein kleines bißchen stolz, daß sie Großmutter Lilli den Weg zum goldenen Licht gezeigt hatte. Sie würde nun all dies auch ihrer Mutter erzählen, damit sie nicht so traurig sein würde. Auch sie sollte sich freuen, daß Großmutter Lilli das goldene Licht gefunden hatte, und vielleicht konnte sie mit ihr gemeinsam üben, Großmutter Lilli und Großvater auch weiterhin zu sehen und zu hören und zu fühlen.

Was da dem Kind überantwortet wird, kann dem lesenden Kind nur zur Last werden, wenn es in seiner Realität Gleiches zu finden hofft und zu leisten sich aufgefordert fühlen muss.

\section{Himmel}

Wie die Vorstellung von Engeln ist auch die vom Himmel als Aufenthaltsort der Verstorbenen auf die christliche Glaubenslehre zurückzuführen. Im

165 Paffrath 2010; Ellsworthy/ Ben-Arab 2009; Höschl/ Kutschera 2008; Jakoby/ Adler 2008; Herrmann/ Bahde 2007; Abedi/ Cordes 2006; Walbrecker/Mair 2006; Aakeson/ Eriksson 2005; Stanko/ Jankowski 2005; Matzen/ Grundmann 2003; Bauer 2001; Treiber/ Blazejowsky 2001; Vinje/ Zahl-Olsen 2000; Horvath/ Horvath 1999; Rylant 1998; Stark/ Höglund 1997; Allan 1996; Ende/ Hechelmann 1988; Janosch 1985; Kübler-Ross/ Rothmayr 1985. 
einschlägigen Textkorpus wird deshalb von einer religiös motivierten Vorstellung vom Himmel ausgegangen, obwohl der alltägliche Sprachgebrauch des Begriffs kaum noch Ausdruck einer religiösen Haltung ist, sondern eher eine unspezifische Vollkommenheit meint. Religiös konnotiert steht der Himmel für die Hoffnung des Menschen, nach dem irdischen Leben mit der Befreiung von allen Lasten und dem Erreichen eines Zustandes größter Glückseligkeit quasi belohnt zu werden. Der Tod hat dann lediglich eine Transferfunktion. Elisabeth Kübler-Ross hat anhand zahlreicher Protokolle von Gesprächen mit Sterbenden und Menschen, die über Nahtoderfahrungen berichten konnten, den Glauben an diese Vorstellung in den Bereich der Gewissheit zu heben versucht. Ohne ihre Verdienste für die Sterbeforschung in Abrede stellen zu wollen, wird ihr aber von Kritikern zu Recht eine überzogen esoterische Haltung vorgeworfen, die in dem von ihr verfassten Bilderbuch Die unsichtbaren Freunde (1984) einen fast unerträglich kitschigen Ausdruck in der Ausgestaltung eines himmlischen Paradieses findet. Ebenso esoterisch mutet die Geschichte von Felix an, einem kleinen Mönch, der Tag und Nacht zu Gott betet, er möge ihm zeigen, wie es im Himmel aussieht. Schließlich lotst ihn ein kleiner Vogel mit seinem Gesang in den Wald und eröffnet ihm mit seiner Himmelsmelodie (Kasuya/ Watari 2007) eine Welt, wie er sie sich nicht schöner hätte vorstellen können, aus der er aber wieder in seine Wirklichkeit zurückkehren darf. Dagegen stellen Katzenkind und Hasenkind in Lakritzbonbons (van Ommen/ de Wanten 2003) während eines gemeinsamen Picknicks ihre Vorstellungen vom Himmel in den Kontext ihrer Freundschaftsbeziehung und fragen sich interessiert-besorgt, ob und wie sie sich dort oben, wo sich doch so viele andere Verstorbene schon aufhalten, wiederfinden könnten. Die Universalität des Todes und auch seine Irreversibilität sind dabei unzweifelhaft. Sie hoffen auf ein Treffen und vereinbaren schon jetzt, gemeinsam für die Ausstattung eines himmlischen Picknicks zu sorgen, womit die für sie derzeit wichtigste Frage nach dem Fortbestehen ihrer Freundschaft über den Tod hinaus geklärt ist. Die Interferenzen von religiösen und philosophischen Kategorien werden hier evident.

\section{VI.2.3 Das philosophische Bilderbuch}

Philosophieren ist jedes Nachdenken über die Unabwendbarkeit der Tatsache, dass alles Lebende auf den Tod zugeht und sich die Welt stets ungerührt weiter dreht. Philosophieren bedeutet „Reflexion über Alltagswissen“ (Horster 1991, 62), Nachdenken über existenzielle Zusammenhänge, Glück, Freiheit, Gerechtigkeit und Tod, Fragen nach dem Sinn der Dinge und Gegebenheiten. Kindern stellen sich solche Fragen in konkreten Alltagszusammenhängen ebenso 
wie während der Beschäftigung mit den fiktionalen Wirklichkeitsentwürfen der KJL. ${ }^{166}$ Die Bandbreite dessen, was innerhalb der Kinder- und Jugendliteratur als philosophisch bezeichnet werden kann, ist demnach nur schwer zu erfassen.

Grundsätzlich können alle Texte als philosophisch gelten, „die Zusammenhänge und Hintergründe sichtbar [...] machen und zur reflektierten Argumentation" (Rank 2002, 806) anleiten, also alle Bilderbücher, die zum Nachdenken über das Wie und Warum des Todes, sein Verhältnis zum Leben und den Verbleib von Toten auffordern.

Wo wäre dann aber die Grenze zu ziehen zwischen einer als, philosophisch' zu bezeichnenden Weise der literarischen Aufarbeitung von real erlebten oder fiktiv gedachten Todeserfahrungen und den vielen anderen (dann vor- oder nicht-philosophischen) Erzähl- und Sachtexten für Kinder und Jugendliche, die sich mit dem Thema, Tod' beschäftigen? Und welches wären [...] die Kriterien, um zwar, problem-orientiertes, aber nicht, philosophisches' Terrain voneinander zu unterscheiden? (Rank 2002, 800f.; H. i. O.)

Diese Fragen können, ebenso wie die nach einer eindeutigen Grenzziehung zu transzendental-religiösen Bilderbüchern, hier nicht beantwortet werden. Um aber den unterschiedlichen Bearbeitungen der Todesthematik im Bilderbuch doch gerecht zu werden, wird im Folgenden Philosophie als kinderliterarisches Thema so eng gefasst, dass nur jene als philosophische Bilderbücher bezeichnet werden, in denen Zusammenhänge zwischen Leben und Tod zur Sprache kommen, ohne dass es um die Verarbeitung eines emotional belastenden Todesfalls geht, oder die den menschlichen Lebensweg als zyklischen Prozess auf den Tod hin darstellen. Es sind damit im Besonderen die Bilderbücher gemeint, mit denen nicht nur zum Reflektieren angeregt wird, sondern die das Reflektieren selbst zum Thema machen, eingebettet in ein dialogisches Konzept von Fragen und Antworten. Der philosophische Duktus äußert sich in der Konzentration auf Sinnfragen und existenzielle Zusammenhänge; die elementaren Fragen des Lebens Woher kommen wir? und Wohin gehen wir? stehen deutlich im Vordergrund und sind Erzählanlass wie Erzählgegenstand. Insgesamt liegen 41 Bilderbücher (Abb. 11) vor, die sich entweder explizit mit dem Werden, Vergehen und Neuwerden im Naturkreislauf auseinandersetzen oder solche, die den Tod als nur ein Motiv unter mehreren aufgreifen und grundlegende Fragen zur Dauer von Leben und der Möglichkeit einer wie auch immer gearteten Nachtod-Existenz stellen. Interferenzen mit der Kategorie der religiösen Bilderbücher liegen dabei auf der Hand.

Vorstellungen, die von einem Werden und Vergehen und Wieder-neu-Werden ausgehen, stellen das Menschsein in die Reihe der zyklischen Vorgänge, wie

166 Zum Philosophieren mit Bilderbüchern vgl. z. B.: Petermann 2007. 
sie in der Natur vorzufinden sind. Eine geläufige Metapher dafür ist der sich ständig wiederholende Wechsel der Jahreszeiten, sichtbar am häufig gewählten Motiv des Baumes, wie auch in der Betrachtung der Tag-Nacht-Wende. Insgesamt 19 Bilderbücher ${ }^{167}$ konzentrieren sich auf Naturphänomene als zentrale Motive, 7 Titel davon gehören zur Kategorie der Sachbilderbücher.

Beispielsweise werden in Opas Kirschbaum (Goodfrey/ Cope 1996) ${ }^{168} \mathrm{im}$ Gespräch zwischen der Enkelin und ihrem Großvater Fragen zum Einfluss der Jahreszeiten auf das Leben eines Kirschbaumes geklärt, dessen wechselnde Laubkleider und begrenzte Lebensdauer, ebenso wie die des Menschen, der Vorstellung von einer göttlichen Ordnung unterworfen werden. Philosophische Erzählungen sind religiöser Art, wenn sie die Erkenntnis des Nicht-Wissens erweitern, indem wie hier religiöse Erklärungsmodelle für das Sterben gegeben werden. Deutlich wird, dass zwar nicht mehr als Glaube und Vermutungen möglich sind, die Akzeptanz der Universalität und Kausalität des Todes aber ein Weg sein kann, angstfrei damit umzugehen.

Der natürliche Zyklus von Werden, Vergehen und Neubeginn kann, muss aber nicht als Symbol für die im christlichen Glauben verankerte Vorstellung von einer Auferstehung in neuer, unversehrter Gestalt verstanden werden. Die Metamorphose von der Larve zum Schmetterling gilt aber schon seit der Antike als „religiöses Gleichnis für das nur scheinbare Sterben“ (Schmidt-Dumont 1998, 78) und ist in drei Bilderbüchern das zentrale Thema: Saalfrank/ Goede 1998; Bröger/ Brandt 1971; Carle 1969. Als subtiles Symbol für den Wandlungsprozess tritt der Schmetterling auch manchmal auf der Bildebene in Erscheinung und sollte dann nicht lediglich als dekoratives Beiwerk verstanden werden.

Warum-Fragen sind philosophische Fragen, die ausgelöst werden in Augenblicken des Staunens über Unbekanntes, Unerklärliches oder im Alltag bisher ungefragt Hingenommenes. So rufen tote Tiere bei Kleinkindern eher Verwunderung als Angst oder Ekel hervor, denn Unbelebtes stört ihr Weltbild und drängt ihnen Fragen auf, ohne zu wissen, dass sie damit den Tod meinen. In Was ist das? fragt der Frosch (Velthuijs 1992) wird diese frühkindliche Frage auf einfache und nachvollziehbare Weise beantwortet. Nach dem Fund einer toten Amsel sucht der Frosch Rat bei verschiedenen Freunden und dem Hasen, der

167 Godfrey/ Corke 2011; Seebaß 2010; Benecke/ Fuss 2008; Häckelmann 2004; Lembcke/ Ellermann 2001; Recknagel/ Dusíkowá 2001; Saalfrank/ Goede 1998; Godfrey/ Cope 1996; Tejima 1996; Hübner/ Höcker 1992; Wynnejones/ Ratcliffe 1992;Bektas/ Guhe 1991; Sturm/ Schleer 1988; Buscaglia 1987; Tsurumi/ Suzuki 1984; Hansen 1981; Bröger/ Brandt 1971; Lehoczky 1971; Carle 1969.

168 Neuauflage: Godfrey/ Corke 2011: Erzähl mir vom Himmel. 
die Tiere kompetent und schnörkellos darüber aufklärt, was tot sein für die Amsel bedeutet. Mit einer Beerdigungszeremonie nehmen die Tiere Abschied und finden schnell wieder zur Freude des täglichen Spiels zurück: Ist das Leben nicht wunderschön?! (Ebd.)

Wie viele Gedanken über das Leben, seine Gegebenheiten und Unwägbarkeiten und eben den Tod gerade in einer schlaflosen Gewitternacht ein Kind beschäftigen können und wie nah diese Fragen, Ängste und Befürchtungen auch einem Erwachsenen sind, führt Michèle Lemieux in dem umfangreichen, jede Altersgruppe ansprechenden Band Gewitternacht (Lemieux 2007) aus. Dort lassen die schlichten Schwarz-Weiß-Zeichnungen viel Raum für eigene Vorstellungen. Ähnlich anregend ist ein Bilderbuch von Wolf Erlbruch, der darin, ohne Die große Frage (Erlbruch 2004) nach dem Sinn des Lebens explizit zu stellen, eine bestechend knappe Antwort gibt: „Sagt der Tod: Du bist auf der Welt, um das Leben zu lieben."

Neugierig und unbelastet wie die Protagonisten in Lakritzbonbons (van Ommen/ de Wanten 2003) geht der kleine, heranwachsende Pip in Mama, wie groß ist der Himmel (Sönnichsen/ Liddle 2003) an die großen Fragen heran und beantwortet sie sich gleich selbst. Je älter er wird, desto philosophischer werden seine Fragen und bald stellt er Fragen über den Himmel, das Leben und die Liebe, bei denen auch oft die Erwachsenen nicht mehr weiterwissen. Er weiß aber: Wo die Liebe ist, da ist der Himmel. Und: Gott hat ja alle lieb, deswegen ist er auch überall. [...] Das heißt [...], der Himmel fängt überall an."

Weil „solche spontanen Ausflüge in die Philosophie für Kinder zwischen drei und sieben Jahren nicht unüblich sind" und älteren Kindern das Fragen möglicherweise vergeht, wenn „von ihnen nur »nützliche« Fragen erwartet“" (Matthews 1995, 13; H. i. O.) werden, ist sehr zu wünschen, dass Bilderbücher wie die vorgestellten Anstöße geben, um mit Kindern gemeinsam über das Leben zu philosophieren und sich alt bekannten Erkenntnissen wieder neu zu nähern.

\section{VI.2.4 Todesfälle und ihre Ursachen}

Dieser Teil der Untersuchung stellt heraus, ob und inwieweit sich das Bilderbucherzählen vom Sterben auf einzelne Beziehungsverhältnisse, Altersgruppen und Todesursachen konzentriert bzw. ob mit dem Gesamtangebot die reale Universalität des Todes auch fiktional abgebildet wird. Die u. st. Tabelle (Abb. 13) weist die Verteilung aller Todesfälle in der Tier- und Menschenwelt in Abhängigkeit von Familienverhältnissen oder anderen (auch verwandtschaftlichen) Beziehungen aus, wobei die Haustiere als eigene Gruppe betrachtet werden, ebenso wie die im phantastischen Tierbilderbuch verorteten Freundschaftsbeziehungen. 
Abb. 13: Übersicht über die Verteilung aller Todesfälle in Beziehungszusammenhängen.

\begin{tabular}{|c|c|c|c|c|c|c|c|c|c|}
\hline \multirow{3}{*}{\begin{tabular}{|l|} 
Zeitraum \\
$1946-$ \\
1971 \\
\end{tabular}} & \multirow{3}{*}{$\begin{array}{c}\begin{array}{c}\text { Ge- } \\
\text { samt- } \\
\text { korpus }\end{array} \\
10\end{array}$} & \multicolumn{8}{|c|}{ Primär vom Tod Betroffene in Beziehungszusammenhängen } \\
\hline & & \multirow{2}{*}{\begin{tabular}{|c} 
Groß- \\
väter
\end{tabular}} & \multirow{2}{*}{$\begin{array}{c}\begin{array}{c}\text { Groß- } \\
\text { müt- } \\
\text { ter }\end{array} \\
-\end{array}$} & \multicolumn{2}{|c|}{$\begin{array}{c}\text { Väter / } \\
\text { Mütter } \\
\text { (ohne Eltern- } \\
\text { verlust) }\end{array}$} & \multirow{2}{*}{$\begin{array}{c}\begin{array}{c}\text { Kin- } \\
\text { der }\end{array} \\
2\end{array}$} & \multirow{2}{*}{$\begin{array}{c}\begin{array}{c}\text { Ande- } \\
\text { re }\end{array} \\
-\end{array}$} & \multirow{2}{*}{\begin{tabular}{|c|}
$\begin{array}{c}\text { Haus- } \\
\text { tiere }\end{array}$ \\
1
\end{tabular}} & \multirow{2}{*}{$\begin{array}{c}\begin{array}{c}\text { Freund- } \\
\text { schaftsbe- } \\
\text { ziehungen } \\
\text { im Tier- } \\
\text { reich }\end{array} \\
-\end{array}$} \\
\hline & & & & - & - & & & & \\
\hline $\begin{array}{l}1972- \\
1981\end{array}$ & 12 & 1 & 2 & - & - & 2 & 1 & 2 & - \\
\hline $\begin{array}{l}1982- \\
1991 \\
\end{array}$ & 39 & 5 & 5 & 2 & 1 & 9 & 3 & 3 & 1 \\
\hline \begin{tabular}{|l}
$1992-$ \\
2001 \\
\end{tabular} & 85 & 10 & 12 & 4 & 3 & 12 & 8 & 12 & 5 \\
\hline $\begin{array}{l}2002- \\
2011 \\
\end{array}$ & 141 & 16 & 18 & 8 & 6 & 28 & 11 & 12 & 8 \\
\hline Gesamt & 287 & 32 & 37 & 14 & 10 & 53 & 23 & 30 & 14 \\
\hline
\end{tabular}

Es zeigt sich, dass mehrheitlich der Tod von Großeltern thematisiert wird, obwohl die in westlichen Gesellschaften verlängerte Lebenserwartung vermuten lässt, dass immer weniger solcher Beziehungsverluste im Kindesalter erlebt werden und solche literarischen Bearbeitungen seltener die Lebenswirklichkeit von Kindern abbilden (vgl. Ewers 2010, 80ff.). Zu bedenken ist aber in jedem Fall, dass das Sterben heute zunehmend aus dem Alltag verdrängt und institutionalisiert wird und die Erfahrungsmöglichkeiten sowohl für Kinder als auch Erwachsene deshalb stark eingeschränkt sind. ${ }^{169}$ Im Bilderbuch wird dagegen nur selten im Krankenhaus ( $\mathrm{N}=12$ ) gestorben und fast nie im Alters- oder Pflegeheim (dort: Fietzek/ Plankenberg 1995; Fährmann/ Ruegenberg 1998), sondern häufig im Kreise der Familie oder der Freunde. Das entspricht der Wunschvorstellung von einem sanften Lebensende in familiärer Geborgenheit. Inwieweit der demographische Wandel unserer Gesellschaft und seine Folgen, wie u. a. die Zunahme von Demenzerkrankungen ${ }^{170}$ und die Notwendigkeit häuslicher Pflege

169 Feldmann $(2004,65)$ spricht in diesem Zusammenhang von einem „Erfahrungsdefizit“, wenn Beziehungsverluste erst im Erwachsenenalter erlebt werden und fehlende Primärerfahrungen „im Ernstfall einer notwendigen Hilfeleistung für Sterbende oft zur Hilflosigkeit und Abwendung" führen.

170 Z. B. von Martin Baltscheit 2010: Die Geschichte vom Fuchs, der den Verstand verlor. München: arsEdition. 
bei gleichzeitigem Mehrbedarf an Pflegestellen, in den nächsten Jahren auch im Bilderbuch thematisch verarbeitet werden, bleibt abzuwarten.

Als Ergebnis ist festzuhalten, dass in 113 Bilderbüchern alte Menschen oder Tiere sterben und damit der Alterstod das vorherrschende Ereignis ist; vier Mal ist die Ursache eine nicht spezifizierte Krebserkrankung ${ }^{171}$, neun Mal wurde Leukämie $^{172}$ diagnostiziert (ausschließlich bei Kindern), zwei Mal ein Herzinfark $t^{173}$. Tödliche Unfälle ${ }^{174}$ sind in zwanzig Bilderbüchern thematisiert, $13 \mathrm{Mal}$ ist die Ursache Gewalt ${ }^{175}$. Das bemerkenswert umfangreiche Teilkorpus zum kindlichen Tod wird im Kapitel VII eingehend analysiert und deshalb hier nicht weiter besprochen.

\section{VI.2.4.1 Großeltern}

Großeltern bzw. Alte sind nicht nur die häufigsten primär vom Tod Betroffenen, sie sind auch oft diejenigen, die Kindern vom Tod erzählen bzw. Jüngere auf den nahenden Verlust vorbereiten. Die Anforderungen an eine Sterbebegleitung, die sich helfend den belastenden Aspekten des Sterbens zu stellen hat, bleiben im Bilderbuch so gut wie unerwähnt. Wenn Großeltern sterben, geht es um die Akzeptanz des natürlichen Alterstodes, auf den die Enkel häufig von Großmutter oder Großvater selbst liebevoll vorbereitet werden. Sie sterben friedlich, im Einklang mit der Welt und sich selbst und verursachen keine Mühe. Der Tod wird klaglos hingenommen und mitunter mit hoffnungsvollen Erwartungen verbunden, worin das erwachsene Wunschbild eines harmonisch ausklingenden Lebensendes verwirklicht ist. Auffällig ist, dass die Bilderbücher, in denen vom Tod von Großmüttern erzählt wird, zu zwei Dritteln religiöse Merkmale aufweisen, während es im Zusammenhang mit dem Tod von Großvätern gerade die Hälfte ist. Über mögliche Ursachen kann nur spekuliert werden, worauf aber verzichtet wird.

171 Feile/ Feile 2008; Gilson/ Dubois 2004; Herbold 2002; Nystrom/ Large 1991.

172 Loske 2011; Schins/ Müller 2005; Blumentritt 2003; Coerr/ Young 1995; Waldmann 1995; Isler 1992; Bergmann 1989; Gaes/ Gaes 1989; Reuter 1989.

173 Jalonen/ Louhi 2007; Aakeson/ Eriksson 2005.

174 Schubiger/ Berner 2011; Wild/ Blackwood 2011; Kim/ Kwon 2010; Paffrath 2010; Schulß/ Bunge 2009; Wegenast/ Meyer 2008; Herrmann/ Bahde 2007; Place 2006; Kaufmann 2004; Treiber/ Blazejovski 2001; Davids/ Münzer 2000; Hermann/ SoléVendrell 1999; Jörg/ Winterhager 1996; Becker/ Mocka 1994; Solotareff 1994; Wolf/ Sopko 1994; Missfeldt/ Schübel 1990; Larreula/ Capdevila i Valls 1988; Kaldhol/ Øyen 1987; Carrick/ Carrick 1980.

175 S. Kap. VI.2.5.4. 
Todesfurcht oder Bitterkeit spielen in diesem Teilkorpus keine Rolle, was sicher einerseits für den kindlichen Adressaten eine verunsichernde, beängstigende Zumutung sein würde, andererseits im wirklichen Leben aber durchaus anders erlebt wird.

Sterbende sind eben nicht nur friedlich, sondern auch unruhig. Sterben ist nicht nur sanft, sondern auch laut und lärmend, es ist nicht nur schmerzfrei, sondern klagend und leidend, es ist nicht stumm und sich-ergebend, sondern widerständig und aufbäumend, von Schmerzen geschüttelt. (Heller 2000b, 30)

Da aber in der Realität nur selten zuhause und in Gegenwart von Angehörigen, schon gar nicht von Kindern, gestorben wird, sei dahingestellt, ob dies im Bilderbuch literarisch aufbereitet werden sollte. Außerdem sind Kindern, die real solche Erfahrungen machen müssen, nicht Bilderbücher, sondern Sicherheit bietende, liebevolle Bezugspersonen zu wünschen.

Ein Bilderbuch, das um eine realistische Sicht auf die Situation eines sterbenden Großvaters aus der Perspektive des Enkels bemüht ist, formuliert dieses Anliegen schon im Untertitel: Bernis Opa. Eine Erzählung für Großeltern, Eltern und Kinder (Witt 2010). Es ist eines von sieben Bilderbüchern ${ }^{176}$, die es kindlichen Protagonisten erlauben, den Sterbeprozess eines Großvaters oder einer Großmutter und deren damit einhergehenden körperlichen Verfall mit zu verfolgen, allerdings ohne demgegenüber negative Gefühle zu entwickeln bzw. ohne dass ein quälendes Sterben auszuhalten ist. Dass alle Titel aus den Jahren 2008 bis 2011 stammen, zeugt von einer neuen Offenheit für eher unattraktive Erzählmotive.

Im Umgang mit den möglichen ambivalent-negativen Gefühlen einem Sterbenden gegenüber zeigt sich eine ähnliche Zurückhaltung. Sie bleiben weitgehend ausgeklammert und damit in den Bereich des Unerlaubten verschoben. Kinder aber, die mit Beziehungsverlusten konfrontiert sind und damit mitunter belastende Gefühle wie Schuldgefühle, Ablehnung oder auch Wut verbinden, können sich mit einer Utopie vom friedlichen, liebevollen Umgang miteinander nicht verstanden fühlen. Dass eine realistische Härte nicht sein muss, dass aber negative Aspekte zumindest vorsichtig literarisch zugelassen werden können, belegen die wenigen Bilderbücher, die Kindern das Gefühl von zornigem Unmut, oder besser: Frustration zubilligen angesichts der Tatsache, dass Verstorbene keine Fragen mehr beantworten (Fried/ Gleich 1997) und ihre Versprechen nicht mehr einlösen können: „Manchmal bin ich auch wütend, weil sie nicht mehr da ist. Manchmal denke ich auch gar nicht an sie. Dann ist es einfach nur schön, dass die

176 Aertssen 2011; Gliemann/ Tritschler 2011; Holzinger/ Stöllinger 2011; Karimé/ Behl 2011; Witt 2010; Fortier/ Legendre 2008; Weigner/ Kreimeier 2008. 
Sonne scheint." (Gliemann/ Tritschler 2011) Eltern, die ihren Kindern mangelnde Trauerfähigkeit unterstellen, wenn diese solche Ambivalenzen zeigen, können mit diesem Bilderbuch eine neue Perspektive auf das andere Trauern von Kindern gewinnen, wie ebenso Kinder sich damit verstanden fühlen dürften.

\section{VI.2.4.2 Elterntod}

Dass diese für Kinder äußerst belastenden Beziehungsverluste in nur wenigen Bilderbuchgeschichten eine Rolle spielen (14 Mal Tod eines Vaters, $10 \mathrm{Mal}$ Tod einer Mutter, sechs Mal Elterntod ${ }^{177}$ ), hat sicher seine Ursache unter anderem in ökonomischen Bedenken der Verlage, die aufgrund der relativ geringen Anzahl real betroffener Kinder und ihrer Familien einen geringen Abnehmerkreis fürchten und deshalb ein Engagement scheuen, wenn sie nicht wie beispielsweise der hospiz-verlag für diesen Themenkreis ausgewiesen sind. Denn solche Bearbeitungen sind kaum dem präventiv-aufklärenden Umgang mit dem Thema Tod dienlich, sondern in ihrer Funktion als literarisches Begleitmaterial in konkreten Krisensituationen auf einen kleinen Adressatenkreis ausgerichtet.

Ausgezählt wurden alle Bilderbücher, in denen der Tod eines Elternteils mindestens Erwähnung findet, weshalb sich ein anderes Bild bietet, wenn nur die Bilderbücher herausgehoben werden, in denen der Tod mehr als ein marginales Ereignis ist und ein Trauerprozess das zentrale Erzählmotiv darstellt. Das auf diese Weise bereinigte Teilkorpus weist erste Titel zum Vater- und Mutterverlust erst in den 1990er-Jahren auf (1994 bzw. 1993), wobei sich bemerkenswerte Unterschiede zwischen den Darstellungen des Vaterverlusts und denen des Mutterverlusts zeigen.

Eine Differenzierung hinsichtlich des zentralen Erzählmotivs Vaterverlust zeigt, dass drei ${ }^{178}$ der insgesamt 14 Bilderbücher den Tod eines Vaters lediglich als marginales Ereignis erwähnen, ohne einen Trauerprozess damit zu verbinden. Acht Titel sind in der realistischen Menschenwelt verortet ${ }^{179}$, vier Bilderbücher eröffnen phantastische Dimensionen ${ }^{180}$. Zwei Titel präsentieren sich, belegt

177 Jianghong 2006: Junger Adler; Kaufmann 1999: Das fremde Kind N.; Recheis/ Kaufmann 1998: Schwesterchen Rabe; Lionni 1964: Swimmy; Gorey 1967: Das unglückselige Kind; de Brunhoff 1947: Die Geschichte von Babar dem kleinen Elefenaten; in diesen Bilderbüchern geht es nicht um Trauer, sondern um eine Neuorientierung bzw. den weiteren Lebenslauf der hinterbliebenen Kinder.

178 Place 2006; Kübler-Ross/ Rothmayr 1985;Arima/ Arima 1984.

179 Carnavas 2011; Jalonen/ Louhi 2007; Saegner 2005; Herbold 2002; Davids/ Münzer 2000; Hermann/ Solé-Vendrell 1999; Becker/ Mocka 1994; Wolf/ Sopko 1994.

180 Paffrath 2010; Place 2006; Dudok Wit 2003; Deru-Renard 2002. 
durch Paratexte, als Produkte therapeutischen Schreibens über real erlebte Verluste $^{181}$. Die Todesursachen bleiben indifferent, wenn es sich nicht um einen Unfalltod $(\mathrm{N}=6)$ handelt, in nur einem Fall wird ein Krebstod angesprochen (Herbold 2002: Papi, wir vergessen dich nicht).

Ganz anders ist das Teilkorpus zum Verlust von Müttern aufgestellt. Autobiographische bzw. faktuale Aspekte, wie sie oben für die Verarbeitung der Trauer um Väter nachgewiesen wurden, spielen hier keine Rolle. In ebenfalls drei Titeln ${ }^{182}$ findet der Tod der Mutter lediglich Erwähnung. Jedoch ist die Trauer kindlicher Protagonisten in nur sieben Bilderbüchern thematisiert, wovon vier in der phantastischen Bärenwelt ${ }^{183}$ verortet sind. Dass nicht mehr als drei Titel die realistische Menschenwelt ${ }^{184}$ betreffen, lässt darauf schließen, dass vom Tod einer Mutter zu erzählen emotional belastender und weniger aushaltbar zu sein scheint als das Erzählen vom Verlust eines Vaters und deshalb in realistischen Szenarien deutlicher vermieden wird. Die niedliche Bärenwelt dient hier als Ausweichterrain für belastende Emotionen, die Kuscheltier-affin dort aufgefangen werden.

Die Frage nach der Authentizität der Darstellungen ist nur vor dem Hintergrund psychologischer Erkenntnisse über die Bedingungen einer gelingenden Trauerverarbeitung zu beantworten.

Erstens sollte das Kind vor dem Verlust eine verhältnismäßig sichere Beziehung zu seinen Eltern gehabt haben; zweitens sollte [...] das Kind schnell und korrekt über das informiert werden, was geschehen ist, sollte alle möglichen Fragten stellen dürfen und darauf eine möglichst ehrliche Antwort erhalten und sollte an der Trauer der Familie teilnehmen, einschließlich aller Bestattungsriten, die die Familie beschließt; drittens sollte das Kind die tröstende Anwesenheit des überlebenden Elternteils genießen oder, wenn das nicht möglich ist, einer bekannten und vertrauten Ersatzperson; außerdem sollte ihm versichert werden, daß diese Beziehung bestehen bleibt. (Bowlby 1983, 355)

Erstaunlich ist, dass sich dieses psychologische Wissen in den aufgefundenen Bilderbüchern weniger deutlich als erwartet niedergeschlagen hat. Selten sind es die hinterbliebenen Mütter oder Väter, die ihren Kindern Erklärungen geben und ihnen eine Stütze sind, sondern immer wieder Großeltern, die sich den Fragen der Enkel stellen. In Du wirst immer bei mir sein (Hermann/ Solé-Vendrell 1999) träumt sich der trauernde Junge den Vater herbei und glaubt ihn zu sehen und zu spüren. Als er darüber spricht, erntet er bei Mutter und Schwester

181 Herbold 2002; Paffrath 2010.

182 Gottanka/ Rutsche 2008; Goodall/Marks 2004; Tsurumi/ Suzuki 1984.

183 Passacantando/ Kiesel 2008; Mürmann/ Meis 2004; Kinder 2001; Cratzius/ Blancke 1995.

184 Lunde/ Torseter 2010; Saegner 2009; Heymans/ Heymans 1993. 
Unverständnis, nur der Großvater gibt eine Erklärung: Alles, was an eurem Papa sterben kann, ist tot. Aber seine Seele, seine Liebe zu dir und zu Peter, und zu Mama, die ist da. Und manchmal, da kann man es spüren, ganz nah - und ganz wirklich. (Ebd.) Auch in Roberts alter Freund (Becker/ Mocka 1994) ist es nicht die Mutter, die dem Sohn, der dessen dringend bedarf, Kraft und Trost spendet. Die für eine kindliche Trauer bekannten negativen Emotionen des Sohnes (Deshalb wurde er manchmal ganz wütend, daß Papa so etwas tun konnte: ihn und Mama so plötzlich zu verlassen.) werden in Gesprächen mit einem alten Freund aufgefangen. Dessen Freundschaft hilft, die Trauer nach dem Unfalltod des Vaters zu überwinden und tröstet sogar darüber hinaus, als das Kind auch den Tod dieses alten Freundes verkraften muss.

Zwei in konkreten Trauersituationen möglicherweise hilfreiche literarische Bearbeitungen, beide von Uwe Saegner und im hospiz-verlag erschienen, stellen die kindliche Gefühlswelt in den Vordergrund, einmal mit einer kindlichen Ich-Erzählsituation (Papa, wo bist du? 2005), einmal mit einer erwachsenen IchErzählerin an der Seite der Protagonistin (Sarahs Mama 2009). Sowohl in Sarahs Mama (Saegner 2009) als auch in Papa, wo bist du? (Saegner 2005) drückt sich die Trauer zunächst in der verzweifelten Suche nach dem verlorenen Elternteil aus. Schließlich ist es die Mutter (Saegner 2005), die dem Kind die Nähe des verstorbenen Vaters als Erinnerungsakt imaginiert, in Sarahs Mama (Saegner 2009) ist es eine nicht näher beschriebene erwachsene junge Frau, die der etwa fünfährigen Protagonistin ihre zahlreichen Fragen ehrlich zu beantworten versucht, wenn auch mit der Tendenz zur verklärenden Niedlichkeit (ein Marienkäfer, in dessen Gestalt die Mutter ebenso gegenwärtig sei wie in dem Duft ihrer Lieblingsblumen). Festzuhalten bleibt außerdem, dass im Teilkorpus des Elternverlusts neben den Erinnerungsleistungen der Trauernden christlich-religiöse Trostbilder für gelingende Trauerprozesse so gut wie keine Rolle spielen. Es scheint, dass mit der Bereitschaft, Kindern (und hinterbliebenen Elternteilen) literarische Hilfestellungen für diese emotionalen Ausnahmesituationen anzubieten, eine säkularisierte Sicht auf den Tod einhergeht.

\section{VI.2.4.3 Andere Todesfälle}

Von den 22 Bilderbüchern, die Todesfälle außerhalb engster familiärer Strukturen betreffen, überwiegt deutlich der Alterstod von Freunden, Nachbarn, Tanten und Onkeln, worin sich das reale Lebensumfeld von Kindern spiegelt. Etwa ein Drittel erzählt in phantastischen Dimensionen (davon 5 Tierbilderbücher), etwa die Hälfte ist der Kategorie der religiösen Bilderbücher zuzurechnen. Als hervorzuhebende Besonderheiten sind zu nennen: der Tod eines Stadtstreichers 
(Fährmann/ Rügenberg 1998: Neues von Pimann), die tödliche Rache eines Affen an seinem menschlichen Peiniger (Waechter 2004: Der Affe des Strandfotografen) und der Krebstod einer jungen Frau (Nystrom/ Large 1991: Anja nimmt Abschied), deren Sterben im häuslich-familiären Umfeld sehr einfühlsam begleitet wird. ${ }^{185}$

\section{VI.2.4.4 Der Tod im Kindesalter}

Das Teilkorpus der Bilderbücher, in denen kindliches Sterben thematisiert wird, umfasst 53 Titel und ist mit fast $20 \%$ des Gesamtkorpus die zweitgrößte Kategorie neben der des Großelternverlusts. Die Spezifika der Darstellungen vom Kindertod werden in Kapitel VII ausdifferenziert und, unter Anwendung des narratologischen Analysemodells (Kap. III), anhand einzelner Ankerbeispiele exemplarisch dargelegt.

\section{VI.2.4.5 Tiere}

Die Skala der Todesursachen bei Tieren, sofern sie expliziert werden, reicht von Altersschwäche ${ }^{186}$ und Unfall ${ }^{187}$, über Umweltverschmutzung ${ }^{188}$, Tötung ${ }^{189}$ und Suizid ${ }^{190}$ bis hin zu menschlicher Grausamkeit ${ }^{191}$. Die meist vertretene Tiergruppe sind Haustiere $(\mathrm{N}=30)$, angeführt von Hunden $(\mathrm{N}=16)$ und Wellensittichen $(\mathrm{N}=5)$, daneben sind es Tiere aus der Welt der Kleintiere und Wald- und Wildtiere, unter denen die Bären $(\mathrm{N}=10)^{192}$ und Elefanten $(\mathrm{N}=5)^{193}$ deutlich dominieren. ${ }^{194}$ Der Tod von Haustieren ist mehrheitlich in realistischen Szenarien

185 S. dazu Kap. VI.2.5.1.

186 Der Hauptanteil liegt bei den phantastischen Titeln.

187 Wild/ Blackwood 2011: Ben \& Bommel; Kim/ Kwon 2010: Abschied von Aika; Place 2006: Grosser Bär; Solotareff 1994: Wer hat Angst vor einem Hasen?; Missfeldt/ Schübel 1990: Der Rapskönig; Carrick/ Carrick 1980: Christoph verliert seinen Freund.

188 Dierks/ Solé-Vendrell 1995: Der schwarze Vogel.

189 S. dazu Kap. VI.2.5.4.

190 Waechter 1998: Der rote Wolf.

191 Waechter 1997: Hier bin ich.

192 Rivett/ Macnaughton 2010; Yumoto/ Sakai 2009; Place 2006; Mürmann/ Meis 2004; Verroen/ Erlbruch 2003; Weigelt/ Kadmon 2003; Blüm/ Göbel 2001; Kinder 2001; Gray/ Cabban 2000; Janosch 1985.

193 Usatschow/ Junge 2008; Abedi/ Cordes 2008; Bourguignon/ D’Heur 2005; Heine 1976; de Brunhoff 1946.

194 Insgesamt konnten 29 Tierarten identifiziert werden, die aber aufgrund geringer Häufungen hier nicht weiter ausdifferenziert werden. 
verortet $(\mathrm{N}=16)$, sieben Mal im phantastischen Tierbilderbuch, drei Mal im anthropomorph-phantastischen Bilderbuch und drei Mal im Sachbilderbuch. Die relativ geringe Anzahl von insgesamt 29 Bilderbüchern zum Tod von Haustieren ist dabei ein überraschendes Ergebnis angesichts der Wahrscheinlichkeit, im realen Leben diese Erfahrung zu machen.

Trost wird im Zusammenhang mit dem Sterben von Tieren selten aus religiösen Vorstellungen geschöpf ${ }^{195}$ und auch weniger in eine Erinnerungskultur eingebettet, meist wird der Tod als absolutes Ende hingenommen. Während aber in den phantastischen Bilderbüchern Tiere nur selten beerdigt werden und sich stattdessen auf den Weg in jenseitige Gefilde begeben, ist das realistische Erzählen vom Tiertod zu fast $50 \%$ an eine Begräbniskultur und an die ritualisierten Gepflogenheiten im Umgang mit menschlichen Verstorbenen angelehnt. Damit kommen die Bilderbücher weitgehend der Forderung Gertraud Fingers (1998, 107f.) nach:

In solchen Situationen ist es wichtig, dass Kinder um das tote Haustier trauern dürfen. Auch wenn die Trauer der Kinder den Erwachsenen wehtut, sollten sie das gestorbene Tier nicht sofort ersetzen. [...] Wie können Erwachsene helfen? Nicht durch das Herbeischaffen eines neuen Tieres, sondern durch das gemeinsame Abschiedsritual. Wenn das Tier gemeinsam beerdigt wird, wenn es einen schönen Sarg erhält und das Grab mit Blumen geschmückt wird, kann das Kind noch ein letztes Mal etwas für sein Tier tun.

Der schnelle Ersatz eines verlorenen Haustieres wird zwar mehrfach angeboten, aber die kindlichen Trauernden dürfen deutlich machen, dass sie Zeit brauchen, um den Verlust zu verwinden, bevor sie sich einem neuen Tierfreund zuwenden können (z. B.: Carrick/ Carrick 1980: Christoph verliert seinen Freund; s. dazu Kap. VI.2.1). Damit wird berücksichtigt, wie wichtig es ist, den Kindern die Initiative zu überlassen und abzuwarten, bis sie selbst mit dem Wunsch nach einem neuen Tier den Trauerprozess für abgeschlossen erklären.

Anderes erzählt das Bilderbuch Abschied von Aika (Kim/ Kwon 2010), in dem die Trauer eines Kindes um seinen Hund im Zentrum steht, ohne sie zum Abschluss zu bringen, wie auf der letzten Doppelseite deutlich wird. Dort wendet sich die Ich-Erzählerin imaginierend an ihren Hund: Manchmal glaube ich, dich $z u$ sehen, wie du auf mich wartest. Aika - mein schneeweißer Hund, ich vermisse dich! Hier wird die Trauer nicht aufgehoben, sie mündet nicht in eine neue Zuwendung zum Leben, sondern verharrt in der Phase des schmerzlichen Vermissens. Möglicherweise liegt dem Erzählen ein autobiographischer Anlass und

195 Meyer/ Schulze 2009; Langen/ Bohnstedt 2008; Krenzer/ Horn 2001; Kirchberg 1997; Lenz/Greif 1978. 
selbsttherapeutisch motivierter Schaffensprozess zugrunde, dessen Authentizität manchen Trauernden vielleicht mehr erreicht als Geschichten, die Trauer zur kurzfristig überwindbaren Angelegenheit erklären und damit bagatellisieren. Ob aber die Unvollkommenheit des Trauerprozesses einer Trauerverarbeitung zuträglich ist, mag ebenso dahingestellt sein. Denn gerade für jüngere Kinder, die um ein Haustier trauern, ist ein positiver Abschluss mit einer annehmbaren Lösung sicher der geeignetere Ansatz, wie z. B. in Abschied von Rosetta (Schopf/ Tophoven 2006). Der Tod seines Zwergkaninchens stürzt dort den etwa 5-jährigen Felix in Verzweiflung und Unverständnis darüber, dass der Tod irreversibel ist. Er hofft auf eine mögliche, Reparatur' des toten Tieres und wird, wie in vielen anderen Bilderbüchern auch, von einer älteren, erwachsenen Vertrauensperson liebevoll darüber aufgeklärt, dass der Tod endgültig ist und dass alles Lebende einmal sterben muss. Felix trauert regelmäßig am Grab Rosettas im Garten von Oma Krahwinkel und will zunächst kein Ersatzhaustier, bis er zwei ausgesetzte Kätzchen findet und sich ihnen zuwendet.

\section{VI.2.5 Sterben und Trauern}

Das Aufgefangen-Sein von Sterbenden und Trauernden in einer Sozialgemeinschaft, wie sie vergangene Jahrhunderte gekannt haben, ist heute einem privaten, zurücknehmenden, die Alltagsanforderungen möglichst nicht belastenden Sterben und Trauern gewichen. Ariès $(1982,746)$ spricht von einer „Abschaffung der Trauer" in "Gemeinschafträumen“ seit der Mitte des 20. Jahrhunderts, die sich großenteils auch in den untersuchten Bilderbüchern spiegelt.

Die Kategorisierung erfolgte anhand der Frage nach dem Prozesscharakter der erzählten Ereignisse, die in zeitlichen Dimensionen und Phasen ${ }^{196}$ beschreibbar sind. Dabei werden folgende Teilkorpora unterschieden:

1. Erzählen auf den Tod hin: Der Tod tritt erst am Ende des Buches ein. Im Zentrum stehen die Auseinandersetzung der Betroffenen mit dem Sterben und die Akzeptanz des Todes.

2. Darstellung von Trauerprozessen: Der Tod ist entweder vor dem Erzählbeginn eingetreten, an den Anfang gesetzt oder geschieht während des Erzählverlaufs. Der Fokus ist auf die Wahrnehmung des/der Trauernden und die Verarbeitung des Verlusts gerichtet.

3. Kombinationen beider Prozesse: Sowohl Prozesse des Sterbens als auch des Trauerns werden dargestellt und psychologisch ausgestaltet.

196 Vgl. dazu: Kübler-Ross 1996, 16ff; Kast 1999, 71ff.; im Vorliegenden: Kap. IV.1. 
Die u. st. Tabelle (Abb. 14) $)^{197}$ macht quantitative Angaben zum Umfang dieser Teilkorpora, wobei auf den ersten Blick die im Verhältnis zum Gesamtkorpus niedrige Anzahl der Trauerprozesse und Sterbeprozesse überraschend erscheint. Andererseits wird daran deutlich, dass neben den Trauer- und Sterbebüchern, die sich durch eine Psychologisierung des Erzählens auszeichnen, zahlreiche andere Bearbeitungen das thematische Repertoire erweitern. Dazu gehören philosophische Herangehensweisen, Sachbilderbücher und märchenhafte Bilderbücher sowie solche, in denen existenzielle Fragen und lebensbezogene Neuorientierungen und nicht die emotionalen Reaktionen auf ein Todesereignis im Vordergrund stehen.

Abb. 14: Inhaltsbezogene Kategorien - Sterbeprozesse und Trauerprozesse und begleitende Motive.

\begin{tabular}{|l|c|c|c|c|c|c|c|}
\hline & \multirow{2}{*}{ Zeitraum } & Gesamt- & \multicolumn{6}{|c|}{ Sterbeprozesse, Trauerprozesse und begleitende Motive } \\
\cline { 3 - 8 } & korpus & $\begin{array}{c}\text { Sterbe- } \\
\text { prozes- } \\
\text { se }^{199}\end{array}$ & $\begin{array}{c}\text { Trauer- } \\
\text { prozes- } \\
\text { se }^{200}\end{array}$ & $\begin{array}{c}\text { Sterbe- } \\
\text { und Trau- } \\
\text { erproz. }\end{array}$ & $\begin{array}{c}\text { andere } \\
\text { Kulturkrei- } \\
\text { se }\end{array}$ & $\begin{array}{c}\text { Pers. } \\
\text { Tod }\end{array}$ & $\begin{array}{c}\text { Krieg/ } \\
\text { Gewalt }\end{array}$ \\
\hline $\begin{array}{l}1946- \\
1971\end{array}$ & 10 & 1 & 1 & - & - & - & 2 \\
\hline $\begin{array}{l}1972- \\
1981\end{array}$ & 12 & 1 & 3 & - & - & - & - \\
\hline $\begin{array}{l}1982- \\
1991\end{array}$ & 39 & $6(3)$ & $6(3)$ & 3 & 1 & 4 & 5 \\
\hline $\begin{array}{l}1992- \\
2001\end{array}$ & 85 & $13(2)$ & $27(2)$ & 2 & 2 & 2 & 12 \\
\hline $\begin{array}{l}2002- \\
2011\end{array}$ & 141 & $29(16)$ & $75(16)$ & 16 & 6 & 12 & 7 \\
\hline Gesamt & $\mathbf{2 8 7}$ & $\mathbf{5 0 ( 2 1 )}$ & $\mathbf{1 1 2 ( 2 1 )}$ & $\mathbf{2 1}$ & $\mathbf{9}$ & $\mathbf{1 8}$ & $\mathbf{2 6}$ \\
\hline
\end{tabular}

Überschneidungen bzw. nicht immer eindeutige Zuordnungen sind unvermeidbar, dennoch lässt sich eine deutliche Entwicklung ablesen: Die Anzahl der von Trauerprozessen erzählenden Bilderbücher hat sich seit der Jahrtausendwende gegenüber dem gesamten vorausgehenden Zeitraum fast verdoppelt und das Erzählen von Sterbeprozessen weist einen noch deutlicheren Zuwachs auf. Diese Steigerungen und insbesondere die vermehrten Kombinationen von Sterben und Trauern zeugen von einer Emotionalisierung und Psychologisierung des Bilderbuchs seit dem Ende des 20. Jahrhunderts und einem offeneren Umgang mit den Vorgängen rund um das Sterben, der auch auf der Bildebene gerade in der Visua-

197 S. a. die tabellarische Übersicht im Anhang (X.2).

198 Anzahl der enthaltenen Kombinationen von Sterben und Trauer in Klammern.

199 Anzahl der enthaltenen Kombinationen von Sterben und Trauer in Klammern. 
lisierung Sterbender oder Verstorbener sichtbar wird. Die Hauptmotive liegen in der Darstellung der psychischen Verarbeitung von Beziehungsverlusten und in der Auseinandersetzung mit dem (eigenen) Sterben und eröffnen damit einen „Blick ins Innere“ (Lypp 1989) der kindlichen Protagonisten. In Analogie zum modernen, psychologischen Kinderroman (vgl. Daubert 2011) ist deshalb für die Mehrheit dieser Bilderbücher der Begriff des modernen psychologischen Bilderbuchs zutreffend, denn auch die BilderbuchautorInnen bedienen sich in adressatengerechter, $\mathrm{d}$. h. dem Verstehenshorizont kindlicher Protagonisten und Rezipienten angepasster Weise derselben literarisch anspruchsvollen Darstellungsmittel. Gemeint ist damit insbesondere die Verwendung von erlebter Rede und innerem Monolog.

Im Gegensatz aber zum psychologischen Kinderroman, unter dem „eine spezifische Textgruppe des modernen realistischen KRs für etwa acht- bis zwölfjährige Adressaten" (Steffens 2002, 309) verstanden wird, bezieht sich die Merkmalsbestimmung des psychologischen Bilderbuchs insgesamt auf „die Akzentuierung der Binnensicht vorrangig kindlichen Denkens, Fühlens und Handelns" (ebd., 308), ohne Realistisches von Phantastischem zu scheiden.

Dass der in dieser Arbeit gewählte thematische Schwerpunkt in besonderer Weise ein literarisches Terrain für psychologische Erzählkonzepte darstellt, wird im Kapitel VII in Anwendung des narratologischen Bilderbuchmodells am Teilkorpus zum Kindersterben nachgewiesen, während diese Analyseebene in den folgenden Kapiteln eine eher untergeordnete Bedeutung hat.

\section{VI.2.5.1 Sterbeprozesse}

Das Erzählen vom Sterben unterscheidet sich in erster Linie in der mehr oder weniger ausgestalteten Erwähnung des Sterbevorgangs und seiner zeitlichen Verortung. In vielen Bilderbüchern wird zwar vom Geschehnis berichtet, per se bei Unfällen, im Vordergrund steht aber oft die Verarbeitung der Trauer über einen Verlust; der dem Moment des Todes (möglicherweise) vorausgehende Sterbeprozess und vor allem die Haltung des Sterbenden bleiben dann unerwähnt. Entscheidendes Kriterium für das Teilkorpus der Sterbeprozesse war deshalb die über die bloße Erwähnung hinausgehende Ausgestaltung des Vorgangs. Die Analyse zeigt, dass sich die Anzahl der Bilderbücher, die Sterbeprozesse thematisieren, in den zurückliegenden dreißig Jahren im dekadischen Rhythmus mehr als verdoppelt hat und zudem den kindlichen Protagonisten ein Miterleben meistens zugebilligt wird. Dieses Zulassen von Nähe zu den lange mit einem Tabu belegten Sterbesituationen zeugt von einer neuen Offenheit im Erzählen für Kinder. ${ }^{200}$

200 Dies ist eine Entwicklung, die sich im Kinder- und Jugendbuchsektor noch deutlicher zeigt, worauf hier nicht näher eingegangen werden kann. Als Beispiele seien 
Sind Sterbevorgänge für das Erzählkonzept bestimmend, können diese auf einer ersten Stufe nach der Figurenperspektive unterschieden werden. Entweder steht das Erleben der sterbenden Figur im Vordergrund (z. B.: Feile/ Feile 2008: Tante Lotti geht in den Himmel; Nilsson/ Tidholm 2003: Adieu, Herr Muffin; Coerr/ Young 1995: Sadako; Sheppard/ Rozier 1971: Herr Pommerin verschenkt sich) oder es wird das beobachtende, selten das retrospektive Miterleben einer betroffenen, zum Sterbenden in Beziehung stehenden Figur dargestellt (z. B.: Aertssen 2011: Als Oma ein Vogel wurde; Weigner/ Kreimeier 2008: Lukas und Oma nehmen Abschied; Herbold 2002: Papi, wir vergessen dich nicht). Auf der Bildebene bleibt es üblicherweise bei der Außenperspektive eines auf das Geschehen blickenden Erzählers. In sechs Bilderbüchern ${ }^{201}$ ist der Tod an das Ende der Darstellung eines ganzen Lebensprozesses gestellt. Dieses Erzählen auf den Tod hin stellt die Vielfältigkeit eines erfüllten Lebens einerseits und die Akzeptanz seines natürlichen Endes andererseits ins Zentrum, wobei, wie z. B. in Vater und Tochter (de Dudok Wit 2003), auch Trauerprozesse eine Rolle spielen können.

In den insgesamt 50 Bilderbüchern (Abb. 14) dieses Teilkorpus', zehn anthropomorph-phantastischen und 25 anthropomorph-realistischen Bilderbüchern, zwölf phantastischen Tierbilderbüchern und drei Sachbilderbüchern, ist mehrheitlich, d.h. $35 \mathrm{Mal}$ das Alter verantwortlich für das Sterben, in fünf Fällen ist die Ursache Leukämie, in zehn weiteren Szenarien sind es nicht näher bestimmte (Krebs-) Erkrankungen. In kaum einem Bilderbuch, abgesehen von einzelnen zum Kindersterben, spielen konkrete Ängste vor dem Tod oder andere belastende Aspekte eine Rolle, weder für den Sterbenden selbst noch für betroffene Angehörige, die meist Enkelkinder sind. Die von E. Kübler-Ross beschriebenen Sterbephasen sind so gut wie nie in die Erzählkonzepte aufgenommen worden. Sie sind auf die letzte Phase, die Annahme des Todes, beschränkt und lassen den Weg dorthin - mit allen problematischen Begleiterscheinungen, wie z. B. dem Hadern mit dem eigenen Schicksal - unerwähnt. Auch die wenigen Hinweise auf die Gebrechlichkeit des Alters und den körperlichen Verfall sind offenbar kein Anlass, das Lebensende als eine Phase physischer und psychischer Belastung zu fürchten oder sich damit klagend auseinanderzusetzen. Die Darstellungen sind durchweg von einer Akzeptanz der Endlichkeit des Lebens geprägt

genannt: Nicholls 2008: Wie man unsterblich wird; Ness 2011: Sieben Minuten nach Mitternacht; Green 2012: Das Schicksal ist ein mieser Verräter.

201 Duffy/ Ryan 2010: Das Geschenk; Guggenheim 2009: Die Vogelforscherin; Meinderts/ Fienieg 2007: Die Geschichte von Jonas und Oma; de Dudok Wit: 2003 Vater und Tochter; Bauer 2001: Opas Engel; Heine 1976: Elefanteneinmaleins. 
und stützen sich besonders häufig auf religiöse Vorstellungen vom Tod als unbeschwerlichem Übergang in eine andere Existenzform.

Das erste recherchierte Bilderbuch, in dem ein Sterbevorgang das Hauptmotiv des Erzählens ist, ist Herr Pommerin verschenkt sich (Sheppard/ Rozier 1971). Dieses phantastische Bilderbuch ist auktorial angelegt und ganz auf die Figur des alten „Herrn Pommerin“ ausgerichtet, der sich bewusst auf eine letzte Reise begibt. Er verschenkt alles was er hat und schließlich sich selbst - seinen Besitz, seinen Körper und seine Träume - an die Welt, die Menschen, die Tiere und die Natur. Der Tod wird in Wort und Bild „auf surreal-phantastische Weise“ entmachtet (Sahr 1987, 137), indem das Sterbenmüssen vom Sterbenden in Eigenregie gestaltet und zu einem Ende gebracht wird, das die Identität zwar auflöst, ihr aber gleichzeitig mit den in der Welt hinterlassen Spuren ein positives Gedenken sichert. Diese philosophische Behandlung des Sterbens entlastet und lässt eine Trauer fast unnötig erscheinen.

Das Motiv der Reise, das häufig in Abschiedsszenarien ${ }^{202}$ expliziert wird, ist neben der Metapher des (ewigen) Schlafes das verbreitetste. Wie bereits beschrieben, sind es häufig die sterbenden Alten selbst, die im Bewusstsein ihres letzten Weges die betroffenen Angehörigen oder Freunde auf den Abschied vorbereiten. Auffällig ist in diesem Zusammenhang, dass besonders in den phantastischen Tierbilderbüchern kindliche Protagonisten fast immer allein mit den Sterbenden sind, ohne dass ihnen andere erwachsene Begleitpersonen an die Seite gestellt sind. Die Verantwortlichkeit für die Auseinandersetzung mit dem Lebensende und die Aufklärung über das mögliche Kommende liegt damit eindeutig bei den (sterbenden) Alten, die offenbar für Informationen sozusagen aus erster Hand stehen und eine Mittlerrolle entbehrlich erscheinen lassen.

Hinsichtlich der Sterbeorte und Begleitumstände des Sterbens gilt weiterhin für das Bilderbuch, was Josef Rabl vor bereits mehr als 30 Jahren bezüglich der in den Auswahllisten des Deutschen Jugendbuchpreises von 1971 bis 1976 aufgeführten Kinderbücher konstatierte:

Wo der Tod alter Menschen ausführlich thematisiert ist, sterben diese fast immer im Kreise ihrer Familie, fast nie im Krankenhaus, Altersheim oder isoliert und verlassen, ausgeliefert einem ambivalenten medizinisch-technischen Fortschritt. Meist waren sie vorher noch rüstig und aktiv; Vergreisung, Schmerzen oder längere Krankheit sind so selten dargestellt wie die ökonomischen oder rechtlichen Folgen eines Todesfalls. Es stellt sich die Frage, welche Bedeutung solche Darstellungen des Sterbens für das Kind haben, stimmen sie doch mit der Realität nur bedingt überein [...]. (Rabl 1982, 212)

202 Z. B. Beuscher/ Haas 2002 Über den großen Fluss; Weigelt, Kadmon 2003 Der alte Bär muss Abschied nehmen. 
Es stellt sich allerdings auch die Frage, welche Funktion negativ konnotierte Szenarien für kindliche Rezipienten haben könnten, da sie in der Realität doch davon - durchaus zu Recht - meist ferngehalten werden und sich sicher nicht mit der Problematik eines langen und schmerzvollen Sterbeprozesses auseinanderzusetzen haben sollten. Dennoch hegen Kinder Befürchtungen, die von solchen Bilderbüchern aufgefangen werden können, die kindliche Fragen offen ansprechen und entlastende Antworten geben. Dem kindlichen Erleben nah und der Bedeutung eines offenen Kommunikationsverhaltens ebenso wie der tröstenden Funktion eines friedvollen Abschiednehmens gerecht werdend, ist beispielsweise das Bilderbuch Abschied von Anna (Holzinger/ Stöllinger 2011), das aus der Perspektive eines kleinen Jungen schonend vom Prozess der Erkrankung und des Sterbens der geliebten Leihoma erzählt. Deren Kranksein wirft Fragen auf, die von den Eltern verständnisvoll und trostreich beantwortet werden. Auch das bereits 1991 erschienene Bilderbuch Anja nimmt Abschied (Nystrom/ Large 1991) stellt die Bedeutung einer Sterbebegleitung sowohl für den Sterbenden selbst als auch für die betroffenen Angehörigen ins Zentrum, wobei hier, wie in zwölf weiteren Bilderbüchern, ein körperlicher Verfall nicht verschwiegen wird. Schon der Untertitel Krankheit und Tod in der Familie (ebd.) weist auf die wichtige Funktion von Gesprächen, Besuchen und Spielen und vor allem der Nähe von vertrauten Menschen hin, denn besonders schlimm wird es für einen Kranken, wenn er vom Leben isoliert wird, wenn in seiner Nähe nicht mehr laut gelacht werden darf, wenn alle so tun, als würde er nicht mehr dazugehören. In Anja nimmt Abschied (Nystrom/ Large 1991) nimmt die etwa Vierzehnjährige zusammen mit ihren Eltern und Geschwistern Anteil am Monate langen Krankheits- und Sterbeprozess ihrer noch jungen Tante, die, liebevoll umsorgt und von Gesprächen, Vorlesen aus der Bibel und gemeinsamem Singen begleitet, schließlich zuhause verstirbt. Bild- und Sprachebene sind parallel angelegt und gestalten anhand der Farbgebung und der Beschreibung die Abnahme von Vitalität der Sterbenden.

In den anderen untersuchten Sterbebilderbüchern wird dieser Vorgang nur selten dargestellt, und dann meist durch das Liegen im Krankenbett und den Verlust von Gesichtsfarbe. Als Oma ein Vogel wurde (Aertssen 2011) stellt darunter eine Ausnahme dar, da das allmähliche Schwächerwerden im Sterbeprozess in Etappen als simultane Anordnung auf der Bilderbuchseite deutlich vor Augen geführt wird (Abb. 15). Nur wenige Illustratoren wagen es wie hier, Sterbende oder Verstorbene ins Bild zu setzen. Entlastend wirkt dabei der Blick aus dem Fenster auf den lächelnd und winkend im Baum sitzenden Enkel, womit buchstäblich gezeigt wird, dass alles im Leben ein Gegenüber hat: Gesundheit und Krankheit, Jugend und Alter, Freude und Trauer. 
Abb. 15: Kristien Aertssen (2011): Als Oma ein Vogel wurde. Hildesheim: Gerstenberg.

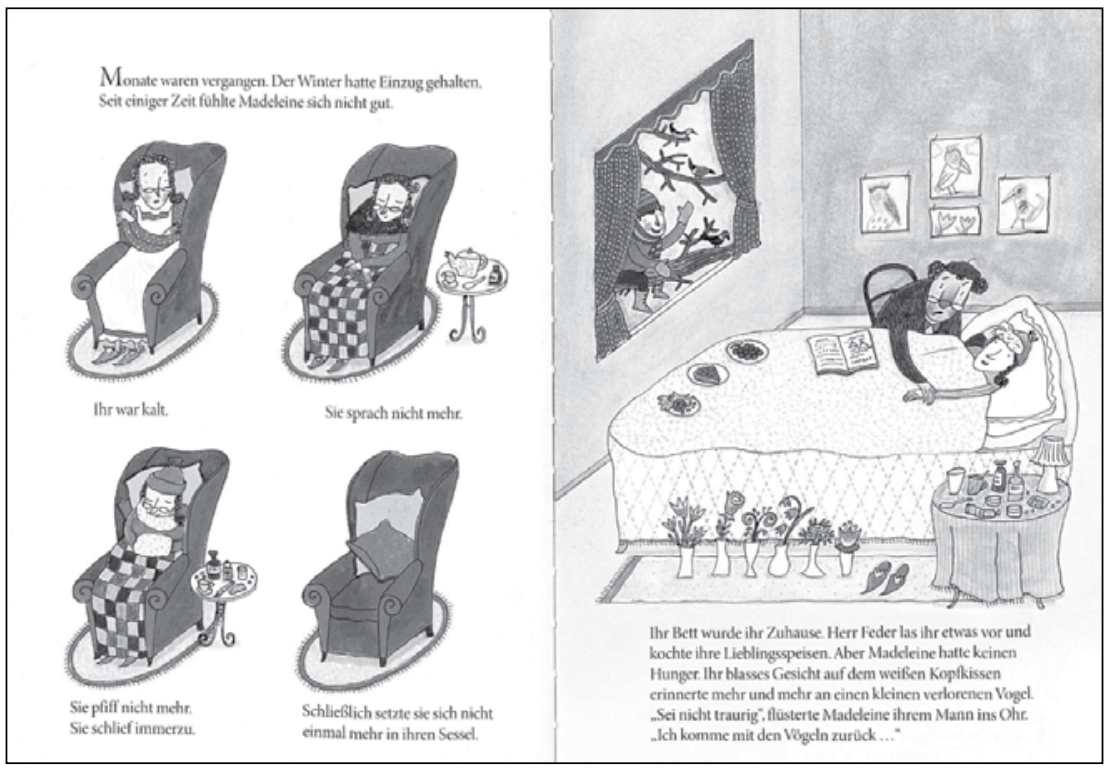

Die Metapher vom Tod als endgültigem Schlaf wird im gesamten Textkorpus auf der Bildebene bemerkenswert selten, d. h. zwanzig Mal aufgegriffen, davon sechs Mal im Zusammenhang mit Sterbeprozessen. Eine herausstechend eindringliche Darstellung präsentiert Anna-Clara Tidholm in Adieu, Herr Muffin (Nilsson/ Tidholm 2007), einer Geschichte vom Sterben eines Meerschweinchens.

Abb. 16: Ulf Nilsson; Anna-Clara Tidholm (2003): Adieu, Herr Muffin. Frankfurt a. M.: Moritz.

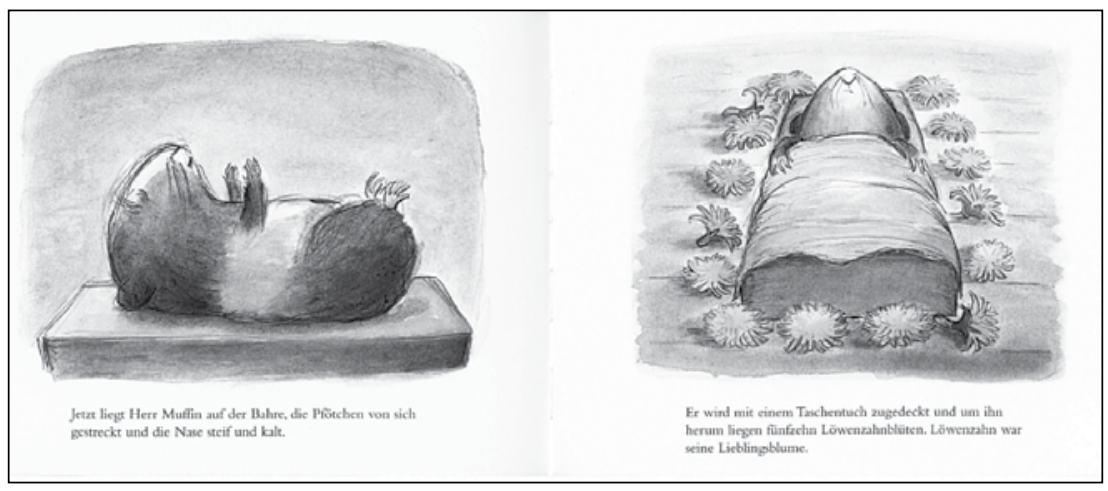


Dort (Abb. 16) wird die Abbildung des offensichtlich totenstarren Herrn Muffin auf der Bahre, die Pfötchen von sich gestreckt und die Nase steif und kalt, dem Bild seiner feierlichen, mit Blumen geschmückten Aufbahrung gegenübergestellt, das ihn wie friedlich schlafend zeigt. Die darin angelegten Trauerrituale sind Thema des folgenden Kapitels.

\section{VI.2.5.2 Trauerprozesse}

Wie bereits erläutert, sind in diesem Teilkorpus nur die Bilderbücher erfasst, die der zeitlichen Dimension und der an Trauerphasen orientierten Darstellung Raum geben ( $\mathrm{N}=112$, Abb. 14). Sie verteilen sich auf die literarischen Subgattungen wie folgt: 18 anthropomorph-phantastische, 66 anthropomorph-realistische Bilderbücher, 20 phantastische Tierbilderbücher, ein realistisches Tierbilderbuch, vier Sachbilderbücher und drei Märchen. Nur etwa die Hälfte dieser Bilderbücher ist religiös konnotiert, was wiederum die Säkularisierung des Umgangs mit Tod und Trauer bestätigt. Das häufigste religiöse Trostbild ist ein unversehrter Nachtodzustand des Wohlergehens im Himmel. Seltener wird Gott ausdrücklich damit in Verbindung gebracht. Die theologische Dimension der Auferstehung, d. h. die mit der Auferstehung Jesu neu begründete hoffnungsvolle Perspektive für die Welt und den einzelnen Menschen, wird in den wenigsten Bilderbüchern explizit ausgedrückt, kann aber von Gläubigen durchaus zwischen den Zeilen mitgelesen werden. ${ }^{203}$

Ein Bilderbuch (Abb. 17), das wie keines in dieser Intensität und Ausführlichkeit die Phase des Nicht-wahrhaben-Wollens und der aufbrechenden Emotionen ausgestaltet, ist Gehört das so??! von Peter Schössow (2005). Angelegt als phantastisches Szenario, erzählt es von der Trauer um einen Kanarienvogel namens Elvis, dessen Leichnam die kindliche Protagonistin in einer knallroten Lackleder-Omahandtasche durch einen Stadtpark trägt.

203 S. Kap. VI.2.2. 
Abb. 17: Peter Schössow (2005): Gehört das so??! München, Wien: Hanser.

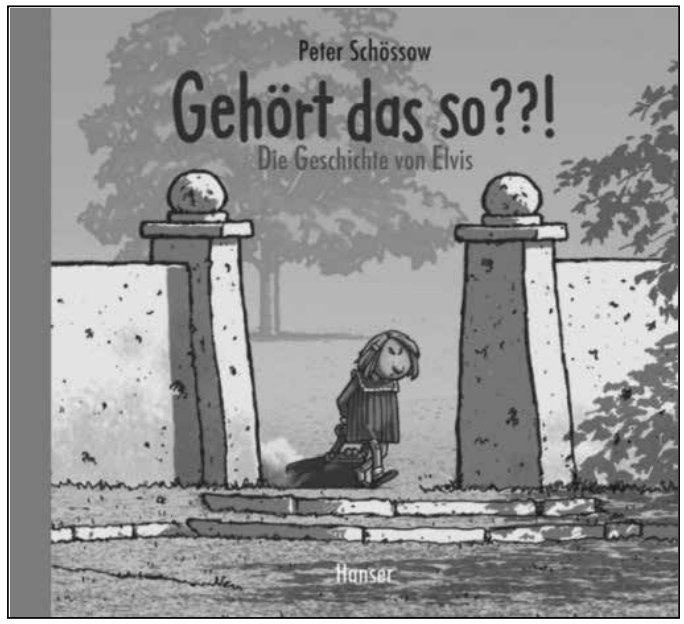

Ihre voll wütender Entrüstung in die Welt gerufene Frage Gehört das so??! bleibt lange ohne Antwort, bis sie endlich auf sechs skurrile Gestalten trifft, die sich ihr zuwenden, Verständnis aufbringen und alles Notwendige für eine Erdbestattung des toten Elvis zusammentragen. Peter Schössow zeigt hier mit sparsamen Worten und umso ausdrucksvolleren Bildern die Bedeutung der tröstenden Anteilnahme (Wir weinten ein bisschen, nahmen uns in die Arme) und des gemeinsamen Zelebrierens der Beerdigung inclusive des erinnernden Gedenkens beim sogenannten Leichenschmaus für eine gelingende Trauerverarbeitung, auch wenn die Protagonistin die letzte Phase der Trauer, die des neuen Selbst- und Weltbezugs, selbst nicht explizit ausdrückt. Zentral für die positive Veränderung der Trauerstimmung ist die Vorstellung, wie es wohl werden würde ... wenn der eine Elvis den anderen Elvis traf. Und da mussten wir lachen, obwohl wir so traurig waren. (Ausl. i. O.) An dieser Stelle wird der christliche Auferstehungsgedanke evident.

Konzepte, mit denen die Möglichkeit einer konkreten Kontaktaufnahme mit Verstorbenen in Aussicht gestellt wird, scheinen dagegen eher ungeeignet, um einen Trauerprozess abzuschließen und eine der Zukunft zugewandte Lebenshaltung zu erreichen. Wenig zielführend für die Entwicklung eines intellektuell und emotional reifen Todeskonzeptes ist es, wenn für das Mysterium des Todes nicht Hoffnungsbilder entworfen, sondern unhaltbare Wahrheiten mit Wort und Bild behauptet werden. Damit sind nicht konfessionelle Heilslehren gemeint, sondern z. B. die Darstellungen von verlebendigten Toten, die beispielsweise in 
Zuckerguss für Isabel (Schins/ Müller 2005) am ,Dia de los Muertos ${ }^{204}$ gerufen werden und mexikanische Friedhöfe bevölkern (Abb. 18).

Abb. 18: Marie-Thérèse Schins; Birte Müller (2005): Zuckerguss für Isabel. Wuppertal: Hammer.

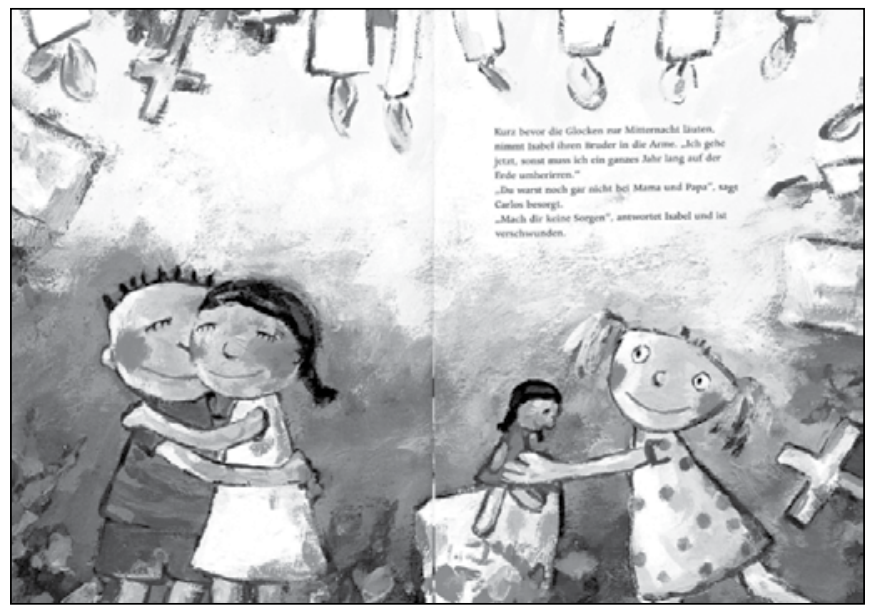

Die Kritik an diesem Bilderbuch bezieht sich nicht auf das rituelle Geschehen, sondern richtet sich gegen die gestalthafte Darstellung der - zudem von der Wirkkraft von Wünschen abhängigen - Zusammenkünfte von Lebenden und Toten (vgl. Plieth 2007, 51). Da Fiktionales und besonders Phantastisches von Realem zu trennen aber ein Lernprozess ist und symbolisches Verstehen i. d. R. erst im späten Grundschulalter erwartet werden kann, sollten solche Erzählkonzepte nicht unkommentiert bleiben, um Allmachtsvorstellungen von Kindern nicht zu fördern. Psychologische Studien belegen, dass Misserfolge von Kindern oft als persönliches Versagen gedeutet werden und schlimmstenfalls nachhaltig pathologisch wirken können (vgl. Wittkowski 1990, 43ff.).

Die Frage nach dem Zeitrahmen, der der Trauer zugebilligt wird, führt zu sehr unterschiedlichen Ergebnissen. In manchen Bilderbüchern lässt das dramaturgische Konzept eine erstaunlich kurze Dauer vermuten, in anderen dauert der Prozess der Verarbeitung ein Jahr und mehr (z. B. Fried/ Gleich 1997: Hat Opa einen Anzug an). Beispielsweise in Du bist nicht allein, Benji Bär (Kinder 2001)

204 ,Tag der Toten', einer der wichtigsten mexikanischen Feiertage, der vom 31.10. bis 2.11. gefeiert wird; in der christlichen Westkirche Allerheiligen. 
aber wird die Verdrängung von Trauer auf eine Weise auf die Spitze getrieben, die offenbar ein erwachsenes Wunschdenken spiegelt. Das Erzählen setzt ein, als der Trauerprozess des kleinen Bären, sofern er ihn überhaupt durchlebt hat, bereits abgeschlossen ist. Anderen Tierkindern erscheint dagegen ein Leben ohne Mutter unvorstellbar, weshalb sie sich um Benji Bär kümmern und ihn bei sich aufnehmen. Er wird sehr bedauert, doch schließlich meldet sich der kleine Bär gelassen lächelnd zu Wort:

„Meine Mama hat mich nicht verlassen. [...] Ich denke die ganze Zeit an sie. Ich erinnere mich an alle Geschichten, die sie mir erzählt hat. Sie hat mir gezeigt, wie ein kleiner Bär überlebt. [...] Schaut mal nach oben. Seht ihr die Sterne? Da oben ist meine Mama. [...] Wenn ich in den Himmel schaue und die Sterne funkeln, weiß ich, sie hört mir zu. "(Kinder 2001)

Dass mnestische Troststrategien wie diese durchaus positive Wirkungen auf individuelle Auseinandersetzungen mit Trauer haben können, ist sicher unstrittig. Sich des Verstorbenen zu erinnern, ist in vielen Bilderbüchern eine Möglichkeit des Lebendighaltens eines Verstorbenen, das vergleichbar ist mit der Vorstellung von einem unüberwindbar fernen Aufenthalt des verlorenen Menschen. Zwar ist keine Kommunikation mehr möglich, aber solange der Verstorbene als gegenwärtig imaginiert wird, scheint er nicht gänzlich verloren. Von der Intensität und der Frequenz der Erinnerungen aber hängt es ab, ob sie als fortgesetzte Verweigerung der Akzeptanz des Todes zu verstehen sind und damit den Abschluss des Trauerprozesses verhindern, oder ob die Erinnerungen ein auf die Zukunft gerichtetes Lebens bereichern, wie z. B. in Und was kommt nach Tausend (Bley 2005). Demgegenüber ist die Vorstellung von der nachhaltigen, den Tod überdauernden Präsenz von Verstorbenen in vererbten Gegenständen, wie z. B. Schriften und Schmuckstücken, in übernommenen Ritualen oder fortgeführten Familientraditionen ganz dem Leben und nicht der Vergangenheit zugewandt. Der Verstorbene selbst kann mittels seines Nachlasses auf die Erinnerungskultur der Hinterbliebenen entscheidenden Einfluss nehmen. Entweder bleibt er gegenwärtig im gegenständlichen Erbe oder in Verfügungen, die über den Tod hinaus wirken und das Leben der Nachkommen mehr oder weniger für einen gewissen Zeitraum bestimmen. Diese Variante ist eine solitäre Erscheinung in Der Abschiedsbrief von Opa Maus (Randerath/ Chudzinski 2007). Dort hinterlässt Opa Maus seinem Enkel einen Brief und einen Kompass, dessen Bedeutung sich dem kindlichen Protagonisten erst erschließt, als er den fertigen Plan für einen Schiffsbau im Keller des Opas findet. Denn im Brief heißt es: 
Ich habe Dir, wie jedem in der Familie, einiges von mir mitgegeben, und wenn Du mich sehr vermisst, dann finde heraus, was es ist. [...] Und wenn Ihr etwas weitermacht, was ich angefangen habe, dann freut mich das.

Die Familie sticht schließlich mit dem fertiggestellten Schiff namens „Opa Maus“ fröhlich in See.

Auch im Nachwirken vollbrachter Taten, in denen der Verstorbene noch anwesend gedacht werden kann, wie z. B. dargestellt in Leb wohl, lieber Dachs (Varley 1986), zeigt sich eine Praxis der Erinnerungskultur, die trotz des Vermissens tröstend wirkt. In Orangen für Opa (Fortier/ Legendre 2008) wird beispielsweise von der Nachhaltigkeit des allmorgendlichen Rituals erzählt, das der Großvater in Form einer geschälten Orange am Bett seiner Enkelin zelebrierte, bevor er krank und seinerseits liebevoll betreut wurde. Seit dessen Tod behält die mittlerweile erwachsene Enkelin die Gewohnheit, am Morgen eine Orange zu essen, im Gedenken an ihren Opa bei. Ein anderes Beispiel ist das vererbte Pfannkuchenrezept in Nie mehr Oma-Lina-Tag? (Stellmacher/ Lieffering 2005), das den kleinen Protagonisten an die liebevolle Nachbarin erinnert, die sich immer während der berufsbedingten Abwesenheit seiner Eltern um ihn kümmerte.

Ein Trauerprozess, der dagegen wiederum eine erwachsene Abgeklärtheit spiegelt, wird in Grossmutter (Hübner/ Höcker 1992) einem Kind im Kindergartenalter zugesprochen. Der Protagonist Tommy wendet sich mit folgender Erkenntnis an seinen Stallhasen:

„Weißt du, die Oma ist jetzt tot, aber das Leben geht weiter. So wie jeden Morgen die Sonne scheint, so wie ich dich morgen noch lieb habe. "... Und eine Zeitlang später hatte Tommy gelernt, dass alle Tränen, alle Traurigkeit vergehen und daß nichts sinnlos ist im Leben." (Ebd.; Ausl. i. O.)

Diese Erkenntnis ist angebunden an die Wahrnehmung von Vorgängen in der Natur, die der Protagonist am Blühen und Verwelken einer ihm wichtigen Blume im heimischen Garten nachvollzieht, ohne in irgendeiner Weise an eine Erinnerungskultur oder transzendente Vorstellungen anzuknüpfen.

Ein Bilderbuch, das für ähnlich weltliche Perspektiven auf den Tod steht, dabei aber dennoch die verbreitete christliche Begräbniskultur praktiziert, erzählt von der Protagonistin Rici, die ihrem Großonkel jedes Jahr selbst gemachte Himbeermarmelade (Barth/ Wünsch 2003) schickte. Als er stirbt, nimmt das Mädchen ganz selbstverständlich am Begräbnis teil. Doch obwohl Georg Kolbe in Gottes Namen beerdigt wird, bleibt die Erzählung dem Diesseits verpflichtet, in dem Trauer und Tränen dazugehören, ohne ins allzu Rührende oder gar Theatralische abzudriften. Mit beeindruckenden Bildern vom blumengeschmückten Sarg in der Kirche und dem großen Trauerzug zum Friedhof werden wie 
in nur wenigen anderen Bilderbüchern kirchliche Traditionen und Rituale als Ehrerbietung für den Toten und öffentliches Abschiednehmen zelebriert. Über den Zeremoniecharakter hinaus aber fußt diese Inszenierung nicht auf Religiosität, wie der Dialog zwischen der kindlichen Protagonistin und ihrem Großvater deutlich macht:

„Opa, bleibt Onkel Georg jetzt für immer in der Grube liegen? Was geschieht mit ihm, wenn er da unten liegt?"

„Aus Onkel Georg wird im Laufe der Jahre ein guter Humus. [...]“

„Geht es Onkel Georg jetzt wirklich gut?"

„Ja, denn er ist aufgehoben in deiner Erinnerung. Du wirst immer wissen, wie lieb er dich hatte. Diese Liebe wirst du nie vergessen, dein ganzes Leben lang nicht."

Hinsichtlich der Komplexität der in den Bilderbüchern dargestellten Trauerprozesse zeigt sich die Tendenz, insbesondere die ersten beiden Trauerphasen auszulassen oder nur andeutungsweise zu thematisieren. Das zentrale Anliegen ist ganz offensichtlich die einsichtige, nicht selten von religiöser Hoffnung getragene, rasche Überwindung der Trauer hin zu einem neuen Weltbezug.

Erwachsenentrauer ist in den Bilderbüchern eine eher marginale Erscheinung, denn die Trauerprozesse sind in der Regel auf das trauernde Kind fokussiert, sodass das Trauern erwachsener Bezugspersonen wenn überhaupt nur beiläufig auftritt. Nur wenige Bilderbücher greifen die Erwachsenentrauer hauptmotivisch auf und stellen sie ins Zentrum des Erzählgeschehens: Aertssen 2011: Als Oma ein Vogel wurde; van de Vendel/ Godon 2007: Grossvater, Kleinvater; Herrman/ Bahde 2007: Luca und der Schmetterling; Rosen/ Blake 2006: Mein trauriges Buch; de Dudok Wit 2003: Vater und Tochter. Dass diese Titel alle nach 2000 erschienen sind, zeugt von einer Öffnung des Bilderbuchs für die Belange erwachsener Adressaten, wie sie sich allgemein im modernen bzw. postmodernen Bilderbuch sowohl auf der inhaltlichen als auch der formalen Darstellungsebene zeigt.

Das aus der Psychologie bekannte Wissen, dass es im Sinne eines gelingenden Trauerprozesses sinnvoll und notwendig ist, nicht alleine zu trauern und die eigenen ambivalenten Gefühle in nahestehenden Mittrauernden gespiegelt zu sehen, wird relativ selten berücksichtigt. Es gibt immer noch nur wenige Bilderbücher, in denen die gemeinsame Betroffenheit von Elternteilen und Kindern hilfreich angegangen wird. Dass Kinder oft mit Wut und Rückzug auf einen schweren Verlust reagieren und Erwachsene dieses Verhalten entweder als Trauerunfähigkeit missdeuten und/oder selbst unfähig sind, sich in ihrer Trauer mitzuteilen, wird in dieser Kombination nur in Eines Morgens war alles ganz anders (Davids/ Münzer 2000) deutlich thematisiert. Die etwa fünfjährige Anna 
"fand ihr Bett plötzlich so groß und das Zimmer so kalt [...], wagte nicht zu rufen, wagte nicht zu weinen", da nach dem Tod ihres Vaters auch die trauernde Mutter für sie nicht mehr erreichbar scheint. In Gesprächen mit Anderen reflektieren beide dann erst die eigene Situation, bevor sie im Vertrauen auf die über den Tod hinaus verbindende Liebe wieder zusammenfinden und das gemeinsame Trauern hilft, den Verlust zu verschmerzen, auch ohne ein religiöses Trostbild. In Papas Arme sind ein Boot (Lunde/ Torseter 2010) wird dagegen aus der kindlichen Ich-Perspektive „in einer poetisch verknappten, sehr präzisen Sprache“ (Jurybegründung DJLP) und mit bühnenhaften, atmosphärisch dichten Bildern vom gemeinsamen Trauern von Vater und Sohn erzählt. Beide vermissen offensichtlich die Mutter des Jungen und geben sich dabei gegenseitig Halt, ohne religiöse Überlegungen oder Erinnerungen einzubeziehen.

Gemeinsam erlebte Trauer an Erinnerungsrituale zu binden und diese auch in einer Gemeinschaft zu zelebrieren, ist der heute zurückgedrängten Trauerkultur vergangener Jahrhunderte nah und tritt fast ausschließlich in den phantastischen Tierbilderbüchern auf. „Tierfiguren verhalten sich häufig nicht nur analog zu Menschen“ (Wrobel 2013, 8), sie übernehmen in den Trauerbilderbüchern auch Vorbildfunktionen als Trostspender für gelingende Trauerverarbeitung. Unter vermenschlichten Tieren ist das Trauern als Gemeinschaftserlebnis das zentrale Moment gelingender Trauerprozesse, im Gegensatz zu den genuin menschlichen Erzählkontexten, die mehr die Individualität von Einzeltrauer oder die Differenz von Kindertrauer und Erwachsenentrauer herausstellen.

Dass das Schreiben über den Tod und die Trauer auch eine Form von Selbsttherapie sein kann, ist manchen Bilderbüchern mit autobiographischen Hinweisen $^{205}$ eingeschrieben, mag aber darüber hinaus auch bei anderen Bilderbüchern ohne paratextuelle Verweise eine Rolle gespielt haben. Nahe liegt die Vermutung gerade bei solchen Erzählkonzepten, die ein allzu erwachsenes Herangehen an Erklärungsmuster und eine schnelle Bewältigung von Trauerarbeit aufzeigen.

\section{Kommunikationsverhalten}

Wenn in den Bilderbüchern geredet wird, dann sind es meist die alten Menschen, die zum Tod Stellung beziehen und dem Trost schon Vorschub leisten, indem sie beispielsweise ihre nachtodliche Gegenwart an Wolkenbilder knüpfen

205 Knoch 2011: Mein Freund Xaverl und ich; Paffrath 2010: Als Papa in den Himmel flog; Rosen/ Blake 2006: Mein trauriges Buch; Herbold 2002: Papi, wir vergessen dich nicht; Wikland/ Lagercrantz 1996: Die lange, lange Reise; Isler 1992: Die Fahrt zum Pferdeparadies. 
(Rogge/ Port 1998: Ein Wolkenlied für Omama) oder auf ein friedvolles Dasein bei Gott verweisen (Alex et al. 1982: Großvater und ich und die traurige Geschichte mit dem Kätzchen). Die Bedeutung von Kommunikation für eine gelingende Trauerverarbeitung thematisieren als erste die bereits erwähnten Bilderbücher Oles Großvater (Gydal/ Danielsson 1974) und Johanna und der Tod (Melin 1977) auf eine Weise, die Kinderfragen ernst nimmt und Verständnishilfen anbietet. Im Gegensatz dazu wird in Marianne denkt an ihre Großmutter (Egger/ Jucker 1986) über Kommunikation lediglich reflektiert, ohne dass Antworten gegeben werden. Die gleichsam Trauerflor tragenden Bilder werden von einem Text begleitet, in dem die personale Ich-Erzählerin unbestimmten Alters retrospektiv von ihren Gefühlen nach dem Tod der Großmutter berichtet:

Am nächsten Tag nahm mich meine Mutter in den Arm. Sie sagte mir, meine Großmutter sei gestorben. Ich konnte gar nicht verstehen, was sie meinte. Eben war ich doch noch bei ihr! Ich wollte wissen, wo sie denn nun war, ob sie etwas spürte, ob sie mich noch sehen konnte. Ich war wütend, daß sie von mir weggegangen war. Plötzlich hatte ich Angst, meine Eltern könnten sterben, oder sogar ich. Ich war unglücklich. Ich wollte, daß meine Großmutter noch da wäre. Meine Eltern redeten viel mit mir. Ich konnte ihnen alles sagen, was ich dachte. Sie hörten mir zu. Ich hatte viele Fragen. Vieles konnten sie mir sagen, vieles wußten sie selber nicht. Wir waren zusammen traurig.

Gerade in einer Vorlesesituation dürften sich Erwachsene angesprochen fühlen, es den Bilderbucheltern gleichzutun, Fragen zuzulassen und nach Antworten zumindest zu suchen, da hier das Erzählte Antworten schuldig bleibt. Daneben ist dieses Bilderbuch eines der insgesamt wenigen, welche die Universalität des Todes als Teil des reifen Todeskonzeptes und gleichzeitig auch die negativen Aspekte eines Trauerprozesses in der Phase der aufbrechenden Emotionen aufgreifen.

Dagegen wirft die offensive Kommunikationsverweigerung ${ }^{206}$ der Mutter die junge Protagonistin in Julia bei den Lebenslichtern (Sommer-Bodenburg/ TiongKing 1989) auf sich selbst zurück. Julia, ein Mädchen im Grundschulalter, ist meist allein mit ihrer Großmutter, weil ihre alleinerziehende Mutter berufstätig ist. Als sie eines Mittags die Großmutter leblos in ihrem Bett vorfindet, geht alles ganz schnell, wie in einem bösen Traum. Die Mutter regelt und organisiert, verfällt in Aktionismus und lässt eigene Trauer nur vermuten. Das Mädchen wird

206 Vier Bilderbücher im Gesamtkorpus: Treiber/ Blazejovsky 2001: Die Blumen der Engel; Davids/ Münzer 2000: Eines Morgens war alles ganz anders; Tidholm/ Tidholm 1990: Die Reise nach Ugri La Brek; Sommer-Bodenburg/ Tiong-King 1989: Julia bei den Lebenslichtern. 
von allem ausgeschlossen, darf an der Beerdigung nicht teilnehmen und bleibt in seiner Trauer unverstanden:

"Das Leben geht weiter. Und glaub mir: Du wirst nicht immer so traurig sein."

"Doch", ruft Julia. „Immer!“"

Mama seufzt. „Julia! Für mich ist das alles auch nicht leicht. Mach es mir bitte nicht noch schwerer."

An dieser Stelle wird klar, dass Kinder nicht in erster Linie durch das Todeserlebnis selbst belastet werden, sondern viel mehr durch den Umgang damit und das fehlende Verständnis für ihre Gefühle. Dass die Mutter, die die Kausalität des Todes und seine Irreversibilität betont, ohne für das Bedürfnis ihrer Tochter nach Trost auch nur ein Ohr zu haben, geschweige ihr eine Orientierung $\mathrm{zu}$ geben, ist für das Grundschulkind höchst belastend. Julia sucht daraufhin die vertraute Nähe ihrer Großmutter auf dem Friedhof und findet Trost im Überschreiten einer phantastischen Grenze, die ihr die Vision einer durchscheinenden, freundlichen Kindergestalt am Grab der Großmutter ermöglicht. Der Übergang in die phantastische Welt vollzieht sich, indem Julia von diesem Kind aufgefordert wird, die Augen zu schließen und sich an einem dunklen, von unzähligen Kerzen ${ }^{207}$ diffus erleuchteten Ort, am See der Lebenslichter wiederfindet. In Anlehnung an den „Gevatter Tod“ aus Grimms Märchen ${ }^{208}$ stellt jede Kerze ein Menschenleben dar, das verlöscht, wenn der Mensch gestorben ist, und noch so lange bei den anderen Lichtern steht, bis sich kein Mensch mehr seiner erinnert. Die Beschreibung dieser Szene erstreckt sich sprachlich über fünf Seiten und betont damit seine Bedeutung, die dieser Ausführlichkeit bedarf. Das Bild mit der Protagonistin Julia und dem den Tod darstellenden Kind auf dem in eine unendliche Tiefe sich ausdehnenden See unterscheidet sich sowohl in der Farbwahl als auch in der Art der Linienführung von den detailgenauen übrigen Darstellungen der realen Lebenswelt und macht auf diese Weise das Phantastische als Phantastisches sichtbar. Angela Sommer-Bodenburg und Thé Tiong-Khing haben mit dem Erzählen vom Übergang in eine phantastische Dimension eine Metapher für die Kraft der Phantasie gefunden, die hier nichts anderes ist als eine Strategie des Selbsttröstens, auf die Kinder wie Julia zurückgreifen müssen, wenn ihnen Halt und Orientierung nicht im Lebensumfeld geboten werden.

207 Kerze als Symbol für das individuelle, endliche Leben, das sich selbst verzehrt.

208 Nachzulesen z. B. in: Der Gevatter Tod. Satz und Illustrationen von Johannes von Freydorf. München: Kunst- und Textwerk Verlag 2008. 
Das bereits erwähnte Bilderbuch Papas Arme sind ein Boot (Lunde/ Torseter 2010) ist gerade auch zur Verdeutlichung der Notwendigkeit eines kommunikativen Miteinanders in Krisensituationen ein hervorzuhebendes Beispiel (Abb. 19). Die intensiven Gespräche, die offenbar helfen, in die Düsternis der von Vater und Sohn empfundenen Trauer wieder etwas Licht zu bringen (auf der Bildebene kunstreich von Øyvind Torseter in bühnenhaften Arrangements inszeniert), zeichnen sich mehr durch Leerstellen als durch viele Worte aus und lassen Raum, um nachzuempfinden, wie wichtig Sicherheit und Geborgenheit für einen gelingenden Trauerprozess sind.

Abb. 19: Stein Erik Lunde; Øyvind Torseter (2010): Papas Arme sind ein Boot. Hildesheim: Gerstenberg.

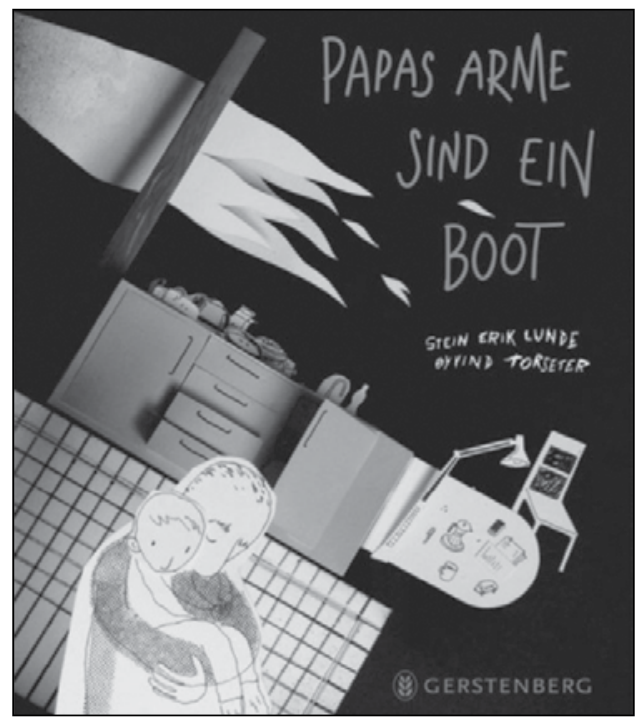

Dass für Kinder im Kindergartenalter eher pragmatische Fragen drängend sind, auch weil sie ein wortgetreues Verständnis von euphemistischen Wendungen an den Tag legen, wird in Lea, Opa und das Himmelsklavier (Karimé/ Behl 2011) literarisch aufbereitet. Hier wird die etwa Vierjährige darüber informiert, dass der Opa in den Himmel gereist sei. „Warum macht Opa das?" und wann kommt er wieder? Und vor allem: Wie kann das vom Opa so geliebte Klavier in den Himmel gelangen? 
Abb. 20: Andrea Karimé; Anne-Kathrin Behl (2011): Lea, Opa und das Himmelsklavier. Wien: Picus.

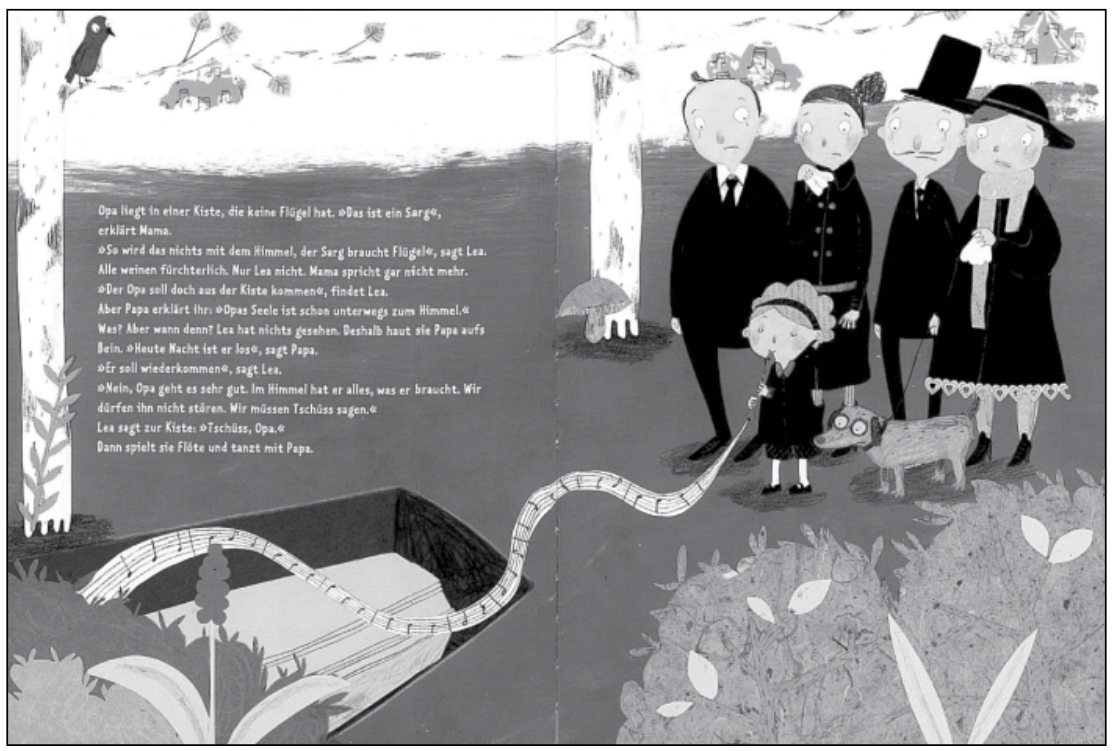

Lea, die ganz selbstverständlich an der Beerdigung teilnehmen darf (Abb. 20), stellt am offenen Grab Überlegungen an, die deutlich machen, dass die Tragweite des Verlusts noch nicht als eine emotionale Grenzerfahrung erfasst wurde, sondern dass konkrete Erklärungen gefordert sind:

„So wird das nichts mit dem Himmel, der Sarg braucht Flügel", sagt Lea. Alle weinen fürchterlich. Nur Lea nicht. Mama spricht gar nicht mehr. "Der soll doch aus der Kiste kommen", findet Lea. Aber Papa erklärt ihr: „Opas Seele ist schon unterwegs zum Himmel." Was? Aber was denn? Lea hat nichts gesehen. [...] Lea sagt zur Kiste: „Tschüss, Opa. “Dann spielt sie Flöte und tanzt mit Papa.

Lea zeigt hier ein altersgerechtes Trauerverhalten, dem weder ein Verständis von der Nonfunktionalität noch von der Irreversibilität zugrunde liegt, und gibt sich letztlich mit der für sie einleuchtenden Erklärung der Erwachsenen zufrieden, im Himmel habe der Opa ein Himmelsklavier: Jetzt ist Lea alles klar! Sie weiß doch schon Bescheid. Opas Musik kann fliegen! (Abb. 21)

Obwohl die Widmung auf dem Vorsatzblatt des Bilderbuchs ${ }^{209}$ eine Nähe zur Realität frühkindlichen Erlebens erwarten lässt, ist aber Kindern dieser

209 „Für Sarah, in deren wunderbarer Frage eine ganze Geschichte gesteckt hat.“ 
Altersgruppe die metaphorische Bedeutung des Erklärungsmusters kaum zugänglich und sie dürften ratlos zurückbleiben.

Abb. 21: Andrea Karimé; Anne-Kathrin Behl (2011): Lea, Opa und das Himmelsklavier. Wien: Picus.

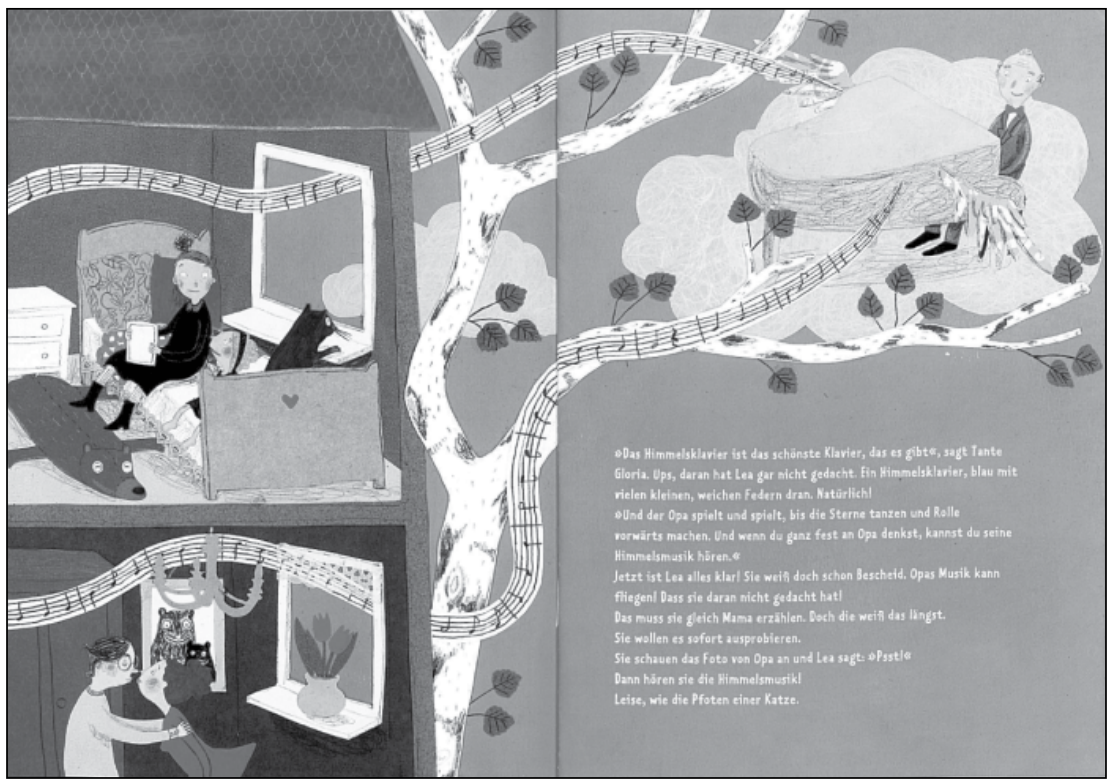

Dieses Bilderbuch ist aber auch ein Beispiel für ein Erzählkonzept, das einen Sterbeprozess und die anschließende Trauerverarbeitung chronologisch verbindet.

Das Erzählen von Sterbeprozessen und Trauerprozessen

In den 21 Bilderbüchern dieser Auswahl ${ }^{210}$ tritt die Emotionalität der kombinierten Sterbe- und Trauerprozesse selten so deutlich zutage wie in den bereits

210 Aertssen 2011: Als Oma ein Vogel wurde; Gliemann/ Tritschler 2011: Ohne Oma; Holzinger/ Stöllinger 2011: Abschied von Anna; Karimé/ Behl 2011: Lea, Opa und das Himmelsklavier; Loske 2011: Sadakos Kraniche; Scharenberg/ Ballhaus 2010: Wenn Oma nicht mehr da ist; Schneider/ Gotzen-Beek 2010: Ein Himmel für Oma; Witt 2010: Bernies Opa; Fortier/ Legendre 2008: Orangen für Opa; Höschl/ Kutschera 2008: Tschüss Oma; Sturm/ Hillen 2008: Justus ist traurig; Weigner/ Kreimeier 2008: Lukas und Oma nehmen Abschied; Bley 2005: Und was kommt nach Tausend?; Gilson/ 
besprochenen Bilderbüchern Leb wohl, lieber Dachs (Varley 1987) und als Oma ein Vogel wurde (Aertssen 2011). Weitere herausragende Beispiele sind Wenn ich nicht mehr bei dir bin, bleibt dir unser Stern (Gilson/ Dubois 2004) ${ }^{211}$, Wenn Oma nicht mehr da ist (Scharenberg/ Ballhaus 2010) und Über den großen Fluss (Beuscher/ Haas 2002) sowie Lukas und Oma nehmen Abschied (Weigner/ Kreimeier 2008). Letzteres ist eine Geschichte über das Sterben und Trauern, in der allen Phasen der nötige Raum gegeben wird, vom behutsamen Konfrontieren mit der Krankheit, der Möglichkeit des persönlichen Abschiednehmens bis hin zur Trauerbewältigung mit schönen Erinnerungen. Die personale Perspektive des Erzählers ermöglicht dem Leser eine größere Nähe zum Erleben des kindlichen Protagonisten und die Gespräche des Jungen mit der Oma und den Eltern zeugen von der Professionalität einer angeleiteten Trauerbegleitung, die auch im Nachwort mit den Hinweisen für Eltern und Erzieher zum Ausdruck kommt. ${ }^{212}$

Das Bilderbuch Der Baum, der nicht sterben wollte (Lundgren et al. 1983) erzählt in großer Ausführlichkeit von der traditionell gewachsenen Verlässlichkeit kollektiven Trauerns, die sich in Riten und Bestattungsgebräuchen einer afrikanischen Dorfgemeinschaft am Fuße des Kilimandscharo zeigt: Totenwäsche, Aufbahren, gemeinsames lautes Klagen bei der Totenwache, üppiger Blumenschmuck, Versprühen von Düften etc. Eine Besonderheit dieses Bilderbuchs, dessen Erzählduktus trotz der emotionalen Anklänge sachlich und unaufgeregt informierend ist und das deshalb zu den Sachbilderbüchern gezählt wird, stellt die Kombination von Fotos und Federzeichnungen dar. Dabei bilden die Fotos der toten Großmutter (Abb. 22), die in ihrem Bett aufgebahrt und später im Sarg gezeigt wird, das traditionelle und von respektvoller Nähe getragene Ritual im Umgang mit Verstorbenen ab.

Dubois 2004: Wenn ich nicht mehr bei dir bin, bleibt dir unser Stern; Simon/ Selle 2003: Der geborgte Stern; Beuscher/ Haas 2002: Über den großen Fluss; Schneider/ Dusíková 1998: Leb wohl, Chaja!; Hübner/ Höcker 1992: Grossmutter; Varley 1984: Leb wohl, lieber Dachs; Lundgren et al. 1983: Der Baum, der nicht sterben wollte; Alex et al. 1982: Großvater und ich und die traurige Geschichte mit dem Kätzchen.

211 S. dazu Kap. VII.

212 Insgesamt 17 aufgefundene Bilderbücher können als Ratgeberbücher bezeichnet werden, da entweder ein Vorwort oder mehrheitlich ein Nachwort auf präventive oder beratende Intentionen hinweist. 
Abb. 22: Gunilla Lundgren; Lars Jacobsson; Militta Wellner (1983):

Der Baum, der nicht sterben wollte. Hamburg: Carlsen.

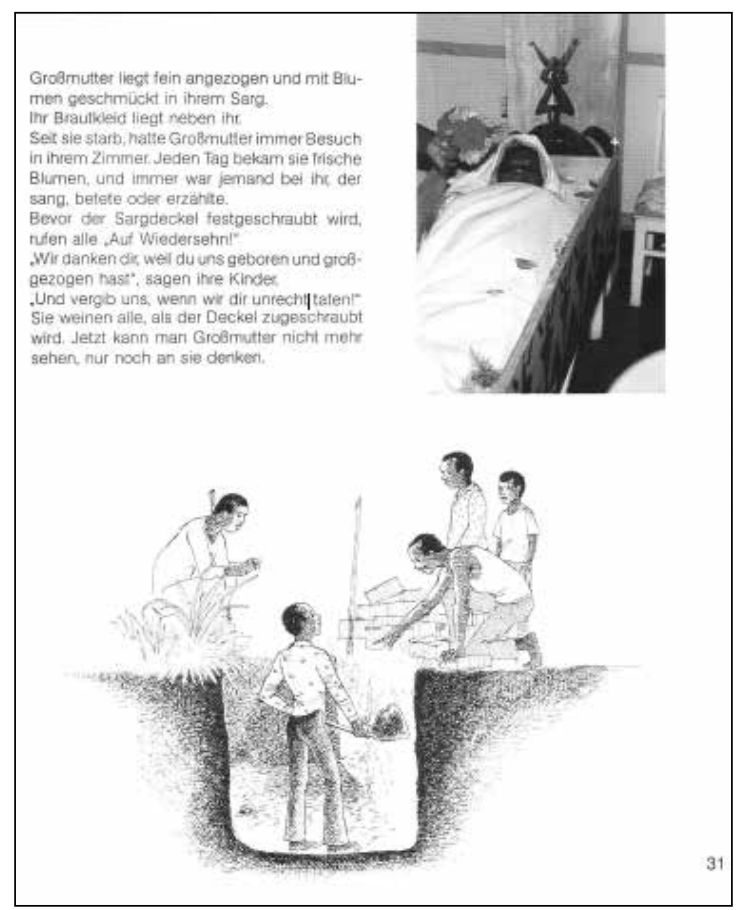

Der sechsjährige Malcolm erlebt erst das Schwächer-Werden der alten, afrikanischen Großmutter, darf am Totenbett von ihr Abschied nehmen und an den rituellen und zeremoniellen Handlungen der Großfamilie teilhaben. Er stellt wichtige Fragen zum Sterben und zum Verbleib der Toten, die von seiner Mutter ehrlich beantwortet werden und gleichzeitig unbeantwortet bleiben, denn auch sie weiß nicht, was nach dem Tod geschieht, erzählt aber den afrikanischen Mythos von der großen Akazie, die einsehen musste, dass alles einem natürlichen Zyklus von Werden, Vergehen und Wiederkehr unterworfen ist.

Dass neuere Erzählkonzepte auch den Tod selbst in personifizierter Gestalt als Kommunikationspartner für kindliche Auseinandersetzungen mit dem Sterben zulassen und welche Anregungen für ein durchaus angemessenes Nachdenken über die eigene Endlichkeit damit gegeben werden, zeigen im Weiteren einige Beispiele. 


\section{VI.2.5.3 Begegnungen mit dem personifizierten Tod}

Seit den ersten Totentanzdarstellungen im Mittelalter hat der Tod bis heute in der bildenden und darstellenden Kunst wie in der Literatur jeder Epoche zahlreiche, ganz eigene Ausdrucksformen erhalten. Wenn hier von Totentanzadaptionen die Rede ist, sind aber nicht Anlehnungen an die Furcht erregenden mittelalterlichen Todesbringer gemeint, sondern der mit menschlichem Habitus versehene, personifizierte Tod. Die vielen Gesichter des Todes in der Tradition des Totentanzes - grausamer Sensenmann, mehrschwänziges Ungeheuer in Seuchenzeiten, knöchernes Gerippe - bleiben in der Bilderbuchwelt für Kinder ungezeigt. In insgesamt achtzehn Bilderbüchern kommt er als kommunizierendes Gegenüber daher, das, obwohl der Tod nicht verhandelbar ist, den zumeist fragenden Kindern Rede und Antwort steht.

Wer über Totentanzadaptionen im Bilderbuch berichtet, darf Nikolaus Heidelbachs Kleiner dicker Totentanz (1984) nicht unterschlagen. Sechzig Bildtafeln, denen nur knappe Bildunterschriften beigegeben sind, präsentieren die heimtückisch-tödliche Bosheit in Person, eine in wallende Gewänder gekleidete, gedrungene Gestalt mit grinsendem Schädel, mit der offenbar jederzeit und überall zu rechnen ist. Dieser Gegenentwurf zu den tradierten, meist unbekleideten Skelett-Gestalten des Mittelalters ist mit niedrigsten (menschlichen) Charakterzügen ausgestattet und zudem Mitglied einer vielköpfigen Totentanz-Familie, womit deutlich wird: Der Tod hat viele Gesichter. Frappierend häufig spielt die ungewollte Komplizenschaft menschlichen (Fehl-) Verhaltens der Profession des kleinen dicken Todes in die Hände, was oft einer sarkastischen Komik nicht entbehrt. Und immer bewegen sich die Darstellungen an der Grenze zum Frivolen oder überschreiten sie: Angesichts der exhibitionistischen Darbietung des kleinen dicken Totentanzes trifft eine alte Frau der Schlag oder der kleine Tod hat sich genüsslich-hämisch in einem knapp bedeckten, weiblichen Schambereich eingenistet u. a. m. Heidelbach zeigt: „Der Tod ist ein Feind des Lebens“ (Heller 2000b, 20). Die in schwarzem Humor schwelgenden Darstellungen des Alltäglichen und des Abgründigen im menschlichen Dasein fordern unbedingt erwachsenes Weltverstehen, kindliches wäre überfordert. Ebenso wie mit Thomas Kriebaums kleiner Tod (2011), dessen Anzug tragende Gestalt, im Gegensatz zum kleinen Totentanz Heidelbachs mit seiner schon begrifflich größeren Nähe zu mittelalterlichen Gestalten, als „Handlungsreisender in finaler Sache“ (Klappentext) nicht ganz eins ist mit sich und der eigenen Berufung.

Ein ganz anderes Bild vom personifizierten Tod zeichnen die gehäuft in den letzten Jahren entstandenen Bilderbücher, in denen der Tod als Erlöser aus leidvoll erlebter Krankheit (Crowther 2011: Der Besuch vom kleinen Tod) oder als 
freundlicher Begleiter (Erlbruch 2007: Ente, Tod und Tulpe) auftritt, als scheiternder Verwalter von Lebenszeit (Schulz/ Krejtschi 2007: Die schlaue Mama Sambona) oder als unglückliche Gestalt, die darunter leidet, als Unglücksbringer nicht willkommen zu sein (Crowther 2011: Der Besuch vom kleinen Tod; Kriebaum 2011: kleiner Tod). Allein zwölf der insgesamt 18 recherchierten Bilderbücher erschienen seit 2002, davon fünf in 2011. Die Bilderbuchkünstler stellen den Tod gestalthaft ins Leben und stützen damit die bei Grundschulkindern verbreitete Auffassung, der Tod komme von außen und sei überlistbar. Der Tod ist in der Vorstellung von Grundschulkindern ein Ereignis, das oft mit äußerer Gewalt, z. B. infolge eines Unfalls, oder mit der Gestalt des Sensenmanns in Verbindung gebracht wird, dessen Vorhaben durch geschicktes Verhalten, Überredungskünste oder Ausweichmanöver vermeintlich vereitelt werden kann. Einen solchen Versuch unternehmen in Warum, lieber Tod...? (Ringtved/ Pardi 2002) vier Kinder, die den Tod - einen düsteren, aber nicht unfreundlichen Kapuzenmann - davon abhalten wollen, die sterbenskranke Großmutter mitzunehmen. Sie versorgen ihn mit Kaffee und verwickeln ihn in ein Gespräch, in dessen Verlauf er ihnen eine Allegorie auf das Leben erzählt: die Geschichte von den Brüdern Leid und Weinen, die mit den Schwestern Freude und Lachen zusammentreffen und feststellen, dass sie zusammengehören und ohne einander nicht sein können. Den Kindern wird einsichtig, dass der Tod nicht aufzuhalten ist und sie sind schließlich bereit, sich von der Großmutter zu verabschieden. Dass dies ein Abschied für immer ist, ist dabei unzweifelhaft und zeugt von einem bereits teilweise ausgeprägten Todeskonzept, das die Irreversibilität einschließt.

Abb. 23: Hermann Schulz; Tobias Krejtschi: Die schlaue Mama Sambona Wuppertal: Hammer.

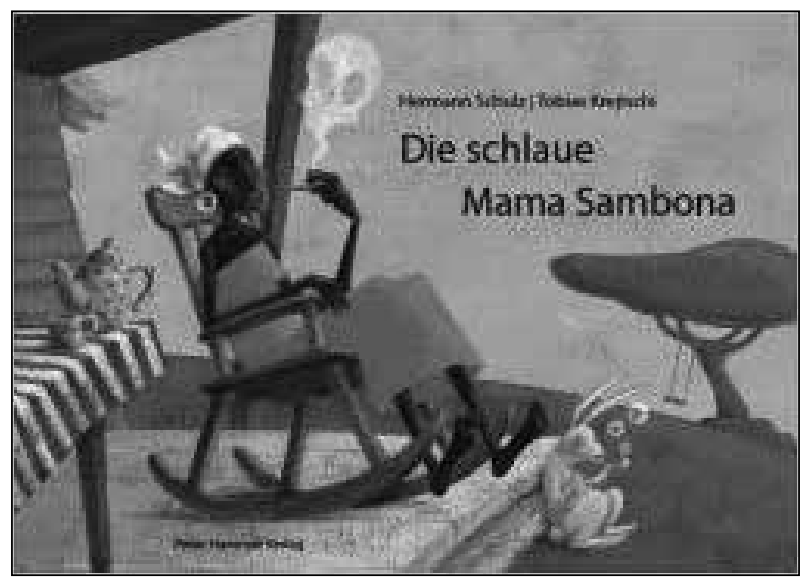


Auf eine ganz eigene, lebensfrohe Weise geht Die schlaue Mama Sambona (Schulz/ Krejtschi 2007) mit dem Tod um. Mit diesem Buch (Abb. 23) greift der Autor eine afrikanische Legende auf und lässt den Tod als Verwalter der Lebenszeit in Gestalt eines strengen Buchhalters auftreten, der von der alten, mit einem unbedingten Willen zum Leben ausgestatteten Mama Sambona ausgetrickst wird. Der Tod kann nach dem dritten vergeblichen Versuch, sie zu holen, vorerst nichts mehr ausrichten, was dem magischen Denken von Kindern im Vorschulalter entgegenkommt und den märchenhaften Charakter dieser Erzählung ausmacht, der sich so vervollständigen ließe: Und wenn sie nicht gestorben ist, dann führt Mama Sambona den Tod noch heute an der Nase herum.

Dagegen hat die Begegnung mit dem Tod bei Jürg Schubiger und Rotraud Susanne Berner (Als der Tod zu uns kam 2011) drastische Folgen.

Abb. 24a: Jürg Schubiger; Rotraut Susanne Berner (2011):

Als der Tod zu uns kam. Wuppertal: Hammer.

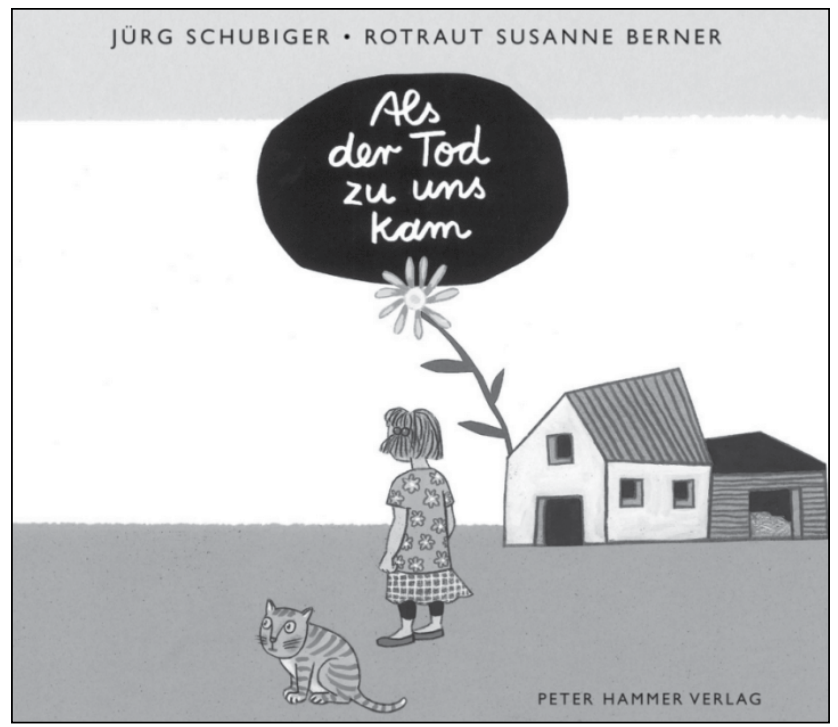

Dort tritt der Tod als ungeschickter Reisender auf und trägt Unglück, Leid und Verlust in eine bis dahin völlig arglose Gesellschaft (Abb. 24a):

Es gab eine Zeit, da kannten wir nicht einmal seinen einfachen Namen. Tod? Nie gehört. Es gab kein letztes Stündchen damals, es gab nur ein erstes, zweites, drittes, tausendstes ... Immer eines dazu. [...] Eines Abends kam er die Straße herauf. [...] Er schien auf der Durchreise zu sein, ein Fremder wie andere auch. Dann, ausgerechnet vor unserer Tür, 
stolperte er. Wir lachten. Wir fanden das sehr komisch, dieses Stolpern, wir hatten nie jemanden stolpern sehen.

Die Stimme dieser Gemeinschaft ist das auf dem Cover abgebildete Mädchen, das offenbar dem kommenden Unheil, das sich schon im Blick der Katze andeutet, entgegensieht. Nachdem ein Haus abgebrannt, der Bruder der Ich-Erzählerin dabei zu Tode gekommen ist und manche, vormals ausgebliebene Verletzungen den Bau eines Krankenhauses notwendig machten, ist die Gemeinschaft um schlechte Erfahrungen reicher und daran aber auch gewachsen, denn die anfängliche Gleichgültigkeit ist einem aufmerksamen Umgang miteinander gewichen. Am Schluss heißt es:

Was der Tod uns damals zurückgelassen hat, ist das Leid, das Mitleid und der Trost. Wenn ein neuer Tag beginnt, wünschen wir uns seither einen guten Morgen. Wenn jemand niest, rufen wir: Gesundheit! Und wenn jemand weggeht, wünschen wir ihm eine gute Reise.

Hier wird mit nüchternem Sprachstil ausgedrückt, dass die Begegnung mit dem Tod Beziehungen hergestellt hat, wie sie offenbar vorher nicht bestanden hatten. Dieser positive Effekt ist ebenso auf der Bildebene nachvollziehbar und tritt in der vergleichenden Betrachtung der ersten und der letzten Bilderbuchseiten (Abb. 24b u. 24c) zutage.

Die zu Beginn auf einer textfreien Doppelbildseite ohne erkennbare sozialemotionale Beziehungen angeordneten Figuren (Abb. 24b) haben nach den Erfahrungen mit dem Tod ganz offensichtlich ein Zusammengehörigkeitsgefühl entwickelt, denn die Mimik der nun eng Zusammenstehenden wirkt ausdrucksvoller und emotionaler (Abb. 24c).

Abb. 24b: Jürg Schubiger; Rotraut Susanne Berner (2011): Als der Tod zu uns kam. Wuppertal: Hammer.

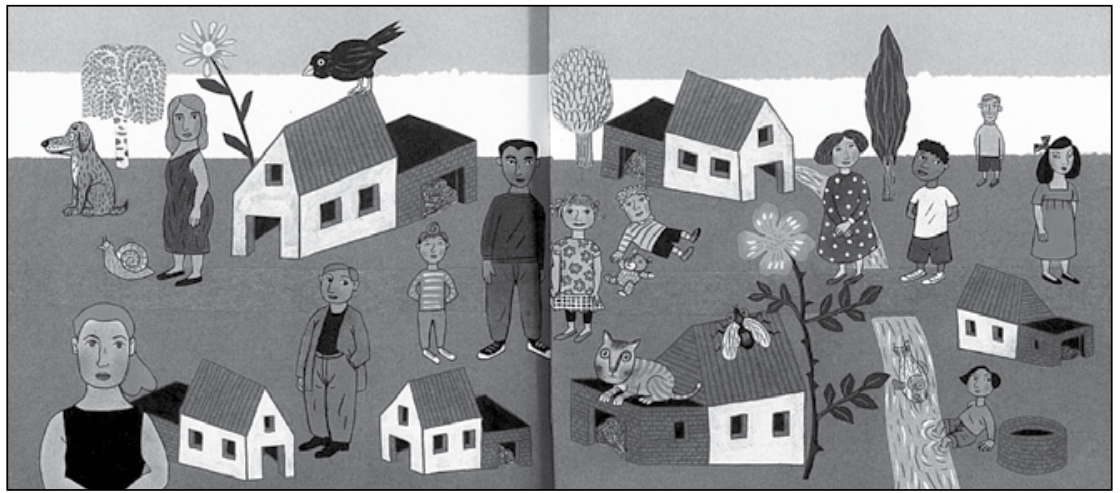


Abb. 24c: Jürg Schubiger; Rotraut Susanne Berner (2011): Als der Tod zu uns kam. Wuppertal: Hammer.

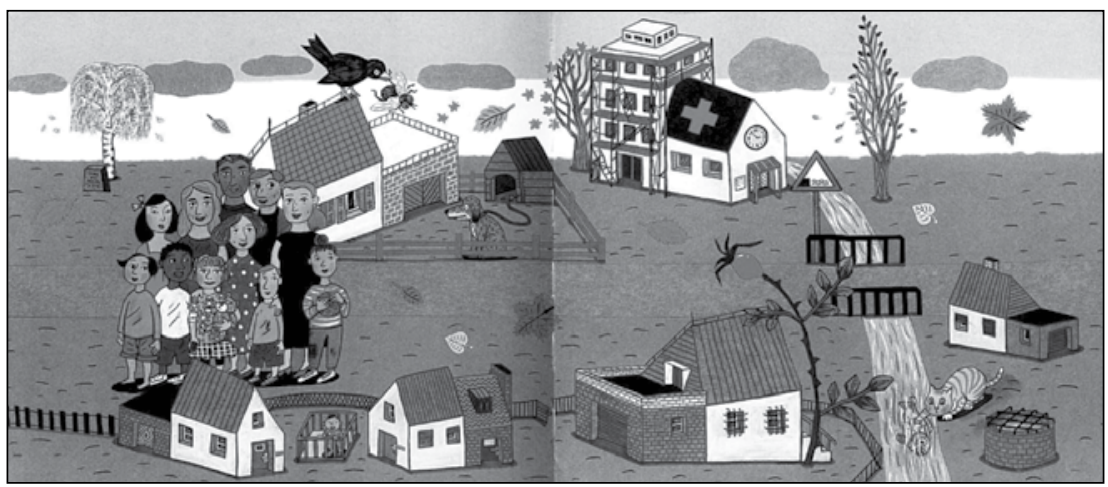

Auch die Ausgestaltung des Lebensraumes hat sich merklich verändert: Das vorher starr wirkende Arrangement von Bäumen, Häusern und Figuren zeigt am Ende eine neue Lebendigkeit, die sich in den Zeichen von Vergänglichkeit findet: herabfallendes Herbstlaub, ein Grabstein, eine Uhr, vorbeiziehende Wolken, Tiere als Teile einer Nahrungskette u. a. m. Der Ikonotext verdeutlicht: Leben und Menschsein bedeutet Bewegung, Veränderung und sich in Beziehung zu setzen, auch in der Auseinandersetzung mit dem Tod, die hier, ausgelöst durch die Erfahrung eines schmerzhaften Verlusts, offensichtlich für den Wert menschlicher Beziehungen und des Lebens insgesamt sensibilisiert.

Abb. 25: Jürg Schubiger; Rotraut Susanne Berner (2011): Als der Tod zu uns kam. Wuppertal: Hammer.

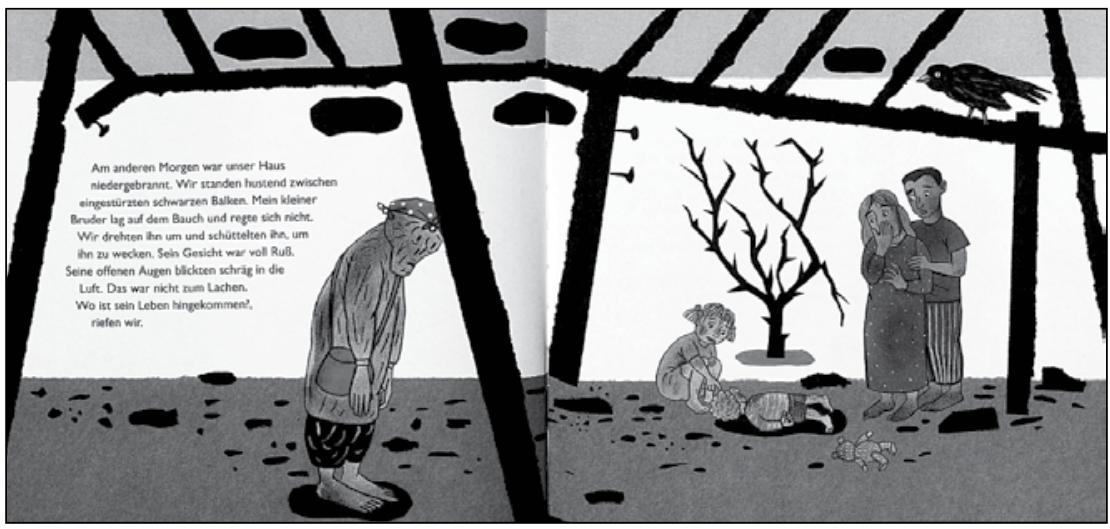


Dass gerade ein Kind das Opfer ist, verschärft die Dramatik der Geschehens, verdeutlicht aber gleichzeitig, dass das Sterben universell ist und sich nicht auf den Alterstod beschränkt. Ein plötzlicher Tod, wie hier infolge eines Hausbrandes, kann jeden treffen. Obwohl der Tod als der Verursacher sichtlich mit seiner Schuld hadert (Abb. 25), ist Mitgefühl für diese traurige Figur sicher nicht gefordert, sondern vielmehr die Erkenntnis, dass der Tod nicht berechenbar ist. Eine Antwort auf die Frage Wo ist sein Leben hingekommen?, die die Schwester und die Eltern stellen, bleibt der Tod schuldig, eine religiöse Perspektive wird nicht angesprochen, unzweifelhaft ist aber, dass dieses Leben unwiederbringlich verloren ist.

Mit dieser Geschichte wird die Entwicklung eines reifen Todeskonzepts nachvollziehbar, das sich von der völligen Unbedarftheit über die Erfahrung, dass ein Unglück jedermann unerwartet tödlich treffen kann (Universalität und Kausalität), zum Bewusstsein der Nonfunktionalität und Irreversibilität vervollständigt. ${ }^{213} \mathrm{Da}$ Kinder dieses komplexe Wissen in der Regel erst zum Ende des Grundschulalters hin ausbilden - es sei denn, ein konkretes Ereignis gibt den Anstoß -, richtet sich dieses Bilderbuch weniger an Jüngere und mehr noch an Erwachsene, die, wie die Ich-Erzählerin in einer nicht näher bestimmten zeitlichen Distanz zum Geschehen, sich reflektierend mit der Bedeutung des Sterbens auseinandersetzen wollen.

Bei Wolf Erlbruch (2007) stehen dagegen die Allgegenwärtigkeit des Todes und die entlastende Wirkung seiner Akzeptanz in Ente, Tod und Tulpe im Vordergrund. Erlbruchs Todes-Figur legt eine gelassene und doch zurückgenommene Souveränität im Umgang mit der fragenden Ente und zuletzt ein so zärtliches Erfüllen seiner Pflicht an den Tag, dass sich als Frage aufdrängt: Darf der Tod so freundlich, ja sympathisch dargestellt werden? Die Antwort darauf mag sich jeder selbst geben, der sich den Adressaten Kind vor Augen führt und bedenkt, dass Bilderbücher Ängste zwar thematisieren, aber nicht aufkommen lassen sollten. So ist auch die Physiognomie der meisten Todesgestalten zu deuten, die häufig klein, d. h. nicht größer als ein Kind sind (s. auch Crowther 2011), in Kindergestalt auftreten (Sommer-Bodenburg/ Tiong-Khing 1989) oder bei Erlbruch mit menschlichen Empfindungen und mit kindlicher Schädelphysiognomie ausgestattet sind. Eine mögliche Deutung billigt, wie schon oben beschrieben, dem Tod eine positive Facette zu, wonach der Mensch mehr gewinnt als er verliert, wenn er den Tod als Begleiter des Lebens akzeptiert. In der gelassenen Hinnahme dürfte die Chance zu einem bewusst gehaltvollen Leben liegen, in der Erkenntnis, dass das Leben seinen Wert erst aus seiner Begrenztheit bezieht.

213 Vgl. auch: Egli 2014, 74. 
Abb. 26: Wolf Erlbruch (2007): Ente, Tod und Tulpe. München: Kunstmann.

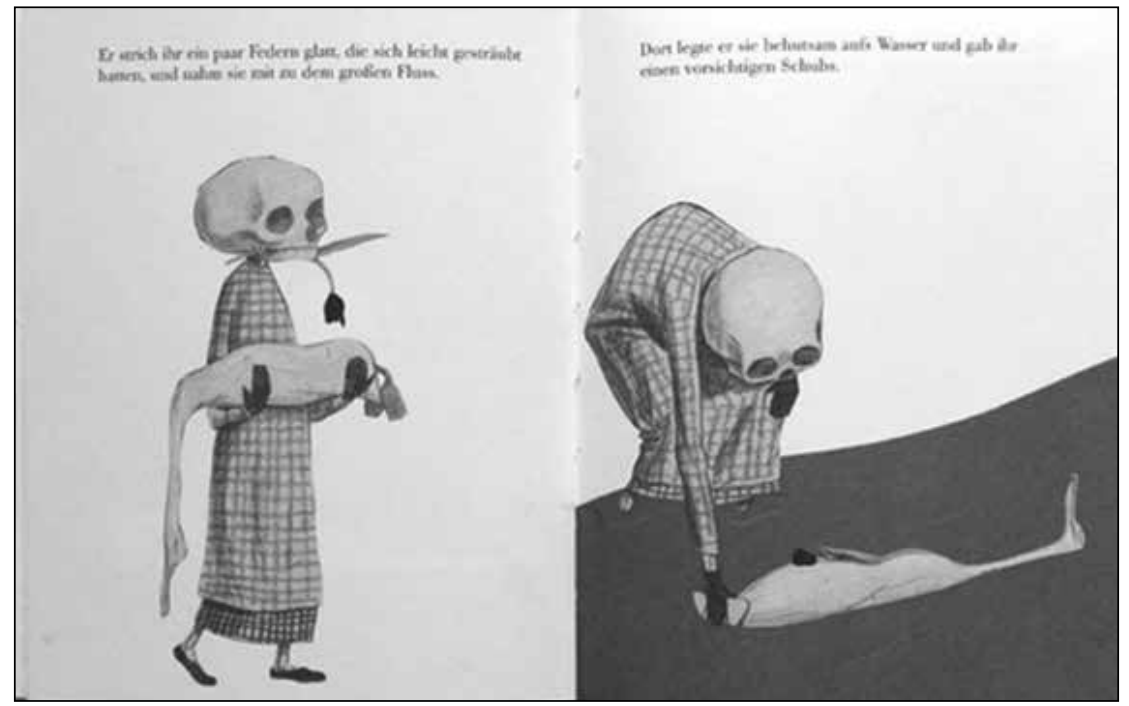

Der maßgebliche Unterschied zu den hinterhältigen Überfällen des Todes in der Bearbeitung Heidelbachs (1984) und dem Schuldhaften bei Schubiger und Berner (2011) liegt bei Erlbruch darin, dass der Tod nicht aktiv ein Lebensende herbeiführt, sondern den Moment des Sterbens abwartet und quasi keine Verantwortung dafür trägt. Er erfüllt eine offenbar notwendige Mittlerrolle für den Übergang vom irdischen ins jenseitige Leben, was sich bildhaft im Hinübertragen der toten Ente zum Fluss ausdrückt (Abb. 26). Dieses Motiv aus der griechischen Mythologie, in der der Fluss Styx die Grenze zwischen der Welt der Lebenden und dem Totenreich Hades markiert, ist ein häufig verwendetes. Unabhängig davon bietet sich die Deutung der Erlbruch'schen Darstellung auch als ein ins Nichts oder zumindest Unbekannte laufender Strom an, womit die Polyvalenz des Erzählkonzepts bestätigt wird, die bereits im Mittelteil der Geschichte mit den Fragen der Ente nach einem möglichen Jenseits und den vagen Antworten des Todes angelegt ist.

Dass das Auftreten des Todes auch einen pragmatischen Aspekt hat, bringt das märchenhafte Bilderbuch Die Ballade vom Tod (Meinderts/ Jekkers 2009) (Abb. 27) nahe. 
Abb. 27: Koos Meinderts; Harrie Jekkers; Piet Grobler (2009):

Ballade vom Tod. Hildesheim: Gerstenberg.

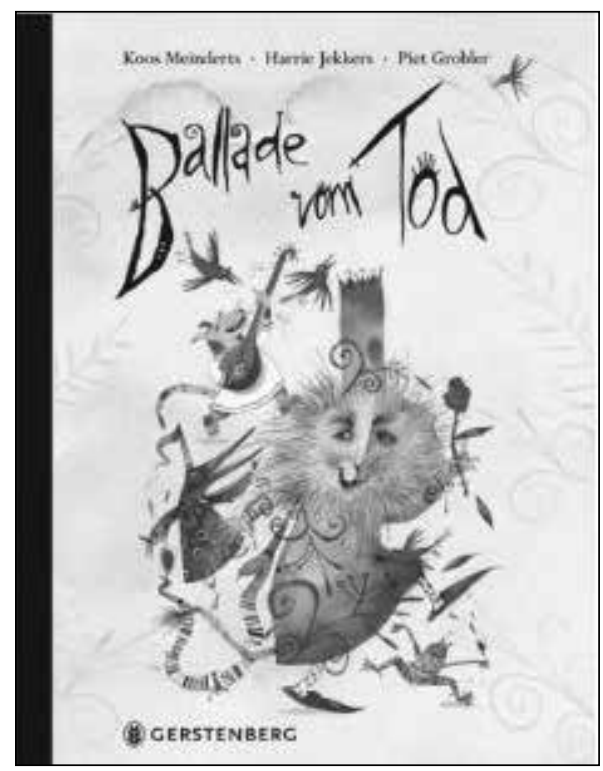

Der Traum vom ewigen Leben ${ }^{214}$ wird darin ab absurdum geführt, denn es zeigt sich, dass nach der Gefangennahme des gestalthaften Todes zwar niemand mehr stirbt, dass das Leben aber seinen Wert und seine Qualität verliert, wenn alle Lebensrisiken keine Risiken mehr sind, wenn überbordendes Verhalten an keine natürlichen Grenzen stößt, wenn der Erdball sich immer mehr bevölkert und bald niemandem mehr ausreichend Platz zum Leben bleibt. Das Problem der Überbevölkerung kann schließlich nur gelöst werden, indem der König, der aus Angst die Gefangenenahme des Todes befahl, sich ihm stellt und sich opfert. Dass der Tod unbedingt zum Leben gehört und seinen Wert erst bestimmt, wird mit dieser Geschichte eindrücklich und nachvollziehbar vor Augen geführt.

In keinem der seit 2000 erschienenen Bilderbücher wirkt der personifizierte Tod Angst einflößend. Er tritt lediglich in seiner Funktion als unabwendbare Tatsachen schaffende Figur auf, die zwar als Bedrohung verstanden, der aber keine Böswilligkeit angelastet werden kann. Wie gezeigt wurde, machen für die Beantwortung der Frage, „wer oder was der Tod sei, [...], ob der Tod nur dazu da ist,

214 Vgl. auch: Thompson 1995: Für immer leben (Ders. unter neuem Titel 2007: Bücher öffnen Welten); Hastings/ Cartwright 1994: Bodkin oder das Rätsel vom ewigen Leben. 
das Leben aus einsichtigen Gründen zu beenden oder ob er auch einen neuen Lebensraum schaffen kann oder gar soll“ (Hoymann 2000, 121), gerade die modernen Totentanzbearbeitungen sehr unterschiedliche Vorschläge, die anzunehmen, abzulehnen oder umzudeuten jedem Einzelnen anheimgestellt werden muss.

\section{VI.2.5.4 Gewalt, Krieg und Drogentod}

Die Recherche ergab 26 Bilderbücher, die gewaltsame bzw. nicht natürliche Todesursachen, mit Ausnahme von Unfällen, thematisieren. Der Schwerpunkt liegt beim Motiv Krieg ${ }^{215}$, daneben werden ein Drogentod ${ }^{216}$, zwei Morde ${ }^{217}$, das Thema Holocaust ${ }^{218}$ und der Atombombenabwurf über Hiroshima ${ }^{219}$ problematisiert.

Die Tötung von Tieren, fast immer durch Menschenhand, findet in 14 Bilderbüchern ${ }^{220}$ statt, ist teilweise aber nur marginal und selten als handlungsbestimmendes Motiv gesetzt, dem ein Trauerprozess folgt. In Sein erster Fisch (Schulz/ Oeser 2000) geht es beispielsweise um die Frage nach der Verantwortung im Umgang mit Tieren, und in Komm, Emil wir gehn heim! (sic!) (Traxler 2004) entgeht das Schwein Emil, das seiner Besitzerin ans Herz gewachsen ist, nur deshalb dem Tod im Schlachthof, weil die Besitzerin dort für sie inakzeptable Zustände vorfindet. Daneben zeigt sich mit $\mathrm{Da}$ bin ich von F. K. Waechter (1997) ein Sonderfall und eine Form der Entgrenzung der Kategorie Adressat, die angesichts des brutalen Szenarios des Ertränkens von ,überschüssigen` Katzenkindern schockierend wirkt. Darin berichtet ein überlebendes Katzenkind in der Ich-Form lakonisch von seinem Kampf zurück ins Leben.

215 Janosch 1968: Böllerbam und der Vogel; Wendt/ Boratynski 1991: Der Krieg und sein Bruder; Popov 1995: Warum?; Wikland/ Lagercrantz 1996: Die lange, lange Reise; Vaugelade 1999: Fabian und der Krieg; Kaufmann 1999: Das fremde Kind N.; Herzog/ Clante 2009: Flieger am Himmel.

216 Schindler/ Jucker 1994: Mia, was ist ein Trip.

217 Waechter 2004: Der Affe des Strandfotografen; Krol/ Kunstreich 2005: Kevin Kanin oder Als es dunkel wurde am Lohewald.

218 Innocenti/ Gallaz 1986: Rosa Weiss; Cohen-Janca/ Quarello 2011: Annes Baum.

219 Ellermann 1990: Papiervogel, flieg!; Coerr/ Young 1995: Sadako.

220 Goodall/ Marks 2004: Ricki und Henri; Mürmann/ Meis 2004: Warum so hart, kleiner Bär?; Traxler 2004: Komm, Emil wir gehn heim!; Billioud/ Gay 2000: Schreckliche Zahnschmerzen; Schulz/ Oeser 2000: Sein erster Fisch; Recheis/ Kaufmann 1998: Schwesterchen Rabe; Waechter 1998: Der rote Wolf; Wikland/ Lagercrantz 1996: Die lange, lange Reise; Waechter 1997: Da bin ich; Cratzius/ Blancke 1995: Das Bärenkind; Douglas-Hamilton 1990: Das Elefanten-Kinder-Buch; Damjan/Casty 1965: Atuk, der Eskimojunge; Arima/ Arima 1984: Pon und Lulu; de Brunhoff 1946: Die Geschichte von Babar dem kleinen Elefanten. 
Wir waren drei. [...] Wir waren zu viel. Da haben uns die Fischer in einen Sack gesteckt, sind mit uns aufs Meer hinausgerudert und haben uns ins Meer geworfen, um uns zu ertränken.

Da riecht uns ein Katzenhai, [...] frisst meinen Bruder, frisst meine Schwester.

[...] Dann steige ich aus, laufe durch Straßen, komm an ein Haus, drücke den richtigen Klingelknopf.

Du machst mir auf. Wie schön. Da bin ich.

Aufgrund des Fehlens jedweder sprachlich ausgedrückter Gefühlregung des Protagonisten ist der Leser gefordert, das eigene Empfinden, seine moralischen und ethischen Überzeugungen zu befragen und vor allem die Bilder, die Empathie einfordern, in sich aufzunehmen. Auf den Punkt gebracht wird diese Konfrontation auf der letzten Buchseite, die mit dem Visavis von Figur und Betrachter den Titel aufgreift. Die Winzigkeit des verlegen die Arme verschränkenden Katzenkindes ist ein bildhafter Appell an den im Betrachter gesuchten Beschützer und Retter, den das Bildkonzept quasi hervorbringt (Abb. 28).

Abb. 28: Friedrich Karl Waechter (1997): Da bin ich. Zürich: Diogenes.

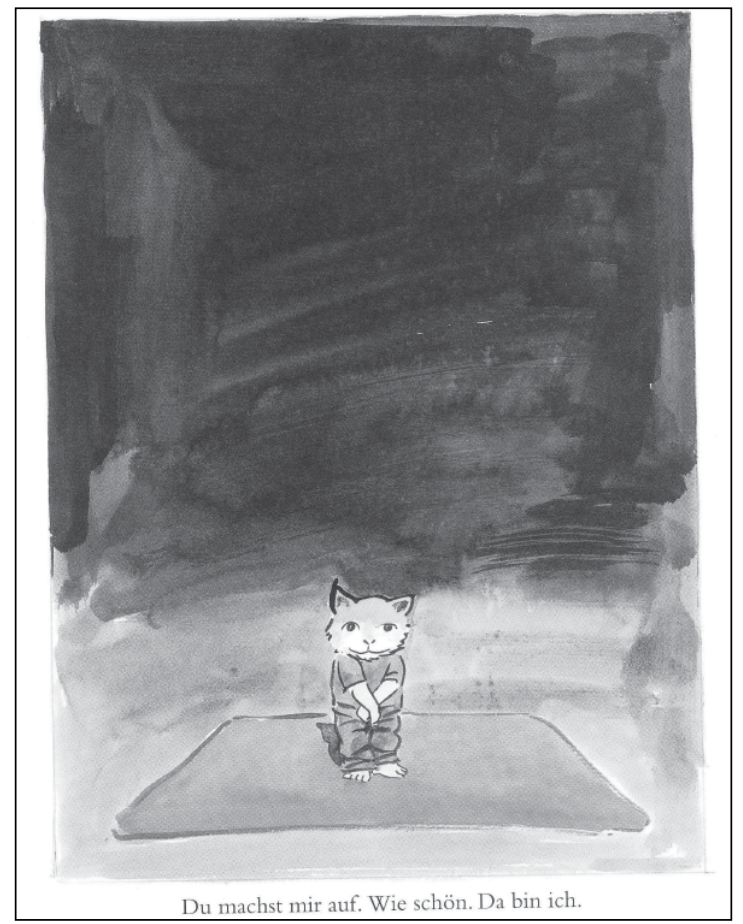


Damit manifestiert sich im Ikonotext das Anliegen des Erzählens: Der Leser soll sich persönlich angesprochen und aufgefordert fühlen, zur Geschichte und damit zum Thema Tierquälerei Stellung zu beziehen.

1968, zur Zeit der Aufnahme kritischer Themen in die KJL, erschien mit Böllerbam und der Vogel von Janosch eine Parabel auf den Krieg, ein Bilderbuch, das mit dem Kriegführen die pure Lust am Töten in Gestalt des fehlsichtigen Soldaten Böllerbam verbindet und zeigt, dass dessen damit einhergehende Dummheit zum eigenen Schaden gereicht. Die Sinnlosigkeit des Krieges, der letztlich niemandem nützt, wird sowohl aus der Perspektive der betroffenen Unschuldigen als auch der Agierenden herausgestellt. Gleiches thematisiert das textfreie Fabel-Bilderbuch Warum? (Popov 1995), in dem die verheerende Wirkung kriegerischer Auseinandersetzungen eindrucksvoll ins Bild gesetzt ist. Dort ist im Wortsinne verbrannte Erde das Ergebnis eines Streits um eine Blume zwischen Maus und Frosch. Die Streitenden rüsten wortlos auf, lassen ihre Artgenossen aufeinander los und schießen mit Kanonen, bis schließlich ihre Welt zerstört in Schutt und Asche liegt. Bilderbücher wie diese wollen aufrütteln und zum Nachdenken anregen, sie sprechen menschliches Fehlverhalten und seine tödlichen Folgen an und sind damit sowohl (politische) Aufklärungsbücher als auch philosophische Bilderbücher, weshalb sie hier mehrheitlich der letztgenannten Kategorie zugeordnet werden.

\section{VI.3 Zusammenfassung der Ergebnisse}

1. Die Ausgangshypothese, in Abhängigkeit vom Erscheinungszeitraum stelle sich das Bilderbuchangebot zum Thema Sterben und Tod zunehmend differenzierter dar, hat sich bestätigt. ${ }^{221}$ Es stellte sich heraus, dass bis 1984 der Tod nur eine marginale thematische Erscheinung bzw. selten das handlungsbestimmende Motiv war und sachorientierte Herangehensweisen vorherrschten. Die Beobachtung, dass seit Anfang der 1980er-Jahre das Philosophieren mit Kindern Konjunktur hat (vgl. Rank 2002, 801), trifft auch auf das recherchierte Textkorpus zu. Ab 1984 erweiterte sich langsam das Spektrum der Subgattungen und Inhaltsmotive, deren Anzahl im jährlichen Querschnitt jedoch durchgehend im niedrigen einstelligen Bereich liegt, weshalb es sinnvoller erscheint, zusammenfassend Aussagen über das im Längsschnitt gewonnene Bild des jeweiligen Gesamtumfangs der einzelnen Gattungs- und Inhaltskategorien zu treffen. Danach dominiert das anthropomorph-realistische Bilderbuch vor dem

221 S. dazu die tabellarische Übersicht im Anhang (X.2). 
anthropomorph-phantastischen Bilderbuch und dem phantastischen Tierbilderbuch. Die geringe Anzahl von drei realistischen Tierbilderbüchern ist auf die eng gefasste Definition zurückzuführen, die für Tiere eine handlungsbestimmende Funktion festlegt. Insgesamt zeigt die Untersuchung, dass das Erzählen vom Tod für Kinder sich mitnichten auf die Tierwelt und ihre gerade in phantastischen Handlungszusammenhängen entlastende Funktion konzentriert, sondern verschiedenen Ansprüchen an Erklärungs- und Trostbilder in sowohl phantastischen als auch realistischen (Erzähl-) Dimensionen gerecht wird.

Die untersuchten Bilderbücher erzählen mehrheitlich von Beziehungsverlusten, auch in Tiergeschichten, die die psychische Konstitution von Kindern direkt berühren und ein entsprechendes Identifikationspotenzial implizieren. Die Konzepte der Sachbilderbücher, der allgemein-philosophischen Ansätze und der phantastischen Tierwelten, die nicht von kindlichen Trauernden erzählen, sind weniger auf Identifikation, sondern mehr auf Empathie und Aufklärung hin angelegt. Vor allem alte Tiere sind idealisierte „Menschenkopien in Tierkörpern“ (Wrobel 2013, 10), die Todesgeschehen erklären, als Trostspender auftreten und dem eigenen Tod mit der Hoffnung auf eine unbekannte nachtodliche Daseinsform gelassen entgegensehen.

Der Verlust von Großeltern, eines Elternteils oder der Tod von Kindern tritt zwar früh auf, jedoch ergibt sich ein deutlicheres und anderes Bild, wenn aus den absoluten Zahlen jeweils die Anzahl der hauptmotivisch erzählenden Bilderbücher herausgehoben wird. Dann zeigt sich, dass komplexe kindliche Trauerprozesse, ausgelöst durch existenziell bedrohliche Beziehungsverluste, erst ab 1993 (Mutter) bzw. 1994 (Vater) für einzelne Erzählgeschehen bestimmend sind. Das Teilkorpus zum Tod von Großeltern ist zwar deutlich umfangreicher und beginnt bereits 1974, ist aber hinsichtlich der Ausgestaltung von Trauerprozessen ebenso reduziert. Auch der Tod im Kindesalter wird zwar schon früher erwähnt, erstmals aber von Elisabeth Kübler-Ross (1985) als Hauptmotiv ins Bilderbuch gebracht. Die Vermutung, dass mehrheitlich Großeltern sterben, hat sich insofern bestätigt, als den 69 ausgezählten Todesfällen (32 Großväter, 37 Großmütter; davon 9 Tierfiguren) jeweils die Teilkorpora Kindertod (N=53), Elternverlust $(\mathrm{N}=27)$ und andere Todesfälle $(\mathrm{N}=22)$ gegenüberstehen.

2. Konkret-religiöse Auffassungen vom Tod, die sich im Glauben an die durch Jesus Christus begründete Auferstehung und das ewige Leben bei Gott ausdrücken, sind in mehr oder weniger ausgeprägter Form in nur etwa $22 \%$ der untersuchten Bilderbücher aufgefunden worden. Damit hat sich die zweite Hypothese bestätigt, es spiegelten sich die Einstellungen einer säkularisierten Ge- 
sellschaft, in der das Vertrauen auf das Aufgefangen-Werden in einer göttlichen Dimension weitgehend abgelöst wurde von einer dem Menschen überantworteten Erinnerungskultur, die den Tod mehr auf seine Auswirkungen für die Hinterbliebenen als für den Verstorbenen hindenkt. Diffuse Vorstellungen von einer Weiterexistenz werden nur selten durch die konkrete Vorstellung eines Bei-GottSeins ergänzt. Transzendentale bzw. religiöse Dimensionen spielen weniger in realistischen, mehr in phantastischen Formaten eine Rolle. Interkulturelle und interreligiöse Aspekte bleiben weitgehend unberücksichtigt. Insgesamt sind nur 10 der Bilderbücher thematisch auf außereuropäische Kulturen wie Afrika oder Südamerika ausgerichtet.

3. Das zeitliche Moment, d. h. die Dauer und die Emotionalität von Sterben und Trauer, steht in mehr als der Hälfte des gesamten Materials im Vordergrund, wovon auf die Untersuchungsdekade ab dem Jahr 2000 mehr als zwei Drittel entfallen. Damit bestätigt sich ebenfalls die dritte Anfangshypothese, auch hinsichtlich der Öffnung des Bilderbuchs für die Trauerprozesse Erwachsener, die zuvor thematisch so gut wie keine Rolle spielten. Kinder werden im Handlungsgeschehen vermehrt an das Sterben herangelassen und der Prozesscharakter des Trauerns tritt in den neueren Bilderbüchern deutlicher hervor, was sich aus textanalytischer Sicht sowohl in der Ausdehnung der erzählten Zeiten als auch der Erzählzeiten ausdrückt. Zudem entwickelte sich das Bilderbuch immer mehr zu einem Medium der Darstellung kindlicher Gefühls- und Gedankenwelten, die sich in der Ausgestaltung der Erzählsituationen und -perspektiven spiegeln, was dazu Anlass gibt, hier vom psychologischen Bilderbuch als Subgattung zu sprechen. Dessen erzähltechnische Spezifika werden im Folgenden am Textkorpus der Bilderbücher zum Tod im Kindesalter nachgewiesen, wobei ergänzend zu den narratologischen Bilderbuchanalysen auch nach der Authentizität der verschiedenen Erzählkonzepte gefragt wird. 


\section{Das Sterben von Kindern im Bilderbuch}

Dieses Textkorpus versammelt alle aufgefundenen Texte, die die Möglichkeit des kindlichen Sterbens und damit die Universalität des Todes implizit wie explizit thematisieren. Im Anschluss an eine mehr quantitativ ausgelegte Kategorisierung werden qualitative Analysen anhand des im Kapitel V.2.3 vorgestellten thanatologisch-diskursanalytischen Ansatzes auf der Basis des narratologischen Bilderbuchmodells (s. Kap. III) durchgeführt und die Ergebnisse mit den Forschungshypothesen, die hier zur Verdeutlichung nochmals aufgeführt werden, abgeglichen.

1. Kindern wird eine gleichberechtigte und gleichzeitig spezifische Teilhabe an Todesgeschehen und Trauerprozessen zugebilligt, die sich insbesondere in der Auseinandersetzung mit dem Kindertod und ihren erzähltechnischen Darstellungsformen zeigt.

2. Die besondere Problematik des Geschwisterverlusts wird nur selten aufgegriffen.

Folgende Leitfragen sind damit verbunden:

In welchem Umfang und mit welcher Qualität bzw. Authentizität wird die Problematik des Todes und der Trauer im kindlichen Alter angesprochen und welche Funktionen sind damit verbunden? In welchem Maße werden Kinderfragen, belastende Aspekte und negative Gefühle zugelassen? Welche Dimensionen eines kognitiven Todeskonzepts sind ausgeprägt? Wie wird die kindliche Perspektive auf den eigenen Tod, der Umgang mit einer eigenen, krankheitsbedingten Todesgewissheit dargestellt? Welche funktionale Bedeutung hat in diesem Zusammenhang insbesondere die Erzählperspektive? In welcher Form ist Emotionalität auf der Bildund auf der Textebene bzw. anhand der wechselseitigen Bezugnahme gestaltet? Inwieweit gehen die Bilderbücher auf die besondere, aus der Thanatopsychologie bekannte Problematik kindlicher Trauerprozesse beim Verlust von Geschwistern oder Gleichaltrigen ein? Spielen negative Gefühle wie Schuldgefühle, ein minderer Selbstwert oder Isolation aufgrund des elterlichen Trauerverhaltens eine Rolle?

Diese Fragestellungen bedingen eine Kategorisierung, die sowohl Gattungsmerkmale als auch Figurenkonzeptionen bzw. -konstellationen und die zentralen Erzählmotive Trauern und Sterben berücksichtigt. Wie oben erwähnt, wurden in das Textkorpus alle Titel aufgenommen, die hauptmotivisch oder marginal kindliches Sterben thematisieren, um Veränderungen des motivischen Stellenwerts im Bilderbuch - umfänglich und inhaltlich - im Verlauf der letzten fast 70 Jahre nachweisen zu können. Eine anschließende Modifizierung des 
Textkorpus' hinsichtlich psychologischer Aspekte ist einerseits der Fokussierung auf die menschlich-kindlichen Protagonisten geschuldet und hebt andererseits die Hauptmotivik kindlichen Sterbens bzw. Trauerns in Abgrenzung zu lediglich marginalen Erwähnungen in Sach-, Tier- oder märchenhaften Bilderbüchern hervor. Die folgenden Kapitel fassen die Ergebnisse zusammen.

\section{VII.1 Ergebnisse der Inhaltsanalysen}

\section{VII.1.1 Subgattungen}

Die quantitative Verteilung der insgesamt 53 zum Kindersterben recherchierten Titel stellt sich gattungsbezogen wie folgt dar:

Abb. 29: Quantitative Verteilung der Subgattungen im Teilkorpus Kindersterben $(N=53)$.

\begin{tabular}{|c|c|}
\hline \multicolumn{2}{|c|}{ Subgattungen im Teilkorpus Kindersterben } \\
\hline $\begin{array}{l}\text { märchenhafte } \\
\text { Bilderbücher } \\
8 \%(\mathrm{~N}=4) \\
\text { phantastische } \\
\text { Tierbilderbücher } \\
11 \%(\mathrm{~N}=6) \\
\text { anthropomorph- } \\
\text { phantastische } \\
\text { Bilderbücher } \\
26 \%(\mathrm{~N}=14)\end{array}$ & $\begin{array}{l}\text { anthropomorph- } \\
\text { realistische } \\
\text { Bilderbücher } \\
36 \%(\mathrm{~N}=19) \\
\text { realistische } \\
\text { Tierbilderbücher } \\
2 \%(\mathrm{~N}=1) \\
\\
\text {-Sachbilderbücher } \\
17 \%(\mathrm{~N}=9)\end{array}$ \\
\hline
\end{tabular}

Die Abbildungen 29 und 30 zeigen, dass das Thema Kindersterben in ausgewogenem Maße in realistische wie phantastische Erzählkonzepte eingebunden ist, auch aufgrund der hybriden Struktur der Sachbilderbücher, deren teils phantastische Elemente, z. B. in Annes Baum (Cohen-Janca/ Quarello 2011), eine entsprechend andere Zuordnung zuließen als die die dargestellte. 
Abb. 30: Die Subgattungen im Teilkorpus Kindersterben in Abhängigkeit vom Erscheinungsjahr

\begin{tabular}{|c|c|c|c|c|c|c|c|}
\hline \multirow[b]{3}{*}{ Zeitraum } & \multirow[b]{3}{*}{$\begin{array}{c}\text { Ge- } \\
\text { samt- } \\
\text { korpus }\end{array}$} & \multicolumn{6}{|c|}{ Subgattungen im Teilkorpus Kindersterben } \\
\hline & & \multicolumn{3}{|c|}{ Realistisch } & \multicolumn{3}{|c|}{ Phantastisch } \\
\hline & & $\begin{array}{c}\text { Anthro- } \\
\text { pomorph- } \\
\text { realisti- } \\
\text { sches } \\
\text { Bilder- } \\
\text { buch } \\
\end{array}$ & $\begin{array}{l}\text { realis- } \\
\text { tisches } \\
\text { Tierbil- } \\
\text { derbuch }\end{array}$ & $\begin{array}{l}\text { Sach- } \\
\text { bilder- } \\
\text { buch }\end{array}$ & $\begin{array}{c}\text { Anthro- } \\
\text { pomorph- } \\
\text { phantasti- } \\
\text { sches } \\
\text { Bilder- } \\
\text { buch } \\
\end{array}$ & $\begin{array}{c}\text { Phantasti- } \\
\text { sches } \\
\text { Tierbil- } \\
\text { derbuch }\end{array}$ & $\begin{array}{c}\text { Märchen- } \\
\text { haftes } \\
\text { Bilder- } \\
\text { buch }\end{array}$ \\
\hline $\begin{array}{l}1946- \\
1971 \\
\end{array}$ & 10 & 1 & - & - & - & 1 & - \\
\hline $\begin{array}{l}1972- \\
1981 \\
\end{array}$ & 12 & - & - & 1 & - & - & 1 \\
\hline $\begin{array}{l}1982- \\
1991 \\
\end{array}$ & 39 & 2 & - & 5 & 1 & - & 1 \\
\hline $\begin{array}{l}1992- \\
2001 \\
\end{array}$ & 85 & 5 & 1 & 1 & 4 & 1 & - \\
\hline $\begin{array}{l}2002- \\
2011 \\
\end{array}$ & 141 & 11 & - & 2 & 9 & 4 & 2 \\
\hline Gesamt & 287 & 19 & 1 & 9 & 14 & 6 & 4 \\
\hline
\end{tabular}

Die Unterscheidung nach Menschenwelt und Tierwelt weist darüber hinaus darauf hin, dass das Kindersterben im Bilderbuch ein fast durchweg menschliches ist. Unter den sechs phantastischen Tiergeschichten befinden sich zudem zwei, die die Perspektive eines um ein Menschenkind trauernden Haustieres einnehmen und sich schon allein deshalb vom übrigen Textkorpus abheben (Kikuta 2003: Du bist immer noch bei mir; Loske 2011: Sadakos Kraniche). In beiden Geschichten verstärkt die Ich-Erzählform das auf Empathie ausgerichtete Erzählen, womit ein weiteres Ergebnis der Untersuchung angesprochen ist: Erst seit dem Ende des 20. Jahrhunderts hat sich das Bilderbuch den psychischen, emotionalen Prozessen des Trauerns um Kinder zugewandt, während vorher mehr sachorientierte Konzepte zur Kausalität des kindlichen Sterbens dominierten. Der Übersicht (Abb. 32) ist außerdem zu entnehmen, dass sich in den letzten Jahren vermehrt deutsche Autoren und Verlage des Themas angenommen haben.

Bevor das Inhaltsspektrum aufgefächert und in Einzelanalysen die Spezifik des Erzählens vom Kindersterben exemplarisch dargelegt wird, wird eine kurze historische Rückschau auf die ersten Bilderbuchbearbeitungen dieses Teilkorpus' gehalten. 


\section{VII.1.2 Die Anfänge des Erzählens vom Kindersterben bis 1985}

Das unglückselige Kind (Gorey 1967) ist das erste recherchierte Bilderbuch, das vom tödlichen Schicksal eines Mädchens erzählt, und gleichzeitig das ungewöhnlichste, da es aufgrund der drastischen Dramatik den Rahmen dieses einschlägigen Teilkorpus' sprengt. ${ }^{222}$ Das 1979 in der Reihe Ich und die Welt im Maier-Verlag erschienene Foto-Bilderbuch Ich will etwas vom Tod wissen (Becker/ Niggemeyer 1979) ist dagegen nicht nur das erste Sachbilderbuch, das in alltagsnahen Geschichten auf eine realistische und undramatische Weise von Sterben, Tod und Trauern erzählt, sondern auch das erste, in dem die Trauer über den Tod eines Kindes zur Sprache kommt.

Angst und Trost, Einmaligkeit und Ewigkeit, Trauer und Hoffen, Verzweiflung und Liebe stehen nebeneinander. Kinder lernen verstehen, daß es kein Leben ohne die Realität des Todes geben kann. (Ebd.; a. d. Nachwort)

Dass diese Realität Kinder sowohl in ihrem Lebensumfeld als auch sie selbst betreffen kann, hat sich im Zeichen des neuen Kindheitsbildes nach 1970 im erzählenden Bilderbuch erstmals 1985 mit Die unsichtbaren Freunde (Kübler-Ross $1985)^{223}$ niedergeschlagen. Bis dahin, d. h. nach 1945, war kindliches Sterben entweder ein Motiv märchenhaften Erzählens (Pludra/ Mossner 1978: Trauermantel und Birke; Hechelmann/ Borchers 1984: Ein Weihnachtstraum) oder nur eine Marginalie innerhalb einer Tiergeschichte, deren Protagonist, ein Ackerpferd, von seinem Leben auf dem Bauernhof bis zu seiner Reise [...] in das Paradies der Tiere erzählt (Kaufmann 1971: Ein Pferd erzählt) und den Tod eines ausdrücklich namenlosen Fohlens nur erwähnt.

Auf das o. g. Bilderbuch von Elisabeth Kübler-Ross und die Bearbeitung des Holocaust-Themas mit Rosa Weiss (Innocenti/ Gallaz 1986) ${ }^{224}$ folgte das 1987 aus dem Norwegischen übersetzte Bilderbuch Abschied von Rune (Kaldhol/ Øyen; OA N 1986). Wie so oft, macht sich auch im hier gegebenen Kontext der Einfluss skandinavischer Literatur auf die Entwicklungen der deutschen KJL bemerkbar. Dieser 1988 mit dem Deutschen Jugendliteraturpreis ausgezeichnete Bilderbuch-Klassiker war in thematischer wie gestalterischer Hinsicht das erste Bilderbuch, das realistisch vom Unfalltod eines Kindes erzählte und noch heute die über mehrere Monate andauernde Trauer seiner Spielgefährtin erfahrbar macht. Beispielhaft ist hier die Verschmelzung inhaltlich-psychologischer

\footnotetext{
222 S. dazu Kap. VII.2.1.

223 S. dazu Kap. VII.1.2.

224 S. dazu Kap. VII.3.2.
} 
Aspekte mit literarästhetischen Ansprüchen, die das in den 1980er-Jahren „neue Selbstverständnis“ des Bilderbuchs „als bimediales Medium“ offenbart, „indem es mit dem spezifischen und komplexen Spannungsverhältnis von Text und Bild im Buch experimentiert“ (Nix 2005, 81).

Abb. 31: Marit Kaldhol; Wenche Øyen (1987): Abschied von Rune. München: Ellermann.

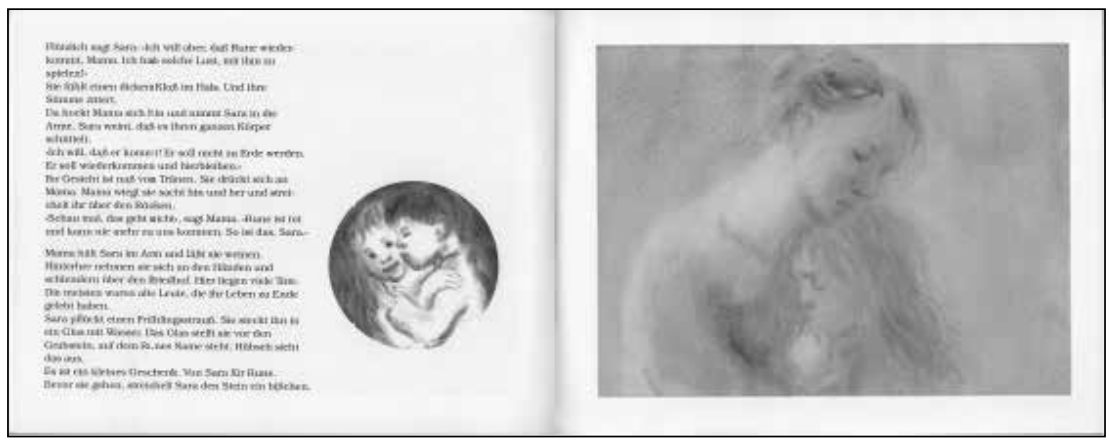

So eröffnen beispielsweise neben dem Text platzierte, schwarz-weiße Vignetten in filmischer Manier einen Blick - wie durch ein Objektiv - in die den Freund erinnernde Gedankenwelt der trauernden Freundin (Abb. 31). Im Kontrast zu den farbigen Bildern der erzählten Gegenwart verweisen sie auf das Nicht-Lebendige, das aber in der Erinnerung wachgerufen werden kann. Der auf der Bildebene angelegte Wechsel der Perspektive - einerseits auf die Protagonistin und das Erzählgeschehen, andererseits die inneren Bilder der Trauernden - greift das Wechselspiel vom auktorialen Standpunkt zum personalen auf. Diese darstellerische Komplexität ${ }^{225}$ ist Ausdruck eines psychologisierten Erzählens, das kennzeichnend ist für den neuen Umgang mit dem Thema Sterben und Trauer.

\section{VII.1.3 Die Spezifik der erzählerischen Vermittlung}

Verglichen mit der Anzahl der Bilderbücher, die von anderen menschlichen Todesfällen berichten, ist im Kontext des Kindersterbens relativ häufiger die Ich-Erzählperspektive mit der entsprechenden Verwendung der grammatischen Form vertreten: Kindliche Figuren kommen im Gesamtkorpus insgesamt $40 \mathrm{Mal}$ als autodiegetische Ich-Erzähler zu Wort, zwölfmal davon im Zusammenhang mit dem kindlichen Sterben. In weiteren 15 Bilderbüchern ist der Ich-Erzähler

225 Vgl. zur Bild-Bild-Montage in Abschied von Rune z. B. Thiele 2003a, 69. 
entweder der Tierwelt oder der Erwachsenenwelt angehörig, davon fünfmal im Teilkorpus Kindersterben. Diese Häufung der auftretenden Ich-Erzähler weist darauf hin, dass das Thema in besonderer Weise Nähe herstellend und auf Empathie zielend angegangen wird.

In Analogie zum psychologischen Kinderroman „konfrontiert [das psychologische Bilderbuch; M.H.] die jungen Leser mit den Auswirkungen belastender Situationen auf die Psyche von Kindern. Psychologisierung und Individualisierung der handelnden Figuren“ zeichnen das Erzählen aus, wobei „der in die Person des kindlichen Protagonisten verlagerte Erzählerstandort einerseits Nähe herstellt und Identifikation ermöglicht“, andererseits hilft, „belastende Erfahrungen dem Verständnishorizont der jungen Leser anzupassen, so dass - trotz der oftmals bedrückenden Inhalte - eine psychische Überforderung vermieden werden kann“ (Daubert 2011, 92). Vor diesem Hintergrund ist das Untersuchungsmaterial differenziert zu betrachten.

Zur Kategorie der psychologischen Bilderbücher gehören demnach alle Werke, in denen die Innenperspektiven der kindlichen Protagonisten entweder explizit von figuralen Ich-Erzählern präsentiert werden oder die personale Erzählweise in der 3. Person mit den verschiedenen Formen der Bewusstseinsdarstellung den Erzählschwerpunkt auf Einsichten in innere Prozesse einer Figur legt. Dies kann mit auktorialen Passagen einhergehen, wenn der Erzähler die Figuren selbst zu Wort kommen lässt bzw. er seine Kenntnisse über die psychische Konstitution, das Denken und Fühlen der kindlichen, meist trauernden Protagonisten preisgibt. Die fließende Grenze zwischen problemorientiertem und psychologischem Erzählen ist hier evident.

An anderer Stelle ist das auktoriale Erzählen das Mittel der Wahl, um unbelegbares ,Allwissen', das als esoterische Behauptungen daherkommt, der kindlichen Psyche anzudienen. ${ }^{226}$ Aus solchen Konzepten kann aber mehr der Wunsch Erwachsener nach Lösungen für unbeantwortbare Fragen und dem damit begründbaren schnellen Trost herausgelesen werden, als dass darin innerpsychische Vorgänge oder Kinderdenken authentisch zur Sprache kommen können.

Zwei der in Ich-Erzählsituationen eingebundenen Geschichten sind von der Kategorie der psychologischen Bilderbücher abzugrenzen, da sie nicht an die Ebene der innerpsychischen Konstitution der Protagonisten heranreichen. Mein Name ist Jason Gaes (Gaes/ Gaes 1989) ist ein sachorientiertes Bilderbuch, in

226 Vgl. o. st. Erläuterungen zu: Georgs Reise zu Gott (Jakoby/ Adler 2008), Luca und der Schmetterling (Herrmann/ Bahde 2007), Die unsichtbaren Freunde (Kübler-Ross/ Rothmayr 1985). 
dem ein achtjähriger Junge informativ über seine Leukämieerkrankung und ihre Überwindung berichtet, und in Als der Tod zu uns kam (Schubiger/ Berner $2011)^{227}$ ist die Ich-Erzählerin mehr ein Wir-Erzähler, sie fungiert quasi als Sprecherin der Gruppe von Menschen, die zu Beginn emotionslos und unverbunden nebeneinander stehen, nach den gemeinsamen Erfahrungen mit dem Tod aber emotional geprägt wirken und sich im übertragenden wie im Wortsinne sichtlich näher gekommen sind. Wie gezeigt wurde (Kap. VI.2.5.3), geht es in diesem Bilderbuch nicht um individualisierte Trauer nach dem Tod eines Kindes, sondern um die Entwicklung eines Verständnisses vom Tod und um grundlegende, philosophische Fragen nach dem Sinn des Lebens und des Sterbens, die mit dieser Geschichte angestoßen werden.

Einen zusammenfassenden Überblick über inhaltliche Facetten des Erzählens vom Kindersterben verschafft das folgende Kapitel.

\section{VII.1.4 Das Spektrum der Inhaltsmotive im Teilkorpus Kindersterben 228}

Auf der Inhaltsebene sind vor allem die primär betroffenen kindlichen Figuren, die Todesursachen, Sterbe- und Trauerprozesse von Interesse. Es fällt auf, dass die primär betroffenen Geschwister fast ausschließlich weiblich sind und auch insgesamt in den Bilderbuchgeschichten doppelt so viele Mädchen wie Jungen sterben $^{29}$ - insbesondere die Sterbeprozesse betreffen in zehn von zwölf Fällen weibliche Figuren. Ob oder inwieweit sich dahinter Autorenintentionen oder -einstellungen verbergen, wäre vorerst nur spekulativ zu beantworten und wird hier nicht weiter verfolgt. Das Geschlechterverhältnis der trauernden Kinder ist dagegen ausgewogen, in der Tabelle (Abb. 32) allerdings nicht mit aufgeführt.

227 S. dazu Kap. VI.2.5.3.

228 Vgl. dazu die detaillierte Übersicht mit Titelangaben im Anhang (X.1).

229 Von den 31 primär betroffenen Kindern, die nicht Geschwister sind, sind 18 weiblich, 13 männlich, so dass sich ein Verhältnis von insgesamt 31 weiblichen zu 15 männlichen Betroffenen ergibt. 
Abb. 32: Quantitative Verteilung von Inhaltsmotiven zum Kindersterben in Abhängigkeit vom Erscheinungszeitpunkt.

\begin{tabular}{|c|c|c|c|c|c|c|c|c|c|c|c|c|}
\hline Zeitraum & $\begin{array}{l}\text { Ge- } \\
\text { samt- } \\
\text { kor- } \\
\text { pus }\end{array}$ & $\begin{array}{l}\text { Kin- } \\
\text { der- } \\
\text { ster- } \\
\text { ben }\end{array}$ & $\begin{array}{l}\text { m } \\
\text { ges. }\end{array}$ & \begin{tabular}{|l} 
w \\
ges.
\end{tabular} & $\begin{array}{l}\text { Ge- } \\
\text { schwis- } \\
\text { ter }\end{array}$ & $\begin{array}{l}\text { Ster- } \\
\text { be- } \\
\text { pro- } \\
\text { zes- } \\
\text { se }^{231}\end{array}$ & $\begin{array}{l}\text { Trau- } \\
\text { er- } \\
\text { pro- } \\
\text { zes- } \\
\text { se }^{232}\end{array}$ & $\begin{array}{l}\text { Leukä- } \\
\text { mie }^{233}\end{array}$ & $\begin{array}{l}\text { Un- } \\
\text { fall- } \\
\text { tod }\end{array}$ & $\begin{array}{l}\text { vor- } \\
\text { ge- } \\
\text { burt- } \\
\text { licher } \\
\text { Tod }\end{array}$ & $\begin{array}{l}\text { Nah- } \\
\text { tod- } \\
\text { er- } \\
\text { fah- } \\
\text { rung }\end{array}$ & $\begin{array}{l}\text { Reli- } \\
\text { gio- } \\
\text { sität } \\
\text { chr./ } \\
\text { tran- } \\
\text { sz. }\end{array}$ \\
\hline $\begin{array}{l}1946- \\
1971\end{array}$ & 10 & 2 & - & - & - & - & - & - & 1 & - & - & - \\
\hline $\begin{array}{l}1974- \\
1981 \\
\end{array}$ & 12 & 2 & - & - & - & - & - & - & - & - & - & $1 / 1$ \\
\hline $\begin{array}{l}1982- \\
1991\end{array}$ & 39 & 9 & - & 5 & $1(w)$ & $2(2)$ & $3(2)$ & $3(2)$ & - & - & - & $1 / 1$ \\
\hline $\begin{array}{l}1992- \\
2001\end{array}$ & 85 & 12 & 6 & 8 & $5(w)$ & 3 & 4 & $3(1)$ & 2 & 1 & 1 & $5 / 4$ \\
\hline $\begin{array}{l}2002- \\
2011\end{array}$ & 141 & 28 & 9 & 18 & $9(6 w)$ & $7(4)$ & $17(4)$ & 3 & 5 & 3 & 1 & $7 / 11$ \\
\hline Gesamt & 287 & 53 & 15 & 31 & 15 & $\begin{array}{l}12 \\
(6)\end{array}$ & $24(6)$ & 9 & 8 & 4 & 2 & $\begin{array}{l}14 / \\
17\end{array}$ \\
\hline
\end{tabular}

Die Ergebnisse hinsichtlich der Anzahl der vorgefundenen Trauerprozesse, Sterbeprozesse und religiöser Aspekte entsprechen in etwa der quantitativen Verteilung im Gesamtkorpus, da auch die Auseinandersetzung mit dem Kindersterben nicht ausschließlich auf eine Trauerverarbeitung ausgerichtet ist und auch teils philosophische Herangehensweisen an die Universalität des Todes am Beispiel des Sterbens von Kindern einbezogen sind. Drei Bilderbücher heben sich vom übrigen Textkorpus ab, da ein personifizierter Tod zum Figurenensemble gehört: Der Besuch vom kleinen Tod (Crowther 2011); Als der Tod zu uns kam (Schubiger/ Berner 2011); Die Königin und ich (Weigelt/ Haas 2011). Dass alle drei Titel 2011 (in Deutschland) erschienen sind, belegt die Aktualität dieser neuen Facette des Erzählens vom Tod für Kinder und deutet auf eine weitere Öffnung des Bilderbuchs hin, das auch mit komplexeren Erzählkonzepten den kindlichen Adressaten nicht aus dem Auge verliert, ihn aber ebenso fordert wie es den erwachsenen Leser anspricht. Spezifische erzählerische Qualitäten werden in nachfolgenden Kapiteln anhand von Einzelanalysen dargelegt.

230 Die Ziffern in Klammern geben die Anzahl der Bilderbücher an, die beide Handlungsebenen (Sterbe- und Trauerprozess) aufweisen.

231 Die Ziffern in Klammern geben die Anzahl der Bilderbücher an, die beide Handlungsebenen (Sterbe- und Trauerprozess) aufweisen.

232 Die Ziffern in Klammern beziehen sich auf überwundene Leukämieerkrankungen. 
Nur äußerst selten wird die Perspektive sterbender Kinder berücksichtigt. Unter den zwölf Bilderbüchern, die kindliche Sterbeprozesse thematisieren, befindet sich nur eines, das den Leser mit der Ich-Erzählsituation an den phantastischen Vorstellungen des progressiv erkrankten Mädchens von einer glücklichen Weiterexistenz teilhaben lässt (Weigelt/ Haas 2011: Die Königin und ich). In Amal und der Brief des Königs (Gajadin/ Ong 1996) nimmt ein kranker Junge sein Leiden an und hofft bis zuletzt auf die Ankunft eines Boten des Königs. Weitere neun Bilderbücher erzählen ebenfalls auf das Todesereignis hin, sie unterscheiden sich jedoch deutlich hinsichtlich ihrer figuralen Fokussierung. Eine Hälfte orientiert sich mit auktorialen oder personalen Erzählsituationen zwar (auch) am Erleben der sterbenden Protagonisten, gewährt aber nur wenig Einblick in ihr Innerstes. ${ }^{233}$ In den fünf weiteren Bilderbüchern stehen nicht die sterbenden Kinder, sondern die sekundär betroffenen, den Sterbeprozess begleitenden Figuren im Zentrum. ${ }^{234}$ Befürchtungen, Sorgen oder Ängste spielen dabei keine bis eine nur untergeordnete Rolle.

Eine Sonderstellung nimmt das Buch Die Fahrt zum Pferdeparadies (Isler 1992) ein, dessen Verfasserin die an Leukämie erkrankte Iris Isler war. Die 1989 verstorbene neunjährige Pferdeliebhaberin hat ihre Hoffnungsvorstellung von einem paradiesischen Ort, an dem Menschen und Pferde ein glückliches Miteinander leben und von dem sie nach einer lange Reise nie wieder zurückkehren werden, in eine auktorial erzählte Geschichte und in selbst gemalte Bilder gefasst. Die Mutter, Edith Isler, berichtet im Anhang des Buches vom Leben ihrer Tochter, vom gemeinsamen Kampf gegen die Krankheit, von den Auswirkungen auf die Familie und von ihren ganz persönlichen Emotionen und Eindrücken. Die phantasievolle Geschichte des Kindes ist für jedermann geeignet, der Bericht der Mutter mehr für Eltern, die ein ähnliches Schicksal zu verkraften haben.

Hinsichtlich der Kausalität des Todes ist auch im Kontext des Kindersterbens nach natürlichen und unnatürlichen Todesursachen zu unterscheiden. Während das natürliche Ende der Körperfunktionen eines erwachsenen Menschen von Alter oder Krankheit bestimmt wird, kann ein junges Leben bereits

233 Crowther 2011: Der Besuch vom kleinen Tod; Blumentritt 2003: Lara's Schmetterlinge (sic!); Gajadin/ Ong 1996: Amal und der Brief des Königs; Coerr/ Young 1995: Sadako; Kübler-Ross/ Rothmayr 1985: Die unsichtbaren Freunde.

234 Loske 2011: Sadakos Kraniche; Sturm/ Hillen 2008: Justus ist traurig; Gilson/ Dubois 2004: Wenn ich nicht mehr bei dir bin, bleibt dir unser Stern; Simon/ Selle 2003: Der geborgte Stern; Reuter 1989: Christian. 
im vorgeburtlichen Zustand ${ }^{235}$ natürlich enden, vom plötzlichen Kindstod ${ }^{236}$ oder von progressiven Krankheiten ${ }^{237}$ betroffen sein, wobei Leukämie ${ }^{238}$ als einziges Krankheitsbild auftritt. Auffällig ist, dass alle drei 1989 erschienenen Titel die Möglichkeit der Überwindung der Leukämieerkrankung thematisieren, während die jüngeren Erzählungen die Dramatik des Geschehens verschärfen und das Lebensende mit einschließen. Die unnatürlichen Todesursachen Unfall ${ }^{239}$, Gewalt und $\mathrm{Krieg}^{240}$ sind im Untersuchungsmaterial ebenfalls vertreten und werden im Rahmen von Einzelanalysen berücksichtigt, ebenso wie die Geschwisterproblematik, auf die das Kapitel VII.2.2.3 näher eingeht.

\section{VII.1.5 Todeskonzepte, Religiosität und Jenseitsvorstellungen}

Da die primär betroffenen Protagonisten dieses Teilkorpus' Kinder sind, was der bei Kindern verbreiteten Auffassung, das Sterben betreffe nur Alte, entgegensteht, ist die Universalität des Todes als Teil eines reifen Todeskonzepts quasi Programm und wird fast immer als bekannt vorausgesetzt. Lediglich im Bilderbuch Lia ist krank (Waldman-Brun 1995) stellt einer der beiden Brüder die Frage konkret: Kann es denn auch passieren, daß man an Lias Krankheit sterben muß? [...] Lia ist doch noch nicht alt! Wie so oft - es wurde bereits festgestellt, dass

235 Thurmann/ Fischer 2010: Am Anfang waren wir zu zweit; Ruß/ Broska 2009: Himmelskind; Proché/ Suchy 2004: Brüderchen bei den Sternen; Stark/ Höglund 1997: Meine Schwester ist ein Engel; Sturm/ Hillen 2008: Justus ist traurig.

236 Vinje/ Zahl-Olsen 2000: Pelle und die Geschichte mit Mia.

237 Unbestimmt: Crowther 2011: Der Besuch vom kleinen Tod; Weigelt/ Haas 2011: Die Königin und ich; Goossens/ Robberecht 2004: Eva im Land der verlorenen Schwestern; Gajadin/ Ong 1996: Amal und der Brief des Königs; Kübler-Ross/ Rothmayr 1985: Die unsichtbaren Freunde.

238 Leukämie: Loske 2011: Sadakos Kraniche; Schins/ Müller 2005: Zuckerguss für Isabel; Blumentritt 2003: Lara's Schmetterlinge (sic!); Coerr/ Young 1995: Sadako; Waldmann-Brun 1995: Lia ist krank; Isler 1992: Die Fahrt zum Pferdeparadies; Bergman 1989: Jeden Tag leben. Hanna und Fredrik haben Leukämie; Gaes/ Gaes 1989: Mein Name ist Jason Gaes; Reuter 1989: Christian.

239 Schubiger/ Berner 2011: Als der Tod zu uns kam (Opfer eines Hausbrandes); Schulß/ Bunge 2009: Als Otto das Herz zum ersten Mal brach (tödlicher Treppensturz); Wegenast/ Meyer 2008: Hannah und ich (Autounfall); Herrmann/ Bahde 2007: Luca und der Schmetterling (vom Zug erfasst); Kaufmann 2004: Ich und du, du und ich (Autounfall); Treiber/ Blazejovsky 2001: Die Blumen der Engel (Autounfall); Kaldhol/ Øyen, 1987: Abschied von Rune (Ertrinken); Gorey 1967: Das unglückselige Kind (Unfall).

240 S. Kap. VI.2.5.4 und VII. 
überwiegend Großeltern Kinderfragen beantworten - ist es der Großvater, der euphemistisch antwortet: [E]s kann bei alten und jungen Menschen geschehen, dass ihr Lebenshäuschen nicht mehr bewohnbar ist. (H. i. O.) Im Konzept dieses Bilderbuchs führt die Krankheit nicht zum Tod, das Erzählen vom Sterben beschränkt sich auf die Erwähnung des bereits verarbeiteten Alterstodes der Großmutter.

Auch die weiteren Teildimensionen eines reifen Todeskonzepts werden in Abhängigkeit vom Erzählfokus - entweder auf den Sterbe- oder den Trauerprozess gerichtet - in diesem Teilkorpus mehr oder weniger explizit ebenfalls angesprochen, meist aber vorausgesetzt, sodass die Bilderbücher über Kindersterben nicht nur emotional, sondern auch hinsichtlich der kognitiven Anforderungen anspruchsvoll sind. Bezüglich der Nonfunktionalität fällt auf, dass sie nur selten ausdrücklich erwähnt wird, beispielsweise in Abschied von Rune (Kaldhol/ Øyen, 1987) oder in Als der Tod zu uns kam (Schubiger/ Berner 2011).

Die Kausalität eines Todes- bzw. Sterbegeschehens steht mit der Universalität in engem Zusammenhang und ist mit den Erzählkonzepten ebenfalls impliziert. Die Frage nach dem Warum und genauer: Warum gerade dieses Kind? wird an keiner Stelle explizit gestellt und scheint mit der Klärung der Todesursache bereits vorweg ausgeräumt. Sie ist nur im Bilderbuch Der geborgte Stern (Simon/ Selle 2003) in einer Leerstelle mitzulesen, da die Akzeptanz und Trauerbewältigung von der Vorstellung gestützt werden, es sei der Wunsch des zu schwachen frühgeborenen Kindes selbst gewesen: Aber Sternchen wollte lieber gehen und an seinem alten Platz am Himmel stehen... (ebd.; Ausl. i. O.).

Dagegen ist die Frage nach dem Verbleib der Verstorbenen zentral und wird häufig von Kindermund formuliert. Sie schließt die Kenntnis der Irreversibilität des Todes gleich mit ein, wenn eine Weiterexistenz jenseits der irdischen Erreichbarkeit vorausgesetzt wird. Eine genauere Vorstellung von der Ausgestaltung eines meist als Himmel bezeichneten Jenseits bleibt fast immer aus. Der Himmel ist entweder ausdrücklich mit Gott verbunden oder wird zum „eindimensionalen Sinnbild eines gesicherten und friedlichen Aufenthaltsortes nach dem Tod“ (Egli 2014, 75), wobei in vielen Fällen von einer Leib-Seele-Trennung ausgegangen wird. Bilder von konkreten Vorstellungen sind selten und zeigen dann die Toten in körperlicher Unversehrtheit: Die unsichtbaren Freunde (Kübler-Ross/ Rothmayr 1985), Die Fahrt zum Pferdeparadies (Isler 1992), Himmelskind (Ruß/ Broska 2009), Der Besuch vom kleinen Tod (Crowther 2011), Die Königin und ich (Weigelt/ Haas 2011).

Ist nach dem Tod nicht der Himmel das imaginierte Ziel, kann es auch das Land eines Königs sein (Gajadin/ Ong 1996: Amal und der Brief des Königs), in 
das eines Tages [...] wir alle müssen, oder das einer Königin im Bilderbuch Die Königin und ich (Weigelt/ Haas 2011), wo dem sterbenskranken Mädchen von der Königin selbst versprochen wird: Aber Sophie, [...] du wirst doch Prinzessin an meinem Hof! Auch wenn solche Vorstellungen fast nie weiter ins Detail gehen, sind in jedem Fall Orte gemeint, die Gutes verheißen.

Die Dimension Hölle spielt nur bei Crowther (2011: Der Besuch vom kleinen Tod) eine zudem untergeordnete Rolle, da Kleiner Tod den Toten ein Feuer macht, das irrtümlich die Assoziation von Fegefeuer weckt (Abb. 33).

Abb. 33: Kitty Crowther (2011): Der Besuch vom kleinen Tod. Hamburg: Carlsen.

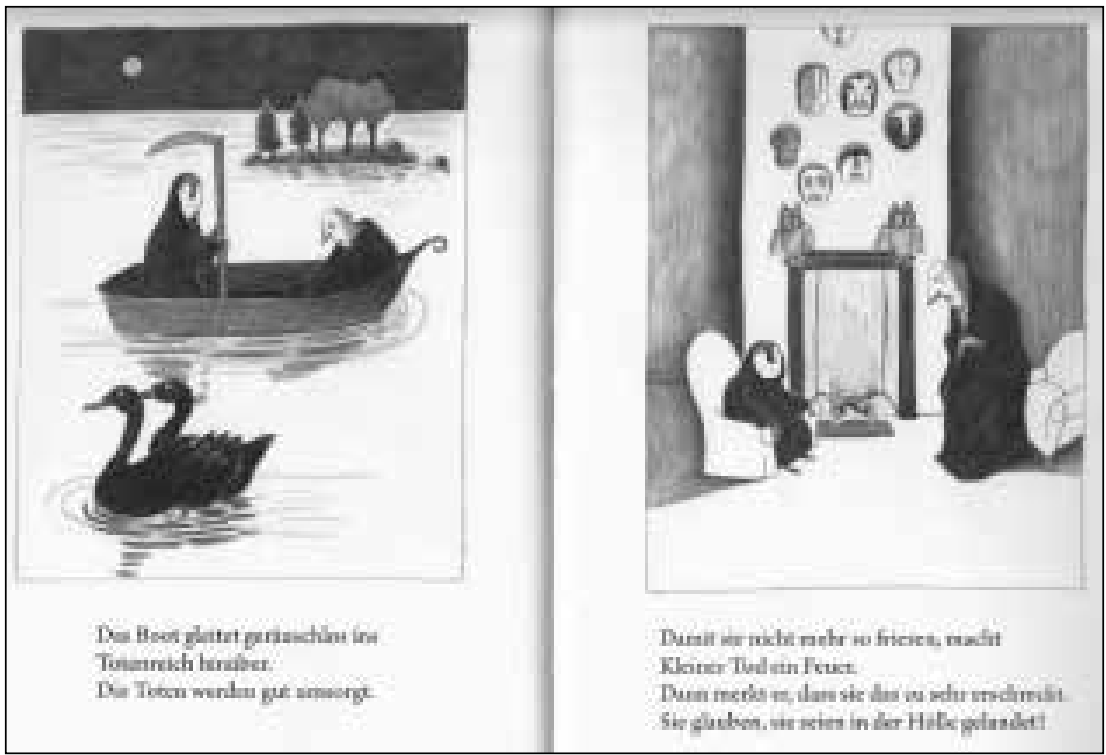

Denn: Die Toten werden gut umsorgt, wie der nichtdiegetische, auktoriale Erzähler verbal und ikonisch glaubhaft versichert. Ängste vor dem Tod kommen in diesem Buch ebenso zur Sprache wie die Erlösung, die ein herbeigesehnter Tod für Sterbenskranke bedeuten kann: Die kranke Elisewin freut sich über den Besuch vom kleinen Tod und kehrt nach ihrem Aufbruch in ein anderes Leben als Engel zurück. Fortan holt sie gemeinsam mit Kleiner Tod die Sterbenden ab: Wenn die Menschen das sanfte Gesicht des Engels sehen, haben sie keine Angst mehr vor dem Sterben.

Neben dem Auftreten von Engeln, die die Toten in ein himmlisches Jenseits begleiten und für einen sanften Übergang sorgen, werden in den Trauer- und 
Sterbebüchern dieses Teilkorpus häufig auch Sterne genannt, die dem Bedürfnis nach konkreten Trostbildern nachkommen und dann entweder für eine Verwandlung in eine jenseitige Existenzform oder für imaginäre Aufenthaltsorte stehen. Eine weitere Funktion von Sternen ist die eines Ankerpunktes für erinnerndes Gedenken, worauf z. B. schon der Titel des Bilderbuchs Wenn ich nicht mehr bei dir bin, bleibt dir unser Stern (Gilson/ Dubois 2004) verweist (Abb. 34).

Abb. 34: Patrick Gilson; Claude K. Dubois (2004): Wenn ich nicht mehr bei dir bin, bleibt dir unser Stern. Gießen: Brunnen-Verl.

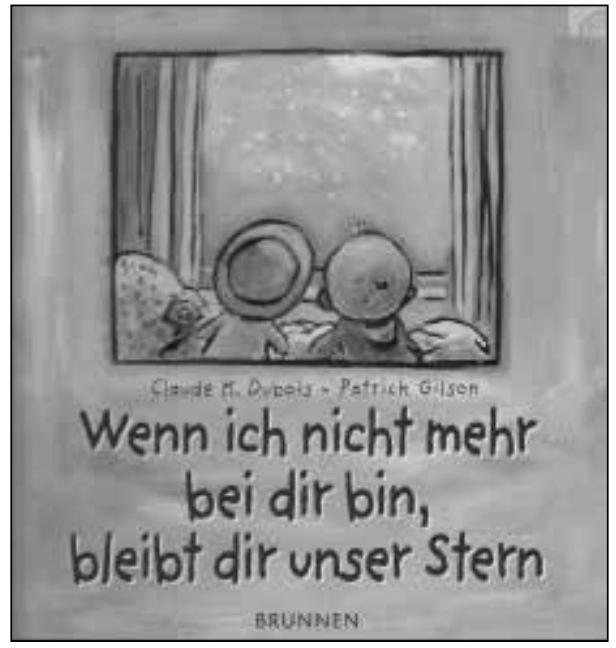

Die mit dem Vorausgegangenen angesprochenen christlich-religiösen und transzendenten Ausrichtungen sind hier mit 60,4\% (14 christlich-religiöse, 17 transzendentale Bilderbücher) in Relation zur Verteilung im Gesamtkorpus deutlich häufiger vertreten (Abb. 32). Darunter ist ebenso der Anteil der christlich-religiösen Bilderbücher mit 26,4\% gegenüber 20,9\% im Gesamtkorpus höher, was damit zusammenhängen mag, dass konkrete Vorstellungen von einem BehütetSein bei Gott für Kinder besonders wichtig erscheinen, da die Eltern ihre Aufgabe als Beschützer nicht mehr wahrnehmen können. Zudem ist der erwachsene Trauernde als intendierter Leser in diese Bücher immer mit eingeschrieben und kann mit solchen Trostbildern von einer behüteten Weiterexistenz des verlorenen Kindes Entlastung erfahren.

Den 31 religiösen Bilderbuchgeschichten stehen in diesem Teilkorpus von insgesamt 53 Titeln 22 gegenüber, die keine Jenseitsvorstellungen anbieten, darunter vier Tiergeschichten und sieben Sachbilderbücher, die wiederum keine 
Trauerprozesse thematisieren. Bezeichnend für das Erzählen in den verbleibenden elf säkularisierten Trauerbilderbüchern, ohne Ausblick auf eine transzendente Existenzform, ist die Konzentration auf eine Erinnerungskultur, die allein in der Verantwortung des Trauernden liegt und mehrheitlich die psychologische Komponente dieser Auswahl ${ }^{241}$ bestimmt. Es befindet sich kein Bilderbuch darunter, das den Erzählfokus auf ein Sterbegeschehen richtet, was auf das Anliegen hindeutet, Sterbenden immer eine hoffnungsvolle, auf ein Jenseits gerichtete Perspektive aufzuzeigen und nicht das absolute Ende zu propagieren. Auch für die trauernden Protagonisten in diesem Teilkorpus gilt, dass ein absoluter Verlust des Verstorbenen im Sinne eines absoluten Verlöschens der Existenz offenbar unaushaltbar ist und das Lebendighalten mit inneren Bildern, oft unterstützt durch Erinnerungsgegenstände, eine auf das Diesseits gerichtete, probate Variante einer postmortalen Existenz (vgl. Hahn 2002, 576) darstellt. Dazu gehören innere Zwiesprachen wie in Ich und $d u$, $d u$ und ich (Kaufmann 2004) ${ }^{242}$ ebenso wie z. B. eine über den Tod hinaus bestehende eheähnliche Verbindung, wie sie vom etwa siebenjährigen Protagonisten Otto in Als Otto das Herz zum ersten Mal brach (Schulß/ Bunge 2009) empfunden wird, der mit seiner nach einem Treppensturz verstorbenen Freundin zuvor im Spiel die Ringe getauscht hatte und sich verwitwet fühlt. Und in Flieger am Himmel (Herzog/ Clante 2009) ist es die Puppe der getöteten Freundin, die an das Fehlen der Spielgefährtin erinnert und an deren Stelle der Trauernden nah ist.

Die folgenden Ausführungen konzentrieren sich auf die Kategorie der psychologischen Bilderbücher, die mit den Schwerpunkten ,Sterbenskranke Kinder, ,Trauernde Kinder, ,Trauernde Geschwister ' und ,Trauernde Eltern' in Einzelanalysen anhand des thanatologisch-diskursanalytischen Ansatzes des narratologischen Bilderbuch-Modells exemplarisch vertreten sind. Dass dabei unterschiedliche analytische Vorgehensweisen realisiert werden, die nicht einer strikten kategorialen Reihung folgen, liegt in der Natur des Bilderbuchs, dessen jeweilige Spezifik eigene Fragestellungen ebenso fordert, wie seine semiotischen Ebenen immer in ihren Wechselwirkungen wahrgenommen und entsprechend beschrieben werden müssen.

241 Herzog/ Clante 2009: Flieger am Himmel; Schulß/ Bunge 2009: Als Otto das Herz zum ersten Mal brach; Wegenast/ Meyer 2008: Hannah und ich; Goossens/ Robberecht 2004: Eva im Land der verlorenen Schwestern; Kaufmann 2004: Ich und du, du und ich; Kikuta 2003: Du bist immer noch bei mir; Reuter 2009: Christian; Ellermann 1992: Der rote Faden; Kaldhol/ Øyen 1987: Abschied von Rune.

242 Einzelfallanalyse in Kap. VII.2.2.2. 


\section{VII.2 Das psychologische Bilderbuch zum Sterben im Kindesalter}

Das Erzählen von innerpsychischen Dimensionen mithilfe der personalen bzw. figuralen Erzählsituationen und den verschiedenen Formen der Bewusstseinsdarstellung ist kennzeichnend für das psychologische Bilderbuch. Das entsprechend modifizierte Teilkorpus umfasst dreißig Titel des ursprünglichen Recherchematerials zum Kindersterben und damit die Bilderbücher, die als Sterbe- bzw. Trauerbilderbücher bezeichnet werden. Die extreme Belastung, die eine progressive Erkrankung für das Kind selbst und seine Eltern bedeutet, ist von Psychologen umfassend erforscht und beschrieben worden, ebenso wie die Problematik kindlicher Trauerprozesse, insbesondere der Geschwistertrauer. ${ }^{243}$ Im Zentrum der folgenden Analysen stehen deshalb die Darstellungsmodi der kognitiven und emotionalen Konstitutionen der Protagonisten, die Interaktionen mit dem sozialen Umfeld und die Ausprägungen der Todeskonzepte und Jenseitsvorstellungen. Untersucht werden das Zusammenspiel von Sprach- und Bildebene und die Einbettung der kindlichen Perspektive in diese Inszenierungen von Ikonotexten. Dabei ist von besonderem Interesse, inwieweit das einzelne Bilderbuch den Erkenntnissen der Thanatopsycholgie zur Entwicklung eines kindgerecht-reifen Todeskonzeptes beitragen kann, annehmbare Hilfestellungen für erkrankte Kinder oder Verarbeitungsstrategien bei Beziehungsverlusten anbietet. Mitzudenken ist hier immer auch die Funktion von Literatur als Anleitung zur „Bildung der Gefühle“ (Mattenklott 1997), die im Zusammenhang mit diesem emotional besonders belasteten Thema von größter Bedeutung ist. Im Folgenden wird an ausgewählten Beispielen dargelegt, in welcher Form Bilderbücher diesem Anspruch gerecht werden können.

Die weitere Kapiteleinteilung spiegelt dabei die verschiedenen Erzählanlässe, die den Geschichten zugrunde liegen, wobei der Zeitpunkt eines Todesereignisses entscheidend ist für die Konzeption als Trauer- oder Sterbebuch. Wie bereits erwähnt, ist die Verarbeitung von Trauer das dominierende zentrale Erzählmotiv, weitere Differenzierungen werden im Folgenden nach primärer Betroffenheit vorgenommen.

243 S. Kap. IV.1. 


\section{VII.2.1 Sterbende Kinder}

\section{VII.2.1.1 Überblick}

Es konnten insgesamt nur sechs Bilderbücher recherchiert werden, in denen die Perspektive sterbender Kinder explizit zur Sprache kommt ${ }^{244}$. Eine solitäre Erscheinung ist darunter das im nächsten Kapitel ausführlich besprochene Bilderbuch Die Königin und ich (Weigelt/ Haas 2011), dessen Geschichte den Sterbeprozess aus der Perspektive einer autodiegetischen kindlichen Erzählinstanz umfasst. Daneben berichtet in Amal und der Brief des Königs (Gajadin/ Ong 1996) ein nichtdiegetischer Erzähler aus der personalen Perspektive des progressiv erkrankten Kindes, bei Crowther (2011: Der Besuch vom kleinen Tod) geht es, wie oben erläutert, einem ebenfalls nichtdiegetischen, auktorialen Erzähler weniger um die emotionale Konstitution des sterbenden Kindes, sondern mehr darum, dem Tod eine Kontur zu geben. Auch in den anderen drei Bilderbuchgeschichten sind es nichtdiegetische Erzählinstanzen, die ihre Perspektive unterschiedlich fokussieren. Gilson und Dubois (2004: Wenn ich nicht mehr bei dir bin, bleibt dir unser Stern) geht es mehr um die emotionale Konstitution des betroffenen Schulfreundes der Sterbenden als um deren eigene, die als gefestigt bezeichnet werden kann, in Sadako (Coerr/ Young 1995) ${ }^{245}$ steht das Schicksal der Protagonistin im Vordergrund. Und Lara's Schmetterlinge (sic!) von Linda Blumentritt (2003) hebt sich von den anderen Bilderbüchern ab, da es als Ratgeberbuch $^{246}$ konzipiert ist und in dieser Funktion Identifikationsangebote für von der Leukämieerkrankung eines Kindes betroffene Familienmitglieder, einschließlich der Geschwister, macht. Die sterbende Protagonistin selbst durchlebt die bekannten Sterbephasen (Kübler-Ross 2004) bis auf die Phase der Depression mehr oder weniger intensiv, von der Nichtakzeptanz über die „»Warumich? «-Stufe" (ebd., 49; H. i. O.) und die Phase des Verhandelns bis zur Akzeptanz, die den Trost für die trauernden Eltern und Geschwister mit einschließt und christlich konnotiert ist. Wie im Gesamtkorpus beschränken sich die anderen Darstellungen vom Kindersterben auf die letzte Phase der Akzeptanz, die von emotionaler Reife geprägt und häufig nachtodliche Möglichkeiten in den Blick

244 Crowther 2011: Der Besuch vom kleinen Tod; Weigelt/ Haas 2011: Die Königin und ich; Gilson/ Dubois 2004: Wenn ich nicht mehr bei dir bin, bleibt dir unser Stern; Blumentritt, Linda 2003: Lara's Schmetterlinge (sic!); Gajadin/ Ong 1996: Amal und der Brief des Königs.

245 S. Kap. VII.3.2.

246 Indizien sind ein Vorwort und Anregungen für eine kreative Anschlussreflexion auf dafür vorgesehenen freien Seiten am Ende des Buches. 
nimmt, so auch im Bilderbuch Die Königin und ich (Weigelt/ Haas 2011), das als Paradebeispiel für die Kategorie der psychologischen Bilderbücher gelten kann.

\section{VII.2.1.2 Die Königin und ich (Udo Weigelt, Cornelia Haas 2011)}

Das phantastische Erzählen dieses 2011 erschienenen Bilderbuchs umfasst die letzte Lebensphase der undefiniert erkrankten Protagonistin Sophie bis zu ihrem Tod (Abb. 35). Sophie macht noch zuhause zum ersten Mal Bekanntschaft mit einer namenlosen Königin, die unvermittelt erscheint und sie in der Folge immer wieder im Krankenhaus besucht, gemeinsam mit ihr spielt und in Gesprächen ihre Sorgen und Ängste auffängt. Beim letzten Treffen geht Sophie schließlich an der Hand der Königin ins Nirgendwoland.

Abb. 35: Udo Weigelt; Cornelia Haas (2011): Die Königin und ich. Mannheim: Sauerländer.

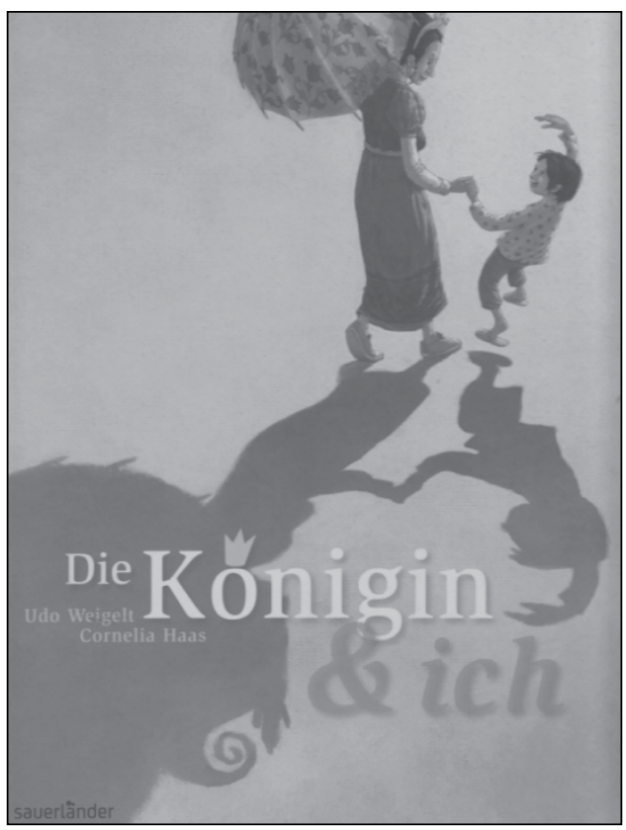

Dass das Bilderbuch „[d]en Kindern des Kinderhospiz Sternenbrücke gewidmet" (Vorsatzblatt ebd.) ist, verweist auf die Thematik des Kindertodes ebenso wie auf das Erzählanliegen und den intendierten Leserkreis, mit dem die von einer progressiven Erkrankung betroffenen Kinder und ihre Angehörigen gemeint 
sind. Der Klappentext verspricht dazu „eine einfühlsame Geschichte zum Thema Sterbebegleitung", deren Bild-Text-Gestaltung im Weiteren auf der Basis thanatopsychologischer Erkenntnisse und anhand des narratologischen Bilderbuchmodells analysiert wird.

\section{Erzählerische Vermittlung}

Bereits im Titel tritt die Ich-Erzählinstanz explizit auf und nimmt auf der ersten Bildseite mit dem etwa 6-jährigen Mädchen Gestalt an, dessen Name erst auf der vierten Doppelseite im Gebrauch der direkten Rede fällt. Im Stil eines Tagebuchberichts, in dem sich Erzählerbericht und erlebte Rede mehrfach vermischen, erzählt das autodiegetische Erzähler-Ich Sophie von ausgewählten inneren und äußeren Geschehensmomenten seiner letzten Lebensphase, die aufgrund der unspezifischen Zeitangaben, Raffungen und Ellipsen nicht genauer als auf wenige Wochen oder auch nur Tage einzugrenzen ist. Die „psychophysische Einheit von erzähltem und erzählendem Ich" (Schmid 2011, 134) ist auf der Sprachebene an keiner Stelle fraglich und legt eine subjektive wie gleichzeitig zurückgenommene Wertungshaltung an den Tag, die mit einer ausschließlich auf die eigene Wahrnehmungsebene beschränkten Kompetenz einhergeht. Die Möglichkeit der Darstellung von Introspektion wird sprachlich eher vorsichtig eingesetzt und entfaltet erst im Zusammenspiel mit der Narrativität der Bildebene seine volle Aussagekraft, wie noch gezeigt wird. Die Identifizierung der Erzählinstanz auf der Bildebene steht damit in engem Zusammenhang, da sie ähnlich einem personalen Erzähler an der Seite des sprachlich sich äußernden autodiegetischen Ichs am Erleben teilnimmt, über Introspektion verfügt und die Gefühlszustände des Mädchens sichtbar macht. Dafür werden einzelne Geschehensmomente als Standbilder aus den schon von der Ich-Erzählinstanz ausgewählten herausgehoben und mit ikonischen Mitteln bedeutungstragend ausgestattet. Das Wissen um die emotionale Konstitution der Protagonistin manifestiert sich als Mitteilung mit intendierter Wirkung in der Farbgebung, der Auswahl der Bildgegenstände und der Bildkomposition. Die Bilder sind entweder Einzelbilder oder Doppelbilder und füllen jeweils die gesamte Seite bzw. Doppelseite in kräftigen, meist warmen Farben und klaren Konturen aus.

Die gegenseitigen Abhängigkeiten der sprachlichen und der visuellen Erzählinstanz und ihr miteinander verwobenes, sich ergänzendes Erzählen, das teilweise auch alternierend vorgeht, zeigen sich vor allem in der unterschiedlichen Perspektive. Sie sind aber immer geprägt von dem jeweiligen Kenntnisstand über die Emotionen der Protagonistin bzw. der Bereitschaft der autodiegetisch erzählenden Protagonistin, sich sprachlich auszudrücken. An welcher Stelle 
erzählendes Ich und erzähltes Ich zusammenfallen, die Erzählerperspektive auf der Bildebene als retrospektiver Blick der verbalen Ich-Erzählerin auf das vergangene eigene Erleben zu deuten ist (wie sie sich selbst hätte sehen können, wäre sie dazu in der Lage), oder sich darin ein nichtdiegetischer Erzähler ausdrückt, der um die emotionale Konstitution der Protagonistin weiß und sie bildhaft einfängt, muss am jeweiligen Einzelbild mit dem Sprachtext abgeglichen und entschieden werden. Mit der sukzessiven Erschließung des Bilderbuchs werden diese Prozesse der Sinnbildung im Weiteren erläutert.

\section{Die Geschichte und der Erzähldiskurs}

Die auf die Erzählerin zurückgehende Reduktion des Geschehens auf einzelne Begebenheiten bzw. Wahrnehmungszustände ist sowohl auf der Sprach- als auch auf der Bildebene angelegt. Sie bringt eine chronologische Erzählung mit zahlreichen Leerstellen hervor, die den implizierten Leser auffordern, Fehlendes empathisch zu antizipieren bzw. mit Kenntnissen aus dem eigenen Erfahrungsschatz aufzufüllen. Auf der formalen Ebene des Layouts wird das etappenweise Erzählen sichtbar in Form von Initialen, die in der Schriftsetzung üblicherweise den Beginn eines neuen Kapitels oder Abschnitts markieren und hier den Anfangsbuchstaben jedes entweder rechts oder links auf einer Doppelbildseite platzierten Textteils typographisch hervorheben. Die vorwiegend verwendete Vorzeitigkeitsform Perfekt ist dem umgangssprachlichen Gebrauch nachempfunden und vermittelt in parataktischen Satzkonstruktionen den Eindruck kindlichen Erzählens, womit dem Text Authentizität verliehen wird.

$\mathrm{Zu}$ Beginn liegt ein alternierendes Erzählen vor, das bildhaft mit einer textfreien Einzelbildseite einsetzt, deren malerischer Stil in kräftigen Acryl-Farben im gesamten Bilderbuch beibehalten wird. Das Seitenlayout des Bilderbuchs wechselt mehrmals zwischen Einzelbildfolgen und doppelseitiger Bildgestaltung, was für die Bildung des jeweiligen Ikonotextes von Bedeutung ist und im Weiteren entsprechend berücksichtigt wird.

Der erste Blick fällt auf ein dunkelhaariges Mädchen, welches, offenbar in einem Kinderzimmer, mit hängenden Schultern und traurig-verzweifeltem Gesichtsausdruck auf einem Bett sitzt (Abb. 36). 
Abb. 36: Udo Weigelt; Cornelia Haas (2011): Die Königin und ich. Mannheim: Sauerländer.

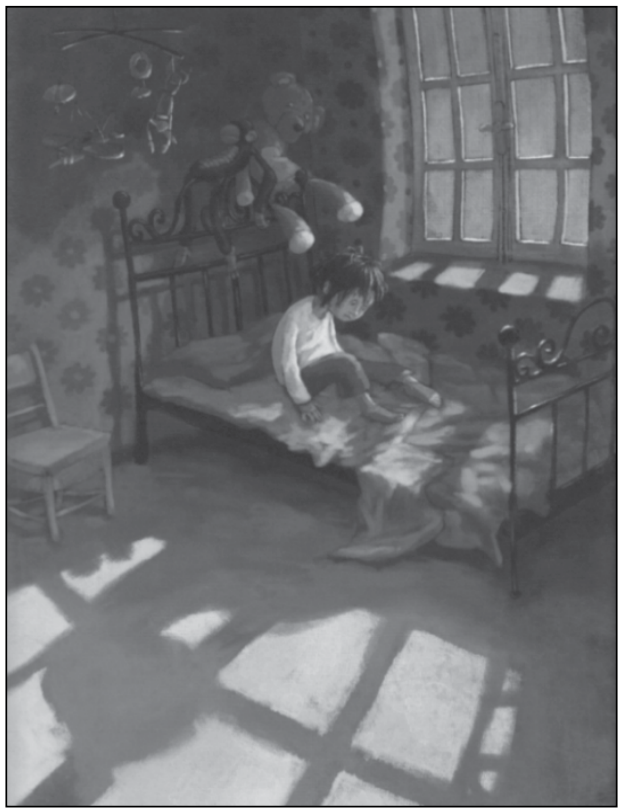

Die zurückgenommene Ausleuchtung des Raumes wird von den Schatten und Lichtquadraten eines Sprossenfensters bestimmt und vermittelt eine Atmosphäre bedrückenden Alleinseins. In deutlichem Kontrast steht dazu die auf der gegenüberliegenden Einzelbildseite abgebildete Szenerie, die vor einem hellblauen Hintergrund ohne ortsbezogene Indizien eine Tee trinkende Frau etwa mittleren Alters zeigt. Ihr freundliches Äußeres, das aufgrund des Kleides und ihres Diadems im zur Form einer Zipfelmütze aufgetürmten Haar zugleich exotisch wirkt, wird noch unterstützt durch das Sitzmöbel, auf dem sie - in Turnschuhen - Platz genommen hat. Der kleine Stuhl erinnert an die in Kindergärten gebräuchlichen und drückt auf diese Weise ihre Hinwendung zum Kind aus, ebenso wie das Schuhwerk. Mit dem darunter angeordneten Text setzt das sprachliche Erzählen in medias res ein und lüftet gleich im ersten Satz die namenlose Identität: Heute kam zum ersten Mal die Königin zu Besuch (H. d. Verf.). In der Verwendung des bestimmten Artikels kommt die fraglose Selbstverständlichkeit ihres Erscheinens zum Ausdruck, und der sichtbar vornehme Habitus, der auf der Sprachebene bestätigt wird, signalisiert zusätzlich, dass die Königin ein ganz besonderer Besuch ist: Wir haben Tee getrunken und uns sehr vornehm unterhalten. [...] Die 
Königin hat den kleinen Finger abgespreizt, wenn sie aus der Tasse getrunken hat. In welchem Zusammenhang der traurige Zustand des Mädchens und der Besuch der Königin stehen, ist an dieser Stelle noch unklar, dass es aber damit mehr auf sich hat als die Beschreibung vermuten lässt, macht der vom übrigen Text abgesetzte Satz Ihr Besuch soll unser Geheimnis bleiben. (H. d. Verf.) ebenso deutlich wie die farblich-atmosphärische Diskrepanz zwischen dem rechten und dem linken Bild. Auf das letztgenannte muss deshalb der Blick nach dem Lesen des Textes unweigerlich zurückfallen und mit einer Erkenntnis einhergehen, die den intendierten Leser bzw. fiktiven Adressaten als Betroffenen in die Geschichte einbezieht und mit der Verwendung des Personalpronomens zu einem Verbündeten macht. Damit wird Empathie eingefordert wie auch darüber hinaus ein Identifikationsangebot gemacht, das verbal auf der nächsten Seite aufgegriffen wird, indem die Protagonistin ihre Erkrankung vorsichtig andeutet und ihre Freude in erlebter Rede ausdrückt:

Schon der zweite Besuch der Königin!

Weil ich mich nicht so wohl gefühlt habe, hat die Königin für mich getanzt: Für mich ganz allein!

Das war lustig, und deswegen musste ich trotz allem lachen. (H. d. Verf.)

Das sich über eine Doppelseite erstreckende Bild zeigt dagegen fast kontrapunktisch eine nur verhalten lächelnde Sophie, die von simultanen, mehrheitlich nur skizzierten Darstellungen der tanzenden Königin umgeben ist, worin sich die Flüchtigkeit des Moments ausdrückt. Im weiteren Verlauf der Erzählung stellt sich heraus, dass die Funktion der Königin in gewisser Weise der eines Totentanzes entspricht, der sich zu den Sterbenden gesellt und ihnen letztlich den Tod bringt. Gleichzeitig ist sie aber auch eine Figur aus einer zweiten, überirdischen Dimension, die eine Weiterexistenz nach dem Tod verspricht. Auch wenn es ungewöhnlich ist, dass eine Königin ein Kind am Krankenbett besucht und allein deshalb Phantastisches erwartet werden kann, wird erst auf der vierten Doppelseite mit der Darstellung eines überdimensional großen Dame-Spiels deutlich, dass es sich um eine phantastische Ebene handelt, die sich in Gegenwart der Königin auftut.

Die Deutung der Königin, als phantastisches Wesen einer sekundären Welt in der primären oder als von der Ich-Erzählerin imaginierte Figur, worauf die erwähnten Skizzen der tanzenden Königin hinweisen könnten, bleibt einer individuellen Entscheidung vorbehalten. Indizien dafür, dass sie nicht als Imagination der kindlichen Protagonistin entworfen ist, finden sich z. B. auf der Textebene: Heute war es langweilig! Die Königin kam nicht. Deshalb habe ich ein Bild von ihr gemalt. Daraus lässt sich schließen, dass Sophie keinen Einfluss auf 
die Besuchsfrequenz hat und die Königin eine autonome Macht repräsentiert, die am Schluss der Geschichte in der Mittlerrolle für den Übergang von der irdischen in eine überirdische Welt gipfelt. Mit dieser Konzeption wird dem intendierten Leser anheimgestellt, die Vermischung von Realität und Phantastik anzunehmen und seine Hoffnungen auf eine Weiterexistenz nach dem Tod zu richten oder sich davon zu distanzieren und sie zumindest als entlastende Phantastereien der Protagonistin zu verstehen.

Bezeichnend für die kommunikative Problematik zwischen erkrankten Kindern und ihren Eltern ist das darauf folgende Gespräch zwischen Sophie und ihrer Mutter, die sie zu ihrem Gemalten befragt (Abb. 37). Der Leser erfährt: Eigentlich erzähle ich ihr ja immer alles. Aber diesmal nicht. Also habe ich gesagt, es wäre nur irgendeine Königin. Von Nirgendwoland. Dass die letzte Information der Imagination Sophies entspricht oder auch ihrer Kenntnis von einer zweiten Welt, offenbart sich an späterer Stelle, als die Königin ihr versichert, sie nähme sie an ihren Hof mit, wie alle Kinder, die sterben.

Abb. 37: Udo Weigelt; Cornelia Haas (2011): Die Königin und ich. Mannheim: Sauerländer.

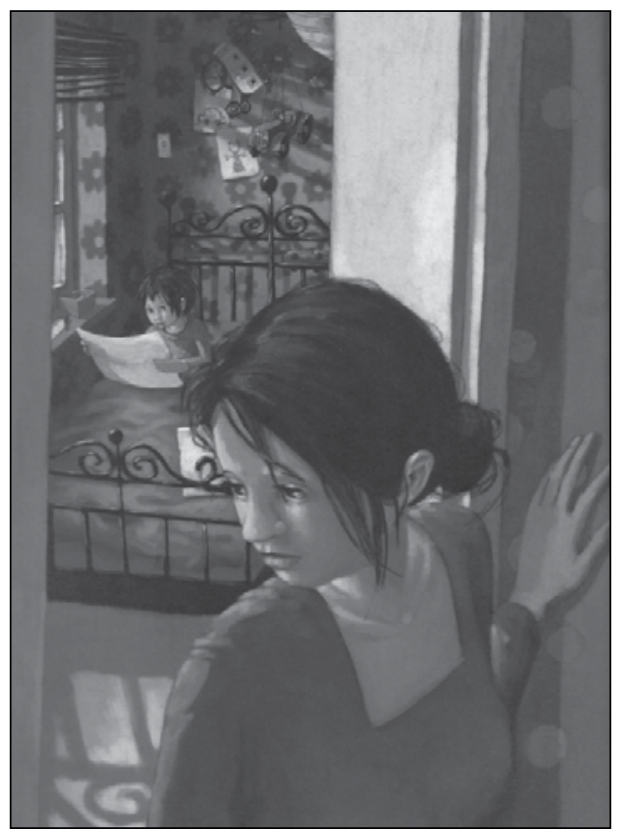


Gleichzeitig darf die Darstellung als impliziter Appell an den fiktiven Adressaten gedeutet werden, Kinderzeichnungen als bedeutsam wahrzunehmen, da sie mehr vom kindlichen Seelenleben preisgeben, als die Kinder selbst zu artikulieren bereit oder in der Lage sind. Dies scheint auch im nachdenklichen Blick der Mutter angelegt zu sein (Abb. 37). Der schuldbewusste Blick des Mädchens im Hintergrund bestätigt das Bündnis, das die Protagonistin, wie bereits beschrieben, auf der ersten Doppelseite des Bilderbuchs dem Leser angetragen hat. Auf der Bildebene zeigt sich demnach ein nichtdiegetischer Erzähler mit Introspektive, der sowohl vom Gefühlszustand der Protagonistin weiß als auch vom Appell der autodiegetischen Erzählerin auf der Sprachebene, das Geheimnis vom Besuch der Königin zu bewahren.

In der Figur des offensichtlich traurigen Mädchens wird die emotionale Düsternis kranker Kinder eingefangen, die sich darin gespiegelt sehen können. Dafür spricht auch die Leseranrede, hinter der sich der Gedanke einer Solidargemeinschaft von Gleichgesinnten bzw. hier Gleich-Betroffenen verbirgt. Ihr Verhalten entspricht dem aus der Psychologie bekannten Wissen über Kommunikationsverweigerung und den emotionalen Rückzug progressiv erkrankter Kinder, die ihre Eltern nicht an ihren Gedanken zum Tod teilhaben lassen wollen, da sie deren emotionale Belastung spüren und sie schonen wollen. Im Verbaltext wird die Sorge um die Eltern später noch explizit angesprochen.

Etwa in der Mitte des Buches wechselt der verbale Erzählmodus ein einziges Mal zum Präsens und es heißt:

Draußen schneit es, aber ich darf nicht raus.

Papa, sagt, dass ich wieder ins Krankenhaus muss.

Das ist aber nicht so schlimm.

Die Ärzte und Schwerstern sind nett.

Es sind auch andere Kinder da.

Hoffentlich kann mich die Königin dort besuchen.

Die damit suggerierte Gleichzeitigkeit von Geschehnis, Erzählvorgang und Rezipieren wird durch die Bildebene verstärkt, die einem impliziten, nur schwach markierten Erzähler zuzuschreiben ist und den intendierten Leser bzw. Betrachter in die Bildkomposition mit einbezieht. Der Standort des nichtdiegetischen Erzählers auf der Bildebene befindet sich etwa in Höhe der Mittelachse der beiden Bildhälften, deren linke eine Hauswand mit geschlossenem Sprossenfenster zeigt und in die rechte Bildhälfte hinein reicht, auf der in einiger Entfernung im Schnee tollende Kinder zu sehen sind (Abb. 38). 
Abb. 38: Udo Weigelt; Cornelia Haas (2011): Die Königin und ich. Mannheim: Sauerländer.

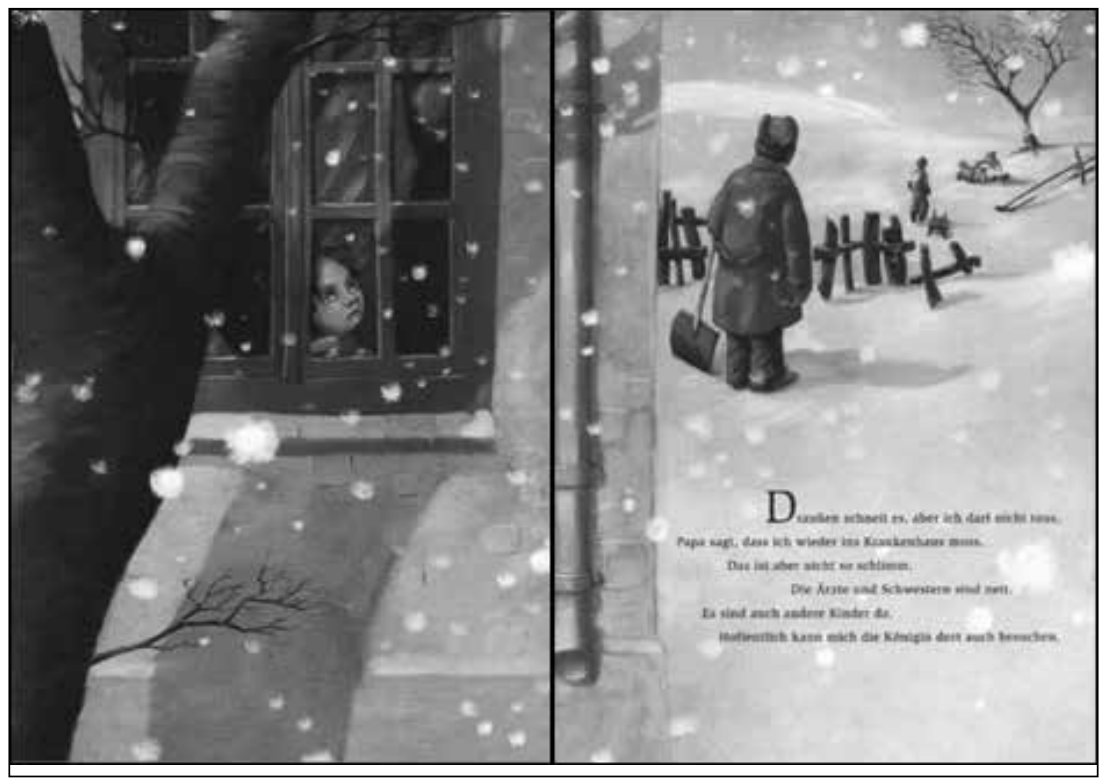

Da die Perspektive von außen auf das Haus und die Hintergrundszene gerichtet ist, kann es sich nicht um die Ich-Erzählinstanz Sophie handeln, da sie das Haus nicht verlassen darf und deshalb auch nicht retrospektiv von der Szene im Hintergrund berichten kann. Der Leserichtung von links nach rechts entsprechend, fällt der Blick etwas oberhalb der linken Bildmitte zuerst auf das traurige Gesicht Sophies, die durch die Fensterscheibe nach oben in die fallenden Schneeflocken schaut, dann auf die rechts außerhalb des Blickfeldes von Sophie dargestellte Szenerie und den darunter im Flattersatz platzierten Text. Diese drei Wahrnehmungsschritte, von links über oben rechts nach rechts unten, sind zusammenzudenken, sodass die Bildeindrücke sich in Verbindung mit dem nüchtern formulierten Text Draußen schneit es, aber ich darf nicht raus. Papa sagt, dass ich wieder ins Krankenhaus muss. in der Gesamtwahrnehmung zur zentralen emotionalen Aussage verdichten: Sophie ist niedergeschlagen und sehnt sich nach unbeschwerter Normalität, wie sie die spielenden Kinder repräsentieren. Indem auf diese Weise Erzählakt, gegenwärtig durch die Verwendung des Präsens, und Rezeptionsakt auf Gleichzeitigkeit angelegt sind, ist eine Nähe zur Erlebenswirklichkeit der Adressaten intendiert, die Empathie hervorruft wie sie auch Projektionen eigener Gefühlszustände zulässt, besonders dann, wenn ihnen, wie der Protagonistin, gerade 
ein Krankenhausaufenthalt bevorsteht oder sie sich bereits dort befinden. Diese impliziten Hinweise verweisen wiederum auf den mit der Widmung des Bilderbuches intendierten Leserkreis, der sich ebenso mit den folgenden Äußerungen der Protagonistin angesprochen fühlen darf. Denn unausgesprochene Befürchtungen werden sprachlich aufgefangen, indem die Erzählerin einen sich selbst und den Leser beschwichtigenden inneren Monolog führt: Das ist aber nicht so schlimm. Die Ärzte und Schwestern sind nett. Es sind auch andere Kinder da. Hoffentlich kann mich die Königin dort auch besuchen. Diese Hoffnung bestätigt sich aber erst später, nachdem der visuelle Erzähler das Erzählen wieder übernommen hat und auf der folgenden Bilderbuchseite den Betrachter mit einem Szenario im Krankenhauszimmer konfrontiert (Abb. 39a), dem das Verlassen des Zuhauses und die Einlieferung ins Krankenhaus als Leerstelle vorausgehen.

Abb. 39a: Udo Weigelt; Cornelia Haas (2011): Die Königin und ich. Mannheim: Sauerländer.

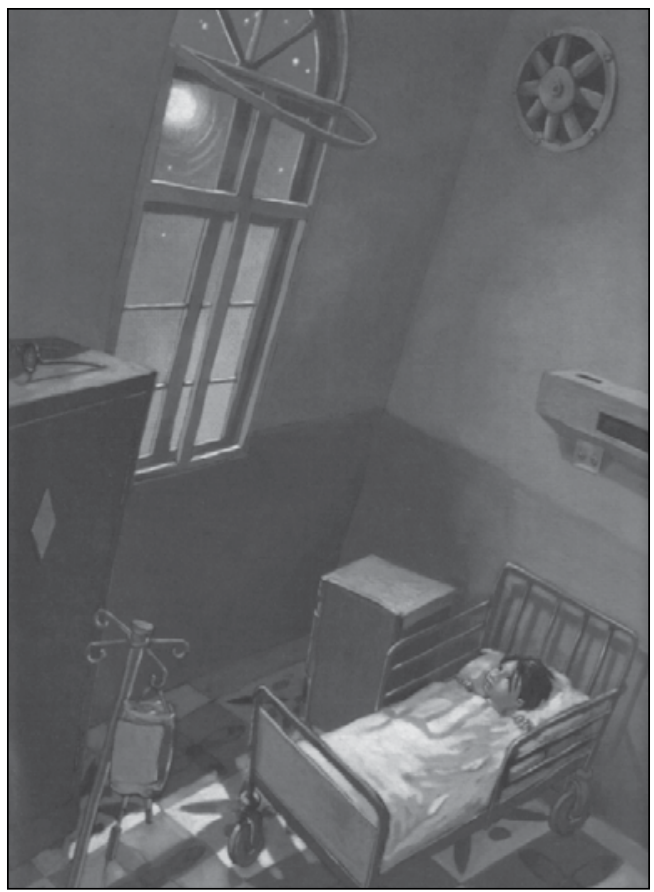

Dieser Sprung ist farblich wie perspektivisch und hinsichtlich der Ausstattung des Umfeldes als dramatischer Wechsel erfahrbar. In Worte gefasst, könnte die 
Bildaussage des erzählenden Ichs lauten: , So lag ich einsam und verängstigt im dunklen Krankenhauszimmer und blickte auf das offene Fenster in der Hoffnung, die Königin käme zu Besuch.' Während die Bildperspektiven bisher dem Betrachter die häusliche Situation auf Augenhöhe mit dem Kind präsentierten, hat der Erzähler hier eine Vogelperspektive eingenommen, die das im vergitterten Bett liegende Kind umso kleiner und verängstigter erscheinen lässt. Die offensichtlich nächtliche Tageszeit tut ihr übriges, um die Isolation des Kindes zu verdeutlichen. Dieses Bild ist fiktionale Realität, der die helle Welt des phantastischen Spiels mit der Königin auf der rechten Einzelbildseite gegenübersteht (Abb. 39b). Der zuvor verbal tatsächlich geäußerte Wunsch erfüllt sich dort, wo auf einer mit warmem Gelb grundierten Fläche - und damit losgelöst von räumlicher und zeitlicher Verortung - das ausgelassene, phantastische Spiel mit der Königin in kreuz und quer gespannten Fäden zu sehen ist.

Abb. 39b: Udo Weigelt; Cornelia Haas (2011): Die Königin und ich. Mannheim: Sauerländer.

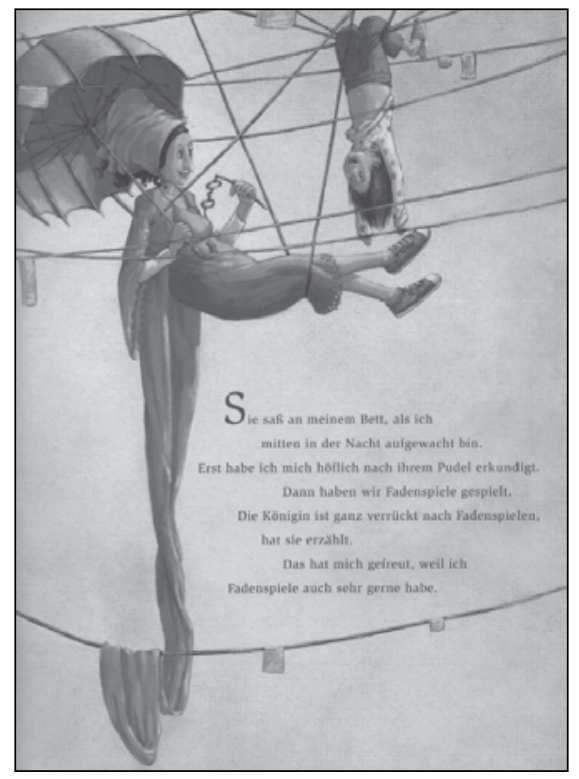

Der Verbaltext, der sich quasi zwischen die Bilder schiebt und das alternierende Erzählen mitbestimmt, liefert auch hier wieder mehr Informationen als die Bildebene, die ihrerseits mit Farben und Minenspiel den eher nüchtern klingenden Text emotional-ästhetisch erweitert bzw. die linke Buchseite (Abb. 39a) konterkariert: 
Sie saß an meinem Bett, als ich mitten in der Nacht aufgewacht bin. [...] Dann haben wir Fadenspiele gespielt.

Die Königin ist ganz verrückt nach Fadenspielen, hat sie erzählt.

Das hat mich gefreut, weil ich Fadenspiele auch sehr gerne habe.

Die mehrfach verwendeten unbestimmten Zeitangaben auf der Sprachebene, die über ein immer wieder neu verwendetes Heute oder Hinweise auf unterschiedliche Tageszeiten nicht hinausgehen, können auf der Bildebene nicht nachvollzogen werden. Insbesondere mit der Aussage Ein paar Tage sind einfach verschwunden. wird Zeit gerafft, die als Leerstelle dem Rezipienten Gelegenheit für ein individuelles Nachspüren des Verlusts von Zeitempfinden gibt, das seine Ursache in Schlaf- und Fieberzuständen hat. Dass es sich um eine dramatische Erkrankung der Protagonistin handeln muss, wird hier zum ersten Mal evident und auf der nächsten Doppelseite (Abb. 40), wiederum verbal, bestätigt. Dort bringt die Ich-Erzählerin auf der linken Doppelbildhälfte ihre Sorge um ihre Eltern in einem Gespräch mit der Königin zum Ausdruck:

Ich habe ihr erzählt, dass Mama und Papa sich meinetwegen so viele Sorgen machen.

Und dass ich nicht weiß, was mit ihnen wird. Das macht mich traurig.

Die Königin seufzte.

"Sophie«, sagte sie dann, »es ist nicht deine Schuld. Du kannst nichts dafür! Ich verspre-

che es dir, ich werde mich um deine Mama und deinen Papa kümmern.

Ganz bestimmt!"

Das hat mich gefreut. (H. d. Verf.)

Abb. 40: Udo Weigelt; Cornelia Haas (2011): Die Königin und ich. Mannheim: Sauerländer.

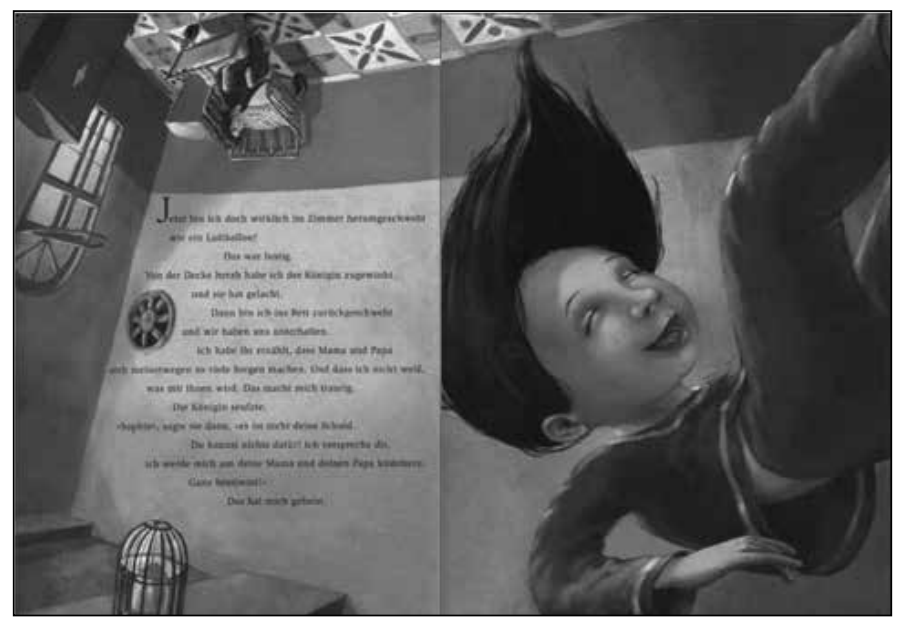


Das Vokabular ist vorsichtig gewählt und vermeidet konkrete Aussagen zu Sterben und Tod. Dennoch ist Sophie sich offensichtlich ihres bevorstehenden Todes bewusst, der sie von den Eltern trennen wird. Woher das Mädchen sein Wissen bezieht, bleibt unerwähnt und es ist deshalb davon auszugehen, dass auf diese Weise Erfahrungen mit sterbenden Kindern aufgegriffen werden, die Kindern ein autonomes Wissen über ihren bevorstehenden Tod zuschreiben (vgl. Kübler-Ross 1984 u. a.). Die autodiegetische Erzählerin ihrer Geschichte ist eine Repräsentantin dieser Autonomie, die an der Ausschließlichkeit ihres kommunikativen Austausches mit der Königin deutlich wird. Der kurze abschließende Satz (s. o.) deutet an, dass die Protagonistin die Sorge um die Eltern an die Königin abgetreten hat. Welche Last ihr damit genommen ist, ist mit der perspektivisch auf den Kopf gestellten Szenerie (Abb. 40) ins Bild gesetzt, die von schwereloser Ausgelassenheit zeugt.

Doch eine letzte Sorge gilt es noch auszuräumen, die wiederum nicht explizit ausformuliert ist, sich aber aus der Antwort der Königin schließen lässt: die Frage danach, was nach dem Tod mit Sophie geschieht. Die Königin versichert ihr, dass sie Prinzessin an ihrem Hof werde: Ich dachte die ganze Zeit, das wüsstest $d u$. Wenn Kinder diese Welt verlassen, dann kommen sie doch zu mir! Das war schon immer so. Das Einzelbild hat keinen Hintergrund und zeigt den Moment der exklusiven, Geborgenheit spiegelnden Gesprächssituation, als die Königin der besorgt-erwartungsvoll blickenden Sophie antwortet. Das warme Rot der ausgefüllten Bildfläche ist emphatisch konnotiert und korrespondiert mit der liebevollen Zuwendung der Königin. Die vorher sprachlich fixierte Reaktion Sophies $D a$ war ich froh. wird dagegen nicht mimisch visualisiert, was in Form eines Simultanbildes o. ä. vorstellbar wäre. Spätestens an dieser Stelle fällt auf, dass das verwendete Vokabular sich häufig des Wortfeldes ,freuen' und verwandter Begriffe bedient, was den positiven Duktus des Bilderbuchs deutlich unterstützt.

Das darauf folgende Bild ist eine Antwort des nichtdiegetischen Erzählers der Bildebene auf die Leerstelle, die die im Raum stehende Frage nach dem Wohin evoziert. Das Einzelbild zeigt eine märchenhafte, aufgrund beleuchteter Fenster augenscheinlich bewohnte Schloss- oder Burganlage, zu der ein unsicher wirkender, unregelmäßiger Holz-Steg hinführt. Diese sichtbar weder einfache noch bequeme Wegstrecke verweist auf die Metapher vom ,letzten Gang' eines Menschen und spiegelt mit ihrer unkomfortablen und ungeschönten Beschaffenheit auf subtile Weise die schwierige Situation progressiv Erkrankter.

Eines der letzten Bilder ist dem letzten Zusammensein der Protagonistin mit den Eltern gewidmet und zeugt davon, wie wichtig es ist, dass ein Kind sich der Liebe der Eltern sicher sein kann und dass deren Gegenwart nicht vom Gefühl der Verzweiflung geprägt sein sollte. Die Ich-Erzählerin berichtet, dass die Eltern 
den ganzen Tag und den ganzen Abend an ihrem Bett saßen, bevor sie einschlief. Die Naheinstellung zeigt das lächelnde Elternpaar, von dem berichtet wird, sie seien gar nicht mehr so aufgeregt. Beide Figuren sind einander und zugleich dem friedlich schlafenden Kind zugewandt.

Darauf folgt die Sterbeszene, die wie ein Aufbruch zu einem Spaziergang wirkt und aus dem verdunkelten Zimmer hinaus in ein helles Licht weist (Abb. 41). Sophie geht an der Hand der Königin und fühlt sich sichtlich sehr gut, so gut wie schon lange nicht mehr. Ihre Körperhaltung bestätigt diese Selbstaussage. Auch darin finden die Erfahrungen mit Sterbenden, die oft kurz vor ihrem Tod eine gesundheitliche Verbesserung verspüren, eine authentische Entsprechung. Der Gesamteindruck der Synthese von Text und Bild wirkt entlastend, denn es wird deutlich, dass die Sterbende nicht leidet und bereit ist, der Königin, Mittlerin zwischen Diesseits und Jenseits, zu folgen. ${ }^{247}$

Abb. 41: Udo Weigelt; Cornelia Haas (2011): Die Königin und ich. Mannheim: Sauerländer.

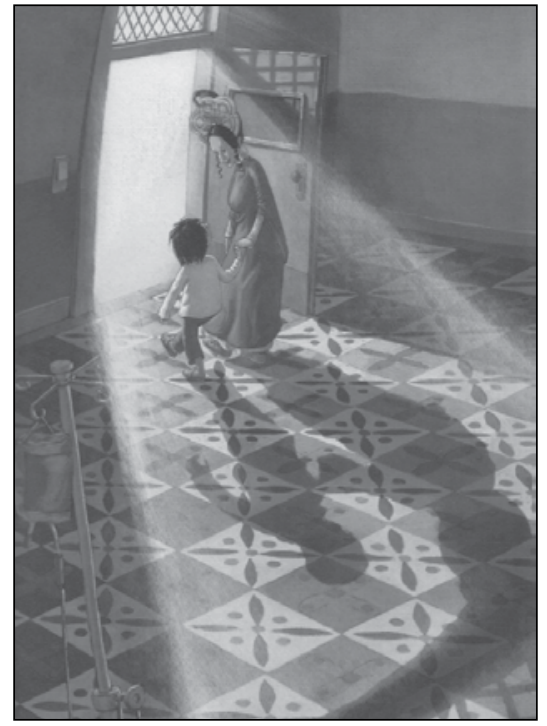

247 Diese Mittlerfunktion des personifizierten Todes in Gestalt der Königin erinnert an die Figur des Todes in Wolf Erlbruchs Ente, Tod und Tulpe (2007), der sich „nur für den Fall“ (ebd.) in der Nähe der Ente aufhält. Eine weitere, deutliche Parallele zeigt sich bei Gajadin/ Ong (1996: Amal und der Brief des Königs): „Wirst du kräftig genug sein, um aufzustehen, wenn der König kommt?" fragt der Doktor. „Ja!" flüstert Amal. „Es geht mir jetzt viel besser, und ich fühle keine Schmerzen mehr." 
Dieses Erzählkonzept fängt die Hoffnungen betroffener Eltern auf, das Sterben möge für ihr Kind ein sanfter Übergang in eine andere Welt sein, in der es behütet sein wird, auch wenn sie sich selbst nicht mehr kümmern können. Wie viel aber oder ob überhaupt Trost mit der von der Sterbeforschung gestützten Vorstellung verbunden sein kann, dass manche Kinder sich nicht fürchten und möglicherweise wissen, wann, ihre Zeit mit der Königin mitzugehen' gekommen ist, ist nur individuell beantwortbar.

\section{Gesamtbeurteilung}

Der das Gesamtwerk erfassende Ikonotext kann als Resümee verstanden werden, mit dem alle Analyseergebnisse deutend und wertend zusammengefasst sind: Dieses Bilderbuch vermittelt eine positive Grundeinstellung zum Leben wie zum Sterben, ohne allzu sehr zu beschönigen und kann, da es auch belastende Seiten zurückhaltend anspricht, Anlass für einfühlsame Anschlusskommunikationen sein. Hinsichtlich der Kommunikationssituation innerhalb der Geschichte ist aber durchaus ein Manko spürbar, da die Protagonistin alle Fragen mit sich selbst bzw. der Königin ausmacht und kein Austausch mit den Eltern stattfindet. Ausgehend von der Grundannahme eines übergeordneten Gesamtgeschehens bleibt aber gleichzeitig offen, ob oder auf welche Weise und gegebenenfalls von wem die Protagonistin bereits vor dem Einsetzen des Erzählvorgangs von ihrer lebensverkürzenden Krankheit Kenntnis erlangt hat. Die Geschichte selbst ist von der Gewissheit der Ich-Erzählerin über ihren bevorstehenden Tod durchdrungen.

Obwohl dem Kind damit eine ähnlich gefestigte Haltung dem Tod gegenüber zugesprochen wird wie in anderen Bilderbüchern den Erwachsenen oder alten Tierfiguren, die mit der Hoffnung auf eine Weiterexistenz ohne Furcht vom eigenen Sterben sprechen, ist die Nähe zu den Erkenntnissen der Sterbeforschung hinsichtlich des Verhaltens progressiv erkrankter Kinder, die sich ihres Zustandes bewusst und gleichzeitig um emotionale Entlastung ihrer Eltern bemüht sind, evident. Der empathische Leser hat die Gelegenheit, seine Fragen und seine Gefühlswelt darin gespiegelt zu sehen und/ oder ein Verständnis für die Situation eines betroffenen Kindes zu entwickeln, das wie kaum jemand dieses Verständnisses bedarf. Die mit dem Erzählkonzept beabsichtigte Entlastung eines möglicherweise selbst betroffenen kindlichen Rezipienten ist ebenso nachvollziehbar wie der Appell an begleitende Eltern, Verständnis für ein zurückgenommenes Verhalten ihrer Kinder zu haben und an ihrer Seite zu sein, offen für ihre Befürchtungen und versteckten Signale eines sie bedrückenden Verantwortungsgefühls ihnen gegenüber und bereit, die eigene emotionale Belastung zurückstellen und vielleicht auch auf eine geheilte, nachtodliche Existenz ihres Kindes zu hoffen. 


\section{VII.2.2 Trauernde Kinder}

\section{VII.2.2.1 Überblick}

Die Perspektive trauernder Kinder, die entweder einen Bruder ${ }^{248}$, eine Schwester $^{249}$, einen Freund ${ }^{250}$ oder eine Freundin ${ }^{251}$ verloren haben bzw. sich um eine an Leukämie erkrankte Schwester ${ }^{252}$ sorgen, wird in insgesamt nur 19 Bilderbüchern erzählerisch sehr unterschiedlich ausgeformt. Fragen oder Erklärungsversuche zu den einzelnen Dimensionen eines kindlichen Todeskonzepts spielen dabei so gut wie keine Rolle, es geht vielmehr um die psychischen Verarbeitungsprozesse des Verlusts, die aber nur teilweise das Spektrum der Trauerphasen umfassen. Ein neuer Selbst- und Weltbezug (vgl. Kast 1999, 83f.) wird in allen Fällen erreicht, fast immer verbunden mit einem erinnernden Gedenken, das eine Beziehung mit dem oder der Verstorbenen aufrechterhält und das Verlustempfinden wachhält.

Darunter befinden sich vierzehn Titel, in denen der Tod von Geschwisterkindern thematisiert wird, und zwar auf sehr unterschiedliche Weise. Auf der Handlungsebene ist zu unterscheiden: Teils liegt der Todeszeitpunkt lange vor dem Einsetzen des Erzählens, teils setzt das Erzählen mit dem Todesereignis ein oder Sterbe- und Trauerprozesse gliedern das Erzählen entsprechend. Zwei Geschichten problematisieren die pathologischen Folgen eines Geschwisterverlusts, dessen Todeszeitpunkt vor dem Bewusstsein der eigenen Identität des überlebenden Protagonisten liegt und dennoch eine Identitätsstörung hervorruft. Das Bilderbuch Am Anfang waren wir zu zweit (Thurmann/ Fischer 2010) ist als therapeutisches Begleitmaterial für verlassene Zwillingskinder (Untertitel) konzipiert und bringt die psychische Belastung aufgrund eines vorgeburtlichen

248 Schubiger/ Berner 2011: Als der Tod zu uns kam; Proché/ Suchy 2004: Brüderchen bei den Sternen.

249 Thurmann/ Fischer 2010: Am Anfang waren wir zu zweit; Ruß/ Broska 2009: Himmelskind; Sturm/ Hillen 2008: Justus ist traurig; Schins/ Müller 2005: Zuckerguss für Isabel; Goossens/ Robberecht 2004: Eva im Land der verlorenen Schwestern; Blumentritt 2003: Lara's Schmetterlinge (sic!); Treiber/ Blazejovsky 2001: Die Blumen der Engel; Vinje/ Zahl-Olsen 2000: Pelle und die Geschichte mit Mia; Steiner 1999: Auf welchem Stern lebt Sina? Olga auf der Suche nach ihrer verstorbenen Schwester; Stark/ Höglund 1997: Meine Schwester ist ein Engel; Pludra/ Mossner 1978: Trauermantel und Birke.

250 Kaufmann 2004: Ich und du, du und ich; Kaldhol/ Øyen 1987: Abschied von Rune.

251 Schulß/ Bunge 2009: Als Otto das Herz zum ersten Mal brach; Wegenast/ Meyer 2008: Hannah und ich; Reuter 1989: Christian.

252 Waldmann-Brun 1995: Lia ist krank. 
Geschwisterverlusts für das überlebende Zwillingskind zur Sprache. ${ }^{253}$ Daneben ist Meine Schwester ist ein Engel (Stark/ Höglund 1997) die Geschichte von der unverarbeiteten Trauer eines Jungen um seine Schwester, die er, obwohl sie bereits vor seiner Geburt verstarb, sehr vermisst und deren Verbleib ihm Kopfzerbrechen macht. Die kindlichen Fragen nach den Lebensbedingungen im Himmel bleiben jedoch unbeantwortet, seine Lehrerin bestraft ihn gar für die in ihren Augen absurden Äußerungen, sodass der Protagonist sich schließlich nicht anders zu helfen weiß, als mittels einer Verkleidung selbst in die Rolle der Schwester zu schlüpfen und sich auf dem Weg des Wieder-Ablegens von Perücke und Kleid von ihr zu verabschieden. Damit wird er zu seinem eigenen Therapeuten und Heiler. Dieses Buch gibt ein Beispiel für die nachhaltig-problematischen Folgen einer unreflektierten, empathielosen Abweisung kindlicher Fragen und eines ebensolchen Umgangs mit kindlichem Verhalten.

Die Krise, die ebenso der erlebte Tod eines Geschwisters in mehrfacher Hinsicht für das zurückgebliebene Geschwisterkind bedeutet, wird oft in einem idealisierten Kontext unterschlagen. $\mathrm{Zu}$ den Bilderbüchern, die die schwierige Situation von Geschwistern zumindest anklingen lassen, gehören auch Justus ist traurig (Sturm/ Hillen 2008) oder Lara's Schmetterlinge (sic!) (Blumentritt 2003), in dem die Brüder der Erkrankten die auf die Schwester fokussierte Aufmerksamkeit der Eltern und Verwandten monieren. Diese Titel sind gleichzeitig, wie auch das Bilderbuch Lia ist krank (Waldmann-Brun 1995), das kein Todesereignis thematisiert, explizit als sogenannte Ratgeberbücher ausgewiesen und unisono mit religiösen Trostkonzepten ausgestaltet, was mehrheitlich auf die Bilderbücher zur Trauer um Geschwister zutrifft. Dem liegt offenbar die Überzeugung zugrunde: „Ohne Hoffnung, gleichsam in der Vorstellung, daß alles Leben in den unweigerlichen Abgrund führt, kann Trauer sich kaum lösen." (Holzschuh 2000, 175)

Nur drei Bilderbücher setzen den Prozess der kindlichen Trauerverarbeitung nach dem Verlust eines Geschwisterkindes auch explizit ins Verhältnis zur Trauer der Eltern. Der fast sechsjährige Justus (Sturm/ Hillen 2008: Justus ist traurig) wird beispielsweise durch den Tod nicht nur der zweijährigen Schwester beraubt, sondern auch der Geborgenheit seines Elternhauses, ohne dass ihn Letzteres in irgendeiner Weise zu belasten scheint. Justus wird, da die Eltern für seine Betreuung keine Zeit haben, schon während des Krankenhausaufenthaltes seiner Schwester bei seiner Patentante untergebracht und bis zur Todesnachricht über den bedrohlichen Gesundheitszustand der Schwester im Unklaren gelassen. Positiv hervor-

253 Dieses Buch ist mit einem umfassend die Problematik erläuternden Anhang versehen. 
zuheben ist zwar, dass Justus ans Totenbett seiner Schwester treten darf, von der Beerdigung aber wird er ausgeschlossen und wohnt für weitere Wochen bei der Tante, die erst später mit ihm das Grab besucht. Justus wird als ein Beispiel für mustergültiges Verhalten präsentiert, das den Eltern keine besondere Aufmerksamkeit und Mühe abverlangt. Der Umgang der Eltern mit ihrer eigenen Trauer und ihre mangelnde Aufmerksamkeit für den ebenfalls trauernden Bruder sind symptomatisch für die Probleme, mit denen Kinder nach dem Tod eines Geschwisters oft zurechtkommen müssen. Dem Protagonisten Justus scheint es dagegen zu genügen, im Gedenken an seine Schwester selbstbemalte Steine auf ihr Grab zu legen und in seiner Tante eine Ansprechpartnerin zu haben. Negative Aspekte, wie das Gefühl von Minderwert oder mögliche Schuldgefühle aufgrund vorausgegangener Geschwisterkonflikte (vgl. Gözütok et al. 2000, 50ff.), spielen keine Rolle, lediglich die Sorge, sich nicht auf seine bevorstehende Einschulung und geplante Freizeitaktivitäten freuen zu dürfen, treibt den hinterbliebenen Bruder um. Obwohl damit Identifikationsmöglichkeiten gegeben sind und die Versicherung entlastet, die Vorfreude sei vollkommen in Ordnung, dürfte in einem Vorlesegespräch im konkreten Einzelfall mehr Verständnis erforderlich sein.

Die folgenden ausführlichen Analysen fokussieren zunächst den Umgang mit dem Verlust eines Freundes, bevor die besondere Problematik eines Geschwisterverlusts in den Blick genommen wird.

\section{VII.2.2.2 Trauer um einen Spielgefährten: Ich und du, du und ich (Angelika Kaufmann 2004)}

Das 2004 erschienene Bilderbuch von Angelika Kaufmann stellt aufgrund des autodiegetischen Erzählkonzepts und einer phantastischen Sequenz ebenfalls eine außergewöhnliche Bearbeitung dar, die, kommunikative Interaktionen mit anderen Figuren lediglich andeutend, ausschließlich die Wahrnehmung und Konstitution des trauernden Kindes erfasst. Das autodiegetische Erzählen in der grammatischen 1. Person ist als direkte Du-Ansprache der etwa 8- bis 9-jährigen Protagonistin an den bei einem Autounfall ums Leben gekommenen Freund konzipiert und macht auf dem Weg reflektierender Gedanken, die in die Vergangenheit wie in die Erzählgegenwart weisen, die psychische Konstitution des Mädchens erfahrbar. Parallel dazu drückt sich auf der Bildebene durchgängig ein nichtdiegetischer Erzähler aus, der im Prozess der Bildung eines Ikonotextes aufgrund seines auf die Perspektive der Protagonistin beschränkten Wissens und seiner Fähigkeit zur Introspektion mit dem autodiegetischen Erzähler der Sprachebene zusammenzudenken ist. Dieses auf besondere Nähe angelegte Erzählkonzept macht den Prozess der Verarbeitung 
eines Verlustschmerzes ebenso nachvollziehbar wie es das Anliegen impliziert, dem intendierten kindlichen Adressaten ein Identifikationsangebot zu machen.

Abb. 42: Angelika Kaufmann (2004): Ich und du, du und ich. Weitra: Bibliothek der Provinz.

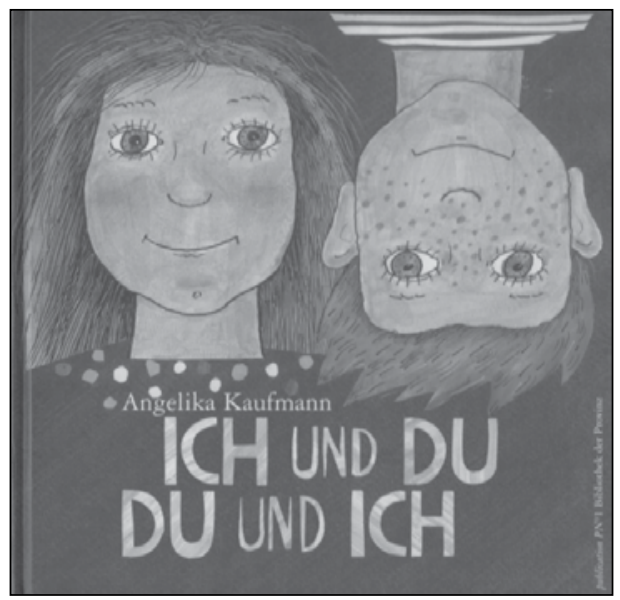

Das Erzählte bildet die vier bekannten Phasen eines Trauerprozesses ab und zeigt, dass sie nicht einer festen Abfolge unterliegen und Zeit benötigen, denn es bleibt offen, wann die Trauer als abgeschlossen gelten kann, worauf weiter unten noch eingegangen wird. Die Bilder vervollständigen und erweitern den kurzen parataktischen Text, der sich fast durchweg am unteren Seitenrand befindet, indem visuelle Ausdrucksmittel Leerstellen füllen, selbst welche öffnen und das jeweilige Empfinden der Protagonistin sichtbar machen.

Komponenten des Erzähldiskurses und ihre Ikonotexte

Die Funktion der formalen Gestaltung für die Generierung des Ikonotextes ist von Angelika Kaufmann mit diesem Bilderbuch kunstvoll inszeniert worden. Auf welche Weise sie die sprachlich erzählten Inhalte auf der Bildebene aufgreift, spiegelt und erweitert, kann bereits am Titelbild nachgewiesen werden (Abb. 42). Der Chiasmus Ich und $d u, d u$ und ich ist dabei Programm: In Leserichtung von links nach rechts erfasst der Betrachter zunächst das Konterfei des weiblichen Ich und das auf dem Kopf stehende des männlichen Du und muss sich unweigerlich veranlasst fühlen, das Buch zu drehen, sodass sich die Reihenfolge der Abgebildeten ändert und die Leserichtung dem zweiten Teil des Chiasmus' entspricht. Dass ein erneutes Drehen notwendig wird, liegt auf der 
Hand. Mit dieser Konzeption der verbindenden Gegenüberstellung ist die Unaufhebbarkeit der emotionalen Bindung an den verlorenen Freund Bild geworden. Im Inneren des Buches wird sie mit dem Titelblatt auf Seite $2^{254}$ (ICH UND $D U$ ) und seiner Entsprechung auf der vorletzten Seite des Buches (DU UND $I C H)$ sprachlich und ikonisch fortgesetzt. Beide Hälften des Titeltextes sind dort jeweils mit Figuren-Initialen gestaltet und rahmen das Erzählen, welches - seinerseits auf den Ebenen des Inhalts und der Form chiastisch angelegt - in dieses verbundene Sprachbild eingebettet ist. Die Großbuchstaben unterstreichen die Wirkung zusätzlich.

Es lassen sich sprach- und bildgestalterisch je zwei deutlich voneinander abgehobene Erzählebenen unterscheiden: einmal die Ebene der Erzählgegenwart, d.h. der schriftlich fixierten Gedankenrede bzw. monologischen Zwiesprache mit dem verstorbenen Freund, und zum anderen eine darin eingeschobene phantastische Erinnerungssequenz. Diese Binnenerzählung ist formal mit den sich zur Mitte verjüngenden Seitenformaten umgesetzt und reduziert sich verdichtend in der Mitte des Buches auf eine nur noch 12,3 cm breite Doppelbildseite.

Abb. 43: Jeweils drei Blätter links und rechts der Mittelfalz in: Angelika Kaufmann (2004): Ich und du, du und ich. Weitra: Bibliothek der Provinz.

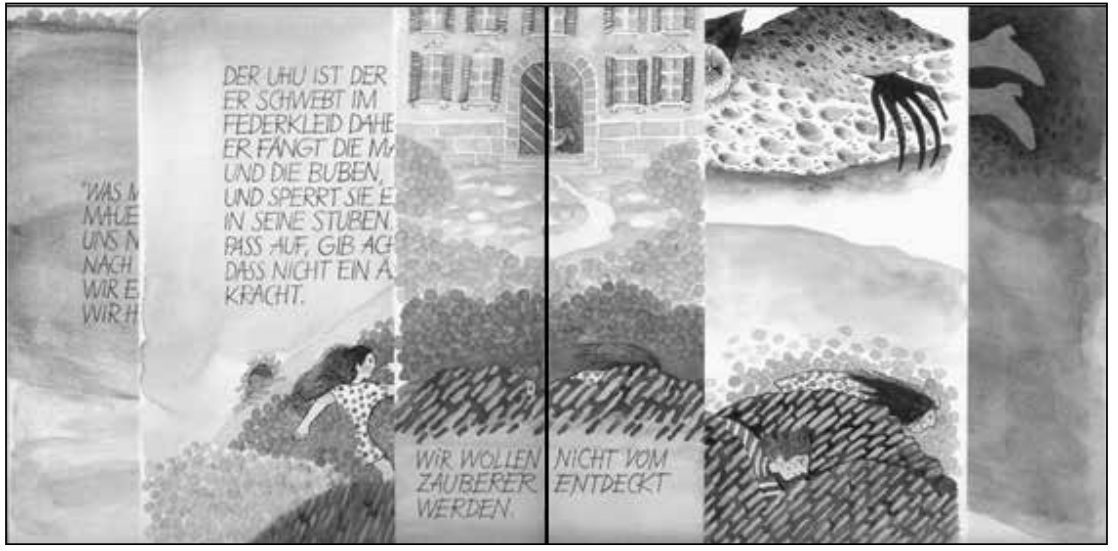

Das,Wir' der befreundeten Kinder steht buchstäblich im Zentrum des Erzählens, nämlich exakt in der Mitte des Buches auf der Sprachebene und im Bild: Wir wollen nicht vom Zauberer entdeckt werden. (Abb. 43; H. d. Verf.) Im umgekehrten

254 Die unpaginierten Seiten werden gezählt ab der Rückseite des Vorsatzblattes, auf dem sich die Widmung für Harry befindet. 
Verlauf weiten sich die Blätter anschließend wieder zur Ursprungsgröße bis zum Übergang zur Erzählgegenwart. Auch in der Seitenanzahl ist diese Symmetrie des Chiasmus' umgesetzt: Vier Blätter gehen dem phantastischen Einschub voraus, der nach drei Blättern exakt an der Mittelfalz des Buches und weiteren drei Blättern endet, gefolgt von wiederum vier Blättern, die den inneren Monolog der Erzählerin wieder aufnehmen.

Neben den bereits genannten Initialbildern stellt die imitierte Kinderhandschrift des Sprachtextes eine weitere „typographische Inszenierung“ (Willberg 1997, 7) der Ich-Erzählperspektive dar, die der kindlichen Protagonistin entspricht und ein zusätzliches Identifikationspotenzial birgt. Erzählzeit und erzählte Zeit sind in Form des inneren Monologs als nahezu deckungsgleich zu betrachten und suggerieren den Eindruck der direkten Teilhabe am innerpsychischen Zustand der Ich-Erzählerin und ihrer Erinnerungsbilder.

\section{Darstellung von Emotionalität}

Das sprachliche und bildliche Erzählen setzt mit der Vorstellung der beiden Protagonisten ein: Ich und du, wir waren Freunde. Wir haben oft miteinander gespielt. Gestritten haben wir uns auch, manchmal haben wir uns sogar geschlagen, und dann haben wir uns wieder vertragen. Es handelt sich demnach um eine ganz normale Freundschaftsbeziehung, wie sie alle Kinder kennen. Die Bildebene zeigt dazu die beiden schon vom Titelbild bekannten, lächelnden Konterfeis, deren Darstellung parallel zum Sprachtext in die Vergangenheit weist, wie sich auf der nächsten Seite bestätigt. Denn es muss etwas geschehen sein, das den deutlich veränderten Gesichtsausdruck des Mädchens verursacht hat. Sein Lächeln ist einer verstummten, im Wortsinne mundlosen Mimik gewichen, die die Figur, im Verbund mit der Darstellung ihrer verschränkten Arme, zugleich aufgebracht erscheinen lässt. Die Entrüstung erschließt sich über das Auge des Betrachters im Zusammendenken der beiden Hälften des Doppelbildes, das links die Protagonistin auf einem Stuhl sitzend zeigt und rechts das kontrastierende Pendant eines leeren Stuhls, dessen Symbolgehalt auf der Hand liegt. Die Leerstelle schließt der Sprachtext bestätigend: Aber eines Tages bist du fortgegangen. $D u$ hast nichts davon gesagt, du hast dich nicht von mir verabschiedet. Wie hast du das nur tun können? Da ein plausibler Grund für das unterstellte Verhalten fehlt, ist das Empfinden der Protagonistin für den empathischen Leser in diesem Moment sicher leicht nachvollziehbar. Es handelt sich dabei um die „Phase der aufbrechenden Emotionen“, die schon auf der nächsten Buchseite in die „Phase des Suchens und sich Trennens“ (Kast 1999, 73ff.) übergeht, sprachlich angestoßen mit der Frage Erinnerst du dich noch? Viele Spiele haben wir uns ausgedacht: Wir 
haben Prinzessin und Räuber gespielt, und Zauberer und Bär, [...] und Begräbnisabhalten. Daran schließt die Sequenz der phantastischen Binnenerzählung an, die aufgrund der verwendeten grammatischen Form des Präsens und der ersten Person Plural das erinnernd-imaginierte Spiel mit dem vermissten Freund gegenwärtig erscheinen lässt. Unterstützt wird dieser Eindruck durch die differenzierte Farbgebung. Die Bilder sind zu Beginn und auf den letzten Seiten des Buches nahezu farblos gestaltet und rekurrieren auf die von der Ich-Erzählerin präsentierte gedankliche Zwiesprache. Das dominante Grau der Bilder korrespondiert mit dem Verlust von Lebensfreude und Lebendigkeit. Farbig wird das ikonische Erzählen erst mit der Rückbesinnung auf das gemeinsame Versteckspielen im Wald, das seine Magie aus dem Handlungsort und dem phantastischen Imaginieren eines Uhu-Zauberers erhält. Wie auf der Bildebene die Farbe, macht auf der Sprachebene der Wechsel vom Perfekt ins Präsens deutlich, wie gegenwärtig diese Erinnerungs- oder Traumsequenz ist und wie viel mehr Leben darin im Vergleich zur Erzählgegenwart steckt: Einmal sind wir einem schönen Vogel nachgelaufen bis tief in den Wald hinein. Wir laufen und laufen, und plötzlich gelangen wir an eine Mauer. Der Bruch auf der Sprachebene ist visuell kongenial umgesetzt: Neben der für diese Binnenerzählung in Großbuchstaben veränderten Typographie macht die Doppelseite den Übergang in die imaginierte Welt sowohl farblich als auch in der Körperhaltung der Protagonistin sichtbar.

Abb. 44: Angelika Kaufmann (2004): Ich und du, du und ich. Weitra: Bibliothek der Provinz.

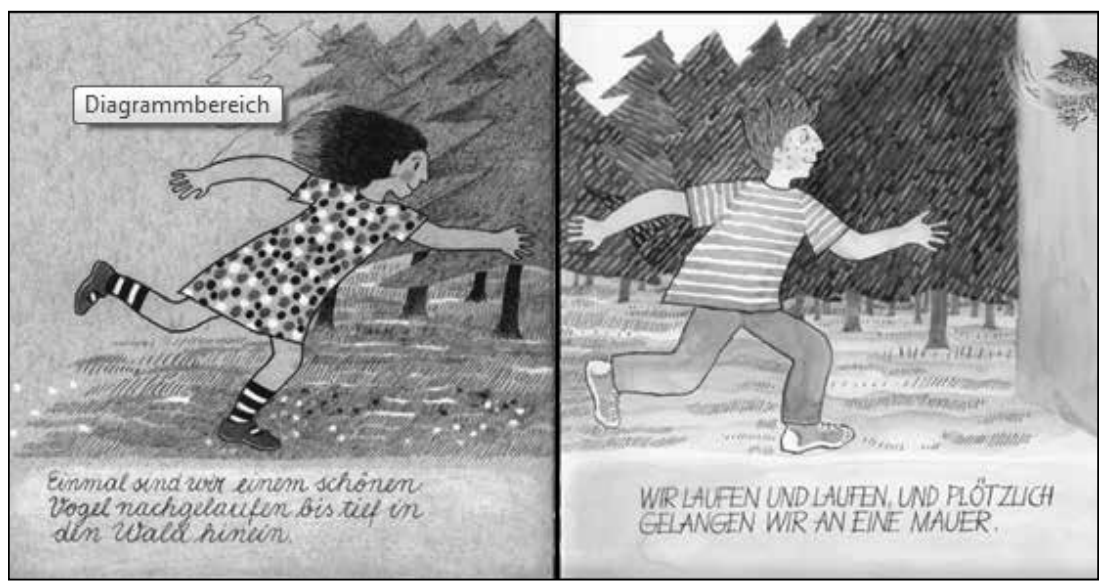

Mit vorwärts ausgestrecktem Arm, fliegenden Haaren und lächelndem Gesicht folgt sie ihrem Freund von der grauen Seite auf die farbige, die zum 
Seitenumbruch ausgestreckten Hände der Beiden berühren sich jedoch nicht, denn es wird eine irreale Ebene betreten, die eine Kontaktaufnahme nicht möglich macht (Abb. 44).

Im Spiel und aus dem Spiel retten sich die Freunde vor dem imaginierten Zauberer wiederum durch ein Loch in der Mauer: Jetzt atmen wir auf. Jetzt sind wir wieder im Wald. Jetzt gehen wir heim. (Abb. 45) Aber das kontrapunktische Bild zeigt, dass dies nur eine Imagination ist, denn die Situation kehrt sich wieder um: Die Farbigkeit wechselt in das Grau der Wirklichkeit, der Freund bleibt auf der farbigen Hälfte der Doppelseite unerreichbar zurück, die nun zurückgewandt ausgestreckten Arme bleiben verzweifelt leer, was die fein gestaltete Mimik noch unterstreicht.

Abb. 45: Angelika Kaufmann (2004): Ich und du, du und ich. Weitra: Bibliothek der Provinz.

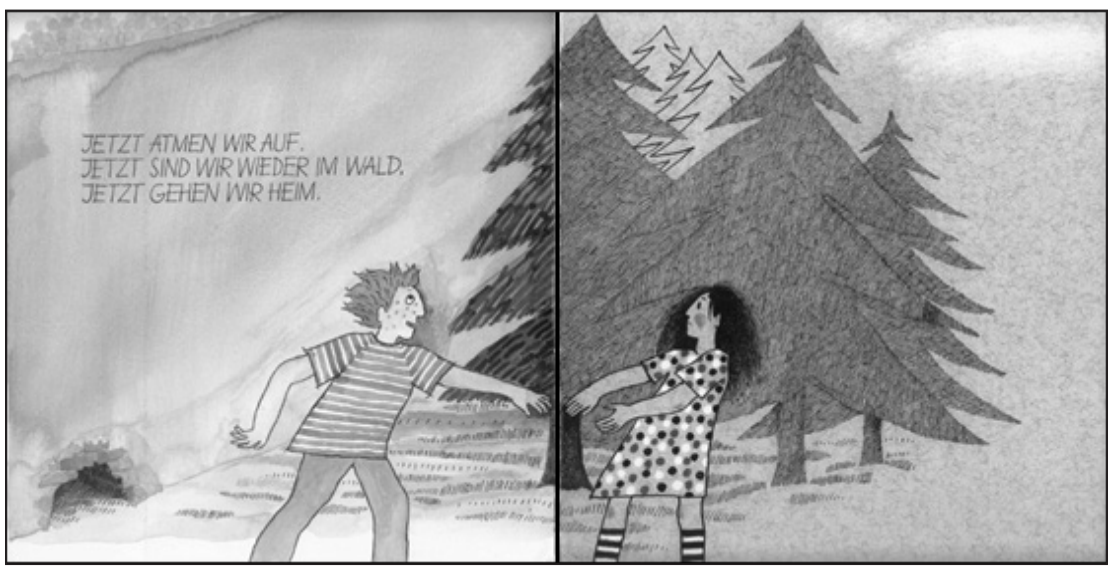

Die stille Fassungslosigkeit des Mädchens ist auf den folgenden Seiten in wenige Sätze und ausdrucksstarke Bilder gekleidet, die auch auf die Phase der Nichtakzeptanz des Verlusts hinweisen: Die Erwachsenen sagen, dass du jetzt tot bist. Ich kann das nicht glauben. Nicht immer sagen die Erwachsenen die ganze Wahrheit. Auf der Bildebene zeigt der nichtdiegetische Erzähler dieses Nicht-wahrhaben-Wollen in der Darstellung einer Geste: Das Mädchen bedeckt mit der rechten Hand ihr Gesicht und wird an der linken von einer erwachsenen weiblichen Person gehalten, die im Gegensatz zum Kind dem Betrachter den Rücken zuwendet und unverhältnismäßig groß dargestellt ist. Text und Bild setzen die von der Erwachsenen sich abgrenzende Position des Kindes in der Konzeption der Doppelseite um, die links das Kind und rechts die Erwachsene mit dem dazugehörigen Textpassus zeigt. 


\section{Todeskonzept und Jenseitsvorstellungen}

Das weitere parallele Erzählen von Text und Bild beschreibt das Ritual des Friedhofsbesuchs und liefert die längst erwartete Information über die Todesursache, womit die Kausalität als Teildimension des reifen Todeskonzeptes die impliziten Hinweise auf die Irreversibilität des Todes ergänzt. Die Aspekte der Universalität und der Nonfunktionalität bleiben gänzlich unerwähnt, ihre Kenntnis wird offenbar vorausgesetzt, woraus sich auch das Alter der Protagonistin von etwa 9 Jahren oder älter ableiten lässt. Obwohl die Bildebene eindeutig auf ein christliches Begräbnis hinweist, spielen christliche Glaubens- und Jenseitsvorstellungen keine Rolle und es wird, wie so oft, eine mnestische Troststrategie praktiziert.

Manchmal gehe ich auf den Friedhof und lege Blumen auf dein Grab. Ein Auto hat dich überfahren, sagen die Erwachsenen. Aber immer, wenn ich die Augen zumache, sehe ich dich ganz genau: dein Gesicht mit den lustigen Augen, mit den Sommersprossen und den abstehenden Ohren. Du bist gestorben - aber tot bist du nicht.

Der letzte Satz impliziert ein reifes Todesverständnis des Mädchens, denn nur wer weiß, was Totsein bedeutet, kann dem eine andere Vorstellung, die des Lebendighaltens in der Erinnerung, entgegenhalten. Zum Text präsentiert die Bildebene eine überzeugend-erweiternde Entsprechung.

Abb. 46: Angelika Kaufmann (2004): Ich und du, du und ich. Weitra: Bibliothek der Provinz.

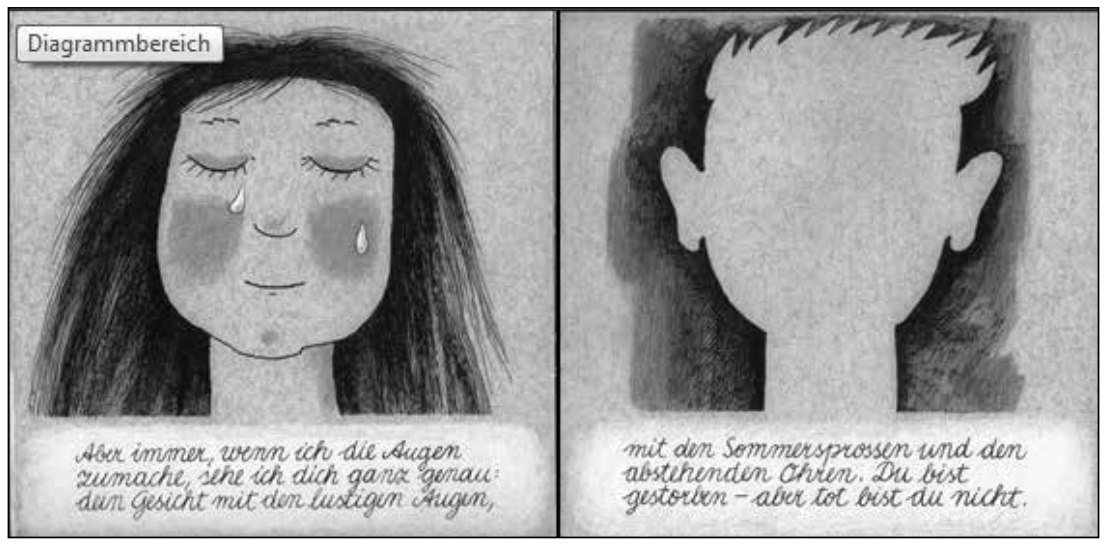

Das Konterfei des Verstorbenen ist gesichtslos, weder die im Text genannten Sommersprossen noch mimische Züge sind in der Silhouette sichtbar (Abb. 46). Dem Betrachter werden nur leere Konturen präsentiert, die lebendige Erinnerung bleibt 
offensichtlich der Protagonistin vorbehalten, die um ihren verloren Freund weint. Diese letzten beiden Bilder weisen auf ein offenes Ende des Trauerprozesses hin und zeigen auf, dass der Tod des Freundes eine unaufhebbare Lücke hinterlassen hat.

\section{Gesamtbeurteilung}

Die Stärke des Erzählens liegt in diesem Bilderbuch auf allen Darstellungsebenen in der konsequenten Fokussierung auf die Wahrnehmung der Protagonistin und manifestiert sich im Ikonotext, dessen Bedeutungsgehalt in der Authentizität des nachempfundenen kindlichen Trauerprozesses liegt. Das liegt nicht zuletzt an der Ich-Erzählsituation und der darin angelegten Kenntnis über (kindliches) Trauern. „Ein Ich gestattet [...], sich ihm extrem anzunähern; der Autor kann es sich überziehen wie eine zweite Haut" (Steinhöfel 2009, 33), und ebenso kann es wie hier Identifikationsprozesse anstoßen, die entlastend wirken können, da das Empfinden eines trauernden Rezipienten darin einen Widerhall findet. Die Verknüpfung von Form und Inhalt ist außerordentlich gelungen.

\section{VII.2.2.3 Geschwistertrauer: Die Blumen der Engel (Jutta Treiber, Maria Blazejovsky 2001)}

Für die exemplarische Analyse eines Bilderbuchs, das die besondere Problematik der Trauer eines hinterbliebenen Geschwisterkindes thematisiert, fiel die Wahl auf das Werk von Julia Treiber und Maria Blazejovsky (2001), da daran eine kunstvoll gestaltete Authentizität des Erzählens nachgewiesen werden kann (Abb. 47).

Abb. 47: Jutta Treiber; Maria Blazejovsky (2001): Die Blumen der Engel. Wien, München: Betz.

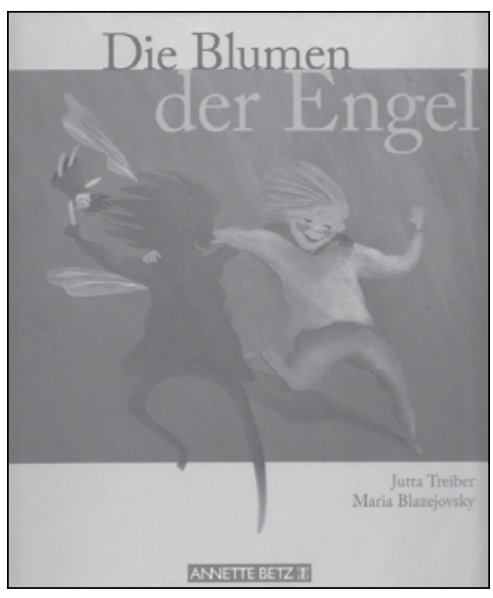


Das Zusammenspiel von Bild- und Textebene orientiert sich konsequent an der Perspektive der siebenjährigen Protagonistin Sonja, die plötzlich mit der Nachricht vom Tod ihrer um ein Jahr jüngeren Schwester Mara konfrontiert wird. Ein nächtlicher Anruf informiert Vater und Tochter über den durch Fremdverschulden verursachten Autounfall, bei dem die Mutter nahezu unverletzt geblieben ist.

\section{Die erzählerische Vermittlung}

Die Geschichte beginnt in medias res auf einem Weißgrund mit der Stimme des nichtdiegetischen Erzählers: Mara ist nicht mehr da. Sie wird nicht wiederkommen. Nie mehr. Gestern war sie noch hier. Gestern haben Sonja und Mara noch zusammen gespielt. Der Eindruck einer absoluten, nicht infrage zu stellenden Tatsache, den die Parataxe hervorruft, korrespondiert mit der Semantik der Satzfolge und wird durch die Anapher noch zusätzlich betont. Der Erzähler berichtet vom Geschehen aus der figuralen Perspektive Sonjas: Sein Gesicht ist blass geworden. [...] Papa hat die Hände vors Gesicht geschlagen. "Mara ist ...«, hat er gesagt. Auf einmal war es totenstill im Zimmer. Nur die Uhr tickte ganz laut. Er verfügt über die Fähigkeit zur Introspektion, die sich im weiteren Erzählvorgang in der Verwendung der Formen des Bewusstseinsberichts, der erlebten Rede und der Gedankenrede äußert. Diese narrativen Modi dominieren die Präsentation der Geschichte im Präsens und schaffen, in weitestgehend parataktischer Syntax dem Sprachduktus einer Siebenjährigen nachempfunden, eine unmittelbare Nähe zum emotionalen Zustand der Protagonistin. Die "perzeptive Perspektive“ (Schmid 2011, 140) ist damit nahezu ausschließlich auf die Wahrnehmungsebene der kindlichen Protagonistin bezogen und wird nur während der Begräbnisszenerie durch einen auktorialen Einschub des Erzählers aufgehoben, der die Dramatik des viel zu frühen Todes betont:

Mara war in der ersten Klasse. Sie hat vor Kurzem ihr erstes Buch gelesen. Ganz allein. Sie war stolz darauf. [...] In ein paar Tagen ist Schulschluss. Mara wird ihn nicht erleben. Mara wird ihre ersten Ferien nicht erleben.

Auf der Bildebene präsentiert sich ein ebenfalls nichtdiegetischer Erzähler, der nicht nur einen betrachtenden Blick auf die Protagonistin richtet und seine Kenntnisse über ihre innerpsychischen Zustände anhand verschiedener und teilweise verzerrender Kameraperspektiven visualisiert, sondern auch sein Wissen vom Unfallgeschehen. Seine Funktion ist eine den Text spiegelnd-ergänzende, die in der emotional konnotierten Erweiterung und entsprechenden Leerstellenfüllungen zu sehen ist. Bemerkenswert ist beispielsweise die Visualisierung des Unglücksmoments (Abb. 48), die dem im Modus der erlebten Rede berichtenden Text, ein Autofahrer habe das Stoppschild übersehen und sei in Mamas Auto 
gefahren, vorausgeht. Dieses Bild füllt die Leerstelle, die zuvor die Auslassungszeichen in der oben zitierten, direkten Rede des Vaters hervorgerufen haben.

Abb. 48: Jutta Treiber; Maria Blazejovsky (2001): Die Blumen der Engel. Wien, München: Betz.

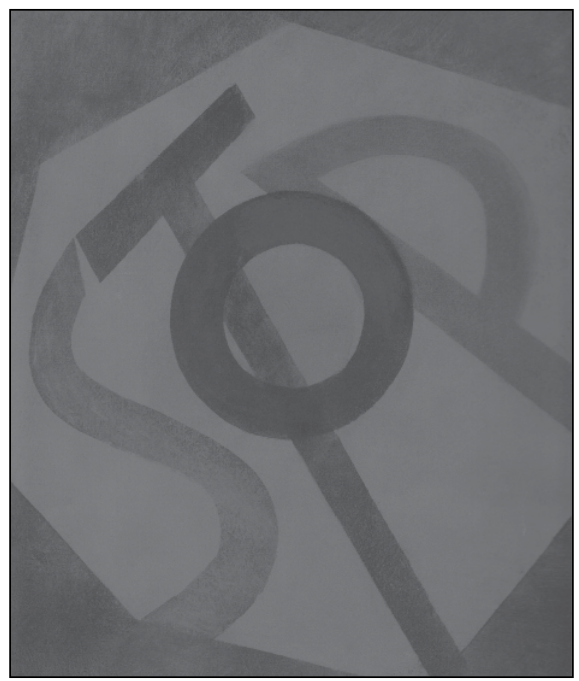

Das bedrohliche Rot der Bildinszenierung (Abb. 48) wirkt für sich, ohne den Moment des Unfalls explizit auszugestalten. Es bleibt dem Betrachter überlassen, ein „mentales Situationsmodell“ (Maiwald 2010, 173) in seinem Kopf entstehen zu lassen, angeregt durch die Farbwahl und die perspektivische Gestaltung, die die Dramatik des Geschehens ästhetisch erfahrbar macht: Das Zerrbild des roten Stoppschilds dominiert die dunkelrot grundierte Einzelbildseite und zeigt eine Schräglage, die der auf der fiktionalen Wirklichkeitsebene entstandenen metaphorisch entspricht. Zusätzlich verstärkt wird der Eindruck durch die Anordnung der vier Buchstaben STOP, die das O hervorhebt und die Buchstabenfolge TOD suggeriert. Als Ikonotext, gebildet aus Ästhetik und Semantik des Dargestellten, lässt sich formulieren, dass das Stoppschild seiner Funktion, diesen Unfall zu verhindern, nicht gerecht wurde und den Tod quasi selbst hervorgebracht hat.

Auf der dem Bild rechts gegenüberliegenden Buchseite setzt das Erzählen wieder verbal ein: Viel später erst kann Papa sprechen. Der darauf folgende Absatz evoziert sogleich eine weitere Leerstelle, in die der Bericht des Vaters hineingedacht werden kann, bevor in Form der erlebten Rede der Protagonistin der 
Leser über das Geschehene (s. o.) aufgeklärt wird bzw. seine aufgrund des Bildes (Abb. 48) entstandenen Vermutungen bestätigt werden.

Es zeigt sich an dieser Stelle deutlich, dass für die Analyse eines Bilderbuchs und das Verständnis seiner Geschichte alle Darstellungsebenen, die verbale, die ikonische und die formale, in ihrem Wechselspiel wahrgenommen werden müssen und ihre Konnotationen nur auf dem Weg eines wechselnd-wandernden Blickpunktes zu erfassen und zusammenzubringen sind, was das Weitere noch bestätigen wird.

Die psychische Konstitution der Trauernden und die Problematik der Geschwistertrauer

Die Nachricht vom Tod der Schwester ruft bei der Protagonistin zunächst keine heftigen Reaktionen hervor, sondern eine eher ungläubige Verstummung, die sich auf der Bildebene im Gesichtsausdruck der vor einem Fenster im Bett Sitzenden ausdrückt. Dieses erste Einzelbild, das wie alle weiteren (teils über die Mittelfalz hinaus) das gesamte Blatt rahmenlos ausfüllt, fängt die in ihren Grundfesten erschütterte Lebenssituation mit der Darstellung ineinander verschobener Häuserfronten ein, die im Hintergrund durch das Fenster des Zimmers sichtbar sind. Bestätigt wird der Eindruck von Instabilität von der auf dem Weißgrund der gegenüberliegenden Textseite beigefügten Vignette eines kleinen Tischchens mit seinen schief stehenden Tischbeinen. Die in der geöffneten Schublade eingeklemmt wirkende Mondsichel korrespondiert ebenso wie eine zeigerlose Uhr mit der Mitteilung des verbalen Erzählers auf der nächsten Textseite: Sie lassen die Zeit stillstehen. Diese introspektive Kenntnis des Erzählers verleiht dem Versuch der Betroffenen Ausdruck, „den Tod, der in der Zeit passiert ist, zu verdrängen, indem man sich außerhalb der Zeit stellt, gegen die Zeit ankämpft“ (Goldbrunner 2000, 86). Auf der Bildebene wird die Schwierigkeit der Akzeptanz des Todes in der ersten Phase der Trauer mit einer Naheinstellung der sich in den Armen Liegenden eingefangen, der Vater mit geschlossenen, die Tochter mit schreckgeweiteten Augen. Die Platzierung dieser Darstellung gliedert den Text in einen Mama und Mara und einen Papa und Sonja betreffenden Teil und entspricht damit der räumlichen Trennung des Vater-Tochter-Paares von der im Krankenhaus liegenden Mutter und dem verstorbenen Kind.

Dass die Protagonistin als nächstes eine pragmatische Frage beschäftigt, zeugt ebenso davon, dass sie die volle Wucht des Verlusts emotional noch nicht erreicht hat: Was wird jetzt mit dem Stockbett werden? Sonja kann doch nicht allein im Stockbett schlafen. Es wird damit das nicht nur bei Kindern nachgewiesene Trauerverhalten angesprochen, das oft als mangelnde Trauerfähigkeit fehlgedeutet wird. Hinzu 
kommt im Fall des Geschwisterverlusts, dass das Kind „die trauernden Eltern nicht wie gewohnt als stabil und gefestigt [erlebt], sondern als aufgewühlt und hilfebedürftig" (Goldbrunner 2000, 89). Kinder brauchen in solchen Situationen aber schon allein deshalb besonders viel Liebe und Aufmerksamkeit, weil sie oft noch keine Worte für ihre Trauer haben und zusätzlich belastet werden, wenn ihnen die extreme Trauer der Eltern als Indiz für den besonderen Wert des verlorenen Kindes und den eigenen minderen Wert erscheinen muss. So auch hier, als die Mutter in Gegenwart Sonjas den Tod ihres Kindes beweint: »Sie hat noch ihr ganzes Leben vor sich gehabt. Sie war mein Sonnenschein. Es wäre besser gewesen, wenn ich gestorben wäre!« Wenn aber Mütter das Leben des verstorbenen Geschwisters über das eigene stellen, berauben sie die hinterbliebenen Geschwister der Sicherheit der mütterlichen Fürsorge und versetzen sie in eine existenzielle Notlage, die diese Kinder zu kompensieren versuchen, indem sie das eigene Leben, dessen Wert ebenfalls infrage gestellt ist, in die Waagschale werfen (vgl. Brocher 1980, 112f.). In Die Blumen der Engel äußert sich die Protagonistin explizit: „Es wäre besser, wenn ich gestorben wäre!" Die erschrockene Beteuerung der Eltern "Du weißt doch, wie lieb wir dich haben « kann nicht verhindern, dass Sonja auf einmal das Gefühl [hat], dass sie nicht mehr sprechen kann. Das in der Realität beobachtbare Verhalten von Eltern wird hier für kindliche Rezipienten in ähnlichen Situationen nachvollziehbar problematisiert und dessen Wirkung authentisch dargestellt. Bild- und Textebene spiegeln in wechselseitiger Ergänzung die plötzliche Isolation des Kindes, da es fast ausschließlich allein auftritt und seine Mimik und Gestik Verzweiflung ausdrücken (Abb. 49).

Abb. 49: Jutta Treiber; Maria Blazejovsky (2001): Die Blumen der Engel. Wien, München: Betz.

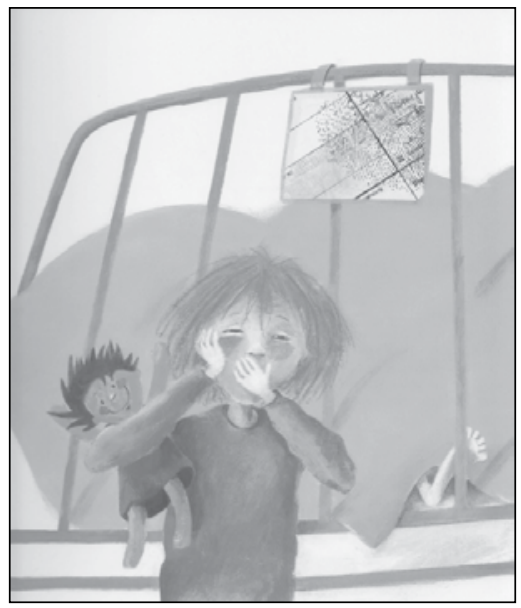


Das Geschwisterkind wird jedoch ganz selbstverständlich in die notwendigen Vorbereitungen für eine christliche Bestattungszeremonie einbezogen, deren Indizien - Leichenbestatter, Leichenhalle, Sarg, Kranzschleife und Pfarrer - den kindlichen Leser mit dem Procedere und dem dazugehörigen Vokabular vertraut machen. Die Perspektive, die der visuelle Erzähler mit der Szenerie in der Leichenhalle präsentiert, zeigt sich als über zahlreiche brennende Kerzen hinweg gerichteter Blick auf die Silhouetten von Vater, Tochter und Puppe Mara, ohne dass die aufgebahrte Verstorbene ins Bild gesetzt ist.

Abb. 50: Jutta Treiber; Maria Blazejovsky (2001): Die Blumen der Engel. Wien, München: Betz.

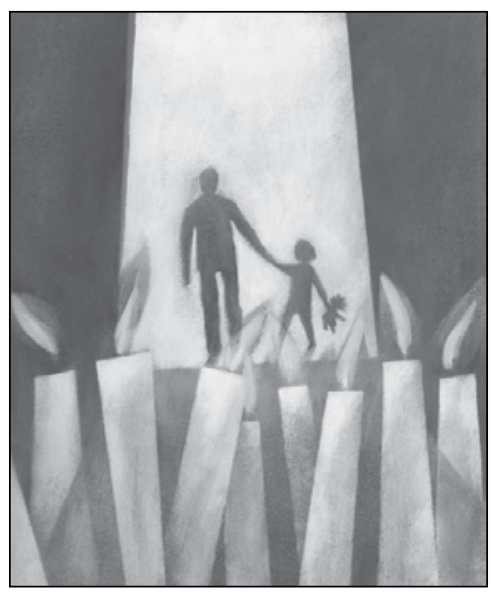

Diese Darstellung evoziert die Frage, wessen Blickrichtung hier gezeigt wird (Abb. 50). Die wahrscheinlichste Lesart dieses Vollbildes ist die, dass der visuelle Erzähler mit den die Hälfte der Bildfläche einnehmenden Kerzen die besondere Atmosphäre des Raumes und der Situation wiedergeben und gleichzeitig subtil auf die Aufgebahrte hinweisen will.

Während der anschließenden Auswahl des Sargschmuckes erschließt sich dann auch der Titel des Buches:

Sie suchen Blumen aus. Oma nimmt weiße Lilien. Weiße Lilien sind die Blumen der Engel, sagt Oma. [...] Sonja zeigt auf die weißen Rosen. Vielleicht sind das die Blumen der kleinen Engel. Papa und Mama wollen einen Kranz mit lauter Sonnenblumen.

In der selbst bestimmten Entscheidung für andere als die von der Oma und den Eltern ausgewählten Blumen drückt sich die Individualität der Trauer der verstummten Protagonistin aus. Es wird deutlich, dass ein gelingender Trauerprozess - wie sich später zeigt - auch der Teilhabe an kulturell-religiös 
konnotierten Ritualen bedarf. Gleichwohl erlebt die Protagonistin die eigentliche Begräbnissituation weiterhin stumm, was wiederum der Erfahrung aus der Praxis entspricht:

Selbst wenn sich Kinder bei der Ausführung von Ritualen äußerlich angepaßt verhalten, ist dies noch kein Zeichen dafür, daß dieser Rahmen als eine Gelegenheit zu intensiver Trauer genutzt werden kann. (Goldbrunner 2000, 91)

Die gesamte Tragweite ihres Verlusts erfasst die Schwester während der Trauerrede des Pfarrers, als dieser sagt: »Der einzige Trost ist, dass wir sie gehabt haben. Die Erinnerungen bleiben. Wir werden Mara nie vergessen. "Die nächste Doppelseite ist von zentraler Bedeutung für das Verständnis der innerpsychischen Vorgänge der Trauernden. Sie stellt nach Genette'schen Kategorien eine Pause im linearen Erzählfluss dar und ist ganz auf die Innenwelt der Protagonistin fokussiert. Dort kommt in erlebter Rede zum Ausdruck, dass der Tod der Schwester als existenzielle Bedrohung empfunden wird: Was für ein Leben soll das werden? Ohne Mara. In diesem Moment verliert die Protagonistin sichtbar den Kontakt zur realen Welt. Ihre ohnehin schon stumme Trauer umgibt sie nun wie ein geschlossener Glaskasten, aus dem sie nicht mehr herauskann. (Abb. 51) Der bildliche Erzähler setzt diese emotionale Ausnahmesituation wörtlich um und zeigt Sonja mit geschlossenen Augen wie in einem transparenten Block erstarrt, dem ein weißer Vogel, das Symbol für ihre Seele, gerade noch zu entkommen vermag. In kongenialer Weise greift dieses Bild die Semantik der Textebene auf: Fast so wie Mara im Sarg.

Abb. 51: Jutta Treiber; Maria Blazejovsky (2001): Die Blumen der Engel. Wien, München: Betz.

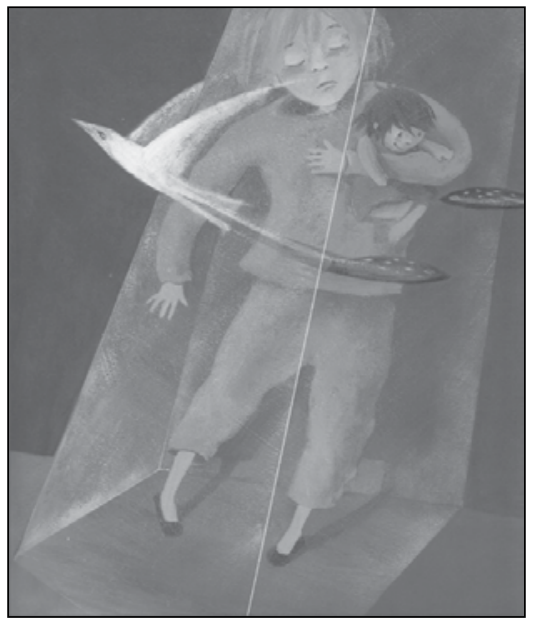


Im weiteren Verlauf der Beerdigungszeremonie bleibt Sonja, von den Erwachsenen fast unbemerkt, stumm und kann nicht weinen. Auch eine besorgte Frage der Freundin der Mutter erreicht sie nicht. Erst eine plötzlich auftretende Figur, die als alte Frau mit grauem Haar und faltigem Gesicht beschrieben wird, nimmt Einfluss auf die weitere Entwicklung des Trauerprozesses. Sie überreicht Sonja ein Päckchen mit einer Engelfigur, die dem Mädchen aber zunächst verborgen bleibt, weil es nicht dazu in der Lage ist, die Schachtel zu öffnen. Darin drückt sich das Unvermögen aus, den Trost, der aus dieser Begegnung hervorgehen wird, bereits in diesem Stadium des Trauerprozesses anzunehmen.

Wer diese Frau ist, bleibt ungeklärt. Zu entscheiden, ob sie als Engelwesen einer anderen Dimension oder als Anteil nehmende Fremde zu deuten ist, wird dem Betrachter des Bildes anheimgestellt, denn der Verbaltext gibt keinerlei Hinweise auf eine esoterische Konnotation. Wohl das Bild lässt diese Deutung aufgrund der am Rücken der Figur angedeuteten, filigran-durchscheinenden Flügel zu. Dem Bilderzähler steht hier offenbar ein vorausdeutendes Wissen zur Verfügung, das der Engelsgabe eine Trostfunktion beimisst, die dem verbalen Erzähler, der Stimme der Protagonistin, zu diesem Zeitpunkt nicht zugänglich ist, worauf weiter unten wieder eingegangen wird.

In der häuslichen Traueratmosphäre nach der Beerdigungszeremonie verschärft sich zunächst die Situation, denn die Eltern sind offenbar mit der eigenen Trauer ausgelastet und nehmen die nicht weniger tiefe Betroffenheit des hinterbliebenen Kindes nicht wahr. „In der Regel bekommen Eltern [wie auch hier; M.H.] Unterstützung von Verwandten, Freunden und Nachbarn, während die Bedürfnisse der hinterbliebenen Geschwister oft übersehen und vernachlässigt werden." (Gözütok et al. 2000, 52) Die Doppelbildseite visualisiert, formal durch den Einbezug der Mittelfalz betont, die Distanz zwischen den links in der totalen Ansicht fast identisch und dunkel dargestellten Gestalten der Erwachsenen und dem rechts allein am Tisch sitzenden Mädchen, dessen rote Haare den Blick auf sich lenken. Im Text heißt es entsprechend: Keiner kümmert sich um Sonja. Keiner merkt, dass Sonja nicht mehr sprechen kann. Keiner sieht, dass sie in einem Glaskasten ist, aus dem sie nicht mehr herauskann. Der Text rekurriert auf den vorher abgebildeten Glaskasten (Abb. 51), der symbolisiert, wie sehr sie die Trauer isoliert und gefangen hält. Dass sie in der Trauer offenbar nicht mehr sie selbst ist, verbildlicht metaphorisch der aus ihr herausgetretene Seelenvogel auf der Rückenlehne ihres Stuhles.

Erst als Sonja später den Ort der größtmöglichen erinnernden Nähe zur Schwester, Maras Bett, aufsucht, vollzieht sich ein Wandel im Trauerprozess. An die Phase der aufbrechenden Emotionen und vorwurfsvollen Ambivalenzen 
(Warum muss ich jetzt allein sein? Warum bist du nicht mehr bei mir?) schließt sogleich die Phase des Suchens und Findens an. Das in dieser Situation gelingende Öffnen des Holzkästchens bringt Sonja ihre Sprache zurück. Sie erkennt im Engel mit einem wunderschönen Gesicht ihre Schwester und kann nun endlich weinen. Es wird deutlich, dass die Trauer einen Ort und einen Anker für Erinnerungen braucht, um die verlorene Beziehung imaginär wieder aufnehmen zu können. Der geschenkte Engel ist dafür ein im Wortsinn greifbares Symbol, das die Vorstellung stützt, die Seele der Verstorbenen sei in den Himmel geflogen. Diese Konkretisierung stellt eine Entlastung dar und befreit die Protagonistin aus der Trauerstarre, sodass es ihr möglich ist, die Eltern an ihrer Form des Trauerns um die verlorene Schwester teilhaben zu lassen.

Der Weg, den sie wählt, führt sie an dem von der ersten Buchseite bekannten, nun wieder standfesten Tischchen vorbei ins Wohnzimmer und ist auf der Bildebene perspektivisch und farblich kongenial inszeniert: Es geht aufwärts ins Licht (Abb. 52). Auch die Uhr trägt wieder Zeiger und der Mond ist durch eine außen an der Schublade hängende Sonne ersetzt worden, womit der Wechsel vom Dunkel der Trauer zum Hellen einer positiven Lebenshaltung und der neuen Bezogenheit zum Leben und zu den Eltern bildhaft ausgedrückt wird. Im Text heißt es:

Dann geht sie ins Wohnzimmer, wo die anderen noch sind.

Sie setzt die Puppe Mara auf Mamas Schoß.

"Schaut, was ich bekommen habe", sagt sie und stellt das Holzkästchen offen auf den Tisch.

Abb. 52: Jutta Treiber; Maria Blazejovsky (2001): Die Blumen der Engel. Wien, München: Betz.

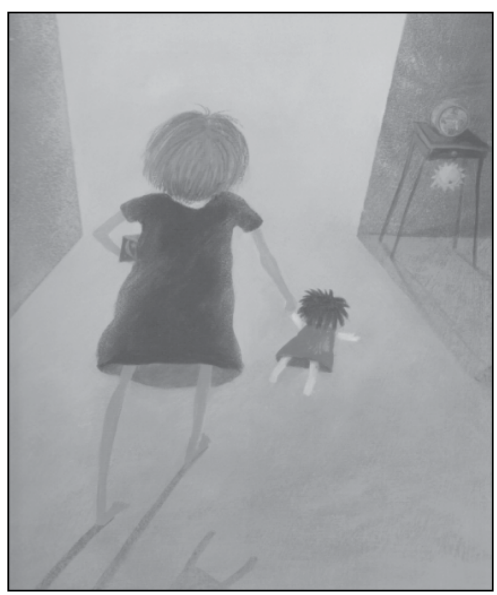


Sonja scheint mithilfe der Puppe ihre Beziehung zur Mutter zu erneuern, denn als Trauergegenstand und Objekt der Erinnerung kommt dieser quasi vererbten Puppe der Verstorbenen eine zentrale Funktion zu. Sie ist auf allen Bildern zu sehen, meist im Arm der Protagonistin, und von herausragender Bedeutung für die oben beschriebene neue Hinwendung zum Leben. Denn das Überlassen der Puppe steht stellvertretend für Sonjas Angebot, ihre Trauer mit den Eltern zu teilen. Bemerkenswert ist, dass nicht die Eltern auf die Tochter zugehen, sondern das Kind seinen eigenen Weg finden muss, um mit der Situation fertigzuwerden. Dass ihr dabei das geheimnisvolle Geschenk der Engelfigur hilft, ist im übertragenden Sinne ein sie von außen erreichender Trost, der in kleinen Gesten, kurzen Begegnungen und eben symbolträchtigen Erinnerungsgegenständen liegen kann.

Das letzte Bild füllt die entstandene Leerstelle, in der die Frage nach der Reaktion der Eltern liegt, indem es in warmen Farben parallel zum Text das für eine Trauerverarbeitung einzig Heilende ins Bild setzt: liebevolle Zuwendung, Verständnis und Sicherheit in den Armen der Eltern (Abb. 53).

Gelingt es den Familienmitgliedern, [wie hier; M.H.] ein gewisses Maß an gegenseitigem Verständnis und Unterstützung im Prozeß des Trauerns zu entwickeln, ohne die Verschiedenheit der individuellen Verarbeitung zu leugnen, ist dies ein positives Anzeichen für die weitere Differenzierung der familiären Beziehungen in Richtung Bezogenheit und Individuation. (Goldbrunner 2000, 91f.)

Abb. 53: Jutta Treiber; Maria Blazejovsky (2001): Die Blumen der Engel. Wien, München: Betz.

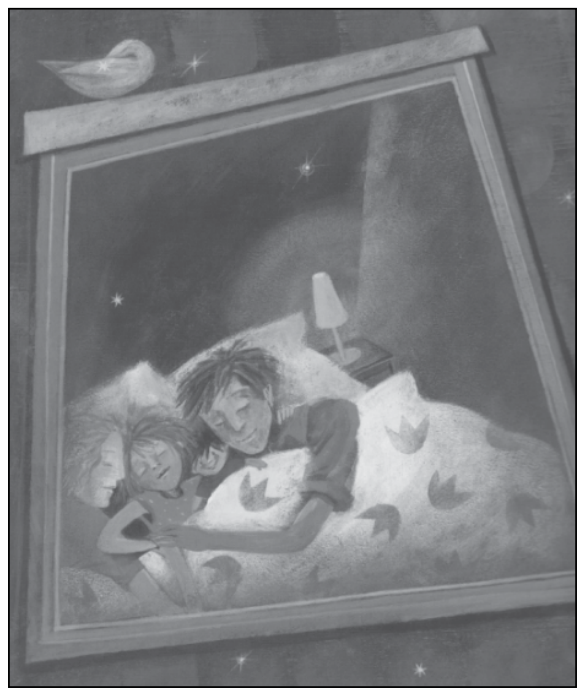


Da dies keine Sache von kurzer Frist sein kann, ist in Anbetracht der erzählten Zeit von wenigen Tagen mit dem Ende des Erzählens nicht auch von einem Abschluss der Trauerarbeit auszugehen, unbedingt aber von einer gelingenden Fortsetzung, für die ein Wechsel zwischen Phasen des Suchens und Findens und einem erneuerten Weltbezug denkbar ist.

\section{Todeskonzept, Jenseitsvorstellungen und Trostbilder}

Wie bereits angesprochen, ist die Dimension der Kausalität mit dem Geschehensmoment des Unfalls bereits abgedeckt. Zudem hat die Protagonistin ihrem Alter durchaus entsprechend offenbar keinen Zweifel an der Irreversibilität des Todes und der damit einhergehenden Nonfunktionalität, was sich am Ausbleiben entsprechender Rückfragen festmachen lässt. Der trauernden Schwester wird ganz selbstverständlich die allgemein im Bilderbuch (und in der Realität) seltene Gelegenheit zum Abschiednehmen in der Leichenhalle ermöglicht, wovon der verbale Erzähler unprätentiös berichtet: Mara liegt in einer hellbraunen Holzkiste. Mara schaut friedlich aus, als würde sie schlafen. Am liebsten würde Sonja zu ihr sagen: Steh auf Mara, du kannst doch nicht den ganzen Tag schlafen. An dieser Stelle drängt sich die Frage nach dem weiteren Verbleib der Schwester auf. Als Antwort auf diese Leerstelle bietet das vor dem nachfolgenden Text eingeschobene Bild eine Verwandlung in ein Engelwesen an, dessen Aussehen dem der verstorbenen Schwester entspricht und als Vorstellungsbild der Protagonistin gewertet werden kann (Abb. 54).

Abb. 54: Jutta Treiber; Maria Blazejovsky (2001): Die Blumen der Engel. Wien, München: Betz.

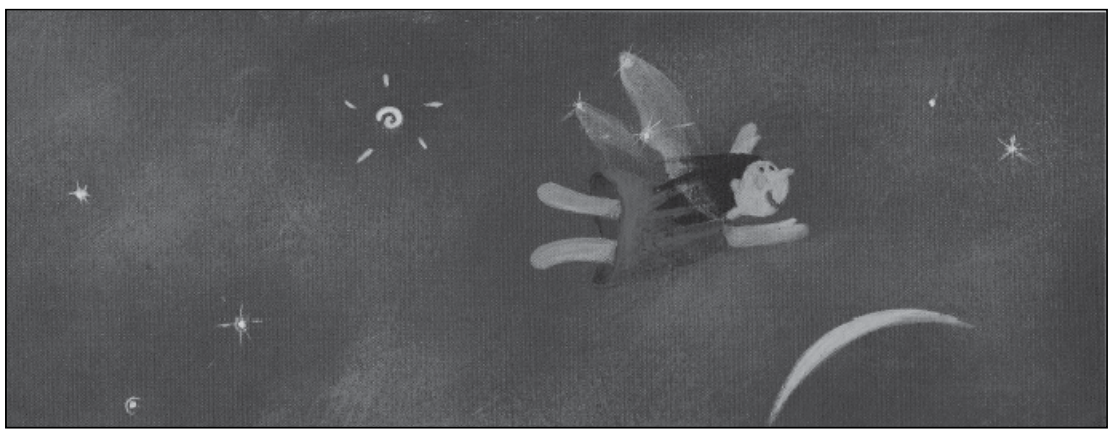

Der vom Vater auf der Textebene angesprochene Himmel als Aufenthaltsort der Seele der Verstorbenen ruft bei der hinterbliebenen Schwester dagegen Verwirrung hervor. Kinder dieser Altersgruppe haben üblicherweise weder ein 
metaphorisches Verständnis ausgeprägt noch können sie Glaubensvorstellungen nachvollziehen. Ihr Weltverständnis ist realitätsverhaftet, sie suchen nach nachvollziehbaren Erklärungen, weshalb sich der Protagonistin die Frage stellt: Fliegt die Seele aus dem Körper heraus, wenn jemand stirbt? Mit der Entscheidung für eine Visualisierung des nachtodlichen Zustandes in Gestalt eines Engels (s. o.) ist eine für die Phantasie der Kinder nachvollziehbare Form gefunden worden. Der christliche Auferstehungsglaube spielt jedoch trotz des entsprechend ausgerichteten Begräbnisses keine Rolle, worin sich der - auch in der Realität nachweisbare - Schwund von gefestigten Glaubensüberzeugungen zeigt.

\section{Gesamtbeurteilung}

Mit diesem Bilderbuch liegt eine authentische Problematisierung der unterschiedlichen Trauer von Erwachsenen und Kindern nach dem Verlust eines Geschwisterkindes vor, die auf erwachsener wie kindlicher Ebene emotionale Identifikationsprozesse anstoßen kann und in dialogischen Rezeptionssituationen aufgearbeitet werden sollte. Obwohl ambivalente Gefühle, wie sie in Geschwisterbeziehungen häufig vorkommen (vgl. Gözütok et al., 52), ausgeblendet werden, ebenso wie konkrete Bilder von der Toten oder vom Herablassen des Sarges, kann das Bilderbuch wichtige Impulse für eine Trauerarbeit geben. Denn es geht darin um die Notwendigkeit einer gelingenden verbalen und nonverbalen Kommunikation als Aufgaben eines jeden Einzelnen in einer Trauergemeinschaft, in der gerade die Erwachsenen sich der Gefühle betroffener Geschwisterkinder bewusst sein sollten. Der Konzeption der Protagonistin dieser Geschichte ist ein Beispielcharakter inhärent, der vorführt, dass und wie Geschwisterkinder trauern, dass sie auch eigene Trauerarbeit zu leisten vermögen, in jedem Fall aber dabei unterstützt und begleitet werden müssen.

\section{VII.2.3 Trauernde Eltern}

Dem üblicherweise kindlichen Adressatenkreis entsprechend ist erwachsene Trauer im Bilderbuch ein selten gewähltes Erzählmotiv. Wie einschneidend der Verlust eines Kindes für Eltern ist, thematisieren insgesamt nur sieben Bilderbücher ${ }^{255}$, wovon lediglich Luca und der Schmetterling (Herrmann/ Bahde 2007) die Trauer der Eltern ins Zentrum stellt (s. u.). Eine mehr begleitende Funktion

255 Ruß/ Broska 2009: Himmelskind; Sturm/ Hillen 2008: Justus ist traurig; Herrmann/ Bahde 2007: Luca und der Schmetterling; Jianghong 2005: Der Tigerprinz; Simon/ Selle 2003: Der geborgte Stern; Treiber/ Blazejovsky 2001: Die Blumen der Engel; Ellermann 1992: Der rote Faden. 
kommt den Eltern in den Geschichten zu, die die Problematik eines trauernden Geschwisterkindes thematisieren und deutlich machen, welchen Einfluss das Elternverhalten auf eine gelingende Trauerverarbeitung hat, worauf im vorstehenden Kapitel bereits eingegangen wurde. ${ }^{256}$

Das älteste der in diesem Teilkorpus erfassten Bilderbücher (Ellermann 1992: Der rote Faden) nähert sich noch sehr verhalten dem Thema Tod und vermeidet Emotionalität, indem spielende Kinder sich Gedanken über die Ursache des frühen Todes eines unbekannten neunjährigen Mädchens machen, dessen Grab sie zufällig auf einem Friedhof entdecken. Der Tigerprinz von Chen Jianghong (2005) ist dagegen eine phantastische Geschichte über eine ihre getöteten Jungen betrauernde Tigermutter, deren Hass auf die schuldigen Menschen durch die Besonnenheit eines Königssohns besänftigt wird.

In mehrfacher Hinsicht hebt sich das Bilderbuch Luca und der Schmetterling (Herrmann/ Bahde 2007) vom übrigen Textkorpus ab. Der autodiegetische Erzähler, der sowohl sprachlich als auch auf der Bildebene identifizierbar ist, ist ein kindliches Ich, das von seinem glücklichen Leben mit seinen Eltern und seinem plötzlichen Unfalltod erzählt.

Abb. 55: Sabine Herrmann; Jo Bahde (2007): Luca und der Schmetterling. Gütersloh: Gütersloher Verlagshaus.

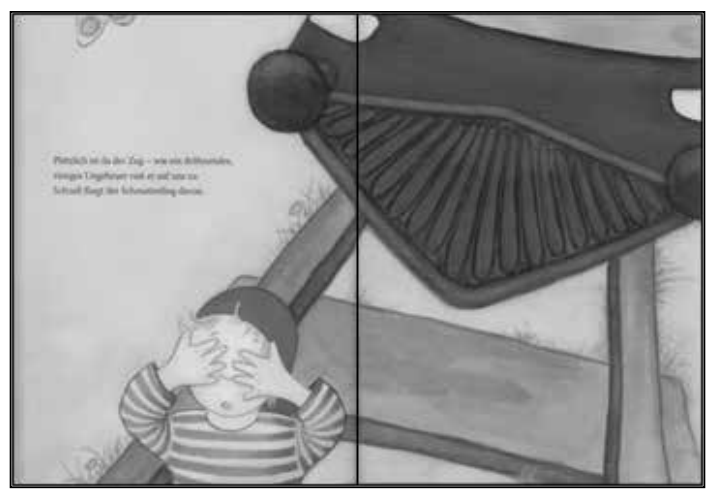

Der Leser ist aufgrund der Erzählperspektive und des durchweg im Präsens verfassten Textes so nah am Protagonisten und seinem Erleben wie nur irgend möglich. Die Unmittelbarkeit der tödlichen Bedrohung erfasst den Betrachter der

256 Ruß/ Broska 2009: Himmelskind; Sturm/ Hillen 2008: Justus ist traurig; Treiber/ Blazejovsky 2001: Die Blumen der Engel. 
Bildebene in Gestalt des die Hälfte der Bildseite einnehmenden Zuges (Abb. 55), wandelt sich aber auf der folgenden Seite sogleich in ein entlastendes Szenario vom Moment des Todes, der vom Ich-Erzähler selbst verbalisiert und offenbar nicht negativ empfunden wird: Ich kann nicht fliegen ... Alles um mich herum wird ganz hell. Die folgenden Szenen zeigen den trotz des Unfalls unversehrten Jungen, wie er von einem zarten Engel in den Himmel begleitet wird, [d]ahin, wo das warme Licht wohnt und das Zusammensein mit dem Engel nichts als ein großer Spaß zu sein scheint.

Abb. 56: Sabine Herrmann; Jo Bahde (2007): Luca und der Schmetterling.

Gütersloh: Gütersloher Verlagshaus.

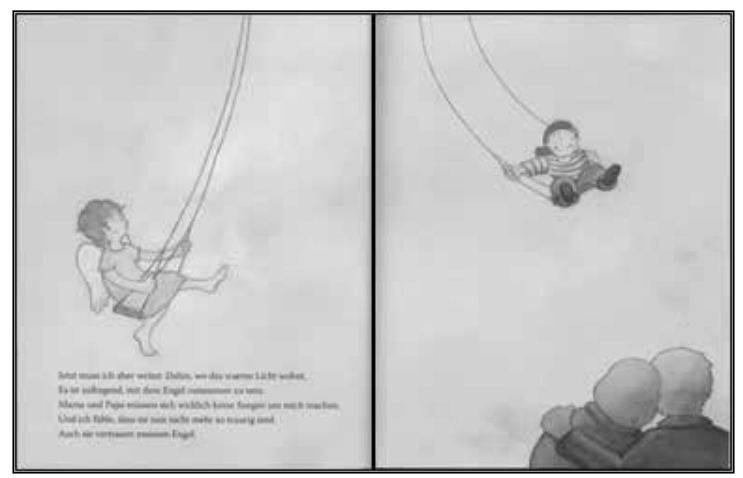

Sprach- und Bildebene vermitteln den Eindruck eines kaum zu übertreffenden Glückszustandes, mit dessen Darstellung ein verklärendes, erwachsenes Wunschdenken auf einen kindlichen Protagonisten in nachtodlicher Existenz projiziert ist (Abb. 56). Wie schon oben zu Die Königin und ich (Weigelt/ Haas 2011) beschrieben, geht auch hier das kindliche Bewusstsein des eigenen Todes mit einem Verantwortungsgefühl für die hinterbliebenen Eltern einher: Mama und Papa müssen sich wirklich keine Sorgen um mich machen. Bild und Text sprechen von einer Fürsorge für die hinterbliebenen Eltern, zu denen der Protagonist in der Sprache der Herzen spricht, die nichts anderes als die Sprache der Erinnerung ist und die Vorstellung von einem Weiterleben suggeriert, einen schnellen Trost inbegriffen. „Und niemals werden wir unsere Kinder vergessen: Aus der Erinnerung schöpfen wir die Kraft und Gewissheit, sie weiterhin in unseren Herzen zu tragen." (Herrmann/ Bahde 2007) ${ }^{257}$ Von der dunklen Seite der

257 Nachwort von Petra Hohn, Trauerbegleiterin und 1. Vorsitzende Bundesverband Verwaiste Eltern in Deutschland e.V. 
Trauer gibt es keine Spur und allzu deutlich wird dem Betrachter nahegelegt, an einen schmerzlosen Tod und eine fröhliche Weiterexistenz zu glauben. Ausgewiesene Adressaten sind damit hinterbliebene Eltern und auch, wie im Paratext ausdrücklich angesprochen, kindliche Trauernde wie Geschwister oder Freunde. Da aber Formen emotional belasteter Trauerreaktionen keine Rolle spielen, klingt darin eine Einstellung an, die Trauer als gesellschaftlich unerwünscht einstuft und sie zum Bereich der lebensbehindernden, möglichst rasch zu überwindenden Ausnahmezustände zählt.

\section{VII.3 Der gewaltsame Kindertod}

Eine ganz offensichtlich und nachvollziehbar vernachlässigte Kategorie des literarischen Todes im Bilderbuch ist der absichtsvoll oder billigend herbeigeführte Kindertod durch Krieg und Gewalt. Die Gründe für die Vermeidung des Themas sind wohl einerseits auf bewahrpädagogische Absichten wie andererseits auf die Schwierigkeiten einer dem kindlichen Verständnis angemessenen literarischen Umsetzung zurückzuführen. Das recherchierte Korpusmaterial weist insgesamt acht Bilderbücher dieser Kategorie auf, deren Motivik sich wie folgt verteilt: Kindermord $^{258}$, Krieg und Flucht in die Fremde ${ }^{259}$, die Geschichte Anne Franks ${ }^{260}$, ein weiteres Schicksal im Kontext des Holocaust ${ }^{261}$ sowie drei Bilderbücher über das real-authentische Schicksal Sadako Sasakis ${ }^{262}$, die infolge des Atombombenabwurfs über Hiroshima an Leukämie erkrankte und starb. Dass in diesem spezifischen Kontext die im Vorangegangenen zugrunde gelegten Analysekriterien modifiziert werden müssen, liegt auf der Hand, insbesondere auch deshalb, weil bis auf eine Ausnahme (Herzog 2009) alle Bilderbücher faktuale Hintergründe haben. Das Bilderbuch über den Kindermord (Krol/ Kunstreich 2005) ist zudem Gegenstand einer Einzelfallanalyse, da es auf allen Darstellungsebenen eine besondere Herausforderung darstellt.

258 Krol/Kunstreich 2005: Kevin Kanin oder Als es dunkel wurde am Lohewald.

259 Herzog/Clante 2009: Flieger am Himmel.

260 Cohen-Janca/Quarello 2011: Annes Baum; Poole/Barrett 2005: Anne Frank.

261 Innocenti/Gallaz 1986: Rosa Weiss.

262 Loske 2011: Sadakos Kraniche; Coerr/Young 1995: Sadako; Ellermann 1990: Papiervogel, flieg! 


\section{VII.3.1 Mord: Kevin Kanin oder Als es dunkel wurde am Lohewald (Dagmar Krol, Pieter Kunstreich 2005)}

Das einzige recherchierte Bilderbuch zum Mord an einem Kind (Abb. 57) ist in der anthropomorphisierten Welt einer Kaninchenkolonie angesiedelt, deren Mitglieder alle Phasen des Schreckens, der Hoffnung und der Verzweiflung nach dem Verschwinden eines Kaninchenjungen und der Trauer nach dem Auffinden der Leiche durchleben müssen. Die notwendige Distanz zum Geschehen gewährleistet die Konzeption als Tiergeschichte, was umso dringlicher ist, als das Erzählte einen realen Hintergrund hat. Schon der Titelzusatz verweist darauf und impliziert zugleich Anlass und Anliegen der Erzählung: Eine Geschichte für die Kinder von Hipstedt. Im Vorwort nimmt die Autorin darauf Bezug:

„Die meisten von euch kennen ihn natürlich nicht, den Lohewald. Aber einige von euch kennen ihn doch, auch wenn er hier anders heißt. Und sie kennen auch die Kanins, denn das sind sie selbst! Sie kannten sogar Kevin Kanin, denn "Kevin Kanin «, das war Felix, ihr Freund und Klassenkamerad. Felix ging in dem kleinen Dorf Hipstedt zur Schule, das von großen Wäldern umgeben ist und in dem jeder jeden kennt. Kein Baum war ihm zu hoch und kein Loch zu tief. [...] Wo er war, da war immer etwas los. Den Kindern wurde nie langweilig in seiner Nähe. Aber eines Tages war er von einem Moment auf den nächsten spurlos verschwunden, und er kam nicht zurück." (Ebd., Vorwort; H. i. O.)

Abb. 57: Dagmar Krol; Pieter Kunstreich (2005): Kevin Kanin oder Als es dunkel wurde am Lohewald. Stuttgart: Kreuz.

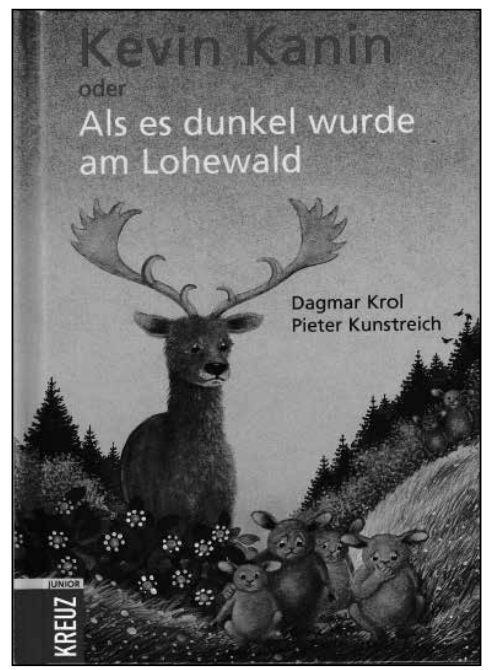


Dagmar Krol, Lehrerin des ermordeten Felix, verfasste diese Geschichte als Hilfe für die zutiefst verunsicherten und entsetzten Schulkameraden, um „diesen starken Gefühlen vorsichtig Worte zu verleihen, Antworten zu geben und Trost anzubieten“ (Krol 2005, Nachwort). Im Vorwort richtet sie sich ausdrücklich an die Kinder, denen „eine sehr traurige“, zugleich „aber auch eine schöne Geschichte“ angekündigt wird, „denn die Kinder von Hipstedt weinen nicht mehr, wenn sie von Felix erzählen. Sie haben zur Freude zurück gefunden." (Krol 2005, Vorwort) Dass und wie nach einer traumatischen Erfahrung eine neue Zuwendung zum Leben gelingen kann - gelungen ist, zeigt dieses Bilderbuch überzeugend auf. Es ist dabei weder eine Mahngeschichte noch ein nach Aufmerksamkeit heischender Sensationsbericht, sondern die literarische Bearbeitung einer realen, belastenden Erfahrung und der gelungenen Überwindung des psychischen Ausnahmezustandes. Die im Vorwort vorweggenommenen Informationen über das Verbrechen und seine emotionale Verarbeitung stellen eine entlastende Notwendigkeit angesichts der Tragik des Erzählten dar. Das Nachwort richtet sich an die vorlesenden Erwachsenen, derer die kindlichen Rezipienten unbedingt bedürfen, berichtet von den Umständen rund um die Entstehung des Buches und verweist darauf, dass Literatur offenbar hilfreich sein kann ${ }^{263}$ :

Unser Entsetzen kannte keine Grenzen, unsere Trauer schrie zum Himmel, und das Bedürfnis zu reden war größer denn je. Plötzlich war klar: Diese Geschichte wurde gebraucht, jetzt sofort, denn Hilfe tat Not. Und sie half. (Krol 2005, Nachwort)

In welchem funktionalen Zusammenhang Sprachästhetik und Bildästhetik stehen und welche Ikonotexte daraus generiert werden können, wird die Analyse im Weiteren zeigen.

\section{VII.3.1.1 Erzählerische Vermittlung und Diskurs}

Auf den 27, meist doppelt bebilderten Seiten ist der relativ umfangreiche Sprachtext im Flattersatz mehrheitlich in die Bilder integriert und zielt mit der typographischen Gestaltung in 12p Schriftgröße und einem nicht immer ausreichenden Kontrast zum farbigen Hintergrund eindeutig auf den versierten erwachsenen Vorleser. Ebenso erfordern Semantik und Syntax aufgrund der bildreichen Wortwahl, der Verwendung zahlreicher Adjektive und adverbialer

263 Demnach scheint an dieser Stelle der Begriff, Lebenshilfe im Sinne einer der Funktionen von Literatur treffend zu sein, obwohl er aufgrund seiner kritisch diskutierten Konnotation in Fachkreisen nicht mehr gebräuchlich ist. 
Konstruktionen ein sensibles dialogisches Vorlesegeschehen, das unbedingt die ausdrucksstarken Bilder aufgreifen sollte.

Dass hier unzweifelhaft die reale Autorin respektive Lehrerin der Kinder als erinnernde Erzählerin der ins Fiktionale verlegten Geschehnisse auftritt und Autorenrede (die Worte der Lehrerin) und Erzählerrede an den Stellen zusammenfallen, die in wörtlicher Rede als direkte Leseransprache verfasst und keinem figuralen Sprecher zugeordnet sind, weist ebenfalls auf einen erhöhten Anspruch an Rezeptionskompetenzen hin. Dabei sind sowohl die Kinder von Hipstedt als auch alle anderen Betroffenen ganz explizit angesprochen und aufgefordert, auf dem Weg der Imagination Erlebtes wiederholend zu verarbeiten, wenn es z. B. heißt: Kannst du dir vorstellen, wie eigenartig es war, als plötzlich alle Kanin-Kinder still und bedrückt in ihren Höhlen saßen? Wer sich davon angesprochen fühlt, wird zu einem miterlebenden Teil der Gemeinschaft. Als weitere Spezifik, die wahrzunehmen durch Kursivdruck erleichtert wird, sind die Wechsel von der auktorialen Erzählerrede zu den Stimmen der Kanin-Kinder hervorzuheben, deren emotionale Konstitutionen als erlebte Rede oder Gedankenrede wiedergegeben werden. Gleichzeitig markieren diese typographischen Zäsuren auch dramaturgisch bedeutende Entwicklungen. So lautet der Text nach wochenlanger, hoffnungsvoller, aber vergeblicher Suche: Er konnte doch nicht verschwunden bleiben? War etwas Fürchterliches geschehen? Warum schwiegen die Großen und bekamen feuchte Augen? (Kursiv i. O.) Nach einiger Zeit wurden Angst und Traurigkeit weniger und die Kanin-Kinder sagten sich: Eines Tages kommen wir darüber hinweg. Ganz egal, wie es jetzt ist, es bleibt nicht so, es bleibt nicht so! (Kursiv i. O.) Bis sie schließlich grausame Gewissheit erhalten: Er kommt nicht zurück? Niemals? Das kann doch nicht sein? (Kursiv i. O.) Der innere Monolog drückt die verzweifelte Ungläubigkeit der Betroffenen aus und legt diese Fragen gleichsam dem miterlebenden Rezipienten in den Mund.

Der naturalistische, in Farb- und Formgebung detailgetreue, malerische Bildstil mit verniedlichten Figuren und teils freundlichem Szenario scheint auf den ersten Blick den Ansprüchen des Mainstream an kindgemäße Bildgestaltung zu genügen, zeigt aber mit surrealistisch anmutenden Bildern, auf die noch einzugehen sein wird, und einem insgesamt authentischen Stil eine darüber hinausgehende Qualität.

\section{VII.3.1.2 Die Ebene der Geschichte}

\section{Die Figuren}

Während die übrigen Tiere des Waldes in ihrer naturgemäßen Physiognomie dargestellt sind, sind die Kanins possierlich-niedliche Wesen mit orangefarbenem 
Fell, deren Anthropomorphisierung im Zeichen ihrer Anlage als Sympathieträger und Identifikationsobjekte steht und sich über die aufrechte Körperhaltung und ihre Mimik ausdrückt. Die Identifikationsmöglichkeiten verteilen sich, ohne einzelne Charaktere hervorzuheben, auf die Gesamtheit der zunächst glücklichen, dann ratlosen, verzweifelten und trauernden Gemeinschaft der Kaninchenkolonie. Im Zentrum stehen die Darstellung und Überwindung des kollektiven Entsetzens, das individueller Perspektiven nicht bedarf. Einzig die Mutter des vermissten Jungen, der als aufgewecktes Kind voller Lebensfreude beschrieben ist, wird als Einzelperson erwähnt, ohne dass auf ihren Gemütszustand eingegangen wird: Mutter Lina wartete und wartete. "Er ist so stark und so schlau«, sagte sie. "Er kommt wieder." Dass selbst eine solcherart ausgeprägte Konstitution des Jungen ihn nicht zu verschonen vermochte, verschärft die Bedrohlichkeit des Geschehens (nicht nur) für Kinder zusätzlich, denn zur Angst um den vermissten Schulfreund kommt der Verlust der Unbeschwertheit, verbunden mit der Angst um das eigene Wohl. In dieser Krisensituation finden die Kanins Halt und Kraft und einen neuen Lebensbezug in ihrer uneingeschränkten Solidargemeinschaft.

\section{Kommunikation und Interaktion}

Das Reden mit Kindern über ein Verbrechen und seine Folgen ist ein besonders schwieriges und deshalb oft vermiedenes Unterfangen, wie es auch in diesem Bilderbuch an der Stelle anklingt, als es heißt: Warum schwiegen die Großen und bekamen feuchte Augen? (Kursiv i. O.) Insgesamt wird aber deutlich, dass Kommunikation und Liebe die Schlüsselwörter dieser Gemeinschaft sind und das Einzige, was erfolgreich der Angst und der Verzweiflung entgegenwirken kann. Das Gemeinschaftserleben zeigt sich in zahlreichen gemeinsamen Aktionen, wie z. B. der Beteiligung an der Suche nach dem Vermissten, den von Hoffnung getragenen Versammlungen und dem gemeinsamen Singen und Beten. In einer solchen Ausnahmesituation bleibt für die Erwachsenen wie für die Kinder ganz offensichtlich nur der Weg der kommunikativen Verarbeitung des Unfassbaren, wobei davon ausgegangen werden kann, dass dabei die Aufarbeitung des Geschehens in pädagogischen Zusammenhängen eine wesentliche Rolle spielt.

\section{Todeskonzepte, Jenseitsvorstellungen und Trauerprozess}

Die Todesumstände bleiben unerwähnt, was einerseits Spekulationen Raum gibt, andererseits aber die grausamen Tatsachen ausspart und gleich auf das Wesentliche verweist: Es geht um die Überwindung des Verlustschmerzes. Alle Phasen eines vollständigen, gelingenden Trauerprozesses lassen sich nachvollziehen: 
Das Nichtwahrhaben-Wollen nach den langen Wochen der Hoffnung, Wut, Schmerz und verzweifelte Hilflosigkeit angesichts der unumkehrbaren Wirklichkeit, das Trostfinden im Erinnern gemeinsamer Erlebnisse und die neue Zuwendung zum Leben im neuen Spiel.

Die Reaktionen der betroffenen Kinder auf die Todesnachricht weisen auf das altersgemäße Todesverständnis der Sieben- bis Neunjährigen hinsichtlich Nonfunktionalität, Irreversibilität und auch Universalität hin. Den Jüngeren werden sich diese Dimensionen spätestens mit der zugemuteten Erfahrung und ihrer pädagogischen Aufarbeitung erschlossen haben. Und dass sich die Relevanz dieser Erfahrung für das eigene Leben hier in kindlicher Angst äußert, ist nur konsequent im Sinne der Authentizität.

Eine Antwort auf das Warum des Todes kann dagegen nicht dem Verweis auf die Kausalität als Dimension des kognitiven Todesverständnisses gegeben werden. Die Sinnfrage verbietet sich hier, weshalb die einfache Erwiderung auf die Frage, was Gott dazu zu sagen habe, auch zugleich die einzig tröstliche ist:

Die Antwort war Liebe: "Gott weint. Und macht die Arme weit auf. Kevin Kanin braucht seinen Körper nicht mehr. Er lebt nun in Gottes heller Welt. Aber nicht nur dort. Er lebt auch in euren Herzen."

Die Kombination von christlicher Glaubenslehre und Erinnerungspraxis manifestiert sich in dem Angebot, sich Kevin Kanin ohne seinen geschundenen Körper bei Gott und gleichzeitig in liebevoller Erinnerung lebendig vorzustellen, und wirkt damit im Kontext dieses Verbrechens besonders entlastend. Wohltuend offen bleibt die Vorstellung eines Bei-Gott-Seins, das für die Kinder von Hipstedt aus der Perspektive ihrer Lehrerin offenbar eine Kraftquelle war. Viel mehr noch scheint allerdings das Erinnern an gemeinsame Erlebnisse mit dem toten Spielgefährten zu helfen. Die Kanin-Kinder erinnern seine Streiche und ziehen den Schluss: Ja, genau, das war Kevin Kanin! Er lebt nicht mehr und lebt doch! [...] Aber das Bedrohliche, das Böse? (Kursiv i. O.) Die Antwort ist wieder Liebe. Jemand hatte von der Liebe gesprochen, hatte gesagt, habt keine Angst, hatte versprochen, das Dunkle siegt nicht. Ins Bild gesetzt sind eine neue Fröhlichkeit der spielenden Kanin-Kinder und die in ihre Mitte gestellte Gegenwärtigkeit des toten Spielgefährten als imaginär-durchscheinende Figur. Und sie trugen Kevin Kanin in ihren Herzen. Im Ikonotext geben Bild- und Sprachebene einem lebensbejahenden Neuanfang Ausdruck.

\section{Ikonotexte}

Die beiden narrativ-ästhetischen Ebenen Bild und Sprache sind durchgängig parallel angeordnet. Das stellenweise auszumachende Pathos auf der Sprachebene 
ist dabei der Erzählwirkung und ihrer Authentizität mehr zu- als abträglich und wird von den Bildern aufgegriffen, ohne zu überziehen. Bild und Sprache gehen eine ausdruckstarke Allianz ein, die die ohnehin hohe sprachliche Emotionalität noch erhöht, wofür neben den Bildmotiven vor allem die Farbgebung ausschlaggebend ist. So steht das Blau-Schwarze des Bildes von der bis in die Nacht erfolglosen Suchaktion für die nächtlichen Lichtverhältnisse ebenso, wie das Dunkle nichts Gutes vermuten lässt.

Abb. 58: Dagmar Krol; Pieter Kunstreich (2005): Kevin Kanin oder Als es dunkel wurde am Lohewald. Stuttgart: Kreuz.

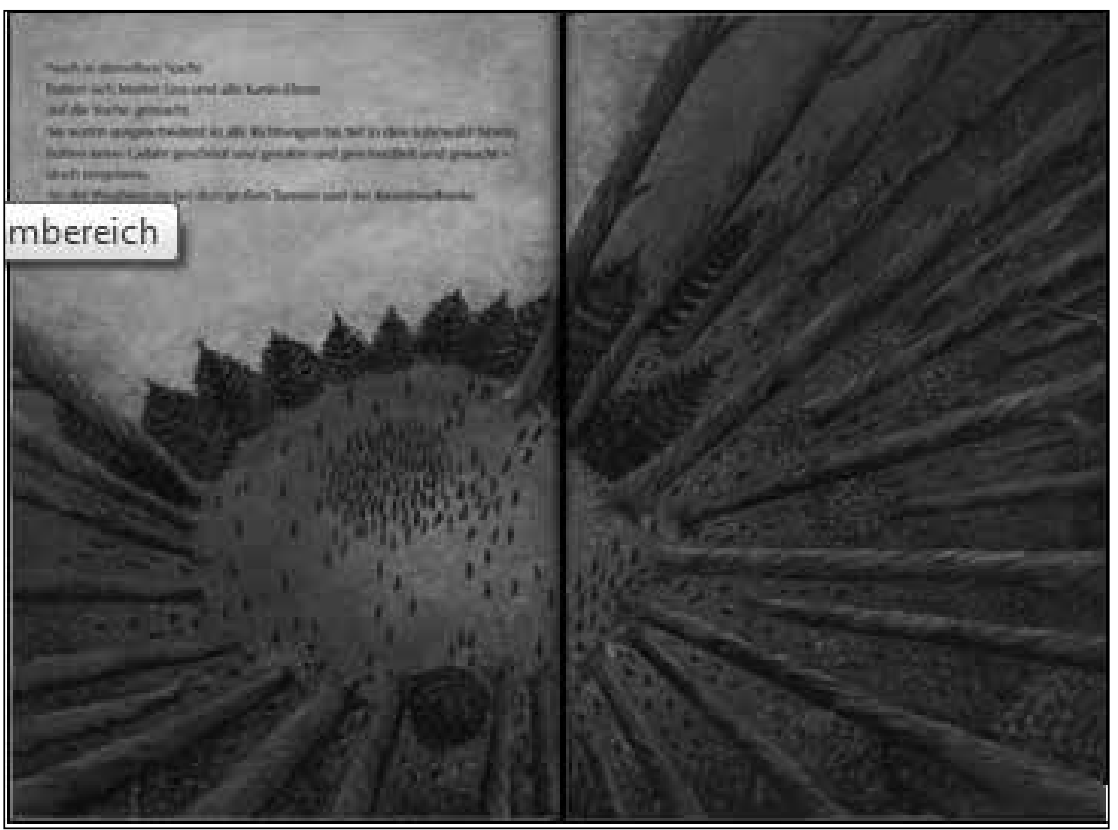

Die Vogelperspektive der Bildkonzeption evoziert dabei eine visuelle Sogwirkung in dieses Dunkel, indem der Blick aus den bedrohlichen Höhen der Bäume des Lohewaldes hinab auf eine Lichtung und die aus allen Richtungen zusammenströmenden Kanins zentriert wird (Abb. 58). Der Text formuliert dazu die traurige Nachricht. Die nachfolgenden zwei Seiten wirken dagegen, der noch bestehenden Hoffnung gemäß, mit ihrer wieder taghellen Gestaltung entlastend, obwohl der Text von wachsender Angst und Unsicherheit kündet. Der Wechsel von freundlich-farbiger zu düsterer Farbgestaltung spiegelt mehrfach deutlich das Schwanken zwischen Hoffnung und Verzweiflung. Das Düstere machte sich 
immer breiter in den Herzen und die Kälte nahm zu, trotz der Sonne am Himmel. Ein Bild, das diese Stimmung unmittelbar spiegelt, zeigt einen grauen, weiten Himmel über dem schmalen, dunklen Streifen des Lohewaldes, der sich vor den Augen des Betrachters über ein flaches Feld hinweg in der Ferne am Horizont ausbreitet. Dem suchenden Blick wird kein freundlicher Ruhepunkt geboten, kein Indiz lässt auf eine positive Wendung hoffen, die Zeit scheint still zu stehen.

Einen Vorwurf an die Adresse der Medien richtet eine Doppelseite, von deren Rändern aus sich sieben schwarze Krähenköpfe mit ihren spitzen, geöffneten Schnäbeln beängstigend begierig auf den Text richten (Abb. 59).

Abb. 59: Dagmar Krol; Pieter Kunstreich (2005): Kevin Kanin oder Als es dunkel wurde am Lohewald. Stuttgart: Kreuz.

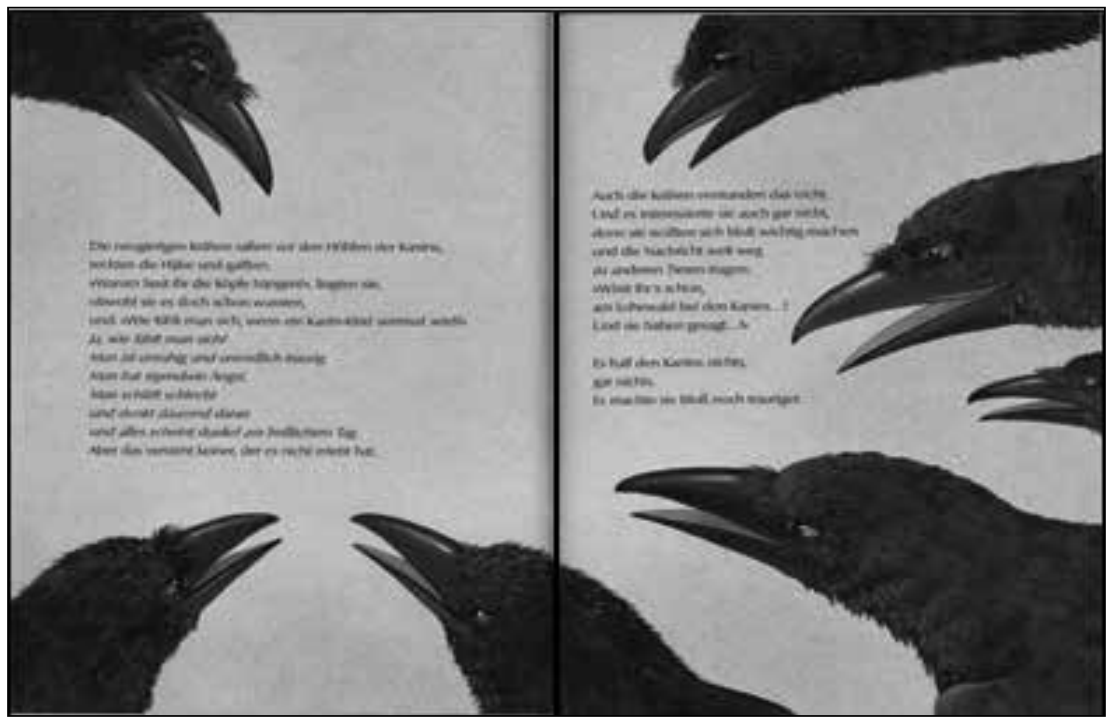

Das offensichtlich unsensible und gaffende öffentliche Interesse ist in Gestalt der neugierigen Vögel, die sich mit ihren quälenden und bedrängenden Fragen bloß wichtig machen und die Nachricht weit weg zu anderen Tieren tragen wollen, als zusätzliche Belastung ästhetisch eindrucksvoll umgesetzt (Abb. 59). Der Text resümiert: Es half den Kanins nichts, gar nichts. Es machte sie bloß noch trauriger.

An anderer Stelle ist eine übergroße, nie gekannte, dunkle Riesenangst als riesige Kugel dargestellt, die mehr als drei Viertel des Doppelbildes verdunkelt und die schreckensvoll davor zurückweichenden Kanins unweigerlich zu überrollen droht (Abb. 60). Doch hier ist mehr als die Angst ins Bild gesetzt. Der 
aufmerksame Betrachter wird die feinen Spritzer und winzigen orangenen Details an der Stelle zwischen Boden und Kugel als den Moment eines brutalen Zermalmens zu deuten wissen und den Tod Kevin Kanins antizipieren.

Abb. 60: Dagmar Krol; Pieter Kunstreich (2005): Kevin Kanin oder Als es dunkel wurde am Lohewald. Stuttgart: Kreuz.

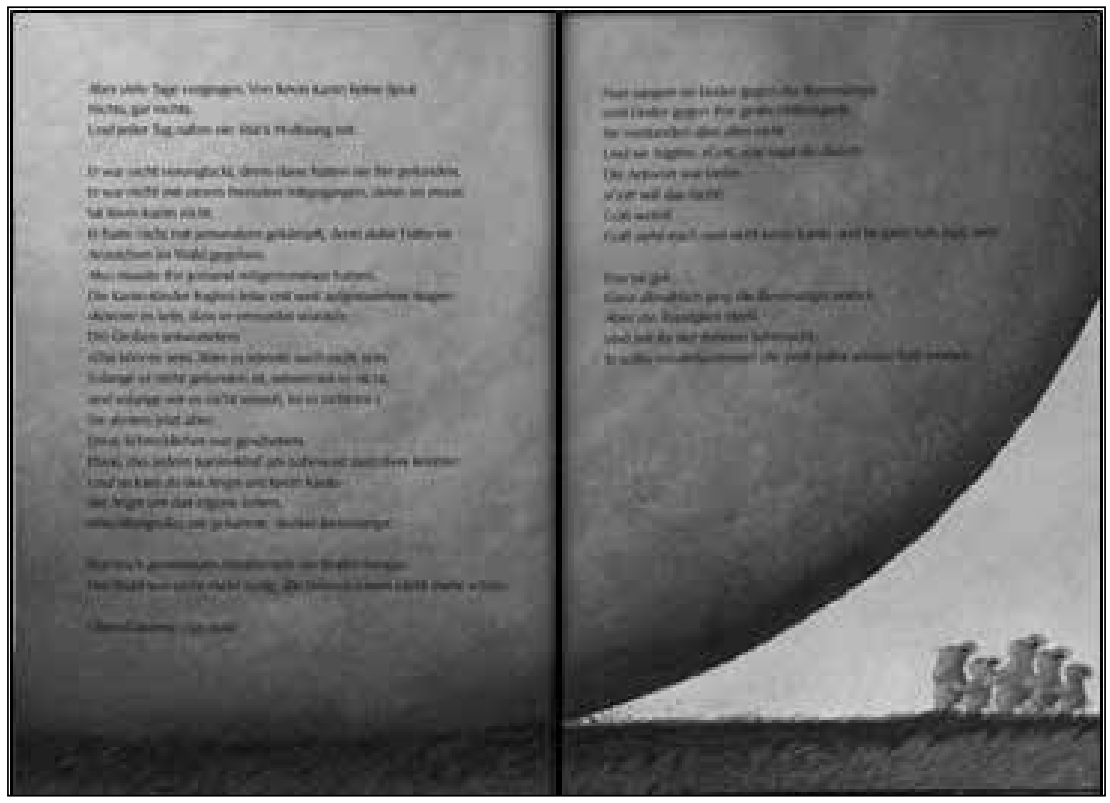

Zunächst aber setzen die Kanins dem Gefühl von Machtlosigkeit und Ausgeliefertsein noch etwas entgegen: Lieder gegen die Riesenangst und Lieder gegen die große Hilflosigkeit. Und sie rufen Gott klagend an: »Gott, was sagst du dazu? « Die Antwort war Liebe: "Gott will das nicht! [...] Gott sieht euch und sieht Kevin Kanin und ist ganz nah. Egal, wo!« Daraus scheint Trost zu erwachsen, der zwar den Verlust nicht vergessen macht, der aber langsam wieder an ein normales Leben denken lässt. Die Stimmungsaufhellung spiegelt sich auf der folgenden Doppelseite in freundlicheren Farben und einer dem frohen Treiben der ersten Seiten des Buches nachempfundenen Szenerie, wenngleich Mimik und Körperhaltung weiterhin bedrückt wirken. Doch bereits mit den nächsten Bildern bewahrheiten sich die schlimmsten Befürchtungen. 
Abb. 61: Dagmar Krol; Pieter Kunstreich (2005): Kevin Kanin oder Als es dunkel wurde am Lohewald. Stuttgart: Kreuz.

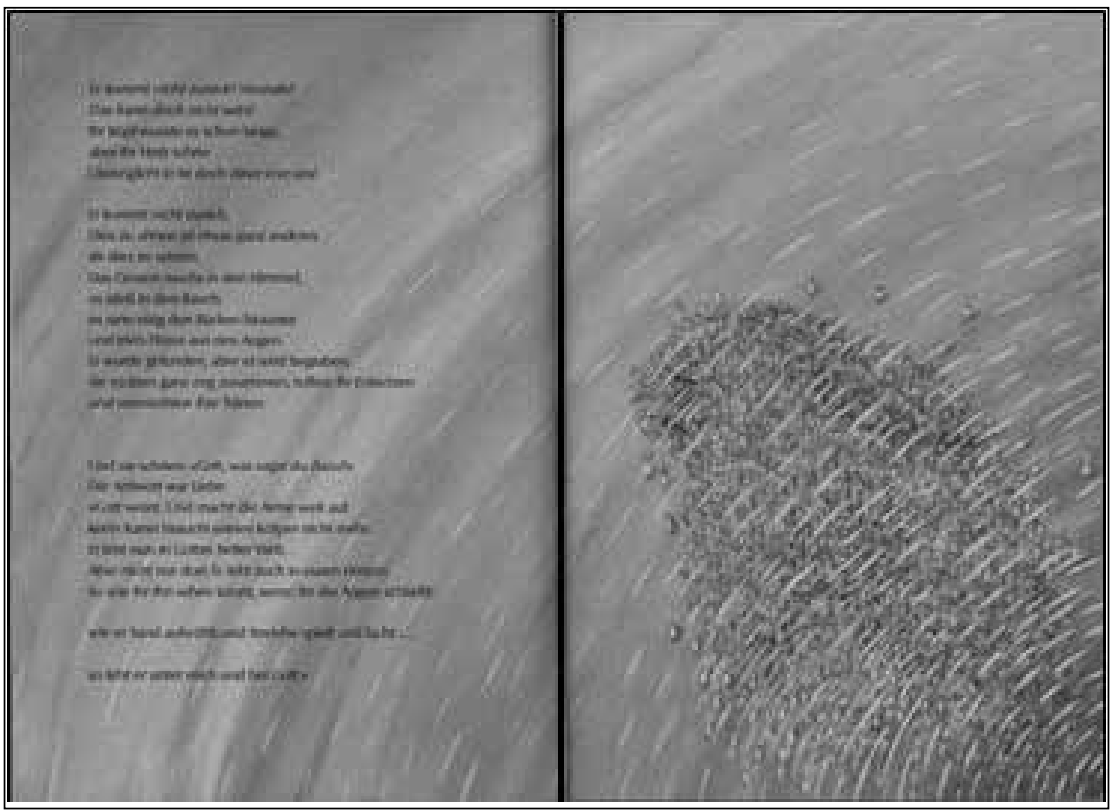

Der Betrachter sieht sich in das unwetterartige Szenario einer Tränenflut versetzt, die die sich aneinanderdrängenden Kanins wie den zugehörigen Text wegzuschwemmen droht (Abb. 61).

Er kommt nicht zurück. Dies zu ahnen ist etwas ganz anderes als dies zu wissen. Das Grauen wuchs in den Himmel, es stieß in den Bauch, es rann eisig den Rücken hinunter und trieb Flüsse aus den Augen. Er wurde gefunden, aber er wird begraben. Sie rückten ganz eng zusammen, teilten ihr Entsetzen und vermischten ihre Tränen.

Der Ikonotext ersteht aus der komplementären Wirkung von metaphorischer Sprache und expressiver Bildgestaltung, wobei auch hier die Vogelperspektive mehr Empathie evoziert, als dass sie der Distanzschaffung dient. Text und Bild sind eins.

\section{Abschließende Bewertung}

Mit der außerordentlich dichten, metaphorischen Textgestaltung von Dagmar Krol und den eindrucksvollen Bildern von Peter Kunstreich ist dieses Bilderbuch zu den Werken zu zählen, die der Emotionalität psychischer Ausnahmezu- 
stände und der positiven Wirkmacht einer intakten sozialen Gemeinschaft auf eine kunstvolle Weise Ausdruck verleihen, der man sich kaum entziehen kann. Da die Exponiertheit des Werkes sowohl aus der Sonderstellung des Themas als auch seiner literarästhetischen Qualität erwächst, kann dieses Bilderbuch ebenso einen Beitrag zur „Bildung der Gefühle“ (Mattenklott 1997) leisten, wie es tröstend wirken kann. ${ }^{264}$

\section{VII.3.2 Krieg und Holocaust als Ursache für Kindersterben}

Die sieben Bilderbücher über kindliche Opfer kriegerisch-gewaltsamer Auseinandersetzungen stellen den Tod von Kindern in zeitgeschichtliche Zusammenhänge und sind damit Sachbücher oder befinden sich zumindest an der Schwelle zum Sachbuch, wobei insbesondere in den Bilderbüchern zum Atombombenabwurf über Hiroshima der historische Bezug teilweise hinter die Ausgestaltung des Sterbeprozesses zurücktritt. Emotional nahegehende Darstellungen verbinden dabei historisches Geschehen mit der Erkenntnis dessen, was Krieg und menschenverachtende Gewalt für jeden Einzelnen bedeuten: Leid und Trauer.

Der Fokus der nachfolgenden Analysen ist insgesamt auf die literarästhetischen Konzepte hinsichtlich der Darstellungen des Sterbens bzw. des Todes und der Trauer gerichtet, weshalb sich auch dem Themenschwerpunkt Holocaust, der „im Rahmen der allgemeinen geschichtserzählenden KJL inzwischen eine eigenständige Gattung darstellt“ (Oeste 2011,7), mit einem thanatologisch ausgerichteten Erkenntnisinteresse genähert wird, ohne auf die spezifischen Aspekte des Erzählens vom Holocaust einzugehen.

\section{VII.3.2.1 Figuren und Geschehen}

In diesem Teilkorpus fallen zwei Hauptmotive zusammen: der Tod eines Kindes und das am individuellen Einzelschicksal „inszenierend erinnerte Menschheitsverbrechen“" (Thielking 1997, 57). In dem Bilderbuch Flieger am Himmel (Herzog/ Clante 2009) ${ }^{265}$, das vom Krieg im nicht näher benannten Heimatland der jungen Protagonistin und seinen Folgen für ihr Leben erzählt, kommt als weiteres Motiv das des Fremdseins als Asylant hinzu (Abb. 62).

264 S. dazu auch den Beitrag von Dagmar Krol in: Eselsohr H.7/2006, S. 9.

265 Im Folgenden wird auf die Wiederholung der bibliographischen Kurzangaben zu den Primärtexten nach der ersten Nennung verzichtet und nur noch der Titel angegeben. 
Abb. 62: Annette Herzog; Katrine Clante (2009): Flieger am Himmel. Wuppertal: Hammer.

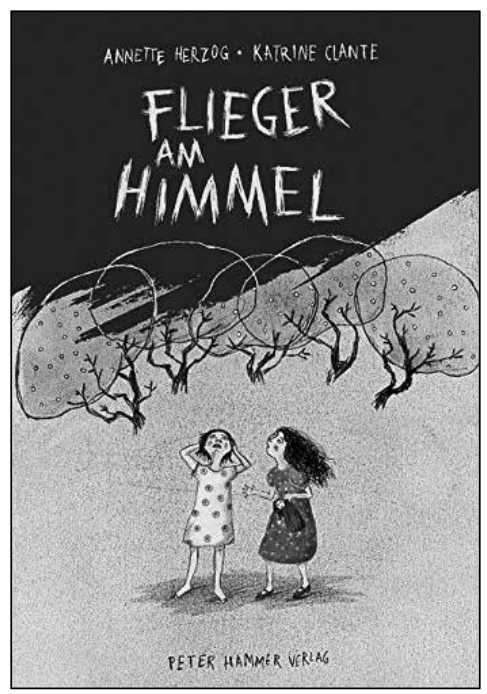

Dieses Fremdsein, das in der Anonymität eines Hochhauses und dem Fehlen von Spielkameraden zum Ausdruck kommt, wiegt umso schwerer, da die autodiegetische Erzählerin um ihre tote Freundin trauert, die bei einem Bombenangriff ums Leben kam. In ihren Albträumen wiederholt und verarbeitet sie die traumatische Erfahrung und findet in ihrem Bruder einen Helfer gegen das Alleinsein: Er faltet mit ihr Papierflieger, die sie, mit ihrer Adresse und einer Nachricht versehen, vom Balkon aus in die Gärten fremder, spielender Kindern abwerfen. Das offene Ende ist ein hoffnungsträchtiges, denn einige Flieger erreichen ihre Adressaten.

Ganz anderes erzählen die Bilderbücher, deren zentrale Figuren zu den bekanntesten Opfern des Zweiten Weltkrieges zählen: Anne Frank, deren Tagebuch die Welt kennt und deren Tod für die Gräuel des Holocaust steht, worauf weiter unten eingegangen wird, und Sadako Sasaki, die im Alter von 12 Jahren, 10 Jahre nach dem Atombombenangriff auf Hiroshima am 6. August 1945, an Leukämie verstarb. Ihre Statue steht heute im Friedenspark von Hiroshima und gemahnt an den Frieden, zu dessen Symbol die Origami-Kraniche wurden, die Sadako während ihres Krankenhausaufenthaltes faltete - im festen Glauben an eine japanische Legende, nach der derjenige, der 1000 Origami-Kraniche faltet, von den Göttern einen Wunsch erfüllt bekommen sollte. Es ist ihr nicht 
gelungen. ${ }^{266}$ Aus unterschiedlichen Perspektiven erinnern drei Bilderbücher an das Schicksal dieses Mädchens und das tausender weiterer Opfer der Atombombe. In Papiervogel, flieg! (Ellermann 1990) erzählt ein älterer Herr einer Gruppe von mit Papierfliegern spielenden Kindern vom Geschehen am 6. August 1945 und dazu die Geschichte Sadakos (Abb. 63).

Abb. 63: Heike Ellermann (1990): Papiervogel, flieg! Freiburg i. Br.: Herder.

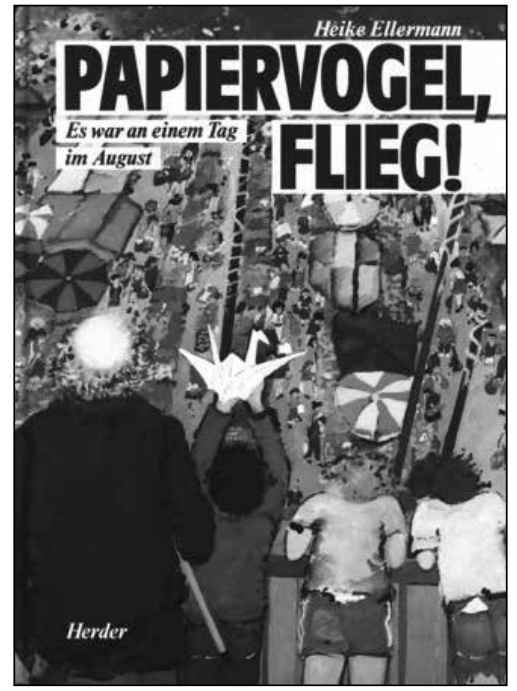

Das Wachhalten der Erinnerung an die Opfer der Atombombe als Mahnung und Aufforderung zu einem friedlichen Miteinander manifestiert sich in diesem Bilderbuch im freundlichen Aufeinanderzugehen der Generationen und dem bereitwilligen, mitfühlenden Verstehen der Kinder als generationsverbindendes Unterfangen.

Mit Sadako (Coerr/ Young 1995) liegt die Bilderbuchadaption (Abb. 64) des Kinderromans Sadako und die tausend Papierkraniche (Coerr 1986) vor.

266 Die weltweite Verbreitung und Anteilnahme, die die Geschichte Sadakos erfuhr, stilisierte die Origami-Kraniche, Symbol der Unsterblichkeit und Hoffnung in der japanischen Mythologie, zum Symbol der internationalen Friedensbewegung und des Widerstands gegen Atomwaffen. Tausende Kraniche werden alljährlich am 6 . August zur Statue im Friedenspark von Hiroshima gesandt, die Sadako mit einem stilisierten Kranich in ihren hoch erhobenen Händen zeigt. 
Abb. 64: Eleanor Coerr; Ed Young (1995): Sadako. Berlin: Altberliner Verlag.

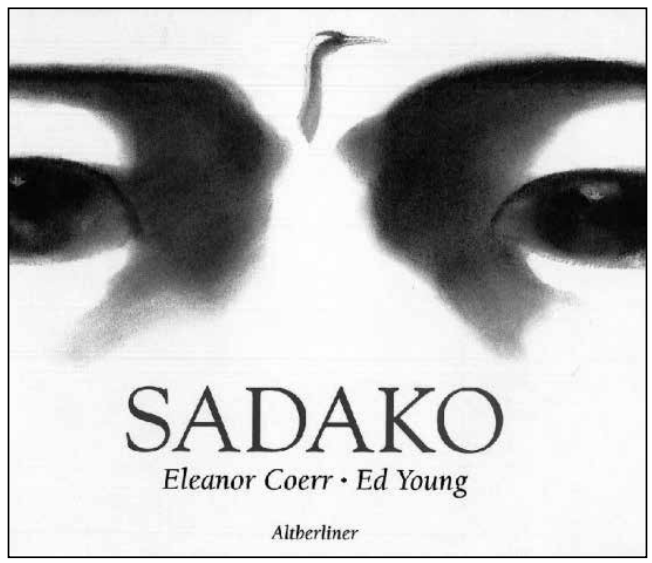

Sadako ist ein überaus sportliches und lebensfrohes Mädchen, als der Ausbruch der Leukämie ihr Leben und das ihrer Familie verändert. Das Erzählen setzt kurz vor der Erkrankung ein und führt den Leser immer näher heran an die emotionalen Wechselbäder von Leiden und Zuversicht. Sadako, die auch nach dem Tod des neunjährigen, ebenfalls an der Atombomben-Krankheit (ebd.) leidenden Kenji die Hoffnung auf Genesung nicht aufgibt, faltet unverdrossen Papierkraniche und verstirbt schließlich, im Gegensatz zu ihrem Freund ungebrochen und geborgen im Kreise ihrer Familie.

Auch das Bilderbuch Sadakos Kraniche (Loske 2011) will die Erinnerung wachhalten, indem der diegetische Erzähler in Gestalt des anthropomorphen Katers der Protagonistin die Aufgabe übernimmt, Sadakos Geschichte hinaus in die Welt zu tragen. Er erzählt von den unbeschwerten Spielen mit der Freundin bis zu dem Moment, als die riesige schwarze Wolke kam, und von der Angst um seine zehn Jahre später erkrankte, Kraniche faltende Freundin. An ihrem Krankenbett träumt sich der Kater in eine unbeschwerte Zukunft:

Wir werden durch den Park spazieren und im April den Kirschbäumen beim Blühen zusehen./ [...]/ Dann werden wir auf dem Rücken eines riesigen Drachens zurück nach Hause kommen. / Doch Sadako kam nicht wieder zurück.

Das Buch entlässt den Leser mit einem Blick auf den nach eigenem Bekunden von der Gewissheit getrösteten Kater, die Erinnerung an Sadako in seinem Herzen zu tragen.

Auch das Erzählen vom Holocaust ist an einem konkreten Kinderschicksal in dem Bilderbuch Anne Frank (Poole/ Barrett 2005) festgemacht (Abb. 65). Darin 
werden das Leben der Familie Frank, das zunehmende Schikanieren der jüdischen Bevölkerung unter dem Nazi-Regime, das Untertauchen der Familie und die Ängste, Träume und Hoffnungen der jugendlichen Anne bis zur Deportation nachgezeichnet.

Abb. 65: Josephine Poole; Angela Barrett (2005): Anne Frank. Würzburg: Arena.

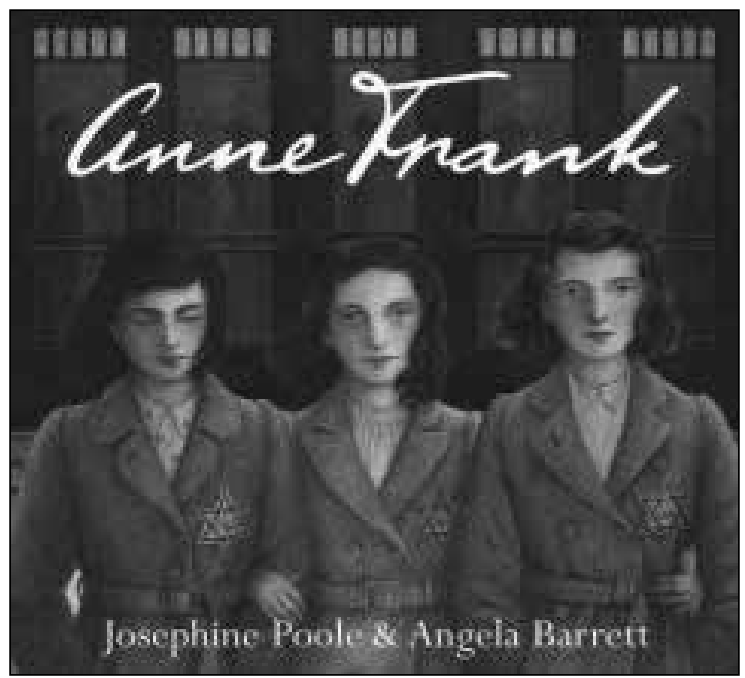

Mit ergänzenden Erläuterungen und einer Zeittafel macht das Sachbilderbuch auch einem jüngeren Publikum zugänglich, was Das Tagebuch der Anne Frank bereits millionenfach erzählt hat.

Auf sehr viel poetischere Weise nähert sich Annes Baum (Cohen-Janca/ Quarello 2011) der Geschichte Anne Franks und bindet sie ein in die metaphorischen Zusammenhänge vom Vergehen und Neuwerden in der Natur (Abb. 66). 
Abb. 66: Irène Cohen-Janca; Maurizio A. C. Quarello (2011): Annes Baum. Hildesheim: Gerstenberg.

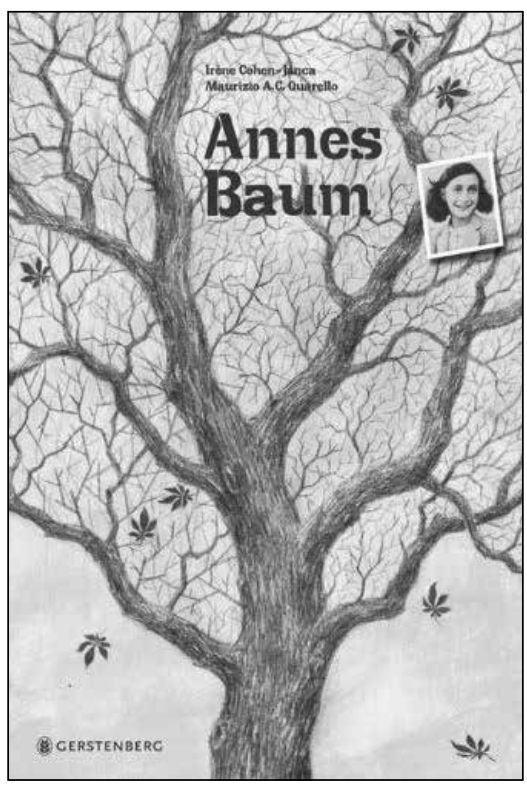

Als Erzählerinstanz tritt der 150-jährige Kastanienbaum auf, der im Hinterhof der Prinsengracht 263 in Amsterdam stand ${ }^{267}$, dem ehemaligen Versteck der Familie Frank, und der für Anne mit seinem jahreszeitlich wechselnden Aussehen die Verbindung zum Leben und das Hoffnung spendende Symbol für beständiges Verändern und Erneuern war. Die Stimme des Baumes ist die eines Zeitzeugen, der so unaufgeregt wie eindringlich von den Anfängen des Faschismus, der um sich greifenden judenfeindlichen Realität der NS-Zeit, der Verschleppung der Familie und dem Tod im Konzentrationslager berichtet. Das Anliegen dieses literarischen Ichs, selbst ein sterbendes Wesen, ist das bewahrende Gedenken, das nach dem erwarteten Tod auf einen Ableger des Baumes übergehen möge (s. w. u. Abb. 70).

267 Der Kastanienbaum stürzte im Sommer 2010 nach einem schweren Sturm um. An seiner Stelle wächst jetzt ein Ableger. (Hinweis auf dem hinteren Vorsatzblatt des Buches). 
Abb. 67: Roberto Innocenti; Christophe Gallaz (1986): Rosa Weiss. Frankfurt a. M.: Ali-Baba.

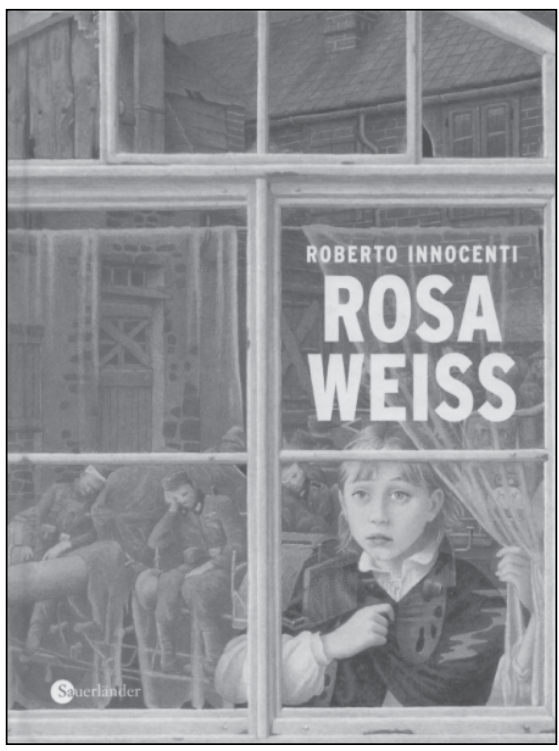

Mit Rosa Weiss (Abb. 67) von Roberto Innocenti (1986) wird schließlich eine Geschichte zur Holocaust-Thematik präsentiert, deren Heldin „zu dem von der Kinder- und Jugendliteratur favorisierten Typ des subversiven Kindes/Mädchens [gehört], für das es wohl keine Entsprechung gab" (Thielking 1997, 55).

Das etwa neunjährige Mädchen aus bürgerlich-behüteten Verhältnissen wird in ihrem hakenkreuzgeschmückten Heimatort Zeugin der Verschleppung eines jüdischen Jungen. Es folgt dem Lastwagen bis vor den Zaun eines Konzentrationslagers und sieht sich dort einer Gruppe hungernder, mit leeren Gesichtern starrender Häftlinge gegenüber (s. w. u. Abb. 72). Rosa fragt nicht und versteht nicht, aber sie reagiert auf die einzige ihr mögliche Weise: Sie versorgt die Hungernden heimlich mit ihren Schulbroten und anderen Vorräten, bis sie gegen Ende des Krieges das Konzentrationslager zerstört vorfindet: Ganz still stand sie da. [...] Plötzlich fiel ein Schuss. Das Ende ist offen, aber hoffnungslos, denn die sprachlichen und ikonischen Indizien sprechen für sich: Die Mutter von Rosa Weiss wartete lange auf ihre Tochter, während der beginnende Frühling die Szenerie mit frischem Grün bedeckt und dem Vergessen anheimstellt (s. Abb. 73). 


\section{VII.3.2.2 Sprach-und Bildebene und ihre Ikonotexte}

\section{VII.3.2.2.1 Sprachebene}

Auffällig sind die mehrheitlich das kollektive, kulturelle Gedächtnis ansprechenden Paratexte: Widmungen (Sadako ${ }^{268}$, Annes Baum ${ }^{269}$, Sadakos Kraniche), Vorworte (Anne Frank) oder Nachworte (Papiervogel, flieg!, Sadakos Kraniche), mit denen zur Erinnerung aufgerufen bzw. die über das Einzelschicksal hinausgehende Bedeutung des Erzählten hervorgehoben wird. Eine Ausnahme ist die Widmung zu Sadakos Kraniche, die nicht inhalts-, sondern autorbezogen ${ }^{270}$ ist. Alle anderen Paratexte bieten entweder historische Zusatzinformationen oder verweisen auf eine wirkungsästhetische Dimension. Mit dem Nachwort in Papiervogel, flieg! geht Jens Thiele (1990a) auf die verbreitete Skepsis gegenüber Bilderbüchern ein, die „etwas aus den Schreckenstagen der Weltgeschichte“ erzählen, und betont die Notwendigkeit und Berechtigung, ,,engagierte Bilderbücher jenseits von Fantasie, Traum und Idylle zu produzieren“ (ebd.). Alle genannten Bilderbücher kommen diesem Anspruch nach, mit unterschiedlich hohem und komplexem Sprachanteil und Bildern, die die Intensität des Erzählten noch steigern.

\section{VII.3.2.2.2 Erzählperspektive und Komplexität des Erzählens}

In Anne Frank sind die unbeteiligte Sachlichkeit des nichtdiegetischen Erzählers und der relativ umfangreiche, informative Sprachtext Indizien für die Subgattung Sachbuch. Annes Baum ist dagegen trotz des Informationsgehalts ein phantastisches Bilderbuch, welches auch mit dem geringeren Sprachtextanteil sowohl dramaturgisch als auch sprach- und bildästhetisch sehr viel komplexer angelegt ist und sich deutlich an den nicht mehr ganz jungen kindlichen Rezipienten bzw. vorlesenden Erwachsenen richtet. Es setzt Kenntnisse voraus, die Kindern beim dialogischen Vorlesen erst vermittelt werden müssen. Das Auftreten des Kastanienbaumes als diegetischer Erzähler, Analepsen und Prolepsen, die zahlreichen Leerstellen sowie die eingefügten Zitate aus dem Tagebuch der Anne Frank, mit denen Anne selbst als intradiegetisch-autodiegetische Stimme zu Wort kommt, erfordern ein hohes Maß an Texterschließungskompetenz und auch historisches Wissen, um globale Textkohärenz herstellen zu können. Die originäre (Tagebuch-) Stimme Annes, die von der Hoffnung spricht, dass sich alles wieder zum Guten

268 Für die Kinder von Hiroshima.

269 In Erinnerung an Ilan Halimi [...] So wie Anne war Ilan nur schuld, Jude zu sein. So wie Anne konnte er nicht die Früchte tragen, die er verhieß.

270 Für Thomas und für meine Kater verweist auf den privaten Hintergrund des Werkes, das als Diplomarbeit entstanden ist. 
wenden wird (Cohen-Janca/ Quarello 2011; kursiv i. O.), lässt den wissenden Leser die Tragik des Geschehens besonders intensiv erfahren.

Während der nichtdiegetische Erzähler in Papiervogel, flieg! und in Rosa Weiss die Emotionalität hinter den rationalen Diskurs zurücktreten lässt und es dem Rezipienten anheimstellt, verstehende Nähe herzustellen, sind in Flieger am Himmel und in Sadakos Kraniche individuelles Verlusterleben und Trauern aus der Perspektive der diegetischen bzw. autodiegetischen Erzählinstanz unmittelbar nachvollziehbar. In Flieger am Himmel ist die zurückliegende Todeserfahrung in Form eines sich wiederholenden Albtraumes in die Erzählgegenwart eingebettet, die bildhafte Sprache lässt an der Intensität des Traumas teilhaben. Sadakos Kraniche beschränkt sich dagegen auf wenige, meist einzeln und simultan auf den doppelseitigen Vollbildern platzierte Sätze, deren Schlichtheit die Teilhabe an den Gedankenspielen des Katers auf das Wesentliche konzentriert.

\section{VII.3.2.2.3 Bildstile und-konzepte}

Die Bilder in Sadakos Kraniche spüren der filigranen japanischen Zeichenkunst nach, verwirklichen dabei in hellen Naturtönen einen eigenen Stil und fügen Darstellungsformen postmoderner Bilderbuchkunst wie Collage, verschiedene Bildperspektiven und Einstellungsgrößen in das metafiktionale Erzählkonzept ein. Die überaus komplexe Erzählweise wird besonders an der Stelle deutlich, die eine ausschließlich auf der Darstellungsebene angesiedelte Metafiktionalität aufweist. Es zeigt sich auf subtile Weise ein außerhalb der Erzählebene und damit über der Kater-Instanz stehender, nichtdiegetischer Erzähler, der auf sich selbst verweist, indem das Erzählte zum Objekt der Reflexion wird.

Abb. 68: Judith Loske (2011): Sadakos Kraniche. Bargteheide: Minedition.

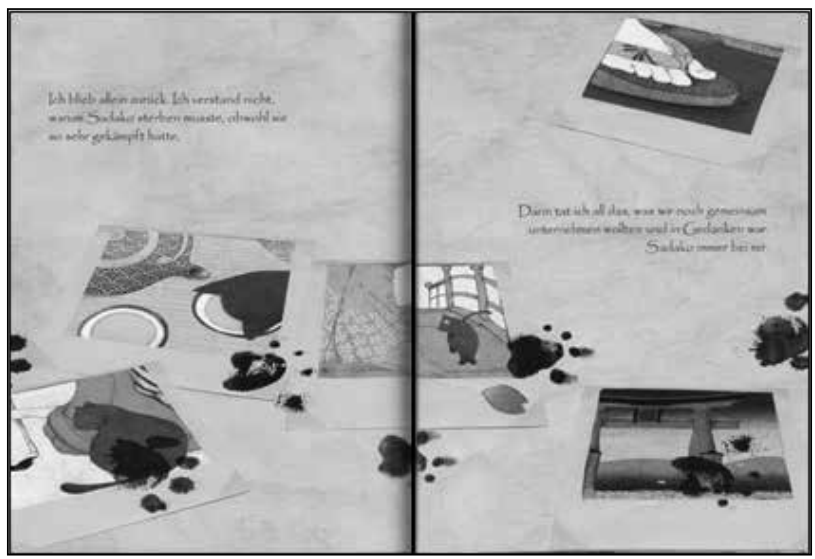


$\mathrm{Zu}$ sehen sind auf einer Doppelseite Tintenabdrücke von Tatzen (Abb. 68), die sich über wie auf dem Boden verstreute Bildkarten - darunter Abbildungen vorausgegangener Bilderbuchseiten (s.o. die Imagination unbeschwerten $\mathrm{Zu}$ sammenseins mit Sadako) - verteilen. Die Kater-Erzählinstanz deckt mit den hinterlassenen Spuren die Künstlichkeit der selbst geschaffenen Fiktion ebenso auf, wie sie selbst als Fiktion entlarvt wird, da sich unter den verstreuten Bildern auch nicht verwendete Bild-Entwürfe befinden. Die Metafiktionalität manifestiert sich demnach in der doppelten Referenz des Erzählten auf sich selbst. Auf der Sprachebene bleibt diese dritte Dimension, die Reflexion der reflektierten Fiktion, unberührt.

Dagegen verweist der realitätsnahe Bildstil, wie besonders in Anne Frank, auch in Papiervogel, flieg! und Rosa Weiss, auf die zeitgeschichtlichen Wahrheiten. Die Authentizität des Erzählten wird in Anne Frank von den fotorealistischen Bildern, zwischen die der Sprachtext als Block vor weißem Hintergrund platziert ist, und der der Patina alter Bilder nachempfundenen Farbgebung bestätigt. Bei Ellermann ist es die Abbildung einer Zeitungsseite, die das Foto eines fliegenden Bombers und ein Bild vom zerstörten und noch brennenden Hiroshima zeigt, in Rosa Weiss ist es das genaue Bildzitat in ,gewollter und beklemmender Nähe zu den Dokumentaraufnahmen aus Konzentrationslagern“ (Thiele 1988, 138). Innocenti vereint in diesen Bildern fiktionales Erzählen mit dem „Realismus der Fotodokumente ${ }^{\text {“271 }}$ und erzeugt damit eine Unmittelbarkeit (vgl. ebd.), die besonders denjenigen aufrüttelt, der das Dokumentarische erkennt. ${ }^{272}$ Die parallele Anordnung von Bild und Sprache und ihr lineares Voranschreiten tragen ihren Teil dazu bei. Innocenti ist es gelungen, „in Bildern einzufangen, wie ein Kind Krieg erlebt, ohne wirklich zu begreifen" (Innocenti 1986 ${ }^{273}$ ), indem er den Erzähler Distanz zur Protagonistin halten und ihr keine emotionalen Regungen entlocken lässt. Rosa Weiss ${ }^{274}$ bleibt dem Leser mit ihrem stummen Tun fremd.

271 „Die Gruppe der sieben Kinder hinter dem Stacheldraht ist von Innocenti absichtsvoll semi-dokumentarisch dargestellt worden, ebenso wie der sich ergebende Junge, dessen Fotografie 1943 bei der Beendigung des Aufstandes im Warschauer Ghetto entstand [...].“ (Thiele 1988, 138).

272 Zur heftigen Kritik zu Rosa Weiß zum Zeitpunkt des Erscheinens vgl. z. B. Thiele 1988.

273 Zitiert nach Ute Blaich: Rosa oder Das Grauen im Krieg. In: Die Zeit. 13 (1986), S. 21, vom 21.3.1986.

274 Der Name ist eine Referenz an die Geschwister Scholl und ihre Widerstandsgruppe „Die weiße Rose“, gleichzeitig eine Metapher für Unschuld und auch für das noch 
Ganz anders intensiv wirken die dezent farbigen, dunstig-körnigen PastellKreide-Zeichnungen Ed Youngs in Sadako. Sie weisen eine atmosphärische Dichte auf, die in einen dynamischen Dialog mit dem Sprachtext tritt. Ihr Ikonotext weist schon auf den ersten Seiten auf das bevorstehende Unglück hin: Die Bilder scheinen mit ihrer gedämpften Atmosphäre nicht zur quirligen Vorfreude der elfjährigen Sadako auf die Feierlichkeiten des beginnenden Friedenstages ${ }^{275}$ zu passen und behalten diese Ausdruckskraft während des gesamten Erzählens vom Leiden und Hoffen des erkrankten Mädchens bei. Eines der hervorzuhebenden Bilder ist die Darstellung des im Grunde nicht Darstellbaren: Als Sadako im Gespräch mit ihrer Freundin den Bombenblitz der Atombombe erinnert, ist nur das blau-graue Schattenbild der beiden Mädchen auf der gleißend-weißen Fläche zu sehen.

Abb. 69: Eleanor Coerr; Ed Young (1995): Sadako. Berlin: Altberliner Verlag.

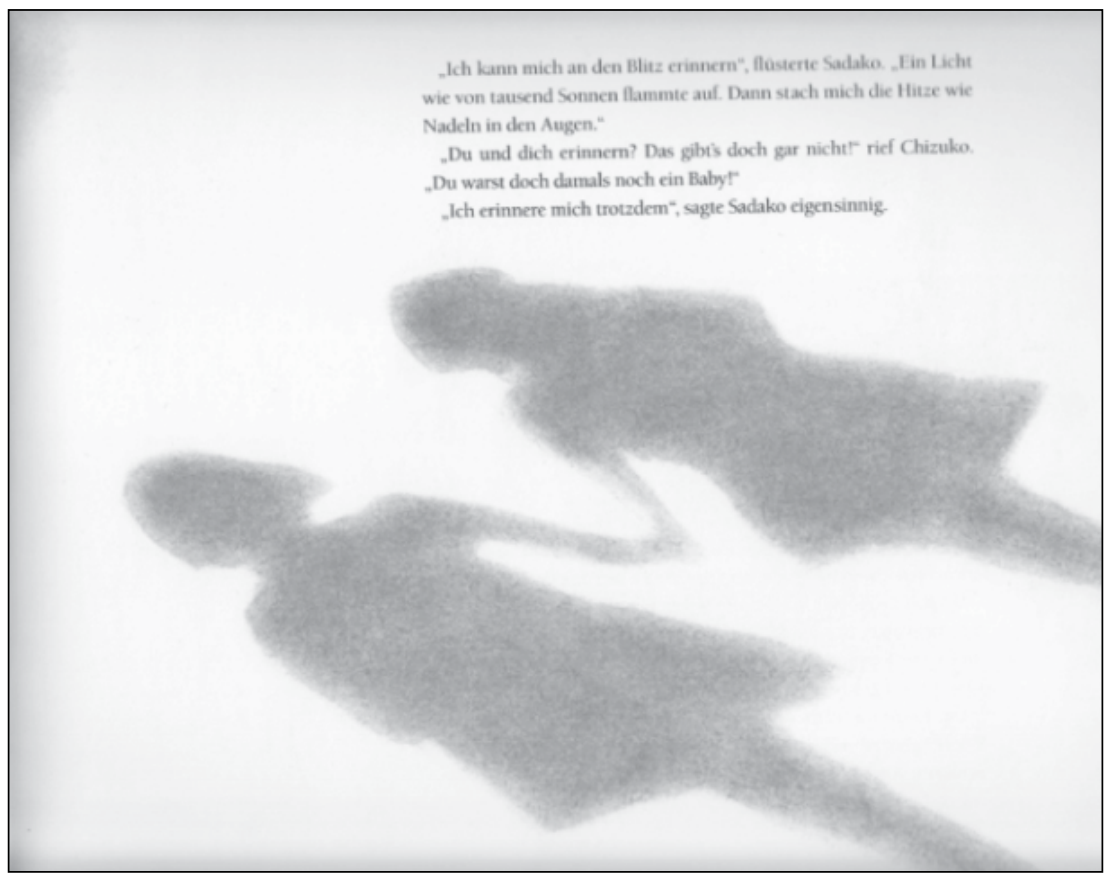

unreflektierte Wissen über die Not und das Leid der Gefangenen in Konzentrationslagern.

275 Zum Gedenken an die Opfer des Atombombenabwurfs über Hiroshima wird in Japan jedes Jahr am 6. August der Friedenstag gefeiert. 
Der Ikonotext dieser auf den ersten Blick so harmlos erscheinenden Bilderbuchseite hebt die tödliche Wirkung der Atombombenexplosion, die von zahllosen Menschen weniger als Schemen hinterlassen hat, ins Bewusstsein (Abb. 69).

In Annes Baum ist das Erzählen alternierend angelegt, d. h., dass sich bis auf wenige Ausnahmen der Sprachtext konsequent auf der linken, gegenüber den Vollbildern auf der rechten Seite befindet. Die feinen, detaillierten Zeichnungen mit deutlichen Akzenten in kräftigen Sepia-Tönen besitzen eine außergewöhnliche und metaphorische Qualität, die auf den letzten Seiten nochmals gesteigert wird (Abb. 70).

Abb. 70: Irène Cohen-Janca; Maurizio A. C. Quarello (2011): Annes Baum. Hildesheim: Gerstenberg.

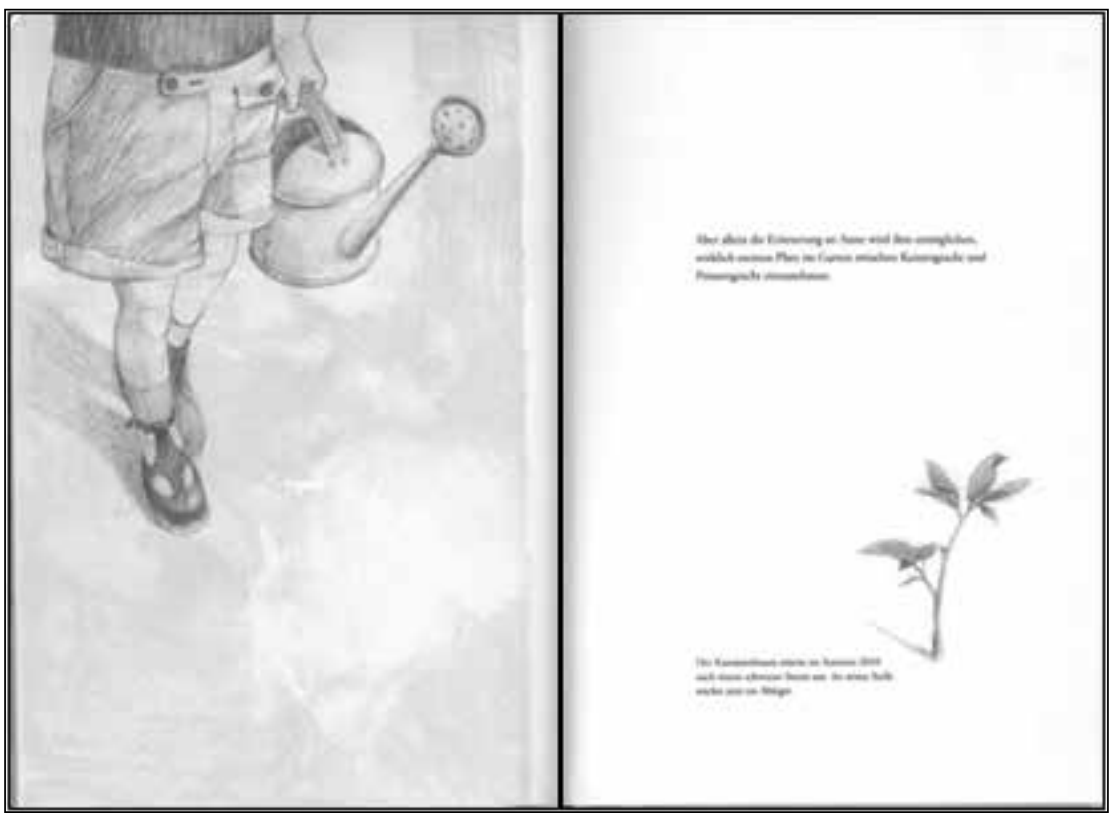

Auf das Bild des sterbenden Kastanienbaumes folgt die Zeichnung eines Kindes mit einer Gießkanne, das von links oben in das Bild hineinläuft, wie auf den Ableger des Kastanienbaumes zu, der auf der gegenüberliegenden Seite rechts unten das Ende des Buches markiert, gemeinsam mit dem Text: Aber allein die Erinnerung an Anne wird ihm ermöglichen, wirklich meinen Platz im Garten zwischen Keizersgracht und Prinsengracht einzunehmen. (Abb. 70) Der Ikonotext ist hier die Symbiose von Symbolik und Auftrag zu tätigem Erinnern: Die zarte 
Pflanze ist das Bindeglied zwischen Vergangenem und Heutigem, ist Träger der Erinnerung, ist Auftrag und Verpflichtung und bedarf der sorgenden Zuwendung der jungen Generation.

Die Zeichnungen ${ }^{276}$ von Catrin Clante in Annette Herzogs Flieger am Himmel sind dagegen teils surreale Bildräume, die sich nicht an ihre skizzenhaft mit feiner Linie gezogenen Grenzen halten. Sie wirken wie Fenster mit dem Blick auf Szenarien, die das Empfinden der Protagonistin und ihre inneren Bilder spiegeln, begleitet von Vignetten, die ebenso treffend gewählt sind.

\section{VII.3.2.2.4 Die Ästhetik des Sterbens und der Trauer - Todeskonzepte und Nachtodtheorien}

Die ästhetische Qualität der Bilder vom Sterben und dem Moment des Todes, sofern verbildlicht, ist insgesamt von hohem Niveau. Die Darstellungen zeigen durchweg behutsame, metaphorische Lösungen. In Annes Baum fügt sich die nüchterne Mitteilung vom Tod Anne Franks im Konzentrationslager BergenBelsen mit dem das Bild beherrschenden Stacheldrahtzaun in einer Winterlandschaft zu einem Ikonotext, der Frösteln macht (Abb. 71).

Abb. 71: Irène Cohen-Janca; Maurizio A. C. Quarello (2011): Annes Baum. Hildesheim: Gerstenberg.

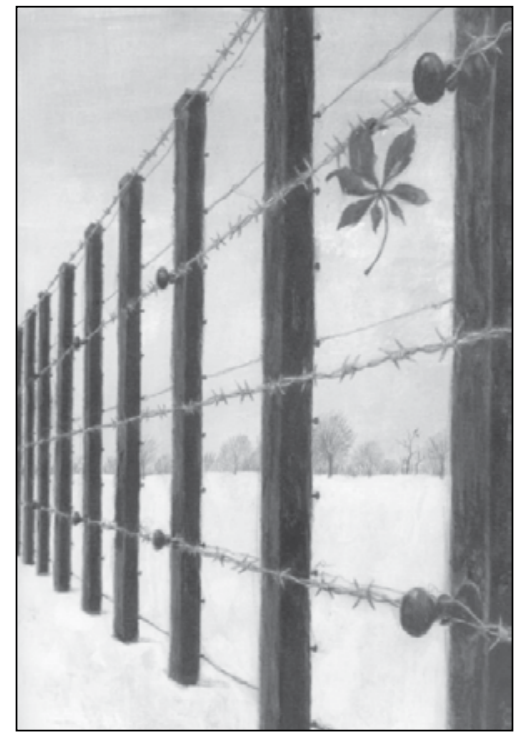

276 Nominierung für den dänischen Buchdesignpreis 2009. 
An den Stacheln des Zaunes hängt ein einzelnes verwelktes Kastanienblatt, das, wie die Gesamtgestaltung, eine Metapher für die ausweglose Lebensfeindlichkeit der Konzentrationslager ist, für den Tod Anne Franks und die vernichtete Hoffnung auf Leben steht. Ein weiteres Todesszenario stellt die Imagination des eigenen Sterbens aus der Perspektive des Kastanienbaumes dar: Vielleicht werde ich bald gefällt, weil die Fäulnis meinen gesamten Körper erfasst. Wenn mein Stamm $z u$ Boden stürzt [...]. Ins Bild gesetzt ist die Vorstellung vom Augenblick des Todes, als der verfallene Baum umstürzt und auch seine letzten welken Blätter verliert. Den Gegenentwurf zum natürlichen Sterben des Baumes und zur Vernichtung des jungen Menschenlebens, das keine Chance hatte, bildet schließlich der frische Ableger, Repräsentant und Träger eines hoffnungsvollen und gedenkenden Neuwerdens (Abb. 70). Im Ikonotext fallen biologische Gesetze und die Verantwortung für das kulturelle Gedächtnis zusammen.

Auch in Rosa Weiss (Abb. 72) ist es ein Stacheldrahtzaun, der von Leid und Tod kündet, ohne das dahinter stattfindende grausame Sterben genauer zu zeigen. Erfahrbar wird es aber im Zusammendenken des mit leeren Augen starrenden Leids in Gestalt abgemagerter Häftlinge und dem stummen Tun Rosa Weiss, von dem der Text berichtet.

Abb. 72: Roberto Innocenti; Christophe Gallaz (1986): Rosa Weiss. Frankfurt a. M.: Ali-Baba.

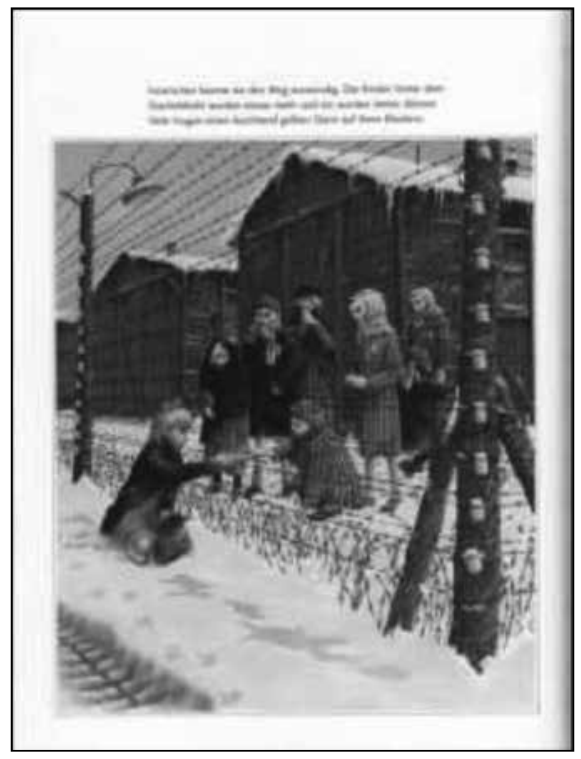


Der Tod des Mädchens zu dem Zeitpunkt, als das Konzentrationslager bereits aufgelöst ist, ist besonders tragisch, auch, weil seinem Schweigen nichts mehr folgen kann. Der Ikonotext verdichtet sich damit zur Anklage. Gleichzeitig aber wird das Szenario vom frischen Grün des Frühlings, Symbol der Hoffnung und neuen Lebens, überdeckt (Abb. 73).

Abb. 73: Roberto Innocenti; Christophe Gallaz (1986): Rosa Weiss. Frankfurt a. M.: Ali-Baba.

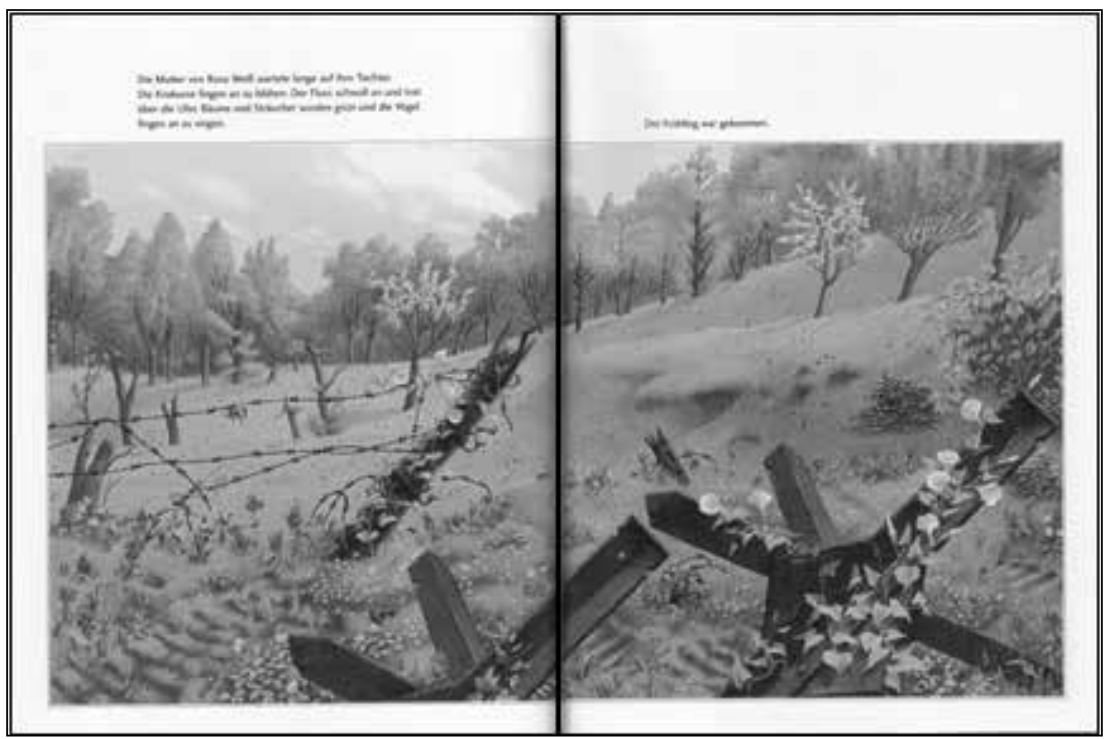

Damit ist das Ende jedoch alles andere als versöhnlich, denn Innocenti bietet dem fassungslosen Betrachter nichts weiter als den Blick auf die Sinnlosigkeit des Tötens. Dem Leser und Betrachter bleibt es dabei überlassen, der Trauer der Mutter, die lange auf ihre Tochter wartete, nachzuspüren oder sich mehr der Darstellung vom neu werdenden Leben auf der letzten Doppelseite des Buches zuzuwenden, dem gleichzeitig das Vergessen innewohnt.

Politische Prognostik über die Verdrängung und eine verhaltene Hoffnungsemblematik gehen in ein problematisches Schlusstableau ein: Eine kleine Vignette, die als letztes Schmuckstück den Bildband beschließt, zeigt ausschnitthaft ein Stückchen Stacheldraht, über dem eine einzelne blaue Glockenblume hängt und verwelkt. (Thielking 1997, 55f.) 
Auf die Problematik, dass es in diesem Holocaust-Buch um den Tod einer deutschen Helferin, nicht aber um den Tod von KZ-Häftlingen geht, kann an dieser Stelle nur hingewiesen werden.

Krieg ist auch die Ursache für den Tod des Mädchens Sanja in Flieger am Himmel. Die Freundin der Toten erinnert im Traum das unbeschwerte gemeinsame Spielen im heimatlichen Garten, bis die Bilder wechseln und die Sonne auf einmal verschwindet. Das Bild zeigt einen schwarz-blauen Farbverlauf als Himmel, dessen bedrohliche Ausdehnung die Mädchen zu verschlingen droht. Mimik und Gestik der Mädchen zeugen vom Erschrecken und der Angst vor den über ihnen fliegenden Bombern. Mit dem von einem Blütenkranz gerahmten Traumbild von der schlafend dargestellten toten Sanja (Abb. 74) bleibt die Härte der Realität, die sich in der Leerstelle zwischen diesen beiden Bilderbuchseiten abspielt, ausgeblendet.

Abb. 74: Annette Herzog; Katrine Clante (2009): Flieger am Himmel. Wuppertal: Hammer.

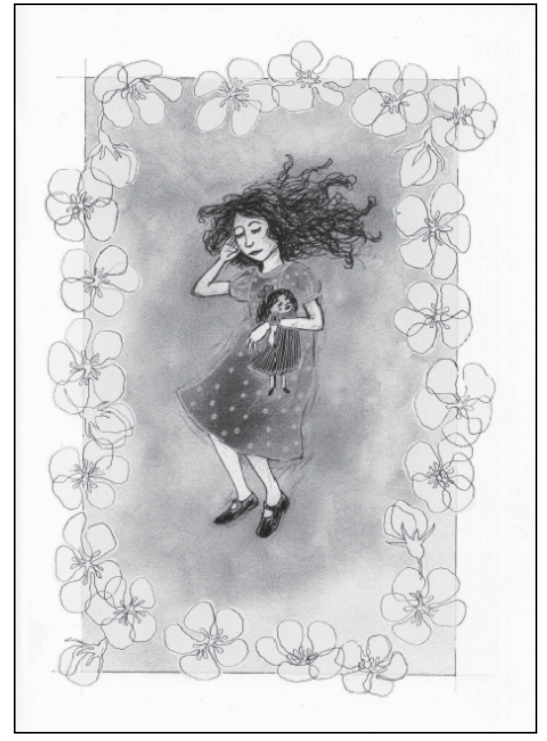

Das Unfassbare der Ereignisse liegt gerade in diesen Leerstellen, die dem Leser nur so viel zumuten, wie sein individueller Erfahrungsschatz es zulässt. Dass es am Ende wiederum Flieger sind, diesmal Papierflieger, die Trost und Hoffnung auf Zukunft verheißen, stimmt insgesamt versöhnlich und zeigt, dass manche Dinge nur anderer Perspektiven bedürfen, um daraus neuen Sinn zu schöpfen. 
Weniger auf Distanz als auf mitfühlende Nähe sind dagegen die Bilder von Ed Young zu Sadakos Sterben und Tod angelegt. Sadako trauert zunächst nach dem Tod des Freundes im Krankenhaus:

"Glaubst du, dass Kenji da draußen auf einer Sterneninsel ist?" fragte Sadako. „Wo auch immer - ich bin sicher, er ist jetzt glücklich", antwortete die Schwester. „Er hat diesen müden, kranken Körper abgestreift, und seine Seele ist frei."

Die konkrete Vorstellung von einer Nachtodexistenz der Seele ist hier das entscheidende Trostmotiv, auch für das eigene Sterben Sadakos. Bevor Sadako selbst noch zu Wort kommt, verschmelzen in der letzten Phase des Sterbens Sprachtext und Bild zu einem Ausdruck versöhnlicher Hinnahme, ist die Bitte der Mutter: "Oh Schar himmlischer Kraniche, Deckt (sic!) mein Kind mit euren Schwingen zu. " in der schemenhaften Darstellung fliegender Kraniche verwirklicht. Den Augenblick des Todes erlebt der Betrachter aus der Perspektive Sadakos selbst und schaut auf eine große Zahl bunter, scheinbar fliegender Papierkraniche in einem grenzenlos schwarzen Raum (Abb. 75):

Sadako schaute hinauf zu dem Kranichschwarm, der von der Decke hing. Die Vögel raschelten und wiegten sich in einer leichten Herbstbrise. Als wären sie lebendig und wollten durchs offene Fenster hinausfliegen. Sadako seufzte und schloß die Augen. Wie schön frei sie waren!

Abb. 75: Eleanor Coerr; Ed Young (1995): Sadako. Berlin: Altberliner Verlag

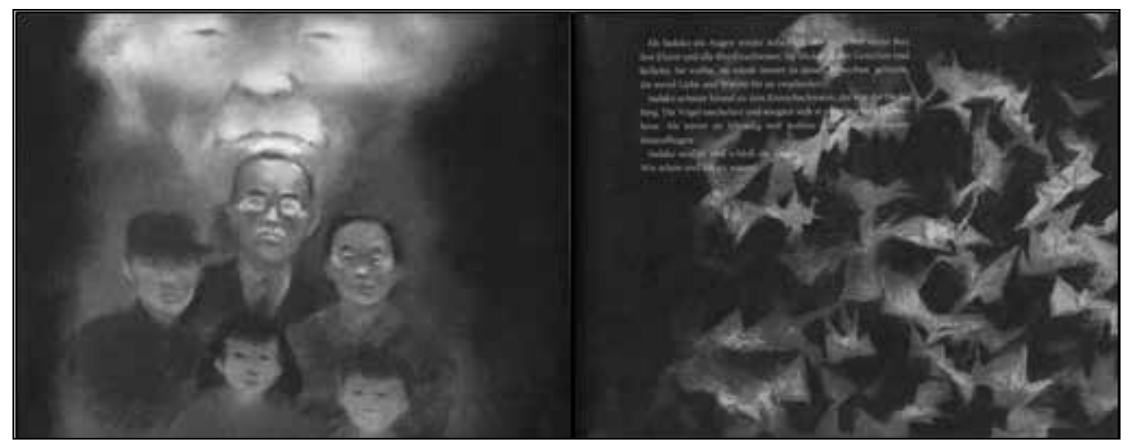

Die linke Seite zeigt die versammelte Familie, einschließlih der verstorbenen Großmutter, die als schemenhafte Erscheinung im Hintergrund auf subtile Weise anwesend ist und damit Sadakos letzte Gedanken sichtbar bestätigt: Sie blickte in ihre Gesichter und lächelte. Sie wußte, sie würde immer zu diesen Menschen gehören, die so viel Liebe und Wärme für sie empfanden. Friedlicher ist der Tod kaum vorstellbar. Ernst und traurig bleibt die Familie und mit ihr der Betrachter 
der Szenerie zurück, zu dessen Trost die auf der Sprach- und Bildebene ausgedrückte Leichtigkeit der Papierkraniche sicher beiträgt. Das Empfinden des Ungerechten dieses Schicksals bleibt gleichwohl davon unberührt.

Auch in Sadakos Kraniche ist das Ende ein sanfter, aber eher unversöhnlicher Tod aus der Perspektive des trauernden Katers: Ich blieb allein zurück. Ich verstand nicht, warum Sadako sterben musste, obwohl sie so sehr gekämpft hatte. Mehr ist nicht zu erfahren über Sadakos Umgang mit dem Sterben, da sie innerhalb des Erzählens selbst keine Stimme erhält. Wirkungs- und rezeptionsästhetisch ist das poetische Konzept ganz auf das Empfinden des Katers angelegt, dessen Trauerprozess auch die Phase des Suchens und Sich-Trennens und die des neuen Weltbezuges aufweist:

Dann tat ich all das, was wir noch gemeinsam unternehmen wollten und in Gedanken war Sadako immer bei mir. / Am Ende meiner Reise verstand ich, dass unsere gemeinsame Zeit für immer einen Platz in meinem Herzen haben wird.

Im Ikonotext von sprachlicher Mitteilung und bildlicher Darstellung des Katers auf der letzten Bilderbuchseite - vorsichtig trägt er einen Papierkranich im Maul - manifestiert sich die metaphorische Gegenwärtigkeit, die Gewissheit, dass Sadako in jedem gefalteten Kranich weiterleben wird.

\section{VII.3.2.2.5 Symbolsprache, Traditionen und Rituale}

Traditionen und Rituale bleiben in den in Kapitel VII.4 vorgestellten Bilderbüchern weitestgehend unberücksichtigt, mit einer Ausnahme: In Sadako wird das alljährliche Friedensfest zum Gedenken an die Atombombenopfer thematisiert und kunstvoll ins Bild gesetzt, und es kommen rituelle Bräuche zur Sprache, mit denen Japaner ihrer Toten gedenken. Die sterbende Sadako wendet sich an ihre Eltern:

„Wenn ich sterbe“, murmelte sie wie im Traum, „stellt ihr dann meine Lieblingsbohnenkuchen für meine Seele auf den Altar? Und laßt am Friedenstag eine Laterne für mich auf dem Ohta schwimmen?"

Die Vorstellung von der Existenz der Seele und ihrer Trennung vom Leib ist hier verbunden mit Anforderungen an die Achtsamkeit der Hinterbliebenen, die ritueller Handlungen bedarf. Sadako vergewissert sich des sorgenden Gedenkens ihrer Familie, ganz wie sie es nach dem Tod der Großmutter erfahren hat, und kann angstfrei sterben. Abgesehen davon und vom Hinweis auf die Legende der 1000 Kraniche liegt der Symbolgehalt der Erzählungen vom Schicksal Sadakos in der Bildästhetik: Die Emotionalität der Geschehnisse drückt sich über die Farbsymbolik wie über die Darstellungen der Origami-Kraniche als Metapher 
für den Tod Sadakos aus. Sie sind in ihrer Funktion als Erinnerungsträger das wesentliche Gestaltungselement der Bilder.

In den Büchern zum Holocaust ist der Stacheldrahtzaun das sichtbare Zeichen für das Gefangen- und Ausgeliefertsein in den Konzentrationslagern des Dritten Reichs und ein Symbol für den Tod von Millionen Menschen. Weitere metaphorische Dimensionen des Todes stellen die Jahreszeitensymbolik und das Vergehen und Neuwerden in der Natur in Gestalt des sterbenden Baumes und seines Ablegers in Annes Baum dar, wie auch in Flieger am Himmel der beginnende Frühling für hoffnungsvoll neu Beginnendes steht.

\section{VII.3.3 Kurzfassung der Ergebnisse zum gewaltsamen Kindertod}

Während die Bilderbücher Kevin Kanin (2005), Flieger am Himmel (2011), Sadako (1995) und Sadakos Kraniche (2011) die individuelle Trauer um einen konkreten Beziehungsverlust thematisieren, geht es in den übrigen mehr um das Aufzeigen der Folgen jeglicher Form gewaltsamer, Menschen verachtender Auseinandersetzungen am Beispiel zeitgeschichtlicher Ereignisse. Im Gegensatz zur ausführlichen Darstellung des Krankheits- und Sterbeprozesses Sadakos (Sadako) und dem individuellen Trauma in Flieger am Himmel wird dem historischen Motiv in den Büchern zum Holocaust weitaus mehr Bedeutung beigemessen, wovon Anne Frank den höchsten Grad an Authentizität aufweist. Allen Büchern ist gemeinsam, dass sie dem Tod und dem Vergessen die Erinnerung entgegenstellen. Ganz explizit wird in Annes Baum vom Tod Anne Franks ein Bogen bis in die Gegenwart geschlagen und damit das Gewicht des individuell-zeitgeschichtlichen Geschehens dem kulturellen Gedächtnis angetragen. Die mahnende Funktion historischer Gedenktage greift Papiervogel, flieg! auf. Und wie Sadakos Kraniche gehört Annes Baum zu den jüngsten poetisch-künstlerischen Konzeptionen, die für komplexe literarästhetische Qualität der Postmoderne im geschichtserzählenden Bilderbuch stehen.

Da mit den zentralen Motiven Krieg und Gewalt weniger die universal-kausalen Zusammenhänge zwischen Leben und Tod angesprochen sind, sondern mehr der Appell im Vordergrund steht, dem vom Menschen ausgehenden Übel mit Mut zu Widerstand und Widerspruch zu begegnen, gebührt dem Tod hier nicht die schicksalsergebene Hinnahme, wie sie in den meisten anderen Zusammenhängen nahegelegt wird. Sadako Sasaki und Anne Frank sind Symbolfiguren eines schuldhaft vom Menschen herbeigeführten kollektiven Todes, der nicht als Folge der Unwägbarkeiten des Lebens, wie sie etwa Krankheiten oder Unfälle darstellen, akzeptiert werden kann. Deshalb geht es um die Ausbildung 
eines sozialen und kulturellen Gedächtnisses ${ }^{277}$, um das Schaffen eines am Historischen wie am Mitmenschlichen ausgerichteten Bewusstseins mit dem Ziel der nachhaltigen Moral- und Wertebildung. In keinem der Bücher dieses Teilkorpus wird das Wissen um die Irreversibilität und Kausalität des Todes infrage gestellt, was mit dem Alter der Protagonisten und des relevanten Adressatenkreises der mindestens Neunjährigen korreliert. Hinsichtlich der Effekte im Prozess der kognitiven Entwicklung und individuellen Einstellungen zum Tod kann von einer Bestätigung bereits erlangten Wissens ausgegangen werden.

\section{VII.4 Zusammenfassung}

Mit der Aufnahme des Kindersterbens in sein Themenspektrum erweist sich das Bilderbuch einmal mehr als Literatur für Kinder, die ihre Adressaten ernst nimmt und die ernstesten Seiten eines Kinderlebens nicht ausspart. Das Identifikationsangebot für trauernde Kinder, die sich beim Tod von Gleichaltrigen oder Geschwistern oft mit zusätzlichen und ganz anderen Fragen beschäftigen als im Zusammenhang mit dem Tod von z. B. Großeltern oder Haustieren, ist aber bis heute mit dem verfügbaren Material noch sehr eingeschränkt. Die Zurückhaltung ist sicher der besonderen Problematik geschuldet, dass Kinder damit auf ihre eigene Sterblichkeit verwiesen werden, aber ebenso auch der Scheu vor der Darstellung belastender Aspekte des Trauerns.

Außerdem richten sich diese Bilderbücher auch an Kinder, die in ihrer persönlichen Lebenssituation mit der eigenen Sterblichkeit in unterschiedlicher Form ${ }^{278}$ konfrontiert sind. Meist fernab eines betulichen Schonraums wird damit eine der wichtigsten Funktionen von Literatur überhaupt erfüllt: Identifikationsangebote zu unterbreiten. Im Erleben und Durchleben fiktionaler Lebenssituationen manifestiert sich literarisches Probehandeln, das Lösungs- bzw. Troststrategien nachvollziehbar und auf das eigene Selbstverständnis und den Umgang mit der persönlichen Situation übertragbar erscheinen lässt.

Abgesehen von den ersten beiden Titeln dieses Teilkorpus' zeigen die Erzählkonzepte erst ab 1995 eine Emotionalisierung und Psychologisierung in den Darstellungen vom Kindertod, die den kindlichen Protagonisten als Reflektorfigur in allen Formen der Rede- und Gedankenwiedergabe zu Wort kommen lassen und damit die den psychologischen Kinderroman längst kennzeichnende „Schwerpunktverlagerung auf die Darstellung kindlicher und jugendlicher

277 Vgl. dazu z. B.: Aleida Assmann: Soziales und kollektives Gedächtnis. Quelle: http://www.bpb.de/files/0FW1JZ.pdf; 21.10.2014.

278 Kübler-Ross 1985; Kaldhol/ Øyen 1987. 
Innenwelten“ (Gansel 2010, 118) auch im Bilderbuch zu Tod und Sterben zeigen. Die universale Möglichkeit eines frühen Todes im Kindesalter stellt eine besondere Nähe zum kindlichen Leser her, die auf der Darstellungsebene noch unterstützt wird durch die in Relation zum übrigen Textkorpus häufiger gewählte Ich-Form der kindlichen Erzählperspektive. Mit den Darstellungskonzepten wird den kindlichen Adressaten allerdings in der Regel ein Wohlverhalten im Sinne von verständiger Akzeptanz des Todes nahegelegt, obwohl der Tod doch wie nichts Anderes im Leben einen irreparablen Einschnitt in das vertraute Netz der Beziehungen bedeutet. Der Rezipient, der kindliche wie der erwachsene, darf sich aufgefordert fühlen, sich an den Protagonisten ein Beispiel zu nehmen und die Trost spendenden Erklärungen und Versprechungen von einem Weiterleben im Himmel, in dem es so unvergleichlich viel schöner sein muss als auf Erden, rasch anzunehmen. Eine frohe Erinnerung an den Verstorbenen ist obligatorisch.

Die aus der Psychologie bekannte spezifische Problematik von Geschwistertrauer wird noch sehr zurückhaltend bearbeitet. Und dass auch negative Gefühle zur Trauer dazugehören und es eines schmerzvollen Prozesses bedarf, sich mit dem unaufhebbaren Verlust wieder neu im Leben einzurichten, wird in nur wenigen Bilderbüchern und auch nur ansatzweise berücksichtigt. Im Bestreben, alles schnell wieder gut sein zu lassen, bleibt das Verständnis für die dunklen und für den Betroffenen kaum vermeidbaren Seiten der Trauer fast immer auf der Strecke. Sicher kann von den der relativen Kürze verpflichteten Bilderbüchern keine so breite Entfaltung der Probleme erwartet werden, wie sie mittlerweile zahlreiche Kinder- und Jugendromane bieten, gelungene Beispiele wie Abschied von Rune (Kaldhol/ Øyen 1987), Auf welchem Stern lebt Sina? (Steiner 1999), Meine Schwester ist ein Engel (Stark/ Höglund 1997), Die Blumen der Engel (Blazejovsky 2001) oder Eva im Land der verlorenen Schwestern (Goossens/ Robberecht 2004) zeigen aber auf, dass tiefe Trauer keine Sache von kurzer Frist sein kann, sondern Zeit braucht und verständnisvoller Begleitung bedarf.

Wie groß das Bedürfnis zu sein scheint, in solchen Grenzsituationen des Lebens anhand von Beispielgeschichten schnelle Hilfe anzubieten, zeigen gerade auch solche Bilderbücher, wie sie vom hospiz-verlag und von ausgewiesenen Trauerbegleitern veröffentlicht wurden. Die in Vorworten und Nachworten als einfühlsam angepriesenen Bilder und Texte entspringen offenbar dem Wunsch nach einem idealen, möglichst nicht belastenden Trauergeschehen. Ob aber diese Idealisierung die Verarbeitung der Trauer um ein Kind wirklich unterstützen kann, müssten interdisziplinäre Ansätze der Rezeptionsforschung und Psychologie in Erfahrung zu bringen versuchen. Da wären dann auch die kindlichen 
Rezipienten zu befragen, weniger die übermittelnden Erwachsenen, was die Forschung wiederum vor ganz eigene Probleme stellt. Denn Kinder verfügen kaum über das notwendige Reflexionsvermögen oder die sprachlichen Kompetenzen zur Verbalisierung ihrer Eindrücke und Empfindungen. Zudem erfordert der thematische Kontext eine psychologisch besonders elaborierte Vorgehensweise. Die Frage nach dem thanatopsychologisch begründbaren Wirkungspotenzial der Bilderbücher zum Kindersterben kann deshalb über die im Zusammenhang mit den Einzelanalysen aufgestellten Vermutungen hinaus nicht beantwortet werden. 



\section{Abschließendes Resümee und Ausblick}

Bilderbücher zum Thema Tod und Sterben werden verschiedensten Ansprüchen gerecht: Sie bieten die Gelegenheit zur Auseinandersetzung mit eigenen Fragen und Fragen von Kindern, geben informative Hinweise auf biologische Zusammenhänge, präsentieren religiöse und säkularisierte Konzepte und zeigen verschiedene kommunikative Umgangsformen auf. Das Angebot ist in jüngster Vergangenheit facettenreicher, komplexer und anspruchsvoller geworden, belegbar an den deutlich philosophische Fragen anstoßenden Konzepten, die dem philosophischen Trend in der KJL, mit ausgelöst von Joostein Gaardners Lauras Stern (1993), folgen, und der gleichzeitigen Emotionalisierung der Sprach- und Bildebene, die sich unter anderem in der vermehrten Wahl der Ich-Perspektive in autodiegetischen Erzählkonzepten und der Darstellung der physischen und psychischen Aspekte intensiv erlebter Sterbe- und Trauerprozesse ausdrückt.

Es hat sich gezeigt, dass Schreckensbilder in den Bilderbüchern so gut wie keine Rolle spielen ${ }^{279}$, aber auch, dass etwa seit der Jahrtausendwende vermehrt Fragen und Befürchtungen, die eigene Sterblichkeit betreffend, Platz haben. Trostvolle Konzepte, die Kinder ernst nehmen und sich ihren Unsicherheiten stellen, stehen neben solchen, die negative Gefühle und zweifelnde Fragen völlig ausblenden. Die Feststellung von Ingun Spiecker-Verscharen (1982, 137ff.), die von ihr untersuchten Kinderbücher setzten in der Bearbeitung des Themas ein fortgeschrittenes Todesverständnis voraus, kann auch für das Bilderbuch der vergangenen 30 Jahre bestätigt werden. Todeskonzepte lassen sich an nur wenigen Bilderbüchern vervollständigen: Die Universalität des Todes wird nur selten direkt angesprochen und die Aspekte der Irreversibilität, Nonfunktionalität und Kausalität werden ebenso meist als bekannt vorausgesetzt. In diesem Zusammenhang bzw. hinsichtlich des Identifikationspotenzials der untersuchten Bilderbücher sollte bemerkt werden, dass sich das menschliche Figurenensemble ausschließlich aus dem behütet-bürgerlichen Milieu rekrutiert. Die kindlichen Protagonisten weisen keinerlei negativ konnotierte charakterliche oder äußerliche Auffälligkeiten auf. Ihr Habitus entspricht den gängigen Vorstellungen von aufgeweckten und bildungsbürgerlich sozialisierten Kindern vorwiegend im Vor- oder Grundschulalter.

279 Die Hölle wird beispielsweise in nur vier Bilderbüchern vorsichtig erwähnt: Crowther 2011: Der Besuch vom kleinen Tod; Erlbruch 2007: Ente, Tod und Tulpe; Abedi/ Cordes 2006: Abschied von Opa Elefant; Allan 1996: Gibt's im Himmel Schokolade? 
Vielfach findet die philosophische Tradition seit Platon, die Seele vom Leib gelöst zu betrachten, in eingängiger und differenzierter Weise einen Widerhall, der Religiosität im weitesten Sinne einschließt und die Hoffnung auf eine wie auch immer geartete Weiterexistenz des psychischen Kerns unseres Ichs nährt. Damit erhält die gegebene Tatsache der Sterblichkeit einen Sinn, der Tod wird als gutes Ende und Tor zu einem neuen Leben vorstellbar, aber nicht behauptet. Dieses Offenhalten der Option auf eine Existenz auch nach dem Tod zeigt sich in den religiösen Bilderbüchern mehrheitlich als allgemeiner Konsens, wobei gleichzeitig die im Glauben verankerte, konkrete Vorstellung eines jenseitigen Bei-Gott-Seins immer mehr an Bedeutung verliert. Das konfessionell ausgestaltete Jenseits wird oft ersetzt von einem "Jenseits im Kopf“ (Egli 2014, 100), das als mnestisches Instrument fungiert und für die Individualisierung der Trauerbewältigung symptomatisch ist. ${ }^{280}$ Damit geht ein Bedeutungsverlust der tradierten Rituale einher, wie er auch in der Realität wahrnehmbar ist. Die Bilderbuchkonzepte zeigen,

dass der Bestattungsmodus und der kirchliche Ritus heute bei einer Vielzahl von Menschen nur marginal bedeutsam sind, dass religiöse Werte, Normen, Deutungsschemata und Handlungsmuster für das Erleben der Hinterbliebenen nicht mit sinngebenden Inhalten unterlegt sind. Entsprechend verlieren diese Zeremonien an Tiefe und Bedeutung und spiegeln den heute sehr ambivalenten Umgang mit der Bestattung wieder (sic!), aber auch den tiefgreifenden, metaphysischen Verlust der Gemeinschaft. (Pennington 2001, 146)

Hinsichtlich der bildgestalterischen Schwerpunkte und ihrer Entwicklungen kann, obwohl sie hier nicht explizit in den Blick genommen wurden, konstatiert werden: Auch das Bilderbuch zum Thema Tod trägt, wenn auch zurückhaltend, den seit den 1990er-Jahren nachweisbaren „Diskontinuitäten in der Bilderbuchliteratur“ Rechnung, die sich in non-linearen, filmischen Erzählstrukturen, „veränderten Zugängen zu Genderkonstruktionen und einer neuen Hinwendung zur Materialität“ (Oetken 2008) ${ }^{281}$ als bedeutsamer Teil der Medienkultur präsentieren. Gegenwärtig bietet der Markt eine Reihe innovativer ästhetischer Lösungen einer Visualisierung von Tod und Trauer, wobei in den letzten Jahren eine Tendenz zur Darstellung des personifizierten Todes auszumachen ist. Insgesamt zeigen sich heute die Erzählkonzepte facettenreich wie nie und bieten

280 Florinne Egli $(2014,11)$ ist in ihrer Untersuchung von „33 zufällig ausgesuchten Bilderbüchern“ zu demselben Ergebnis gelangt.

281 Kurzfassung zum Online-Volltext der Dissertation von M. Oetken 2008: http://oops. uni-oldenburg.de/747/ 
gleichzeitig eine seit den 1990er-Jahren zunehmende Nähe zur Lebensrealität von Kindern, die sehr deutlich auch die primäre Betroffenheit von Kindern erfasst. Drei motivische Spezifika konnten in den Bilderbüchern zum Kindertod ausgemacht werden: die Auseinandersetzung mit der eigenen Sterblichkeit aus der Perspektive eines Kindes, kindliche Trauerprozesse nach dem Verlust eines gleichaltrigen Kindes oder eines Geschwisters und die gewaltsamen Ursachen für das Sterben von Kindern.

Obwohl die Aufschlüsselung des Gesamtkorpus' geradezu dazu auffordert, zahlreiche weitere Forschungsfragen zu stellen, z. B. hinsichtlich stilistischer Schwerpunkte oder sozialwissenschaftlicher Aspekte, Fragen nach Kommunikationsstrukturen und anderen kulturwissenschaftlichen Dimensionen, müssen diese Desiderate hier unberücksichtigt bleiben. Von Interesse wären beispielsweise auch Ansätze der feministisch orientierten Literaturwissenschaft mit Fragen zur Darstellung von weiblichem und männlichem Rollenverständnis, Fragen nach der Komplexität der sprachlichen und bildlichen Ausgestaltung von kommunikativen Interaktionen und ihrer möglichen generationsbezogenen oder genderspezifischen Unterschiede u. a. m.

Rezeptions- und wirkungsästhetischer Ausblick

Die vordergründige Funktion von Kinderliteratur, die in ihrem Wesen immer auch pädagogisch angelegt ist und den Kindern "Mitgliedschaftsentwürfe“ (Hurrelmann) anbietet, um bei der Aneignung von Welt und der Entwicklung des Selbstkonzepts unterstützend wirksam zu sein, ist im ausgewählten Textmaterial mit dem Anliegen verbunden, einfache und entlastende Varianten einer Antwort auf das Wie und Warum des Todes zu finden.

Die menschliche Gabe der Verdrängung ist angesichts des medial massenhaft präsentierten Sterbens ${ }^{282}$ eine Notwendigkeit. „Ein kurzweiliges Betroffensein ist das Maximum, das wir uns mit den begrenzten Kräften unseres emotionalen Haushalts leisten können." (Heller 2000b, 19) Daneben zeigt sich aber auch ein verbreitetes Interesse, sich mit der eigenen Sterblichkeit und den Unwägbarkeiten eines verlängerten Lebensverlaufs und eines durch chronisch-degenerative Erkrankung verlängerten Sterbens auseinanderzusetzen.

Sterben wird heute gesellschaftlich nicht mehr nur ,umschwiegen', sondern besprochen und thematisiert. Sterben wird nicht ausschließlich ignoriert, sondern in vielfältigen existenziellen, fachlichen und künstlerischen Zugängen behandelt. Es gibt eine

282 „Siebzig Morde täglich können sich Kinder im Fernsehen laut einer Studie des Nachrichtenmagazins SPIEGEL ansehen." (Witt-Loers 2009, 13). 
ernsthaft-existenzielle Auseinandersetzung mit dem Sterben, die sehr deutlich von berührenden und tiefgehenden menschlichen Erfahrungen, von erschütternden Betroffenheiten bestimmt ist. (Ebd., 18; H. i. O.)

„Sterben als Thema ist, in.“ (Ebd., 17; H. i. O.) Dies zeigt auch das insgesamt hohe Aufkommen von Kinderliteratur zum Thema Tod, das - neben einer ökonomisch begründbaren Motivation - vermutlich auch Ausdruck des erwachsenen Bedürfnisses von Autoren und Illustratoren ist, sich mit der eigenen Endlichkeit und/oder Verlusterfahrungen auseinanderzusetzen. Und wenn sich in unserer säkularisierten Gesellschaft der Trend fortsetzt, den Tod kognitiv-wissenschaftlich anzugehen, mit Professionalisierung und Selbstbestimmung (Patientenverfügungen, lebensverlängernde medizinische Methoden, Alterssuizid, Sterbehilfe u. a. m.) auf das physische Sterben Einfluss zu nehmen, sind sicher weitere Auswirkungen auf kinderliterarische Konzepte zu erwarten. Die sozial-existenziellen Erfordernisse, denen sich Erwachsene, Schwerkranke und ihre Angehörigen stellen müssen, um eine eigene Form der ars moriendi verwirklichen zu können, gehören selbstredend nicht zu den Entwicklungsaufgaben, die gesunde Kinder im Vor- oder Grundschulalter bis hin zum Erwachsenenalter zu bewältigen haben. Eine „maximale Darstellungsdifferenziertheit“ (Eichhorn/ Groeben 1996, 196) kann deshalb für die Kinderliteratur kein erklärtes Ziel sein. Kindliches Erkenntnisinteresse ist auf das Leben und seine individuellen Anforderungen gerichtet, auf das Verstehen und Verarbeiten alltäglicher Erfahrungen, da aber aufgrund der gestiegenen Lebenserwartung in den Industrienationen zunehmend häufiger das Miterleben des geistig-physischen Verfalls der immer älter Werdenden dazugehört, gibt es mittlerweile auch dazu kinderliterarische Bearbeitungen. Als Beispiel sei das Bilderbuch Der Fuchs, der den Verstand verlor von Martin Baltscheit (2010) genannt, das sich mit der Problematik des Alt-Werdens und der Altersdemenz auseinandersetzt und 2011 mit dem Deutschen Jugendliteraturpreis ausgezeichnet wurde.

Da Kinder zudem im familiären Umfeld von Sterbenden und Begräbnissen oft ferngehalten werden und Großeltern aufgrund der gestiegenen Lebenserwartung in höherem Alter versterben, scheint insbesondere der Alterstod ein Kinder nicht betreffendes Phänomen zu sein. Diesem „Erfahrungsentzug“ (Feldmann 2004, 66) wirken solche pädagogischen Einrichtungen entgegen, die keinen bewahrpädagogischen Auftrag mehr verfolgen und Friedhof-, Krematoriums- und Krankenbesuche zu ihrem Programm zählen. Eine entsprechend weitergehende Reflexion der Notwendigkeiten auf allen Ebenen des kinderliterarischen Handlungs- und Symbolsystems ist nur wünschenswert. Dafür müssen aber noch 
weitere Erkenntnisse über das Fragebedürfnis und -verhalten von Kindern gewonnen werden.

Für den Umgang mit fragenden Kindern gilt gleichwohl:

Alles, was ihren Horizont mindert (sei es ein Zuwenig oder ein Zuviel), ist für sie kontraproduktiv; es beeinträchtigt die Entwicklung differenzierter Erfahrungs-, Denk- und Sprachmuster, durch die sowohl die emotionale als auch die intellektuelle Reifung Heranwachsender beeinflusst wird. Kinderbücher zum Thema ,Sterben und Tod' sollten dieser Erkenntnis entsprechend konzipiert sein: Es wäre gut, d.h. lebensförderlich, wenn in ihnen Schreckensvorstellungen bearbeitet und dauerhaft tragfähige Hoffnungsbilder angeboten würden. Das wäre ein Akt offener, religiöser Kommunikation, der auf Orientierung ausgerichtet ist. (Plieth 2007, 53)

Der Tod ist zwar eine auch für Kinder stets präsente mediale Erscheinung, diese hat aber so gut wie nichts mit dem eigenen Erleben zu tun. Unbestritten sind die prägenden Effekte einer zugewandten und verständigen sozialen Kommunikation und Interaktion für die emotional-empathische Persönlichkeitsentwicklung von Kindern, die aber denen abgeht, die mit (medialen) Erfahrungen und Bildern von Gewalt und Tod allein gelassen werden - oder gar selbst Gewalt erfahren. Dem entgegenzuwirken ist nicht nur eine Aufgabe des Konzepts der „Death Education" ${ }^{283}$, einer thanatologischen, der ars vivendi zugewandten Pädagogik, sondern ein allgemein-sozialer und nicht zuletzt ein literarisch anzugehender Auftrag. Dass das gegenwärtige Bilderbuchangebot diesem durchaus folgt, konnte aufgezeigt werden. Bilderbücher können ihren Beitrag zu einer Generationen übergreifenden Kommunikation gerade zu diesem schwierigen Thema aber nur dann leisten, wenn sie auch in dieser Funktion wahrgenommen werden.

Bilderbuchliteratur kann helfen, eigene Positionen zu bestätigen oder neue Perspektiven zu gewinnen. Sie bildet verschiedenste Facetten der Unsicherheiten und Problemfelder ab, die sich im Zusammenhang mit Tod und Sterben auftun, und macht damit Angebote zur Auseinandersetzung aus akutem Anlass oder aktuellem Interesse - für Erwachsene wie für Kinder. Wer die Denkanstöße aufzunehmen und die dargestellten Trauerprozesse und Trostbilder vielleicht als probate Entlastung eigener emotionaler Ausnahmezustände aufzufassen vermag, tut viel für sein Selbstkonzept und einen reifen Umgang mit dem Tod und damit dem Leben.

283 „Diese [vornehmlich aus Amerika stammende] Konzeption versucht, Todeswirklichkeit als wesentlichen Bestandteil fremder und eigener Lebenswirklichkeit zu erfassen und in den Umgang mit den damit verbundenen Gefühlen, Einstellungen und Handlungen einzuüben." (Henneke 2009, 94). 
Es geht nicht darum, den Tod zu »evakuieren «, sondern [...] in erster Linie schon darum, den jungen Menschen durch Erziehung so auf das Leben vorzubereiten, daß er seine Sterblichkeit in seinen Lebensplan einbezieht. Damit ist kein negatives "memento mori« in seiner bedrohlichen Bedeutung gemeint, sondern eine Lebensphilosophie, die Leben und Tod gleichrangig und in ihrer Beziehung zueinander einbezieht. (Mischke 1996, 261; H. i. O.)

Dann wird die ars moriendi zur ars vivendi, ohne dem Leben seine notwendige Unbeschwertheit zu nehmen. Was die Literatur und insbesondere Bilderbücher dazu beitragen können, sollte im Blick behalten werden. 


\section{Literaturverzeichnis}

\section{IX.1 Primärliteratur - Gesamtkorpus der untersuchten Titel}

Aakeson, Kim Fupz; Eriksson, Eva (2005): Erik und das Opa-Gespenst. Aus d. Dän. v. Dagmar Brunow (OA DK 2004). Hamburg: Oetinger.

Abedi, Isabel; Cordes, Miriam (2006): Abschied von Opa Elefant. Eine Bilderbuchgeschichte über den Tod. Hamburg: Ellermann.

Aertssen, Kristien (2011): Als Oma ein Vogel wurde. Aus d. Franz. von Rosemarie Griebel-Kruip (OA F 2007). Hildesheim: Gerstenberg.

Alex, Marlee; Alex, Benny (Fotos); Wickelsoe, Otto (Fotos) (1982): Grossvater und ich und die traurige Geschichte mit dem kleinen Kätzchen. Aus d. Engl. v. Dorothee Degen-Zimmermann (OA DK 1982). Basel: Brunnen-Verl. (ABCTeam, Wenn Kinder fragen, Nr. 2, 686).

Allan, Nicholas (1996): Gibt's im Himmel Schokolade? Aus d. Engl. v. Barbara Rojahn-Deyk (OA GB 1996). Hildesheim: Gerstenberg.

Ansorge, Bettina (1989): Buttje aus dem Moor. Oldenburg: Lappan.

Arima, Shizuko; Arima, Junko (1984): Pon und Lulu. Hamburg: Saatkorn-Verl.

Barth, Friedrich Karl; Wünsch, Dorota (2003): Himbeermarmelade. Wuppertal: Hammer.

Barth, Rolf; Droessler, Thorsten (2008): Herr Wolke. Dorles Oma. Eine Geschichte für das Leben. Berlin: Traumsalon-Ed.

Bauer, Jutta (2001): Opas Engel. Hamburg: Carlsen.

Becker, Antoinette; Mocka, Susanne (1994): Roberts alter Freund. Eine Geschichte von Freundschaft und Abschiednehmen. Ravensburg: Ravensburger Buchverl.

Becker, Antoinette; Niggemeyer, Elisabeth (1979): Ich will etwas vom Tod wissen. Geschichten vom Tod und vom Leben. Ravensburg: Maier (Ich und die Welt).

Bektas, Habib; Guhe, Irmtraud (1991): Mein Freund, der Opabaum. Erlangen: Boje-Verl.

Benecke, Mark; Fuss, Lisa (2008): Wo bleibt die Maus? Vom Kreislauf des Lebens. Düsseldorf: Sauerländer.

Bergman, Thomas (1989): Jeden Tag leben. Hanna und Fredrik haben Leukämie. Übertr. ins Dt. u. bearb. von Heidrun Flüeler (OA CH). Luzern: Kinderbuchverlag.

Bernhard, Thomas; Schweiggert, Alfons (2006): Viktor Halbnarr. Ein Wintermärchen nicht nur für Kinder. München: Verl. Sankt Michaelsbund. 
Beuscher, Armin; Haas, Cornelia (2002): Über den großen Fluss. Vom Abschiednehmen und Trauern, vom Mutfinden und Trostgeben. Düsseldorf: Sauerländer.

Billioud, Jean-Michel; Gay, Michel (2000): Schreckliche Zahnschmerzen. Aus d. Franz. v. Tobias Scheffel (OA F). Frankfurt a. M.: Moritz.

Bley, Anette (2005): Und was kommt nach tausend? Eine Bilderbuchgeschichte vom Tod. Ravensburg: Ravensburger Buchverl. Maier.

Blüm, Norbert; Göbel, Doro (2001): Franka \& Nonno auf den Spuren des Bären Ludewig. 2. Aufl. Hamburg: Ed. Riesenrad.

Blumentritt, Linda (2003): Lara’s Schmetterlinge (sic!). Mit bunten Flügeln in ein neues Leben. Zwingenberg: Bissinger.

Boritzer, Etan; Forrest, Nancy (2007): Was ist Tod? Aus d. Am. v. Jochen Weiss (OA USA 2000). Berlin: Abentheuer-Verl.

Bourguignon, Laurence; D’Heur, Valérie (2005): Der alte Elefant. Aus d. Franz. von Irmtraud Fröse-Schreer und Ursula Weigert (OA B). Gießen: BrunnenVerl.

Broere, Rien; Bode, Ann de (1998): Opa kommt nicht wieder. (OA B 1995). Triesen: Ed. Fuchs und Hase.

Bröger, Achim; Brandt, Katrin (1971): Raupengeschichte. Zürich, Freiburg i. Br.: Atlantis.

Brunhoff, Jean de (1946): Die Geschichte von Babar dem kleinen Elefanten. Aus d. Franz. v. Claudia Schmölders (OA F 1931). Ravensburg: O. Maier.

Burningham, John (1984): Mein Opa und ich. Aus d. Engl. v. Irina Korschunow (OA BG 1984). Zürich, Schwäbisch Hall: Parabel.

Burningham, John (1988): Grosspapa. Aus d. Engl. v. Rolf Inhauser (OA GB). Aarau: Sauerländer.

Burningham, John (1997): Wolkenland. Aus d. Engl. v. Rolf Inhauser (OA GB). Aarau: Sauerländer.

Buscaglia, Leo F. (1987): Aus dem Leben von Freddie, dem Blatt. Eine Erzählung, die uns hilft, den Sinn von Leben und Tod zu verstehen. Aus d. Am. v. Rolf Merkle (OA USA). Mannheim: PAL-Verl.-Ges.

Carle, Eric (1969): Die kleine Raupe Nimmersatt. Aus d. Am. v. Viktor Christen (OA USA 1969). Oldenburg, Hamburg: Stalling (Stalling-Künstlerbilderbuch).

Carnavas, Peter (2011): Die wichtigen Dinge. Übersetzt von Harald Kiesel (OA AUS 2010). Köln: Boje-Verl. 
Carrick, Carol; Carrick, Donald (1980): Christoph verliert seinen Freund. Christoph und Ben. Aus d. Am. v. Marion von der Kammer (OA USA). Hamburg: Carlsen (Reinbeker Kinderbücher).

Clément, Claude; Clément, Frédéric (1987): Der Maler und die wilden Schwäne. Eine Erzählung. Aus d. Franz. v. Claudia Daiber-Amann (OA F 1986). Buxtehude: Verl. an d. Este.

Clément, Frédéric (1988): Der Geigenbauer von Venedig. Buxtehude: Verl. an d. Este.

Coerr, Eleanor; Young, Ed (1995): Sadako. Aus d. Engl. v. Maria Andreas-Hole (OA USA 1993). Berlin: Altberliner Verl.

Cohen-Janca, Irène; Quarello, Maurizio A. C. (2011): Annes Baum. Aus d. Franz. v. Tobias Scheffel (OA F). Hildesheim: Gerstenberg.

Cole, Babette (1997): Fall um! Aus d. Engl. v. Rolf Inhauser (OA GB). Aarau, Frankfurt a. M., Salzburg: Sauerländer.

Cratzius, Barbara; Blancke, Ursula (1995): Das Bärenkind. Berlin: W. Mann.

Crowther, Kitty (2011): Der Besuch vom kleinen Tod. Aus d. Franz. v. Maja von Vogel (OA F 2004). Hamburg: Carlsen.

Dale, Elizabeth; Joos, Frédéric (1995): Felix. Aus d. Engl. v. Ursula Heckel (OA GB 1994). Hamburg: Carlsen (Andersen Press bei Carlsen).

Dale, Elizabeth; Joos, Frédéric (2003): Baffy. Aus d. Engl. v. Ursula Heckel (OA USA). Hamburg: Forschungskreis Heimtiere in der Gesellschaft (Lizenz Carlsen).

Damjan, Mischa; Casty, Gian (1965): Atuk, der Eskimojunge. Die Geschichte vom Eskimojungen, der lernt, daß Liebe stärker ist als Haß. (OA CH 1964). München: Parabel (Lizenz NordSüd 1964).

Damjan, Mischa; Wilkoń, Józef (2008): Atuk. Neuausg. Zürich: NordSüd.

Davids, Barbara; Münzer Gabriele (2000): Eines Morgens war alles ganz anders. Freiburg i. Br.: Lambertus.

Deru-Renard, Beatrice; Edith (2002): Ein kleiner König weint doch nicht. Aus d. Franz. v. Tobias Scheffel (OA F 2002). Frankfurt a. M.: Moritz.

Dierks, Hannelore; Solé-Vendrell, Carme (1995): Der schwarze Vogel. Düsseldorf: Patmos.

Doray, Malika (2003): Wenn ich an meine Oma denk ... Aus d. Franz. v. Alexander Potyka (OA F 2002). Wien: Picus-Verl.

Douglas-Hamilton, Oria (1990): Das Elefanten-Kinder-Buch. (OA A). Salzburg: Bilderbuchstudio Neugebauer Press.

Dros, Imme; Geelen, Harrie (1992): Das O von Opa. Eine Geschichte. Aus d. Niederl. v. Mirjam Pressler (OA NL). Köln: Middelhauve. 
Dros, Imme; Geelen, Harrie (2000): Das ist das Haus am krummen Baum. Aus d. Niederl. v. Mirjam Pressler (OA NL 1997). München: Middelhauve.

Duda, Christian; Friese, Julia (2007): Alle seine Entlein. (OA CH). Zürich: Bajazzo.

Dudok Wit, Michael de (2003): Vater und Tochter. Aus d. Niederl. v. Arnica Esterl (OA NL 2002). Stuttgart: Verl. Freies Geistesleben.

Duffy, Carol Ann; Ryan, Rob (2010): Das Geschenk. Aus d. Engl. v. Ulrike Becker (OA GB 2010). München: Kunstmann.

Durant, Alan; Gliori, Debi (2004): Für immer und ewig. Aus d. Engl. v. Daniela Mibus (OA GB). Kiel: Wittig (Ein Doubleday-Buch).

Egger, Bettina; Jucker, Sita (1986): Marianne denkt an ihre Grossmutter. Zürich, Recklinghausen, Wien, Paris: Bohem Press.

Ellermann, Heike (1990): Papiervogel, flieg! Es war an einem Tag im August. Freiburg i. Br.: Herder.

Ellermann, Heike (1992): Der rote Faden. Oldenburg: Lappan.

Ellsworthy, Allan; Ben-Arab, Mariam (2009): Opa ist überall. Hamburg: Edelkids. Elschner, Géraldine; Schwarz, Lieselotte (2002): Sternenkind. (OA CH). Gossau, Zürich: Neugebauer.

Ende, Michael; Hechelmann, Friedrich (1988): Ophelias Schattentheater. Stuttgart: Thienemann.

Erlbruch, Wolf (2004): Die große Frage. Wuppertal: Hammer.

Erlbruch, Wolf (2007): Ente, Tod und Tulpe. München: Kunstmann.

Essen, Georg; Schuler, Renate; Bernard-Kress, Margret (1999): Von Tod und Auferstehung den Kindern erzählt. Kevelaer: Butzon \& Bercker.

Eustis, Helen; Michl, Reinhard (1985): Das rothaarige Mädchen. Eine Geschichte aus dem Wilden Westen. Aus d. Am. v. Eva Riekert (OA USA). Stuttgart: Thienemann.

Fabian, Gerhard; Stepanek, Ludmilla (1987): Leb wohl, Hoppi. Abschied von einem kleinen Freund. München: Claudius.

Fährmann, Willi; Ruegenberg, Lukas (1998): Neues von Pimann. Kevelaer: Butzon \& Bercker.

Feile, Ruth; Feile Katrin (2008): Tante Lotti geht in den Himmel. München: Rieder.

Feth, Monika; Pin, Isabel (2007): Opa, ich kann Hummeln zähmen. Düsseldorf: Sauerländer.

Fietzek, Petra; Plankenberg Anna (1995): Eine Sonne für Oma. Basel, Freiburg i. Br., Wien: Herder. 
Fortier, Natali; Legendre, Françoise (2008): Orangen für Opa. Aus d. Franz. v. Rosemarie Griebel-Kruip (OA F). Düsseldorf: Sauerländer.

Fried, Amelie; Gleich, Jacky (1997): Hat Opa einen Anzug an? München, Wien: Hanser.

Gaes, Jason; Gaes, Tim u. Adam (1989): Mein Name ist Jason Gaes. Ich bin acht Jahre, ich hatte Krebs. Aus d. Am. v. Angelika Kutsch (OA USA). Hamburg: Carlsen.

Gajadin, Chitra; Ong, Helen (1996): Amal und der Brief des Königs. Nach einem Schauspiel des Nobelpreisträgers Rabindranath Tagore. Aus d. Niederl. v. Joachim Georg (OA NL). Stuttgart: Ed. Anker (Edition Anker - Regenbogen).

Galeano, Eduardo; Santos, Antonio; Enzenberg, Carina von (2010): Geschichte von der Auferstehung des Papageis. (OA CH). Zürich: Bajazzo.

Gätjen, Heike; Kauss, Uwe (2007): Wie ist das mit dem Tod? Willi wills wissen. Die Reportage für Kinder und alle, die es wissen wollen. Frankfurt a. M.: Baumhaus-Verl. (Ein Baumhaus-Willi-wills-wissen-Buch, 10).

Geelen, Harrie (1993): Hermann, das Kind und die Dinge. Aus d. Niederl. v. Mirjam Pressler (OA NL 1993). Köln: Middelhauve.

Geelhaar, Anne; Appelmann, Karl-Heinz (1994): Oma auf dem Regenbogen. Schwedt: KiRo-Verl.

Gemmel, Stefan; Muckenschnabl, Markus (2002): Paneelos Melodie. Neureichenau: Ed. Zweihorn. (S. Neuausgabe 2012: Elfenmelodie. Illustriert von Susanne Zuda. Edition Lichtland).

Gerstein, Mordicai (2000): Wie der Schatten eines fliegenden Vogels. Eine jüdische Legende aus Kurdistan. Aus d. Engl. v. Richard Rosenstein (OA USA). Stuttgart: Verl. Freies Geistesleben.

Ghazinoor, Ghodsi (1993): Die kleine Schnecke. Aus d. Niederl. v. Diethelm Hofstra (OA NL). Unkel/Rh: Horlemann.

Gilson, Patrick; Dubois, Claude K. (2004): Wenn ich nicht mehr bei dir bin, bleibt dir unser Stern. Aus d. Niederl. v. Irmtraud Fröse-Schreer (OA NL). Gießen: Brunnen-Verl. (Brunnen-Kinder- \& -Jugendbücher).

Gliemann, Claudia; Tritschler, Patrick (2011): Ohne Oma. Karlsruhe: Monterosa. Godfrey, Jan; Cope, Jane (1996): Opas Kirschbaum. Aus d. Engl. v. Hanna Schott (OA GB). Wuppertal: Oncken.

Godfrey, Jan; Corke, Estelle (2011): Erzähl mir vom Himmel. Aus d. Engl. v. Ines Weber (OA GB). Asslar: GerthMedien. (Neuaufl. von: Godfrey, Jan; Cope, Jane (1996): Opas Kirschbaum. Wuppertal: Oncken).

Goethe, Johann Wolfgang von; Erlbruch, Wolf (1998): Das Hexen-Einmal-Eins. München: Hanser. 
Goodall, Jane; Marks, Alan (2004): Rickie und Henri. Eine wahre Geschichte. Aus d. Engl. v. Peter Christian Hammelsbeck (OA GB). Kiel: Mined.

Goossens, Philippe; Robberecht, Thierry (2004): Eva im Land der verlorenen Schwestern. Aus d. Niederländ. v. Isabelle Fuchs (OA NL). Düsseldorf: Sauerländer.

Gorey, Edward (1967): Das unglückselige Kind. Aus d. Am. v. Wolfgang Hildesheimer (OA USA 1961). Zürich: Diogenes (Klub der Bibliomanen, 5).

Gottanka, Hans; Rutsche, Gerda M. (2008): Galaxia vom goldenen Stern besucht München. Augsburg: Wißner.

Gray, Nigel; Cabban, Vanessa (2000): Der kleine Bär und sein Opa. Aus d. Engl. v. Norbert Landa (OA AUS). Rheinfelden: OZ-Verl.

Güdel, Helen (2009): Apollo, das Maultier. Eine Geschichte aus den Bergen. (OA CH). Zürich: Atlantis.

Guggenheim, Rosa Monika (2009): Die Vogelforscherin. (OA CH). Sulgen, Zürich: Niggli.

Gydal, Monica; Danielsson, Thomas; Andersson, Mats (1974): Oles Großvater. Aus d. Schwed. v. Elke Pirck (OA S). Hamburg: Carlsen (Reinbeker Kinderbücher, 4).

Gydal, Monica; Danielsson, Thomas; Andersson, Mats (1975): Ole sieht einen Verkehrsunfall. Aus d. Schwed. v. Elke Pirck (OA S). Hamburg: Carlsen.

Häckelmann, Romy (2004): Fünfstern. Recklinghausen: KinderVest-Verl. (Nordfriesische Inselgeschichte).

Haerdter, Marie-Claude; Redl, Margarete (1976): Tobis böser Traum. Berlin: Basis-Verl. (Kiebitz, 3).

Hagen, Hans; Geelen, Harrie (1996): Still, ich denke an das Huhn. Aus d. Niederl. v. Mirjam Pressler (OA NL). München: Middelhauve.

Hansen, Gerth (1981): Wenn Tiere sterben. Aus d. Engl. v. Eva M. Späth (OA DK 1981). Würzburg: Arena (Natur entdecken, Tiere erleben).

Harranth, Wolf; Oppermann-Dimow, Christina (1981): Mein Opa ist alt, und ich hab ihn sehr lieb. Wien, München: Jungbrunnen.

Hastings, Selina; Cartwright, Reg (1994): Bodkin oder das Rätsel vom ewigen Leben. Eine alte Geschichte. Aus d. Engl. v. Nele Moost (OA GB 1988). Berlin: W. Mann.

Hechelmann, Friedrich; Borchers, Elisabeth (1984): Ein Weihnachtstraum. München: Hirmer.

Heidelbach, Nikolaus (1984): Kleiner dicker Totentanz. Köln: DuMont.

Heidelbach, Nikolaus (1999): Was machen die Jungs? Weinheim: Beltz \& Gelberg. 
Heine, Helme (1976): Elefanteneinmaleins. Velber, Hannover: Middelhauve.

Heinrichsdorf, Pierre Markus (1995): Honiggelb und Steingrau. Eine Geschichte vom Sterben und Abschiednehmen. Hildesheim: Gerstenberg.

Henmo, Sverre; Scharnberg, Stefanie (2006): Für immer mein Opa. Aus d. Norweg. v. Gabriele Haefs (OA N). Hamburg: Carlsen.

Hentig, Hartmut; Hentig, Urd (1993): Die hässliche kleine Fledermaus. Bielefeld: Pendragon.

Herbold, Marie (2002): Papi, wir vergessen dich nicht. Das Tagebuch der 13-jährigen Marie Herbold während Krankheit und Tod von ihrem Papi. (OA CH). Gossau, Zürich: NordSüd.

Hermann, Inger; Solé-Vendrell, Carmé (1999): Du wirst immer bei mir sein. Düsseldorf: Patmos.

Herrmann, Sabine; Bahde, Jo (2007): Luca und der Schmetterling. Ein Bilderbuch vom Abschiednehmen. Gütersloh: Gütersloher Verl.-Haus.

Herzog, Annette; Clante, Katrine (2009): Flieger am Himmel. Wuppertal: Hammer.

Hesselbarth, Susann (2011): Das Leben leben! Oldenburg: Lappan.

Heymans, Annemie; Heymans, Margriet (1993): Die Prinzessin vom Gemüsegarten. Aus d. Niederl. v. Mirjam Pressler (OA NL). Aarau: Sauerländer.

Hole, Stian (2009): Garmans Sommer. Aus d. Norw. v. Ina Kronenberger (OA N). München: Hanser.

Holzinger, Michaela; Stöllinger, Heide (2011): Abschied von Anna. (OA A). Innsbruck, Wien: Tyrolia-Verl.

Horvath, Klara; Horvath, Maria (1999): Leben nach dem Tod. Hard: Klamato.

Höschl, Eva; Kutschera, Nana (2008): Tschüss Oma. Ein Kinderbuch zu Abschied und Trauer. Wuppertal: hospiz-verlag.

Hubka, Christine; Hammerle, Nina (2004): Wo die Toten zu Hause sind. (OA A). Mit einem pädagogischen Anhang „Wie mit Kindern über den Tod reden?“. Innsbruck: Tyrolia-Verl.

Hübner, Franz; Höcker, Kirsten (1992): Grossmutter. Salzburg, München: Neugebauer Press.

Hüttner, Hannes; Sell, Lothar (1982): Das Lachen. Nach einem Motiv aus Chewsuretien. Berlin: Kinderbuchverlag.

Imbsweiler, Gerd; Rappo, Petra (2003): Schildkrötenträume. Zürich: Bajazzo.

Innocenti, Roberto; Gallaz, Christophe (1986): Rosa Weiss. Aus d. Franz. v. Abraham Teuter (OA CH 1985) Frankfurt a. M.: Ali-Baba-Verlag. 
Isler, Iris (1992): Die Fahrt zum Pferdeparadies. (OA CH). Zürich: Verl. pro juventute.

Jakoby, Bernard; Adler, Michaela (2008): Georgs Reise zu Gott. Hg. v. Eva-Maria Popp. Pfarrkirchen: Basic Erfolgsmanagement.

Jalonen, Riitta; Louhi, Kristiina (2007): Das Mädchen unter dem Dohlenbaum. Aus d. Finn. v. Anu Pyykönen-Stohner (OA FIN 2004). München: Hanser.

Janisch, Heinz; Blau, Aljoscha (2005): Rote Wangen. Berlin: Aufbau.

Janosch (1968): Böllerbam und der Vogel. Köln: Middelhauve.

Janosch (1985): Der alte Mann und der Bär. (OA CH). Zürich: Diogenes (Diogenes-Kinder-Klassiker).

Jeffers, Oliver (2011): Das Herz in der Flasche. Aus d. Engl. (OA GB 2010). Berlin: Aufbau.

Jianghong, Chen (2005): Der Tigerprinz. Aus d. Franz. v. Erika u. Karl Klewer (OA F 2005). Frankfurt a. M.: Moritz.

Jianghong, Chen (2006): Junger Adler. Aus d. Franz. v. Erika und Karl A. Klewer (OA F). Frankfurt a. M.: Moritz.

Jianghong, Chen (2009): An Grossvaters Hand. Meine Kindheit in China. Aus d. Franz. v. Tobias Scheffel (OA F 2008). Frankfurt a. M.: Moritz.

Jörg, Sabine; Winterhager, Daniele (1996): Wiedersehen in Falun. Stuttgart: Thienemann.

Kaldhol, Marit; Øyen, Wenche (1987): Abschied von Rune. Aus d. Norw. v. Angelika Kutsch (OA N). München: Ellermann.

Karimé, Andrea; Behl, Anne-Kathrin (2011): Lea, Opa und das Himmelsklavier. (OA A). Wien: Picus-Verl.

Kasuya, Masahiro; Watari, Yoko (2007): Himmelsmelodie. Aus d. Japan. v. Johannes Keussen (OA J 2006). Kiel: Wittig.

Kaufmann, Angelika (1971): Ein Pferd erzählt: Ich bin nur ein Pferd, ein ganz gewöhnliches Ackerpferd. (OA A). Bad Goisern: Neugebauer-Press.

Kaufmann, Angelika (1999): Das fremde Kind N. Weitra: Verl. Publikation PN ${ }^{\circ}$ 1 Bibliothek der Provinz.

Kaufmann, Angelika (2004): Ich und du, du und ich. Weitra: Verl. Publikation $\mathrm{PN}^{\circ} 1$ Bibliothek der Provinz.

Kaufmann, Angelika; Lobe, Mira (1985): Leb wohl, Fritz Frosch. (OA A). Wien: Jugend und Volk.

Kikuta, Mariko (2003): Du bist immer noch bei mir. Aus d. Jap. v. Claudia Peter (OA J). Hamburg: Carlsen (Carlsen-Comics). 
Kim, Min-Ki; Kwon, Moon-hee (2010): Abschied von Aika. Aus d. Korean. v. Jerome Lee (OA Korea 2002). Stäfa: aracari.

Kinder, Martina (2001): Du bist nicht allein, Benji Bär. Aus d. Franz. v. Gerlinde Wiencirz (OA B). München: arsEdition.

Kirchberg, Ursula (1997): Trost für Miriam. München: Ellermann.

Knoch, Betina Yoshita (2011): Mein Freund Xaverl und ich. Berlin: Dt. Literaturges.

Krenzer, Rolf; Horn, Reinhard (2001): Mach's gut, kleiner Freund. Lippstadt: Kontakte-Musikverl.

Kriebaum, Thomas (2011): kleiner Tod. (OA A). Wien: Luftschacht.

Krol, Dagmar; Kunstreich, Pieter (2005): Kevin Kanin oder Als es dunkel wurde am Lohewald. Eine Geschichte für die Kinder von Hipstedt. Stuttgart: Kreuz (Kreuz Junior).

Kübler-Ross, Elisabeth; Rothmayr, Madlaina (1985): Die unsichtbaren Freunde. (OA CH). Glattbrugg-Zürich: Oesch.

Langen, Annette; Bohnstedt, Antje (2008): Vier Pfoten am Himmel. Freiburg: Herder.

Larreula, Enric; Capdevila i Valls, Roser (1988): Die Hochzeit der verflixten Hexe. Aus d. Span. v. Dorothea Löcker und Alexander Potyka (OA ES 1987). Wien: Picus.

Laube, Sigrid; Blazejovsky, Maria (1998): Großvater hebt ab. Wien, München: Jungbrunnen.

Lehoczky, György (1971): Mukis Wunderbaum. Texte von Michaela Bach nach Motiven von György Lehoczky. München: Betz.

Lembcke, Marjaleena; Ellermann, Heike (2001): Das Eisschloss. Oldenburg: Lappan.

Lemieux, Michèle (1996): Gewitternacht. Weinheim: Beltz \& Gelberg.

Lenz, Siegfried; Greif, Jörg (1978): Lotte macht alles mit. München: Lentz.

Lévy, Didier; Roussel, Matthieu (2005): Angelman. Aus d. Franz v. Edmund Jacoby (OA F). Hildesheim: Gerstenberg.

Lindgren, Astrid; Törnqvist, Marit (2003): Sonnenau. Aus d. Schwed. v. AnnaLiese Kornitzky (OA S). Hamburg: Oetinger.

Lionni, Leo (1964): Swimmy. Aus d. Am. v. James Krüss (OA USA 1963). Köln: Middelhauve.

London, Jonathan; Long, Sylvia (1994): Liplaps Wunsch. Wie Grossmutter sich in einen Stern verwandelte. Aus d. Am. v. Mirjam Pressler (OA USA 1994). München: arsEdition. 
Loske, Judith (2011): Sadakos Kraniche. Bargteheide: Minedition.

Loth, Sebastian (2010): Jolante sucht Crisula. Die Geschichte einer unendlichen Freundschaft. (OA CH). Zürich: NordSüd.

Lunde, Stein Erik; Torseter, Øyvind (2010): Papas Arme sind ein Boot. Aus d. Norweg. v. Maike Dörries (OA N). Hildesheim: Gerstenberg.

Lundgren, Gunilla; Jacobsson, Lars (Fotos); Wellner, Militta (Ill ). (1983): Der Baum, der nicht sterben wollte. Aus d. Schwed. v. Ellen Jacobsen (OA S 1983). Hamburg: Carlsen (Reinbeker Kinderbücher).

Lyoth, Nadine; Meyer, Daniel (2002): Welche Farbe hat der Tod? Mit Unterrichtsanregungen. Aarau: Sabe-Verl.

MacCardie, Amanda; Crossland, Caroline (1997): Mach's gut, kleiner Frosch. Aus d. Engl. v. Ingrid Weixelbaumer (OA GB). Mödling-Wien: Verl. St. Gabriel.

Marx, Agnes; Herrmann, Sabine (1998): Franziska und der alte Gärtner. Limburg: Lahn-Verl.

Matzen, Ulla; Grundmann, Annett (2003): Das Mädchen Jane und die blaue Wolke. Berlin: MITeinander-Verl. (Lesen für alle).

Meinderts, Koos; Fienieg, Annette (2007): Die Geschichte von Jonas und Oma. Aus d. Niederländ. v. Joost Nijhoff (OA NL 2007). Königstein im Taunus: Titania-Verl.

Meinderts, Koos; Jekkers, Harrie; Grobler, Piet (2009): Ballade vom Tod. Aus d. Niederl. v. Rolf Erdorf (OA NL). Hildesheim: Gerstenberg.

Melin, Margareta (1977): Johanna und der Tod. Aus d. Schwed. v. Lilly u. Franz Gölzenleuchter (OA S). Fotos: Beate Rosebrock u. Lothar Müller. Gelnhausen, Berlin: Burckhardthaus-Verlag.

Mersch, Monika (2006): Mona's Reise. (sic!) Eine Geschichte von der Vorbereitung einer Seele zur Erdenreise bis zu ihrer Heimkehr in die Lichtwelt. Deutsch-Evern: Sternentaler Verlag.

Meyer; Lehmann; Schulze (2009): Tschüss, kleiner Piepsi! Bilder von Susanne Göhlich. Leipzig: Klett Kinderbuch. (Die wilden Zwerge).

Missfeldt, Jochen; Schübel, Christine (1990): Der Rapskönig. Wiesbaden, Zürich: Parabel.

Moritz, Andrea; Gerke, Sabine (2001): Tod und Sterben Kindern erklärt. Gütersloh: Gütersloher Verl.-Haus.

Müller, Birte (2003): Auf Wiedersehen, Oma. (OA CH). Gossau. Zürich: Neugebauer.

Mürmann, Hermann J.; Meis, Hannelore (2004): Warum so hart kleiner Bär? Nottuln: Ed. Dharma Do. 
Newman, Lesléa; Himler, Ronald (2007): Die beste Katze der Welt. Aus d. Engl. v. Peter Baumann (OA USA). Oldenburg: Lappan.

Niederer, Werner (2010): Zwischen zwei Weihnachten. (OA CH). Bern: Blaukreuz Bern.

Nilsson, Ulf; Eriksson, Eva (2006): Die besten Beerdigungen der Welt. Aus d. Schwed. v. Ole Könnecke (OA S 2006). Frankfurt a. M.: Moritz.

Nilsson, Ulf; Tidholm, Anna-Clara (2003): Adieu, Herr Muffin. Aus d. Schwed. v. Ole Könnecke (OA S 2002). Frankfurt a. M.: Moritz.

Nystrom, Carolyn; Large, Annabel (1991): Anja nimmt Abschied. Krankheit und Tod in der Familie. Aus d. Engl. v. Hanna Rumler-Gross (OA GB). Giessen: Brunnen-Verl.

Nystrom, Carolyn; Reeves, Eira (1995): Was kommt nach dem Tod? Kinder entdecken den christlichen Glauben. Aus d. Engl. v. Anne Meiss (OA GB 1992). Marburg an der Lahn: Francke.

Ommen, Sylvia van; Wanten, Willy de (2003): Lakritzbonbons. Aus d. Niederl. v. Willy de Wanten (OA NL 2002). Frankfurt a. M.: Moritz.

Paffrath, Stefanie (2010): Als Papa in den Himmel flog. Amaliendorf-Aalfang: S. Paffrath.

Paola, Tomie de (1979): Die goldene Kugel. Aus d. Am. v. Marion von der Kammer (OA USA). Hamburg: Carlsen.

Passacantando, Boris Joh; Kiesel, Harald (2008): Das Panda-Mädchen. Frankfurt a. M.: Baumhaus-Verl. (Ein Baumhaus-Bilderbuch).

Pilz, Andreas; Heinze, Gabine (1994): Mach's gut, Opa! Leipzig: Benno (Kleine Kinder - große Sorgen).

Place, François (2006): Grosser Bär. Aus d. Franz.v. Bernadette Ott (OA F). Köln: Boje-Verl.

Pludra, Benno; Mossner, G. Ruth (1978): Trauermantel und Birke. Berlin: Kinderbuchverlag.

Poole, Josephine; Barrett, Angela (2005): Anne Frank. Aus d. Engl. v. Mirjam Pressler (OA USA 2005). Würzburg: Arena.

Popov, Nikolaj (1995): Warum? (OA CH). Gossau: Neugebauer.

Popp, Eva-Maria; Adler, Michaela (2007): Tim trauert um seinen Freund. Pfarrkirchen: Basic Erfolgsmanagement.

Proché, Sabrina; Suchy, Elisabeth (2004): Brüderchen bei den Sternen. Seebenstein: ReBos, Bosmanszky.

Randerath, Jeanette; Chudzinski, Daniela (2007): Der Abschiedsbrief von Opa Maus. Stuttgart: Thienemann. 
Recheis, Käthe; Kaufmann, Angelika (1998): Schwesterchen Rabe. Freiburg: Kerle.

Recheis, Käthe; Sormann, Christine (1999): Kleine Schwarzpfote. (OA A). Wien: Gabriel-Verl.

Recknagel, Friedrich; Dusíková, Maja (2001): Sarahs Weide. Gossau, Zürich, Hamburg: NordSüd.

Reinheimer, Sophie; Wenz-Viëtor, Else (2008): Vom Himmel der Tiere. Oldenburg: Lappan.

Reuter, Elisabeth (1989): Christian. München: Ellermann.

Ringtved, Glenn; Pardi, Charlotte (2002): Warum, lieber Tod ...? Aus d. Dän. v. Jürgen Lassig (OA DK 2001). Bremen: Rößler.

Rivett, Rachel; Macnaughton, Tina (2010): Sei nicht traurig, kleiner Bär! Aus d. Am. v. Irmtraud Fröse-Schreer (OA USA). Gießen: Brunnen-Verl. (BrunnenKinder- \& -Jugendbücher).

Rogge, Jan-Uwe; Port, Moni (1998): Ein Wolkenlied für Omama. Reinbek bei Hamburg: Rowohlt.

Rohner, Viola; Wünsch, Dorota (2011): Wie Großvater schwimmen lernte. Wuppertal: Hammer.

Rosen, Michael; Blake, Quentin; Rosenstein, Richard (2006): Mein trauriges Buch. Stuttgart: Verl. Freies Geistesleben.

Rosenlöcher, Thomas; Gleich, Jacky (2010): Der Mann, der lieber tot sein wollte. Rostock: Hinstorff.

Ruß, Julia; Broska, Elke (2009): Himmelskind. Witten: SCM R. Brockhaus.

Rylant, Cynthia (1998): Auch Hunde kommen in den Himmel. Aus d. Am. v. Friedrich Langreuter (OA USA 1995). München: arsEdition.

Saalfrank, Heike; Goede, Eva (1998): Abschied von der kleinen Raupe. Würzburg: Echter.

Saegner, Uwe (2005): Papa, wo bist Du? Ein Kinderbuch zu Tod und Trauer für Kinder. Wuppertal: hospizverlag.

Saegner, Uwe (2009): Sarahs Mama. Wenn die Mutter stirbt - ein Kinderbuch. Wuppertal: hospiz-verlag.

Scharenberg, Lucy; Ballhaus, Verena (2010): Wenn Oma nicht mehr da ist. (OA A). Wien: Betz im Verl. Ueberreuter.

Scheffler, Ursel; Timm, Jutta (2010): Schmetterlingspost. Eine Geschichte von Trost und Erinnerung. München: arsEdition.

Schindler, Regine; Jucker, Sita (1994): Mia, was ist ein Trip? (OA CH). Zürich: Bohem-Press. 
Schins, Marie-Thérèse; Müller, Birte (2005): Zuckerguss für Isabel. Wuppertal: Hammer.

Schins, Marie-Thérèse; Müller, Birte (2008): Eine Kiste für Opa. Berlin: Aufbau.

Schneider, Antonie; Dusíková, Maja (1998): Leb wohl, Chaja! (OA CH). Gossau, Zürich: NordSüd.

Schneider, Antonie; Gotzen-Beek (2010): Ein Himmel für Oma. Ein Bilderbuch über das Sterben und den Tod. Münster: Coppenrath. (Neuaufl.: Schneider/ Dusíková 1998: Leb wohl, Chaja!).

Schopf, Sylvia; Tophoven, Manfred (2006): Abschied von Rosetta. Wien, München: Betz.

Schössow, Peter (2005): Gehört das so??! Die Geschichte von Elvis. München: Hanser.

Schubiger, Jürg; Berner, Rotraut Susanne (2011): Als der Tod zu uns kam. Wuppertal: Hammer.

Schulß, Axel; Bunge, Daniela (2009): Als Otto das Herz zum ersten Mal brach. Köln: Boje-Verl.

Schulz, Hermann; Krejtschi, Tobias (2007): Die schlaue Mama Sambona. Wuppertal: Hammer.

Schulz, Hermann; Oeser, Wiebke (2000): Sein erster Fisch. Wuppertal: Hammer.

Schwikart, Georg; Fischer, Uta (2010): Von Sterben, Tod und Trauer den Kindern erzählt. Kevelaer: Butzon \& Bercker.

Seebaß, Ursula (2010): Apfel und Birne. Wangen: Smiling Life.

Seehafer, Klaus; Lesch, Christiane (1986): Sieben Tiere zum Himmel. Düsseldorf: Patmos.

Sheppard, Gordon; Rozier Jacques (1971): Herr Pommerin verschenkt sich. Aus d. Am. v. Rolf Inhauser (OA USA 1971). Aarau: Sauerländer.

Simon, Annette; Selle, Barbara (2003): Der geborgte Stern. Frickenhausen: Initiative Regenbogen, Glücklose Schwangerschaft.

Solotareff, Grégoire (1994): Wer hat Angst vor einem Hasen? Unter Mitarbeit von Gerhard Pöhlmann. Frankfurt a. M.: Moritz.

Sommer-Bodenburg, Angela; Tiong-King, Thé (1989): Julia bei den Lebenslichtern. München: Bertelsmann.

Sönnichsen, Imke; Liddle, Elizabeth (2003): Mama, wie groß ist der Himmel? Aus d. Engl. v. Christof Stählin (OA GB 2002). Stuttgart: Gabriel-Verl.

Stalfelt, Pernilla (2000): Und was kommt dann? Das Kinderbuch vom Tod. Aus d. Schwed. v. Birgitta Kicherer (OA S). Frankfurt a. M.: Moritz. 
Stanko, Jörg; Jankowski, Heike (2005): „Flieg Hilde, flieg!“. Schalksmühle: PomaskaBrand (Limette-Kinderbücher).

Staring, Jennine; Dematons, Charlotte; Kemperman, Martin (2002): Was kann Lukas trösten? Die traurige Geschichte mit Pauline. Aus d. Am. v. Irmtraud Fröse-Schreer (OA USA). Gießen: Brunnen-Verl. (Brunnen-Kinder- \& Jugendbücher).

Stark, Ulf; Höglund, Anna (1997): Meine Schwester ist ein Engel. Aus d. Schwed. v. Birgitta Kicherer (OA S). Hamburg: Carlsen.

Stavarič, Michael; Schwab, Dorothee (2010): Die kleine Sensenfrau. (OA A). Wien: Luftschacht.

Steiner, Liliane (1999): Auf welchem Stern lebt Sina? Olga auf der Suche nach ihrer verstorbenen Schwester. (OA CH). Zürich: Lehrmittelverlag Kanton Zürich.

Stellmacher, Hermien; Lieffering, Jan (2005): Nie mehr Oma-Lina-Tag? Stuttgart: Gabriel-Verl.

Sturm, Gabriele; Hillen, Jasmin Sophie (2008): Justus ist traurig. Ein Kinderbuch für trauernde Kinder und die Menschen, die sie auf diesem Weg begleiten. Kirchen: Wilma-Verl.

Sturm, Hans; Schleer, Irene (1988): Das Apfelbaumjahr. Buxtehude: Verl. an d. Este.

Surkus-Anzenhofer, Armin; Wiede, Regina (2010): „Ich bin nur eine Sternstunde weit weg." Trier: Paulinus.

Tejima, Keizaburo (1996): Schwanenwinter. Aus d. Jap. (OA J 1983). Frankfurt a. M.: Moritz.

Thompson, Colin (1993): Auf der Suche nach Atlantis. Oldenburg: Lappan.

Thompson, Colin (1995): Für immer leben. Aus d. Engl. v. Hildegard Krahé (OA GB). Oldenburg: Lappan.

Thompson, Colin (1997): Bücher öffnen Welten. Aus d. Engl. v. Hildegard Krahé (OA GB). Oldenburg: Lappan.

Thompson, Colin (2001): Wenn Sally fliegt. Aus d. Engl. v. Johanna und Martin Walser (OA GB). Ravensburg: Ravensburger Buchverl.

Thönnes, Dietmar; Kurtz, Cornelia (2002): Von Sterben, Tod und Beerdigung den Kindern erzählt. Kevelaer: Butzon \& Bercker.

Thurmann, Ilka-Maria; Fischer, Uta (2010): Am Anfang waren wir zu zweit. Ein Buch für verlassene Zwillingskinder. Mit einem Vorwort von Irene Behrmann und einem Begleittext von Ilka-Maria Thurmann. Frankfurt a. M.: MabuseVerl. 
Tidholm, Thomas; Tidholm, Anna-Clara (1990): Die Reise nach Ugri-La-Brek. Aus d. Schwed. v. Salah Naoura (OA S). Weinheim: Beltz \& Gelberg.

Traxler, Hans (2004): Komm, Emil wir gehn heim! München: Hanser.

Treiber, Jutta; Blazejovsky, Maria (2001): Die Blumen der Engel. Wien, München: Betz.

Treiber, Jutta; Rassmus, Jens (2006): Der Großvater im rostroten Ohrensessel. (OA A). Wien: Dachs-Verl.

Tsurumi, Masao; Suzuki, Mamoru (1984): Guten Morgen alter Baum. (OA J). Wien: Jugend und Volk.

Usatschow, Andrej; Junge, Alexandra (2008): Geschichte ohne Ende und Anfang. Aus d. Russ. v. Simone Peil (OA RUS). Zürich: NordSüd.

Vainio, Pirkko (1993): Die Schneegans. Gossau: NordSüd.

Vendel, Edward van de; Godon, Ingrid (2007): Grossvater, Kleinvater. Aus d. Niederländ. v. Rolf Erdorf (OA NL 2007). Hamburg: Carlsen.

Varley, Susan (1984): Leb wohl, lieber Dachs. Aus d. Engl. v. Ingrid Weixelbaumer (OA GB 1984). München: Betz.

Vaugelade, Anaïs (1999): Fabian und der Krieg. Aus d. Franz. v. Tobias Scheffel (OA F). Frankfurt a. M.: Moritz.

Velthuijs, Max (1992): „Was ist das?“ fragt der Frosch. Aus d. Engl. v. Rolf Inhauser (OA GB 1991). Aarau, Frankfurt a. M., Salzburg: Sauerländer.

Verroen, Dolf; Erlbruch, Wolf (2003): Ein Himmel für den kleinen Bären. Aus d. Niederl. v. Marcel Glück (OA NL). München: Hanser.

Vinje, Kari; Zahl-Olsen, Vivian (2000): Pelle und die Geschichte mit Mia. Aus d. Norw. v. Elisabeth Wohlenberg (OA N). Gießen: Brunnen-Verl.

Waechter, Friedrich Karl (1997): Da bin ich. (OA CH). Zürich: Diogenes.

Waechter, Friedrich Karl (1998): Der rote Wolf. (OA CH). Zürich: Diogenes.

Waechter, Friedrich Karl (2004): Der Affe des Strandfotografen. (OA CH). Zürich: Diogenes.

Walbrecker, Dirk; Mair, Martina (2006): Ist Omi jetzt ein Engel? München: Pattloch.

Waldmann-Brun, Sabine (1995): Lia ist krank. Lahr: Johannis.

Wegenast, Bettina; Meyer, Kerstin (2008): Hannah und ich. Düsseldorf: Sauerländer.

Weigelt, Udo; Haas, Cornelia (2011): Die Königin und ich. Mannheim: Sauerländer. 
Weigelt, Udo; Kadmon, Cristina (2003): Der alte Bär muss Abschied nehmen. Eine Geschichte über Abschied und Zuversicht. (OA CH). Gossau, Zürich: NordSüd.

Weigner, Sylvia; Kreimeier, Birgit (2008): Lukas und Oma nehmen Abschied. Eine Geschichte über Sterben und Trauern. Ratingen: Bloom's.

Wendt, Irmela; Boratynski, Antoni (1991): Der Krieg und sein Bruder. Düsseldorf: Patmos.

Westera, Bette; Straaten, Harmen van (2001): Seinen Opa wird Jan nie vergessen. Aus d. Niederl. v. Andrea Grotelüschen (OA NL 2000). Oldenburg: Lappan.

Wickli, Anna-Barbara; Villiger, Daniela (1997): Danke, lieber Fuchs. Krinau: Wickli.

Wikland, Ilon; Lagercrantz, Rose (1996): Die lange, lange Reise. Aus d. Schwed. v. Angelika Kutsch (OA S 1995). Hamburg: Oetinger.

Wild, Margaret; Blackwood, Freya (2011): Ben \& Bommel. Aus d. Engl.v. Michael Stehle (OA AUS). Stuttgart: Urachhaus.

Wild, Margaret; Brooks, Ron (1997): Das Licht in den Blättern. Aus d. Engl. v. Susanne Koppe (OA AUS). Frankfurt a. M.: Moritz.

Wilhelm, Hans (1987): Ich hab dich so lieb. Aus d. Am. v. Ursula Heckel (OA USA 1985). Hamburg: Carlsen (Reinbeker Kinderbücher).

Wilkoń, Józef (2002): Frau Drosselmann. (OA CH). Zürich: Bohem Press.

Willis, Jeanne; Ross, Tony (2007): Kalle Mäuserich. Aus d. Engl. v. Eva Schweikart (OA GB 2007). Düsseldorf: Sauerländer.

Witt, Eva (2010): Bernis Opa. Eine Erzählung für Großeltern, Eltern und Kinder. München: Bayerische Krebsges.

Wolf, Winfried; Duroussy, Nathalie (1992): Indianerjunge Kleiner Mond. Gossau, Zürich, Hamburg: NordSüd.

Wolf, Winfried; Sopko, Eugen (1994): Weihnachten bei Grossvater. (OA CH). Gossau Zürich: NordSüd.

Wynnejones, Pat; Ratcliffe, Sheila (1992): Die Geschichte von der Larve Geronimo. Frau Gattys Gleichnisse aus der Natur, nacherzählt von Pat Wynnejones. Aus d. Engl. v. Walter A. Siering (OA GB 1991). Stuttgart: Christliches Verl.Haus.

Yano, Shigeko (1985): Hinter dem Hügel. Düsseldorf: Patmos.

Yumoto, Kazumi; Sakai, Komako (2009): Der Bär und die Wildkatze. Aus d. Jap. v. Ursula Gräfe (OA J 2008). Frankfurt a. M.: Moritz. 


\section{IX.2 Weitere erwähnte Primärliteratur}

Comenius, Johann Amos (1979): Orbis sensualium pictus. Hoc est, omnium fundamentalium in Mundo Rerum \& in Vita Actionum pictura \& nomenclatura = Die sichtbare Welt. Taschenbuch-Ausg., Nachdr. d. Erstausg. von 1658, 2. Aufl. Dortmund: Harenberg (Die bibliophilen Taschenbücher, 30).

Baltscheit, Martin (2011): Die Geschichte vom Fuchs, der den Verstand verlor. 2. Aufl. Berlin: Bloomsbury Kinderbücher \& Jugendbücher.

Der Gevatter Tod. Drei Versionen des Märchens (2000). Unter Mitarbeit von Johannes von Freydorf (Satz und Illustrationen). München: Kunst- und Textwerk Verlag.

Ende, Michael (1973): Momo. Stuttgart: Thienemann.

Ende, Michael (1979): Die unendliche Geschichte. Stuttgart: Thienemann.

Funke, Cornelia (2003-2007): Tintenherz (2003), Tintenblut (2005), Tintentod (2007). Berlin: Dressler.

Gebhardt, Hertha von (1947): Die Kinderwiese. Berlin: Dressler.

Lindgren, Astrid (1974): Die Brüder Löwenherz. Unter Mitarbeit von Anna-Liese Kornitzky. (OA S 1973) Hamburg: Oetinger.

McAfee, Annalena; Browne, Anthony (1984): Mein Papi, nur meiner! oder: Besucher die zum Bleiben kamen. (OA GB) Frankfurt a. M.: Alibaba.

Nilsson, Ulf; Eriksson, Eva; Könnecke, Ole (2009): Als wir allein auf der Welt waren. (OA S) Frankfurt a. M.: Moritz.

Ohba, Tsugumi; Obata, Takeshi (2007): Deathnote. A. d. Japanischen von Kay Hermann, Bd. 1, 3. Aufl. Hamburg.

Tolkien, J. R. R. (1969/70): Der Herr der Ringe. (OA GB 1954/55) Stuttgart: KlettCotta.

Waechter, Philip (2004): ich. Weinheim [u. a.]: Beltz \& Gelberg.

\section{IX.3 Sekundärliteratur}

Abmeier, Armin (2008): Alphabet \& Zeichenstift. Die Bilderwelt von Rotraut Susanne Berner. München: Hanser.

Abraham, Ulf (2012): Fantastik in Literatur und Film. Eine Einführung für Schule und Hochschule. Berlin: Erich Schmidt Verlag (Grundlagen der Germanistik, 50).

Abraham, Ulf; Sowa, Hubert (2012): Bilder lesen und Texte sehen. Symbiosen im Deutsch- und Kunstunterricht. In: Praxis Deutsch 39 Jg., H. 232, S. 4-11. 
Abraham, Ulf; Beisbart, Ortwin; Holoubek, Helmut (Hgg.) (1996): Was Kinder berührt. Kinderwelten in Bilderbüchern? Bamberg: Lehrstuhl Didaktik der Dt. Sprache und Literatur.

Aley, Peter (1972): Einblick in die Welt des Bilderbuchs - Anmerkungen zum Anspruchsniveau der neuesten Produktion. In: Klaus Doderer (Hg.): Bilderbuch und Fibel. Eine kritische Analyse der Literatur für Leseanfänger. Weinheim: Beltz (Beltz-Monographien), S. 97-152.

Amuat, Renate (Hg.) (2005): Last minute - der Tod macht auch vor der Schule nicht Halt. Materialien für Lehrerinnen und Lehrer. 4. Aufl. Zürich: Verl. Pestalozzianum.

Anthony, S. (1940): The child's discovery of death. Keagan, Trench, Trubner, London.

Arbeitskreis für Jugendliteratur (Hg.) (1984): Der Deutsche Jugendliteraturpreis 1956-1983. Ausschreibungen, Begründungen, Laudationes, Kriterien. Unter Mitarbeit von Heide Peetz (Red.). München.

Arbeitskreis für Jugendliteratur (Hg.) (1985): Das Bilderbuch. Eine Auswahl von Bilderbüchern aus aller Welt. Unter Mitarbeit von Ottilie Dinges und Elisabeth Hohmeister (Red.). 7. Aufl. München.

Arens-Wester, Veronika (1994): Grenzsituationen. Mit Kindern über Sterben und Tod sprechen. Essen: Verl. Die Blaue Eule (Religionspädagogische Perspektiven, 19).

Ariès, Philippe (1976): Studien zur Geschichte des Todes im Abendland. München: Hanser.

Ariès, Philippe (1982): Geschichte des Todes. München: Dt. Taschenbuch Verlag (DTV Wissenschaft).

Armbröster-Groh, Elvira (2001): Abschied von Rune. Ein Bilderbuch zum Thema Tod. In: Gabriele Cromme und Wilhelm Steffens (Hgg.): Kinder- und Jugendliteratur. Lesen - Verstehen - Vermitteln. Festschrift für Wilhelm Steffens. Baltmannsweiler: Schneider (Didaktik der Kinder- und Jugendliteratur, 1), S. $18-25$.

Astington, J. W.: Wie Kinder das Denken entdecken. München, Basel: Reinhardt 2000.

Bamberger, Richard (1965): Jugendlektüre. Jugendschriftenkunde, Leseunterricht, Literaturerziehung. 2. Aufl. Wien: Jugend u. Volk.

Bamberger, Richard (1975): Jugendschriftenkunde. Wien, München: Jugend u. Volk.

Bardola, Nicola (2009): Mit Bilderbüchern wächst man besser. Stuttgart [u. a.]: Thienemann. 
Baumgärtner, Alfred Clemens (Hg.) (1968): Aspekte der gemalten Welt. 12 Kapitel über das Bilderbuch von heute. Weinheim: Beltz.

Baumgärtner, Alfred Clemens (1973): Perspektiven der Jugendlektüre. Beiträge zur Leseerziehung. 2., erw. Aufl. Weinheim: Beltz.

Baumgärtner, Alfred Clemens (Hg.) (1974): Deutsches Jugendbuch heute. Unter Mitarb. von Marianne Exner u. Dorothea Otte. Velber: Friedrich.

Baumgärtner, Alfred Clemens (1990): Das Bilderbuch. Geschichte - Formen Rezeption. In: Bettina Paetzold und Luis Erler (Hgg.): Bilderbücher im Blickpunkt verschiedener Wissenschaften und Fächer. Bamberg: Nostheide, S. 4-22.

Baumgärtner, Alfred Clemens; Pleticha, Heinrich; Franz, Kurt; Lange, Günter; Payrhuber, Franz-Josef (Hgg.) (1995): Kinder- und Jugend-Literatur. Ein Lexikon. Autoren, Illustratoren, Verlage, Begriffe. Begründet von Alfred Clemens Baumgärtner und Heinrich Pleticha. Meitingen: Corian.

Beinert, Wolfgang (2010): Tod und jenseits des Todes. 2., veränd. Aufl. Kevelaer: Verl.-Gemeinschaft Topos plus (Topos-Taschenbücher, 355).

Beitl, K. (1960): Hölle. IV. Volkskundlich. In: Josef Höfer und Karl Rahner (Hgg.): Lexikon für Theologie und Kirche (1957-1967), Bd. 5. 2., völlig neu bearb. Aufl. Freiburg i. Br.: Herder, S. 449-450.

Berger, Klaus (1997): Ist mit dem Tod alles aus? Stuttgart: Quell.

Berger, Manfred (1986): Das Kaufhausbilderbuch. Fragmente zu einem vernachlässigten Genre der Kinder- und Jugendliteratur. In: Informationen des Arbeitskreises für Jugendliteratur. München: Arbeitskreis für Jugendliteratur, S. 25-45.

Bilderbuchmuseum Burg Wissem (2000): Anthony Browne - Künstler der Blicke. Katalog zur Ausstellung. Oldenburg.

Bilderbuchmuseum Burg Wissem (2001): Nikolaus Heidelbach. Katalog zur Ausstellung. Troisdorf.

Bilderbuchmuseum Burg Wissem (2007): Chen Jianghong: Illustration und Malerei. Katalog zur Ausstellung. Troisdorf.

Blei, Claudia (1998): Zur bild- und sprachästhetischen Darstellung des Eigenen und Fremden im deutschsprachigen Bilderbuch. (2 Bde.) Dresden, Techn. Univ.

Blei-Hoch, Claudia (2002): „Komm, lass uns doch ein Bilderbuch anschauen...“ Einblicke in den Forschungsstand zur Rezeption von Bilderbüchern. In: ide, Informationen zur Deutschdidaktik 26 (2), S. 65-75.

Blei-Hoch, Claudia (2006): Bilderbuch. In: Heinz-Jürgen Kliewer und Inge Pohl (Hgg.): Lexikon Deutschdidaktik. Baltmannsweiler: Schneider, S. 56-58. 
Blum, Cornelia (2000): Trauernde (Geschwister-)Kinder seelsorgerlich begleiten - Was können wir tun? In: Wolfgang Holzschuh (Hg.): Geschwister-Trauer. Erfahrungen und Hilfen aus verschiedenen Praxisfeldern. Regensburg: Pustet, S. 160-188.

Blunck, Lars (Hg.) (2010): Die fotografische Wirklichkeit. Inszenierung - Fiktion Narration. Bielefeld: Transcript (Image).

Bodarwé, Christoph (1989): Reden vom Tod ist Reden vom Leben. Neuere Kinder- und Jugendliteratur zum Thema „Tod“ als Impuls für die religionspädagogische Praxis in Sonderschulen. Essen: Verl. Die Blaue Eule (Religionspädagogische Perspektiven, 10).

Bode, Andreas (2004): Stilwandel im deutschen Bilderbuch 1950-2000. In: Günter Lange, Kurt Franz und Heinrich Pleticha (Hgg.): Von der Steinzeit bis zur Gegenwart. Historisches in der Kinder- und Jugendliteratur. Festschrift für Heinrich Pleticha zum 80. Geburtstag. Baltmannsweiler: Schneider, S. 92103.

Bode, Andreas (2005): Tendenzen im Bilderbuch von 1950 bis zur Gegenwart. In: Kurt Franz und Günter Lange (Hgg.): Bilderbuch und Illustration in der Kinder- und Jugendliteratur. Baltmannsweiler: Schneider (Schriftenreihe der Deutschen Akademie für Kinder- und Jugendliteratur Volkach e.V, 31), S. 17-31.

Bode, Andreas (2006): Bilderbücher und Kinderbuchillustrationen. In: Rüdiger Steinlein, Heidi Strobel, Thomas Kramer und Theodor Brüggemann (Hgg.): SBZ/DDR. Von 1945 bis 1990. Stuttgart: Metzler (Handbuch zur Kinder- und Jugendliteratur; Bd. 7), S. 829-902.

Boehm, Gottfried (1994): Die Wiederkehr der Bilder. In: Ders. (Hg.): Was ist ein Bild. München, 11-38.

Born, Monika (1989): Religiöse Aussagen in neueren Bilderbüchern. In: Marlies Göcking und Heinz-Jörg Eckhold (Hgg.): Religion in der Kinder- und Jugendliteratur. Annweiler, Essen, S. 139-148.

Born, Monika (2002): Religiöse Kinder- und Jugendliteratur. In: Günter Lange (Hg.): Taschenbuch der Kinder- und Jugendliteratur. Bd. 1: Grundlagen Gattungen. 3., unveränd. Aufl. Baltmannsweiler: Schneider, S. 399-414.

Born, Monika (2003): Mit Bildern glauben lernen. Die Wahrnehmung religiöser Spuren im Bilderbuch. In: Willi Fährmann, Vera Steinkamp und Michael Schlagheck (Hgg.): Religion in der Kinder- und Jugendliteratur. Was Menschen ersehnen. (Spurensuche 14) Mülheim an der Ruhr: Kath. Akad. Die Wolfsburg. 
Born, Monika (2006): Bilderbücher - gemalte und verdichtete Welt. In: Michael Sahr und Monika Born (Hgg.): Kinderbücher im Unterricht der Grundschule. 7., erg. Aufl. Baltmannsweiler: Schneider, S. 88-114.

Born, Monika (2007): Für ein klares Profil religiöser Kinder- und Jugendbücher. In: Jürgen Heumann (Hg.): Auf der Suche nach Religion. Die Wiederkehr der Religion im Kinder- und Jugendbuch. Oldenburg, S. 9-20.

Bowlby, John (1980): Das Glück und die Trauer. Herstellung und Lösung affektiver Bindungen. Stuttgart: Klett-Cotta (Konzepte der Humanwissenschaft).

Bowlby, John (1983): Verlust, Trauer und Depression. Frankfurt a. M.: FischerTaschenbuch-Verlag.

Bowlby, John (2006a): Bindung und Verlust. 3 Bde. München, Basel: E. Reinhardt.

Bowlby, John (2006b): Bindung und Verlust. Bd. 3, Verlust - Trauer und Depression. München, Basel: E. Reinhardt.

Brandt, Heike (1989): Der Tod gehört zum Leben. Kinder- und Jugendbücher zum Thema Sterben. Berlin: Pädag. Zentrum.

Braun, Barbara (1995): Vorläufer der literarischen Sozialisation in der frühen Kindheit. Eine entwicklungspsychologische Fallstudie. Frankfurt a. M.: Lang (Europäische HochschulschriftenReihe 6, Psychologie, 511).

Brednich, Rolf Wilhelm (Hg.) (2009): Erzählkultur. Beiträge zur kulturwissenschaftlichen Erzählforschung. Hans-Jörg Uther zum 65. Geburtstag. Berlin, New York: Walter de Gruyter.

Bringeus, Nils-Arved (1995): Bild und Text. Einführung in ein Problemfeld. In: Leander Petzoldt (Hg.): Bild und Text. Einführung in ein Problemfeld. Frankfurt a. M. [u. a.]: Lang, S. 26-36.

Brocher, Tobias (1981): Wenn Kinder trauern. Wie sprechen wir über den Tod? 2. Aufl. Zürich: Kreuz-Verl.

Brocher, Tobias (1993): Zwischen Angst und Übermut. Vom Umgang mit sich selbst. Düsseldorf, Wien: ECON-Taschenbuch-Verl.

Brocher, Tobias (2000): Mit Kindern über den Tod sprechen. In: Johann-Christoph Student (Hg.): Im Himmel welken keine Blumen. Kinder begegnen dem Tod. 5., neubearb. Aufl. Freiburg i. Br.: Herder (Herder-Spektrum, 4967), S. 24-39.

Brock, Michael H. F (2007): ... und tschüss! Farben zwischen Himmel und Erde. Kinder und Jugendliche sehen, erleben und erfahren Sterben, Tod und Trauer. Stuttgart: Raumzeit3-Verl.

Brüning, Barbara (1998): Mit Kinderbüchern zum Philosophieren anregen. In: Beiträge Jugendliteratur und Medien 50 (2), S. 66-76. 
Brunken, Otto; Barth, Susanne; Brüggemann, Theodor (Hgg.) (1987): Vom Beginn des Buchdrucks bis 1570. Stuttgart: Metzler (Handbuch zur Kinder- und Jugendliteratur, Bd. 1).

Brunken, Otto; Barth, Susanne; Brüggemann, Theodor (Hgg.) (1991): Handbuch der Kinder- und Jugendliteratur von 1570 bis 1750. Stuttgart: Metzler (Handbuch zur Kinder- und Jugendliteratur Bd. 2).

Brunken, Otto; Giesa, Felix (Hgg.) (2013): Erzählen im Comic. Beiträge zur Comicforschung; 4. Wissenschaftstagung der Gesellschaft for Comicforschung (ComFor). Essen: Bachmann.

Brunken, Otto; Giesa, Felix (2013): Zu diesem Band. In: Otto Brunken und Felix Giesa (Hgg.): Erzählen im Comic. Beiträge zur Comicforschung; 4. Wissenschaftstagung der Gesellschaft für Comicforschung (ComFor). Essen: Bachmann, S. 9-16.

Brunken, Otto; Hurrelmann, Bettina; Michels-Kohlhage, Maria; Wilkending, Gisela (Hgg.) (2008): Handbuch zur Kinder- und Jugendliteratur. Von 1850 bis 1900. Stuttgart: Metzler. (Handbuch zur Kinder- und Jugendliteratur, Bd. 5).

Brunken, Otto; Hurrelmann, Bettina; Pech, Klaus-Ulrich; Brüggemann, Theodor (Hg.) (1998): Handbuch zur Kinder- und Jugendliteratur 1800-1850. Stuttgart: Metzler. (Handbuch zur Kinder- und Jugendliteartur, Bd. 4).

Buchberger, Michael; Kasper, Walter (Hgg.) (1993-2001): Lexikon für Theologie und Kirche. 3., völlig neu bearb. Aufl. ( 11 Bde.) Freiburg: Herder.

Bucher, Anton A. (Hg.) (2010): „In der Mitte ist ein Kreuz“. Kindertheologische Zugänge im Elementarbereich. Stuttgart: Calwer Verl.

Burghardt, Anja (2013): IV.3 Einleitung. In: Silke Lahn, Jan Christoph Meister (Hgg.): Einführung in die Erzähltextanalyse. 2., aktual. Aufl. Stuttgart: Metzler, S. 199-203.

Bürgin, Dieter (1981): Das Kind, die lebensbedrohende Krankheit und der Tod. Bern: Huber.

Cevela, Inge (1996): Jung ist der Vater von Alt. Die Beziehung von alten und jungen Menschen in der Darstellung der KJL. In: TueB (4), S. 16-31.

Cevela, Inge; Lexe, Heidi (Red.) (1998): Deine Nähe spür ich noch... Sterben, Tod, Trauer als Themen der Kinder- und Jugendliteratur. Wien: Studien- und Beratungsstelle für Kinder- und Jugendliteratur (STUBE).

Chatman, Seymour (1975): The Structure of Narrative Transmission. In: Roger Fowler (Hg.): Style and structure in literature. Essays in the New Stylistics. Oxford: Blackwell (Language and style series, 16), S. 213-258.

Collet, Lora J.; Lester, D. (1969): The fear of death and the fear of dying. Journal of Psychology 72, S. 179-181. 
Cramer, Barbara (2003): Der Tod im Bilderbuch. Ist sterben wie einschlafen? In: Friedhof und Denkmal 48 (2), S. 3-29.

Cramer, Barbara (2004): Bilderbücher zu Sterben und Tod aus dem Jahr 2003. In: Beiträge Jugendliteratur und Medien 56 (3), S. 202-206.

Cramer, Barbara (2008): Bist du jetzt ein Engel? Mit Kindern über Leben und Tod reden. Ein Handbuch. Tübingen: DGVT-Verl.

Cramer, Barbara (2009): Tut Sterben weh? Kindliche Vorstellungen vom Tod und wie Kinderliteratur Fragen beantworten kann. In: JuLit 35 (2009) H. 1, S. 3-8.

Cramer, Barbara (2012): Bist du jetzt ein Engel? Mit Kindern über Leben und Tod reden. Ein Handbuch. 2., überarb. und erw. Aufl. Tübingen: DGVT-Verl.

Cramer, Gabriele (2011): „Wenn Welt den Anfang nimmt und das Ende kommt“. Mythisches in der Kinder- und Jugendliteratur. Überarbeitete Fassung. In: Georg Langenhorst (Hg.): Gestatten: Gott! Religion in der Kinder- und Jugendliteratur der Gegenwart. München: Verl. St. Michaelsbund, S. 137-144.

Criegern, Axel von (1996): Vom Text zum Bild. Wege ästhetischer Bildung. Weinheim: Dt. Studien-Verl.

Cromme, Gabriele; Steffens, Wilhelm (Hgg.) (2001): Kinder- und Jugendliteratur. Lesen - Verstehen - Vermitteln. Festschrift für Wilhelm Steffens. Baltmannsweiler: Schneider (Didaktik der Kinder- und Jugendliteratur, 1).

Dankert, Birgit (1988): „Da wurden ihm die Toten so bekannt...“. Sterben und Tod als literarisches Thema. In: Informationen des Arbeitskreises für Jugendliteratur (3), S. 5-27.

Dehn, Hille; Thiele, Jens (1985): Bilder entdecken - Anregungen zur Beurteilung von Illustrationen. In: Thiele, Jens (Hg.) (1985): Bilderbücher entdecken. Untersuchungen, Materialien u. Empfehlungen zum kritischen Gebrauch einer Buchgattung. Oldenburg: Isensee, S. 142-164.

Deutsche Staatsbibliothek Berlin (Hg.) (1989): Almanach zur Kinderliteratur der DDR. Bücher \& Bilder. Hamburg: Kath. Akad.

Dietschi Keller, Ursula (1995): Bilderbücher für Vorschulkinder. Bedeutung und Auswahl. Zürich: Pro Juventute.

Dinges, Ottilie (1974): Glück und Heil in der Kinderliteratur. In: ru (Zeitschrift für die Praxis des Religionsunterrichts) (4), S. 66-73.

Dinges, Ottilie (1979): Die religiöse Dimension in heutigen Kinderbüchern. In: Katechetische Blätter 104 (7), S. 534-541.

Dinges, Ottilie (1981): Die religiöse Dimension in heutigen Kinderbüchern. In: Josef Rabl (Hg.): Religiöse Kinderliteratur. Religionspädagogische Beiträge 1967-1980. München, Mainz: Chr. Kaiser; Matthias-Grünewald-Verl, S. 6273. 
Dinges, Ottilie (1984): Fragestellungen zu einer umfassenden ästhetischen und didaktischen Analyse des Bilderbuches. In: Arbeitskreis für Jugendliteratur (Hg.): Der Deutsche Jugendliteraturpreis 1956-1983. Ausschreibungen, Begründungen, Laudationes, Kriterien. Unter Mitarbeit von Heide Peetz (Red.). München, S. 125-131.

Dinges, Ottilie (1990): Sterben und Tod im Bilderbuch. In: Die katholische öffentliche Bücherei (KÖB) (3), S. 1-12.

Doderer, Klaus (Hg.) (1972): Bilderbuch und Fibel. Eine kritische Analyse der Literatur für Leseanfänger. Weinheim: Beltz (Beltz-Monographien).

Doderer, Klaus (Hg.) (1975f.): Lexikon der Kinder- und Jugendliteratur. Personen-, Länder- u. Sachartikel zu Geschichte u. Gegenwart d. Kinder- u. Jugendliteratur. 3 Bde. Weinheim: Beltz.

Doderer, Klaus (1973a): Das Poetische Bilderbuch im 19. Jahrhundert. In: Klaus Doderer und Helmut Müller (Hgg.): Das Bilderbuch. Geschichte und Entwicklung des Bilderbuchs in Deutschland von den Anfängen bis zur Gegenwart. Weinheim [u. a.]: Beltz, S. 99-182.

Doderer, Klaus (1973b): Das bürgerliche Bilderbuch im 19. Jahrhundert. In: Klaus Doderer und Helmut Müller (Hgg.): Das Bilderbuch. Geschichte und Entwicklung des Bilderbuchs in Deutschland von den Anfängen bis zur Gegenwart. Weinheim [u. a.]: Beltz, S. 183-224.

Doderer, Klaus; Müller, Helmut (Hgg.) (1973): Das Bilderbuch. Geschichte und Entwicklung des Bilderbuchs in Deutschland von den Anfängen bis zur Gegenwart. Weinheim [u. a.]: Beltz.

Dohmen, Christoph (1998): Paradies. II. Biblisch-theologisch. In: Michael Buchberger und Walter Kasper (Hgg.) (1993-2001): Lexikon für Theologie und Kirche. Bd. 7. 3., völlig neu bearb. Aufl. Freiburg: Herder, S. 1360-1362.

Dolle-Weinkauff, Bernd (2013): Heinrich Hoffmanns Struwwelpeter im Kontext der Entstehung und Entwicklung des narrativen Bilderbuchs. In: Otto Brunken und Felix Giesa (Hgg.): Erzählen im Comic. Beiträge zur Comicforschung. 4. Wissenschaftstagung der Gesellschaft für Comicforschung (ComFor). Essen: Bachmann, S. 199-220.

Dolle-Weinkauff, Bernd; Ewers, Hans-Heino (Hg.) (1996): Theorien der Jugendlektüre. Beiträge zur Kinder- und Jugendliteraturkritik seit Heinrich Wolgast. Weinheim: Juventa (Jugendliteratur - Theorie und Praxis).

Dolle-Weinkauff, Bernd; Ewers, Hans-Heino; Pohlmann, Carola (Hg.) (1999): Kinder- und Jugendliteraturforschung 1998/1999. Stuttgart: Metzler.

Dolle-Weinkauff, Bernd; Ewers, Hans-Heino; Pohlmann, Carola (Hgg.) (2012): Kinder- und Jugendliteraturforschung 2011/2012. Mit einer Gesamtbibliografie der Veröffentlichungen des Jahres 2011. Frankfurt a. M. [u. a.]: Lang. 
Dreßing, Gabriele (2004): Zwischen Bibel und Bilderbuch. Religiöse Kinder- und Jugendliteratur im Spiegel des Katholischen Kinder- und Jugendbuchpreises. St. Ingbert: Röhrig-Univ.-Verl.

Duhr, Katharina Betina (2010): Tod und Sterben in der modernen Kinder- und Jugendliteratur. Herzogenrath: Murken-Altrogge (Studien zur Medizin-, Kunst- und Literaturgeschichte, Bd. 65).

Egli, Florinne (2014): „Wo ist sein Leben hingekommen?“. Sterben und Tod in ausgewählten Bilderbüchern der Gegenwart. Zürich: Chronos (Beiträge zur Kinder- und Jugendmedienforschung, 4).

Eichhorn, Stephanie; Groeben, Norbert (1996): Tod und Sterben in der neueren Kinder- und Jugendliteratur. Eine inhaltsanalytische Erkundungsstudie. In: Siegener Periodicum zur internationalen empirischen Literaturwissenschaft (SPIEL) Bd. 15 (2), S. 183-201.

Elias, Norbert (1982): Über die Einsamkeit der Sterbenden in unseren Tagen. Frankfurt a. M.: Suhrkamp.

Engelbert-Michel, Angela (1998): Das Geheimnis des Bilderbuches. Ein Leitfaden für Familie, Kindergarten und Grundschule. Frankfurt a. M.: Brandes \& Apsel.

Ennulat, Gertrud (2003): Kinder trauern anders. Wie wir sie einfühlsam und richtig begleiten. Freiburg i. Br., Basel, Wien: Herder.

Ensberg, Claus (2006): Tod und Sterben in der erzählenden KJL. In: Alfred Clemens Baumgärtner, Heinrich Pleticha, Kurt Franz, Günter Lange und FranzJosef Payrhuber (Hgg.): Kinder- und Jugend-Literatur. Ein Lexikon. Autoren, Illustratoren, Verlage, Begriffe. (Teil 6: Themen/ Motive/ Stoffe. 28. Erg.-Lfg. Oktober 2006). Meitingen: Corian, S. 1-46.

Ewers, Hans-Heino (1987): Das doppelsinnige Kinderbuch. Erwachsene als Leser und als Mitleser von Kinderliteratur. In: Fundevogel (41/42), S. 8-12.

Ewers, Hans-Heino (Hg.) (1992): Komik im Kinderbuch. Erscheinungsformen des Komischen in der Kinder- und Jugendliteratur. Weinheim: Juventa (Jugendliteratur, Theorie und Praxis).

Ewers, Hans-Heino (1992): Pippi Langstrumpf als komische Figur. Anmerkungen zu einem Kinderbuchklassiker. In: Hans-Heino Ewers (Hg.): Komik im Kinderbuch. Erscheinungsformen des Komischen in der Kinder- und Jugendliteratur. Weinheim: Juventa (Jugendliteratur, Theorie und Praxis), S. 127-134.

Ewers, Hans-Heino (1994): Die Emanzipation der Kinderliteratur. In: Schweizerisches Jugendbuch-Institut (Hg.): Horizonte und Grenzen. Standortbestimmung in der Kinderliteraturforschung. Arbeitsbericht Nr. 17 des Schweizerischen Jugendbuch-Instituts. Zürich: Schweizerisches Jugendbuch-Inst., S. 75-87. 
Ewers, Hans-Heino (1995): Die Emanzipation der Kinderliteratur. Anmerkungen zum kinderliterarischen Funktionswandel seit Ende der 60er Jahre. In: Renate Raecke und Ute D. Baumann (Hgg.): Zwischen Bullerbü und Schewenborn. Auf Spurensuche in 40 Jahren deutschsprachiger Kinder- und Jugendliteratur. München: Arbeitskreis für Jugendliteratur, S. 16-28.

Ewers, Hans-Heino (2000): Literatur für Kinder und Jugendliche. Eine Einführung in grundlegende Aspekte des Handlungs- und Symbolsystems Kinderund Jugendliteratur. Mit einer Auswahlbibliographie Kinder und Jugendliteraturwissenschaft. München: W. Fink Verlag.

Ewers, Hans-Heino (2008): Romantik. In: Reiner Wild (Hg.): Geschichte der deutschen Kinder- und Jugendliteratur. 3., vollst. überarb. und erw. Aufl. Stuttgart: Metzler, S. 96-130.

Ewers, Hans-Heino (2012): Jenseits des Nationalen. Kinder- und Jugendliteratur und Germanistik im Zeitalter der Globalisierung. In: Bernd Dolle-Weinkauff, Hans-Heino Ewers und Carola Pohlmann (Hgg.): Kinder- und Jugendliteraturforschung 2011/2012. Mit einer Gesamtbibliografie der Veröffentlichungen des Jahres 2011. Frankfurt a. M. [u. a.]: Lang, S. 12-17.

Ewers, Hans-Heino; Lypp, Maria; Nassen, Ulrich (Hgg.) (1990): Kinderliteratur und Moderne. Ästhetische Herausforderungen für die Kinderliteratur im 20. Jahrhundert. Weinheim, München: Juventa (Jugendliteratur - Theorie und Praxis).

Ewers, Hans-Heino [et al.] (Hgg.) (2002): Kinder- und Jugendliteraturforschung 2001/2002. Stuttgart, Weimar: J.B. Metzler.

Fährmann, Willi (2001): Philosophisches und Religiöses in der Kinder- und Jugendliteratur. In: Marlies Göcking und Karl-Heinz Eckhold (Hgg.): Religion in der Kinder- und Jugendliteratur. (Spurensuche 11) Mülheim an der Ruhr: Kath. Akad. Die Wolfsburg.

Fährmann, Willi; Steinkamp, Vera; Schlagheck, Michael (Hgg.) (1997): Religion in der Kinder- und Jugendliteratur. (Spurensuche 9) Mülheim an der Ruhr: Kath. Akad. Die Wolfsburg.

Fährmann, Willi; Steinkamp, Vera; Schlagheck, Michael (Hgg.) (2003): Religion in der Kinder- und Jugendliteratur. Was Menschen ersehnen. (Spurensuche 14) Mülheim an der Ruhr: Kath. Akad. Die Wolfsburg.

Fassbind-Eigenheer, Ruth (2005): Und wenn sie nicht gestorben sind... Tod in Bildern und Texten für Kinder und Jugendliche. In: Renate Amuat (Hg.): Last minute - der Tod macht auch vor der Schule nicht Halt. Materialien für Lehrerinnen und Lehrer. 4. Aufl. Zürich: Pestalozzianum, S. 85-93.

Feldmann, Klaus (2004): Tod und Gesellschaft. Sozialwissenschaftliche Thanatologie im Überblick. Wiesbaden: VS Verl. für Sozialwiss. 
Feyerabend, Wolfgang (1989): Welt im Bilderbuch - Bilderbuchwelt? In: Deutsche Staatsbibliothek Berlin (Hg.): Almanach zur Kinderliteratur der DDR. Bücher \& Bilder. Hamburg: Kath. Akad, S. 52-56.

Fischer, Erika (1987): Todesvorstellungen von Jugendlichen. Eine empirische Untersuchung zu kognitiven Todesvorstellungen und. emotionalem Todeserleben jugendlicher Hauptschüler. Regensburg: Roderer.

Fischer, Erika (1994): Bilderbücher als Lernhilfen im Unterricht. Tod und Sterben in Bilderbüchern. In: Jugendbuchmagazin 44 (2), S. 68-75.

Fowler, Roger (Hg.) (1975): Style and structure in literature. Essays in the New Stylistics. Oxford: Blackwell (Language and style series, 16).

Frank, Hilmar; Frank, Tanja (1999): Zur Erzählforschung in der Kunstwissenschaft. In: Eberhardt Lämmert (Hg.): Die erzählerische Dimension: eine Gemeinsamkeit der Künste. Berlin: Akademie Verlag, S. 35-52.

Franz, Kurt; Lange, Günter (2000): Bilderwelten. Vom Bildzeichen zur CD-Rom. Baltmannsweiler: Schneider.

Franz, Kurt; Lange, Günter (Hgg.) (2005): Bilderbuch und Illustration in der Kinder- und Jugendliteratur. [Tagung am 28. und 29. April 2005 in Volkach]. Baltmannsweiler: Schneider (Schriftenreihe der Deutschen Akademie für Kinder- und Jugendliteratur Volkach e.V, 31).

Freud, Siegmund: Gesammelte Werke. 18 Bände. Frankfurt a. M.: Fischer.

Freud, Siegmund: Zeitgemäßes über Krieg und Tod (GW Bd. X), S. 323-355.

Fricke, Harald [et al.] (Hgg.) (2000): Reallexikon der deutschen Literaturwissenschaft. 3. Aufl. Berlin [u. a.]: de Gruyter (II).

Fromm, Hans; Nevala, MariaLiisa; Schellbach-Kopra, Ingrid (Hgg.) (2005): Jahrbuch für finnisch-deutsche Literaturbeziehungen. Mitteilungen aus der Deutschen Bibliothek. Helsinki: Dt. Bibliothek (37).

Früh, Werner (2007): Inhaltsanalyse. Theorie und Praxis. 6., überarb. Aufl. Konstanz: UVK Verl.-Ges.

Fuchs, Werner (1973): Todesbilder in der modernen Gesellschaft. Frankfurt a. M: Suhrkamp.

Furman, Erna (1977): Ein Kind verwaist. Untersuchungen über Elternverlust in der Kindheit. Stuttgart: Klett-Cotta (Konzepte der Humanwissenschaften).

Gansel, Carsten (2010): Moderne Kinder- und Jugendliteratur. Vorschläge für einen kompetenzorientierten Unterricht. 4., überarb. Aufl. Berlin: Cornelsen Scriptor (Scriptor PraxisDeutsch).

Gebhard, Ulrich (1994): Kind und Natur. Die Bedeutung der Natur für die psychische Entwicklung. Opladen: Westdt. Verl.

Genette, Gérard (1972): Discours du récit. In: Ders.: Figures III. Paris, S. 67-282. 
Genette, Gérard (2010): Die Erzählung. 3., durchges. und korr. Aufl. München: Fink.

Gerndt, Helge (2009): Mit Bildern erzählen. Skizze für ein enzyklopädisches Stichwort. In: Rolf Wilhelm Brednich (Hg.): Erzählkultur. Beiträge zur kulturwissenschaftlichen Erzählforschung. Hans-Jörg Uther zum 65. Geburtstag. Berlin, New York: Walter de Gruyter, S. 309-326.

Goldbrunner, Hans (2000): Die Bedeutung von Raum und Zeit für die Trauer von Geschwistern. In: Wolfgang Holzschuh (Hg.): Geschwister-Trauer. Erfahrungen und Hilfen aus verschiedenen Praxisfeldern. Regensburg: Pustet, S. 81-93.

Gorschenek, Margareta; Rucktäschel, Annamaria (Hgg.) (1979): Kinder- und Jugendliteratur. München: Fink (Uni-Taschenbücher Germanistik, Pädagogik, Psychologie, 742).

Gözütok, Mine; Jerneizig, Ralf; Langenmayr, Arnold (2000): Die Bedeutung von Geschwistern und die Bearbeitung ihres Verlustes in der Trauertherapie. In: Wolfgang Holzschuh (Hg.): Geschwister-Trauer. Erfahrungen und Hilfen aus verschiedenen Praxisfeldern. Regensburg: Pustet, S. 45-66.

Graduiertenkolleg Uni Freiburg (2012): Forschung — GRK 1767: Faktuales und fiktionales Erzählen. Online verfügbar unter: http://www.grk-erzaehlen.unifreiburg.de/ForschungundStruktur; 16.12.2012.

Groß, Dominik (Hg.) (2010): Die Realität des Todes. Zum gegenwärtigen Wandel von Totenbildern und Erinnerungskulturen. Frankfurt a. M. [u. a.]: Campus.

Grünewald, Dietrich (1991): Kongruenz von Wort und Bild. Rafi Schami und Peter Knorr: „Der Wunderkasten“. In: Jens Thiele (Hg.): Neue Erzählformen im Bilderbuch. Untersuchungen zu einer veränderten Bild-Text-Sprache. Oldenburg: Isensee, S. 17-49.

Grünewald, Dietrich (1988): „Knochenmann und schwarzer Vogel“. Anmerkungen zum Bild des Todes. In: Informationen des Arbeitskreises für Jugendliteratur (3), S. 28-38.

Grünewald, Dietrich (1989): Das Prinzip Bildgeschichte. Hg. v. Comicgesellschaft. Online verfügbar unter: http://www.comicgesellschaft.de/pdf/Tagun g06nov_gruenewald.pdf; aufger. am 14.12.2013.

Grünewald, Dietrich (1995): Moderne Erzählformen im Bilderbuch. Ein Plädoyer für Vielfalt und den Versuch einer sinnlichen Aneignung über Möglichkeiten ästhetischer Praxis. In: Günter Lange und Wilhelm Steffens (Hgg.): Moderne Formen des Erzählens in der Kinder- und Jugendliteratur der Gegenwart unter literarischen und didaktischen Aspekten. Würzburg: Königshausen \& Neumann, S. 131-154. 
Grumbach-Wendt, Marion; Zernikow, Boris (2013): Todeskonzepte und individuelle Bedürfnisse von sterbenden Kindern und Jugendlichen. In: Boris Zernikow (Hg.): Palliativversorgung von Kindern, Jugendlichen und jungen Erwachsenen. 2., überarb. Aufl. Berlin [u. a.]: Springer, S. 85-92.

Guratzsch, Herwig; Neyer, Hans Joachim (Hgg.) (2002): Wilhelm Busch. Die Bildergeschichten. Historisch-kritische Gesamtausgabe in drei Bänden. Bearb. von Hans Ries, u. Mitw. von Ingrid Haberland. Hannover: Schlüter.

Haas, Gerhard (2002): Das Tierbuch. In: Günter Lange (Hg.): Taschenbuch der Kinder- und Jugendliteratur. Bd. 2; Medien, Themen, Poetik, Produktion, Rezeption, Didaktik. Baltmannsweiler: Schneider, S. 287-307.

Haas, Gerhard (Hg.) (1974): Kinder- und Jugendliteratur. Zur Typologie und Funktion einer literarischen Gattung. Stuttgart: Reclam.

Haas, Gerhard (Hg.) (1984): Kinder- und Jugendliteratur. Ein Handbuch. 3., völlig neu bearb. Aufl. Stuttgart: Reclam.

Haas, Gerhard (2003): Aspekte der Kinder- und Jugendliteratur. Genres - Formen und Funktionen - Autoren. Frankfurt a. M.: Lang (Kinder- und Jugendkultur, -literatur und -medien, 22).

Haas, Gerhard (2005): Literarische Phantastik. Strukturelle, geistesgeschichtliche und thematische Aspekte. In: Gerhard Härle und Gina Weinkauff (Hgg.): Am Anfang war das Staunen. Wirklichkeitsentwürfe in der Kinder- und Jugendliteratur. Baltmannsweiler: Schneider, S. 117-134.

Haas, Gerhard (2006): Funktionen von Fantastik. In: Jörg Knobloch und Gudrun Stenzel (Hgg.): Zauberland und Tintenwelt. Fantastik in der Kinder- und Jugendliteratur. Beiträge Jugendliteratur und Medien 58, 17. Beiheft. Weinheim: Juventa, S. 26-38.

Hafner, Johann (2003): Gott ist nicht der Himmel. Die Notwendigkeit einer nichtgöttlichen Transzendenz. In: Stefan Schreiber und Stefan Siemons (Hgg.): Das Jenseits. Perspektiven christlicher Theologie. Darmstadt: Wissenschaftliche Buchgesellschaft, S. 143-175.

Hahn, Alois (1968): Einstellungen zum Tod und ihre soziale Bedingtheit. Eine soziologische Untersuchung. Stuttgart: Enke.

Hahn, Alois (2002): Tod und Weiterleben in vergleichender soziologischer Sicht. In: Rolf Trauzettel und Jan Assmann (Hgg.): Tod, Jenseits und Identität. Perspektiven einer kulturwissenschaftlichen Thanatologie. Freiburg, München: Alber, S. 575-586.

Halbey, Hans Adolf (1968): Wir fordern Qualität im Bilderbuch. In: Jugend und Buch (1), S. $17 \mathrm{f}$.

Halbey, Hans Adolf (1974): Das deutsche Bilderbuch der Gegenwart. In: Alfred Clemens Baumgärtner (Hg.): Deutsches Jugendbuch heute. U. Mitarb. von 
Marianne Exner u. Dorothea Otte. (In Zusammenarb. mit Inter Nationes, Bonn-Bad Godesberg). Velber: Friedrich, S. 37-60.

Halbey, Hans Adolf (1997): Bilderbuch: Literatur. Neun Kapitel über eine unterschätzte Literaturgattung. Weinheim: Beltz Athenäum.

Hallberg, Kristin (1982): Litteraturvetenskapen och bilderboksforskningen. In: Tidskrift för Litteraturvetenskap (3-4), S. 163-168.

Hann, Ulrich (1977): Die Entwicklungsgeschichte des deutschsprachigen Bilderbuches im 20. Jahrhundert. Eine Untersuchung d. Konstitution der Welt im Bilderbuch und der Versuch ihrer kunst- und sozialgeschichtlichen Einordnung. Göttingen.

Hansen, Per Krogh (2013): 3.1 Aspekte der Thematik. In: Silke Lahn, Jan Christoph Meister (Hgg.): Einführung in die Erzähltextanalyse. 2., aktual. Aufl. Stuttgart: Metzler, S. 204-210.

Härle, Gerhard; Weinkauff, Gina (Hgg.) (2005): Am Anfang war das Staunen. Wirklichkeitsentwürfe in der Kinder- und Jugendliteratur. Baltmannsweiler: Schneider.

Harms, Wolfgang (Hg.) (1990): Text und Bild, Bild und Text. DFG-Symposion 1988. Stuttgart: Metzler (Germanistische Symposien-Berichtsbände, 11).

Havekost, Hermann; Langenhahn, Sandra; Wicklein, Anne (Hgg.) (1993): Helden nach Plan? Kinder- und Jugendliteratur der DDR zwischen Wagnis und Zensur. Oldenburg: BIS.

Heller, Andreas (Hg.) (2000a): Kultur des Sterbens. Bedingungen für das Lebensende gestalten. 2., erw. Freiburg i. Br.: Lambertus-Verl.

Heller, Andreas (2000b): Ambivalenzen des Sterbens - Einschätzungen zum gegenwärtigen Umgang mit dem Sterben und den Sterbenden. In: Andreas Heller (Hg.): Kultur des Sterbens. Bedingungen für das Lebensende gestalten. 2., erw. Freiburg i. Br.: Lambertus-Verl., S. 17-34.

Heller, Birgit (Hg.) (2003): Aller Einkehr ist der Tod. Interreligiöse Zugänge zu Sterben, Tod und Trauer. Freiburg i. Br.: Lambertus.

Heller, Birgit (2009): Abwehr oder Solidarität? Zum Umgang mit Sterbenden, Toten und Trauernden. In: Birgit Heller und Franz Winter (Hgg.): Tod und Ritual. Interkulturelle Perspektiven zwischen Tradition und Moderne. 2. Aufl. Wien: Lit-Verl. (Schriftenreihe der Österreichischen Gesellschaft für Religionswissenschaft, 2), S. 9-26.

Heller, Birgit; Winter, Franz (Hgg.) (2009): Tod und Ritual. Interkulturelle Perspektiven zwischen Tradition und Moderne. 2. Aufl. Wien: Lit-Verl. (Schriftenreihe der Österreichischen Gesellschaft für Religionswissenschaft, 2). 
Hennecke, Elisabeth (1987): Ein Kind lernt mit dem Tod zu leben. Religionspädagogische Überlegungen zum Elternverlust. Essen: Verl. Die Blaue Eule (Religionspädagogische Perspektiven, 5).

Hennecke, Elisabeth (2009): Das Reale und das Magische des Todes. Religionspädagogische Überlegungen zu Todesvorstellungen von Kindern. In: UNIKATE. Natur-/Geisteswissenschaften: Sterben, Tod - und dann? (Schriftenreihe der Unversität Duisburg-Essen, 35), S. 89-98.

Herre, Bettina (1990): Existenzielle Herausforderung. Tod und Sterben in der Kinder- und Jugendliteratur. In: Bulletin: Jugend + Literatur 21 (5), S. 13-20.

Herzog, Markwart; Gerl-Falkovitz, Hanna-Barbara (Hgg.) (2001): Sterben, Tod und Jenseitsglaube - Ende oder letzte Erfüllung des Lebens? Schwabenakademie. Stuttgart: Kohlhammer (Irseer Dialoge, Kultur und Wissenschaft interdisziplinär, 3).

Heumann, Jürgen (Hg.) (2005): Über Gott und die Welt. Religion, Sinn und Werte im Kinder- und Jugendbuch. Frankfurt a. M.: Lang (Religion in der Öffentlichkeit, 8).

Heumann, Jürgen (Hg.) (2007): Auf der Suche nach Religion. Die Wiederkehr der Religion im Kinder- und Jugendbuch. Oldenburg: Didaktisches Zentrum Carl-von-Ossietzky-Univ.

Hirlinger-Fuchs, Franziska (2001): Bilderbücher und ihre Wirklichkeiten vom Struwwelpeter bis zur Menschenfresserin. Normen, Werte und Rollenbilder in deutschsprachigen Bilderbüchern von 1844-1966. Heidelberg: Carl-AuerSysteme-Verl.

Höfer, Josef; Rahner, Karl (Hgg.): Lexikon für Theologie und Kirche (1957-1967). 2., völlig neu bearb. Aufl. Freiburg i. Br.: Herder.

Hoffmann, Detlef; Thiele, Jens (1986): Künstler illustrieren Bilderbücher. Oldenburg: BIS.

Hoheisel, Karl (2001): Leben und Tod im Lichte der Religionen. In: Markwart Herzog und Hanna-Barbara Gerl-Falkovitz (Hgg.): Sterben, Tod und Jenseitsglaube - Ende oder letzte Erfüllung des Lebens? Stuttgart: Kohlhammer (Irseer Dialoge, Kultur und Wissenschaft interdisziplinär, 3), S. 65-88.

Hohmeister, Elisabeth (1999): Bildnerische Entwicklungen in den Illustrationen der 90er Jahre. In: Jens Thiele (Hg.): Experiment Bilderbuch. Oldenburg: BIS (Schriftenreihe der Forschungsstelle Kinder- und Jugendliteratur der Carlvon-Ossietzky-Universität Oldenburg, 1), S. 29-47.

Hohmeister, Elisabeth (1999): „Wie im Bilderbuch...“. Inhalte und Tendenzen im Bilderbuch der 90er-Jahre. In: Renate Raecke (Hg.): Kinder- und Jugendliteratur in Deutschland. Unter Mitarbeit von Heike Gronemeier. München: Arbeitskreis für Jugendliteratur, S. 170-178. 
Hohmeister, Elisabeth (2007): (K)einer sieht mich an. Augen, Blicke und Blickonstruktionen im Bilderbuch. In: Jens Thiele und Sabine Wallach (Hgg.): Verborgene Kindheiten. Soziale und emotionale Probleme in der Kinderliteratur. Oldenburg: BIS, S. 57-72.

Hollstein, Gudrun; Sonnenmoser, Marion (2006): Werkstatt Bilderbuch. Allgemeine Grundlagen, Vorschläge und Materialien für den Unterricht in der Grundschule. 2., aktual. Aufl. Baltmannsweiler: Schneider.

Holzschuh, Wolfgang (Hg.) (2000): Geschwister-Trauer. Erfahrungen und Hilfen aus verschiedenen Praxisfeldern. Regensburg: Pustet.

Hopp, Margret (2007): Bilderbücher und die Entwicklung kindlicher Medienkompetenz. In: kjl\&m 59 (2007) H. 1, S. 28-34.

Hopp, Margarete (2010): Kinder fragen nach dem Tod. Kindliche Todesvorstellungen, Trauerreaktionen und religiöse Trostbilder. In: kjl\&m 62 (2010) H. 4, S. 3-10.

Hopp, Margarete (2010): Die neuen Bilderbücher über Sterben, Tod und Trauer. In: kjl\&m 62 (2010) H. 4, S. 23-30.

Hopp, Margarete; Lieber, Gabriele (2013): Medienaffine Bilderbücher und ihre Potentiale zur Entwicklung von Medienkritik. In: Gabriele Lieber (Hg.): Lehren und Lernen mit Bildern. Ein Handbuch zur Bilddidaktik. Baltmannsweiler: Schneider, S. 293-307.

Horster, Detlef (1991): Literaturbericht zum Philosophieren mit Kindern. In: Zeitschrift für Didaktik der Philosophie 13 (H. 1), S. 61-64.

Horstkotte, Silke; Leonhard, Karin (Hgg.) (2006a): Lesen ist wie Sehen. Intermediale Zitate in Bild und Text. Köln: Böhlau.

Horstkotte, Silke; Leonhard, Karin (2006b): Einleitung. In: Dies. (Hgg.): Lesen ist wie Sehen. Intermediale Zitate in Bild und Text. Köln: Böhlau, S. 1-15.

Hoymann, Joseph (2000): Wieviel Leben hat der Tod. Ein Nach-Denken über „Der Gevatter Tod“ (KHM 44) und „Die Boten des Todes“ (KHM 177) und über die Frage nach den Möglichkeiten und Grenzen des märchenhaften Erzählens. In: Märchenspiegel 11 (4), S. 119-121.

Hurrelmann, Bettina (2008a): Gattungen der Kinder- und Jugendliteratur 18501900. In: Otto Brunken, Bettina Hurrelmann, Maria Michels-Kohlhage und Gisela Wilkending (Hgg.): Handbuch zur Kinder- und Jugendliteratur. Von 1850 bis 1900. Stuttgart: Metzler, S. 91-94.

Hurrelmann, Bettina (2008b): Bilderbücher und Bildergeschichten. In: Otto Brunken, Bettina Hurrelmann, Maria Michels-Kohlhage und Gisela Wilkending (Hgg.): Handbuch zur Kinder- und Jugendliteratur. Von 1850 bis 1900. Stuttgart: Metzler, S. 145-202. 
Hurrelmann, Bettina (2008c): Einleitung. In: Otto Brunken, Bettina Hurrelmann, Maria Michels-Kohlhage und Gisela Wilkending (Hgg.): Handbuch zur Kinder- und Jugendliteratur. Von 1850 bis 1900. Stuttgart: Metzler, S. 1-6.

Iser, Wolfgang (1976): Der Akt des Lesens. Theorie ästhetischer Wirkung. München.

Iser, Wolfgang (1994): Der Akt des Lesens. Theorie ästhetischer Wirkung. 4. Aufl. München: Fink (UTB für Wissenschaft Uni-Taschenbücher Literaturwissenschaft, 636).

Iskenius-Emmler, Hildegard (1988): Psychologische Aspekte von Tod und Trauer bei Kindern und Jugendlichen. Frankfurt a. M.: Lang (Europäische HochschulschriftenReihe 6, Psychologie, 263).

Jankélévitch, Vladimir; Restorff, Brigitta; Lange, Christoph; Kapielski, Thomas (2005): Der Tod. Frankfurt a. M.: Suhrkamp.

Jennemann, Ruth-Gisela (2009): Wie Kinder im Grundschulalter den Tod erleben. Analyse ausgewählter Bilderbücher zum Thema Sterben Tod und Trauer unter theologischen psychologischen und pädagogischen Aspekten. Würzburg: Echter (Erfurter Theologische Studien, 93).

Josting, Petra (2008a): Kinder- und Jugendliteratur im Faschismus. In: Reiner Wild (Hg.): Geschichte der Kinder- und Jugendliteratur. 3. überarb. Aufl. Stuttgart: Metzler, S. 276-294.

Josting, Petra (2008b): Kinder- und Jugendliteratur im Exil. In: Reiner Wild (Hg.): Geschichte der Kinder- und Jugendliteratur. 3. überarb. Aufl. Stuttgart: Metzler, S. 295-311.

Jugendliteratur (1978): Begegnung mit dem Tod. Das Sterben ist kein Tabu in Kinderbüchern. In: Jugendliteratur. Zeitschrift d. Schweizerischen Bundes für Jugendliteratur (2), S. 7-9.

Kalteis, Nicole (2007): Schlafend zu sterben ist ein Luxus, der uns nur selten gewährt wird. Über das Moment des Todes in der Jugendliteratur. In: TueB (3), S. 17-20.

Kammhuber, Andrea (1989): Tod und Sterben im Kinderbuch. In: Marlies Göcking und Heinz-Jörg Eckhold (Hgg.): Religion in der Kinder- und Jugendliteratur. Annweiler, Essen (Spurensuche; Forschungsgespräche der Katholischen Akademie „Die Wolfsburg“), S. 125-138.

Kast, Verena (1999): Trauern. Phasen und Chancen des psychischen Prozesses. Stuttgart: Kreuz Verlag.

Kelleter, Frank (2002): Der Tod als Gegenstand wissenschaftlicher Diskursanalyse. Hg. v. Interdisziplinärer Arbeitskreis Thanatologie. Johannes GutenbergUniversität Mainz. Mainz (Beiträge zur Thanatologie, 23). Online verfügbar 
unter http://www.psych.uni-mainz.de/abteil/soz/thanatologie/Literatur/heft23. pdf; aufger. am 24.11.2010.

Kirsch, Anja (2009): Bestattungskultur im Wandel. Einige diskursanalytische Beobachtungen. In: Birgit Heller und Franz Winter (Hgg.): Tod und Ritual. Interkulturelle Perspektiven zwischen Tradition und Moderne. 2. Aufl. Wien: Lit-Verl. (Schriftenreihe der Österreichischen Gesellschaft für Religionswissenschaft, 2), S. 175-188.

Klempnauer, Günther (1977): Wenn ich nur noch einen Tag zu leben hätte. Aussagen von Jugendlichen. Gesammelt u. gewertet von Günther Klempnauer. Stuttgart: Kreuz.

Kliewer, Heinz-Jürgen (1990): Die Siebziger Jahre. In: Reiner Wild und Otto Brunken (Hgg.): Geschichte der deutschen Kinder- und Jugendliteratur. Stuttgart: Metzler, S. 328-353.

Kliewer, Heinz-Jürgen; Pohl, Inge (Hgg.) (2006): Lexikon Deutschdidaktik. Baltmannsweiler: Schneider.

Klug, Andreas (1997): Einstellungen zu Sterben, Tod und Danach. Aachen: Mainz.

Knecht, Gertrud (1991): Tabuthema Tod. In: TueB (1), S. 2-11.

Knobloch, Jörg; Stenzel, Gudrun (Hgg.) (2006): Zauberland und Tintenwelt. Fantastik in der Kinder- und Jugendliteratur. Beiträge Jugendliteratur und Medien 58, 17. Beiheft. Weinheim: Juventa.

Knopf, Julia; Abraham, Ulf (Hgg.) (2014): Bilderbücher. Praxis. Baltmannsweiler: Schneider (Deutschdidaktik für die Primarstufe, 2).

Köbert, R.; Schatz, W. (1960): Islam. In: Josef Höfer und Karl Rahner (Hgg.): Lexikon für Theologie und Kirche (1957-1967), Bd. 5. 2., völlig neu bearb. Aufl. Freiburg i. Br.: Herder, S. 790-799.

Koch, Laurentius (1995): Engel. VII. Ikonographisch. In: Michael Buchberger und Walter Kasper (Hgg.) (1993-2001): Lexikon für Theologie und Kirche, Bd. 3. 3., völlig neu bearb. Aufl. Freiburg i. Br.: Herder, S. 652-653.

Korff Schmising, Barbara von (1996): Krankheit, Behinderung, Sterben und Tod. Einige Bemerkungen zu neueren Kinder- und Jugendbüchern. In: JuLit 22 (1996) H. 1, S. 48-54.

Korff Schmising, Barbara von (2004): Ewiges Leben? Ewige Ruhe? In: Bulletin: Jugend + Literatur 35 (1), S. 16.

Korff Schmising, Barbara von (2009): Die letzte Reise. Im Bilderbuch wird der Tod in vielen Facetten dargestellt. In: JuLit 35 (2009) H. 1, S. 24-29. 
Krebs-Dijksma, Brigitte (1988): Ein altes Thema wird neu untersucht. Ein Überblick über die Sekundärliteratur zu Sterben und Tod in der Kinder- und Jugendliteratur. In: Jugendliteratur und Medien 40 (4), S. 107-111.

Kreidt, Ulrich (2008): Bilder in der Kinder- und Jugendliteratur. In: Otto Brunken, Bettina Hurrelmann, Maria Michels-Kohlhage und Gisela Wilkending (Hgg.): Handbuch zur Kinder- und Jugendliteratur. Von 1850 bis 1900. Stuttgart: Metzler, S. 95-144.

Kremer, Jacob (1996): Jenseits. II. Biblisch-theologisch. In: Michael Buchberger und Walter Kasper (Hgg.) (1993-2001): Lexikon für Theologie und Kirche, Bd. 5. 3., völlig neu bearb. Aufl. Freiburg: Herder, S. 769-770.

Kretschmer, Bernhard (2001): Sterben als Übergang im Kulturvergleich. Die Dimensionen des Todes in Sitte, Brauchtum und Recht der Völker. In: Markwart Herzog und Hanna-Barbara Gerl-Falkovitz (Hgg.): Sterben, Tod und Jenseitsglaube - Ende oder letzte Erfüllung des Lebens? Stuttgart: Kohlhammer (Irseer Dialoge, Kultur und Wissenschaft interdisziplinär, 3), S. 41-64.

Kretschmer, Christine (2010): Bilderbücher in der Grundschule. Braunschweig: Westermann (Praxis Pädagogik).

Kruse, Iris; Sabisch, Andrea (Hgg.) (2013): Fragwürdiges Bilderbuch. Blickwechsel - Denkspiele - Bildungspotenziale. München: kopaed.

Kuebler-Ross, Elisabeth (1984): Kinder und Tod. Zürich: Kreuz-Verl.

Kübler-Ross, Elisabeth (1996): Interviews mit Sterbenden. Gekürzte Taschenbuchausg., 17. Aufl. Gütersloh: Gütersloher Verl.-Haus Mohn.

Kübler-Ross, Elisabeth; Schaup, Susanne (2004): Verstehen, was Sterbende sagen wollen. Einführung in ihre symbolische Sprache. Aus d. Am. v. Susanne Schaup. München: Knaur-Taschenbuch-Verl.

Kuhn, Markus (2013): Filmnarratologie. Ein erzähltheoretisches Analysemodell. Berlin: de Gruyter.

Kuhnert, Heinz (1976): Das Bilderbuch in der Kinderliteratur der DDR seit 1945. Berlin: Kinderbuchverlag.

Kuhnert, Heinz (1993): Kinderliteratur der DDR: Was bleibt? In: Hermann Havekost, Sandra Langenhahn und Anne Wicklein (Hgg.): Helden nach Plan? Kinder- und Jugendliteratur der DDR zwischen Wagnis und Zensur. Oldenburg: BIS, S. 107-130.

Künnemann, Horst (1974): Das Bilderbuch. In: Gerhard Haas (Hg.): Kinder- und Jugendliteratur. Zur Typologie und Funktion einer literarischen Gattung. Stuttgart: Reclam, S. 98-125.

Künnemann, Horst (1984): Das Bilderbuch. In: Gerhard Haas (Hg.): Kinder- und Jugendliteratur. Ein Handbuch. 3., völlig neu bearbeitete Aufl. Stuttgart: Reclam, S. 153-176. 
Kunzler, Michael (1995): Engel. VI. Praktisch-theologisch. In: Michael Buchberger und Walter Kasper (Hgg.) (1993-2001): Lexikon für Theologie und Kirche, Bd. 3. 3., völlig neu bearb. Aufl. Freiburg: Herder, S. 651-652.

Lahn, Silke (2013): IV.1 Wer erzählt die Geschichte? Parameter des Erzählers. In: Silke Lahn, Jan Christoph Meister (Hgg.): Einführung in die Erzähltextanalyse. 2., aktualisierte Aufl. Stuttgart: Metzler, S. 61-100.

Lahn, Silke; Meister, Jan Christoph (Hgg.) (2013): Einführung in die Erzähltextanalyse. 2., aktual. Aufl. Stuttgart: Metzler.

Lämmert, Eberhardt (Hg.) (1999a): Die erzählerische Dimension: eine Gemeinsamkeit der Künste. Berlin: Akademie Verlag.

Lämmert, Eberhardt (1999b): Zu diesem Band. In: Eberhardt Lämmert (Hg.): Die erzählerische Dimension: eine Gemeinsamkeit der Künste. Berlin: Akademie Verlag, S. VII-XII.

Lange, Günter (Hg.) (2002a): Taschenbuch der Kinder- und Jugendliteratur. Bd. 1: Grundlagen, Gattungen. 3., unveränd. Aufl. Baltmannsweiler: Schneider.

Lange, Günter (Hg.) (2002b): Taschenbuch der Kinder- und Jugendliteratur. Bd. 2: Medien, Themen, Poetik, Produktion, Rezeption, Didaktik. Baltmannsweiler: Schneider.

Lange, Günter; Daubert, Hannelore (Hgg.) (2012): Kinder- und Jugendliteratur der Gegenwart. Ein Handbuch. Grundlagen, Gattungen, Medien, Lesesozialisation und Didaktik. 2., korr. und erg. Aufl. Baltmannsweiler: Schneider.

Lange, Günter; Franz, Kurt; Pleticha, Heinrich (Hgg.) (2004): Von der Steinzeit bis zur Gegenwart. Historisches in der Kinder- und Jugendliteratur: Baltmannsweiler: Schneider.

Lange, Günter; Steffens, Wilhelm (Hgg.) (1995): Moderne Formen des Erzählens in der Kinder- und Jugendliteratur der Gegenwart unter literarischen und didaktischen Aspekten. Würzburg: Königshausen \& Neumann.

Lange, Konrad (1893): Künstlerische Erziehung der deutschen Jugend. Darmstadt.

Langenhahn, Sandra (1993): Bilderbücher als Spiegelbild von Kindheit in der DDR? In: Hermann Havekost, Sandra Langenhahn und Anne Wicklein (Hg.): Helden nach Plan? Kinder- und Jugendliteratur der DDR zwischen Wagnis und Zensur. Oldenburg: BIS, S. 161-194.

Langenhorst, Georg (Hg.) (2011): Gestatten: Gott! Religion in der Kinder- und Jugendliteratur der Gegenwart. München: Verl. St. Michaelsbund.

Lautenschläger, Gabriele (1998): Paradies. IV. Frömmigkeitsgeschichtlich. In: Michael Buchberger und Walter Kasper (Hgg.) (1993-2001): Lexikon für 
Theologie und Kirche, Bd. 7. 3., völlig neu bearb. Aufl. Freiburg: Herder, S. 1362-1363.

Leist, Marielene (2004): Kinder begegnen dem Tod. 5. Aufl. Gütersloh: Gütersloher Verl.-Haus.

Lieber, Gabriele (Hg.) (2013): Lehren und Lernen mit Bildern. Ein Handbuch zur Bilddidaktik. 2. Aufl. Baltmannsweiler: Schneider.

Lieber, Gabriele; Jahn, Ina Friederike; Danner, Antje (Hgg.) (2009): Durch Bilder bilden. Empirische Studien zur didaktischen Verwendung von Bildern im Vor- und Grundschulalter. Baltmannsweiler: Schneider.

Lypp, Maria (1989): Der Blick ins Innere. Menschendarstellungen im Kinderbuch. In: Grundschule 21 (1989), 1, S. 24-27.

Lypp, Maria (2009): Tiersein - Menschsein - Ichsein. Der Weg des Ich durch den Spiegel kinderliterarischer Tierfiguren. In: Caroline Roeder (Hg.): Ich! Identität(en) in der Kinder- und Jugendliteratur. kjl\&m (09.extra). München: kopaed, S. 68-78.

Maier, Karl Ernst (1964): Jugendschrifttum. Formen, Inhalte, pädagogische Bedeutung. Bad Heilbrunn: Klinkhardt.

Maier, Karl Ernst (1993): Jugendliteratur. Formen, Inhalte, pädagogische Bedeutung. 10., überarb. und erw. Aufl. (EA 1964, bis 1980 mit d. Titel Jugendschrifttum). Bad Heilbrunn: Klinkhardt.

Maier, Karl Ernst (1995): Das Bilderbuch. In: Alfred Clemens Baumgärtner, Heinrich Pleticha, Kurt Franz, Günter Lange und Franz-Josef Payrhuber (Hgg.): Kinder- und Jugend-Literatur. Ein Lexikon. Autoren, Illustratoren, Verlage, Begriffe. Bd. 4, Teil 5; 1. Erg.-Lfg. März 1996. Meitingen: Corian, S. $1-20$.

Herzog, Markwart; Gerl-Falkovitz, Hanna-Barbara (Hgg.): Sterben, Tod und Jenseitsglaube - Ende oder letzte Erfüllung des Lebens? Stuttgart: Kohlhammer (Irseer Dialoge, Kultur und Wissenschaft interdisziplinär, 3).

Martínez, Matías (Hg.) (2011): Handbuch Erzählliteratur. Theorie, Analyse, Geschichte. Stuttgart: Metzler.

Mattenklott, Gundel (1994): Zauberkreide. Kinderliteratur seit 1945. Frankfurt a. M.: Fischer-Taschenbuch-Verl. (Fischer, 12053).

Mattenklott, Gundel (1997): Herzklopfen. Beiträge der Kinderliteratur zur Bildung der Gefühle. In: Bernhard Rank und Cornelia Rosebrock (Hgg.): Kinderliteratur, literarische Sozialisation und Schule. Weinheim: Dt. StudienVerl., S. [117]-137.

Mattenklott, Gundel (2011): G.Ott, ein neuer Protagonist in der Kinder- und Jugendliteratur. In: Georg Langenhorst (Hg.): Gestatten: Gott! Religion in der 
Kinder- und Jugendliteratur der Gegenwart. München: Verl. St. Michaelsbund, S. 27-38.

Matthews, Gareth B. (1993): Philosophische Gespräche mit Kindern. 2. Aufl. Berlin: Freese.

Matthews, Gareth B. (1995): Die Philosophie der Kindheit. Wenn Kinder weiter denken als Erwachsene. Weinheim [u. a.]: Beltz, Quadriga.

Mayring, Philipp (2007): Qualitative Inhaltsanalyse. Grundlagen und Techniken. 9. Aufl. Weinheim [u. a.]: Beltz.

Mergenthaler, Volker (2002): Sehen schreiben - Schreiben sehen. Literatur und visuelle Wahrnehmung im Zusammenspiel. Tübingen (Hermaea. Germanistische Forschungen. Neue Folge. Herausg. v. Joachim Heinzle und Klaus-Detlef Müller. Bd. 96).

Mischke, Marianne (1996): Der Umgang mit dem Tod. Vom Wandel in der abendländischen Geschichte. Berlin: Dietrich Reimer (Reihe historische Anthropologie, 25).

Mitchell, W. J. T. (1994): Picture Theory: Essays on Verbal und Visual Representation. Chicago.

Motté, Magda (1989): Religiöse und christliche Elemente in der neueren Lyrik für Kinder. In: Marlies Göcking und Heinz-Jörg Eckhold (Hgg.): Spurensuche. Religion in der Kinder- und Jugendliteratur. Annweiler, Essen, S. 9-52.

Motté, Magda (1997): Auf der Suche nach dem verlorenen Gott. Religion in der Literatur der Gegenwart. Mainz: Matthias-Grünewald-Verl. (Religion und Ästhetik, 6).

Motté, Magda (2011): ,ethisch-existentiell' / ,transzendental-religiös / ,christlich. Dimensionen moderner Literatur für Kinder und Jugendliche. In: Georg Langenhorst (Hg.): Gestatten: Gott! Religion in der Kinder- und Jugendliteratur der Gegenwart. München: Verl. St. Michaelsbund. S. 146-157.

Mühle, Heidi (1995): Alle müssen sterben - ich auch? Wie Kinder nach dem Tod fragen und wie Bilderbücher trösten. In: Egbert Haug-Zapp et al. (Hgg.): Wenn Kinder nach Gott fragen. Reinbek: Rowohlt, S. 56-67.

Müller, Gerhard Ludwig (1995): Fegfeuer. III. Historisch -theologisch; IV. Systematisch-theologisch. In: Michael Buchberger und Walter Kasper (Hgg.) (1993-2001): Lexikon für Theologie und Kirche, Bd. 3. 3., völlig neu bearb. Aufl. Freiburg i. Br.: Herder, S. 1205-1208.

Müller, Helmut (1973): Vorläufer. In: Klaus Doderer und Helmut Müller (Hgg.): Das Bilderbuch. Geschichte und Entwicklung des Bilderbuchs in Deutschland von den Anfängen bis zur Gegenwart. Weinheim [u. a.]: Beltz, S. 1-66. 
Munnichs, J. M. A (1972): Die Einstellung zur Endlichkeit und zum Tod. In: Hans Thomae und Ursula Lehr (Hgg.): Altern. Probleme und Tatsachen. Frankfurt a. M: Akademische Verlagsgesellschaft, S. 579-612.

Neumeyer, Harald (2010): Methoden diskursanalytischer Ansätze. In: Vera Nünning und Ansgar Nünning (Hgg.): Methoden der literatur- und kulturwissenschaftlichen Textanalyse. Ansätze - Grundlagen - Modellanalysen. Stuttgart: Metzler, S. 177-200.

Niermann, M. Monika (1977): Erziehungsziele in Bilderbüchern für Kinder von 2 bis 6 Jahren. Grundlegung eines Modells zur Analyse von Bilderbüchern. Frankfurt a. M., Bern: Lang (Europäische Hochschulschriften: Reihe 11, Pädagogik; Bd. 46).

Niethammer, Dietrich (2008): Das sprachlose Kind. Vom ehrlichen Umgang mit schwer kranken und sterbenden Kindern und Jugendlichen. Stuttgart: Schattauer (Schriftenreihe der Uexküll-Akademie für Integrierte Medizin).

Nikolajeva, Maria (1988): The magic code. The use of magical patterns in fantasy for children. Stockholm: Almqvist \& Wiksell.

Nikolajeva, Maria (2002): The verbal and the visual: The picturebook as a medium. In: Roger D. Sell (Hg.): Children's literature as communication. The ChiLPA Project. Amsterdam, Philadelphia, PA: John Benjamins Pub. (Studies in narrative, v. 2), S. 85-108.

Nikolajeva, Maria; Scott, Carole (2001): How picturebooks work. New York: Garland Pub.

Nitsche, Norbert Martin (2010): Trauerarbeit von Eltern und Geschwistern nach dem Tod eines Schulkindes. Eine empirische Untersuchung. Weingarten: Pädag. Hochsch., Diss. Online verfügbar unter: http://opus.bsz-bw.de/hsbwgt/ volltexte/2010/72/pdf/DISS-Endversion-11-4-10.pdf; aufger. am 18.04.2011.

Nitz, Genoveva (1998): Paradies. V. Ikonographie. In: Michael Buchberger und Walter Kasper (Hgg.) (1993-2001): Lexikon für Theologie und Kirche, Bd. 7. 3., völlig neu bearb. Aufl. Freiburg i. Br.: Herder, S. 1363-1364.

Nix, Angelika (2005): „Mitten im Nichts“ - Zur bimedialen Darstellung von Abschied, Tod und Trauer in zwei skandinavischen Bilderbüchern. In: Hans Fromm, MariaLiisa Nevala und Ingrid Schellbach-Kopra (Hgg.): Jahrbuch für finnisch-deutsche Literaturbeziehungen. Mitteilungen aus der Deutschen Bibliothek. Helsinki: Dt. Bibliothek (37), S. 80-97.

Nocke, Franz-Josef (2005): Eschatologie. 7. Aufl. Düsseldorf: Patmos.

Nodelman, Perry (1988): Words about pictures. The narrative art of children's picture books. Athens: University of Georgia Press.

Nodelman, Perry (1991): The Eye and the I: Identification and First-Person Narratives in Picture Books. In: Children's Literature 19 (1), S. 1-30. 
Nünning, Vera; Nünning, Ansgar (Hgg.) (2010a): Methoden der literatur- und kulturwissenschaftlichen Textanalyse. Ansätze - Grundlagen - Modellanalysen. Stuttgart: Metzler.

Nünning, Vera; Nünning, Ansgar (2010b): Wege zum Ziel: Methoden als planvoll und systematisch eingesetzte Problemlösestrategien. In: Vera Nünning und Ansgar Nünning (Hgg.): Methoden der literatur- und kulturwissenschaftlichen Textanalyse. Ansätze - Grundlagen - Modellanalysen. Stuttgart: Metzler, S. 1-27.

Oberhuemer, Pamela; Müller, Helga; Engelbrechten, Erika von (1988): Kind und Bilderbuch. Erfahrungen - Beispiele - Informationen für Praxis, Ausbildung und Fortbildung. Freiburg i. Br.: Herder (Praxismaterial Kindergarten).

Oeste, Bettina (2011): Mensch versus Monster. Hitler-Konzeptionen in der deutschsprachigen Kinder- und Jugendliteratur nach 1945. Baltmannsweiler: Schneider.

Oetken, Mareile (Hg.) (2005): Texte lesen - Bilder sehen. Beiträge zur Rezeption von Bilderbüchern. Oldenburg: Bibliotheks- und Informationssystem der Univ. (Schriftenreihe der Forschungsstelle Kinder- und Jugendliteratur der Carl-von-Ossietzky-Universität Oldenburg, 3).

Oetken, Mareile (2008): Bilderbücher der 1990er Jahre. Kontinuität und Diskontinuität in Produktion und Rezeption. Diss. Online verfügbar: http://docser ver.bis.uni-oldenburg.de/publikationen/dissertation/2008/oetbil08/oetbil08. html.

Paetzold, Bettina; Erler, Luis (Hgg.) (1990): Bilderbücher im Blickpunkt verschiedener Wissenschaften und Fächer. Bamberg: Nostheide.

Paus, Ansgar (1995): Engel. I. Religionsgeschichtlich. In: Michael Buchberger und Walter Kasper (Hg.) (1993-2001): Lexikon für Theologie und Kirche, Bd. 3. 3., völlig neu bearbeitete Aufl. Freiburg: Herder, S. 646.

Paus, Ansgar (1998): Paradies. I. Religionswissenschaftlich. In: Michael Buchberger und Walter Kasper (Hgg.) (1993-2001): Lexikon für Theologie und Kirche, Bd. 7. 3., völlig neu bearbeitete Aufl. Freiburg: Herder, S. 1359-1360.

Payrhuber, Franz-Josef (2011): Moderne realistische Jugendliteratur. In: Günter Lange (Hg.): Kinder- und Jugendliteratur der Gegenwart. Ein Handbuch. Grundlagen, Gattungen, Medien, Lesesozialisation und Didaktik. Baltmannsweiler: Schneider, S. 106-124.

Pech, Klaus-Ulrich (2008): Vom Biedermeier zum Realismus. In: Reiner Wild (Hg.): Geschichte der deutschen Kinder- und Jugendliteratur. 3., vollst. überarb. und erw. Aufl. Stuttgart: Metzler, S. 131-170.

Pennington, Margot (2001): Memento mori. Eine Kulturgeschichte des Todes. Stuttgart: Kreuz. 
Petermann, Hans-Bernhard (2007): Kann ein Hering ertrinken? Philosophieren mit Bilderbüchern. Weinheim: Beltz.

Petzoldt, Leander (Hg.) (1995): Bild und Text. Einführung in ein Problemfeld. Internationale Konferenz des Komitees für Ethnologische Bildforschung in der Société Internationale pour Ethnologie et Folklore (SIEF), 2. - 6. Oktober 1990. Innsbruck. Frankfurt a. M. [u. a.]: Lang.

Plieth, Martina (2005): Religiöse Vorstellungen in neueren Kinderbüchern zum Thema ,Sterben, Tod und Traurigkeit. In: Jürgen Heumann (Hg.): Über Gott und die Welt. Religion, Sinn und Werte im Kinder- und Jugendbuch. Frankfurt a. M.: Lang (Religion in der Öffentlichkeit, 8), S. 141-161.

Plieth, Martina (2007): Religiöse Ver(w)irrung. Erschreckendes zum Thema "Tod und Sterben“ im Kinder- und Jugendbuch. Tendenzen - Perspektiven Defizite. In: Jürgen Heumann (Hg.): Auf der Suche nach Religion. Die Wiederkehr der Religion im Kinder- und Jugendbuch. Oldenburg: Didaktisches Zentrum Carl-von-Ossietzky-Univ, S. 35-56.

Plieth, Martina (2009): Kind und Tod. Zum Umgang mit kindlichen Schreckensvorstellungen und Hoffnungsbildern. 4. Aufl. Neukirchen-Vluyn: Neukirchener Verl.

Pries-Kümmel, Elisabeth (2005): Das Alter in der Literatur für junge Leser. Lebenswirklichkeiten älterer Menschen und ihre Darstellung im Kinder- und Jugendbuch der Gegenwart. Frankfurt a. M.: Lang (Kinder- und Jugendkultur, -literatur und -medien, 34).

Rabl, Josef (1979): Sterben und Tod als Thema in neueren Kinderbüchern. In: Jugendbuchmagazin 29 (1979), S. 121-126.

Rabl, Josef (Hg.) (1981a): Religiöse Kinderliteratur. Religionspädagogische Beiträge 1967-1980. München, Mainz: Chr. Kaiser; Matthias-Grünewald-Verl.

Rabl, Josef (1981b): Der Tod - eine Lebensfrage. Zur Darstellung von Sterben und Tod in der neuesten Kinderliteratur. In: Josef Rabl (Hg.): Religiöse Kinderliteratur. Religionspädagogische Beiträge 1967-1980. München, Mainz: Chr. Kaiser; Matthias-Grünewald-Verl, S. 189-202.

Rabl, Josef (1982): Religion im Kinderbuch. Analyse zeitgenössischer Kinderliteratur unter religionspädagogischem Aspekt. Hardebek: Eulenhof-Verl.

Raecke, Renate (Hg.) (1999): Kinder- und Jugendliteratur in Deutschland. Unter Mitarbeit von Heike Gronemeier. München: Arbeitskreis für Jugendliteratur.

Raecke, Renate; Baumann, Ute D. (Hgg.) (1995): Zwischen Bullerbü und Schewenborn. Auf Spurensuche in 40 Jahren deutschsprachiger Kinder- und Jugendliteratur. Hrsg. aus Anlass des 40jährigen Bestehens des Arbeitskreises für Jugendliteratur e.V. 1955-1995. München: Arbeitskreis für Jugendliteratur. 
Raecke-Hauswedell, Renate (1988): Von der Fähigkeit zu trauern. Eine Auswahl von Bilder-, Kinder- u. Jugendbüchern zum Thema Sterben, Tod u. Trauer. München: Arbeitskreis für Jugendliteratur.

Raimbault, Ginette (1981): Kinder sprechen vom Tod. Klinische Probleme der Trauer. 2. Aufl. Frankfurt a. M.: Suhrkamp.

Ramachers, Günter (1994): Entwicklung und Bedingungen von Todeskonzepten beim Kind. Frankfurt a. M., New York: P. Lang (Europäische Hochschulschriften. Reihe VI, vol. 489).

Ramseger, Ingeborg (1979): Das Bilderbuch. In: Margareta Gorschenek und Annamaria Rucktäschel (Hg.): Kinder- und Jugendliteratur. München: Fink (Uni-Taschenbücher Germanistik, Pädagogik, Psychologie, 742).

Rank, Bernhard (2002): Philosophie als Thema von Kinder- und Jugendliteratur. In: Günter Lange (Hg.): Taschenbuch der Kinder- und Jugendliteratur. Bd. 2: Medien, Themen, Poetik, Produktion, Rezeption, Didaktik. Baltmannsweiler: Schneider, S. 799-826.

Rank, Bernhard (2006): Phantastik in der Kinder- und Jugendliteratur. In: Jörg Knobloch und Gudrun Stenzel (Hgg.): Zauberland und Tintenwelt. Fantastik in der Kinder- und Jugendliteratur. Beiträge Jugendliteratur und Medien 58, 17. Beiheft. Weinheim: Juventa, S. 10-25.

Rank, Bernhard; Rosebrock, Cornelia (Hgg.) (1997): Kinderliteratur, literarische Sozialisation und Schule. Weinheim: Dt. Studien-Verl.

Rau, Marie Luise (2013): Kinder von 1 bis 6. Bilderbuchrezeption und kognitive Entwicklung. Frankfurt a. M.: Lang (Kinder- und Jugendkultur, -literatur und -medien, 84).

Reil, Margit (1994): Grenzerfahrungen in Texten für junge Leser. Trennung und Tod in Kinder- und Jugendbüchern. Bamberg: Lehrstuhl Didaktik der Dt. Sprache und Literatur.

Retter, Hein (1989): Beurteilung von Bilderbüchern. Pädagogische Probleme und empirische Befunde. Seelze-Velber: Kallmeyer.

Reuter, Stephanie (1994): Tod und Sterben - ein Thema für den Schulunterricht. Konzeption und Evaluierung einer Unterrichtsreihe zum Thema „Tod und Sterben" für Schülerinnen und Schüler der gymnasialen Oberstufe. Frankfurt a. M., Berlin [u. a.]: Lang.

Richter, Dieter (Hg.) (1982): Das Land wo man nicht stirbt. Märchen vom Leben und vom Tod. Frankfurt a. M.: Fischer-Taschenbuch-Verl. (Fischer-Taschenbücher, 5247).

Richter, Dieter (1987): Das fremde Kind. Zur Entstehung der Kindheitsbilder des bürgerlichen Zeitalters. Frankfurt a. M.: Fischer. 
Richter, Karin (1996): Kinderliteratur und Kinderliteraturforschung in der DDR. In: Bernd Dolle-Weinkauff und Hans-Heino Ewers (Hgg.): Theorien der Jugendlektüre. Beiträge zur Kinder- und Jugendliteraturkritik seit Heinrich Wolgast. Weinheim: Juventa (Jugendliteratur - Theorie und Praxis), S. 191210.

Richter, Karin (2002): Kinder- und Jugendliteratur der DDR. In: Günter Lange (Hg.): Taschenbuch der Kinder- und Jugendliteratur. Bd. 1; Grundlagen, Gattungen, 3., unveränd. Aufl. Baltmannsweiler: Schneider, S. 137-157.

Ries, Hans (1992): Illustration und Illustratoren des Kinder- und Jugendbuchs im deutschsprachigen Raum 1871-1914. (Forschungsvorhaben zur historischen Kinder- und Jugendliteratur im Rahmen der Arbeitsstelle für Kinderund Jugendliteraturforschung der Universität zu Köln; hrsg. von Theodor Brüggemann). Osnabrück: Wenner.

Roeder, Caroline (Hg.) (2009): Ich! Identität(en) in der Kinder- und Jugendliteratur. kjl\&m (09.extra). München: kopaed.

Rösch, Heidi (1997): Bilderbücher zum interkulturellen Lernen. Baltmannsweiler: Schneider.

Rosenfeld, Hellmut (1974): Der mittelalterliche Totentanz. Entstehung - Entwicklung - Bedeutung. 3., verb. und verm. Aufl. Köln: Böhlau (Beihefte zum Archiv für Kulturgeschichte, 3).

Rychener, Ingeborg (2011): Wie Kinder ein Bilderbuch verstehen. Eine empirische Studie zur Entwicklung des Textverstehens. Schulsynode. Bern [u. a.]: Lang (Explorationen. Studien zur Erziehungswissenschaft. Bd. 60; hrsg. von der Schweizerischen Gesellschaft für Bildungsforschung).

S. S. (1890): Kinderbücher. In: Der Kunstwart. Rundschau über alle Gebiete des Schönen. 4. Jg. (2. Dezemberheft), S. 81-84.

Sachs-Hombach, Klaus (Hg.) (2005): Bildwissenschaft. Disziplinen, Themen, Methoden. Frankfurt a. M.: Suhrkamp (Suhrkamp-Taschenbuch Wissenschaft, 1751).

Sahr, Michael (1986): Tod und Endlichkeit - Ein neuentdecktes Thema in der Kinderliteratur. In: Jugendbuchmagazin (2), S. 72-79.

Sahr, Michael (1887): Problemorientierte Kinderbücher im Unterricht der Grundschule. Baltmannsweiler: Pädag. Verl. Burgbücherei Schneider.

Sahr, Michael (2000): Das phantasie- und das realitätsorientierte Kinderbuch im Unterricht. In: Michael Sahr und Monika Born (Hgg.): Kinderbücher im Unterricht der Grundschule. 6., korr. Aufl. Baltmannsweiler: Schneider, S. 119-175.

Sahr, Michael; Born, Monika (Hgg.) (2000): Kinderbücher im Unterricht der Grundschule. 6., korr. Aufl. Baltmannsweiler: Schneider. 
Sahr, Michael; Born, Monika (Hgg.) (2006): Kinderbücher im Unterricht der Grundschule. 7., erg. Aufl. Baltmannsweiler: Schneider.

Sartre, Jean-Paul; Brenner, Hans Georg (Übers.) (1958): Was ist Literatur? Ein Essay. Hamburg: Rowohlt (Rowohlts deutsche Enzyklopädie; Sachgebiet Literatur, 65).

Schaufelberger, Hildegard (1990): Kinder- und Jugendliteratur heute. Themen, Trends und Perspektiven. Freiburg i. Br.: Herder (Praxishilfen Kindergarten, Hort, Schule).

Scherer, Gabriela; Volz, Steffen; Wiprächtiger-Geppert, Maja (Hgg.) (2014): Bilderbuch und literar-ästhetische Bildung. Aktuelle Forschungsperspektiven. Trier: WVT (Koblenz-Landauer Studien zu Geistes-, Kultur- und Bildungswissenschaften, 12).

Scheuermann, Barbara J. (2005): Erzählstrategien in der zeitgenössischen Kunst. Narrativität in Werken von William Kentridge und Tracey Emin. Köln.

Scheuermann, Barbara J. (2010): Narreme, Unbestimmtheitsstellen, Stimuli. Erzählen im fotografischen Einzelbild. In: Lars Blunck (Hg.): Die fotografische Wirklichkeit. Inszenierung - Fiktion - Narration. Bielefeld, S. 191-206.

Schiefer Ferrari, Markus (2003): Geschwisterliche Verbundenheit über den Tod hinaus. Hoffnungskonzepte in Kinder- und Jugendbüchern. In: Stefan Schreiber und Stefan Siemons (Hgg.): Das Jenseits. Perspektiven christlicher Theologie. Darmstadt: Wissenschaftliche Buchgesellschaft, S. 231-252.

Schikorsky, Isa (2003): Kinder- und Jugendliteratur. Köln: DuMont-Literaturund-Kunst-Verl. (DuMont-Schnellkurs, 535).

Schindler, Regine (1981): Der Tod - Eine Lebensfrage: „Profane Realisation“ religiöser Inhalte. In: Mechthild Voss-Eiser (Hg.): Religion im kinder-und Jugendbuch. Hardebek: Eulenhof Verlag, S. 224-236.

Schmid, J. (1960): Jenseits. In: Josef Höfer und Karl Rahner (Hgg.): Lexikon für Theologie und Kirche (1957-1967), Bd. 5. 2., völlig neu bearb. Aufl. Freiburg i. Br.: Herder, S. 890-892.

Schmid, Wolf (2008): Elemente der Narratologie. 2., verb. Aufl. Berlin: de Gruyter (De-Gruyter-Studienbuch).

Schmid, Wolf (2011): 1. Erzählstimme 2. Perspektive. In: Matías Martínez (Hg.): Handbuch Erzählliteratur. Theorie, Analyse, Geschichte. Stuttgart: Metzler, S. 131-145.

Schmidt-Dumont, Geralde (1997): Semantische Wortfelder zur Charakterisierung von bildlicher Gestaltung. In: Steffen Peltsch (Hg.): Auch Bilder erzählen Geschichten ... Beziehungen zwischen Text und Bild im Kinder- und Jugendbuch. Weinheim: Juventa-Verl. (Beiträge Jugendliteratur und Medien, Beiheft 8), S. 101-107. 
Schmidt-Dumont, Geralde (1998): Nachdenken über unser Leben in Raum und Zeit. Das philosophische Thema „Tod und Transzendenz" im Bilderbuch und im Kinderbuch. In: Beiträge Jugendliteratur und Medien 50 (1998) H. 2, S. 77-90.

Schmidt-Henkel, Hinrich (1990): Die getrösteten Tröster. Der Tod in der Kinderliteratur. Ein Rundblick in Europa. In: Adolf Holl (Hg.): Neues vom Tod. Heutige Umgangsformen mit dem Sterbenmüssen. Wien, S. 209-228.

Schmitz, Walter (1995): Engel. VIII. In der Literatur. In: Michael Buchberger und Walter Kasper (Hgg.): Lexikon für Theologie und Kirche, Bd. 3. 3., völlig neu bearbeitete Aufl. Freiburg: Herder, S. 653-654.

Schmoll, H.-J; Wolff, Georg (Hgg.) (1979): Sterbebeistand bei Kindern und Erwachsenen. Stuttgart: Enke.

Schneider, Silvia (1995): Entwicklungsbedingungen sozialer Handlungsfähigkeit. Formen der Interaktionsstrukturierung beim gemeinsamen Bilderbuchlesen von Eltern und Kind. Frankfurt a. M.: Lang (Europäische HochschulschriftenReihe 6, Psychologie, 496).

Schreiber, Stefan; Siemons, Stefan (2003): Was ist Jenseits. In: Stefan Schreiber und Stefan Siemons (Hgg.): Das Jenseits. Perspektiven christlicher Theologie. Darmstadt: Wissenschaftliche Buchgesellschaft, S. 9-15.

Schulz, Farriba (2013): „Spieglein, Spieglein an der Wand..... Kindheit in nominierten Bilderbüchern des Deutschen Jugendliteraturpreises von 1956 bis 2009. Hamburg: Kovač (Poetica, 124).

Schwarcz, Joseph H. (1982): Ways of the illustrator. Visual communication in children's literature. Chicago: American Library Association.

Schwarcz, Joseph H.; Schwarcz, Chava (1991): The picture book comes of age. Looking at childhood through the art of illustration. Chicago: American Library Association.

Schweikardt, Christoph; Groß, Dominik (2010): Die „Realität des Todes“ - eine thematische Einführung. In: Dominik Groß (Hg.): Die Realität des Todes. Zum gegenwärtigen Wandel von Totenbildern und Erinnerungskulturen. Frankfurt a. M. [u. a.]: Campus, S. 9-18.

Schweizerisches Jugendbuch-Institut (Hg.) (1994): Horizonte und Grenzen. Standortbestimmung in der Kinderliteraturforschung; Kolloquium 25 Jahre Schweizerisches Jugendbuch-Institut vom 2. bis 4. Dezember 1993. Arbeitsbericht Nr. 17 des Schweizerischen Jugendbuch-Instituts. Zürich.

Sell, Roger D. (Hg.) (2002): Children's literature as communication. The ChiLPA Project. Amsterdam, Philadelphia, PA: John Benjamins Pub. (Studies in narrative, v. 2). 
Siegel, Steffen (2006): Bild und Text. Ikonotexte als Zeichen hybrider Visualität. In: Silke Horstkotte und Karin Leonhard (Hgg.): Lesen ist wie Sehen. Intermediale Zitate in Bild und Text. Köln: Böhlau, S. 51-74.

Sommer. Roy (2010): Metoden strukturalistischer und narratologischer Ansätze. In: Vera Nünning und Ansgar Nünning (Hgg.): Methoden der literatur- und kulturwissenschaftlichen Textanalyse. Ansätze - Grundlagen - Modellanalysen. Stuttgart: Metzler, S. 91-108.

Spiecker-Verscharen, Ingun (1982): Kindheit und Tod. Die Konfrontation mit dem Tod in der modernen Kinderliteratur. Frankfurt a. M.: Haag \& Herchen (Studien zur Kinder- und Jugendmedien-Forschung, 9).

Staiger, Michael (2013): Zur Komplexität des Erzählens im Bilderbuch. Narratologische Desiderate und Ansatzpunkte. In: Iris Kruse und Andrea Sabisch (Hgg.): Fragwürdiges Bilderbuch. Blickwechsel - Denkspiele - Bildungspotenziale. München: kopaed, S. 65-76.

Steffens, Wilhelm (2002): Der psychologische Kinderroman. Entwicklung, Struktur, Funktion. In: Günter Lange (Hg.): Taschenbuch der Kinder- und Jugendliteratur. 3., unveränd. Aufl. Baltmannsweiler: Schneider-Verl. Hohengehren (Bd. 1; Grundlagen, Gattungen), S. 308-331.

Steinhöfel, Andreas (2009): Im Zentrum des Labyrinths - Ist da ein Ich im Ich? Anmerkungen zum Schreiben als Ich-Erzähler. In: Caroline Roeder (Hg.): Ich! Identität(en) in der Kinder- und Jugendliteratur. kjl\&m (09.extra); S. 32-35.

Steinlein, Rüdiger (2008): Neubeginn, Restauration, antiautoritäre Wende. In: Reiner Wild (Hg.): Geschichte der deutschen Kinder- und Jugendliteratur. 3., vollst. überarb. und erw. Aufl. Stuttgart: Metzler, S. 312-342.

Steinlein, Rüdiger; Strobel, Heidi; Kramer, Thomas (Hgg.) (2006): SBZ/DDR. Von 1945 bis 1990. Stuttgart: Metzler (Handbuch zur Kinder- und Jugendliteratur Bd. 7).

Steitz-Kallenbach, Jörg (Hg.) (2001): Kinder- und Jugendliteraturforschung interdisziplinär. Beiträge der Ringvorlesung „Aktuelle Forschungsperspektiven zur Kinder- und Jugendliteratur und zu Kinder- und Jugendmedien“ der Forschungsstelle für Kinder- und Jugendliteratur (OlFoKi) der Carl-vonOssietzky-Universität Oldenburg Sommersemester 2000. Oldenburg: BIS (Schriftenreihe der Forschungsstelle Kinder- und Jugendliteratur der Carlvon-Ossietzky-Universität Oldenburg, 2).

Steitz-Kallenbach, Jörg (Hg.) (2002): Medienumbrüche. Wie Kinder und Jugendliche mit alten und neuen Medien kommunizieren. Bremen: Aschenbeck \& Isensee. 
Steitz-Kallenbach, Jörg (2006): Sachbuch. In: Heinz-Jürgen Kliewer und Inge Pohl (Hgg.): Lexikon Deutschdidaktik. Bd. 2. Baltmannsweiler: Schneider, S. 646-649.

Stern, Erich (1957): Kind, Krankheit und Tod. München: Reinhardt.

Stockar, Denise von (2009): Wie kommt das Ich im Bilderbuch daher ... Psychologische Aspekte und narratologischer Standpunkt. In: Caroline Roeder (Hg.): Ich! Identität(en) in der Kinder- und Jugendliteratur. kjl\&m (09.extra), S. 58-67.

Strasser, Klaus; Petzold, Ernst Richard (2000): Trauerbedingte körperliche Reaktionen. Unter besonderer Berücksichtigung des Geschwisterverlustes. In: Wolfgang Holzschuh (Hg.): Geschwister-Trauer. Erfahrungen und Hilfen aus verschiedenen Praxisfeldern. Regensburg: Pustet, S. 30-44.

Student, Johann-Christoph (Hg.) (2000): Im Himmel welken keine Blumen. Kinder begegnen dem Tod. 5., neubearb. Aufl. Freiburg i. Br.: Herder (HerderSpektrum, 4967).

Tabbert, Reinbert (1987): Maurice Sendak. Bilderbuchkünstler. Bonn: Bouvier (Sammlung Profile, 26).

Tabbert, Reinbert (1999): Bilderbücher als dramatische Kunst. Ein Beitrag zur Theorie eines traditionellen Mediums. In: Bernd Dolle-Weinkauff, HansHeino Ewers und Carola Pohlmann (Hgg.): Kinder- und Jugendliteraturforschung 1998/1999. Stuttgart: Metzler, S. [11]-17.

Tabbert, Reinbert (2005): Engel in der Kinderliteratur: Fallstudien über Phantastik, Kitsch und gesellschaftliche Normen. In: Gerhard Härle und Gina Weinkauff (Hgg.): Am Anfang war das Staunen. Wirklichkeitsentwürfe in der Kinder- und Jugendliteratur. Baltmannsweiler: Schneider, S. 135-148.

Tabbert, Reinbert (2006): Fantastische Bilderbücher. In: Jörg Knobloch und Gudrun Stenzel (Hgg.): Zauberland und Tintenwelt. Fantastik in der Kinder- und Jugendliteratur. Beiträge Jugendliteratur und Medien 58, 17. Beiheft. Weinheim: Juventa, S. 119-128.

Tausch-Flammer, Daniela; Bickel, Lis (1998): Wenn Kinder nach dem Sterben fragen. Ein Begleitbuch für Kinder, Eltern und Erzieher. Freiburg i. Br., Basel, Wien: Herder.

Thiele, Jens (Hg.) (1985): Bilderbücher entdecken. Untersuchungen, Materialien u. Empfehlungen zum kritischen Gebrauch einer Buchgattung. Oldenburg: Isensee.

Thiele, Jens (1988): Von den Schwierigkeiten, den Holocaust im Bilderbuch darzustellen. In: Werner Anders (Hg.): Antisemitismus und Holocaust. Ihre Darstellung und Verarbeitung in der deutschen Kinder- und Jugendliteratur; Oldenburg: BIS, S. 137-147. 
Thiele, Jens (1990a): Nachwort. In: Ellermann, Heike: Papiervogel, flieg! Freiburg i. Br.: Herder.

Thiele, Jens (1990b): Wurzelkinder und Honigpumpe. Zum Verhältnis von Kunstmoderne und Bilderbuch. In: Hans-Heino Ewers, Maria Lypp und Ulrich Nassen (Hgg.): Kinderliteratur und Moderne. Ästhetische Herausforderungen für die Kinderliteratur im 20. Jahrhundert. Weinheim, München: Juventa (Jugendliteratur - Theorie und Praxis), S. 141-174.

Thiele, Jens (1991): Bilderbücher verstehen. Neue Überlegungen zu einem alten Anspruch. In: Jens Thiele (Hg.): Neue Erzählformen im Bilderbuch. Untersuchungen $\mathrm{zu}$ einer veränderten Bild-Text-Sprache. Oldenburg: Isensee, S. 7-16.

Thiele, Jens (1996): Theoretische Positionen zum Bilderbuch in Nachkriegszeit und Gegenwart. In: Bernd Dolle-Weinkauff und Hans-Heino Ewers (Hgg.): Theorien der Jugendlektüre. Beiträge zur Kinder- und Jugendliteraturkritik seit Heinrich Wolgast. Weinheim: Juventa (Jugendliteratur - Theorie und Praxis), S. 263-284.

Thiele, Jens (1997): Überhöhte Erwartungen an einen scheinbar einfachen Gegenstand. Zu den Schwierigkeiten einer Rezeptionsforschung im Bereich der Kinderbuchillustration. In: Schweizerisches Jugendbuchinstitut (Hg.): Siehst du das? Die Wahrnehmung von Bildern in Kinderbüchern - Visual Literacy. Kolloquium vom 26. Bis 28. September 1996. Red. Verena Rutschmann u. Denise von Stockar, Zürich, S. 149-168.

Thiele, Jens (Hg.) (1999): Experiment Bilderbuch. Tagungsband. Workshop zur künstlerischen Neubestimmung der Kinderbuchillustration, 10.11. 12.11.1997. Oldenburg: BIS (Schriftenreihe der Forschungsstelle Kinder- und Jugendliteratur der Carl-von-Ossietzky-Universität Oldenburg, 1).

Thiele, Jens (2001): Kunst für Kinder? Zur Bedeutung des Bilderbuchs in der bildnerisch-literarischen Sozialisation des Kindes. In: Jörg Steitz-Kallenbach (Hg.): Kinder- und Jugendliteraturforschung interdisziplinär. Oldenburg: BIS (Schriftenreihe der Forschungsstelle Kinder- und Jugendliteratur der Carlvon-Ossietzky-Universität Oldenburg, 2), S. 31-57.

Thiele, Jens (2002): Das Bilderbuch. In: Günter Lange (Hg.): Taschenbuch der Kinder- und Jugendliteratur. Bd. 1, Grundlagen, Gattungen. 3., unveränd. Aufl. Baltmannsweiler: Schneider, S. 228-245.

Thiele, Jens (2003a): Das Bilderbuch. Ästhetik, Theorie, Analyse, Didaktik, Rezeption. 2., erw. Aufl. Oldenburg: Isensee.

Thiele, Jens (2003b): Das Bilderbuch. In: Jens Thiele und Jörg Steitz-Kallenbach (Hgg.): Handbuch Kinderliteratur. Grundwissen für Ausbildung und Praxis. Freiburg i. Br. [u.a.]: Herder, S. 70-98. 
Thiele, Jens (2004): Ist das Kind noch im Bilde? Die Emanzipation des Bilderbuchs von pädagogischen und bildnerischen Komponenten. In: JuLit 30. Jg (2004) H. 3, S. 12-26.

Thiele, Jens (2005a): Im Bild sein ... zwischen den Zeilen lesen. Zur Interdependenz von Bild und Text in der Kinderliteratur. In: Mareile Oetken (Hg.): Texte lesen - Bilder sehen. Beiträge zur Rezeption von Bilderbüchern. Oldenburg: BIS (Schriftenreihe der Forschungsstelle Kinder- und Jugendliteratur der Carl-von-Ossietzky-Universität Oldenburg, 3), S. 11-29.

Thiele, Jens (2005b): „Dem Kind gemäß?“Wenn Texte und Bilder für Kinder das Lesen dekonstruieren. In: Gudrun Stenzel (Hg.): Kinder lesen - Kinder leben. Kindheiten in der Kinderliteratur. Beiträge Jugendliteratur und Medien 57, 16. Beiheft, S. 143-152.

Thiele, Jens (Hg.) (2007a): Neue Impulse der Bilderbuchforschung. Unter Mitarbeit von Elisabeth Hohmeister. Baltmannsweiler: Schneider.

Thiele, Jens (2007b): Neue Impulse der Bilderbuchforschung. Fragestellungen der Tagung. In: Jens Thiele (Hg.): Neue Impulse der Bilderbuchforschung. Wissenschaftliche Tagung der Forschungsstelle Kinder- und Jugendliteratur der Carl von Ossietzky Universität Oldenburg, 13. - 15. September 2006. unter Mitarbeit von Elisabeth Hohmeister. Baltmannsweiler: Schneider, S. 7-15.

Thiele, Jens (2007c): „Verborgene Kindheiten“ sichtbar machen - Einführung in das Thema. In: Jens Thiele, Sabine Wallach (Hgg.): Verborgene Kindheiten. Soziale und emotionale Probleme in der Kinderliteratur. Oldenburg: BISVerl. der Carl-von-Ossietzky-Univ., S. 1-8.

Thiele, Jens (2007d): Wenn die Bilder dunkel werden. Zur Inszenierung kindlicher Probleme im Bilderbuch. In: Jens Thiele, Sabine Wallach (Hgg.): Verborgene Kindheiten. Soziale und emotionale Probleme in der Kinderliteratur. Oldenburg: BIS-Verl. der Carl-von-Ossietzky-Univ., S. 39-56.

Thiele, Jens (2011): Das Bilderbuch. In: Günter Lange (Hg.): Kinder- und Jugendliteratur der Gegenwart. Ein Handbuch. (Grundlagen, Gattungen, Medien, Lesesozialisation und Didaktik). Baltmannsweiler: Schneider, S. 217-230.

Thiele, Jens; Oetken, Mareile (Hgg.) (1997): Experiment Bilderbuch. Impulse zur künstlerischen Neubestimmung der Kinderbuchillustration. Oldenburg: BISVerl. der Carl-von-Ossietzky-Univ.

Thiele, Jens; Steitz-Kallenbach, Jörg (Hgg.) (2003): Handbuch Kinderliteratur. Grundwissen für Ausbildung und Praxis. Freiburg i. Br. [u. a.]: Herder, S. 7098.

Thiele, Jens; Wallach, Sabine (Hgg.) (2007): Verborgene Kindheiten. Soziale und emotionale Probleme in der Kinderliteratur: Oldenburg: BIS-Verl. der Carlvon-Ossietzky-Univ. 
Thielking, Sigrid (1994): „Rosa Weiss wollte wissen...“. Ansätze und Strategien zur didaktischen Vermittlung des Themas Holocaust. In: Der Deutschunterricht (1994), H. 4, S. 50-57.

Thomae, Hans; Lehr, Ursula (Hgg.) (1972): Altern. Probleme und Tatsachen. Frankfurt a.M: Akademische Verlagsgesellschaft.

Trauzettel, Rolf; Assmann, Jan (Hgg.) (2002): Tod, Jenseits und Identität. Perspektiven einer kulturwissenschaftlichen Thanatologie. Freiburg, München: Alber.

Unverzagt, Gerlinde (2007): Kinder fragen nach dem Tod. Mit einem schwierigen Thema richtig umgehen. Freiburg, Basel, Wien: Herder.

Vach, Karin (2014): Typographie im Bilderbuch. In: Gabriela Scherer, Steffen Volz, Maja Wiprächtiger-Geppert (Hgg.): Bilderbuch und literar-ästhetische Bildung. Aktuelle Forschungsperspektiven. Trier: WVT (Koblenz-Landauer Studien zu Geistes-, Kultur- und Bildungswissenschaften, 12), S. 247-264.

Varga, Áron Kibédi (1990): Visuelle Argumentation und visuelle Narrativität. In: Wolfgang Harms (Hg.): Text und Bild, Bild und Text. DFG-Symposion 1988. Stuttgart: Metzler (Germanistische Symposien-Berichtsbände, 11), S. 356367.

Varga, Beatrix (1991): Leben und Sterben bei Kindern. Regensburg: Roderer (Theorie und Forschung Psychologie, 146).

Völpel, Annegret (2008): Jüdische Kinder- und Jugendliteratur bis 1945. In: Reiner Wild (Hg.): Geschichte der Kinder- und Jugendliteratur. 3. überarb. Aufl. Stuttgart: Metzler, S. 260-275.

Vorgrimler, Herbert (2002): Neues theologisches Wörterbuch. Darmstadt: WBG.

Voss-Eiser, Mechthild (Hg.) (1981): Religion im kinder-und Jugendbuch. Hardebek: Eulenhof Verlag.

Wagerer, Gertie (1997): Das religiöse Kinderbuch - Engführungen, Defizite, neue Dimensionen. Überlegungen angesichts der Verleihung des Dt. Kath. Kinderbuchpreises. In: TueB (5), S. 32-37.

Wagner, Peter (2006): Nachwort. In: Silke Horstkotte und Karin Leonhard (Hgg.): Lesen ist wie Sehen. Intermediale Zitate in Bild und Text. Köln: Böhlau, S. 211-225.

Weber-Kellermann, Ingeborg (1997): Die Kindheit. Eine Kulturgeschichte. Frankfurt a. M.: Insel.

Weinmann, Andrea (2013): Kinderliteraturgeschichten. Frankfurt a. M.: Lang.

Weismann, Willi; Jansen, Ruth; Stegner, Sylvia (1980): Deutschsprachige Bilderbücher. Ein Verzeichnis 1945-1975 erschienener Titel. München, New York: K.G. Saur. 
Wenzel, Horst (1995): Hören und Sehen. Schrift und Bild. Kultur und Gedächtnis im Mittelalter. München.

Wieler, Petra (1997): Vorlesen in der Familie. Fallstudien zur literarisch-kulturellen Sozialisation von Vierjährigen. Weinheim: Juventa (Lesesozialisation und Medien).

Wild, Reiner (Hg.) (2008): Geschichte der deutschen Kinder- und Jugendliteratur. 3., vollst. überarb. und erw. Aufl. Stuttgart: Metzler.

Wild, Reiner (2008a): Aufklärung. In: Reiner Wild (Hg.): Geschichte der deutschen Kinder- und Jugendliteratur. 3., vollst. überarb. und erw. Aufl. Stuttgart: Metzler, S. 43-95.

Wild, Reiner (2008b): Von den 70er Jahren bis zur Gegenwart. In: Reiner Wild (Hg.): Geschichte der deutschen Kinder- und Jugendliteratur. 3., vollst. überarb. und erw. Aufl. Stuttgart: Metzler, S. 343-412.

Wild, Reiner; Brunken, Otto (Hgg.) (1990): Geschichte der deutschen Kinderund Jugendliteratur. Stuttgart: Metzler.

Wilkening, Karin (1997): Wir leben endlich. Zum Umgang mit Sterben, Tod und Trauer. Göttingen: Vandenhoeck \& Ruprecht (Transparent, 43).

Wilkending, Gisela (2008): Vom letzten Drittel des 19. Jahrhunderts bis zum ersten Weltkrieg. In: Reiner Wild (Hg.): Geschichte der deutschen Kinder- und Jugendliteratur. 3., vollst. überarb. und erw. Aufl. Stuttgart: Metzler, S. 171240.

Winkel, Heidemarie (2002): „Trauer ist doch ein großes Gefühl ...“. Zur biographiegenerierenden Funktion von Verlusterfahrungen und der Codierung von Trauerkommunikation. Konstanz: UVK-Verl.-Ges. (Analyse und Forschung Sozialwissenschaften).

Wittekind, Folkart (2009): Religion im Kinder- und Jugendbuch. Über Gott und die Welt: Religion als Thema der KJL. In: kjl\&m 60 (2009) H. 1, S. 11-19.

Wittgenstein, Ludwig (1992): Tractatus logico-philosophicus. 23. [Dr.]. Frankfurt a. M.: Suhrkamp.

Wittkowski, Joachim (1978): Tod und Sterben. Ergebnisse der Thanatopsychologie. Heidelberg: Quelle und Meyer.

Wittkowski, Joachim (1990): Psychologie des Todes. Darmstadt: Wissenschaftliche Buchgesellschaft.

Witt-Loers, Stephanie (2009): Sterben, Tod und Trauer in der Schule. Eine Orientierungshilfe mit Kopiervorlagen. Göttingen: Vandenhoeck \& Ruprecht.

Wolff, Georg (1979): Was wissen denn schon die Kinder? In: H.-J. Schmoll und Georg Wolff (Hgg.): Sterbebeistand bei Kindern und Erwachsenen. Stuttgart: Enke, S. 49-56. 
Wolgast, Heinrich (1894): Über Bilderbuch und Illustration. Hamburg: Schröder \& Jeve.

Wolgast, Heinrich (1896): Das Elend unserer Jugendliteratur. Ein Beitrag zur künstlerischen Erziehung der Jugend. Hamburg.

Wrobel, Dieter (2013): Basisartikel „Hund - Katze - Maus“. Tiere in Texten. In: Praxis Deutsch 40. Jg., H. 240, S. 4-11.

Wuckelt, Agnes (2005): Religionspädagogische Aspekte. Ars moriendi - abschließlich leben und sterben lernen. In: Martin Hörning (Hg.): Der Tod gehört zum Leben. Sterben und Sterbebegleitung aus interdisziplinärer Sicht. Münster: Lit (Ethik interdisziplinär, 7), S. 123-138.

Wülfing, Isabella (1986): Alter und Tod in den Grimmschen Märchen und im Kinder- und Jugendbuch. Herzogenrath: Murken-Altrogge (Studien zur Medizin-, Kunst- und Literaturgeschichte, 11).

Wülfrath-Wiedenmann, Irene (1987): Alt und Jung - Großeltern und Kinder in der realistischen Kinder- und Jugendliteratur. In: Informationen des Arbeitskreises für Jugendliteratur, hrsg. vom Arbeitskreis für Jugendliteratur e.V., München, 13 (1987) H. 5, S. 46-55.

Wülfrath-Wiedenmann, Irene (1990): Kind und Großelterntod - Neuere Perspektiven in der Kinderliteratur. In: JuLit, 16 (1990) H. 4, S. 29-40.

Wülfrath-Wiedenmann, Irene (1992): Kind und Großelterntod - Neueste Perspektiven in der Kinderliteratur. In: Lehren und Lernen. Zeitschrift des Landesinstituts für Erziehung und Unterricht, 18 (1992) H. 6, S. 1-17.

Zöhrer, Marlene (2010): Weltliteratur im Bilderbuch. Wien: Praesens. 


\section{Anhang}

\section{X.1 Das Teilkorpus Kindersterben in tabellarischer Übersicht}

\begin{tabular}{|c|c|c|c|c|c|c|c|c|c|c|c|c|}
\hline Jahr & Titel & Fr. & Ge. & $\mathrm{U}$. & Kr. & Gw. & p.T. & Ich-E. & Rel. & Ph. & Rea. & OA \\
\hline 2011 & 1. Annes Baum (Sachb.) & & & & & $\mathrm{x}$ & & $\mathrm{x}$ & & $\mathrm{x}$ & & $\mathrm{F}$ \\
\hline 2011 & $\begin{array}{l}\text { 2. Der Besuch vom kleinen } \\
\text { Tod }\end{array}$ & & & & $\mathrm{x}$ & & $\mathrm{x}$ & & $\mathrm{x}$ & $\mathrm{x}$ & & $\mathrm{F}$ \\
\hline 2011 & 3. Sadakos Kraniche & & & & & $\mathrm{x}$ & & $\mathrm{x}$ & $\mathrm{x}$ & $\mathrm{x}$ & & $\mathrm{D}$ \\
\hline 2011 & 4. Als der Tod zu uns kam & & $\mathrm{x}$ & $\mathrm{x}$ & & & $\mathrm{x}$ & $\mathrm{xx}$ & & $\mathrm{x}$ & & $\mathrm{D}$ \\
\hline 2011 & 5. Die Königin und ich & & & & $\mathrm{x}$ & & $\mathrm{x}$ & $\mathrm{xx}$ & $\mathrm{x}$ & $\mathrm{x}$ & & $\mathrm{D}$ \\
\hline 2010 & 6. Zwischen zwei Weihnachten & $\mathrm{x}$ & & $\mathrm{x}$ & & & & & $\mathrm{x}$ & & $\mathrm{x}$ & $\mathrm{CH}$ \\
\hline 2010 & $\begin{array}{l}\text { 7. Am Anfang waren wir zu } \\
\text { zweit }\end{array}$ & & $\mathrm{x}$ & & & & & & $\mathrm{x}$ & & $\mathrm{x}$ & $\mathrm{D}$ \\
\hline 2009 & 8. Flieger am Himmel & $\mathrm{x}$ & & & & $\mathrm{x}$ & & $\mathrm{xx}$ & & & $\mathrm{x}$ & $\mathrm{D}$ \\
\hline 2009 & 9. Himmelskind & & $\mathrm{x}$ & & & & & & $\mathrm{x}$ & & $\mathrm{x}$ & $\mathrm{D}$ \\
\hline 2009 & $\begin{array}{l}\text { 10. Als Otto das Herz zum } \\
\text { ersten Mal brach }\end{array}$ & $\mathrm{x}$ & & $\mathrm{x}$ & & & & & & & $\mathrm{x}$ & $\mathrm{D}$ \\
\hline 2008 & 11. Georgs Reise zu Gott & $\mathrm{x}$ & & & & & & & $\mathrm{x}$ & & & $\mathrm{D}$ \\
\hline 2008 & 12. Justus ist traurig & & $\mathrm{x}$ & & $\mathrm{x}$ & & & & $\mathrm{x}$ & & $\mathrm{x}$ & $\mathrm{D}$ \\
\hline 2008 & 13. Hannah und ich & $\mathrm{x}$ & & $\mathrm{x}$ & & & & $\mathrm{xx}$ & & & $\mathrm{x}$ & $\mathrm{D}$ \\
\hline 2007 & 14. Luca und der Schmetterling & & & $\mathrm{x}$ & & & & $\mathrm{xx}$ & $\mathrm{x}$ & $\mathrm{x}$ & & $\mathrm{D}$ \\
\hline 2006 & 15. Mona’s Reise (sic!) & & & & & & & & $\mathrm{x}$ & $\mathrm{x}$ & & $\mathrm{D}$ \\
\hline 2005 & 16.Der Tigerprinz & & & & & & & & & $\mathrm{x}$ & & $\mathrm{F}$ \\
\hline 2005 & 17. Kevin Kanin & $\mathrm{x}$ & & & & $\mathrm{x}$ & & & $\mathrm{x}$ & $\mathrm{x}$ & & $\mathrm{D}$ \\
\hline 2005 & 18.Zuckerguss für Isabel & & $\mathrm{x}$ & & $\mathrm{x}$ & & & $\mathrm{xx}$ & $\mathrm{x}$ & $\mathrm{x}$ & & $\mathrm{D}$ \\
\hline 2005 & 19. Anne Frank (Sachb.) & & & & & $\mathrm{x}$ & & & & & & USA \\
\hline 2004 & $\begin{array}{l}\text { 20. Wenn ich nicht mehr bei dir } \\
\text { bin, ... }\end{array}$ & $\mathrm{x}$ & & & $\mathrm{x}$ & & & & $\mathrm{x}$ & & $\mathrm{x}$ & NL \\
\hline 2004 & $\begin{array}{l}\text { 21. Eva im Land der verlorenen } \\
\text { Schwestern } \\
\end{array}$ & & $\mathrm{x}$ & & & & & $\mathrm{xx}$ & & & $\mathrm{x}$ & NL \\
\hline 2004 & 22. Ich und du, du und ich & $\mathrm{x}$ & & $\mathrm{x}$ & & & & $\mathrm{xx}$ & & $\mathrm{x}$ & & $\mathrm{D}$ \\
\hline 2004 & 23. Brüderchen bei den Sternen & & $\mathrm{x}$ & & & & & & $\mathrm{x}$ & & $\mathrm{x}$ & $\mathrm{D}$ \\
\hline 2003 & 24. Lara’s Schmetterlinge (sic!) & & $\mathrm{x}$ & & $\mathrm{x}$ & & & & $\mathrm{x}$ & & $\mathrm{x}$ & $\mathrm{D}$ \\
\hline 2003 & 25. Du bist immer noch bei mir & $\mathrm{x}$ & & & & & & & & & $\mathrm{x}$ & $\mathrm{J}$ \\
\hline 2003 & 26.Sonnenau (Märchen) & & $\mathrm{x}$ & & & & & & $\mathrm{x}$ & $\mathrm{x}$ & & $S$ \\
\hline 2003 & 27. Der geborgte Stern & & & & & & & & $\mathrm{x}$ & $\mathrm{x}$ & & $\mathrm{D}$ \\
\hline 2002 & 28. Paneelos Melodie (Märchen) & & $\mathrm{x}$ & & & & & & $\mathrm{x}$ & $\mathrm{x}$ & & $\mathrm{D}$ \\
\hline 2001 & 29. Die Blumen der Engel & & $\mathrm{x}$ & $\mathrm{x}$ & & & & & $\mathrm{x}$ & & $\mathrm{x}$ & $\mathrm{A}$ \\
\hline 2000 & $\begin{array}{l}\text { 30. Pelle und die Geschichte mit } \\
\text { Mia }\end{array}$ & & $\mathrm{x}$ & & & & & & $\mathrm{x}$ & & $\mathrm{x}$ & $\mathrm{N}$ \\
\hline 1999 & $\begin{array}{l}\text { 31. Auf welchem Stern lebt } \\
\text { Sina? }\end{array}$ & & $\mathrm{x}$ & & & & & & $\mathrm{x}$ & $\mathrm{x}$ & & $\mathrm{CH}$ \\
\hline 1997 & 32. Wolkenland & & & & & & & & $\mathrm{x}$ & $\mathrm{x}$ & & GB \\
\hline
\end{tabular}




\begin{tabular}{|c|c|c|c|c|c|c|c|c|c|c|c|c|}
\hline Jahr & Titel & Fr. & Ge. & U. & Kr. & Gw. & p.T. & Ich-E. & Rel. & Ph. & Rea. & OA \\
\hline 1997 & $\begin{array}{l}\text { 33. Meine Schwester ist ein } \\
\text { Engel }\end{array}$ & & $\mathrm{x}$ & & & & & $\mathrm{xx}$ & $\mathrm{x}$ & $\mathrm{x}$ & & $S$ \\
\hline 1997 & 34. Da bin ich & & & & & $\mathrm{x}$ & & $\mathrm{xx}$ & & $\mathrm{x}$ & & $\mathrm{CH}$ \\
\hline 1996 & $\begin{array}{l}\text { 35. Amal und der Brief des } \\
\text { Königs }\end{array}$ & & & & $\mathrm{x}$ & & & & $\mathrm{x}$ & & $\mathrm{x}$ & NL \\
\hline 1996 & 36. Schwanenwinter & & & & $\mathrm{x}$ & & & & & $\mathrm{x}$ & & $\mathrm{J}$ \\
\hline 1995 & 37. Sadako (Sachb.) & $\mathrm{x}$ & & & & $\mathrm{x}$ & & & $\mathrm{x}$ & & $\mathrm{x}$ & USA \\
\hline 1995 & 38. Lia ist krank & & $\mathrm{x}$ & & $\mathrm{x}$ & & & & $\mathrm{x}$ & & $\mathrm{x}$ & $\mathrm{D}$ \\
\hline 1992 & 39. Der rote Faden & & & & & & & & & & $\mathrm{x}$ & $\mathrm{D}$ \\
\hline 1992 & \begin{tabular}{|l|}
$\begin{array}{l}\text { 40. Die Fahrt zum } \\
\text { Pferdeparadies }\end{array}$ \\
\end{tabular} & & & & $\mathrm{x}$ & & & & $\mathrm{x}$ & $\mathrm{x}$ & & $\mathrm{CH}$ \\
\hline 1990 & $\begin{array}{l}\begin{array}{l}\text { 41. Das Elefanten-Kinder-Buch } \\
\text { (Sachb.) }\end{array} \\
\end{array}$ & & & & & & & $\mathrm{x}$ & & & & A \\
\hline 1990 & 42. Papiervogel, flieg! (Sachb.) & & & & & $\mathrm{x}$ & & & & & & $\mathrm{D}$ \\
\hline 1989 & $\begin{array}{l}\text { 43. Jeden Tag leben. Hanna und } \\
\text { Fredrik haben Leukämie } \\
\text { (Sachb.) }\end{array}$ & & & & $\mathrm{x}$ & & & & & & & $\mathrm{CH}$ \\
\hline 1989 & $\begin{array}{l}\text { 44. Mein Name ist Jason Gaes } \\
\text { (Sachb.) }\end{array}$ & & & & $\mathrm{x}$ & & & $\mathrm{xx}$ & & & & USA \\
\hline 1989 & 45. Christian & $\mathrm{x}$ & & & $\mathrm{x}$ & & & & & & $\mathrm{x}$ & $\mathrm{D}$ \\
\hline 1987 & 46. Abschied von Rune & $\mathrm{x}$ & & $\mathrm{x}$ & & & & & & & $\mathrm{x}$ & $\mathrm{N}$ \\
\hline 1986 & 47. Rosa Weiss (Sachb.) & & & & & $\mathrm{x}$ & & & & & & $\mathrm{CH}$ \\
\hline 1985 & 48. Die unsichtbaren Freunde & $\mathrm{x}$ & & & $\mathrm{x}$ & & & & $\mathrm{x}$ & $\mathrm{x}$ & & $\mathrm{CH}$ \\
\hline 1984 & $\begin{array}{l}\text { 49. Ein Weihnachtstraum } \\
\text { (Märchen) }\end{array}$ & & & & & & & & $\mathrm{x}$ & & & $\mathrm{D}$ \\
\hline 1979 & $\begin{array}{l}\text { 50. Ich will etwas vom Tod } \\
\text { wissen (Sachb.) }\end{array}$ & & & & & & & & $\mathrm{x}$ & & & $\mathrm{D}$ \\
\hline 1978 & $\begin{array}{l}\text { 51. Trauermantel und Birke } \\
\text { (Märchen) }\end{array}$ & & $\mathrm{x}$ & & & & & & $\mathrm{x}$ & & & $\mathrm{D}$ \\
\hline 1971 & 52. Ein Pferd erzählt & & & & & & & $\mathrm{x}$ & & $\mathrm{x}$ & & $\mathrm{A}$ \\
\hline 1967 & 53. Das unglückselige Kind & & & & & $\mathrm{x}$ & & & & & $\mathrm{x}$ & USA \\
\hline
\end{tabular}

Markierungen in den Spalten:

Jahr $=$ Trauerprozesse

Titel $=$ Sterbeprozesse

\begin{tabular}{|ll|ll|}
\hline Abkürzungen: & OA: & Originalausgabe \\
Fr.: & Freund & p. T.: & personifizierter Tod \\
Ge.: & Geschwister & Ph.: & Phantastisches Bilderbuch \\
Gw.: & Gewalt & Rea.: & Realistisches Bilderbuch \\
Ich-E.: & $(\mathrm{x})=$ Ich-Erzähler & Rel.: & Religiöses Bilderbuch \\
Ich-E.: & $(\mathrm{xx})=$ kindlicher Ich-Erzähler & $\mathrm{U} .:$ & Unfall \\
Kr.: & Krankheit & & \\
\hline
\end{tabular}




\section{X.2 Das Gesamtkorpus in tabellarischer Übersicht}

\begin{tabular}{|c|c|c|c|c|c|c|c|c|c|c|c|c|c|c|c|c|c|c|c|c|c|}
\hline 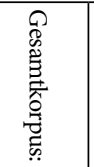 & 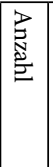 & 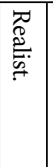 & 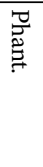 & 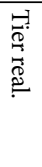 & 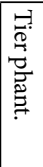 & 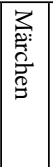 & 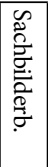 & 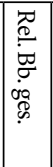 & 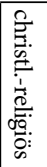 & 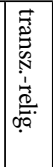 & 范 & 莺 & 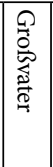 & 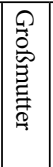 & 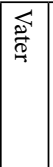 & 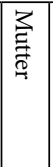 & 졸 & 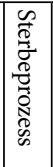 & 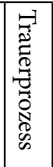 & 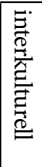 & \begin{tabular}{|l|l}
$\overrightarrow{0}$ \\
0 \\
0 \\
0 \\
0 \\
0 \\
0
\end{tabular} \\
\hline 1946 & 1 & & & & 1 & & & & & & & & & & & & & & & & \\
\hline 1964 & 1 & & & & 1 & & & & & & & & & & & & & & & & \\
\hline 1965 & 1 & & 1 & & & & & & & & & & & & & & & & 1 & & \\
\hline 1967 & 1 & 1 & & & & & & & & & & & & & & & 1 & & & & \\
\hline 1968 & 1 & & & & & 1 & & & & & & & & & & & & & & & \\
\hline 1969 & 1 & & & & & & 1 & & & & & 1 & & & & & & & & & \\
\hline 1971 & 4 & & 1 & & 1 & & 2 & 1 & 1 & & 2 & 2 & & & & & 1 & 1 & & & \\
\hline 1974 & 1 & 1 & & & & & & & & & & & 1 & 1 & & & & & 1 & & \\
\hline 1975 & 1 & 1 & & & & & & & & & & & & & & & & & & & \\
\hline 1976 & 2 & & & & 1 & & 1 & & & & 1 & & & & & & & 1 & & & \\
\hline 1977 & 1 & & & & & & 1 & 1 & 1 & & & & & & & & & & & & \\
\hline 1978 & 2 & 1 & & & & 1 & & 2 & 1 & 1 & & & & & & & 1 & & & & \\
\hline 1979 & 2 & & & & & 1 & 1 & 2 & 1 & 1 & & & & & & & 1 & & & & \\
\hline 1980 & 1 & 1 & & & & & & & & & & & & & & & & & 1 & & \\
\hline 1981 & 2 & 1 & & & & & 1 & & & & & 1 & & 1 & & & & & 1 & & \\
\hline 1982 & 2 & & & & & 1 & 1 & 1 & 1 & & & & 1 & & & & & 1 & 1 & & \\
\hline 1983 & 1 & & & & & & 1 & 1 & 1 & & & & & 1 & & & & 1 & & 1 & \\
\hline 1984 & 6 & 2 & 1 & & 2 & 1 & & 3 & & 3 & 2 & 1 & 1 & 1 & 1 & 1 & 1 & 1 & 1 & & 1 \\
\hline 1985 & 5 & 1 & 2 & & & 2 & & 3 & 2 & 1 & 1 & & & & 1 & & 1 & 1 & & & 1 \\
\hline 1986 & 3 & 1 & & & & 1 & 1 & 1 & & 1 & & & & & & & 1 & & 1 & & \\
\hline 1987 & 5 & 2 & & & 1 & 1 & 1 & 1 & & 1 & 1 & 1 & & & & & 1 & 2 & 2 & & \\
\hline 1988 & 5 & 1 & 3 & & & & 1 & 2 & 1 & 1 & 1 & 1 & 1 & & & & & & & & 1 \\
\hline 1989 & 5 & 2 & 1 & & & & 2 & 1 & & 1 & & & & 2 & & & 3 & 1 & 1 & & 1 \\
\hline 1990 & 4 & & 1 & & 1 & & 2 & 2 & & 2 & & & 1 & 1 & & & 2 & & & & \\
\hline 1991 & 3 & 1 & 2 & & & & & 1 & 1 & & 2 & 1 & 1 & & & & & 1 & & & \\
\hline 1992 & 7 & 4 & 1 & & 2 & & & 3 & 1 & 2 & & 2 & 1 & 1 & & & 2 & 1 & 2 & & \\
\hline 1993 & 6 & 1 & 3 & & 2 & & & 1 & & 1 & 4 & & 1 & 1 & & 1 & & 1 & 1 & & \\
\hline 1994 & 8 & 4 & 1 & & 2 & 1 & & 5 & 1 & 4 & & & 1 & 2 & 2 & & & 1 & 4 & & 1 \\
\hline 1995 & 10 & 3 & 2 & & 1 & 1 & 3 & 5 & 4 & 1 & 1 & & & 2 & & 1 & 2 & 3 & 1 & 1 & \\
\hline 1996 & 7 & 4 & & 1 & 1 & & 1 & 2 & 2 & & 3 & 2 & & & & & 2 & 1 & 1 & & \\
\hline 1997 & 9 & 3 & 2 & & 4 & & & 7 & 2 & 5 & & & 2 & 1 & & & 3 & 2 & 4 & & \\
\hline 1998 & 11 & 5 & 2 & & 4 & & & 9 & 5 & 4 & 2 & 1 & 2 & 2 & & & & 2 & 5 & & 1 \\
\hline 1999 & 9 & 3 & 2 & & 1 & 1 & 2 & 4 & 2 & 2 & 2 & & & 1 & 1 & & 1 & & 3 & & \\
\hline 2000 & 8 & 4 & & & 2 & 1 & 1 & 4 & 1 & 3 & 1 & & 1 & 1 & 1 & & 1 & 1 & 2 & 1 & \\
\hline 2001 & 10 & 3 & 4 & & 2 & & 1 & 9 & 3 & 6 & 1 & 2 & 2 & 1 & & 1 & 1 & & 4 & & \\
\hline 2002 & 10 & 1 & 3 & & 2 & 2 & 2 & 6 & 1 & 5 & 1 & & & 1 & 2 & & 1 & 2 & 5 & & 1 \\
\hline 2003 & 16 & 5 & 3 & & 7 & 1 & & 12 & 4 & 8 & 2 & & 1 & 3 & 1 & & 4 & 5 & 8 & 1 & \\
\hline 2004 & 12 & 3 & 4 & 1 & 3 & & 1 & 3 & 2 & 1 & 2 & 1 & & & & 2 & 4 & 1 & 6 & & 1 \\
\hline 2005 & 12 & 4 & 4 & & 3 & & 1 & 8 & 4 & 4 & & & 2 & & 1 & & 4 & 2 & 8 & 1 & \\
\hline 2006 & 12 & 5 & 4 & & 2 & 1 & & 6 & 2 & 4 & 1 & & 3 & 1 & 1 & & 1 & 1 & 5 & & 1 \\
\hline 2007 & 16 & 6 & 3 & & 4 & 1 & 2 & 7 & 2 & 5 & 3 & & 3 & 2 & 1 & & 1 & 1 & 8 & 2 & 2 \\
\hline 2008 & 16 & 7 & 5 & & 3 & & 1 & 10 & 4 & 6 & 1 & 1 & 2 & 3 & & 2 & 3 & 5 & 9 & 1 & \\
\hline 2009 & 12 & 8 & & 1 & 1 & 1 & 1 & 5 & 2 & 3 & 2 & & 2 & & & 1 & 3 & 1 & 7 & & 1 \\
\hline 2010 & 18 & 9 & 4 & & 2 & 2 & 1 & 11 & 5 & 6 & 2 & 1 & 1 & 5 & 1 & 1 & 2 & 3 & 10 & 1 & 1 \\
\hline 2011 & 17 & 9 & 4 & & 1 & 2 & 1 & 8 & 3 & 5 & 3 & 1 & 2 & 3 & 1 & & 5 & 7 & 9 & & 5 \\
\hline Gesamt & 287 & 107 & 63 & 3 & 57 & 23 & 34 & 147 & \begin{tabular}{|l|}
60 \\
\end{tabular} & 87 & 41 & 19 & 32 & 37 & \begin{tabular}{|l|}
14 \\
\end{tabular} & 10 & 53 & \begin{tabular}{|l|}
50 \\
\end{tabular} & 112 & \begin{tabular}{|l|}
9 \\
\end{tabular} & 18 \\
\hline
\end{tabular}




\section{DuEPublico}

\section{Duisburg-Essen Publications online}

Dieser Text wird über DuEPublico, dem Dokumenten- und Publikationsserver der Universität Duisburg-Essen, zur Verfügung gestellt. Die hier veröffentlichte Version der EPublikation kann von einer eventuell ebenfalls veröffentlichten Verlagsversion abweichen.

DOI: $\quad$ 10.3726/978-3-653-06019-5

URN: urn:nbn:de:hbz:464-20200422-165607-0

Hopp: Sterben, Tod und Trauer im Bilderbuch seit 1945.

Berlin: Peter Lang (2015)

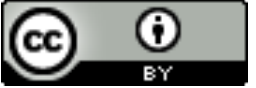

Dieses Werk kann unter einer Creative Commons Namensnennung 4.0 Lizenz (CC BY 4.0) genutzt werden. Die frei zugängliche digitale Publikation wurde ermöglicht mit Mitteln des BMBF-Projektes OGeSoMo der Universitätsbibliothek Duisburg-Essen. 